\title{
Stratigraphy, facies architecture and emplacement history of the c. 3.6 ka B.P. Ngatoro Formation on the eastern flanks of Egmont Volcano, western North Island, New Zealand.
}

\author{
A thesis \\ submitted to Victoria University of Wellington \\ in fulfilment of the \\ requirements for the degree of \\ Master of Science in Geology
}

Victoria University of Wellington 2014 


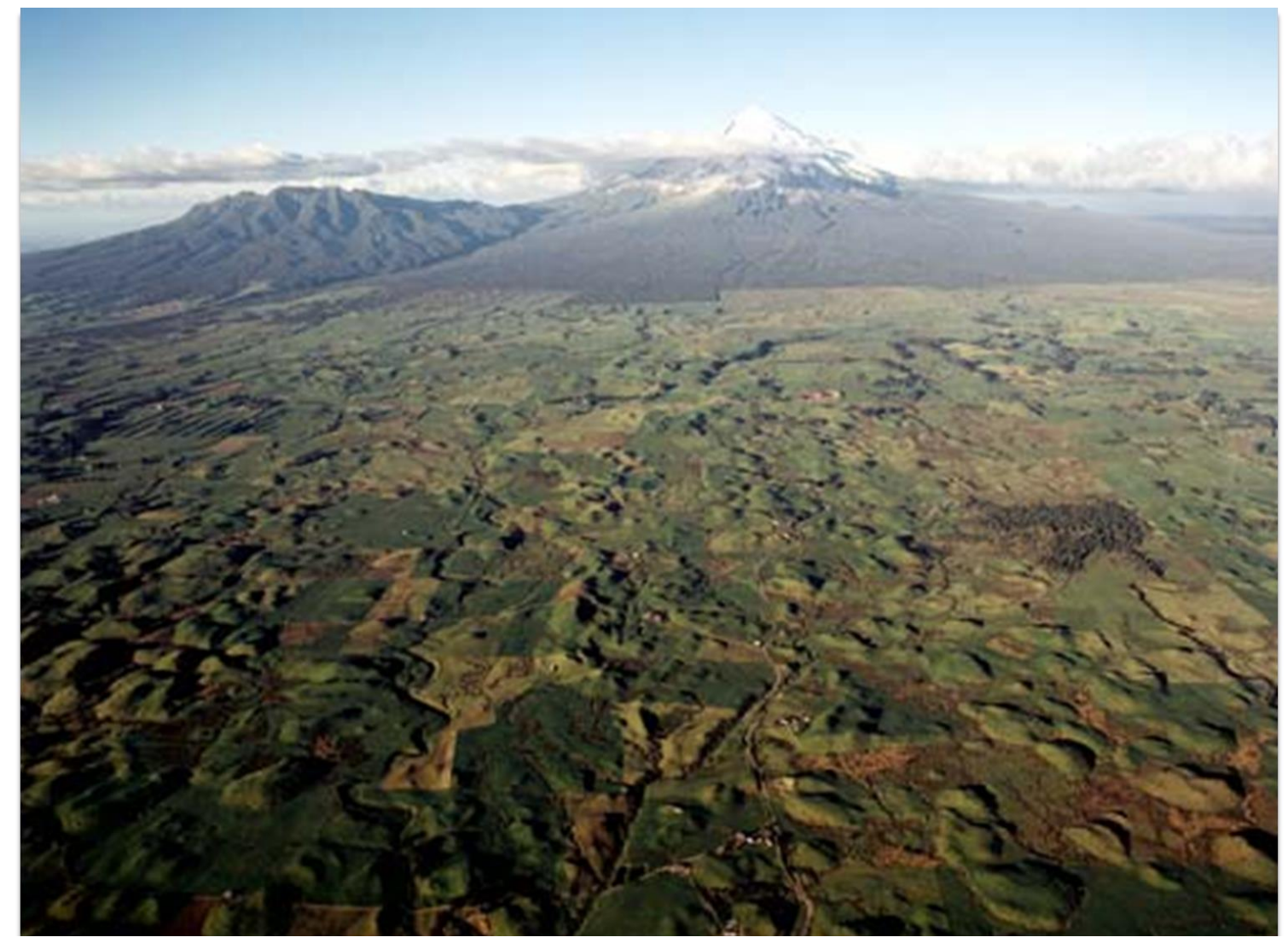

"All inferences from experience suppose ... that the future will resemble the past" - David Hume (1777) 
I would like to dedicate this thesis to my mother, Penny Dixon. You are a constant inspiration to me in all that you do. Without your encouragement to pursue excellence, both in science and in life, this thesis would not have been possible.

Love, Your "Baby Boy" 


\section{Acknowledgements}

Firstly I would like to extend my upmost gratitude to my supervisors - A/Prof Brent Alloway, Dr Cliff Atkins and A/Prof Gillian Turner. Your cheerful input, guidance and review have made this thesis more than I could have ever hoped for. You were calm when I was stressed, wise when I was naive and knowledgeable when I knew nothing!

I would like to acknowledge the George Mason Charitable Trust Scholarship for providing, not only financial support, but for creating an avenue for me to share my work with the people of Taranaki. Thank you.

To the landowners of rural Taranaki who allowed me to wander their land and dig up their nicely groomed track cuttings and embankments, I appreciate both your interest and the access.

I would like to acknowledge the staff at Victoria University of Wellington. In particular, Dr Rob McKay for your help with MatLab and the grain size statistics. You saved the day.

To Amy Hillenaar, I love you more than anything. Thank you so much for supporting me throughout this whole journey (p.s you are not expected to read this).

Anna and Joel Chisholm, Steph and Dave Ayling, Cam and Jess Fowler, and Patrick and Liz Cunliffe - Family and friendship are most appreciated in challenging moments. You are all much appreciated.

Finally, thank you to my amazing parents. You raised me to love God and love people - You raised me right. 


\section{Abstract}

The Ngatoro Formation is an extensive volcaniclastic deposit distributed on the eastern lower flanks of Egmont Volcano, central North Island, New Zealand. Formally identified by Neall (1979) this deposit was initially attributed to an Egmont sourced water-supported mass flow event c. $3,600{ }^{14} \mathrm{C}$ years B.P. The Ngatoro Formation was subsequently described by Alloway (1989) as a single debris flow deposit closely associated with the deposition of the underlying Inglewood Tephra (c. $3,600{ }^{14} \mathrm{C}$ yrs B.P) that had laterally transformed into a hyperconcentrated- to- flood flow deposit. Such water-supported mass flows have been well documented on volcanoes both within New Zealand (i.e. Mt Ruapehu) and elsewhere around the world (i.e. Mt Merapi, Central Java and Mt St Helens, Washington). This thesis comprises field mapping, stratigraphic descriptions, field and laboratory grain size and shape analysis, tephrochronology and palaeomagnetic analysis with the aim of refining the stratigraphy, facies architecture and emplacement history of the c. $3,600{ }^{14} \mathrm{C}$ yrs B.P. Ngatoro Formation.

This study has found that the Ngatoro Formation has a highly variable and complex emplacement history as evidenced by the rapid textural changes with increasing distance from the modern day Egmont summit. The Ngatoro Formation comprises two closely spaced mass flow events whose flow and emplacement characteristics have undergone both proximal to distal and axial to marginal transformations. On surfaces adjacent to the Manganui Valley on the deeply incised flanks of Egmont Volcano, the Ngatoro Formation is identified as overbank surge deposits whereas at the boundary of Egmont National Park it occurs as massive, pebble- to boulder-rich debris flow deposits. At intermediate to distal distances (17-23 km from the modern Egmont summit) the Ngatoro Formation occurs as a sequence of multiple coalescing dominantly sandy textured hyperconcentrated flow deposits. The lateral and longitudinal textural variability in the Ngatoro Formation reflects downstream transformation from gas-supported block-and-ash flows to water-supported debris flows, then subsequently to turbulent pebbly-sand dominated hyperconcentrated flows.

Palaeomagnetic temperature estimates for the Ngatoro Formation at two sites (Vickers and Surrey Road Quarries, c. $10 \mathrm{~km}$ from the present day Egmont summit) indicate clast 
incorporation temperatures of c. $300^{\circ} \mathrm{C}$ and emplacement temperatures of c. $200^{\circ} \mathrm{C}$. The elevated emplacement temperatures supported by the Ngatoro Formation's coarse textured, monolithologic componentry suggest non-cohesive emplacement of block-and-ash flow debris generated by the sequential gravitational collapse of an effusive lava dome after the paroxysmal Inglewood eruptive event (c. 3,600 ${ }^{14} \mathrm{C}$ yrs B.P.). The occurrence of a prominent intervening paleosol between these two events suggest that they are not part of the same eruptive phase but rather, the latter is a product of a previously unrecognised extended phase of the Inglewood eruptive event. This study recognises the potential for gravitational dome collapse, the generation of block-and-ash flows and their lateral transformation to water-support mass flows (debris, hyperconcentrated and stream flows) occurring in years to decades following from the main eruptive phase. This insight has implications with respect to the evaluation of post-eruptive hazards and risk. 


\section{Contents}

Dedication iv

Acknowledgement v

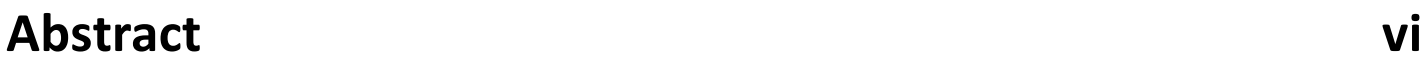

Contents viii

List of Figures $\quad$ xii

List of Tables $\quad$ xviii

$\begin{array}{ll}\text { Chapter One - Introduction } & 1\end{array}$

1. Introduction 1

1.1. Field Area 1

1.2. Previous Work 3

1.3. Importance of Study 10

1.4. Research Objectives 11

2. Volcanic Processes Review 12

2.1. Andesitic Volcanism 12

2.1.1. Regional Processes 12

2.1.2. Eruption Styles 13

2.2. Lahar 14

2.2.1. Debris Flow 15

2.2.2. Hyperconcentrated Flow 17

2.2.3. Flow Transformation Processes 18

$\begin{array}{ll}\text { 2.3. Mass Flow Generation } & 19\end{array}$

2.3.1. Edifice-Collapse Related Cohesive Mass Flows 19

2.3.2. Pyroclastic Flow Transformation 20

2.3.3. Rainfall Induced Mass Flows 22

3. Case Studies 24

3.1. Mount Ruapehu, New Zealand $\quad 24$

3.2. Mount Merapi, Eastern Java, Indonesia $\quad 27$

3.3. Mount St Helens, United States of America 30 
1. Field Investigations 35

2. Measured Sections $\quad 37$

3. Tephrochronology 37

3.1. Sample Selection and Processing $\quad 40$

3.2. Measurement and Data Analysis 41

4. Sedimentology 43

4.1. Grain Size 44

4.2. Clast Form and Roundness $\quad 49$

5. Palaeomagnetic Analysis 51

5.1. The Conglomerate Test 51

5.2. Sampling and Drilling $\quad 54$

5.3. Sample Processing 56

5.4. Data Processing $\quad 57$

Chapter Three - Results $\quad \mathbf{5 9}$

1. East Egmont (EE-1) 60

$\begin{array}{ll}\text { 1.1. Stratigraphy } & 61\end{array}$

1.2. Tephrochronology 61

1.3. Interpretation 62

2. Vickers Quarry (VQ-1, VQ-2 and VQ-3) 64

2.1. Stratigraphy 66

2.2. Tephrochronology and $\mathrm{C}^{14}$ Chronology 67

2.3. Sedimentology 68

$\begin{array}{ll}\text { 2.4. Interpretation } & 69\end{array}$

3. Surrey Road Quarry (SQ-1, SQ-2 and SQ-3) 73

$\begin{array}{ll}\text { 3.1. Stratigraphy } & 74\end{array}$

3.2. Tephrochronology $\quad 75$

3.3. Interpretation 76

4. York Road (YR-1 and YR-2) 80

4.1. Stratigraphy $\quad 81$

4.2. Tephrochronology $\quad 82$

4.3. Sedimentology $\quad 82$

4.4. Interpretation $\quad 83$

5. Tariki-SH3 (TR-1) 85

5.1. Stratigraphy 86

5.2. Tephrochronology $\quad 87$

5.3. Interpretation $\quad 87$ 
6. Tariki Underpass (TU-1, TU-2, TU-3 and TU-4) 89

6.1. Stratigraphy 90

6.2. Tephrochronology 93

6.3. Sedimentology 94

6.4. Interpretation $\quad 94$

7. Suffolk Road Junction (SF-1) 99

$\begin{array}{ll}\text { 7.1. Stratigraphy } & 100\end{array}$

$\begin{array}{ll}\text { 7.2. Tephrochronology } & 100\end{array}$

$\begin{array}{ll}\text { 7.3. Interpretation } & 101\end{array}$

8. Kaimata Sawmills (MG-1) 103

$\begin{array}{ll}\text { 8.1. Stratigraphy } & 104\end{array}$

$\begin{array}{ll}\text { 8.2. Tephrochronology } & 105\end{array}$

$\begin{array}{ll}\text { 8.3. Sedimentology } & 105\end{array}$

$\begin{array}{ll}\text { 8.4. Interpretation } & 106\end{array}$

9. Palaeomagnetic Analysis 107

$\begin{array}{ll}\text { 9.1. Preliminary Investigation } & 107\end{array}$

9.2. Main Lower Unit Investigation 109

9.2.1. Magnetic Susceptibility 109

9.2.2. Palaeomagnetic Directions 110

$\begin{array}{ll}\text { 9.2.3. Thermal History } & 117\end{array}$

9.3. Preliminary Upper Unit Investigation 122

9.3.1. Magnetic Susceptibility 122

9.3.2. Palaeomagnetic Directions 122

$\begin{array}{ll}\text { 9.3.3. Thermal History } & 127\end{array}$

$\begin{array}{ll}\text { Chapter Four - Discussion } & 130\end{array}$

1. Internal Architecture 130

$\begin{array}{lr}\text { 1.1. Distribution } & 130\end{array}$

1.2. Deposit Characteristics 130

1.2.1. Debris Flow Deposits 132

1.2.2. Hyperconcentrated Flow Deposits 133

$\begin{array}{ll}\text { 1.3. Lateral and Longitudinal Variability } & 133\end{array}$

1.3.1. Proximal 133

$\begin{array}{ll}\text { 1.3.2. Intermediate } & 134\end{array}$

$\begin{array}{ll}\text { 1.3.3. Distal } & 138\end{array}$

2. Emplacement History 139

2.1. Precursory Events 139

2.2. Emplacement Mechanisms 140

2.3. Emplacement Temperature 143

2.4. Flow Transformation 145 
2.5. Emplacement of the Manganui Tephra and Te Popo Formation

2.6. Summary of Emplacement

3. Hazards

Chapter Five - Conclusions

1. Conclusions

2. Future Work 155

References

Appendix A - Stratigraphy, Sedimentology and EMP Results

Appendix B - Electron Microprobe Data

Appendix C - Sedimentological Data

Appendix D - Palaeomagnetic Data 


\section{List of Figures}

Figure

Figure 1: Map of the Taranaki Peninsula with key geomorphological features. Basemap 1:250,000 from Land Information New Zealand...

Figure 2: Tephrostratigraphic units described by Neall (1972). These include the Korito and Inglewood Tephra..

Figure 3: Composite tephrostratigraphy from Egmont Volcano encompassing deposits from Maketawa Tephra (c. 2,900yrs B.P.) to Mahoe (c. 11,000yrs B.P.) (Alloway et al., 1995).

Figure 4: Isopach map (cm) for the Inglewood Tephra (Alloway et al., 1995)

Figure 5: (A) Stratigraphic description and (B) stratigraphic log (in meters) of the Ngatoro Formatio, including the underlying Inglewood Tephra, located at the Johns Road junction with State Highway 3 near the Tariki rail overpass (Alloway, 1989).

Figure 6: Mapped distribution of the Ngatoro Formation and other Quaternary deposits on the Taranaki Peninsula (Neall and Alloway, 2004).

Figure 7: Diagram showing the transitions between magma types, intrusive and extrusive volcanic rocks and their relative compositions (Sigurdsson et al., 2000).

Figure 8: Diagram of regional tectonic processes associated with the formation of andesite volcanoes (Tarbuck and Lutgen,s 2009)

Figure 9: Cumulative grainsize distribution comparing debris flows with lahar-runout flow and stream flow on Mt St Helens (Scott, 1988)

Figure 10: Modified location map of major Mt Ruapehu Lahar courses from Cronin et al. (1997b). Whangaehu River represented in orange..

Figure 11: (A) 1861 mass flow deposit exposed beneath the 1945 ash and 1975 lahar deposit. (B) Exposed, crudely stratified lahar deposits located $9 \mathrm{~km}$ from the Crater Lake -stratification interpreted as pulses or transformations of the mas flow. An upper main channel of the Whangaehu River (C) before and (D) after the $18^{\text {th }}$ March 2007 Crater Lake breakout mass flow(Graettinger et al, 2010).

Figure 12: Map showing mass flow distribution in the 13 rivers since $A D$ 1500. The mass flows are concentrated in the south and south western sector (Lavigne et al., 2000).

Figure 13: The Boyong River (A) before and (B) after the 22 November 1994 Merapi eruption (Lavigne and Thouret, 2002), and a bridge on the same river (C) before and (D) after the 20 February Merapi eruption (Lavigne et al., 2000)........

Figure 14: Monthly distribution of rain triggered mass flows in the Boyong River during two monsoon seasons following the 1994 Merapi eruption (Lavigne and Thouret, 2002)..

Figure 15: Deposits and associated grain size statistics of the 1980 South Fork lahar, 1982 lahar, and associated laharrunout flows (Scott, 1988).

Figure 16: Map showing the distribution of the 1980 and 1982 Lahars on Mt St Helens. Letter A-F represents deposits identified in Fig 15 (Scott, 1988). 
Figure 18: (A) Exposed Pine Creek lahars including a large $(5 \times 12 \mathrm{~m})$ egg-shaped mega-clast. (B) Bar deposits of the North

Fork lahar. Deposits include hydrothermally altered clasts and rounded alluvial clasts bulked from the existing river bed. (C) Deposits of the 1982 peak runout flow at Kid Valley. Low density clast are buoyed on the deposits surface. The ' $C$ ' marks the position of the largest clasts within the inversely graded unit. (D) Flood-plain facies of 3 older lahars from the Coal Bank section (Scott, 1988).

Figure 19: Map Egmont Volcano and its ring plain showing the extent of the Ngatoro Formation according to Neall and Alloway (2004), and the location of sections studied in this thesis. Base map 1:250,000 from Land Information New Zealand...

Figure 20: Photos of the sections sampled for Electron Microprobe reference dataset. (A) East Egmont and (B) Dawson Falls sections - Photos courtesy of A/Prof Brent Alloway..

Fig 21: Stratigraphic sections sampled as reference Electron Microprobe dataset. Reference dataset and stratigraphic sections courtesy of A/Prof Brent Alloway

Figure 22: The JEOL 733 Superprobe Electron Microprobe at Victoria University used in this study.......

Figure 23: Selected electron microscope images of the showing typical vesiculated glass selvedges used in the acquisition of major elemental glass composition data.

Figure 24: Wentworth grain size scale (Wentworth, 1922)

Figure 25: Photographs of the sections sampled for grain size and shape analysis - (A) Vickers Quarry (proximal), (B) York Road, (C) Tariki Underpass (intermediate) and (D) Kaimata Sawmills (distal).

Figure 26: Coarse sieve stack and laboratory scales used in the grain size analysis

Figure 27: Ternary diagram showing the clast shape classes defined by Sneed and Folk (1958) based on the ratios of the clast 3 principal axis.

Figure 28: Clast roundness scale. Ranges from very angular (0.1) to well rounded (0.9) (Krumbien, 1941; Waddell, 1932).........

Figure 29: Plot showing the strong correlation between palaeomagnetic temperature estimates and measured temperatures at Mt St Helens and El Chichon (Paterson et al., 2010).

Figure 30: (A) Water cooled, diamond tipped palaeomagnetic drill being used to sample a large andesite boulder at Vickers Quarry. (B) The palaeomagnetic drill used to collect the core samples. (C) The orienting stage and magnetic compass being used to orient a sample. (D) The stage, magnetic compass and sun compass used to orient samples.......

Figure 31: Example of a labelled palaeomagnetic core and specimen. (Inset) Schematic of the palaeomagnetic specimen labelling system with respect to the $X, Y$ and $Z$ axis.

Figure 32: Typical stepwise thermal demagnetisation results from Mt St Helens. Results presented in Zijderveld Diagrams (top), Equal Area Stereographic Projections (Middle) and Intensity vs Temperature Plots (Bottom). This figure shows both (a) single component of magnetisation and (b) two companents of magnetisation within the samples (Paterson et al., 2010).......

Figure 33: Aerial photograph showing the location of section EE-1 relative to the Manganui River and Ski Field. Photo courtesy of Taranaki Regional Explorer (2014).

Figure 34: Stratigraphy of section EE-1.

Figure 35: Photograph of section EE-1 with relevant lithostratigraphic units

Figure 36: View up the Manganui Valley towards section EE-1. The valley walls comprise $<100 m$ thick block and ash flow deposits overlying lava flow and autobreccia deposits. 
Figure 37: Section EE-1 exposing the Korito, Inglewood and Manganui Tephra. Upper pyroclastic surge deposits stratigraphically correlate with the Ngatoro Formation.

Figure 38: Aerial photograph showing the location of sections.VQ-1, VQ-2 and VQ-3. Photo courtesy of Taranaki Regional Explorer (2014).

Figure 39: Stratigraphy of section VQ-1, VQ-2 and VQ-3

Figure 40: Photograph of the basal pumiceous lapilli sequence at section VQ-1 with relevant lithostratigraphic units.

Figure 42: Photograph of section VQ-2 with relevant lithostratigraphic units. Photo courtesy of A/Prof Brent Alloway.

Figure 4: Photograph of section VQ-3 basal pumiceous lapilli sequence and paleosol with relevant lithostratigraphic units...

Figure 44: Photograph showing the Korito Tephra and Inglewood.a and Inglewood.b subunits at the base of sections VQ-1 and $V Q-2$.

Figure 45: Photograph showing the discontinuous basal sole layer at Vickers Quarry

Figure 46: Photograph show the Ngatoro Formation overlying the Korito Tephra and Inglewood.a and Inglewood.b subunits at sections $V Q-1$ and $V Q-2$..

Figure 47: Truncated tree heights with accompanying photographs showing the excavated charred and desiccated in situ trees..

Figure 48: Aerial photograph showing the location of sections SQ-1, SQ-2 and SQ-3. Photo courtesy of Taranaki Regional Explorer (2014).

Figure 49: Stratigraphy of sections $S Q-1, S Q-2$ and $S Q-3$

Figure 50: Photograph of section SQ-2 with relevant lithostratigraphic units. Photo courtesy of A/Prof Brent Alloway...

Figure 51: Photograph of section SQ-3 with relevant lithostratigraphic units. Photo courtesy of A/Prof Brent Alloway.....

Figure 52: Photograph showing the Inglewood.b subunit, organic rich paleosol with wood fragments and the basal sole layer described at Surrey Road Quarry.

Figure 53: Photograph showing the Ngatoro Formation enveloped by the Inglewood.b subunit and paleosol and the overlying Manganui.a subunit at section SQ-2. Photo courtesy of A/Prof Brent Alloway.......

Figure 54: Photograph showing the Manganui.b and Manganui.c subunits with interbedded overbank pebbly sand debris flow deposits at section SQ-3.

Figure 55: Photograph showing a debris flow deposit of the Te Popo Formation incised (orange line) into the underlying Ngatoro Formation and Manganui.a subunit forming a boulder-rich channel deposit.

Figure 56: Photograph showing the subunits of the Manganui Tephra (light blue) eroded away by channel deposits of the overlying Te Popo Formation.

Figure 57: Aerial photograph showing the location of sections YR-1 and YR-2. Photo courtesy of Taranaki Regional Explorer (2014).

Figure 58: Stratigraphy of sections $Y R-1$ and $Y R-2$

Figure 59: Photograph of the basal pumiceous lapilli sequence at YR-1 with relevant lithostratigraphic units.

Figure 60: Photograph showing two pebble and cobble rich sand units with interbedded pumiceous lapilli at section YR-2 with relevant lithostratigraphic units. 
Figure 61: Photograph showing the pumiceous lapilli overlain by a pebble and cobble rich sand unit at section YR-2 with relevant lithostratigraphic units.

Figure 62: Photograph showing the marginal debris flow deposits of the Ngatoro Formation overlying the Korito Tephra, and Inglewood.a and Inglewood.b at section YR-1..

Figure 63: Aerial photograph showing the location of section TR-1. Photo courtesy of Taranaki Regional Explorer (2014).....

Figure 64: Stratigraphy of section TR-1.

Figure 65: Photograph of section TR-1 with relevant lithostratigraphic units

Figure 66: Photograph of the basal pumiceous lapilli and overlying organic-rich clay at section TR-1 with relevant lithostratigraphic units.

Figure 67: Photograph showing the basal Inglewood Tephra overlain by the organic-rich paleosol at section TR-1.

Figure 68: Photograph showing hyperconcentrad flow deposits and debris flow deposits at section TR-1.

Figure 69: Aerial photograph showing the location of sections TU-1, TU-2, TU-3 and TU-4. Photo courtesy of Taranaki Regional Explorer (2014)

Figure 70: Stratigraphy of sections TU-1, TU-2, TU-3 and TU-4

Figure 71 (Above): Photograph showing the basal pumiceous lapilli sequence at section TU-1 with relevant lithostratigraphic units. Photo courtesy of A/Prof Brent Alloway.....

Figure 72: Photograph showing the organic-rich sand unit at section TU-1. Photo courtesy of A/Prof Brent Alloway.....

Figure 73: Photograph showing the stratified sandy units overlying the basal pumiceous lapilli sequence at section TU-2 with relevant lithostratigraphic units. Photo courtesy of A/Prof Brent Alloway.

Figure 74: Photograph showing the three basaltic, scoriaceou slapilli beds overlying pebbly sand basal deposits at TU-4 with relevant lithostratigraphic units.

Figure 75: Photograph showing sandy hypercocnentrated flow deposits of the Ngatoro Formation overlying the Korito Tephra, and the Inglewood.a and Inglewood.b subunits at section TU-2. Note the three interbedded sole layers..

Figure 76: Photograph showing the load deformation of the sole layer and the incised hypercocnentrated flow deposits of the Ngatoro Formation in to the basal lapilli sequence at section TU-1. Photo courtesy of A/Prof Brent Alloway.

Figure 77: Photograph showing the flame dewatering structures in the hypercocnentrated flow deposits at section TU-1. Photo courtesy of A/Prof Brent Alloway.

Figure 78: Photograph showing the Manganui.a, Manganui.b and Manganui.c subunits overlying hyperconcentrated flow deposits of the Ngatoro Formation at section TU-4.

Figure 79: Aerial photograph showing the location of section SF-1. Photo courtesy of Taranaki Regional Explorer (2014)......

Figure 80: Stratigraphy of section SF-1

Figure 81: Photograph of section SF-1 with relevant lithostratigraphic units

Figure 82: Photograph showing the sandy hypercocnentrated flow and pebbly sand debris flow deposits of the Ngatoro Formation overlying the Korito and Inglewood Tephra.. 
Figure 86: Photograph showing the basal pumiceous lapilli sequence at section MG-1 with relevant lithostratigraphic units..

Figure 87: Photograph showing the hyperconcentrated flow and debris flow deposits at section MG-1....

Figure 88: Zijderveld diagram and magnetic intensity plots showing the demagnetisation of specimen VQ2-3C. The specimen exhibits a single component of magnetisation

Figure 89: Room temperature magnetic susceptibility versus temperature plot for the main lower unit investigations specimens. Specimens plots are distinguished by colour based on clast

Figure 90: Remanent magnetisation intensity versus temperature plots showing examples of a gradual, almost linear loss

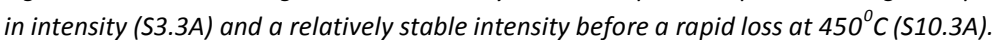

Figure 91: Lambert (equal area) stereoplots and Zijderveld diagrams showing the predominant styles of behaviour of specimens during thermal demagnetisation

Figure 92: Lambert (equal area) stereoplots and Zijderved diagrams showing the behaviour of specimens which differs from the predominant behaviour shown in Figure 91.

Figure 93: Lambert (equal area) stereoplots showing the low temperature $\left(C_{l}\right)\left(\right.$ left) and high temperature $\left(C_{h}\right)$ (right) components of each specimen (top) and as a clast mean (bottom) - Clast S3 (yellow); S4 (black); S5 (purple); S7 (light blue); S10 (red); S11 (dark blue); S12 (green); and S15 (orange).

Figure 94: Idealised illustration providing a visual representation of the high, intermediate and low temperature components of magnetisation.

Figure 95: Plot showing the incorporation and emplacement temperature estimates based on PCA outlined in Table 8........

Figure 96: Room temperature magnetic susceptibility verses temperature plot for the preliminary upper unit investigations specimens. Specimens plots are distinguished by colour based on clast

Figure 97: Remanent magnetisation intensity versus temperature plots showing demagnetisation behaviour exhibited by the specimens.

Figure 98 (below): Lambert (equal area) stereoplots and Zijderveld diagrams showing the predominant behaviour of specimens during thermal demagnetisation

Figure 99: Lambert (equal area) stereoplots and Zijderved diagrams showing the behaviour of specimens which differs from the predominant behaviour shown in figure 98.

Figure 100: Stereoplots showing the low temperature $\left(C_{l}\right)$ (left) and high temperature $\left(C_{h}\right)$ (right) components of each specimen (top) and as a clast mean (bottom) - Clast S16 (orange); S17 (light blue); S18 (green); and S19 (black)..

Figure 101: Plot showing the incorporation and emplacement temperature estimates based on PCA outlined in Table 9......

Figure 102): Normally graded, fine sand to silt, sole layer at the base of the Ngatoro Formation......

Figure 103: Measured sections indicating the transition from proximal pyroclastic surge and debris flow deposits to intermediate and distal hypercocnentrated flow deposits. Grain size histograms show the deposits becoming more sorted and fine grained with distance from Egmont Volcano.

Figure 104: Measured sections indicating the transition from thick, axial cobble and boulder rich debris flow deposits to thin, marginal pebbly sand debris flow deposits. Grain size histograms show the deposits becoming more sorted and fine grained with distance from the channel axis.

Figure 105: Measured sections indicating the transition from massive, coarse textured channel deposits to massive-tostratified, fine textured marginal deposits. Grainsize histograms for the marginal deposits indicate they are sorted, fine grained, pebbley sand deposits. 
Figure 106: Photographs of the well-developed paleosol between the underlying Inglewood.b subunit and overlying Ngatoro Formation debris flow deposits.

Figure 107: Photographs of block and ash flow generation from the collapse of an effusive lava dome on Unzen Volcano, February 251992 (Ui et al., 1999)

Figure 108: Schematic map indication the positions of the seismographs and continuous GPS site as part of the Egmont Volcano monitoring program (Johnston et al., 2011)

Figure 109: Combined volcanic hazard zone map (Neall and Alloway, 1995). The areas classified as being at risk of debris/hyperconcentrated flows and associated flood flows are identified in purple to the north-east, north-west and south-west of Egmont Volcano. 


\section{List of Tables}

$\underline{\text { Table }}$

Table 1: Inglewood Tephra sections described by Neall (1972).

Table 2: Sedimentary characteristics and criteria for differentiating between types of volcanic, water-supported mass

flows (modified from Palmer et al. 1991; Alloway et al. 2005; Zenack et al. 2009).....

Table 3 (Next Page): Table describing the features of the facies outlined in the facies model of Scott (1988)......

Table 4: Location and identification number of lapilli beds and entrained pumice clasts sampled for EMP analysis

Table 5: Reference dataset for ATHO-G standard and the measured raw and recalculated dataset from reference measurements during the sample analysis.

Table 6: Description of sorting based on the inclusive graphic standard deviation (Boggs, 2006)...

Table 7: Description of skewness based on the inclussice graphic skewness (Boggs, 2006)...

Table 8: Table of the Principle Component Analysis (PCA) results for the main lower unit investigation. The table includes the $C_{l}$ and $C_{h}$ components with their declination, inclination and $\alpha 95$ angles.

Table 9: Table of the Principle Component Analysis (PCA) results for the main lower unit investigation. The table includes the $C_{l}$ and $C_{h}$ components with their declination, inclination and $\alpha 95$ angles..

Table 10: Block and ash, debris and hyperconcentrated flow deposit characteristics of the Ngatoro Formation described in this study. Modification of the Table 2 presented in Section 2, Chapter One.

Table 11: Incorporation temperature estimate of the Ngatoro Formation from this study compared with block and ash flow temperatures from comparable volcanoes. 


\section{Chapter One: Introduction}

\section{Introduction}

\subsection{Field Area}

Taranaki Region located in western North Island, New Zealand, is situated on the eastern edge of the Indo-Australian Plate and is strongly influenced by the oblique-compressional tectonic boundary associated with the subduction of the Pacific Plate occurring immediately eastward of the North Island. Within this tectonic regime, Taranaki Region occurs in the transitional zone between tectonic contraction, strike-slip motion and tectonic rotation that characterises eastern North Island to normal faulting that pervades in western portions of the North Island (Townsend et al., 2008). The geomorphology of the Taranaki Peninsula is dominated by Egmont Volcano (also known as Mount Egmont or Mount Taranaki) set in a complex landscape of eroded extinct andesitic volcanoes (i.e. Pouakai \& Kaitake Volcanoes),

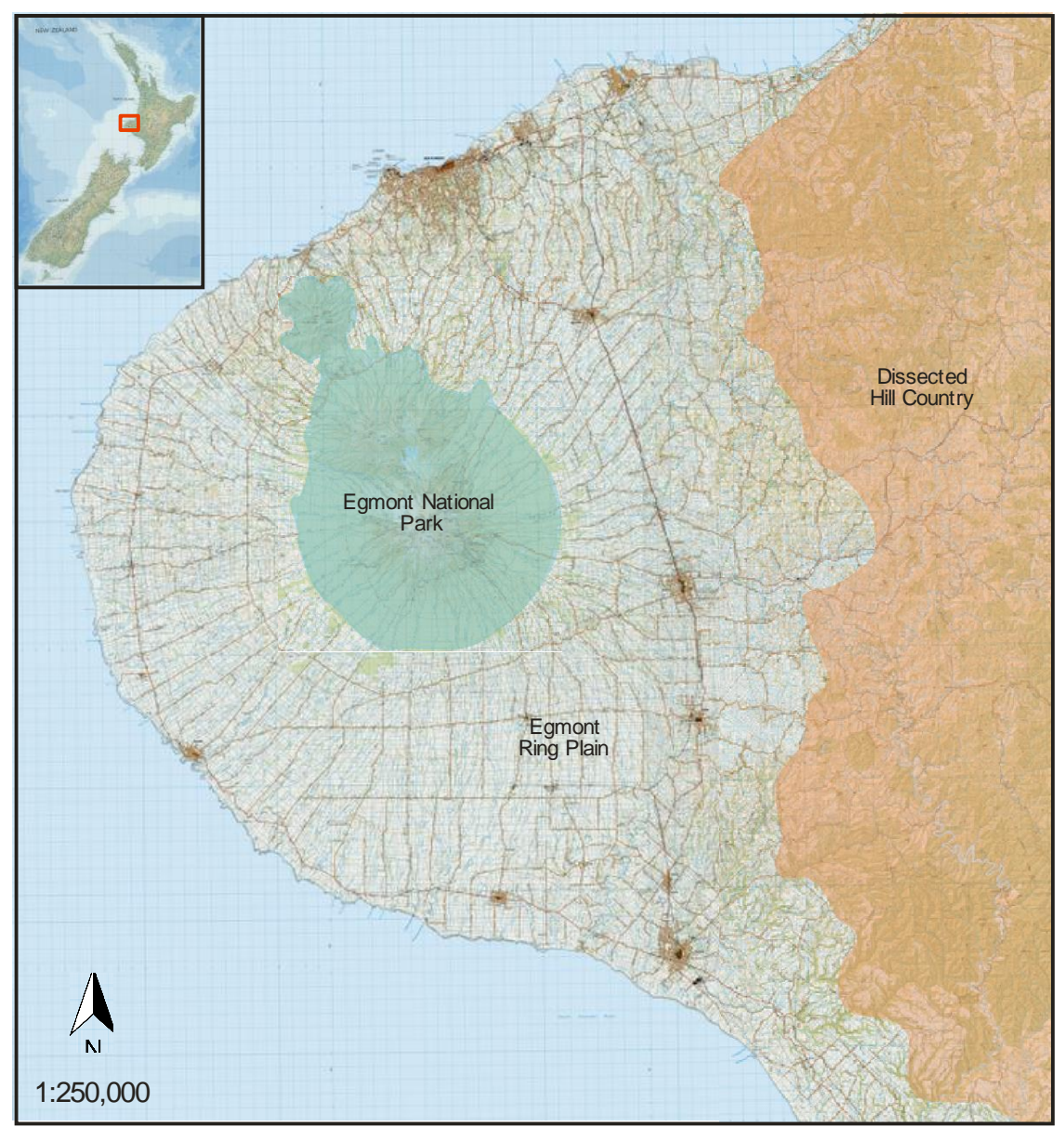

Figure 1: Map of the Taranaki Peninsula with key geomorphological features. These include Egmont National Park (green), the Egmont ring plain and the dissected hill country (orange). Base map 1:250,000 from Land Information New Zealand. 
uplifted and fault-cut marine terrace and weathered volcaniclastic surfaces and a dissected inland hill country dominated by Tertiary-aged mudstones, siltstones and sandstones (Figure 1).

Egmont Volcano is a $2158 \mathrm{~m}$ high andesitic stratovolcano which sits at the southern end of the NNW-SSE Taranaki Volcanic Lineament; comprising the Sugar Loaf Islands (1.75 Ma); Kaitake (c. $0.50 \mathrm{Ma}$ ); Pouakai (c. $0.25 \mathrm{Ma}$ ); and Egmont Volcano at the southern-most end (Neall, 1986). Composed of dominantly pyroxene-plagioclase-hornblende-phyric andesite and basaltic andesite (Price et al., 1992), the edifice comprises a prominent high-angle lava flow mantled upper cone and a ring plain of extensive coalesced laharic, pyroclastic and alluvial volcaniclastic fans (Alloway et al., 1995). Volcaniclastic deposits of the Egmont ring plain record a highly active and intermittent eruptive history stretching over the last 130,000 years with the last definitive eruption occurring c. 1755 A.D (Druce 1966; Alloway et al., 1995). Egmont Volcano has undergone multiple collapse and reconstruction phases over this time represented by multiple debris avalanche deposits - for example, the c. $23 \mathrm{ka}$ Ngaere and the c. 105 ka Okawa Formation (Alloway et al., 2005). The modern volcanic edifice represents $<8 \%$ by volume of the total erupted material over its history and was likely constructed in the last 10,000 years (Downey et al., 1994).

The geographical location of Egmont Volcano presents several volcanic hazards for the Taranaki region given its significant industrial, agricultural and urban development. Unlike the prominent central North Island andesite volcanoes (Mount Ruapehu, Tongariro and Ngauruhoe) Egmont Volcano has not erupted since European colonisation to the region though there is archeological evidence that pre-European Maori did perhaps witness volcanic activity centred at Egmont Volcano (Alloway et al. 1990). Taranaki has a population of 104,127 people or $2.6 \%$ of the national population (Statistics New Zealand, 2006) with the majority of the population occupying the volcanic ring plain. Taranaki has a highly productive agriculture sector - $60 \%$ of the region's total $723,610 \mathrm{Ha}$ comprising dairy farmland (Taranaki Regional Council, 2012). The Ministry of Economic Development New Zealand state the income from energy resource levies and royalties on petroleum resources was NZ\$360,612,600 in the 2011-12 financial year, with the majority coming from Taranaki's commercially producing condensate and natural gas fields. 


\subsection{Previous Work}

The first documented evidence for activity on Egmont volcano was recorded by A. W. Burrell who found pumiceous clasts lodged in the forks of living Matai (Podocarpus spicatus) and Rimu (Dacrydium cupressinum) in 1888 , later published in Oliver (1931). The first detailed study of ash and lapilli layers was published by Druce (1966) who identified nine eruptives since 1600 A.D. This included the Korito and Inglewood Tephra which underlie the Ngatoro Formation. The first compiled record of Egmont Volcanoes tephrostratigraphy, by Neall (1972), focused on western Taranaki, and included 10 previously unknown tephra formations and constituent members (Figure 2).

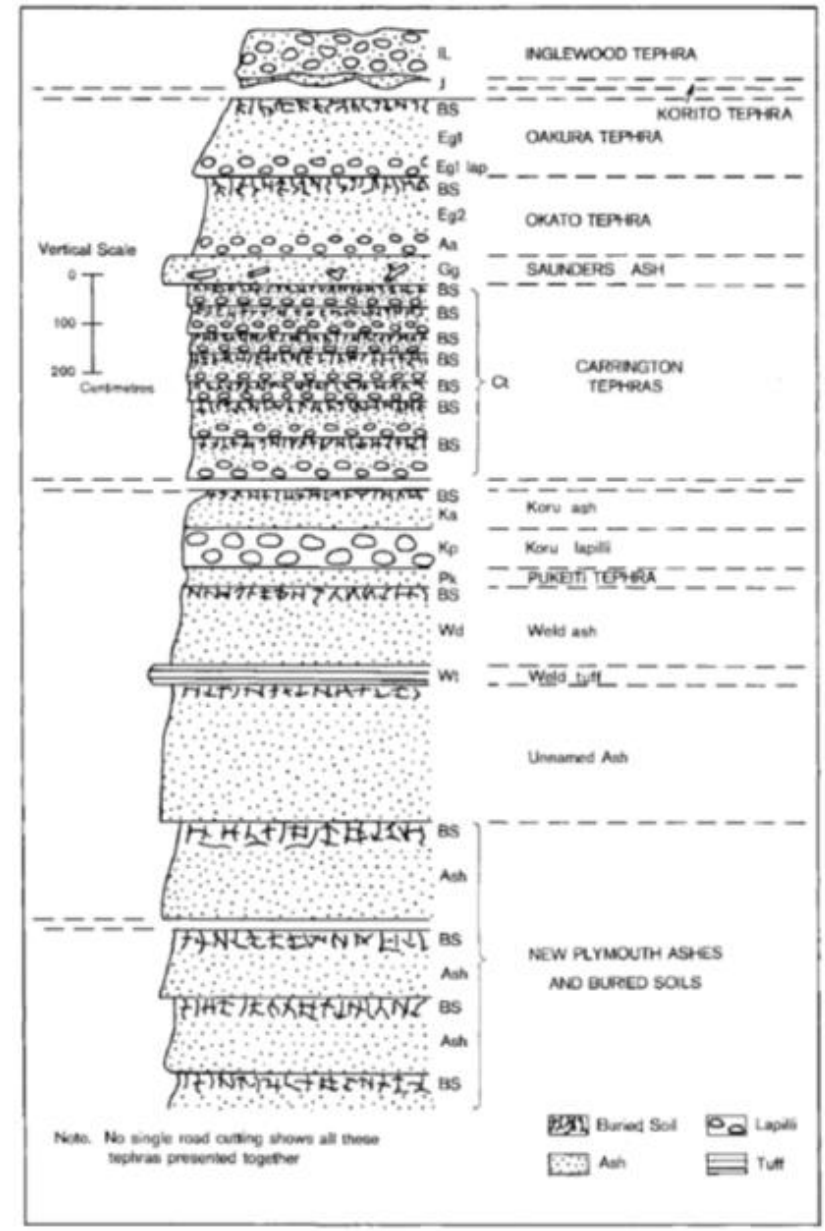

Figure 2: Tephrostratigraphic units described by Neall (1972). These include the Korito and Inglewood Tephra.

The Inglewood Tephra was formally named and described by Neall (1972). Named after the township located $15 \mathrm{~km}$ south-east of New Plymouth, the Inglewood Tephra was described as a single bed containing creamy pumiceous lapilli, blocks near source and an upper contact to topsoil formed on the modern day ground surface. No shower bedding or charcoal was observed and was considered to be less than 5,000 years old. The Inglewood Tephra was described at two locations (Table 1).

The Inglewood Tephra was subsequently redefined by Alloway et al. (1995) to include two closely spaced pumiceous lapilli beds exposed on the eastern Taranaki landscape. These beds were informally named Inglewood.a and Inglewood.b in order of decreasing age (Figure 3). On the lower flanks of Egmont Volcano, the lapilli beds are typically separated by $<0.14 \mathrm{~m}$ of medial-ashy material which thins with increasing distance from source to ultimately form a single composite tephra bed. On the upper flanks, both lapilli beds are separated by a variably thick pyroclastic density current deposit. An isopach map of 
Inglewood Tephra (encapsulating both lapilli beds and its distal composite) was mapped by Alloway et al. (1995) extending broadly north-eastward in the direction of the settlements of Kaimata, Ratapiko as well as across to Onaero Beach on the north Taranaki coast (Figure 4).

The Inglewood Tephra has been dated at 3,690 $\pm 80{ }^{14} \mathrm{C}$ yrs B.P. using a peat sample directly beneath the Inglewood.a bed located at Onaero Beach (Alloway, 1989; Alloway et al., 1995), and at 3,610 $\pm 80{ }^{14} \mathrm{C}$ yrs B.P. from wood fragments directly underlying the Ngatoro Formation (Neall, 1979). The proximal Inglewood Tephra has been correlated with the distal Eg-2, medium to coarse ash bed sampled from Waikato Lake cores (Lowe, 1988). The Eg-2 ash has a radiocarbon age of $3,700{ }^{14} \mathrm{C}$ yrs B.P. Based on these radiocarbon dates the Inglewood Tephra is considered to have an age of c. $3,600{ }^{14} \mathrm{C}$ yrs B.P.

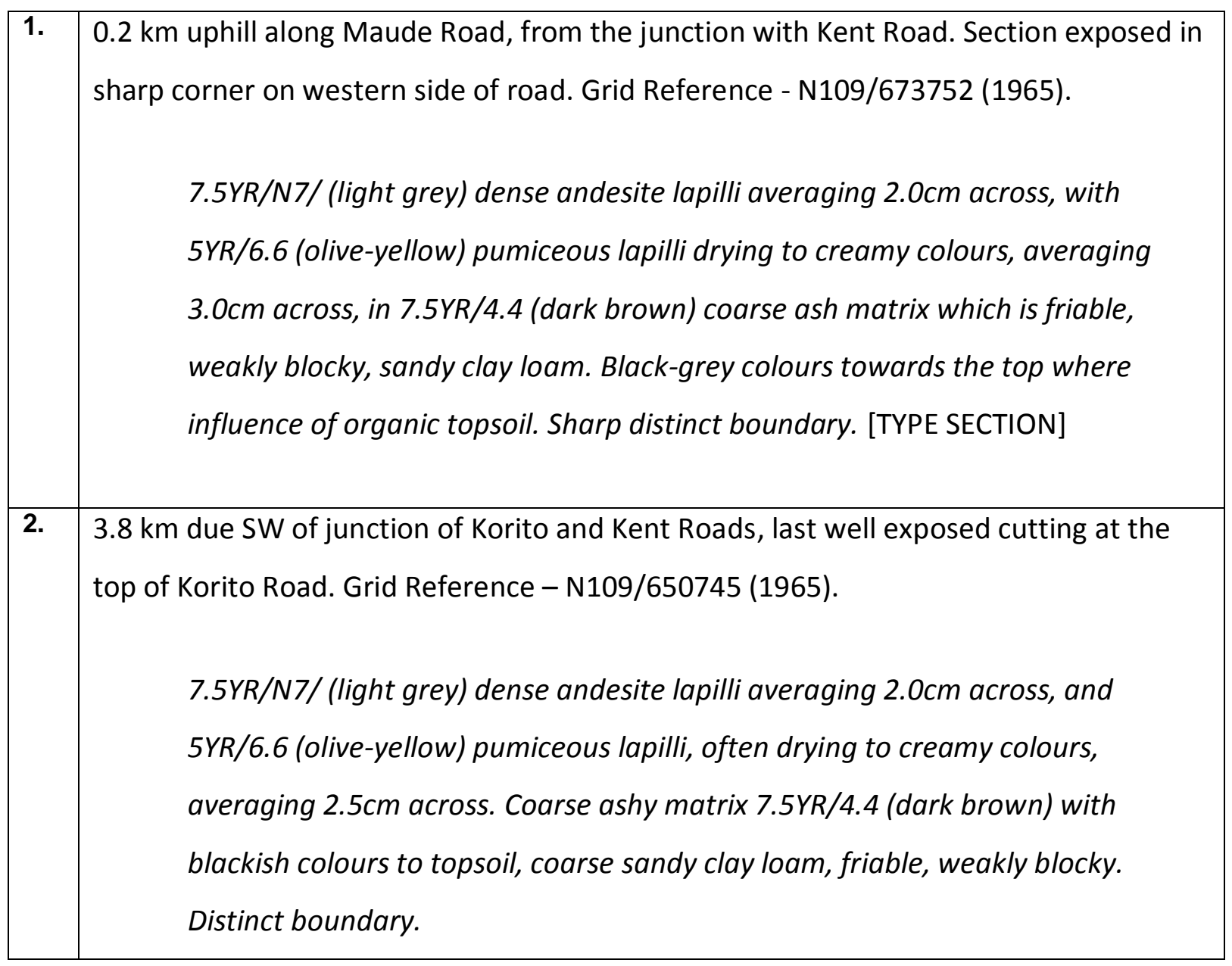

Table 1: Inglewood Tephra sections at Maude Road and Korito Road described by Neall (1972). 


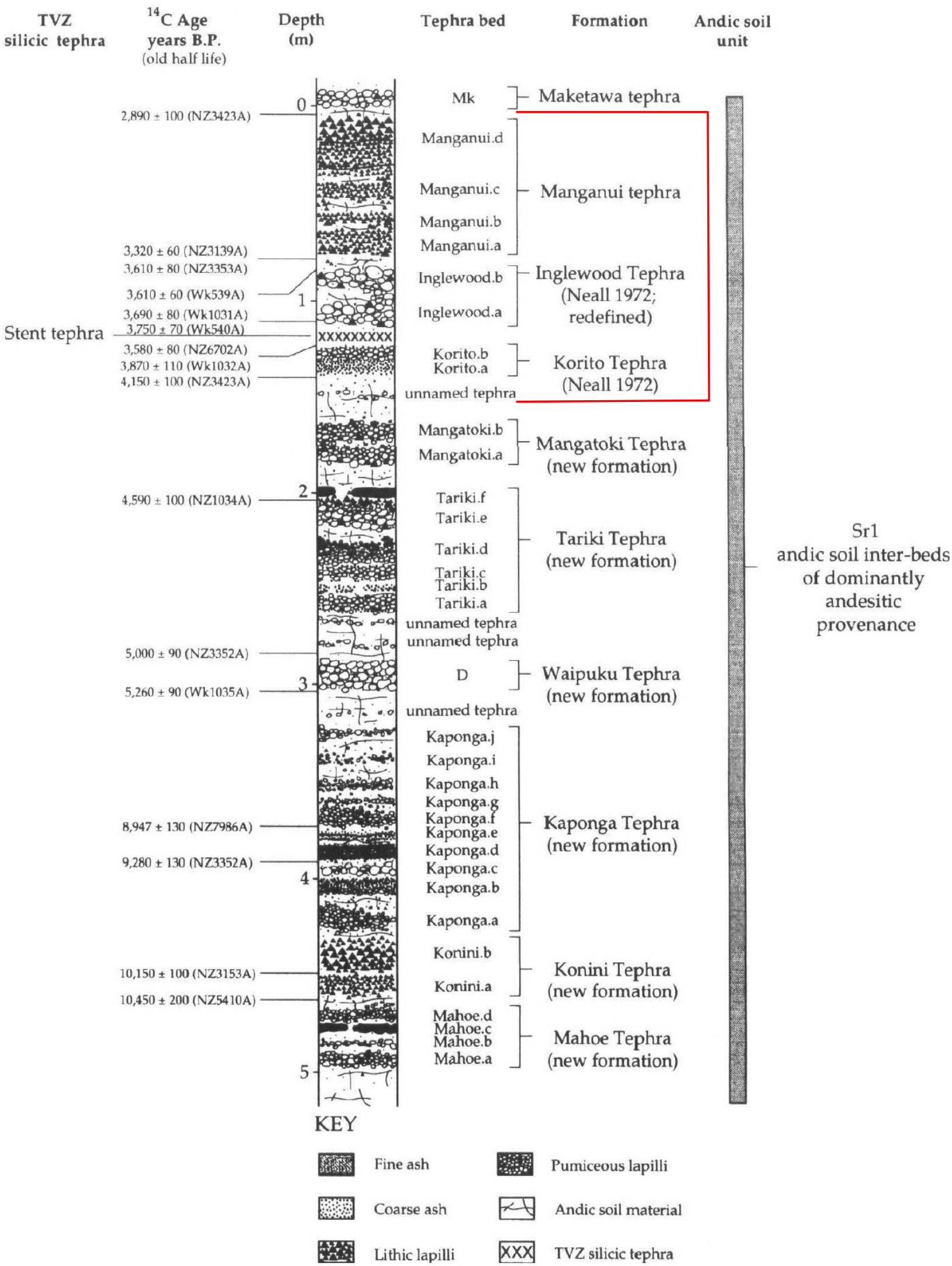

Figure 3: Composite tephrostratigraphy from Egmont Volcano encompassing deposits from the Maketawa Tephra (c. 2,900yrs B.P.) to Mahoe Tephra (c. 11,000yrs B.P.) (Alloway et al., 1995). The tephra sequence described in this thesis is marked by the red line. 


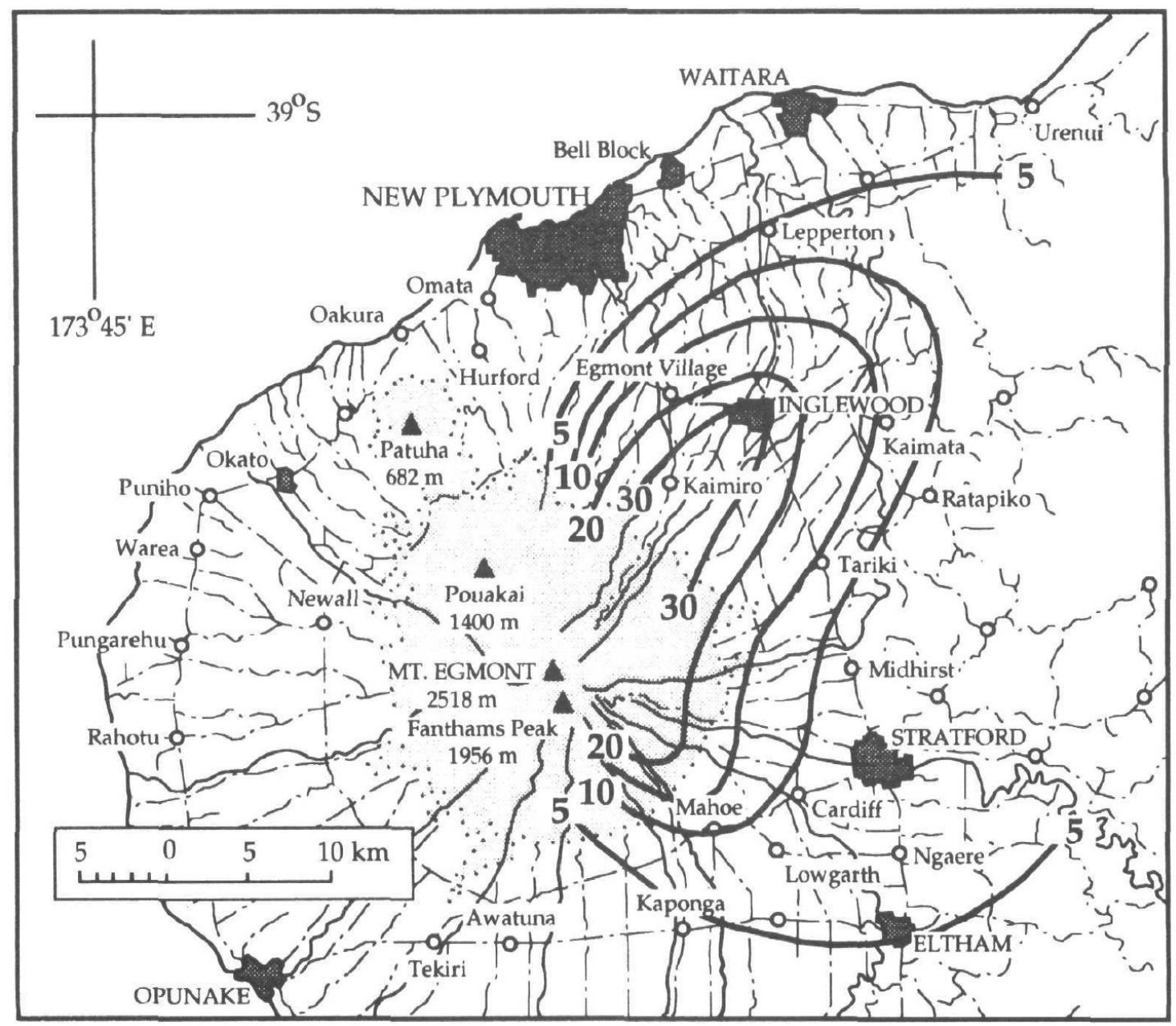

Figure 4: Isopach map (in centimetres) indicating the distribution of the Inglewood Tephra (Alloway et al., 1995).

Closely associated with Inglewood Tephra was a single lahar deposit formally named by Neall (1979) as Ngatoro Formation after the Ngatoro Stream where it was first recognized and is well exposed. The type section for the Ngatoro Formation is $0.4 \mathrm{~km}$ to the north and north east of Bedford Road and south of Norfolk Road Junction. The Ngatoro Formation was subsequently studied by Alloway (1989) in his PhD thesis who described the formation as a single debris flow deposit which transformed both laterally from its flow axes to its margins as well as downstream to a hyperconcentrated flow then subsequently to a flood flow deposit as it passaged down Manganui and Waitara River tributaries. The lower boundary of the Ngatoro Formation is separated from Inglewood. $b$ tephra below by $<0.10 \mathrm{~m}$ of andic medial or hydrous material and its upper boundary from Manganui tephra above by $<0.20 \mathrm{~m}$ of andic medial or hydrous material. The Manganui Tephra manifests as multiple scoriaceous basaltic lapilli associated with an eruption from Fanthams Peak (Petrie, 1988). 
Based on radiocarbon dates associated with Inglewood Tephra in Taranaki (Neall, 1972; Alloway, 1989; Alloway et al., 1995) and from distal sites in the Waikato (Lowe, 1988) the Ngatoro Formation is considered to have an age of c. $3,600{ }^{14} \mathrm{C}$ yrs B.P. (Alloway, 1989; Lowe, 1988).

To complement the two sections designated by Neall (1979), a new stratigraphic section was designated by Alloway (1989) (Figure 5). This is a prominent westward facing cut slope along State Highway 3 opposite the junction with Johns Road, Tariki (Figure 5a and b). The distribution of the Ngatoro Formation is divided into a north-eastern lobe (nt1) and an eastern lobe (nt2) (Figure 6):

- $\quad$ nt1 - The north-eastern lobe is c. $1.0 \mathrm{~km}$ wide and preserved on the inter-fluves between the upper tributaries of the Ngatoro Stream. At c. $15.2 \mathrm{~km}$ from the modern Egmont summit the deposit becomes channelized within the Ngatoro and Ngatoroiti Streams, separated by the Kahui Formation exposed on the inter-fluve surface. The deposits are then combined where they enter the Manganui River c. $26.1 \mathrm{~km}$ north-east of the modern Egmont summit.

- nt2 - The eastern lobe is preserved in the Maketawa and Mangatengehu Streams, with the southern extent buried beneath the overlying Te Popo Formation. At c. 14.6 $\mathrm{km}$ from the modern Egmont summit a northern and southern sub-lobe is formed separated by the Kahui Formation exposed on the inter-fluves. The northern sublobe deposits are distributed between the Maketawa Stream and a tributary of the Waitepuku Stream, becoming channelized at c. $16.6 \mathrm{~km}$ north-east of the modern Egmont summit, and the southern sub-lobe deposits are distributed between Waitepuku and Mangatengehu Streams.

- Both lobes nt1 and nt2 merge at the junction of the Manganui River and Ngatoro Stream, with the deposits extending c. $17.0 \mathrm{~km}$ northwards down the Manganui River valley. The distribution of the Ngatoro Formation was depicted in the Quaternary Geological Map of the Taranaki Region in Neall and Alloway (2004) (Figure 6). 


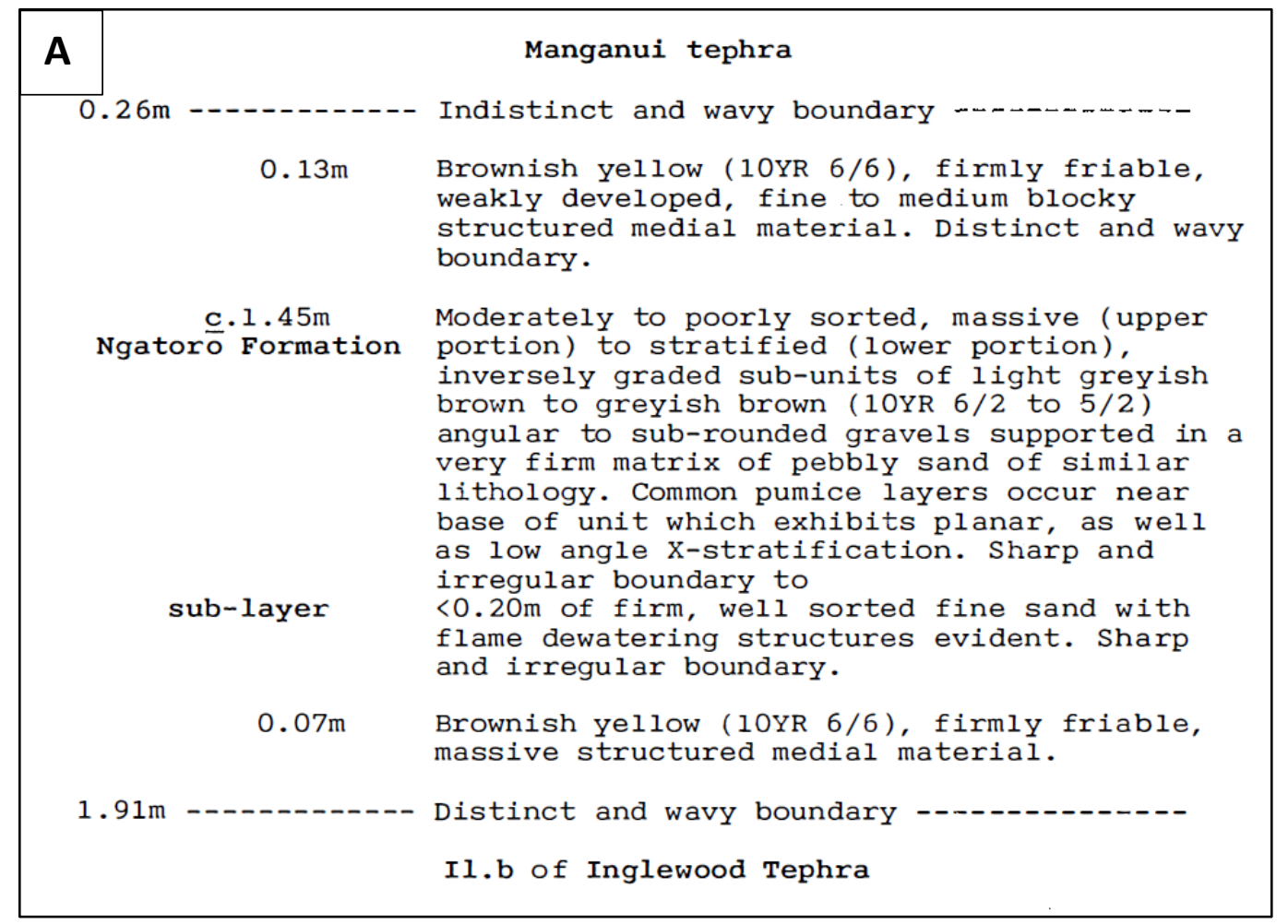

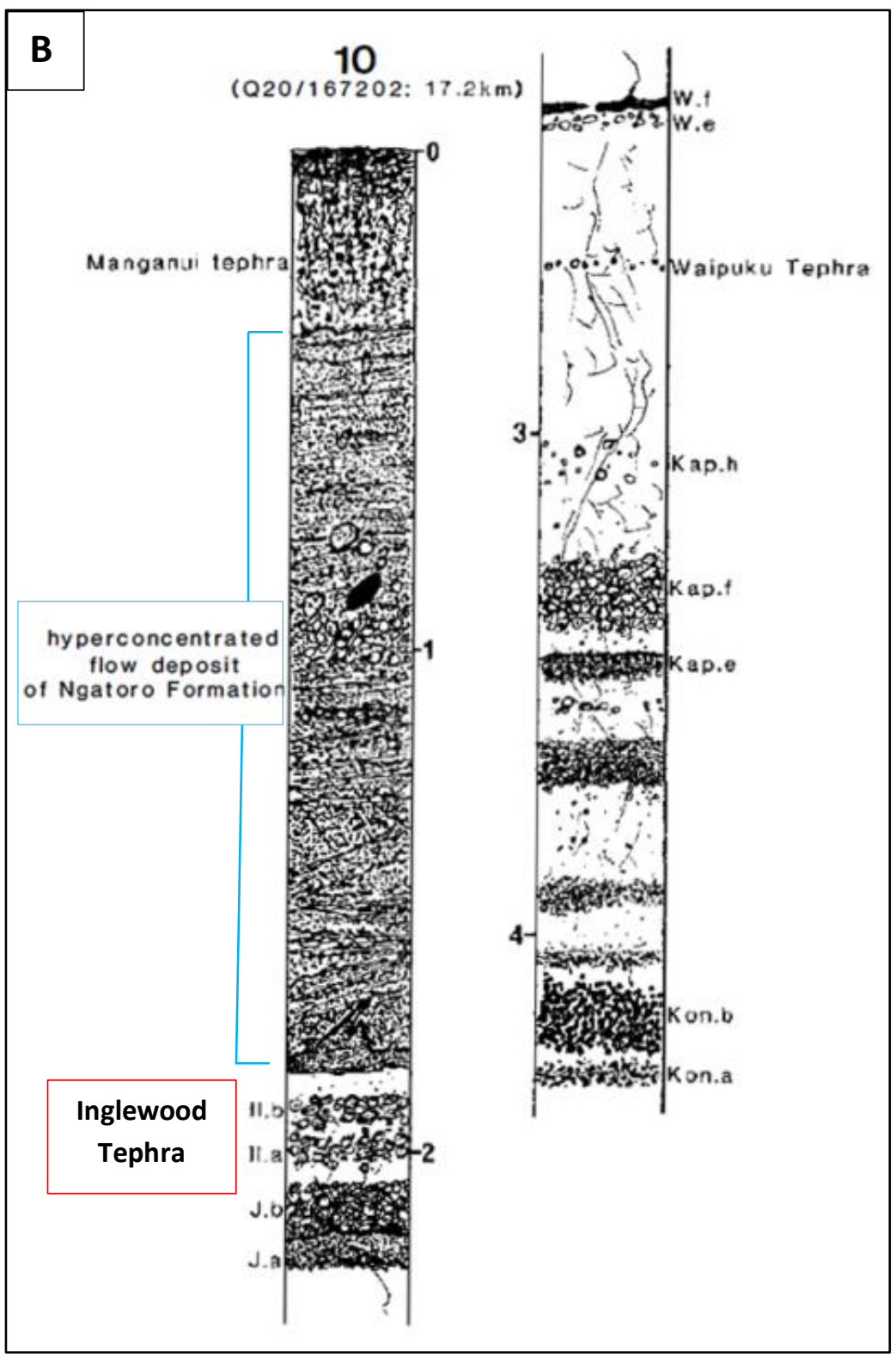

Figure 5: (A) Stratigraphic description and (B) stratigraphic log (in meters) of the Ngatoro Formation, including the underlying Inglewood Tephra, located at the Johns Road junction with State Highway 3 near the Tariki rail overpass (Alloway, 1989). The Inglewood Tephra subunits are noted as II.a and II.b respectively. 


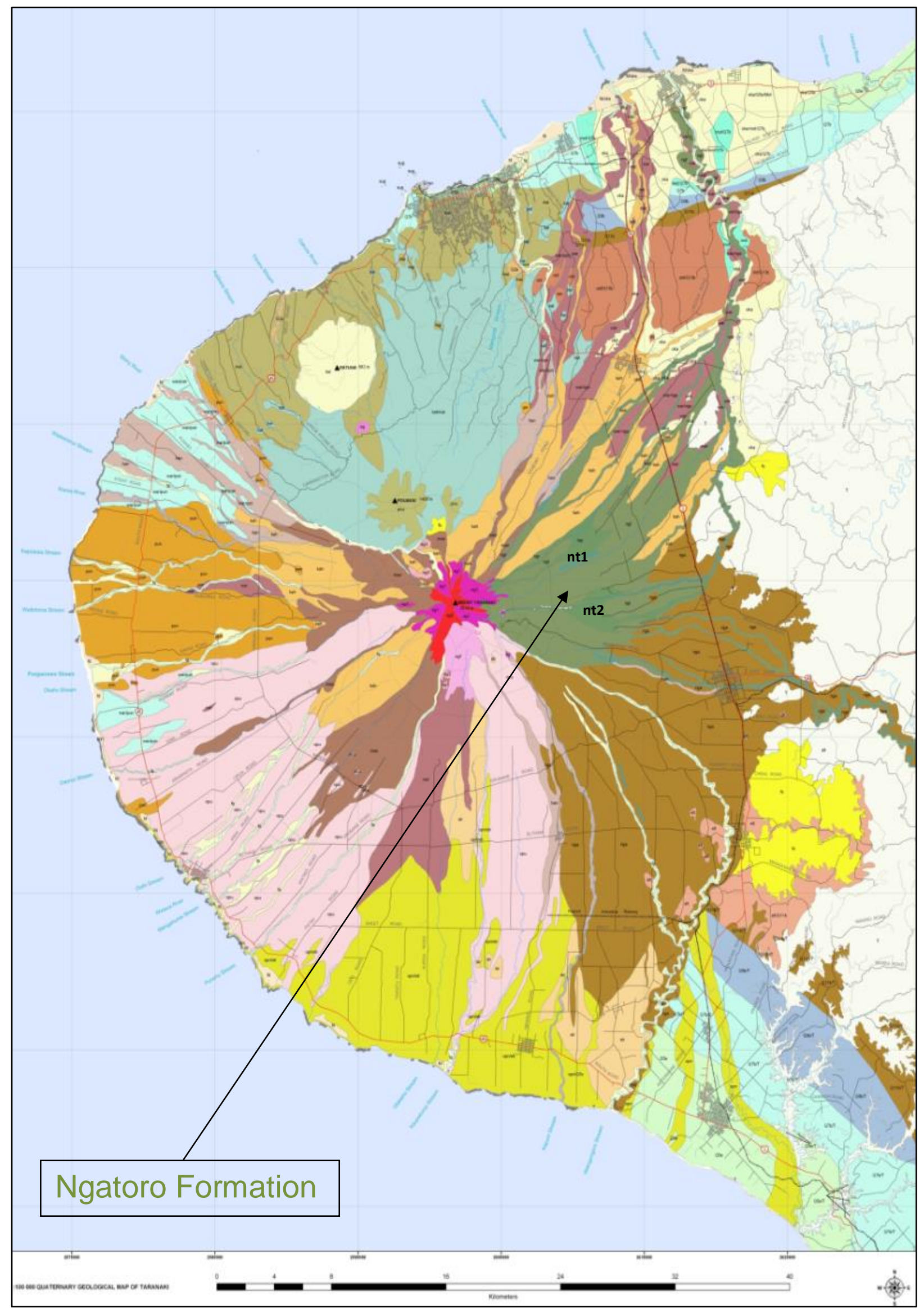

Figure 6: Mapped distribution of the Ngatoro Formation, including nt1 and nt2 lobes, and other Quaternary deposits on the Taranaki Peninsula (Neall and Alloway, 2004). 


\subsection{Importance of this Study}

Detailed studies of past eruptive events expressed in the geological record are imperative to understanding likely impact scenarios during future eruptive events centred at Egmont Volcano. Such evidence suggests that water-supported mass flows (lahars), comparable in size and distribution to the Ngatoro Formation, are a common volcanic process associated with eruptive activity centred on Egmont Volcano (Neall, 1976; Alloway, 1989; Alloway et al., 1995; Neall and Alloway, 1995; Neall and Birks, 2004; Alloway et al. 2005). It can therefore be inferred that similar events can be expected to occur during future eruptive events.

Egmont Volcano is located in a populous and economically important region, so understanding the hazards posed by Egmont Volcano is vital for future regional planning, determining the location and design of infrastructure as well as, minimising loss of lives, property and livelihood. To understand the potential risk posed by future laharic events requires an insight into the mechanisms of emplacement, lateral variations and transformations of the flow, emplacement conditions (eg. temperature, sediment load, and flow regime), and timing.

Previous studies indicate that the Ngatoro Formation was immediately associated with the same eruptive phase that generated Inglewood Tephra. However, there is increasing evidence to suggest that the currently recognised Inglewood eruptive phases are temporally unrelated to the triggering and emplacement of Ngatoro Formation, and that Ngatoro Formation instead of forming a single deposit is indeed a series of closely-spaced events with broadly similar debris and hyperconcentrated flow characteristics.

This thesis aims to:

- Understand what the relationship is, if any, between the Ngatoro Formation and the Inglewood Tephra, and to determine the processes that generated Ngatoro Formation?

- How was the Ngatoro Formation emplaced and how does the internal architecture vary with increasing distance from source and from its axes to lateral margins? 
- How are these changes influenced by the type of triggering event and its volume, grain-size characteristics and influencing factors such as catchment/stream containment (or lack thereof) and the potential for sediment bulking?

These aims are achieved through detailed descriptions, measured sections, geochemical characterisation of stratigraphically enveloping tephra, grain size/shape analysis and palaeomagnetic analysis at multiple locations. Ultimately, this information will provide insights into what processes can reasonably be expected to occur during and/or in the aftermath of a future eruption at Egmont Volcano.

\subsection{Research Objectives}

- Describe and measure the internal architecture and lateral transformations of the Ngatoro Formation using field observations and standard sedimentological analysis.

- Relate the internal architecture to the varying stages and phases of the lahar.

- Use palaeomagnetic analysis to understand the thermal history of the Ngatoro Formation and estimate its emplacement temperature.

- Relate emplacement temperatures, stratigraphy, internal architecture and sedimentology to understand the emplacement mechanisms of the Ngatoro Formation, and its spatial and temporal relationships to associated eruptive activity.

- Use the Ngatoro Formation as a prehistoric analogue for what could reasonably be expected to occur should Egmont Volcano reawaken in the future. 


\section{Volcanic Processes Review}

\subsection{Andesitic Volcanism}

Andesitic volcanoes are dominant features in landscapes commonly associated with convergent plate boundaries. A large majority of the over 800 active volcanoes around the world are andesitic composite cones located along plate boundaries at the margins of oceanic basins; most notably along the circum-pacific belt known as the "Pacific Ring of Fire" (Tarbuck and Lutgens, 2009). Andesite, the second most common volcanic rock type, is an extrusive igneous rock containing mainly phenocrysts of zoned plagioclase, pyroxene or hornblende and a glassy or fine grained ground mass (Figure 7) (Sigurdsson et al., 2000). Andesite is considered to be a fine grained volcanic rock characteristically medium dark in colour and containing 54-62\% silica (Scott, 1988).

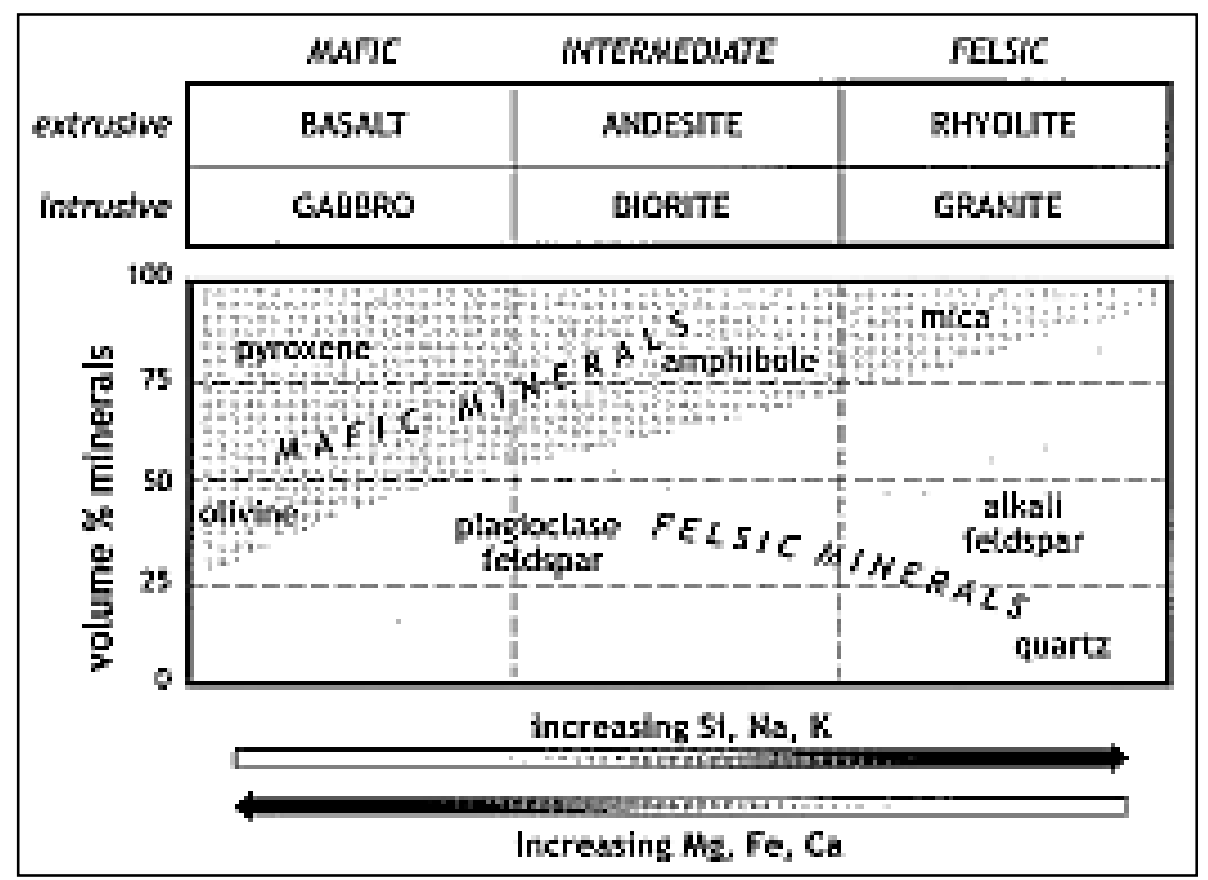

Figure 7: Diagram showing the transitions between magma types, intrusive and extrusive volcanic rocks and their relative compositions (Sigurdsson et al., 2000).

\subsubsection{Regional Processes}

Andesite volcanoes are commonly associated with convergent plate boundaries where the older, colder and denser oceanic crust sinks beneath the relatively buoyant continental crust (Figure 8). As the oceanic crust sinks, the increased heat and pressure forces volatiles out of the crust and into the overlying mantle. These volatiles act to reduce the melting temperature of the mantle, resulting in basaltic magma production. After sufficient magma 
has accumulated, it begins to rise to the Earth's surface (Tarbuck and Lutgens, 2009). This process forms island archipelagos, or more commonly known as island arcs. As an intermediate member between basaltic and rhyolitic magmas, andesite magma forms through fractional crystallisation of this basaltic magma (eg. Island arcs such as Mount Ngauruhoe, New Zealand) (Price et al., 2010), or through simple mixing of the magmatic end members (eg. The Ecuadorian Andes) (Schiano et al., 2010).

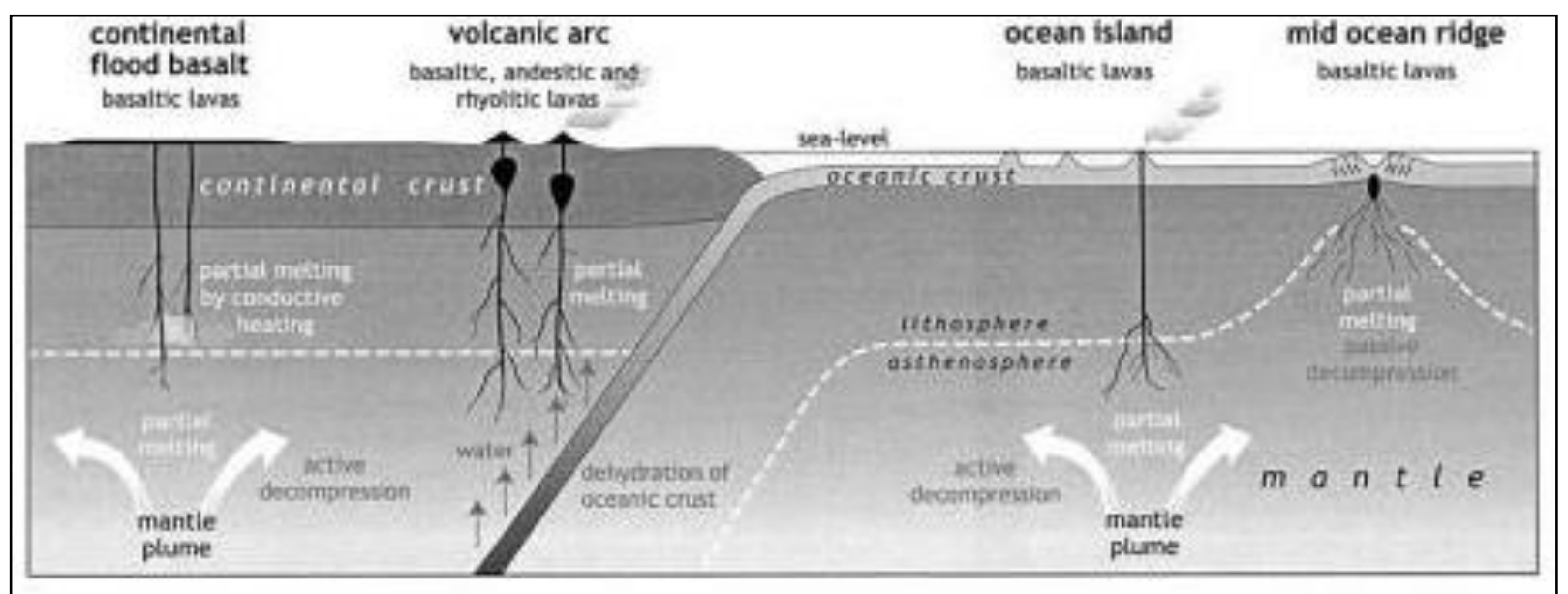

Figure 8: Diagram of regional tectonic processes associated with the formation of andesite volcanoes (Tarbuck and Lutgens, 2009).

\subsubsection{Eruption Styles}

The two dominant eruptive styles associated with andesite stratovolcanoes are plinian and vulcanian:

Plinian eruptions produce a steady and turbulent stream of fragmented magma and magmatic gas ejected from the vent at high velocities. This continuous eruptive style produces an eruption column containing pyroclasts, magmatic gas and entrained air that can commonly reach heights of 30km and remain for tens of hours (Wilson, 1958). These eruptive events can be characterised by specific parameters such as explosiveness (VEI>5), eruptive volume (typically $>10^{-9} \mathrm{~m} / \mathrm{s}$ ) and timing (Sigurdsson et al., 2000). Examples include; Mount Vesuvius, Italy (79 AD); Krakatoa Volcano, Indonesia (1983); and Mount Pinatubo, Philippines (1991).

Vulcanian eruptions are characterised by a series of short, discrete explosions with short repose time (Parfitt and Wilson, 2008). These eruptions are often described as the volcano clearing its throat (or vent) where a piece of cooled magma or material from a previous 
eruption that has fallen into the vent forms a plug that prevents gas and other material escaping from the volcanoes interior (Sigurdsson et al., 2000; Parfitt and Wilson, 2008).

This explosive eruptive style produces ejection velocities of $200-400 \mathrm{~ms}^{-1}$ and can distribute blocks and bombs up to $5 \mathrm{~km}$ from the vent (Sigurdsson et al., 2000). Associated with vulcanian eruptions are eruption plumes, pyroclastic flows and surges, lahars and thick lava flows (Wohletz and Heiken, 1992). Vulcanian eruptions are generally associated with intermediate composition magma (andesite, dacite) and the material ejected is dominantly non-juvenile (Sparks et al., 1997). Examples include; Mount St Helens, United States of America (1980); Soufriére Hills Volcano, Montserrat (1997); and Island of Volcano (1888).

It should be noted however that any one volcano, including Egmont Volcano, is not limited solely to a specific eruptive style. The type of eruption can change both between and during an eruptive event.

\subsection{Lahar}

The term "lahar" is Indonesian in origin and was introduced by Scrivenor (1929) in a report of mudflows produced by the ejection of the crater lake at Kelut Volcano, East Java (Lavigne et al., 2000). The term was then used by Van Bremmelen (1949) to describe debris flows containing debris and angular blocks, chiefly of volcanic origin. This definition included both the lahar and its related deposits. Other definitions include flows involving a mixture of debris and water occurring in volcanic channels (Smith and Fritz, 1989); fluid mixtures of debris, mud and water descending from a volcano (Murcia et al., 2008); and a volcanic debris flow and its deposit (Scott, 1988).

An issue that is apparent throughout relevant literature is the wide range of deposits and flows that are classified as "lahars" due to the vague and diverse definitions used. Smith (1986) outlines some of these variations:

- Restricted composition to pyroclastic material (Schmid, 1981).

- Must originate from the flanks of a volcano (Crandell, 1971).

- Debris flows not originating from volcanoes (Fairchild, 1984).

- Doesn't stipulate it being a debris flow (Hyde, 1975). 
- Implies a hot pyroclastic flow (Fritz and Harrison, 1983).

The wide range of definitions leads to the conclusion that the term "lahar" is too general and does not describe the variability of the flow properties or the internal lateral variation in the deposits. The term lahar was deemed too general by Smith (1986) because the flow crosses rheological boundaries and encompasses a highly variable and wide range of grain sizes. In this thesis, the term lahar is used to describe a "rapidly flowing, gravity-driven, mixture of rock debris and water (other than normal stream flow) from a volcano" (Smith and Fritz, 1989).

Lahars are described by both their phase and stage. The phase describes the flow type at a specific time and place while the stage describes the height of the flow above the channel bottom. The stages of the lahar include the initial waxing, the peak flow and the final longduration waning stage (Vallance, 2005). The phases of the lahar include the debris flow, hyperconcentrated flow and stream flow (Smith, 1986; Vallance, 2005). In this thesis the term "lahar" is avoided with preference given to the less ambiguous debris flow and hyperconcentrated flow. Deposit characteristics of the range of sediment rich mass flows are described in Table 2 (modified from Palmer et al. 1991; Alloway et al. 2005; Zenack et al. 2009).

\subsubsection{Debris Flow}

Debris flows are a water-supported mass flow with plastic properties that deposit sediment en masse when the shear stress decreases below the yield strength of the debris flow (Smith, 1986). The flow is constrained to a sediment concentration of $>60 \%$ by volume (Lavigne et al., 2000; Lavigne and Suwa, 2004) or $80 \%$ by weight (Lavigne et al., 2000). Within the flow, clasts are supported by cohesive matrix strength, buoyancy and dispersive pressure (Smith, 1986).

Debris flows can be described as either cohesive or non-cohesive based on their clay content. Cohesive debris flows have $>5 \%$ clay content and generally begin as water saturated debris avalanches that laterally transform, where as non-cohesive debris flows have $<5 \%$ clay content and form through the entrainment of material and water as they flow downstream (Murcia at al., 2008). 


\begin{tabular}{|c|c|c|}
\hline Deposit Type & Sedimentary Characteristics & Contacts \& Geometry \\
\hline $\begin{array}{l}\text { Debris flow (df) deposits } \\
\text { (Non-cohesive mass-flow } \\
\text { deposits) }\end{array}$ & $\begin{array}{l}\text { - } \quad \text { Matrix-supported } \\
\text { - } \quad \text { Predominantly monolithologic angular to sub-angular gravel- to } \\
\text { boulder-sized clasts in a sandy matrix } \\
\text { - } \quad \text { Very poorly to poorly sorted } \\
\text { - } \quad \text { Unassive, unstratified } \\
\text { - } \quad \text { Typically } 0.4-0.6 \mathrm{~m} \text { but up to } 1.8 \mathrm{~m} \text { thick } \\
\text { - } \quad \text { Deposits often reflect transformation of debris to } \\
\text { hyperconcentrated flow: they consist of an inversely graded, } \\
\text { fine-grained layer with faint stratification and a coarse, massive, } \\
\text { poorly sorted unit that grades into a finer-grained, bedded } \\
\text { upper part }\end{array}$ & $\begin{array}{l}\text { Typically tabular, non-erosive, } \\
\text { some lenticular with scored basal } \\
\text { contacts. }\end{array}$ \\
\hline Channel facies & $\begin{array}{l}\text { - } \quad \text { Predominantly clast-supported with subordinate sandy matrix } \\
\text { - } \quad \text { Very coarse, gravel- to boulder-sized clasts } \\
\text { - } \quad \text { Massive, lack of internal stratification but often show a thin } \\
\text { matrix-supported base Non-graded lateral transition to } \\
\text { marginal overbank deposits } \\
\text { - } \quad \text { Op to } 5 \text { m thick } \\
\text { Often upward transition to bedded, sandy deposits with weak } \\
\text { horizontal fabric (hyperconcentrated flow) } \\
\text { Intercalated lenses of cross-bedded and well well-sorted sands } \\
\text { (fluvial) due to rapid post-depositional reworking }\end{array}$ & $\begin{array}{l}\text { Erosive basal and marginal } \\
\text { contacts } \\
\text { Channel-confined, several tens of } \\
\text { metres wide, }\end{array}$ \\
\hline Marginal facies & $\begin{array}{l}\text { - Fine gravelly sands but coarser near channel Poorly sorted near } \\
\text { channel, becoming moderately to well-sorted with distance } \\
\text { from channel margins } \\
\text { - Faint internal stratification near channel, becoming } \\
\text { progressively more distinct with thin horizontal and often very } \\
\text { low-angle cross beds near the deposit margin } \\
\text { - Ungraded } \\
\text { Up to } 2 \text { m thick but pinch out over } 20 \text { to } 250 \mathrm{~m} \text { from the } \\
\text { channel margins }\end{array}$ & $\begin{array}{l}\text { Non-erosive } \\
\text { Wedge-shaped, extend up to } 250 \\
\text { m from channel margins }\end{array}$ \\
\hline $\begin{array}{l}\text { Hyperconcentrated flow } \\
\text { (hcf) deposits }\end{array}$ & $\begin{array}{l}\text { - Gravelly sands, isolated gravel- to cobble-sized clasts, } \\
\text { predominantly monolithologic } \\
\text { - } \quad \text { Poorly to moderately sorted ;Massive or bedded } \\
\text { - } \quad \text { Reverse-to-normal grading, normal grading or no grading } \\
\text { - Typically 0.2-0.5 m thick, up to } 2 \text { m faintly bedded coarser } \\
\text { units, up to } 1.2 \text { m well-bedded fine-grained units } \\
\text { - } \quad \text { Occurrence of pumice "trains" and aligned clasts } \\
\text { Post-depositional deformation and dewatering structures } \\
\text { (flame, dish and pillar structures) }\end{array}$ & $\begin{array}{l}\text { Typically non-erosive, though } \\
\text { more dilute units lenticular with } \\
\text { erosive basal contacts } \\
\text { Sheets, up to } 2.5 \mathrm{~km} \text { wide }\end{array}$ \\
\hline $\begin{array}{l}\text { Transitional hcf/normal } \\
\text { stream-flow deposits }\end{array}$ & $\begin{array}{l}\text { - } \quad \text { Fine- to coarse-grained sands Moderately to well-sorted } \\
\text { Horizontal bedding to low-angle cross-bedding, lenses of cross- } \\
\text { bedded fine sands and gravels } \\
\text { - } \quad \text { Ungraded } \\
\text { - } \quad \text { Few-cm to } 0.5 \mathrm{~m} \text { thick units }\end{array}$ & $\begin{array}{l}\text { Erosive, wavy basal contacts } \\
\text { Lenticular, often steep and } \\
\text { overlapping cut' } n \text { 'fill channels }\end{array}$ \\
\hline $\begin{array}{l}\text { Normal Stream-flow } \\
\text { deposits }\end{array}$ & $\begin{array}{l}\text { - } \quad \text { Clast-supported } \\
\text { - Fine to coarse sands, sands and rounded gravels- to boulder- } \\
\text { sized rounded clasts } \\
\text { Well to moderately sorted in individual beds, but overall } \\
\text { apoorly sorted as an aggradational deposit } \\
\text { - Horizontal lamination of sands, low-angle cross-stratification } \\
\text { and prominent scour-fill cross-bedding } \\
\text { - } \quad \text { of alternating thin lenses (few } \mathrm{mm} \text { to } 1 \mathrm{~cm} \text { thick) of well-sorted } \\
\text { sands and beds (1 to } 10 \mathrm{~cm} \text { thick) of moderately to poorly } \\
\text { sorted gravels and sands } \\
\text { Massive to faintly bedded aggradational sequences of silts and } \\
\text { sands with intercalated crossbedded lenses of fine gravels and } \\
\text { - } \quad \text { Un to } 4 \mathrm{~m} \text {-thick sequences of alternating sandy and pebbly } \\
\text { beds, }>10 \mathrm{~m} \text { thick }\end{array}$ & $\begin{array}{l}\text { Erosive, lenticular } \\
\text { Complex sequences of } \\
\text { overlapping cut'n'fill channels up } \\
\text { to } 150 \text { m wide }\end{array}$ \\
\hline
\end{tabular}

Table 2: Sedimentary characteristics and criteria for differentiating between types of volcanic, water-supported mass flows (modified from Palmer et al. 1991; Alloway et al. 2005; Zenack et al. 2009). These include debris flows, hyperconcentrated flows and normal stream flows. 


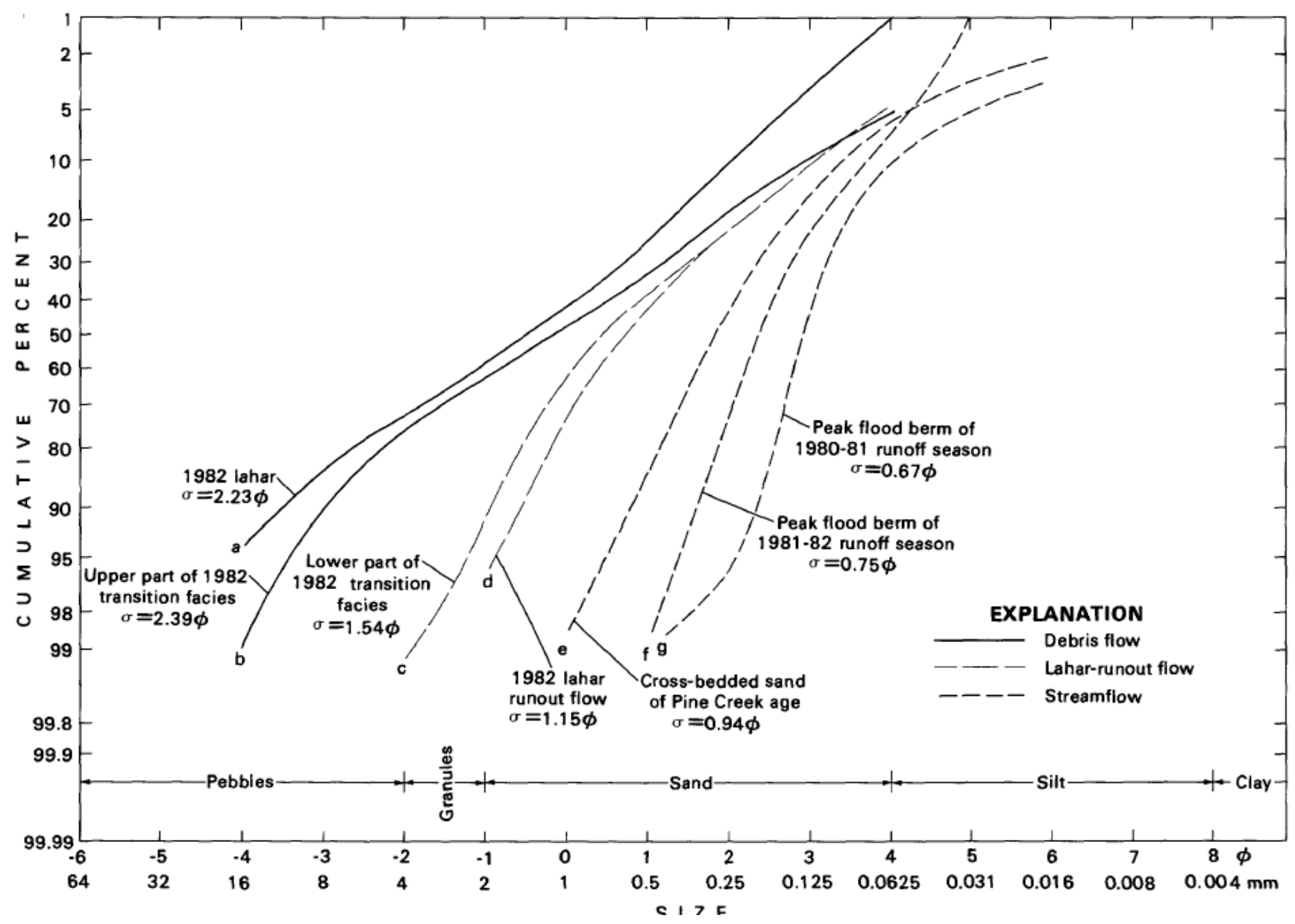

Figure 9: Grain size verses cumulative percentage distribution comparing debris flows with lahar-runout flow and stream flow on Mt St Helens (Scott, 1988).

Deposits:

Poorly sorted, lack of internal stratification and support of larger clasts in a finer grained matrix; can show none, reverse, reverse-to-normal, and coarse tail normal grading. Generally deposits are matrix supported (rarely clast supported) with variable clast orientation and imbrication (Smith, 1986). In general, debris flow material can be more poorly sorted than pyroclastic deposits (Lavigne et al., 2000) and can be differentiated from other phases based on grain size distributions (Figure 9).

\subsubsection{Hyperconcentrated flow}

Hyperconcentrated flow is considered the runout phase of the proximal lahar from which it was transformed (Scott, 1988; Murcia et al., 2008; Pierson, 2005). The flow is constrained to a sediment concentration $20-60 \%$ by volume (Lavigne et al., 2000; Lavigne and Suwa 2004) or $40-80 \%$ by weight (Lavigne et al., 2000). Smith (1986) uses the term to describe high- 
discharge, visibly turbulent flows where inter-grain interaction is an important sediment support mechanism and where neither turbulence is the sole support mechanism or where deposition en masse occurs. Features suggest rapid sediment deposition from suspension and by traction.

\section{Deposits:}

Gravel Dominated Deposits - Poorly sorted, clast supported, often normally graded, lack of reverse grading at the base with a coarse sand and pebble matrix. Large cobbles and boulders with long axis perpendicular to flow direction while small cobbles and gravels parallel to flow direction (Smith, 1986).

Sand Dominated Deposits - Absence of cross stratification, dominated by horizontal bedding, alternating well and poorly sorted fine and coarse beds, and laterally continuous for $2-10 \mathrm{~m}$. The laminated sands also contain large clast scattered throughout up to $1 \mathrm{~m}$ in diameter (Smith, 1986).

Graded Stratified Deposits - Massive, normally graded base grading upward to a horizontally stratified upper. Lower is massive, pebbly, coarse-grained sand, or pebble- to cobble-sized gravel with a texture and fabric as per gravel dominated deposits. Upper is horizontally bedded, poorly sorted, medium to very coarse grained sand with lenses of pebbles and cobbles (Smith, 1986).

\subsubsection{Flow Transformation Processes}

Dilution:

As a water-supported mass flow moves down active river systems, water is incorporated in to the front of the flow causing dilution, a progressive loss in the flow's carrying capacity and phase changes within the lahar. This process has the most significant effect on smaller flows as the volumes of large flows are significantly greater than the existing river water (Vallance, 2005). In large lahars, size segregation processes become less important with downstream erosion and dilution processes becoming the important mechanisms (Scott, 1988). 


\section{Bulking:}

Flow bulking is the addition of significant volumes of sediment to an existing flow through the erosion of local clastic material (Oldrich et al., 2005). Erosion is strongest along steep river channels containing loose clastic sediment and weakest in river channels with a gentle gradient or those underlain by strong bedrock (Vallance, 2005). During the erosion process trees and vegetation can also be uprooted. Surficial cover beds including soils occurring at the ground surface can also be incorporated into the body of the flow.

Vallance (2005) found that in any typical river valley water-rich hyperconcentrated flows are more erosive than the more sediment rich debris flows. This is due to the more turbulent flow achieved from the two phased (solid and liquid) hyperconcentrated flow than the single phase debris flow.

\subsection{Mass Flow Generation}

\subsubsection{Edifice-Collapse Related Cohesive Mass Flows}

Debris flow transformations can occur from the large volume, catastrophic debris avalanches produced during the large scale collapse of a volcanic edifice. Debris avalanches are a gravity driven rapid movement of incoherent, unsorted masses of rock, soil, water, snow, ice and vegetation (Scott, 1988; Palmer and Neall, 1989). The most likely trigger of these edifice collapses are by the intrusion of magma, resulting in a subsequent oversteepening of the volcanoes flank, magmatic intrusions into the sub-volcanic crust, hydromagmatic or phreatomagmatic processes, and volcanic and/or tectonic earthquakes (Vallance, 2005; Capra et al., 2002).

The potential for catastrophic edifice collapse, and subsequent lahar generation, is increased by the presence of hydrothermally altered rock. Within the hydrothermal systems, acid sulphate leaching removes mobile elements, replaces them with sulfates and forms silica phases (eg. cristobalite and opal) and clay minerals (eg. kaolinite and smectite) (Vallance, 2005). This alteration weakens the rock, resulting in increased disintegration during transportation. 
With the very poorly sorted nature, water saturation and high hydrothermally altered clay content of debris avalanches, they commonly laterally transform into cohesive debris flows (>5 wt\% clay content). Capra et al. (2002) compiled the process associated with this transformation to a debris flow:

- Failure within a soil, rock or sediment mass.

- Partial or complete liquefaction of the mass by high pore-fluid pressures.

- Conversion of landslide translational energy to internal vibrational energy.

- Transformation during transport of the distal water-saturated portion of the debris avalanche.

- Post-depositional remobilisation of water-saturated parts of the debris avalanche.

- Ruptures of natural dams formed by the debris avalanche deposit.

As these debris flows move downstream, they begin to incorporate exotic debris from the valley floors and adjacent embankments. Due to the size of debris avalanche-sourced debris flows, they very rarely laterally transform to the more dilute hyperconcentrated flows as they migrate downstream (Vallance, 2005).

\subsubsection{Pyroclastic Flow Transformation}

Pyroclastic flows and surges are a flowing mixture of hot gas and pyroclastic material (Scott, 1988 ) that move due to gravity down the flanks of a volcano. Pyroclastic surges are a flow that is more dispersed and less likely to approximate steady state conditions than a pyroclastic flow. These highly mobile and super-heated pyroclastic flows can be divided into pumice-and-ash flows and block-and-ash flows. Pumice-and-ash flows are pumice rich flows associated with plinian eruptions where large quantities of juvenile material are ejected. Occurring during rhyolitic eruptions, these pumice-and-ash flows form through the collapse of an eruption column and deposit what are called ignimbrites or rhyolitic tuffs (Sparks and Wilson, 1976; Williams and McBirney, 1979).

Block-and-ash flows on the other hand are gas supported mixtures of large volcanic blocks and ash usually resulting from gravitational collapse of an extruding summit lava dome or eruptive column. Often known as Merapi-style nuees ardentes, block-and-ash flows are a type of gravity driven pyroclastic flow associated with subduction zone andesitic volcanoes such as Unzen (Japan), Montserrat (Lesser Antilles) and Merapi (Indonesia) volcanoes 
(Charbonnier and Gertisser, 2008). Block-and-ash flows (commonly less than $1 \mathrm{~km}^{3}$ ) are low in volume (Michol et al., 2008) but move as successive pulses which can continue for 8 to 20 minutes (observed on Unzen Volcano in 1995) (Ui et al., 1999). Block-and-ash flows move at great velocity and at very high temperatures - velocities calculated for Merapi Volcano events in 2006 range from $62.6 \mathrm{~m} / \mathrm{s}$ (proximal) to $13.5 \mathrm{~m} / \mathrm{s}$ (distal) (Charbonnier and Gertisser, 2008); and temperatures measured from the Soufriere Hills Volcano events in 1997 range from $364^{\circ} \mathrm{C}$ to $640^{\circ} \mathrm{C}$ (Cole et al., 2002).

Block-and-ash flows comprise three different flow parts; (1) a ground-hugging, high concentration basal avalanche; (2) a highly turbulent ash cloud surge; and (3) a billowing ash plume at the top (Hanenkamp, 2011). The path of the flow is controlled by the existing topography, with each flow part associated with different deposits. The deposits reflect the differences in velocity, density, flow volume and particle size between the flow parts.

Block-and-ash flows are generated through the gravitational collapse of an expanding or expanded lava dome (Ui et al., 1999; Charbonnier and Gertisser, 2008). Dome growth can occur through exogenous and endogenous processes (Ui et al., 1999) with gravitational instability occurring both during and after dome growth (Cole et al., 2002). Exogenous dome growth occurs when new lava is squeezed out from the vent and slowly spreads laterally while endogenous dome growth occurs when magma is intruded within the dome and no new lava is extruded on the dome surface. Deposits have been classified into three general facies by Charbonnier and Gertisser (2008). Basal Avalanche - often confined to the valleys and form ground-hugging, high-density granular and/or inertial grain-flow; produce chaotic morphology although ridges and furrows can also be broadly parallel to flow; and have steep, boulder and clast-supported fronts. Ash Cloud Surge - a turbulent and highly mobile deposit which mantles topography; elutriation occurs due to rapid convection and lateral expansion of gas which moved ahead of the ash cloud; and burnt vegetation provides evidence for hot gas transport. Overbank - poorly sorted, decimetre to metre-sized blocks supported in a fine to medium ash.

Block-and-ash flows can laterally transform into lahars as the super-heated pyroclastic material and gas rapidly melts and mixes with snow and ice. When the pyroclastic flow is almost stationary the water within the pyroclastic flow deposit is discharged, along with 
adjacent snow melt. As the flow moves down river valleys it further mixes with river water and incorporates existing loose sediment in the valley (a term referred to as bulking) forming a debris flow then redistributes the sediment as the lahar transforms both laterally and downstream through its phases. The incorporation of water occurs at the front of the lahar in active river valleys because the lahar flows faster than the existing river, resulting in a dilution of the lahar and a decrease in the lahars capacity to carry large clasts (Vallance, 2005).

\subsubsection{Rainfall-Induced Mass Flows}

Debris and hyperconcentrated flows can be triggered by the sediment bulking of flood waters following heavy rainfall events (Hodgson, 1993; Lavigne et al., 2000; Lavigne and Thouret, 2002). Rainfall-induced mass flows are most common in tropical areas due to the high incidence on intense rainfall events as well as the volume and availability of recently erupted unconsolidated pyroclastic material concentrated within tributaries on the flanks of active volcanoes (eg. Mount Merapi and Mt Pinatubo). The triggering of a mass flow is dependant of the rainfall intensity, total amount and duration of rainfall, and other secondary variables (Lavigne and Thouret, 2002; Lavigne et al., 2000) such as:

- Slope and channel gradient.

- Volume and thickness of the source deposits.

- Physical characteristics of the pyroclastic deposits (eg. Permeability, pore pressure and grain size).

- Morphology of the drainage systems.

- Type and abundance of vegetation cover.

It is a known phenomenon that these rainfall-induced mass flows can occur both during and between volcanic events (Hodgson, 1993; Lavigne et al., 2000; Rodolfo and Arguden, 1991). Lavigne et al. (2000) described both syn-and-post eruptive rainfall-induced mass flows at Mount Merapi, Eastern Java, Indonesia:

- Syn-Eruptive - Hot lahars are generated by rainfall during or soon after an eruptive event. 8 out of the 61 lahars since 1500's at Merapi were due to this mechanism. 
- Post-Eruptive - These are generally smaller and more frequent than the hot lahars. Size and frequency depends on the rainfall characteristics and the total volume and grain size characteristics of the pyroclastic material in the source area.

Lavigne and Suwa (2004) and Lavigne et al. (2000) discuss the two main types of rainfall events in tropical areas where rainfall-induced lahars are most common:

- Stationary Rainfall - Stationary rainfall triggered one third of the hyperconcentrated flow and stream flow events and triggered $90 \%$ of the debris flow events. Lavigne and Suwa (2004) found that as demonstrated on many volcanoes, rainfall intensity is the main factor in lahar generation at Mt Semuru, Indonesia. In most cases lahars were triggered by stationary rainfall over $25 \mathrm{~mm} / \mathrm{hr}$ or where there was a high "working rainfall" (Total rainfall over the 7 days preceding the lahar event).

- Migratory Rainfall - This rainfall triggered two thirds of the hyperconcentrated flow and stream flow events. During this rain, lahars are usually triggered by long lasting low intensity rainfall.

At Mount Semeru located in eastern Java, Indonesia - 92\% of mass flows were triggered during the rainy season from October to April (Lavigne and Suwa, 2004). This is supported by studies at Merapi where most rainfall events occur between $12: 00$ and 19:00 with $80 \%$ of rainfall events occurring during the rainy season - therefore mass flows are usually generated in the afternoon and during the monsoon season (Lavigne et al., 2000). Although, individually, rainfall-induced lahars are not as voluminous or destructive as other triggering mechanisms (pyroclastic flow transformation, derbis avalanche transformation), their high frequency means they can contribute just as much sediment to the surrounding ring-plains (Hodgson, 1993). 


\section{Case Studies}

The study of volcanoes with similar volcanic setting, processes and eruptive history provide an insight and analogue for what could be expected on Egmont Volcano. Mount Ruapehu and Mount St Helens are andesite volcanoes with a very active history encompassing plinian and vulcanian eruptions, debris avalanches, debris flows and hyperconcentrated flows - all of which are observed occurring within the volcaniclastic stratigraphy of Egmont Volcano. The detailed study of these volcanoes provides a template for the study, interpretation and comparison of deposits described at Egmont Volcano.

\subsection{Mount Ruapehu, New Zealand}

Mount Ruapehu is an andesitic stratovolcano located in the central North Island of New Zealand. At 2,797m high it is the largest stratovolcano in New Zealand (Lecointre et al., 2004 ) and has a $110 \mathrm{~km}^{3}$ cone with a volumetrically equivalent ring plain of volcaniclastic sediment (Cronin et al., 1997a). In 1995, from September $18^{\text {th }}$ until October $12^{\text {th }}$, the eruption began with a series of phreatomagmatic eruptions and ended with the complete

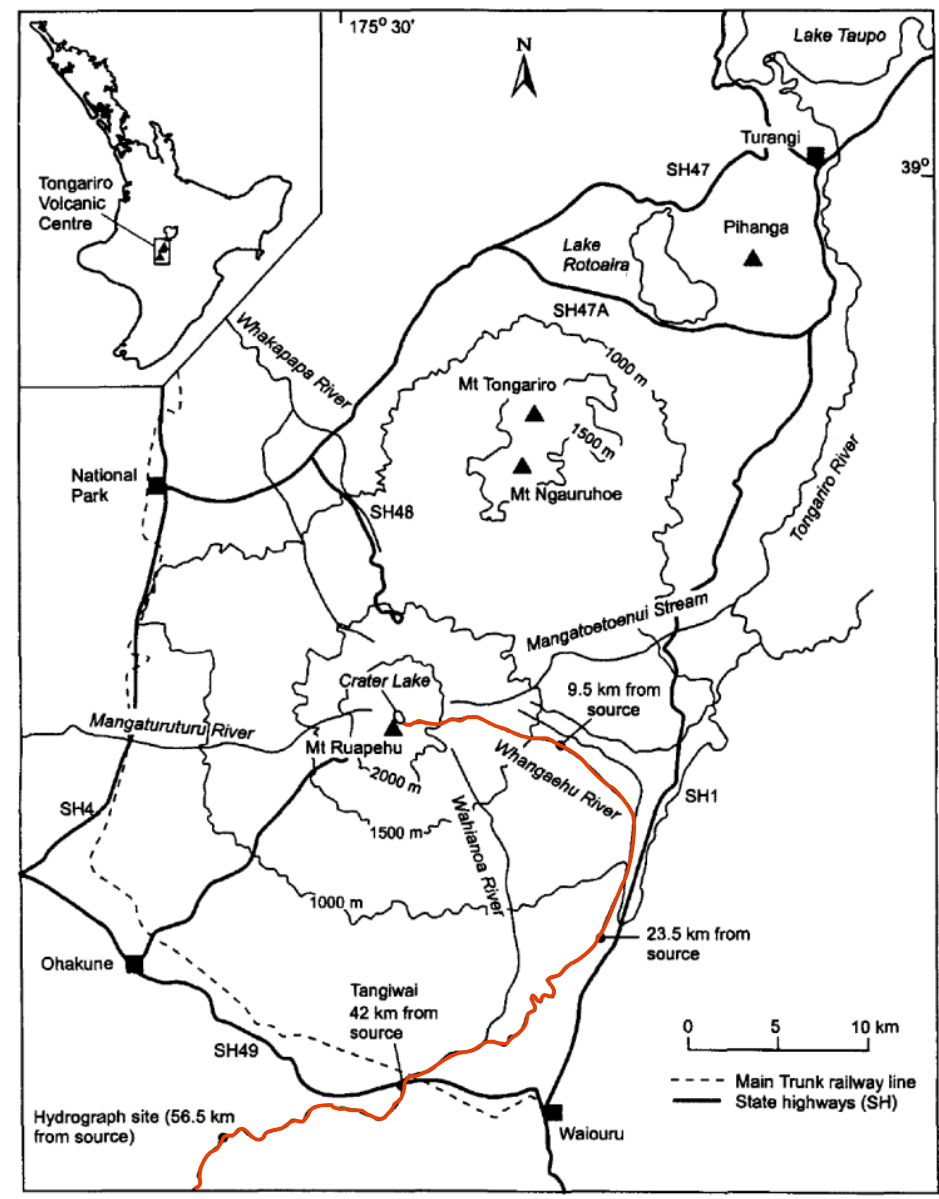

Figure 10: Modified location map of major Mt Ruapehu Lahar courses from Cronin et al. (1997b). Whangaehu River

represented in orange. 
draining of the Crater Lake. During this eruptive period multiple lahars were triggered, mainly in the Whangaehu River on the eastern flank of the volcano (Figure 10) (Cronin et al., 1997a; Cronin et al., 1997b). The triggering of lahars on Mt Ruapehu is a widely known phenomenon with the risks they pose highlighted in the 1953 Christmas Eve Tangiwhai rail disaster where 151 lives were lost when the natural barriers holding back the Crater Lake collapsed forming a laharic sequence down the Whangaehu River sweeping out the rail bridge (Vignaux and Weir, 1990).

Cronin et al. (1997a) describe four main types of lahars associated with 1995 Mt Ruapehu eruptive sequence:

- Snow-Slurry Lahars: Watery slurries of ice, snow and clastic sediment generated when expelled water and debris from the Crater Lake is bulked with sediment from the Whangaehu glacier and subsequent river channel. These lahars extended over 47 $\mathrm{km}$ from source. Deposits are massive mixtures of homogeneous sediment, snow and ice. Ice fragments within the deposits were granule to fine pebble-sized with rare ice fragments up to $0.25 \mathrm{~m}$. Bulk densities of these deposits ranged from $0.47-$ $0.91 \mathrm{Mg} \mathrm{m}^{-3}$.

- Large Dilute Lahars: Large, voluminous $\left(5.6 \times 10^{6} \mathrm{~m}^{3}\right.$ to $\left.2.6 \times 10^{6} \mathrm{~m}^{3}\right)$ hyperconcentrated flows associated with major overflowing of the Crater Lake during phreatomagmatic eruptions. These lahars extended over $84 \mathrm{~km}$ from source. Deposits are sand rich, massive, poorly sorted, boulder bearing, muddy sandy gravels in the upper channel ( $9 \mathrm{~km}$ from source) transitioning to slightly gravelly sands and sand (42 km from source). Up to $2 \mathrm{~m}$ thick, deposits exhibit faint-to-strong planar fabric or weak bedding and concentrations of clasts up to small cobbles.

- Concentrated Lahars: Generated by similar means to large dilute lahars, concentrated lahars were less voluminous and had much lower peak discharges. High sediment concentrations of $46-52 \%$ by volume were maintained up to $42 \mathrm{~km}$ from source due to the bulking of loose sediment in the channels deposited in previous laharic events. Deposits are massive, matrix-supported, boulder bearing slightly gravelly muddy sand (9.5 km from source) transitioning to weakly planarbedded, fine gravel bearing muddy sand ( $23.5 \mathrm{~km}$ from source) and weakly planarbedded, slightly gravely muddy sand (28-42 km from source). 
- Remobilised Tephra Lahars: Generated by the collapse of tephra-laden ice and snow on the upper flanks and/or rain-induced reworking of accumulations of fresh tephra. Deposits are massive to weakly planar-bedded, fine gravel-bearing muddy sand (9.5 $\mathrm{km}$ from source) transitioning to planar-bedded sandy mud ( $23.5 \mathrm{~km}$ from source). The lahars, and subsequent deposits, contained high percentages of reworked, fresh scoriaceous lapilli.

These findings were supported by Lecointre et al. (2004), Graettinger et al. (2010)

(Figure 11) and Cronin et al. (1997b) who described Holocene and recent lahars on Mt Ruapehu and compared these with the laharic sequences from the 1995 eruption.
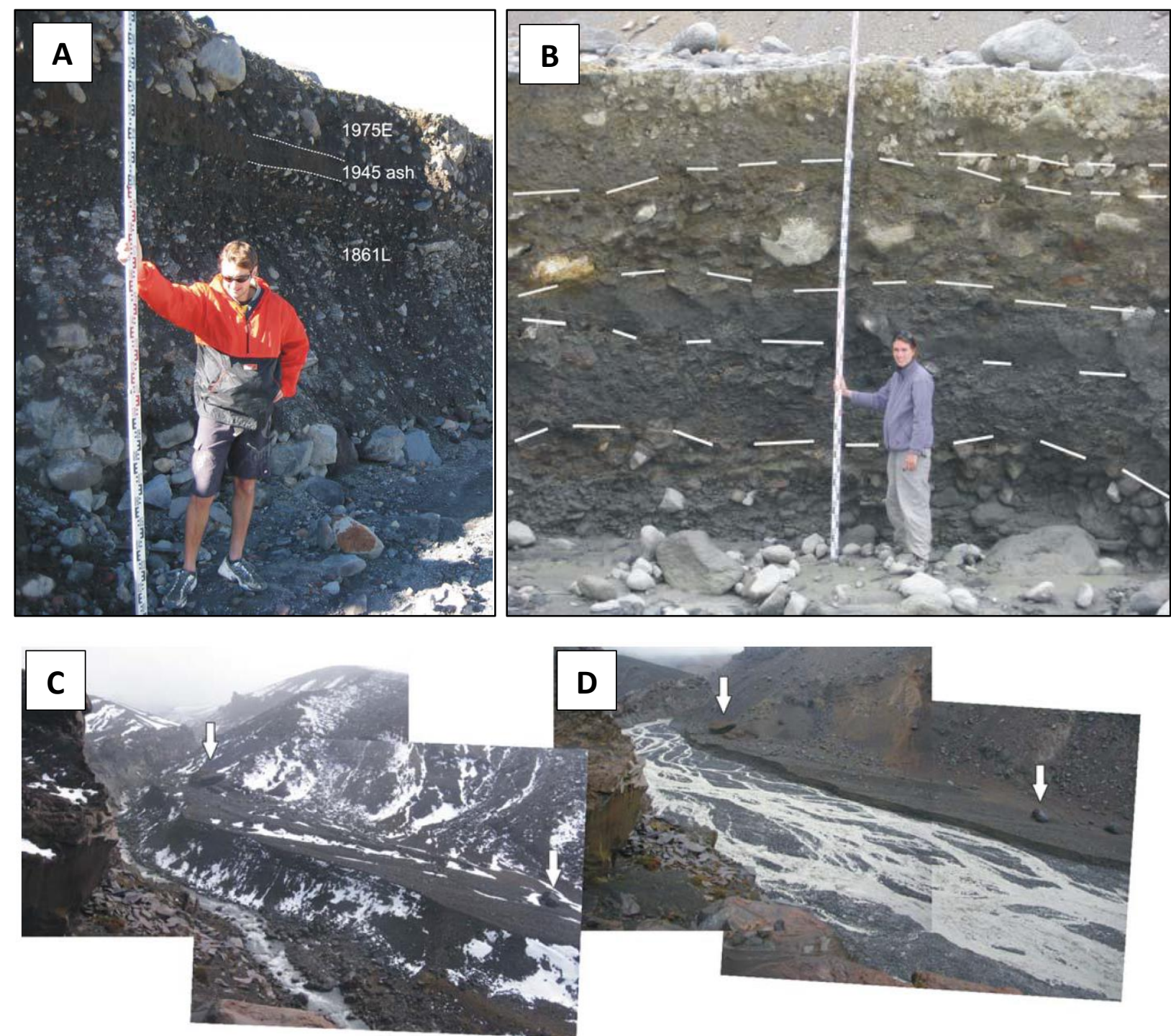

Figure 11: (A) 1861 mass flow deposit in the Whangaehu Valley exposed beneath the 1945 ash and 1975 lahar deposit. (B) Exposed, crudely stratified lahar deposits located in the Whangaehu Valley $9 \mathrm{~km}$ from the Crater Lake - stratification interpreted as pulses or transformations of the mass flow. Photos of the upper main channel of the Whangaehu River- (C) before and (D) after the $18^{\text {th }}$ March 2007 Crater Lake breakout mass flow (Graettinger et al, 2010). 


\subsection{Mount Merapi, Eastern Java, Indonesia}

Merapi Volcano is a $2965 \mathrm{~m}$ tall andesitic stratovolcano located in eastern Java, Indonesia. On the basis of its composition and eruptive style Merapi Volcano provides probably one of the best analogies for comparison with Egmont Volcano. With 61 reported eruptions since the mid-1500's, Merapi Volcano is the second most active volcano, behind Mt Semeru, and the second most hazardous volcano, behind Kelud Volcano, in Indonesia (Thouret et al., 2000). Volcanic processes associated with Merapi Volcano include lava flows, volcanic blocks and bombs, block-and-ash flows, mass flows and ash plumes (Suryo and Clarke, 1985). Merapi Volcano is particularly prone to mass flow generation, with 23 of the 61 recorded eruptions triggering lahars (Figure 12 and 13) and $280 \mathrm{~km}^{2}$ of the slopes comprising laharic material (Lavigne et al., 2000; Lavigne and Thouret, 2002). Lahar generation is common due to the high volume of material produced by pyroclastic flows every 2-4 years, the rainfall intensity during the rainy season (Figure 14) and a very dense drainage system (Lavigne and Thouret, 2002).

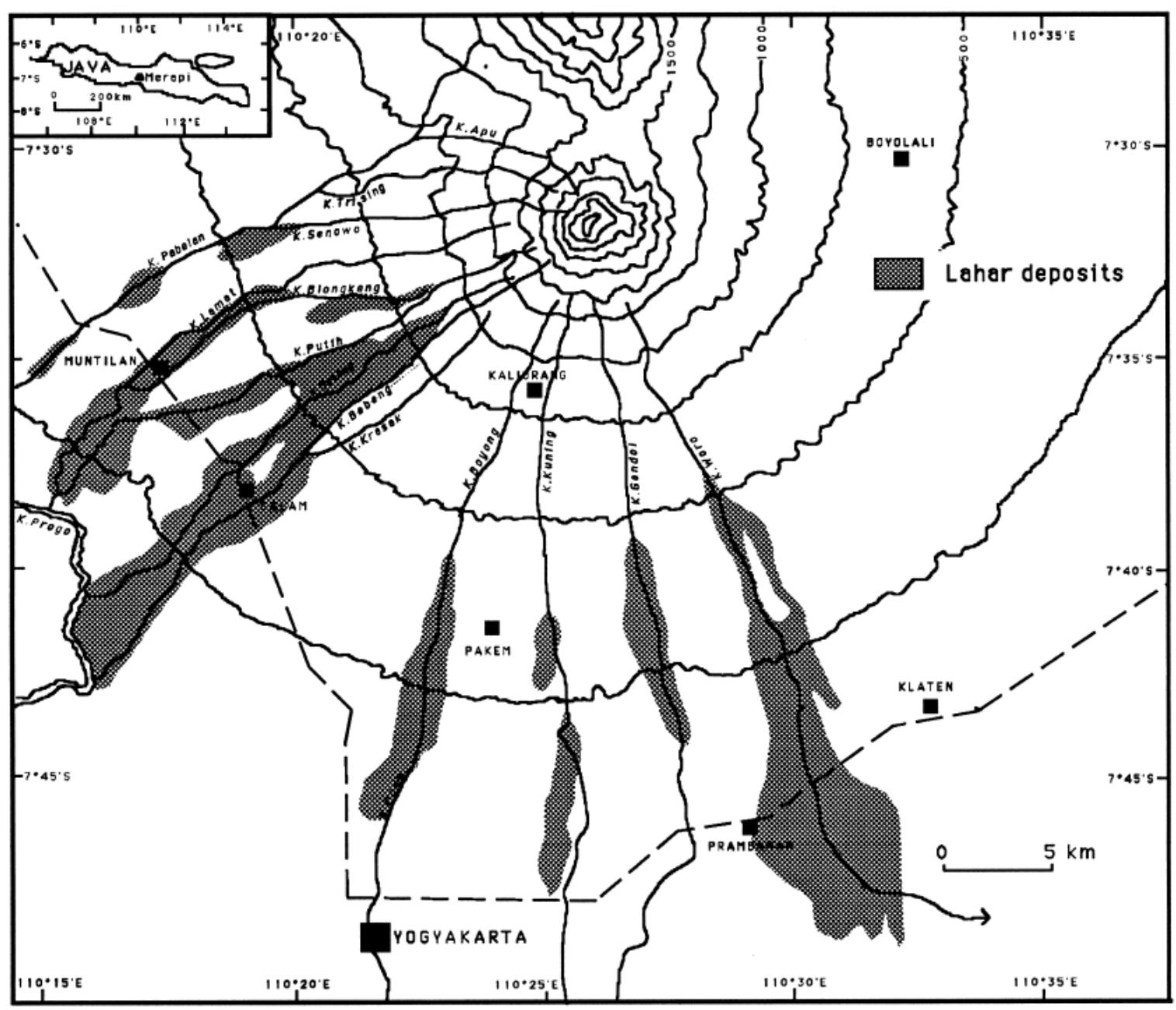

Figure 12: Map showing mass flow distribution in 13 rivers around Mt Merapi since AD 1500. The mass flows are concentrated in the south and south western sector of the volcano (Lavigne et al., 2000). 

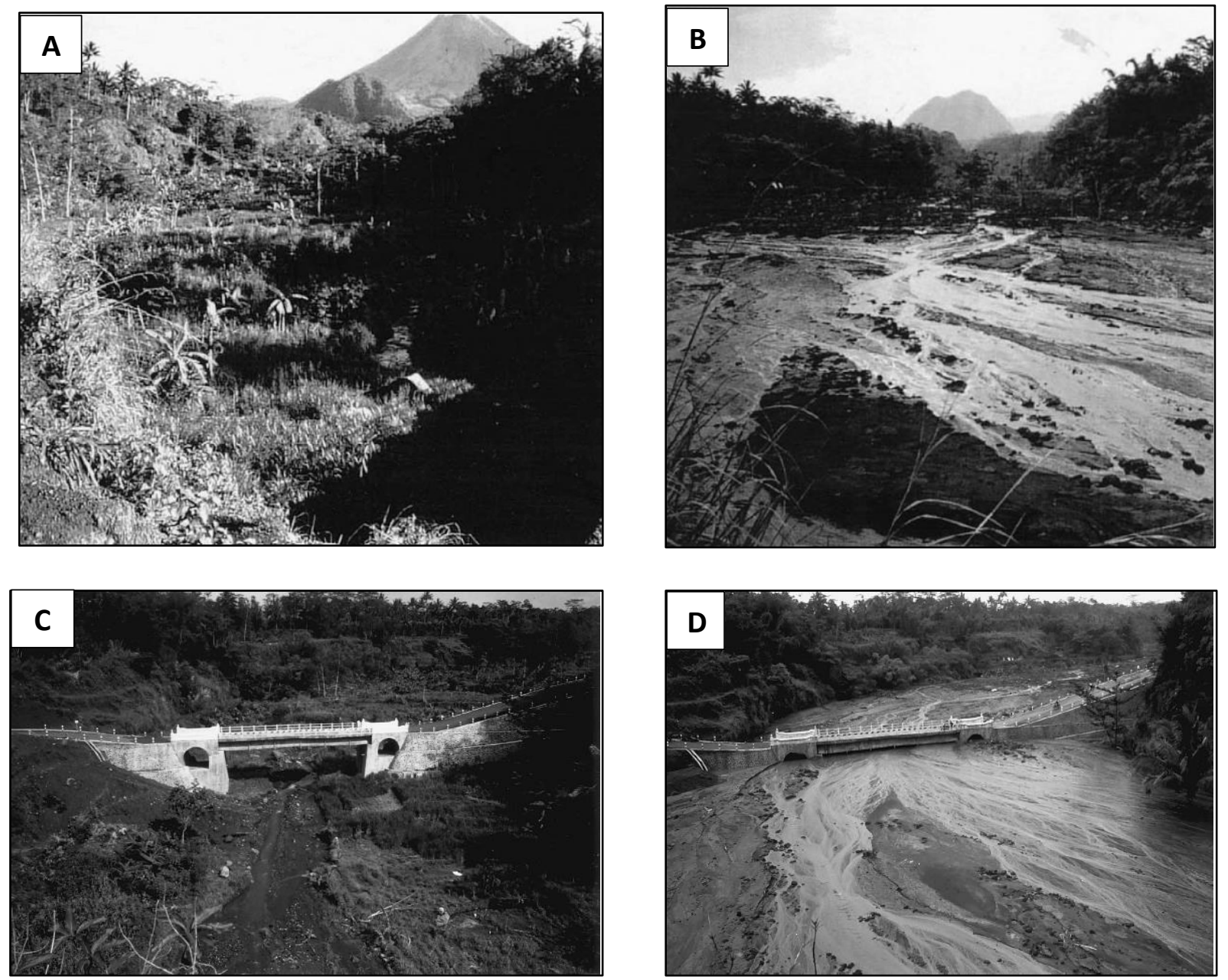

Figure 13: The Boyong River (A) before and (B) after the 22 November 1994 Merapi eruption (Lavigne and Thouret, 2002), and a bridge on the same river (C) before and (D) after the 20 February Merapi eruption (Lavigne et al., 2000). These photos emphasise the rapid and catastrophic deposition of sediment by mass flows on Merapi Volcano.
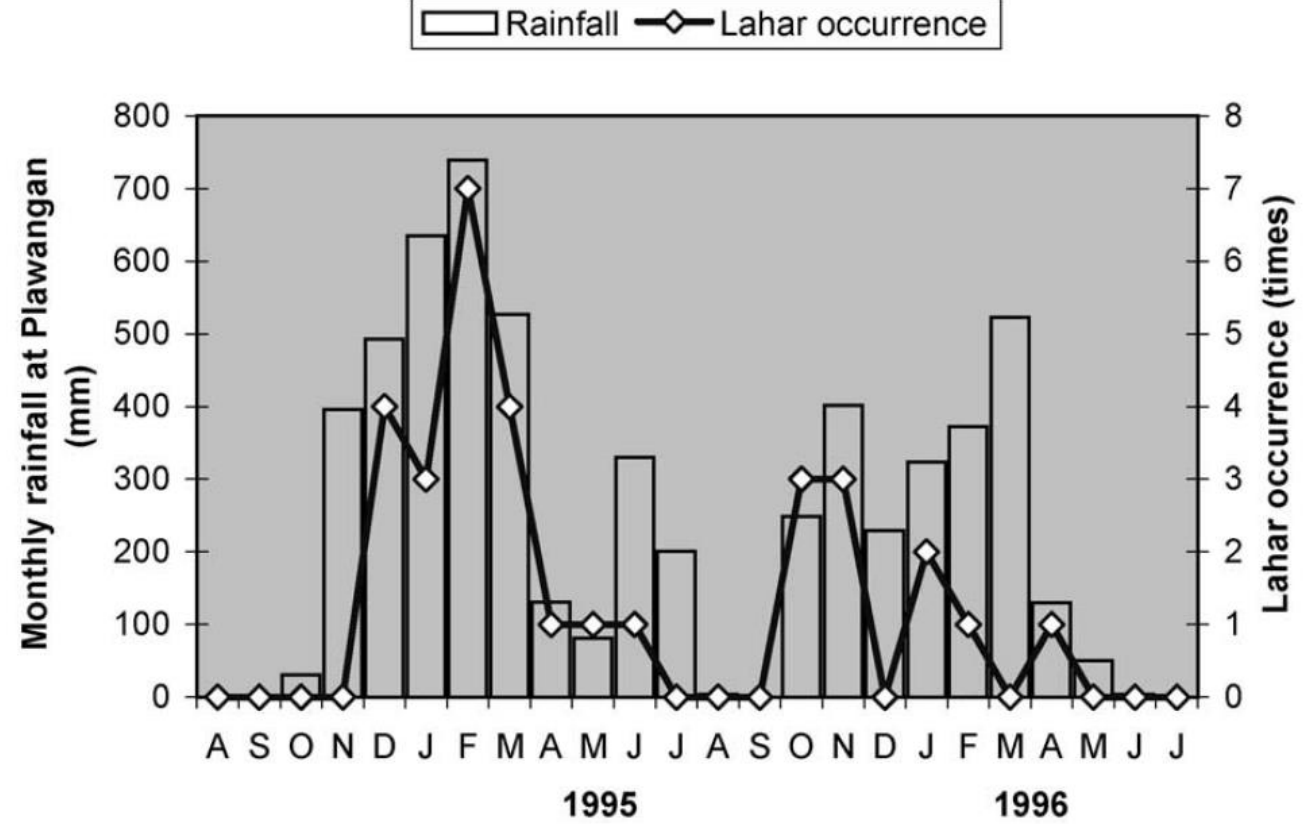

Figure 14: Monthly distribution of rain triggered mass flows in the Boyong River during two monsoon seasons following the 1994 Merapi eruption. This shows a strong correlation between high rainfall and mass flow generation, and a decrease in mass flow occurrence with time since the eruption occurred (Lavigne and Thouret, 2002). 
Pyroclastic flows on Merapi are triggered by almost constantly generated lava domes and their subsequent collapse. The resulting block-and-ash flows can travel up to $13 \mathrm{~km}$ from source and laterally transform to water-supported mass flows (Figure 13) where heavy rainfall occurs near the summit following the eruptive event (Suryo and Clarke, 1985). Rainfall is considered to be the dominant mechanism for mass flow generation with rainfall intensities averaging $40 \mathrm{~mm}$ in 2 hours, the absence of a crater lake and few rivers draining from the edifice having permanent flow (Figure 14) (Lavigne et al., 2000). The intensity of rainfall required to generate mass flows is considered $>25 \mathrm{~mm} / \mathrm{h}$ however the actual intensity is also dependant on rainfall duration and permeability of the pyroclastic material (Lavigne et al., 2000; Lavigne and Thouret, 2002).

Lavigne and Thouret (2002) described $<1.0 \mathrm{~m}$ thick, massive to stratified, non-cohesive, clay to boulder size deposits with textures commonly consisting of sandy gravel or gravelly sand. Sedimentary characteristics were used to define the main deposit types:

- Coarse grained $\left(\mathrm{M}_{\mathrm{z}}=-0.5\right.$ to $\left.-2.5 \phi\right)$, normally graded to ungraded and inversely graded, poorly sorted $\left(\sigma_{G}>3 \phi\right)$, coarsely-skewed $\left(S_{K_{G}}>-0.1 \phi\right)$ and clast-supported debris flow deposits.

- Less coarsely grained $\left(\mathrm{M}_{z}=-2.0\right.$ to $\left.0.5 \phi\right)$, sorted $\left(\sigma_{G}=1.5\right.$ to $\left.3 \phi\right)$, less coarsely skewed $\left(\mathrm{Sk}_{\mathrm{G}}-0.3\right.$ to $\left.0.3 \phi\right)$ and matrix-supported debris flow deposits.

- Fine grained $\left(\mathrm{M}_{\mathrm{z}}=0\right.$ to $\left.2.0 \phi\right)$, poorly sorted $\left(\sigma_{G}=1.0\right.$ to $\left.2.0 \phi\right)$, sandy hyperconcentrated flow deposits. 


\subsection{Mount St Helens, United States of America}

Mount St Helens is an active andesitic stratovolcano located in Washington State in the United States of America. Standing at 2,550m, the cone and surrounding ring plain were devastated during a catastrophic eruption on May $18^{\text {th }} 1980$. Mt St. Helens was chosen as a case study in this study since the downstream sedimentological attributes were so well characterised (i.e. see Fig. 15) and provide an important methodological framework for attempting to understand the emplacement of Ngatoro Formation.

During the 1980 eruption of Mt St Helens the adjacent landscape was dramatically transformed in minutes to hours by a voluminous debris avalanche $\left(2.5 \mathrm{~km}^{3}\right)$ associated with large scale collapse of the volcanoes northern flank, a lateral blast, debris flows and associated transformations, pyroclastic flows and ash fall (Scott, 1988; Major et al., 2005). These styles of volcanic processes are not uncommon on Mt St Helens with more than 35 debris and hyperconcentrated flows inundating the north-western river systems more than $50 \mathrm{~km}$ from their source (Scott, 1988) (Figure 15 and 16).

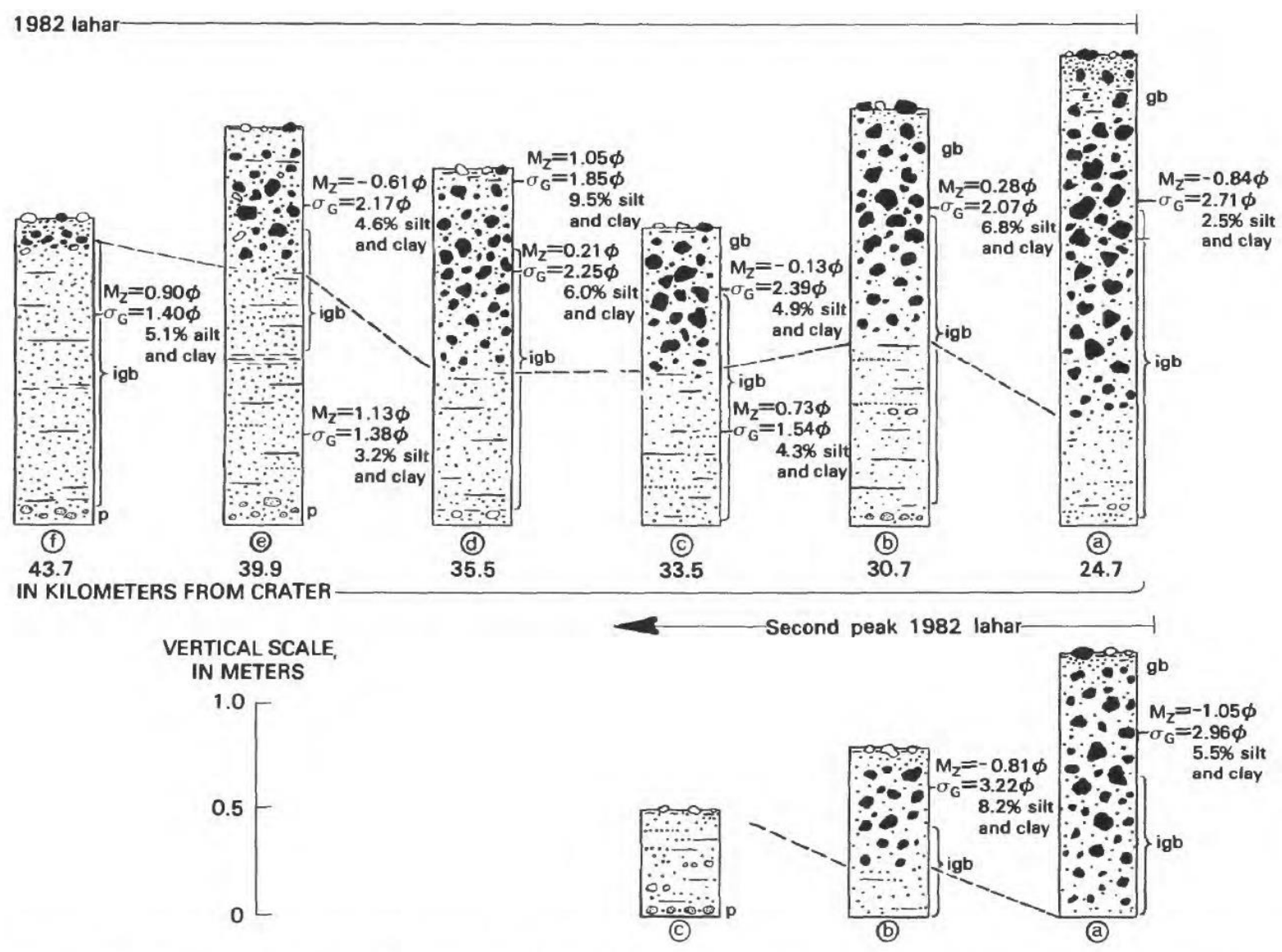

Figure 15: Deposits and associated grain size statistics of the 1980 South Fork lahar, 1982 lahar, and associated lahar-runout flows (Scott, 1988). 


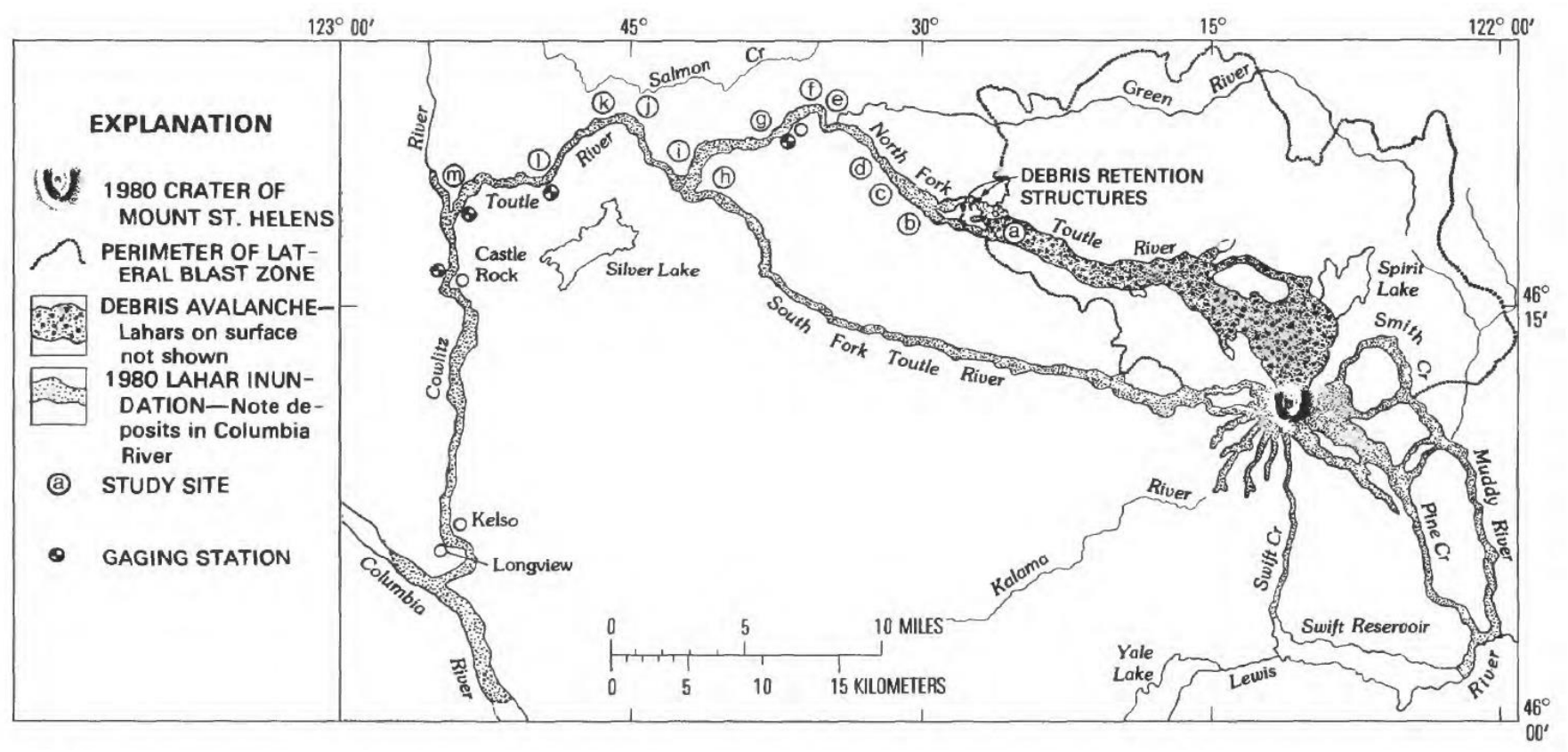

Figure 16: Map showing the distribution of the 1980 and 1982 Lahars on Mt St Helens. Letter A-F represents deposits identified in Fig 15 (Scott, 1988).

The main mechanisms for lahar formation included (Scott, 1988; Major et al., 2005;

Hodgson, 1993):

- Pyroclastic surge transformation: Catastrophically ejected, lithic-rich pyroclastic surge deflated forming a debris flow in the South Fork of the Toutle River. The water source for the transformation from gas-supported to water-supported flows is sourced from snow melt or the incorporation of river water.

- Debris avalanche transformation: Water saturated, poorly sorted debris from the large scale edifice dewatered forming debris and hyperconcentrated flows. The transformation from debris avalanche to debris flow at Mt St Helens was not a direct transformation; this has been attributed to the relatively young age of the modern cone $(50,000$ years) manifested in its lack of hydrothermally altered rock (Glicken, 1998). The transformation occurred, 5 hours after the main eruption, through the process of liquefaction and subsequent dewatering of the trapped groundwater, glacial ice and locally entrained river water within the debris avalanche. It is suggested that the liquefaction and dewatering was triggered by a succession of "harmonic tremors".

- Flood surge bulking: Large debris flows formed in the Toutle River system when flood surges were triggered by the collapse of naturally occurring volcanic dams. As the flood waters move downstream the flow is bulked through the erosion and subsequent incorporation of alluvial deposits within the river. 
Peak velocities and discharges range from $6.0-8.0 \times 10^{3} \mathrm{~m}^{3} \mathrm{~s}^{-1}$ and $6-12 \mathrm{~ms}^{-1}$ during the largest event in the North and South Fork Toutle River, $2.9 \times 10^{4} \mathrm{~m}^{3} \mathrm{~s}^{-1}$ during the Pine Creek lahar and $2.2 \times 10^{4} \mathrm{~m}^{3} \mathrm{~s}^{-1}$ (Hodgson, 1993).

Scott (1988) developed a facies model for the 1980 lahar deposits in the Toutle-Cowlitz River system. This model includes a lahar channel facies, lahar flood-plain facies, laharrunout facies, transition facies, and lahar related stream flow facies (Figure 17 and 18). This facies model is summarised in table 3.

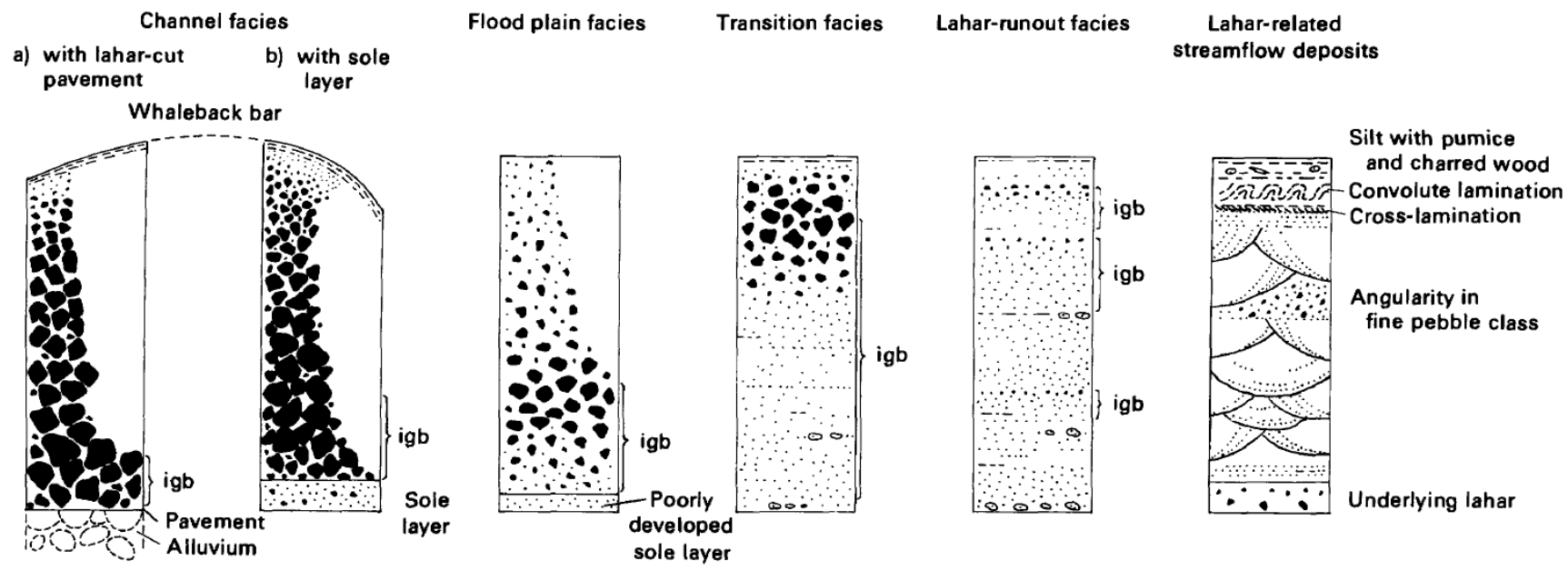

Figure 17: Representative stratigraphy associated with the Mt St Helens lahar facies model of Scott (1988). This includes the channel facies, flood plain facies, transition facies, lahar-runout facies, and lahar-related stream flow deposits. 

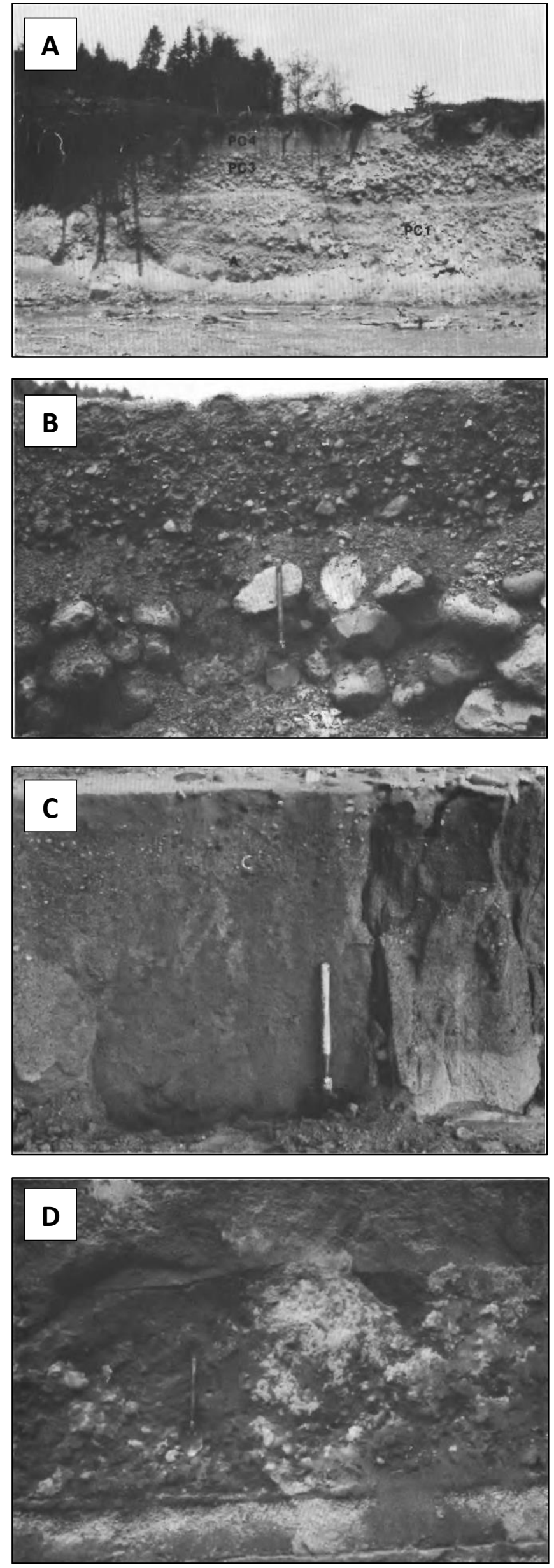

Figure 18: (A) Exposed Pine Creek lahars including a large $(5 \times 12 \mathrm{~m})$ egg-shaped mega-clast. (B) Bar deposits of the North Fork lahar. Deposits include hydrothermally altered clasts and rounded alluvial clasts bulked from the existing river bed. (C) Deposits of the 1982 peak runout flow at Kid Valley. Low density clasts are buoyed on the deposits surface. The ' $C$ ' marks the position of the largest clasts within the inversely graded unit. (D) Floodplain facies of 3 older lahars from the Coal Bank section (Scott, 1988).

Table 3 (Next Page): Table describing the features of the facies outlined in the facies model of Scott (1988). 


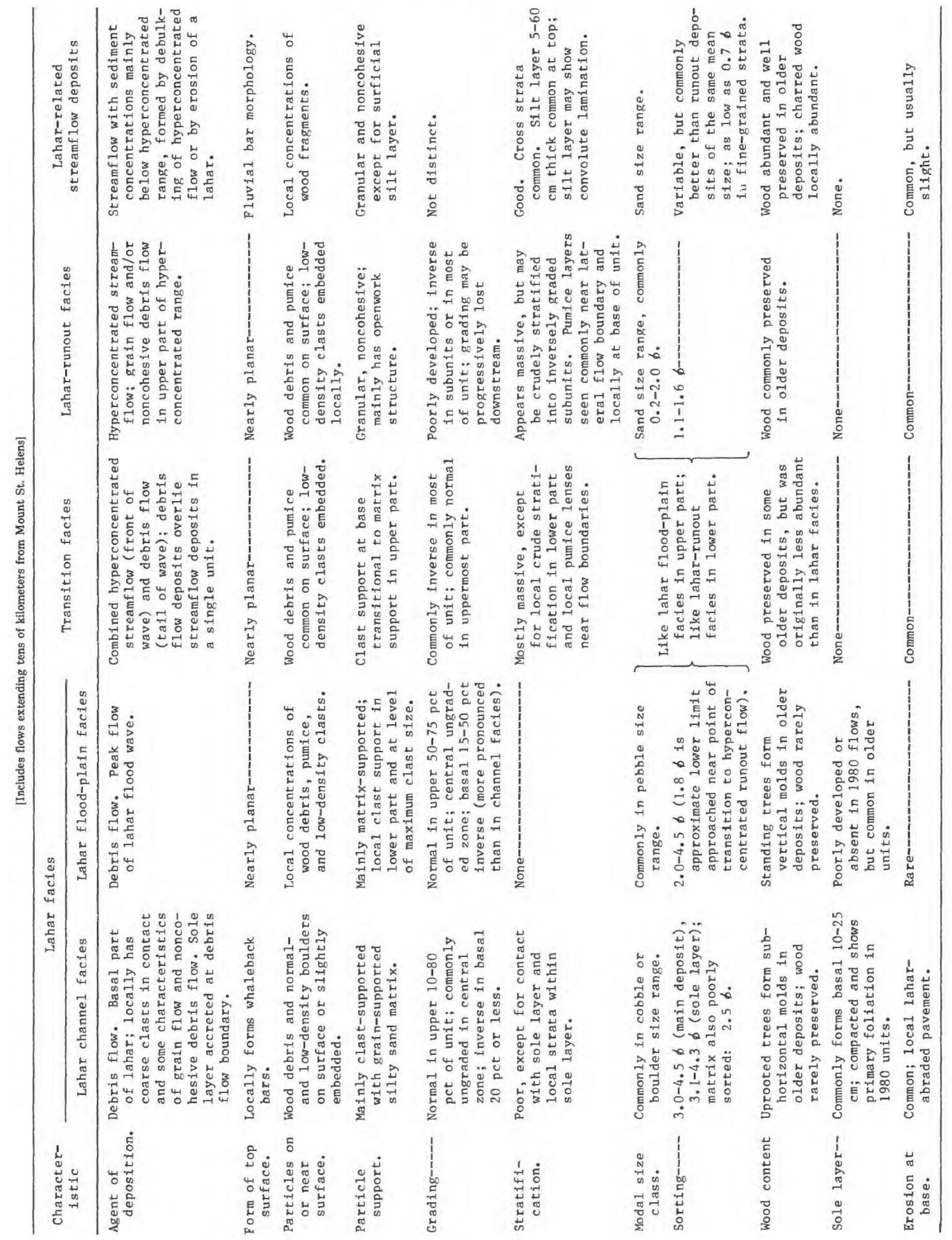




\section{Chapter Two: Methodology}

\section{Field Investigations}

To understand the internal architecture and emplacement history of the Ngatoro

Formation, the characteristics and stratigraphic context of the deposit must be described from proximal to distal, and flow axes to margin locations. A reconnaissance of prospective study locations was conducted in January 2013 using the Quaternary Geological Map of the Taranaki Peninsula (Neall and Alloway, 2004) as a guideline for the extent of the formation. Eight sites were identified for detailed investigation (Figure 19). These sites are as follows:

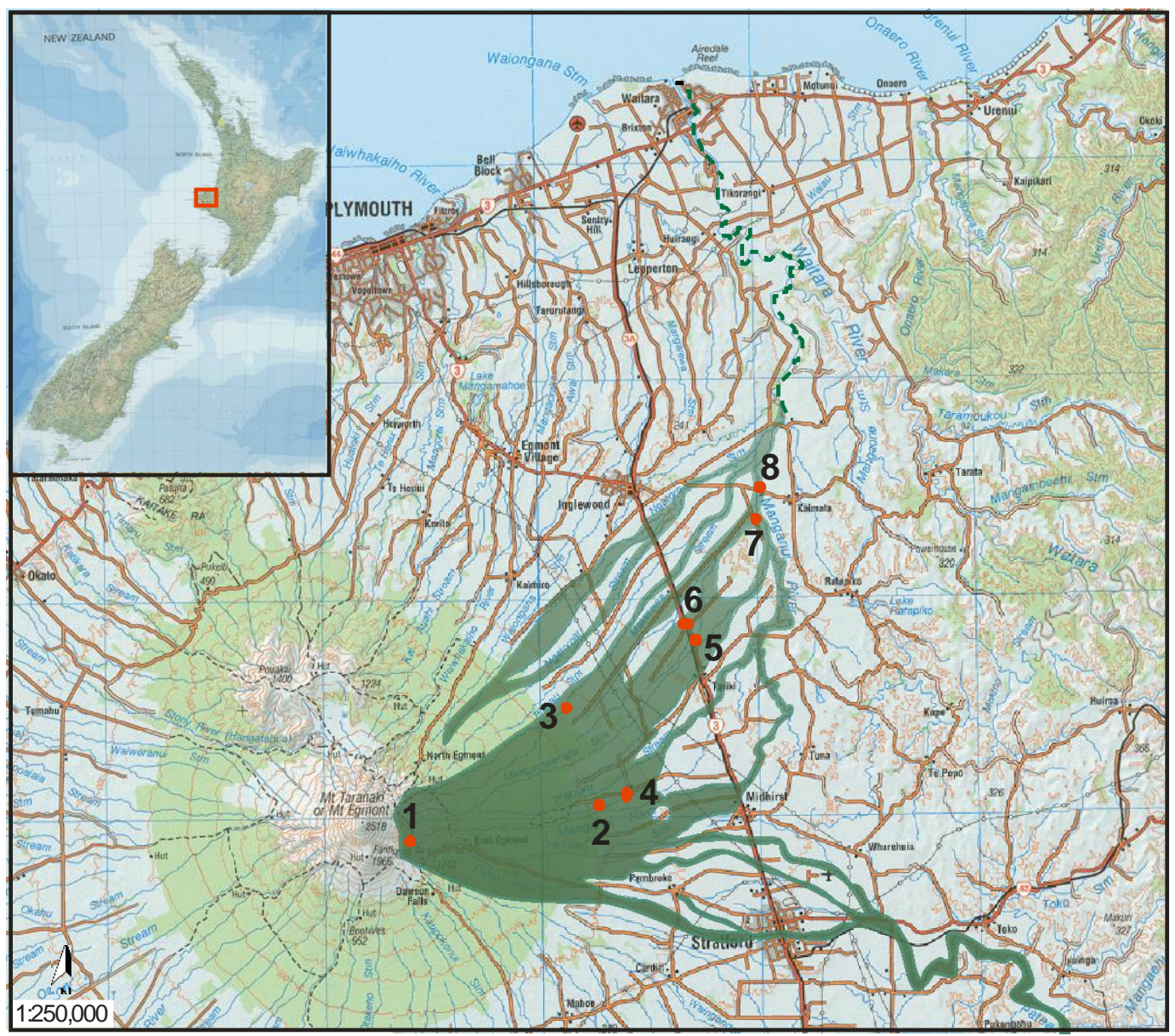

Figure 19: Map Egmont Volcano and its ring plain showing the extent of the Ngatoro Formation according to Neall and Alloway (2004), and the location of sections studied in this thesis marked by red dots. Base map 1:250,000 from Land Information New Zealand. 
1) Eastern Egmont (2.7 km from the modern summit) ( $\mathrm{S} 39^{\circ} 18^{\prime} 22.20^{\prime \prime}, \mathrm{E} 174^{\circ} 05^{\prime} 30.16^{\prime \prime}$, $1257 \mathrm{~m}$ ): The section is located on a westward facing escarpment above the Manganui Valley (source tributary of the Manganui River) on the track to the Manganui Ski Field.

2) Vickers Quarry (10 km from the modern summit) (S 39 $17^{\prime} 29.99^{\prime \prime}, \mathrm{E} 174^{\circ} 10^{\prime} 40.86^{\prime \prime}$, $526 \mathrm{~m}$ ): Three sections in pristine, freshly exposed quarry walls (two eastward facing and one north facing) located at Vickers Quarry on York Rd, Stratford. Vickers Quarry is located adjacent to the Manganui River. Sections were mainly confined to the western wall located on the boundary with Egmont National Park.

3) Surrey Road Quarry (10 km from the modern summit) (S 39 $16^{\prime} 14.82^{\prime \prime}$, E 174 ${ }^{\circ} 10^{\prime} 28.73^{\prime \prime}$, $501 \mathrm{~m}$ ): Three south-facing sections located in a farm quarry located off the end of Surrey Road, at the boundary with Egmont National Park. The quarry is located adjacent an upstream tributary of the Mangatengehu River.

4) York Road (13.6 km from the modern summit) (S $39^{\circ} 16^{\prime} 40.42^{\prime \prime}$, E $174^{\circ} 13^{\prime} 08.49^{\prime \prime}, 400 \mathrm{~m}$ ): Two closely-spaced sections (one east and one west facing) located on either side of a road underpass on York Rd, Stratford (1.2 km northeast of the Derby Road intersection).

5) Tariki - SH3 (17.1 km from the modern summit) (S $39^{\circ} 13^{\prime} 28.77^{\prime \prime}$, E $174^{\circ} 14^{\prime} 24.22^{\prime \prime}$, $276 \mathrm{~m}$ ): Northward-facing section located in an old farm quarry on State Highway 3 at the Mangamawhete River Bridge.

6) Tariki Underpass (17.4 km from the modern summit) (S $39^{\circ} 12^{\prime} 51.86^{\prime \prime}$, E 174 ${ }^{\circ} 14^{\prime} 04.09^{\prime \prime}$, $265 \mathrm{~m}$ ): Four sections located on the northern side of the Tariki Underpass on the westward facing cut slope opposite the John's Road junction.

7) Suffolk Road Junction (22.8 km from the modern summit) ( $339^{\circ} 10^{\prime} 07.15^{\prime \prime}, \mathrm{E}$ $\left.174^{\circ} 16^{\prime} 12.82^{\prime \prime}, 158 \mathrm{~m}\right)$ : Northeast facing section located at the Waitepuke Stream Bridge on Suffolk Road, $50 \mathrm{~m}$ south of the Norfolk Road junction.

8) Kaimata Sawmill (23.8 $\mathbf{k m}$ from the modern summit) (S $39^{\circ} 09^{\prime} 30.39^{\prime \prime}$, E 174 ${ }^{\circ} 16^{\prime} 31.25^{\prime \prime}$, $144 \mathrm{~m}$ ): Section located on the southwest-facing cut slope at the Manganui River bridge on Tarata Road, next to Kaimata Sawmills. 


\section{Measured Sections}

At each site, one or more sections were measured in detail. This involved clearing the outcrop of vegetation and debris using a spade and trowel. Individual lithostratigraphic units were identified and thickness measured using a standard tape measure. Detailed descriptions using basic geological rock and soil descriptive terms for grain size, colour, mineralogy, sorting, clast features, bedding, sedimentary structures and boundary relationships were made.

At some of the sites, sampling of tephra for Electron Microprobe Analysis (EMP) and sediment for grain size/shape analysis was carried out to help characterise and interpret the lithostratigraphic units.

\section{Tephrochronology}

Taranaki's Quaternary stratigraphic record contains many tephra beds sourced from Egmont (including Fanthams Peak), Pouakai and Kaitake Volcanoes. These are manifested in the cover-bed stratigraphy as weathered coarse ash and pumiceous and/or lithic lapilli beds. Morphologically distinctive tephra can be recognised in the field on the basis of a combination of colour, bedding and stratigraphic association and therefore are useful as a mappable isochronous horizon that can be used to constrain depositional events both spatially and temporally.

Geochemical characterisation of tephra using major element composition of glass shards and minerals by electron microprobe analysis (EMP) is a commonly used tephra correlation tool employed by tephrochronologists around the world (i.e. Alloway et al, 1995; Cronin et al, 1996; Fenderman and Carey, 1980; Sandiford et al, 2001). Generally, EMP analysis has not been routinely employed on Egmont sourced tephra on account of the rapid weathering of glass to andic material, the occurrence and abundance of crystal microlites in the glassy matrix and the highly vesicular nature of the glass which precludes a 10 um beam obtaining meaningful analysis. This study provides a very comprehensive attempt to correlate Egmont-sourced tephra. 
Assuming glass compositional differences between different Egmont-sourced tephra enveloping the Ngatoro Formation, EMP analysis of the major elemental glass composition provides a potential quantitative means for the correlation and discrimination of tephra beds between stratigraphic sections. All tephra interbeds at described localities are correlated with an existing major element glass shard EMP dataset (B.V. Alloway, unpublished data) from two reference sections located on the eastern lower flanks of Egmont Volcano - the first on a roadside cutting on Pembroke Road close to the Manganui ski field car park and at another roadside cutting on Manaia Road in the vicinity of Dawson Falls (Figure 20 and 21). These sections are described by Alloway et al. (1995).
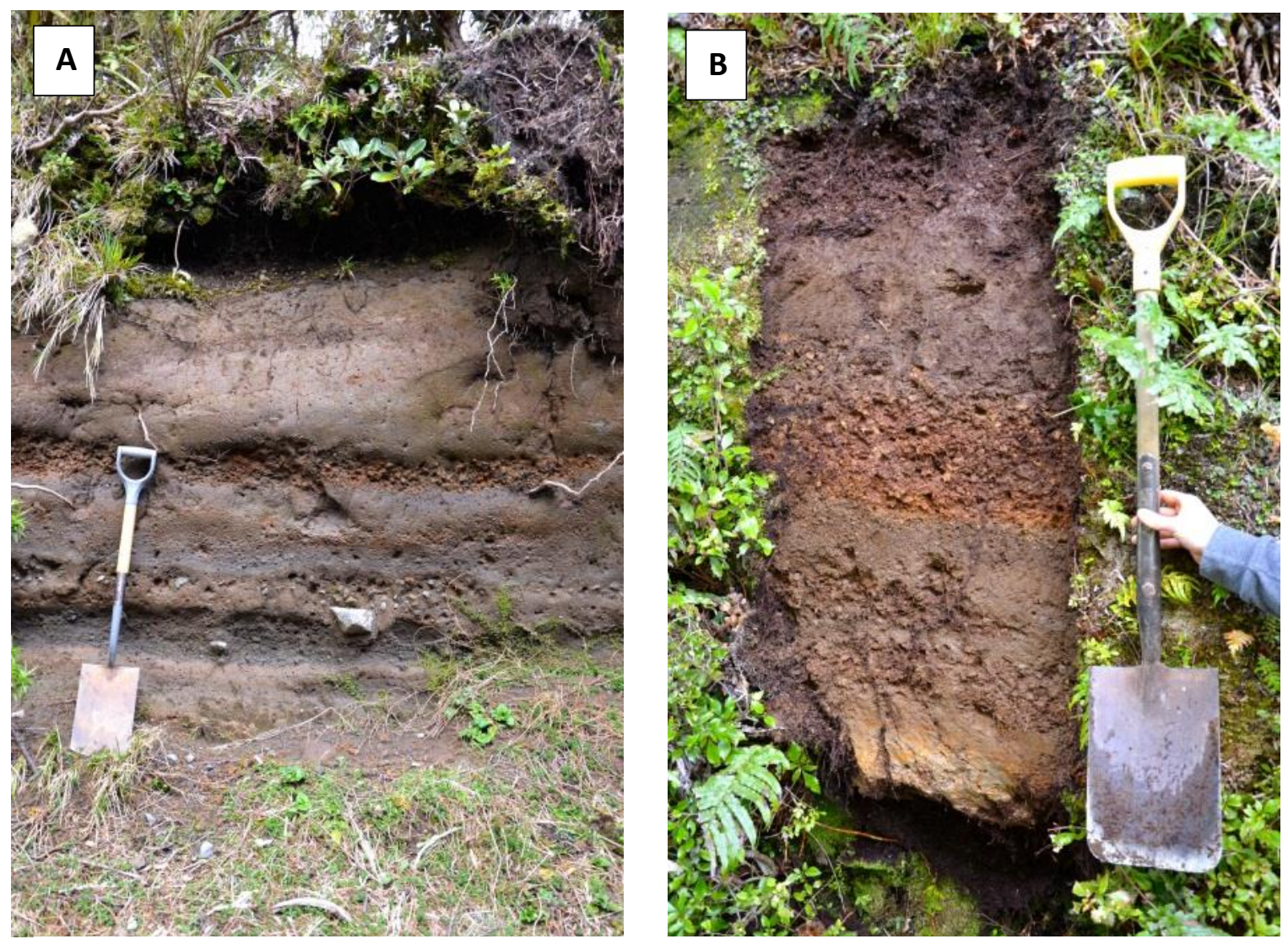

Figure 20: Photos of the sections sampled for Electron Microprobe reference dataset which correspond to the stratigraphic columns presented in figure 21. (A) East Egmont and (B) Dawson Falls sections - Photos courtesy of A/Prof Brent Alloway. 
East Egmont

$S 39^{\circ} 18^{\prime} 26.9^{*}$
W $174^{\circ} 06^{\circ} 14.2^{\prime \prime}$
Dawson Falls

S $39^{\circ} 19^{\prime} 31.7^{\prime \prime}$

W $174^{\circ} 06^{\prime} 22.1^{\prime \prime}$

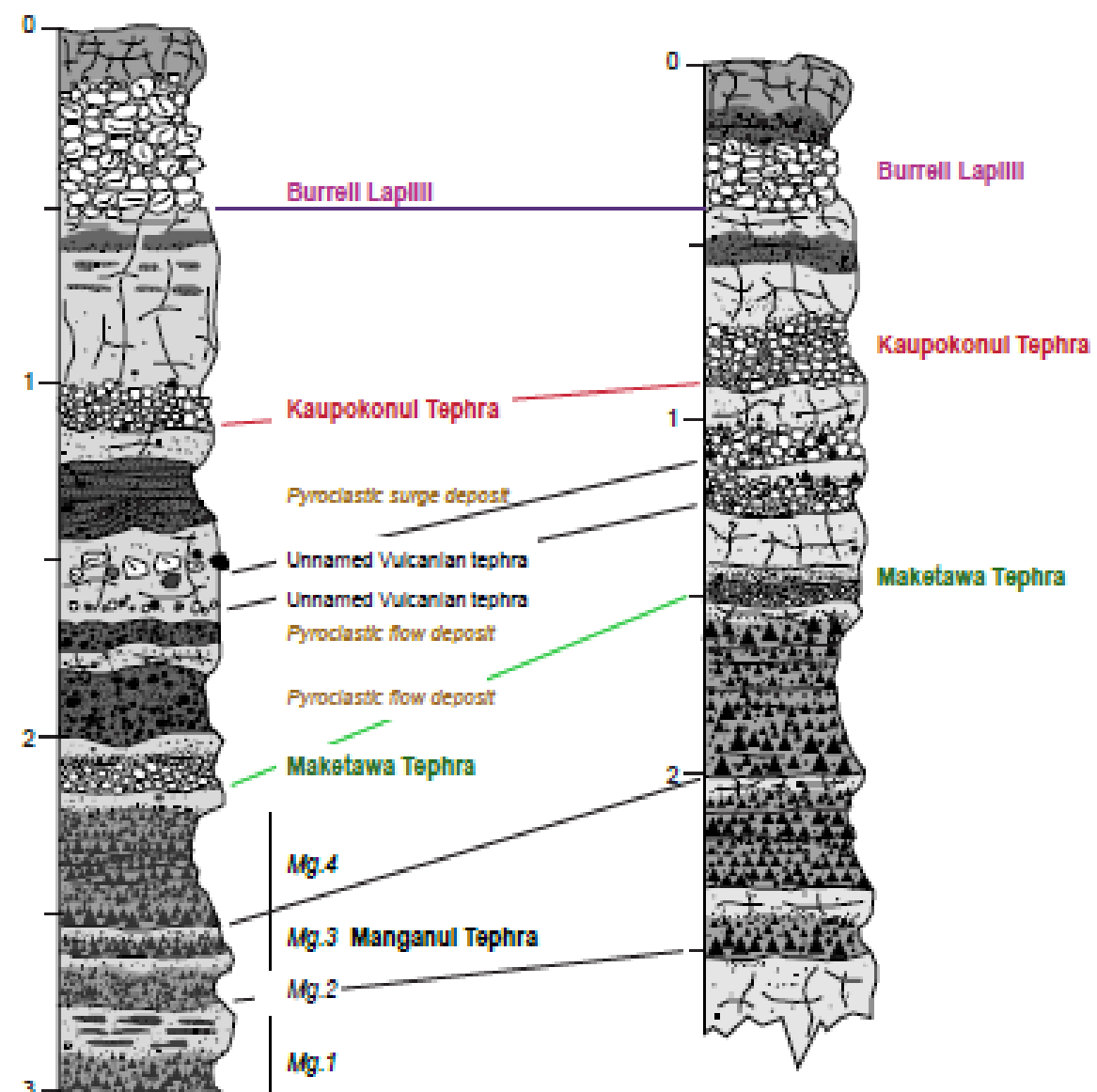

Unnamed Vulcanlan tephra

Fig 21: Stratigraphic sections sampled as reference Electron Microprobe dataset. Section photographs presented in figure 20. Reference dataset and stratigraphic sections courtesy of A/Prof Brent Alloway. 


\subsection{Sample Selection and Processing}

Thirty-one tephra beds associated with volcaniclastic sequences containing Ngatoro Formation were selected for laboratory analysis. Samples were collected from key reference sections at Eastern Egmont, Vickers Quarry, York Road, Tariki Underpass, Suffolk Road Junction and Kaimata Sawmill. Each sample was processed using the following method:

- Pumiceous clasts from 26 of the samples were selected based on high glass content, low weathering and sufficient glass preservation (Table 4). The stratigraphic position of each sample is presented with relevant measured sections in Appendix A.

- The pumice was then crushed with wooden blocks and wet sieved between 1 phi $(\phi)$ $(500 \mu \mathrm{m})$ and $4 \phi(63 \mu \mathrm{m})$ then dried at $30^{\circ} \mathrm{C}$ in a laboratory oven. Each sample was then dry sieved into $>1 \phi, 1-2 \phi, 2-3 \phi$ and $3-4 \phi$ sub-samples.

- The 1-2ф sub-sample was selected for EMP analysis due to its abundance of wellpreserved glass.

- Each sub-sample was set in a 6 sample mount using epoxy resin.

- Each sample mount was then polished to expose the glass.

- Each epoxy mount was carbon coated in preparation for analysis. The carbon coating gives the sample mount a conductive coating that prevents the sample charging up and reducing the effective electron energy.

\begin{tabular}{|l|l|l|}
\hline Location: & Sample Section: & Tephra Sample Number: \\
\hline East Egmont & EE-1 & TS-14, TS-15 and TS-16 \\
\hline Vickers Quarry & VQ-1 & TS-19, TS-20, TS-21, TS-22 and TS-28 \\
\hline York Road & $\begin{array}{l}\text { YR-1 } \\
\text { YR-2 }\end{array}$ & $\begin{array}{l}\text { TS-23, TS-24 and TS-25 } \\
\text { TS-31 }\end{array}$ \\
\hline Tariki Underpass & $\begin{array}{l}\text { TU-1 } \\
\text { TU-2 }\end{array}$ & $\begin{array}{l}\text { TS-11, TS-12 and TS-13 } \\
\text { TS-29 and TS-30 }\end{array}$ \\
\hline Suffolk Road & SF-1 & TS-7, TS-8, TS-9 and TS-10 \\
\hline Kaimata Sawmills & MG-1 & TS-1, TS-2, TS-3, TS-4 and TS-5 \\
\hline
\end{tabular}

Table 4: Location and identification numbers of lapilli beds and entrained pumice clasts sampled for EMP analysis. Annotated measured sections for each sample location are presented in Appendix A. 


\subsection{Measurement and Data Analysis}

The major elemental glass composition of the tephra were analysed using JEOL 733

Superprobe equipped with three wavelength dispersive spectrometers located at Victoria University of Wellington, New Zealand (Figure 22). The analysis of $\mathrm{SiO}_{2}, \mathrm{TiO}_{2}, \mathrm{Al}_{2} \mathrm{O}_{3}, \mathrm{FeO}$, $\mathrm{MnO}, \mathrm{MgO}, \mathrm{CaO}, \mathrm{Na}_{2} \mathrm{O}, \mathrm{K}_{2} \mathrm{O}$ and $\mathrm{Cl}$ was performed using a $15 \mathrm{kV}$ accelerating voltage under a static electron beam operating at $8 \mathrm{nA}$.

The following methodology was used in the Electron Microprobe analysis:

- The Electron Microprobe was calibrated using standards of known chemical composition.

- Measurement drift was corrected for by measuring the ATHO-G and VG-568 glass standards (Table 5) on average every fifteen to twenty sample measurements.

- The vesiculated glass selvedges identified within each sample (Figure 23) were measured fifteen to twenty times in order to reduce uncertainty in the resultant major elemental glass composition data.

- Measurements considered outliers were excluded based on qualitative analysis.

- The raw data, excluding statistical outliers, was recalculated using multipliers calculated from the ATHO-G and VG-568 standard measurements.

- The recalculated data was standardised to $100 \%$ to allow for direct comparison between samples.

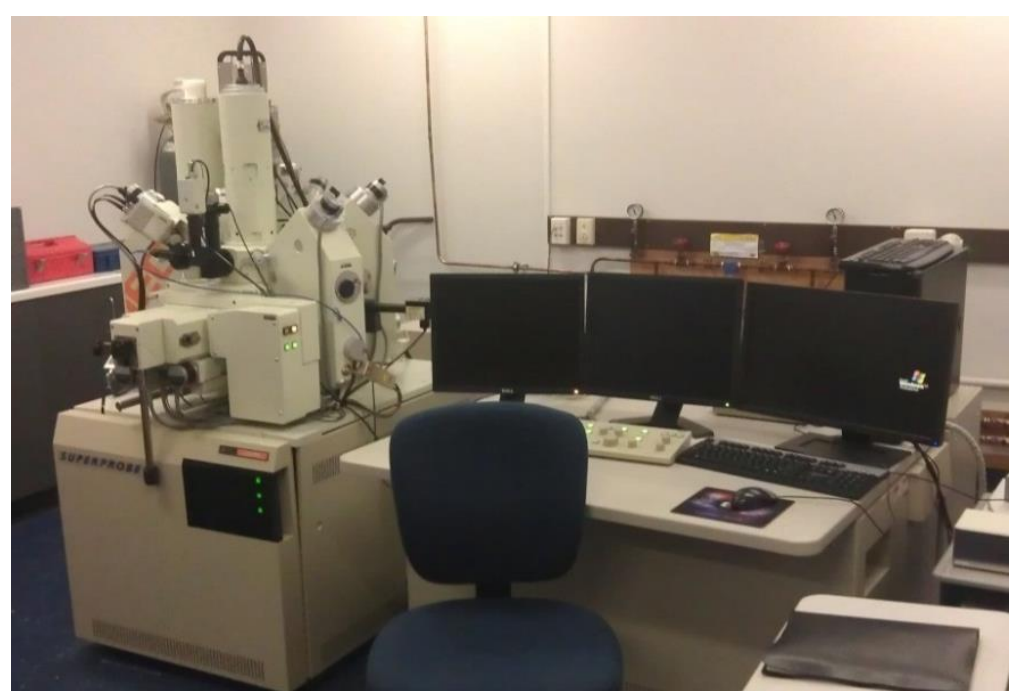

Figure 22: The JEOL 733 Superprobe Electron Microprobe at Victoria University used in this study. An Electron Microprobe $(E M P)$ is a specialised Electron Microscope with the primary purpose of major elemental analysis of hard polished surfaces such as mineral thin sections or epoxy mounts. The major elemental composition of a given sample is achieved by measuring the intensities and wavelengths of the $x$-rays produced by exposing the sample to a focused stationary electron beam. The wavelength of the returned $x$-rays identifies the element present in the samples, while the intensity of the $x$-rays is related to the concentration of that mineral using a ZAFcalculation. 


\begin{tabular}{|c|c|c|c|c|c|c|c|c|c|c|c|}
\hline & $\mathrm{SiO}_{2}$ & $\mathrm{Al}_{2} \mathrm{O}_{3}$ & $\mathrm{TiO}_{2}$ & $\mathrm{FeO}$ & MgO & Mno & $\mathrm{CaO}$ & $\mathrm{Na}_{2} \mathrm{O}$ & $\mathrm{K}_{2} \mathrm{O}$ & $\mathrm{Cl}$ & Total \\
\hline ATHO-SD & 75.60 & 12.20 & 0.26 & 3.27 & 0.10 & 0.10 & 1.70 & 3.73 & 2.64 & 0.0 & 99.65 \\
\hline \multicolumn{12}{|c|}{ RAW DATA } \\
\hline Average & 74.71 & 12.18 & 0.24 & 3.29 & 0.10 & 0.10 & 1.76 & 3.81 & 2.75 & 0.00 & 98.93 \\
\hline SD & 0.30 & 0.09 & 0.02 & 0.11 & 0.01 & 0.03 & 0.02 & 0.29 & 0.04 & 0.00 & 0.44 \\
\hline Multiplier & 1.012 & & & & & & 0.966 & 0.980 & 0.960 & & \\
\hline \multicolumn{12}{|c|}{ RECALCULATED DATA } \\
\hline Average & 75.61 & 12.18 & 0.24 & 3.29 & 0.10 & 0.10 & 1.70 & 3.73 & 2.64 & 0.00 & 99.58 \\
\hline SD & 0.30 & 0.09 & 0.02 & 0.11 & 0.01 & 0.03 & 0.02 & 0.29 & 0.04 & 0.00 & 0.44 \\
\hline
\end{tabular}

Table 5: Reference dataset for the ATHO-G standard sample which includes the raw and recalculated data from 90 reference measurements taken during the sample analysis. The full EMP dataset is presented in Appendix B. All EMP data is presented in wt\%.
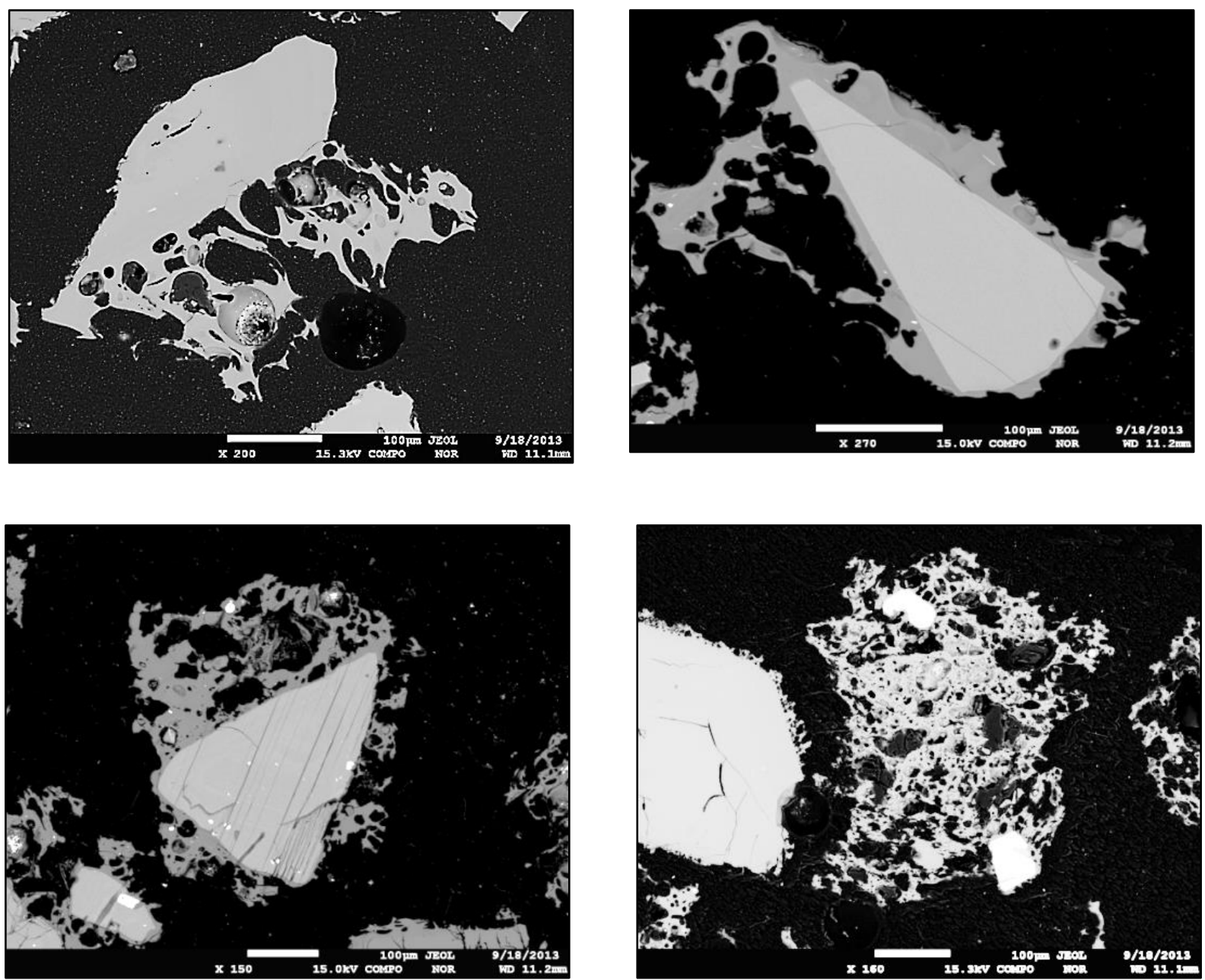

Figure 23: Selected electron microscope images showing four samples with typical vesiculated volcanic glass selvedges used for the acquisition of major elemental glass composition data. The highly vesiculated nature and significant weathering of the volcanic glass within the samples made EMP analysis challenging. 


\section{Sedimentology}

Volcaniclastic deposits are very challenging to quantitatively describe due to their coarsegrained texture, rapid lateral and vertical transformations, complex relationships with enveloping formations and very poor sorting - grain sizes range from clay to large boulders $(<2.0 \mathrm{~m})$ with a wide range of clast shapes. However, a textural analysis of a deposit can provide a useful tool for comparing and contrasting flow deposits, correlating units, and inferring the flow dynamics and origin. The methods employed in this study to quantitatively describe a deposit include grain size, clast roundness and clast form.

- Grain Size - This describes the range in intermediate axis length of grains/clast within the deposit. The intermediate axis is selected to correlate with the sieve stack data where the intermediate axis is the determining factor if a particle will pass through the set size mesh (Boggs, 2006).

- Clast Form - The clast form is described by the relative lengths of the principal axis (X, Y, Z). The Sneed and Folk (1958) definition of maximum projection sphericity uses the ratio of the maximum projection area of a sphere the same volume as the clast and the maximum projection area of the clast. This classifies clast as compact, platy, bladed or elongated.

- Clast Roundness - Clast roundness is the measure of the sharpness of corners and edges of a grain (Boggs, 2006), defined by the ratio of the average ratio of curvature of the particle edges verses the radius of curvature of the largest inscribed sphere (Scott, 1988).

The methods of Scott (1988) were used as a guide for determining the grain size and shape analyses presented in this thesis. Some variation in the methodology occurred due to ongoing developments and refinements in analytical techniques. Scott (1988) quantitatively describes lahar deposits in the Toutle-Cowlitz River System associated with the May 1980, Mount St Helens eruptive sequence. These methods are briefly summarised below:

Grain Size: Lahar deposits containing pebble-size and finer were analysed by wet sieving the sand and coarser constituent and by pipette-analysis of the silt and clay fractions. Grain size distributions of deposits considered too coarse for laboratory analysis were analysed in the field using the grid sampling and point counting method of Wolman (1954). This coarse 
constituent data could then be combined with a laboratory matrix analysis to obtain a full size distribution using the frequencies by weight determined in normal laboratory analysis by Kellerhals and Bray (1971).

Clast Form and Roundness: The -3 to $-4 \phi$ and -4 to $-5 \phi$ size fractions were selected as they are well represented in both the finer grained peak flow and sole layer, and coarser grained laharic deposits. Each of the reported roundness values is calculated from a minimum of 50 measurements made using reference clasts of known standard roundness. Both scoriaceous and pumiceous clasts were excluded from roundness estimates due to the more rapid rounding compared to the dominant andesite clasts.

Statistics: The graphical statistical method of Folk $(1966,1980)$ was used to calculate the graphic mean $\left(\mathrm{M}_{\mathrm{z}}\right)$, graphic standard deviation $\left(\sigma_{G}\right)$, graphic skewness $\left(\mathrm{SK}_{\mathrm{G}}\right)$ and graphic kurtosis $\left(\mathrm{K}_{\mathrm{G}}\right)$. This method was selected for its comparable graphic standard sorting measure to the widely used $\sigma_{\phi}$ of Inman (1952). Using the Wentworth class size intervals (phi units) the $\phi_{16}$ and $\phi_{84}$ could be more easily measured or extrapolated using the Folk $(1966,1980)$ method. Where possible the inclusive graphical standard deviation $\left(\sigma_{l}\right)$ and inclusive graphic skewness $\left(\mathrm{Sk}_{\mathrm{l}}\right)$ were also calculated for comparison.

\subsection{Grain Size}

The grain size distribution of the Ngatoro Formation was analysed at four different locations ranging from proximal to distal - Vickers Quarry (10 km from the present summit), York Road $(13.6 \mathrm{~km})$, Tariki Underpass $(17.4 \mathrm{~km})$ and Kaimata Sawmill $(23.8 \mathrm{~km})$ sections. This analysis comprised both a field and laboratory component. The grain size analysis uses the grain size scale of Wentworth (1922).

\section{Field Measurement and Sampling}

The analysis of grain size distributions was made difficult by the very poorly sorted nature of the proximal Ngatoro Formation. With clasts up to $2.0 \mathrm{~m}$, this made the point or grid counting method from Scott (1988) challenging as this is within the range of unit thickness. To address this, a practical approach was taken by classifying and describing units based on:

- Bulk sample of sediment ranging from $-5 \phi$ to $10 \phi$ which encompasses gravel to silt and clay for laboratory analysis. 
- Measuring the long axis of the five largest clasts in the field.

At each location, the outcrop was divided into lithostratigraphic units. In coarse-grained proximal deposits the matrix was sampled while in intermediate and fine grained distal deposits, samples were representative of the whole unit. Eighteen samples ( $-5 \phi$ to $10 \phi)$ were collected at the four locations (Figure 25).

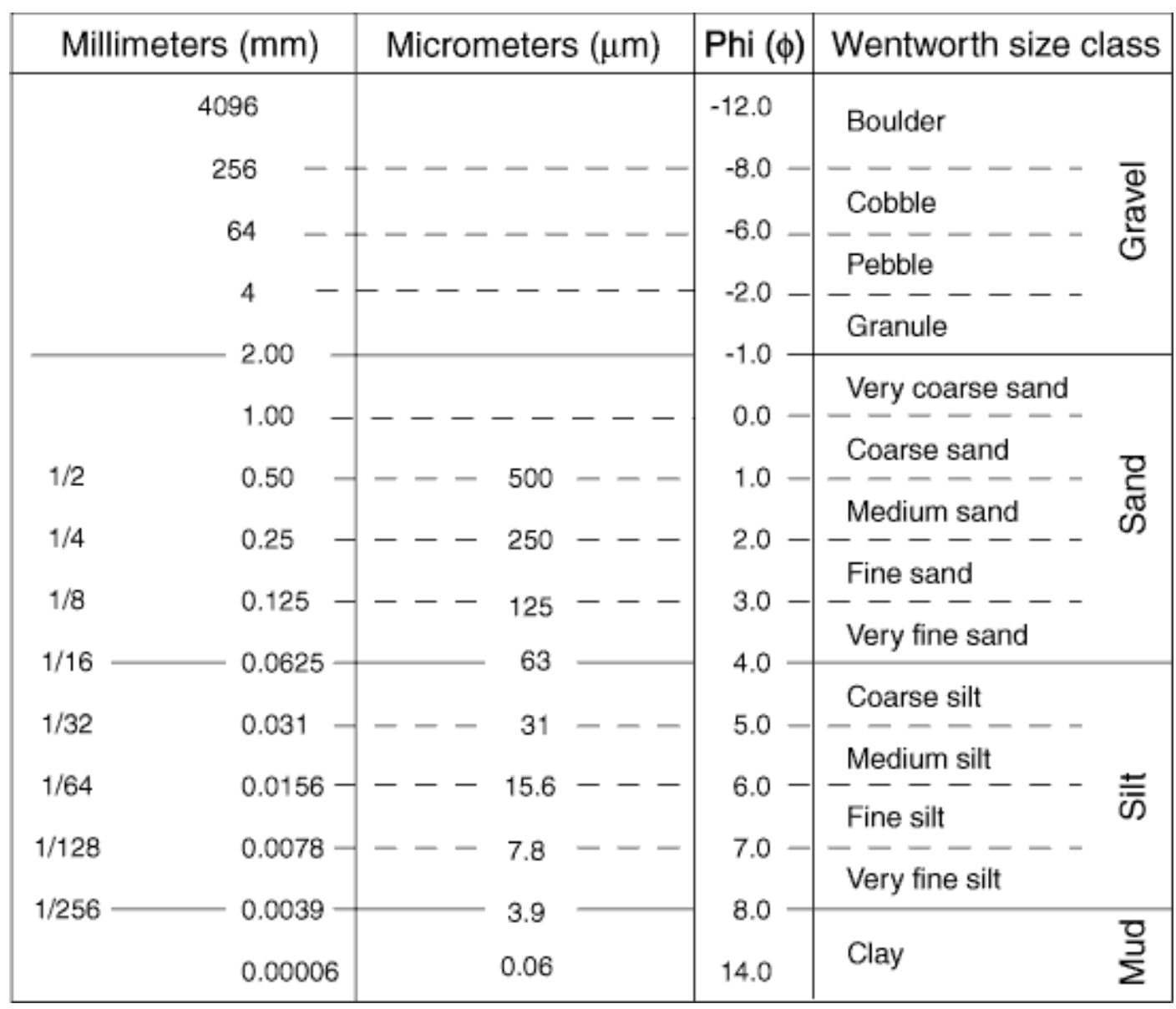

Figure 24: Wentworth grain size scale (Wentworth, 1922).Grainsizes are measured in either millimetres $(\mathrm{mm})$ or Phi $(\varphi)$ and divided into gravel, sand, silt and mud size classes. 

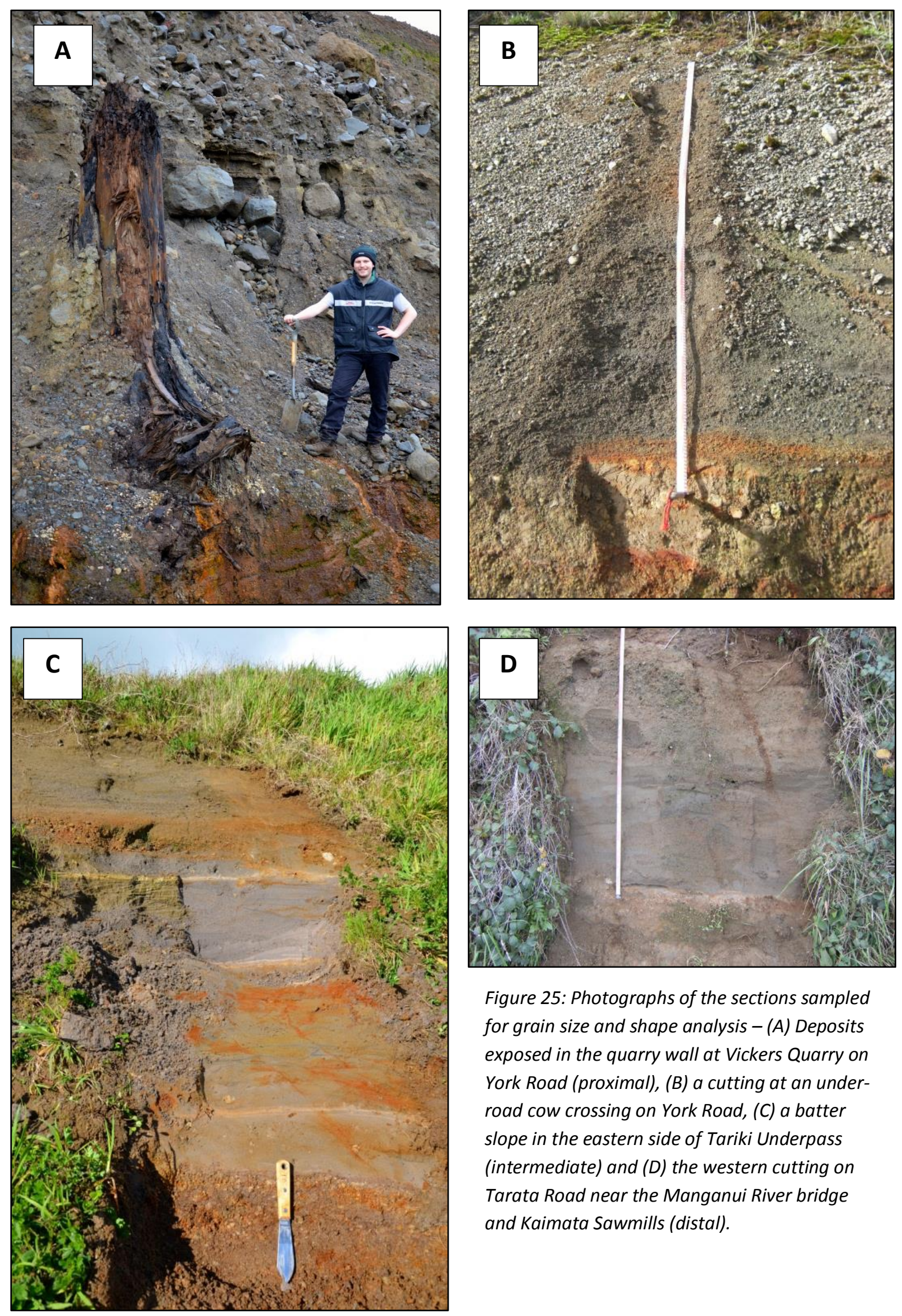

Figure 25: Photographs of the sections sampled for grain size and shape analysis - (A) Deposits exposed in the quarry wall at Vickers Quarry on York Road (proximal), (B) a cutting at an underroad cow crossing on York Road, (C) a batter slope in the eastern side of Tariki Underpass (intermediate) and (D) the western cutting on Tarata Road near the Manganui River bridge and Kaimata Sawmills (distal). 


\section{Laboratory Analysis}

In the laboratory, each of the eighteen samples was processed using the following method:

- Sample was dried at $30^{\circ} \mathrm{C}$ in a laboratory oven for approximately 3 days.

- The sample was then split into sub-samples using an aluminium splitter box. Subsamples ranged from $90.0 \mathrm{~g}$ to $1300.0 \mathrm{~g}$ depending on how poorly sorted the sample was.

- Sub-samples were hand-picked to remove organic material.

- The sub-sample was weighed.

- The sub-sample was then wet sieved using $60 \mu \mathrm{m}$ sieve cloth and distilled water. The fine fraction was collected in a glass beaker, with the coarse fraction retained in the sieve cloth. Both the fine and coarse constituents were dried at $40^{\circ} \mathrm{C}$ in a laboratory oven until dry.

- The fine fraction was weighed and recorded.

- The coarse fraction was sieved from $-5 \phi$ to $5 \phi$ using a dry sieve stack at $0.5 \phi$ intervals for 10 minutes (Figure 26). Each interval was weighed and recorded.

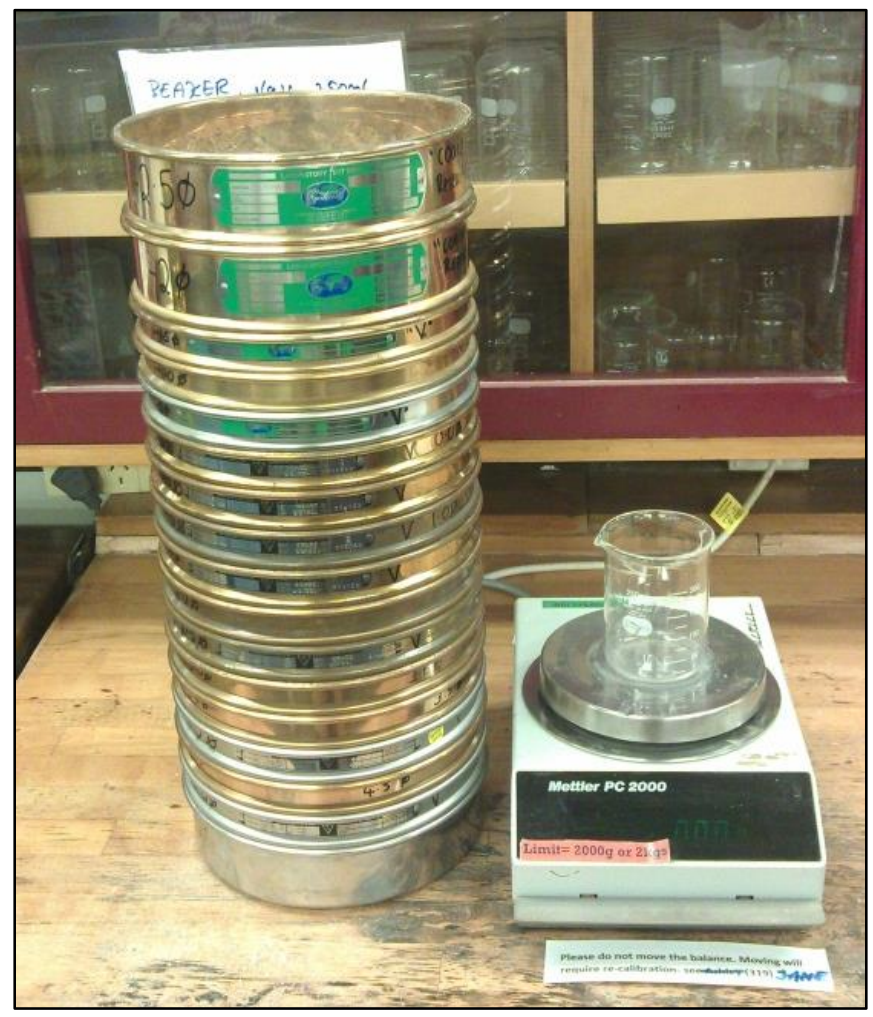

Figure 26: Coarse sieve stack and laboratory scales used in the grain size analysis. 
The initial intention was to analyse the $<4 \phi(<63 \mu \mathrm{m})$ fraction using a Micrometrics Sedigraph III Plus. However, magnetic flocculation of the fine magnetic particles to the magnetic stirrer in the Sedigraph produced biased grain size distributions. Therefore the fine fraction is recorded simply as a weight percentage (wt\%) finer than $4 \phi$.

\section{Statistics}

The weight of sample in each $0.5 \phi$ sieve was converted to a weight percentage of the whole sample and plotted on a histogram. The weight percentage and summary statistics were calculated using a MatLab script. The summary statistics included the Graphic Mean (eq. 1.0), Inclusive Graphic Standard Deviation (eq. 2.0), Inclusive Graphic Skewness (eq. 3.0) and Graphic Kurtosis (eq. 4.0) (Folk and Ward, 1957; Boggs, 2006). The inclusive graphic standard deviation is used to estimate the sorting from "Very Well Sorted" to "Extremely Poorly Sorted" (Table 6) and the inclusive graphic skewness describes the grain size distribution from "Strongly Fine Skewed" to "Strongly Coarse Skewed" (Table 7) (Boggs, 2006).

Graphic Mean

$$
M_{z}=\frac{\emptyset_{16}+\emptyset_{50}+\emptyset_{84}}{3}
$$

Inclusive Graphic

Standard Deviation

Inclusive Graphic

Skewness

Graphic Kurtosis

$$
\sigma_{i}=\frac{\emptyset_{84}-\emptyset_{16}}{4}+\frac{\emptyset_{95}-\emptyset_{5}}{6.6}
$$

$$
S K_{t}=\frac{\left(\emptyset_{84}+\emptyset_{16}-2 \emptyset_{50}\right)}{2\left(\emptyset_{84}-\emptyset_{16}\right)}+\frac{\left(\emptyset_{95}+\emptyset_{5}-2 \emptyset_{50}\right)}{2\left(\emptyset_{95}-\emptyset_{5}\right)} \quad \text { eq. } 3.0
$$

$$
K_{G}=\frac{\left(\emptyset_{95}-\emptyset_{5}\right)}{2.44\left(\emptyset_{75}-\emptyset_{25}\right)}
$$




\section{Standard Deviation}

\begin{tabular}{cc}
\hline$<0.35 \phi$ & Very Well Sorted \\
$0.35-0.50 \phi$ & Well Sorted \\
$0.50-0.71 \phi$ & Moderately Well Sorted \\
$0.71-1.00 \phi$ & Moderately Sorted \\
$1.00-2.00 \phi$ & Poorly Sorted \\
$2.0-4.00 \phi$ & Very Poorly Sorted \\
$>4.00 \phi$ & Extremely Poorly Sorted
\end{tabular}

Table 6: Description of grain size sorting based on the inclusive graphic standard deviation (Boggs, 2006).

\section{Skewness}

\begin{tabular}{cc}
\hline$>+0.30$ & Strongly Fine Skewed \\
+0.30 to +0.10 & Fine Skewed \\
+0.10 to -0.10 & Near Symmetrical \\
-0.10 to -0.30 & Coarse Skewed \\
$<-0.30$ & Strongly Coarse Skewed
\end{tabular}

Table 7: Description of skewness in a grain size distribution based on the inclusive graphic skewness (Boggs, 2006).

\subsection{Clast Form and Roundness}

Clasts attain characteristic shapes reflecting the erosional history of the clast. This can be used to help interpret the transport and depositional processes which influence a clast in a particular deposit. Two units from the Vickers Quary section and one unit from the York Road section were sampled. The analysis of clast form and roundess was performed on both field samples and laboratory samples using the method of Sneed and Folk (1958) and Krumbien (1941). The size range targeted for clast form and roundness was $-3 \phi$ to $-8 \phi$. This range includes the $-3 \phi$ to $-6 \phi$ range used by Scott (1988) to allow for comparison with laharic deposits on Mt St Helens, Washington, USA. The analysis was also confined to andesite clasts with any pumiceous or scoriaceous clasts excluded from clast shape and 
roundess analysis due to their more rapid rates or abrasion and rounding - as per the method of Scott (1988).

The clast form analysis uses the method of Sneed and Folk (1958) (Figure 27) where the long, intermediate and short axis are measured with callipers then plotted with the relative ratios are defined by ten classes: $C$, Compact; $C P$, Compact Platy; $C B$, Compact-Bladed; $C E$, Compact-Elongate; P, Platy; B, Bladed; E, Elongate; VP, Very Platy; VB, Very Bladed; VE, Very Elongate. The roundness analysis uses the 0.1 to 0.9 scale of Krumbien (1941) (Figure 28) and is plotted as histograms with roundness categories into very-angular, angular, subangular, sub-rounded, round and well-rounded according to Waddell (1932).

5.

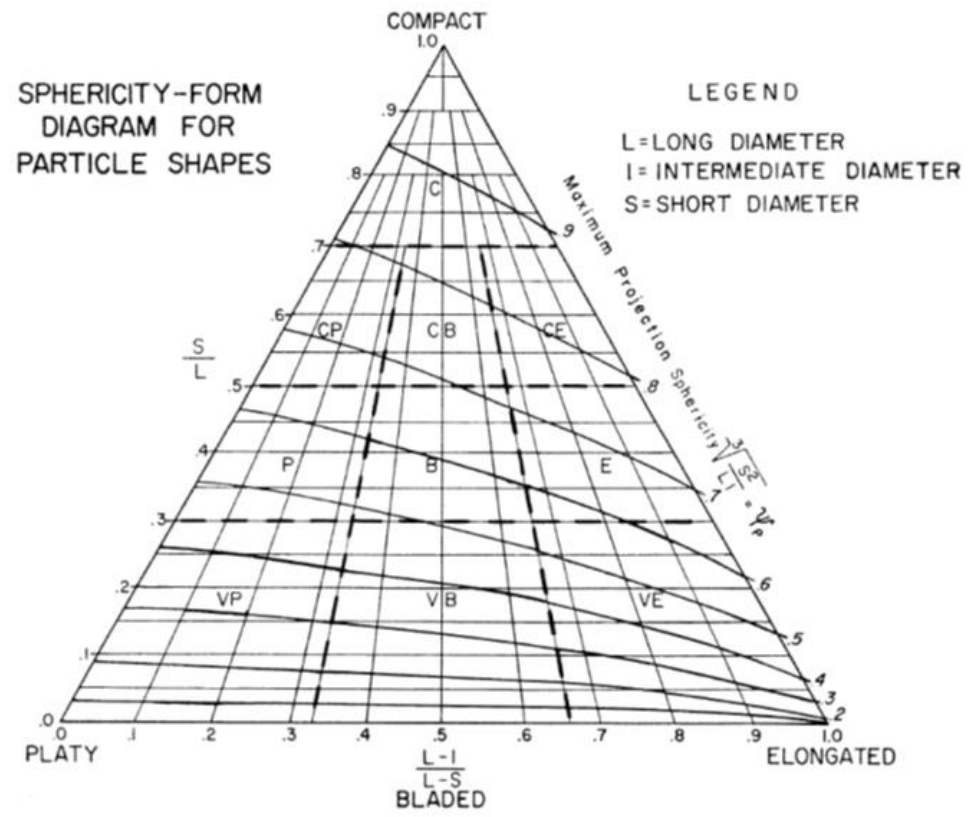

Figure 27: Ternary diagram showing the clast shape classes defined by Sneed and Folk (1958) based on the ratios of the clasts 3 principal axis.

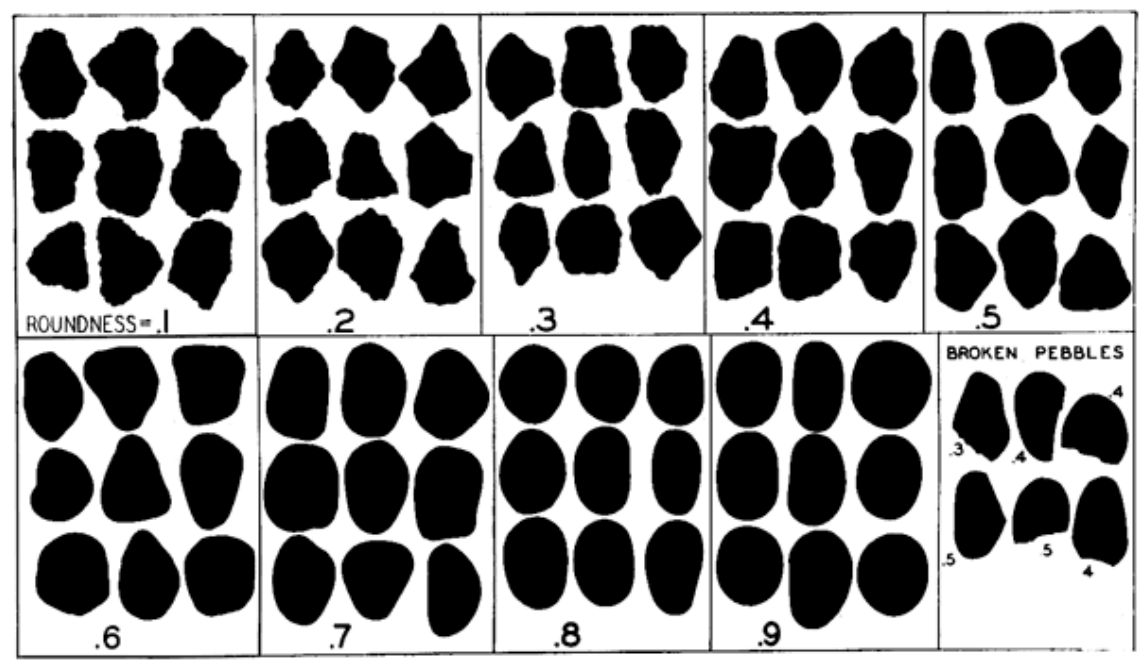

Figure 28: Clast roundness scale. Ranges from very angular (0.1) to well rounded (0.9) (Krumbien, 1941; Waddell, 1932). 


\section{Palaeomagnetic Analysis}

As a rock containing magnetic minerals is heated and subsequently cooled in an external magnetic field, it acquires a thermoremanent magnetisation (TRM) whose vector direction is parallel to and intensity is directly proportional to the applied geomagnetic field in which it cooled (Hoblitt and Kellogg, 1979; Butler, 1992). Progressive thermal demagnetization of the TRM preserved volcanic rocks can be used to estimate their emplacement temperatures (Clement et al., 1993) due to magnetic grains of different size and composition within the rock producing a range of blocking temperatures $\left(T_{B}\right)$ below which the magnetic grain preserves its remanence. Blocking temperatures range from ambient temperatures through to the Currie Temperature $\left(T_{c}\right)$ of the magnetic grans within the rock. The remanence acquired within a specific blocking temperature range is considered a Partial Thermal Remanent Magnetisation (pTRM) (Hoblitt and Kellogg, 1979; Butler, 1992). Stepwise thermal demagnetisation progressively removes the pTRM's and enables emplacement temperature estimates $\left(T_{E}\right)$ and insight into the causal events leading up to the emplacement of volcaniclastic deposits such as the Ngatoro Formation.

Previous palaeomagnetic studies on Egmont Volcano have been centred on the lava flows on Egmont's upper cone and Fanthams Peak (Downey et al., 1994) and a preliminary investigation of two flow deposits (Paintin, 1982). An initial study of North Island volcanoes by Cox (1969) included 3 samples from Egmont Volcano. The first significant palaeomagnetic study was carried out by Downey et al. (1994) where samples at 26 sites from 5 different lava flow sequences from both Egmont Volcano and Fanthams Peak were analysed using stepwise thermal demagnetization. Spot directions obtained from the samples were then compared with an established regional palaeosecular variation curve to estimate the emplacement ages of the lava flow sequences.

\subsection{The Conglomerate Test}

Taranaki andesite is known to contain titanomagnetite (Turner et al., 2008) with $T_{B}$ ranging up to the Curie temperature of magnetite $\left(585^{\circ} \mathrm{C}\right)$. If clasts were emplaced above this temperature and cooled in situ, then:

- All ferromagnetic grains will be magnetized in the direction of the ambient field at the time, so progressive demagnetization through the blocking temperature 
spectrum will reveal a unidirectional magnetization (except perhaps in the very lowest blocking temperature grains which may carry a viscous component of magnetization acquired during sampling and handling)

- All clasts will be magnetized in the same direction - the direction of the local geomagnetic field at the time of emplacement.

If the clasts were emplaced at some intermediate temperature, $T_{E}$, between ambient temperature and $585^{\circ} \mathrm{C}$, then only the grains with $T_{B}<T_{E}$ will have been magnetized in situ, and so retain a record of the local field direction- grains with higher $T_{B}$ will have been magnetized prior to emplacement, and so their magnetization vectors are likely to have been rotated before emplacement. In such a scenario we would expect to see:

- Change(s) in the direction of pTRM within clasts when demagnetized above $T_{E}$.

- Agreement of the low $T_{B}$ component between clasts, but a lack of agreement of the high $\mathrm{T}_{B}$ components.

This approach has been carried out on clasts of varying size collected from proximal deposits of the Ngatoro Formation. These proximal deposits contain in-situ trees with significant charring, suggesting elevated emplacement temperatures. A possible mechanism for this high temperature emplacement is the transformation of high temperature block-and-ash flows generated by effusive dome growth and collapse to debris flows and/or hyperconcentrated flows. In similar investigations Curie temperatures of approximately $580^{\circ} \mathrm{C}$ have been observed (Clement et al., 1993) and block-and-ash flow emplacement temperatures up to $640^{\circ} \mathrm{C}$ (Cole et al., 2002) suggest that a uniform palaeomagnetic orientation within the deposit, combined with stratigraphically correlated block-and-ash flow deposits, would support a transformation from block-and-ash flows to debris flows (Scott, 1988). A non-uniform direction would suggest either the flow did not reach Curietemperature, or a different, colder mechanism is responsible for the lahar formation (Hoblitt and Kellogg, 1979; Butler, 1992; Clement et al., 1993). This palaeomagnetic test is refered to as a 'conglomerate test'.

Palaeomagnetic emplacement temperature estimates have been widely used on lava flows, pyroclastic flows and lahars around the world, but the method has not become a common practice throughout New Zealand. Paterson et al. (2010) emphasises the usefulness of the 
method for determining emplacement temperatures of pyroclastic density currents on $\mathrm{Mt}$ St Helens, USA; Volcan Lascar, Chile; Volcan de Colima, Mexico; and Mt Vesuvius, Italy. When comparing palaeomagnetic temperature estimates to measured temperatures of pyroclastic density currents, Paterson et al. (2010) found the palaeomagnetic estimates to be very accurate, producing a correlation coefficient $\left(R^{2}\right)$ of 0.996 (Figure 29).

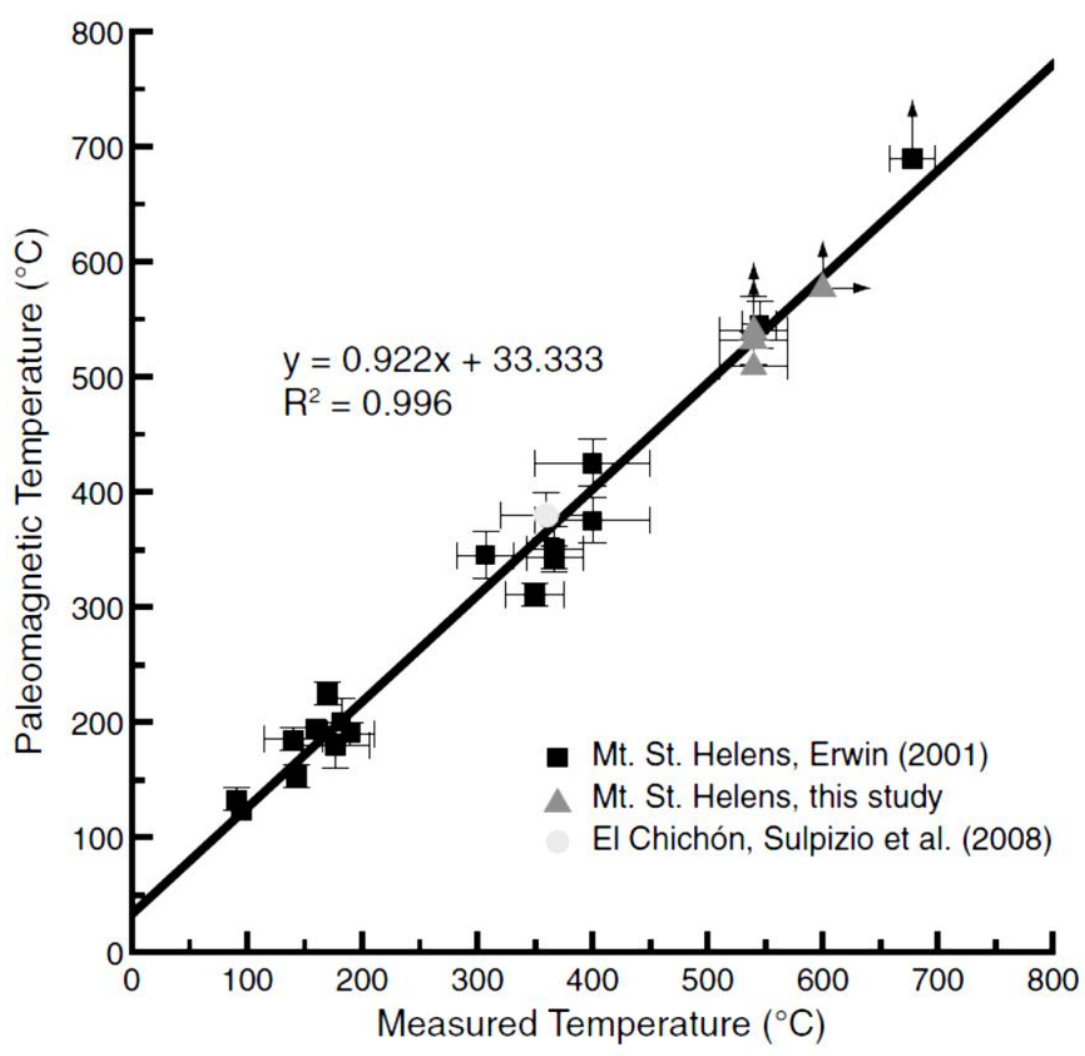

Figure 29: Plot showing the strong correlation between palaeomagnetic temperature estimates and measured temperatures of volcanic mass flows at Mt St Helens and El Chichon (Paterson et al., 2010).

The palaeomagnetic investigation presented in this thesis includes a preliminary alternating field demagnetization investigation, a main thermal demagnetization investigation of a lower flow unit and a further preliminary thermal demagnetization investigation of a second upper flow unit. Alternating field demagnetisation is the processes of exposing the sample to an alternating field that decays from the maximum amplitude $\left(\mathrm{B}_{\mathrm{AF}}\right)$ to zero over a set time. This results in the magnetic grains with magnetic coercivities $\left(h_{c}\right)$ less than the amplitude of the alternating field $\left(\mathrm{B}_{\mathrm{AF}}\right)$ being demagnetised, leaving the Natural Remanent Magnetisation (NRM) of grains with $h_{c}>H_{A F}$ remaining. This is carried out in three orthogonal directions to expose all grains of different orientations equally. 
Thermal demagnetisation involves heating the samples to a specific temperature ( $\left.T_{\text {demag }}\right)$ then subsequently cooling to ambient temperatures in a zero magnetic field. During the cooling, magnetic grains with blocking temperatures $\left(T_{B}\right) \leq T_{\text {demag }}$ are remagnetised randomly, thereby no longer contributing to the overall remaining magnetisation. Between demagnetisation steps the direction and intensity of the remanent magnetisation, and the magnetic susceptibility was measured. The direction and intensity measurements provide insight into the emplacement history of the sampled clasts and susceptibility measurements will identify thermal alteration of the magnetic grains during the heating and cooling process.

\subsection{Sampling and Drilling}

The palaeomagnetic investigation involved sampling at Vickers Quarry and Surrey Road Quarry (Figure 30). These are proximal locations near the Egmont National Park boundary; both with excellent exposure of the Ngatoro Formation with cobble/boulder deposits in the quarry walls providing ideal material for a palaeomagnetic conglomerate test.

Andesitic cobbles and boulders $(0.2 \mathrm{~m}$ to $1.4 \mathrm{~m}$ in diameter) were cored using a water cooled, $25 \mathrm{~mm}$ diameter diamond tipped core drill bit driven by a modified chainsaw engine (Figure 30b). A minimum core length of $40 \mathrm{~mm}$ was required to ensure at least two specimens could be recovered. An $X, Y$ and $Z$ axis was used to describe the cores orientation where the $Z$ axis is the core's axis and the $\mathrm{Y}$ axis is the plane perpendicular to the $\mathrm{Z}$ axis (Figure 31). The core orientation was then measured with respect to the modern geomagnetic field using a geological compass mounted on an adjustable stage (Figure $30 \mathrm{c}$ and d). The azimuth of the cores $\mathrm{Y}$ axis with respect to magnetic north was measured with both the geological compass and with respect to the sun with a sun compass mounted on the same stage. The plunge of the $\mathrm{Z}$ axis relative to horizontal was measured using an inclinometer. Due to the young and undeformed nature of the sediment, no bedding correction was required for dipping bedding planes. Clasts were selected on the basis of stratigraphic position; appropriate size, minimal weathering and, most importantly, in-situ position (Any post-depositional rotation of the clast produces erroneous palaeomagnetic directions). 

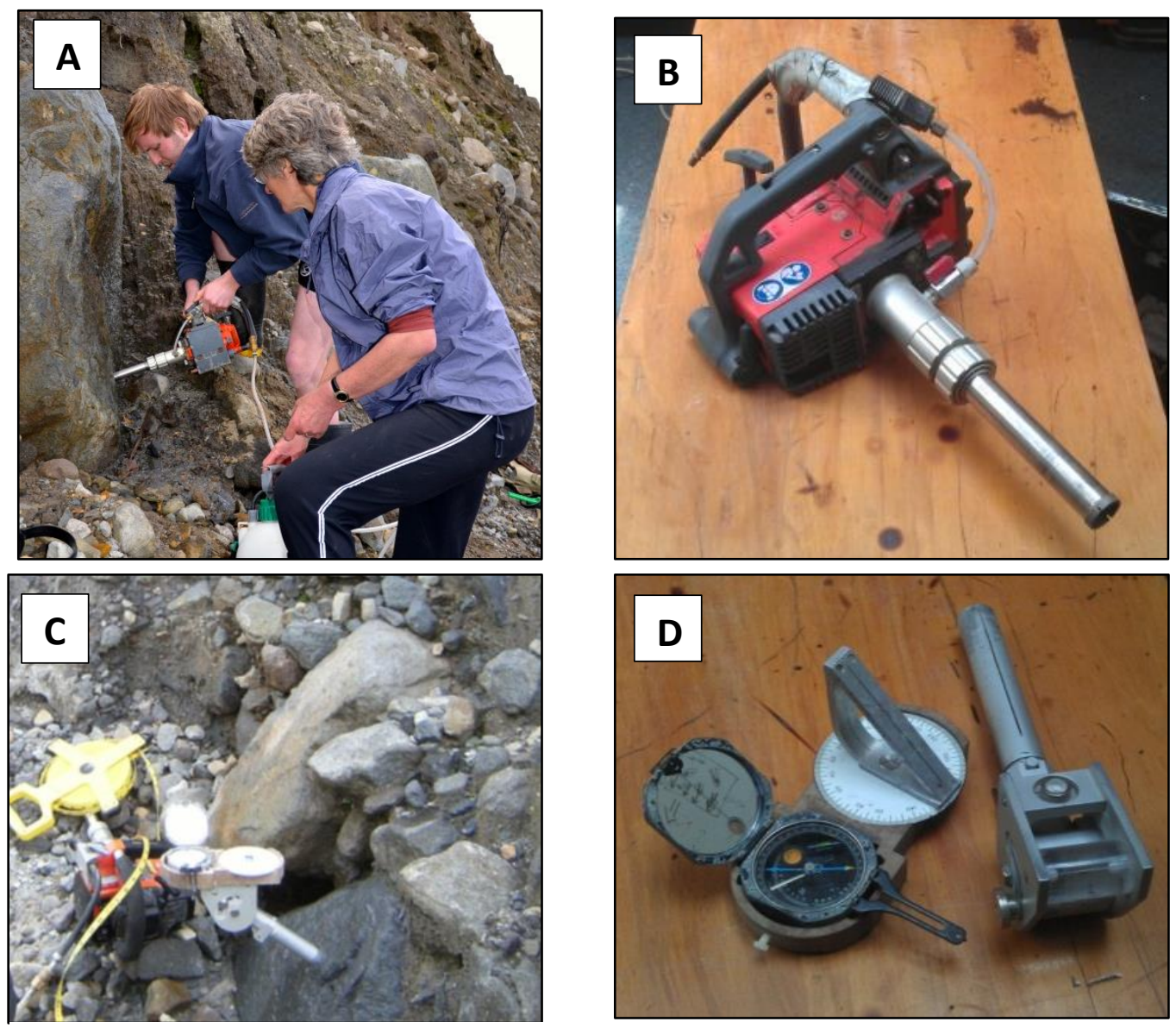

Figure 30: (A) Water cooled, diamond tipped palaeomagnetic drill being used to sample a large andesite boulder at Vickers Quarry. (B) The palaeomagnetic drill used to collect the core samples. (C) The orienting stage and magnetic compass being used to orient a sample. (D) The stage, magnetic compass and sun compass used to orient samples. Photo " $A$ " courtesy of A/Prof Brent Alloway.

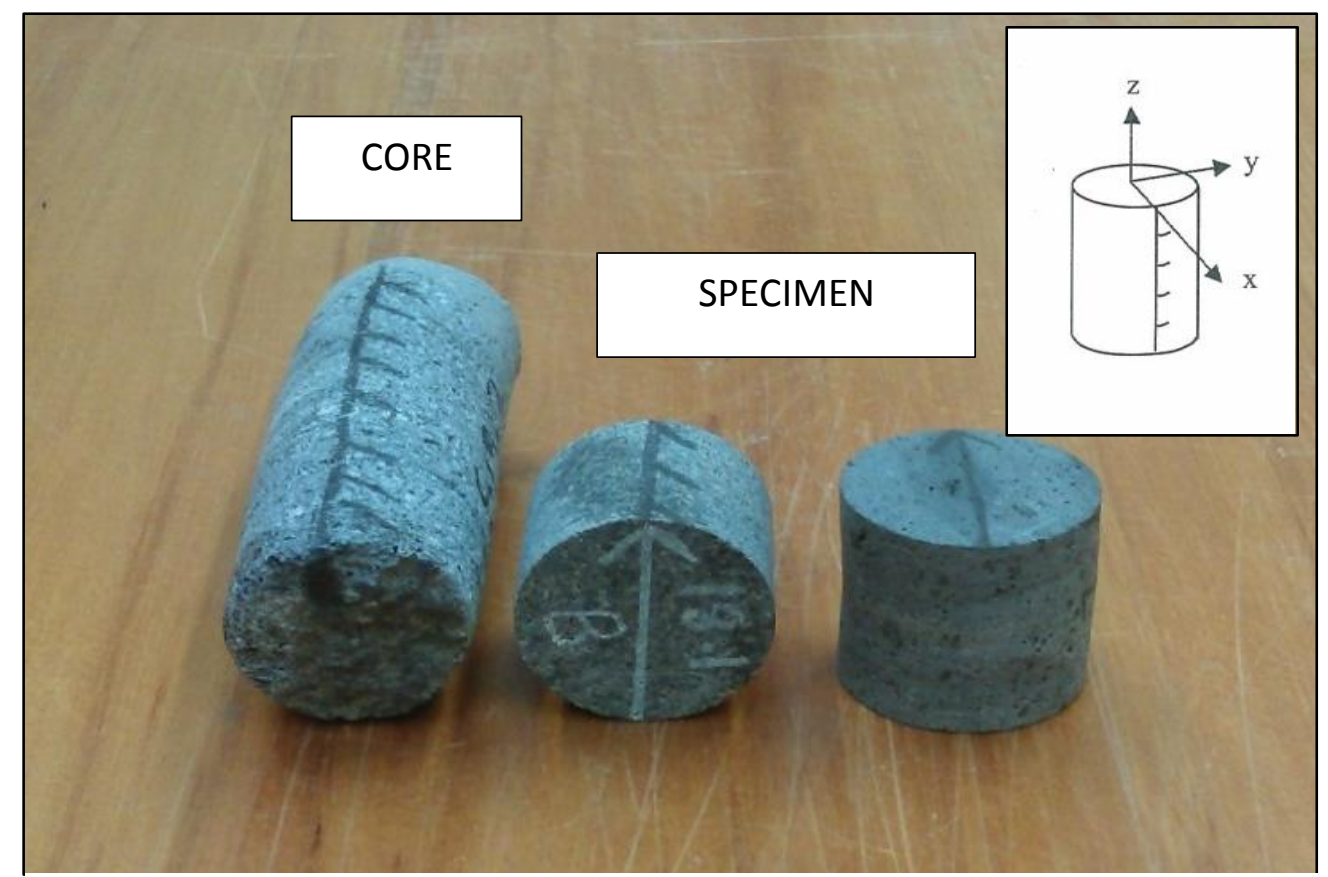

Figure 31: Example of a labelled palaeomagnetic core and specimen. (Inset) A schematic of the palaeomagnetic specimen labelling system used with respect to the $X, Y$ and $Z$ axis. 
The following drilling program was carried out:

- Preliminary Investigation (September, 2012): 3x Clasts - 9 x Cores

- Lower Flow Unit Investigation (April, 2013): 15 x Clasts - 45 x Cores

- Preliminary Upper Flow Unit Investigation (November, 2013): 4 x Clasts - 12 x Cores

\subsection{Sample Processing}

Each labelled and named core was cut into $22 \mathrm{~mm}$ long specimens using a liquid cooled rock saw. Each specimen was subsequently given a specific specimen number and remarked to preserve its known orientation.

The room temperature magnetic susceptibility of each sample was measured after each demagnetisation step and susceptibility with temperature of representative samples using a Bartington Instruments Ltd MS2 Magnetic Susceptibility Meter. Room temperature susceptibility measurements will reveal any thermally induced alteration of the magnetite mineralogy (eg. Inversion or oxidisation) - this results in a loss in the original magnetisation (Butler, 1992). Susceptibility with temperature measurements indicates the composition of the magnetic grains within the rock. The intensity and direction of the remanent magnetisation was measured using an Agico's JR6 Spinner Magnetometer. Thermal demagnetisation was carried out in a quartz glass tube lined, thermostatically-controlled oven with separate air cooled cooling chamber with zero ambient magnetic field.

For each stage of the investigation a representative suite of the specimens from each core and clast were selected for processing.

- Preliminary Lower Flow Unit Investigation: Alternating field demagnetisation was carried out on 3 specimens sampled from two different clasts. The alternating field demagnetisation ranged from 0 to $80 \mathrm{mT}$ at $5 \mathrm{mT}$ intervals.

- Main Lower Flow Unit Investigation: Thermal demagnetisation was carried out on 32 specimens from 16 cores sampled from 8 clasts. This included 5 clasts from the Vickers Quarry site and 3 from the Surrey Road Quarry site. The thermal demagnetisation ranged from 0 to $550^{\circ} \mathrm{C}$ at $50^{\circ} \mathrm{C}$ intervals. Magnetic susceptibility was measured after each demagnetisation step. 
- Preliminary Upper Flow Unit Investigation: Thermal demagnetisation was carried out on 16 specimens from 8 cores sampled from 4 clasts. The thermal demagnetisation ranged from 0 to $550^{\circ} \mathrm{C}$ at $50^{\circ} \mathrm{C}$ intervals. Magnetic susceptibility was measured after each demagnetisation step.

\subsection{Data Processing}

The remanent magnetisation direction and intensity data were analysed using Remasoft 3.0: Palaeomagnetic data browser and analyser. The remanent magnetisation direction data is presented as Equal Area Stereographic Projections and Zijderveld Diagrams are used to present the direction and intensity of the remanent magnetisation throughout the demagnetisation steps (Figure 32). The magnetic susceptibility is presented in plots of susceptibility versus demagnetisation level. The best estimate of the remanent magnetisation direction was found using principal component analysis (Kirschvinck, 1980) and a $95 \%$ confidence limit expressed as an angular radius from the calculated mean direction (alpha-95). 
(a)

MSH2M3
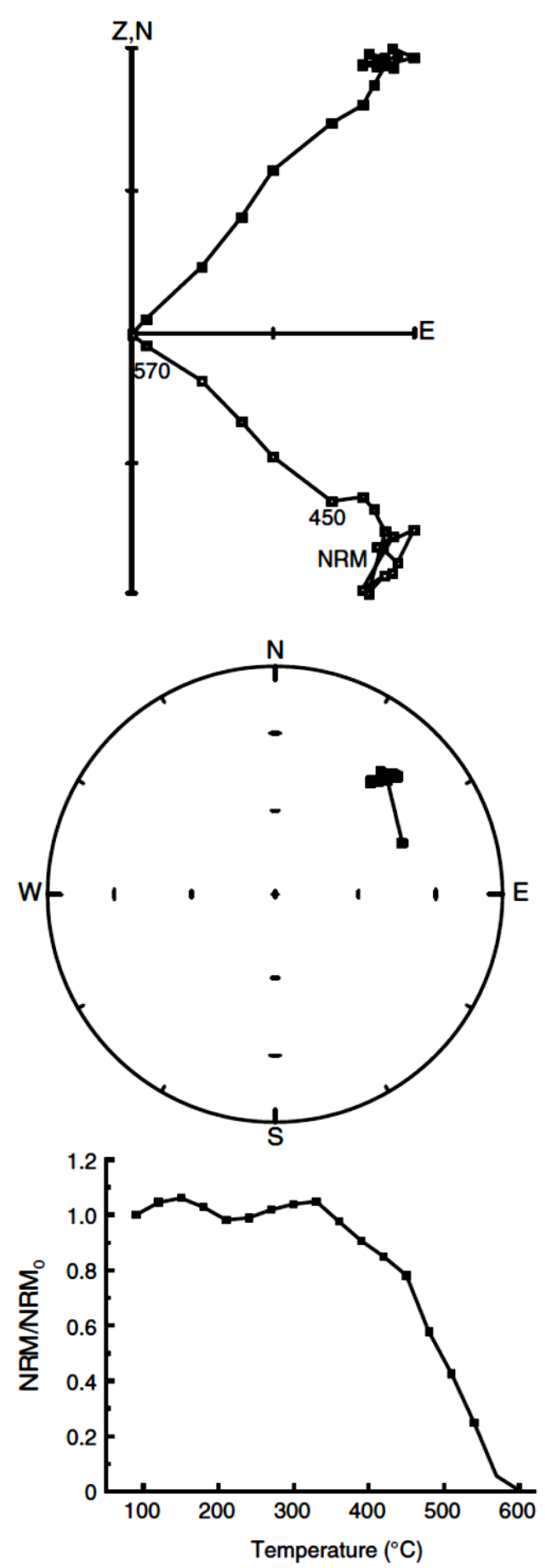

(b)
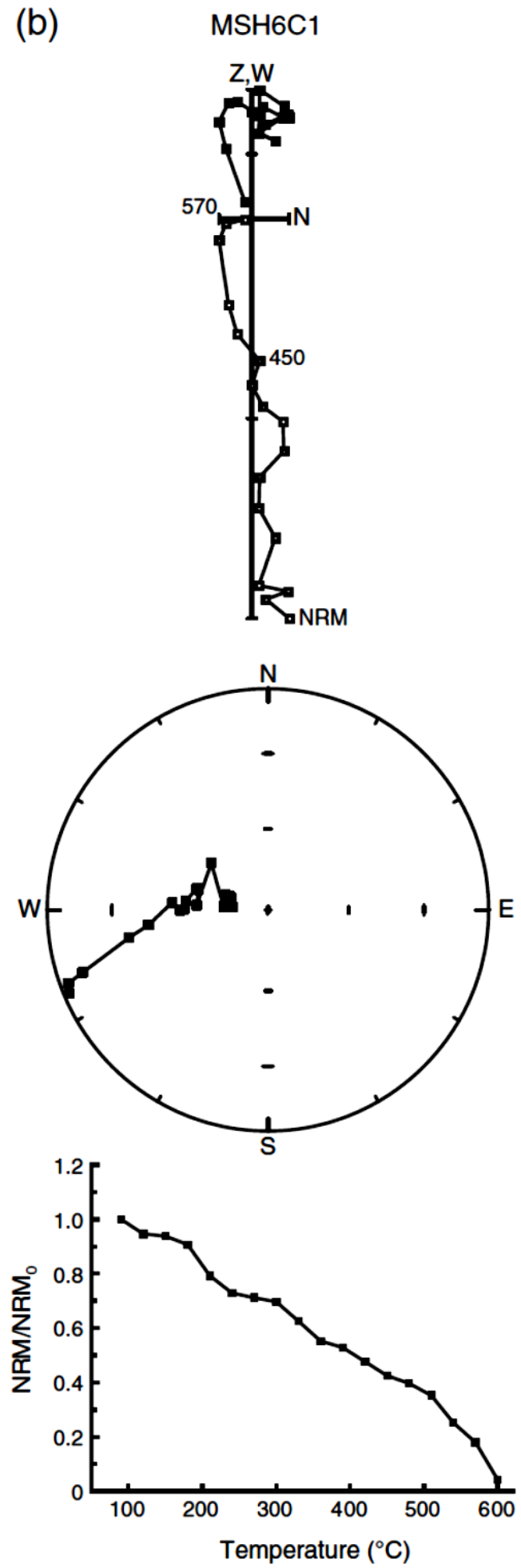

Figure 32: Typical stepwise thermal demagnetisation results from Mt St Helens. Results presented in Zijderveld Diagrams (top), Equal Area Stereographic Projections (Middle) and Intensity vs Temperature Plots (Bottom). This figure shows both (a) single component of magnetisation and (b) two components of magnetisation within the samples (Paterson et al., 2010). 


\section{Chapter Three: Investigation Results and}

\section{Interpretation}

A summary of the volcaniclastic stratigraphy, associated tephrostratigraphy and sedimentology of each location with appropriate interpretations are presented in this chapter. Each measured section is divided into lithostratigraphic units (ie. EE-1, Unit 1) with detailed measured sections, lithostratigraphic descriptions, grain size and shape analysis results and electron microprobe analyses results presented in Appendix A. The complete datasets from the Electron Microprobe Analysis and grain size/shape analysis is presented in Appendix $B$ and Appendix $C$ respectively.

The palaeomagnetic results and appropriate interpretations are also included separately at the end of the chapter. These are presented separately as palaeomagnetic sampling only occurred at two key proximal sections (Vickers (VQ) and Surrey Road (SQ) Quarries). The complete palaeomagnetic results and data are presented in Appendix $D$.

The following notation is used to distinguish between stratigraphic sections, EMP tephra samples and grain size samples:

- Measured Sections:

- EMP Samples:

- Grain size Samples:
East Egmont, Section One [EE-1] Tariki Underpass, Section Three [TU-3]

Tephra Sample One [TS-1]

Tephra Sample Twenty [TS-20]

Vickers Quarry, Sample One [VQ-S1]

York Road, Sample Two [YR1-S2] 


\section{East Egmont (EE-1)}

The East Egmont section is located $2.7 \mathrm{~km}$ east from the present-day summit of Egmont Volcano on the margins of the Manganui Valley (Figure 33). At this site one measured section (Figure 34) and tephra sampling for EMP analysis was carried out.

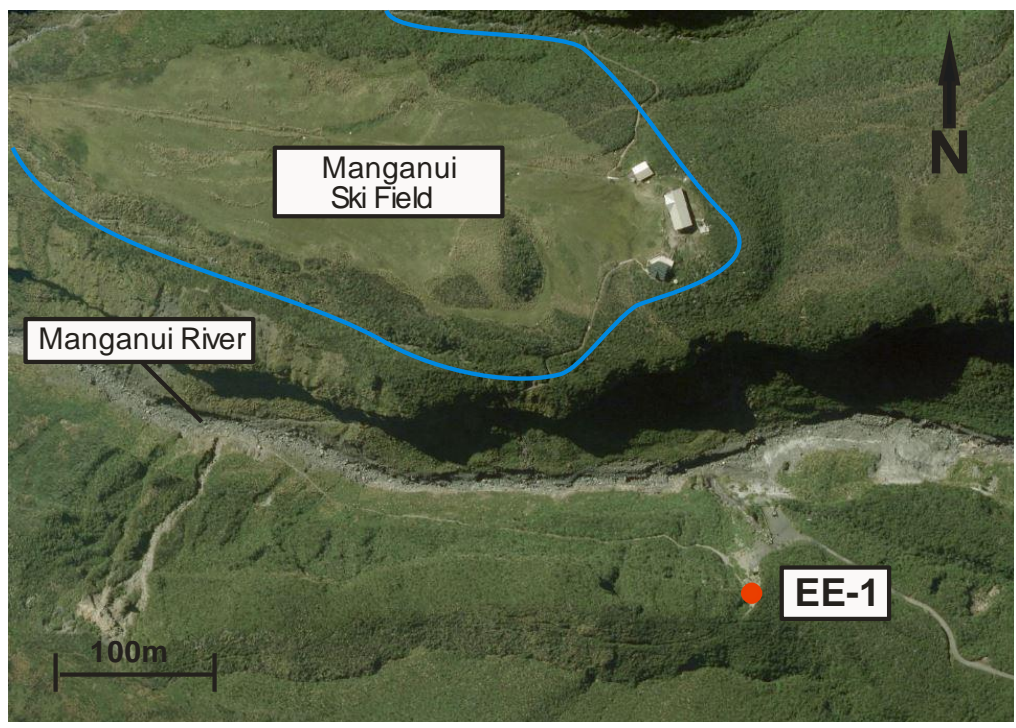

Figure 33: Aerial photograph showing the location of section $E E-1$ relative to the Manganui River and Ski Field. Photo courtesy of Taranaki Regional Explorer (2014).
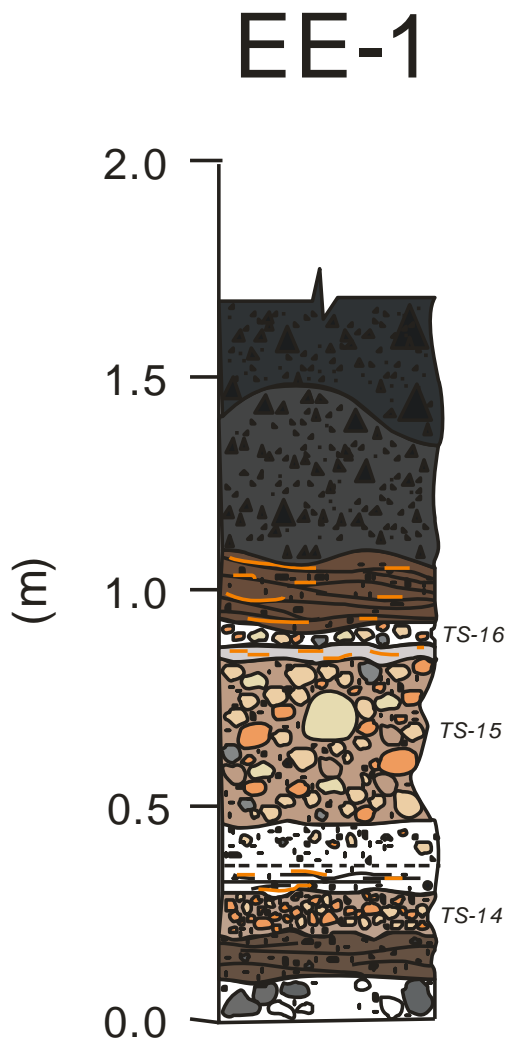

Figure 34: Stratigraphy of section EE-1.

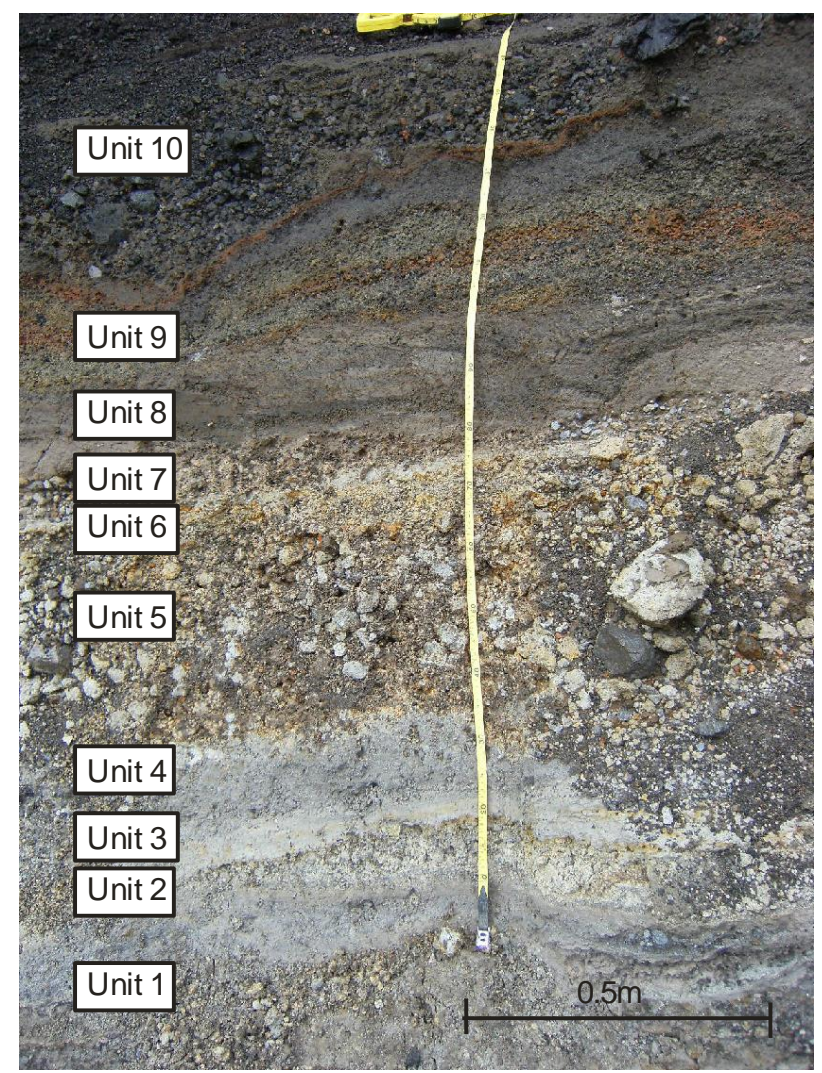

Figure 35: Photograph of section EE-1 with relevant lithostratigraphic units described in Appendix A. 


\subsection{Stratigraphy}

The EE-1 (Appendix A) section exposes four $\mathrm{cm}$ - to dm-thick scoriaceous and/or pumiceous ash and lapilli beds overlying a $>70 \mathrm{~m}$ thick unit of extremely poorly sorted and consolidated, massive, boulder-rich sands and gravel (Figure 35). The first unit (EE-1, Unit 1) comprises cm scale bedded fine sand and silt with few andesite pebbles and pumiceous lapilli. The first lapilli bed (EE-1, Unit 2) is a $\leq 0.1 \mathrm{~m}$ thick, fine to medium, pumiceous lapilli in a coarse sandy ash matrix overlain by a $<0.2 \mathrm{~m}$ thick, laminated to massive, fine coarse sand and silt with lenses $(0.01 \mathrm{~m})$ of fine to coarse pumiceous sand (EE-1, Unit $3 \& 4)$.

The second lapilli bed (EE-1, Unit 5 ) is a $<0.4 m$ thick, poorly sorted, fine to very coarse pumiceous lapilli with few dispersed angular to sub-angular coarse to very coarse lithic lapilli overlain by a $<0.05 \mathrm{~m}$ thick, well sorted, fine sand and silt (EE-1, Unit 6).

The third lapilli bed (EE-1, Unit 7) is a $<0.1 \mathrm{~m}$ thick, fine to coarse pumiceous lapilli with few to common, angular, grey lithic lapilli overlain by a $\leq 0.2 \mathrm{~m}$ thick stratified and low-angle cross stratified, alternating silty fine sand and fine to medium sand (EE-1, Unit 8). This is overlain by $a<0.4 \mathrm{~m}$ thick, faintly stratified to massive, fine to coarse, basaltic, scoriaceous lapilli (EE-1, Unit 9) then a >0.15m thick, massive, very poorly sorted, fine to coarse, basaltic, scoriaceous lapilli and blocks (EE-1, Unit 10).

\subsection{Tephrochronology}

Glass shards of the three pumecious lapilli beds at the base of EE-1 were analysed for major element composition and then correlated with the reference tephra dataset (Section B1, Appendix B) and stratigraphic logs published in Alloway et al (1995). Major element glass analyses from the first pumiceous lapilli bed (EE-1, TS-14) is indistinguishable from those determined for Korito Tephra (c. $4,100{ }^{14} \mathrm{C}$ yrs B.P). The second and third pumiceous lapilli beds (EE-1, TS-15 \& -16 respectively) correlate with the lower and upper sub-units (Inglewood.a and b, respectively) of Inglewood Tephra dated at c. 3,600 ${ }^{14} \mathrm{C}$ yrs B.P (Alloway et al., 1995). The upper-most basaltic, scoriaceous lapilli bed correlates with the Manganui.a subunit of the Manganui Tephra dated at c. 3,100 ${ }^{14}$ C yrs B.P (Section 1: Alloway et al., 1995). 


\subsection{Interpretation}

The basal coarse-grained deposits underlying Unit 1 are interpreted to be undifferentiated block-and-ash flow deposits. Similar deposits are observed nearby within the valley walls of the Manganui Gorge adjacent to the ski-field (Figure 36), with some deposits exceeding 70m thick overlying lava flow and autobreccia deposits. Constrained by the overlying Korito Tephra (EE-1, Unit 2), the block-and-ash flows have a minimum age of c. $4,100{ }^{14} \mathrm{C}$ yrs B.P.

The three basal pumiceous lapilli beds (EE-1, Units 2, 5 \& 7) are interpreted to correlate with the Korito Tephra and the lower and upper subunits of the Inglewood Tephra, respectively, based on stratigraphic associations and confirmed by glass shard chemistry (Figure 37). Beds EE-1, Units 3, 4, 6 \& 8 are typically moderate to well-sorted, fine to coarse-grained ashy textured with $\mathrm{mm}$ - to $\mathrm{cm}$-planar to low angle cross-laminations. Laterally these beds pinch and swell in overall thickness, and perceptibly thin up-elevation. Combined these features indicate pyroclastic surge emplacement and are likely associated with the passage of ashelutriating, valley-confined block-and-ash-flow units that now form prominent but discontinuously exposed remnants of decimetre to metre-thick faintly stratified to massive deposits visible on either side of the present-day stream valley. The basaltic, scoriaceous lapilli, containing ballistic bombs at the top of the section (EE-1, Unit 9) is interpreted to be the Manganui.a bed of the Manganui Tephra based on direct stratigraphic correlation with Alloway et al. (1995) (Figure 37).

The pyroclastic surge deposit (EE-1, Unit 8), enveloped by the Inglewood.b (EE-1, Unit 7) and Manganui.a (EE-1, Unit 9) beds, appears to occur in a similar stratigraphic position with debris and hyperconcentrated flow deposits of Ngatoro Formation as described by Alloway et al (1989) beyond the confines of Egmont National Park (10 km from Egmont Volcano summit) (Figure 38). Therefore this pyroclastic surge deposit could represent a co-eruptive event closely associated with the generation and emplacement of Ngatoro Formation. The enveloping tephra constrain the age of the pyroclastic surge deposit (EE-1, Unit 8) to between c. $3,100{ }^{14} \mathrm{C}$ yrs and c. $3,600{ }^{14} \mathrm{C}$ yrs B.P. 


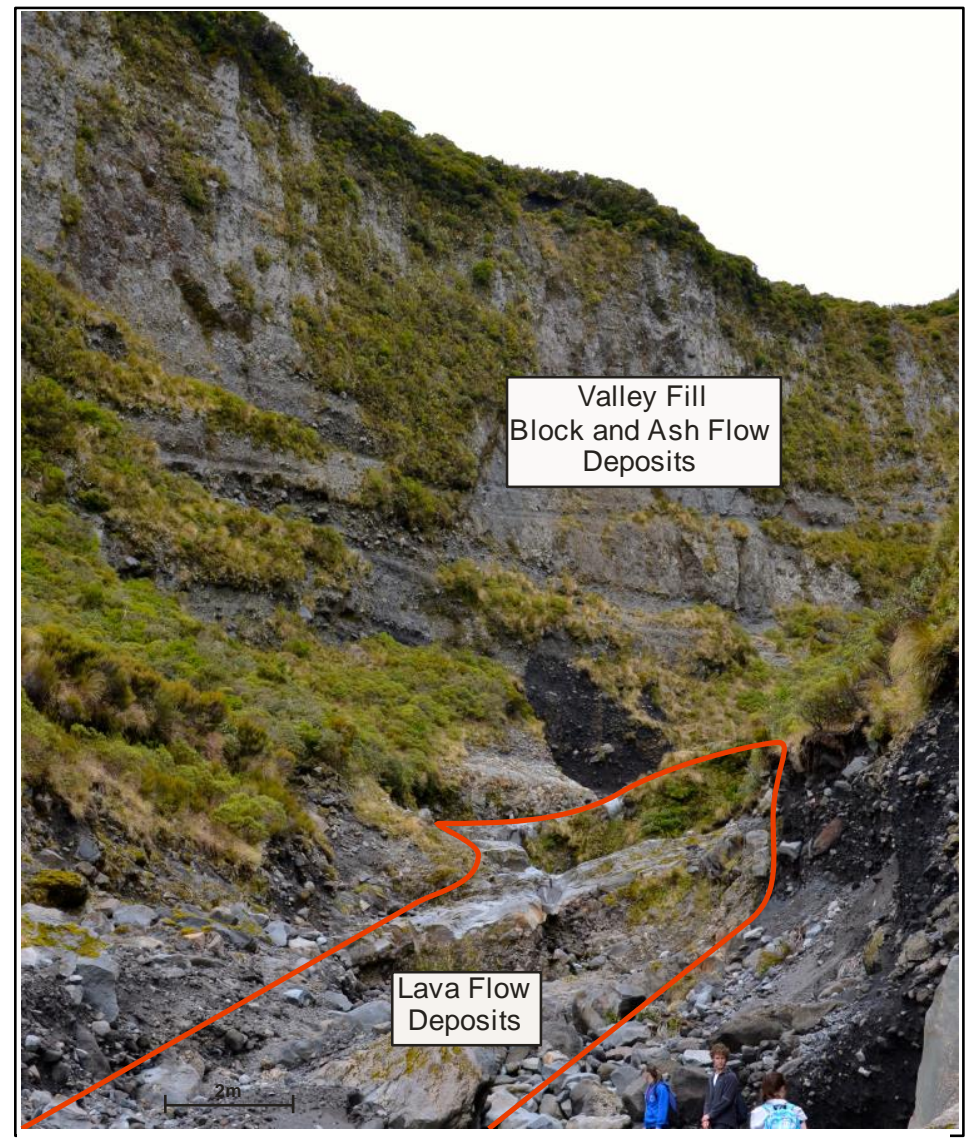

Figure 36 (Above): View up the Manganui Valley towards section EE-1. The valley walls comprise $<100 m$ thick block-andash flow deposits overlying lava flow and autobreccia deposits.

Figure 37 (Below): Interpretation of lithostraticgraphic units (see figure35) at section EE-1. This section exposes the Korito, Inglewood and Manganui Tephra. Upper pyroclastic surge deposits stratiaraphically correlate with the Naatoro

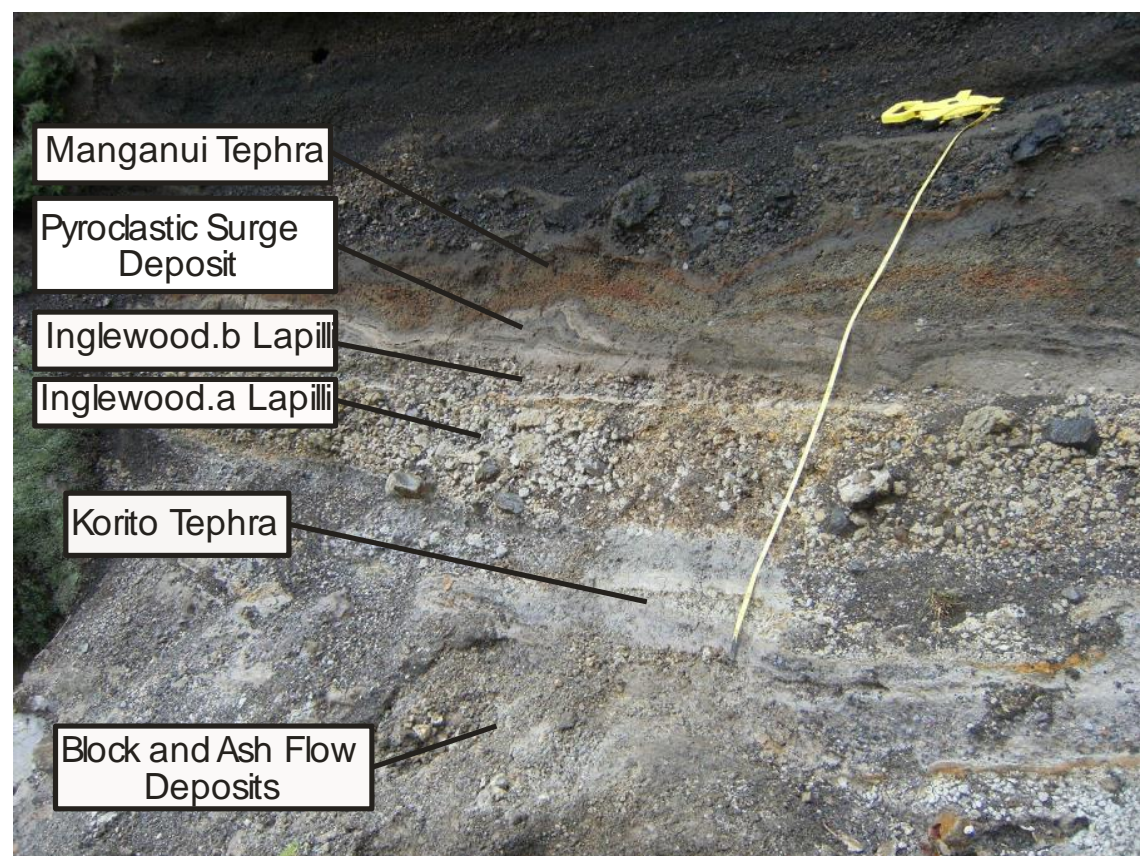




\section{Vickers Quarry (VQ-1, VQ-2 and VQ-3)}

The Vickers Quarry sections are located $10 \mathrm{~km}$ east from the present-day summit of Egmont

Volcano on the banks of the Manganui River (Figure 38). At this site three measured sections, and sampling for EMP analysis and grain size/shape analysis was carried out.

Figure 38 (Right): Aerial

photograph showing the location of sections. VQ-1, VQ-2 and VQ-3. Photo courtesy of Taranaki Regional Explorer (2014).
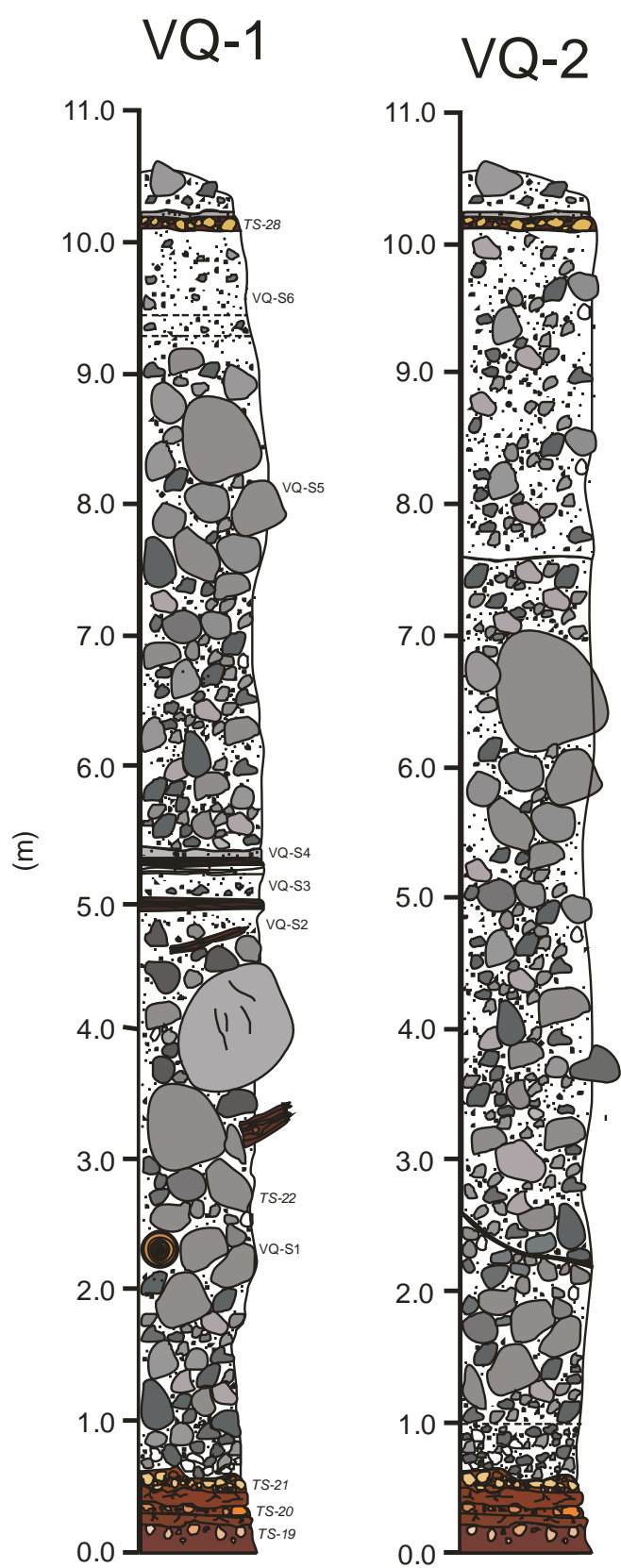

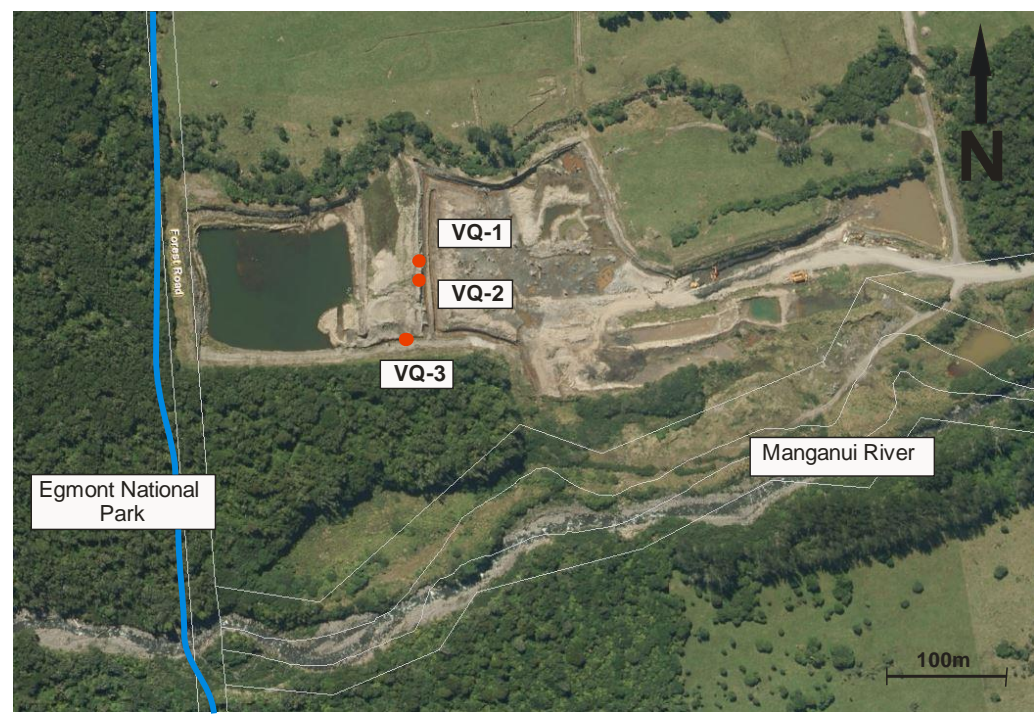

Figure 39 (Left): Stratigraphy of section VQ-1, VQ-2 and VQ-3.

Figure 40 (Below Right): Photograph of the basal pumiceous lapilli sequence at section VQ-1 with relevant lithostratigraphic units presented in Appendix $A$.
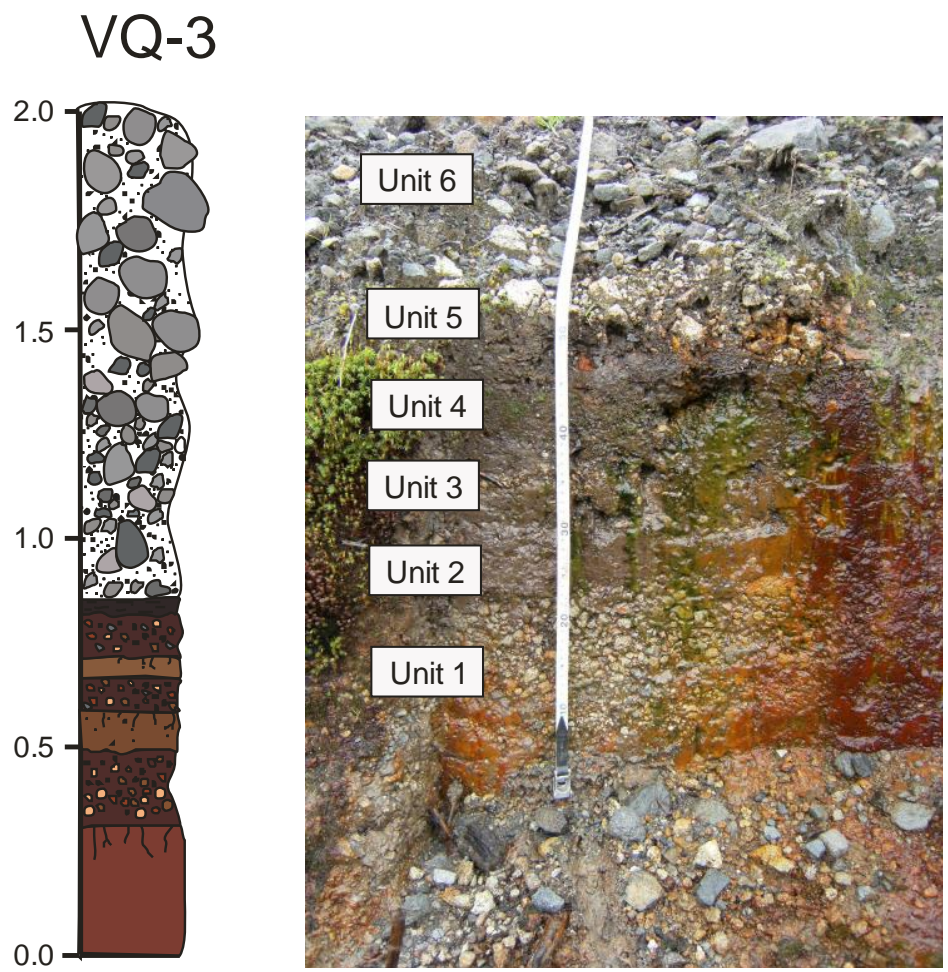

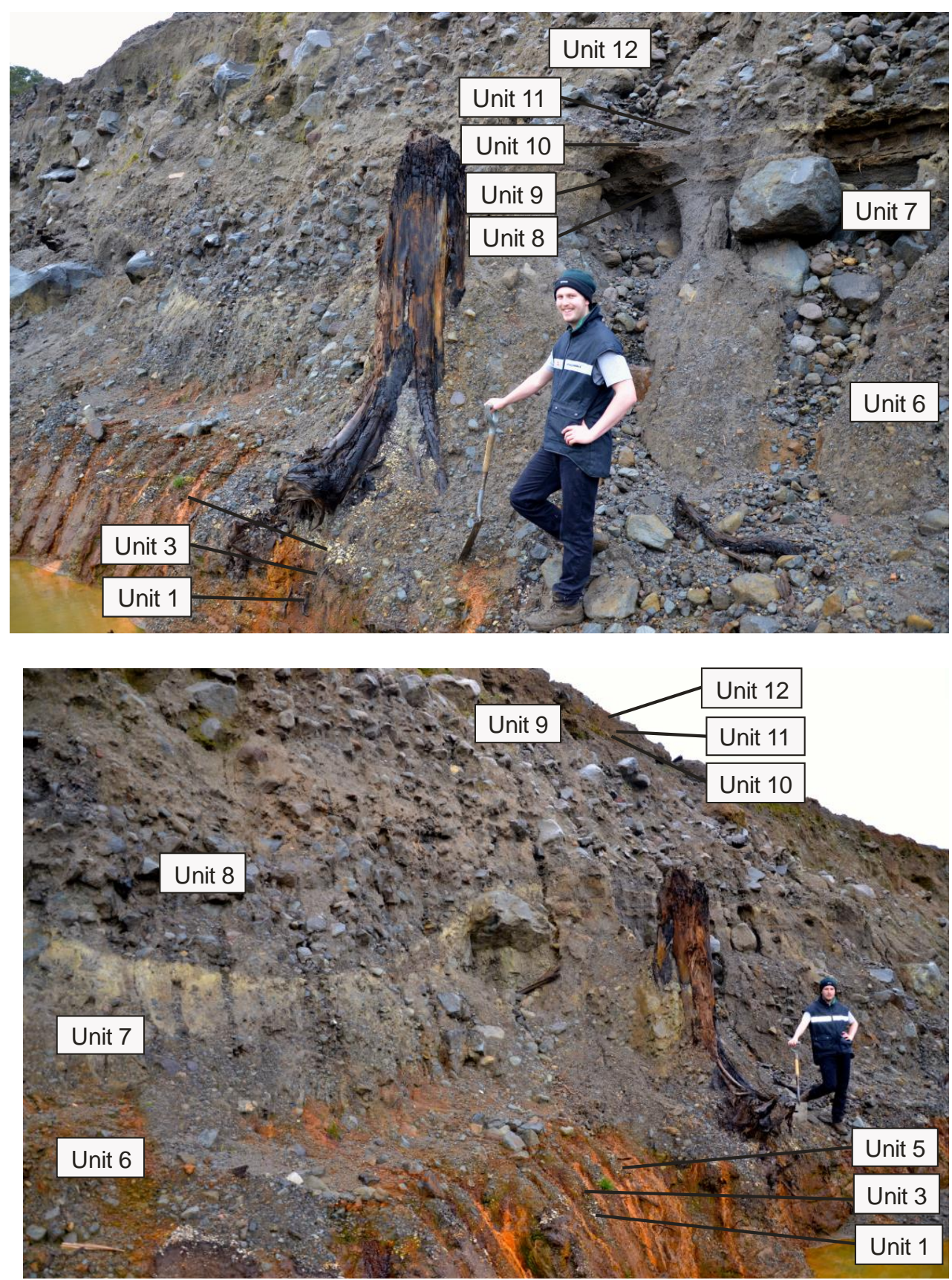

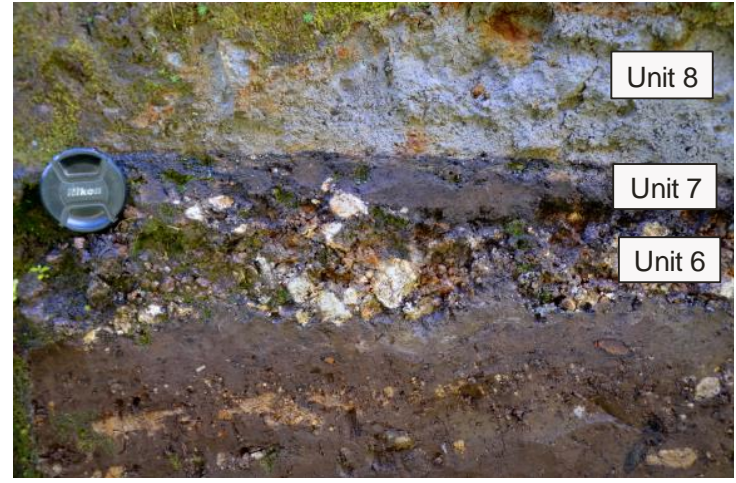

Figure 43 (Above Left): Photograph of section VQ-3 basal pumiceous lapilli sequence and paleosol with relevant lithostratigraphic units presented in Appendix A.
Figure 41 (Top): Photograph of section VQ-1 with relevant lithostratigraphic units presented in Appendix A. Photo courtesy of A/Prof Brent Alloway

Figure 42 (Above): Photograph of section VQ-2 with relevant lithostratigraphic units presented in Appendix A. Photo courtesy of A/Prof Brent 


\subsection{Stratigraphy}

The stratigraphy described at Vickers Quarry sections VQ-1, 2 \& 3 (Appendix A) comprises up to $10 \mathrm{~m}$ of cobble-and boulder-rich deposits overlying a basal pumiceous lapilli sequence (Figure 41, $42 \& 43$ ). There are three closely-spaced cm-scale basal lapilli beds (VQ-1, Units $1,3 \& 5)$ observed at the base of the Vickers Quarry section. The first of the basal lapilli beds (VQ-1, Unit 1 ) is a $<0.2 m$ thick, massive, fine to coarse pumiceous lapilli with few lithic lapilli. The second basal tephra bed (VQ-1, Unit 3 ) is a $\leq 0.05 \mathrm{~m}$ thick, fine to medium pumiceous lapilli with few lithic lapilli. The third basal lapilli bed (VQ-1, Unit 5) is a $<0.15 \mathrm{~m}$ thick, fine to coarse pumiceous lapilli bed. At Vickers Quarry, these basal lapilli beds are separated from the overlying boulder-rich volcaniclastic deposits by a $<0.05 \mathrm{~m}$ thick, dark blackish-brown, highly carbonaceous silts (VQ-1, Units 2 \& 4). The uppermost pumiceous lapilli bed is overlain at VQ-3 by a $0.04 m$ thick, organic-rich, firm and semi-deformable silt (VQ-3, Unit 7) (Figure 44) - this bed is not preserved at VQ-1 and VQ-2.

Overlying these basal lapilli beds is a $<0.05 \mathrm{~m}$ thick, laterally discontinuous, massive, normally graded, fine sand to silt unit (Figure 42 ) overlain by a 1.9-4.4m thick, laterally variable, massive, faintly reverse graded, pebbles, cobbles and boulders, clast-supported in a sandy matrix (VQ-1, Unit 6). This vertically grades to a fine to coarse, cobble and boulders clast-supported in a sand matrix (VQ-1, Unit 7). The upper $1.0 \mathrm{~m}$ of Units $6 \& 7$ laterally transforms to massive pebble-rich fine to coarse sand with two beds of fine sandy silt. The cobble-and boulder-rich deposits are overlain by a $<0.05 \mathrm{~m}$ thick, leaf litter accumulation (VQ-1, Unit 8) that laterally transforms to a dark brown, organic-rich silt. This is subsequently overlain by a $<0.5 \mathrm{~m}$ thick, massive to faintly stratified, fine to medium pebbly sand deposit (VQ-1, Unit 9). This deposit laterally transforms to a massive, gravel and pebble rich sandy deposit. The upper boundary of this unit is marked by a $\leq 0.03 \mathrm{~m}$ thick accumulation of dark blackish brown leaf litter and wood fragments (VQ-1, Unit 10).

Overlying the leaf litter accumulation is a $<5.0 \mathrm{~m}$ thick unit of massive, poorly sorted, reversely graded lower to ungraded middle, fine to coarse pebbles, cobbles and boulders, clast-supported in a sand matrix (VQ-1, Unit 12) grading to fine to coarse pebbly sand (VQ-1, Unit 13 \& 14). These deposits laterally vary in thickness with in-filled erosional channels (VQ2, Unit 8) comprising massive, poorly sorted, fine to coarse, cobbles and boulders in a fine to coarse pebble and sand matrix (Figure 42). 
The top of VQ-1 and VQ-2 is marked by a laterally continuous, $<0.05 \mathrm{~m}$ thick, massive, medium to coarse pumiceous lapilli in a silty ash matrix (VQ-1, Unit 15) overlain by a $<0.05 \mathrm{~m}$ thick, massive, moderately sorted, silty fine to medium sand with few charred wood fragments (VQ-1, Unit 16), and a $<0.5 \mathrm{~m}$ thick, massive, poorly sorted, reversely graded to ungraded, fine to coarse pebbles and cobbles clast-and/or matrix-supported in fine to coarse sand (VQ-1, Unit 17).

\subsection{Tephrochronology and ${ }^{14} \mathrm{C}$ Chronology}

Glass shards of the four pumiceous lapilli beds and entrained pumice clasts from VQ-1/VQ-2 were analysed for major element composition and then correlated with the reference tephra dataset (Section B1, Appendix B) and stratigraphic logs published in Alloway et al. (1995). Major element glass analyses from the first pumiceous lapilli bed (VQ-1, TS-19) is indistinguishable from those determined for Korito Tephra (c. $4,100{ }^{14} \mathrm{C}$ yrs B.P). The second and third pumiceous lapilli beds (VQ-1, TS-20 \& 21 respectively) correlate with the lower and upper subunits (Inglewood.a and b, respectively) of Inglewood Tephra dated at c. 3,600 ${ }^{14}$ C yrs B.P (Alloway et al., 1995).

Pumiceous clasts sampled from within the cobble and boulder rich deposits (VQ-1, TS-22) show a much broader range of major elemental compositions than the basal lapilli beds and are indistinguishable from the Korito and Inglewood Tephra. The pumiceous lapilli analysed from the top of the section (VQ-1, TS-28) is geochemically indistinguishable from the Inglewood.a and Inglewood.b subunits of the Inglewood Tephra. The lapilli's stratigraphic position 9.5m above the Inglewood.a and Inglewood.b subunits (VQ-1, Units 3 \& 5) makes the correlation of this lapilli bed with the existing stratigraphic framework more complicated (for possible explanations see Section 2.4).

A prominent feature of the Vickers Quarry site is the presence of truncated large $(<2-\mathrm{m}$ diameter) podocarp-hardwood trees extending upwards from a paleo-ground surface that includes Inglewood Tephra close to the ground surface contact. This forested paleosurface was buried by rapid and catastrophic emplacement of the cobble-and boulder-rich deposits (VQ-1, Units 6 \& 7). These trees were radiocarbon dated at $3,236 \pm 35{ }^{14} \mathrm{C}$ yrs B.P by Neall et al. (2012) indicating the paleoforest prior to the emplacement of the Inglewood Tephra. 


\subsection{Sedimentology}

Sample VQ-S1 (VQ-1, Unit 6) exhibits a bimodal distribution with a major peak at $-4.0 \phi$ and a minor peak at $1.0 \phi$, and a mean of $-1.53 \phi$. The sample is very poorly sorted $(S . D=3.16 \phi)$, coarse skewed $(\mathrm{SKt}=-13.54)$ and has a fine constituent of $6.79 \mathrm{wt} \%<4 \phi$. Field measurements from this unit show the largest five clasts range in diameter from $0.75 \mathrm{~m}$ to $3.2 \mathrm{~m}$. This very coarse deposit vertically grades to a finer grained and less poorly sorted unit (VQ-1, Unit 7). Sample VQ-S2 (VQ-1, Unit 7) exhibits a broad, bimodal grain size distribution with a major peak at $-2.0 \phi$ and a minor peak at $0.5-1.0 \phi$, and a mean of $0.00 \phi$. The sample is very poorly sorted $(S . D=2.56 \phi)$, fine skewed $\left(S K_{t}=0.13\right)$ and has a fine constituent of $7.97 w t \%<4 \phi$. Sample VQ-S3 from the fine to coarse pebbly sand (VQ-1, Unit 9) bound by accumulations of organic material (VQ-1, Units 8 \& 10) exhibits a broad, single modal peak at $1.0 \phi$ and a mean of $0.07 \phi$. The sample is very poorly sorted $(S . D=2.30)$, fine skewed $\left(S K_{t}\right.$ $=0.13$ ) and has a fine constituent of $4.46 w t \%<4 \phi$. Sample VQ-S4 (VQ-S1, Unit 11) taken from the thin, fine textured, pebbly sand unit overlying the second organic layer (VQ-1, Unit 10) exhibits a single modal peak at $1.0 \phi$ and a mean of $1.44 \phi$. The sample is very poorly sorted $(S . D=2.35 \phi)$, fine skewed $\left(S_{t}=0.73\right)$ and has a fine constituent of $13.53 \mathrm{wt} \%<4 \phi$. Sample VQ-S5 taken from the second, cobble and boulder rich unit (VQ-1, Unit 12) exhibits a bimodal distribution with a major peak at $-4.5 \phi$ and a minor peak at 1.0-2.0 $\phi$, and a mean at $2.15 \phi$. This vertically grades to a fine grained unit shown by sample VQ-S6 (VQ-1, Unit 14) which exhibits a modal peak at 1.0-2.0 $\phi$ with a single, outlying peak at $-5.0 \phi$.

Clast form analysis of the two main cobble and boulder rich units VQ-S1 (VQ-1, Unit 6) and VQ-S5 (VQ-1, Unit 12) indicate that both the deposits at Vickers Quarry comprise dominantly Compact-Bladed and sub-rounded clasts. Analysis of VQ-S1 (VQ-1, Unit 6) shows a shape distribution of Compact bladed (30\%), Compact-Elongate (19\%) and Bladed (19\%) with a range from compact to very-bladed. The roundness estimates exhibit a peak in the rounded class $(0.5)$ with a mean and median of 0.5 , and a range from sub-angular (0.3) to rounded (0.7). Analysis of VQ-S5 (VQ-1, Unit 12) shows a main shape distribution of Compact-Bladed (28\%), Compact (18\%) and Compact-Elongate (14\%) with a range from compact to very-bladed. The roundness estimates for VQ-S5 exhibit a peak at rounded $(0.5)$ but has a mean and median of sub-rounded (0.4), and a range from angular (0.2) to rounded (0.6). 


\subsection{Interpretation}

The interbedded, basal pumiceous lapilli beds (VQ-1, Units 1, $3 \& 5$ ) are interpreted to be the Korito Tephra (c. 4,100 ${ }^{14}$ C yrs B.P) and the Inglewood.a and Inglewood.b subunits of the Inglewood Tephra (c. 3,600 ${ }^{14} \mathrm{C}$ yrs B.P) based on stratigraphic position and geochemical composition. This is overlain by an organic rich silt unit interpreted to be a paleosol (VQ-3, Unit 7). The paleosol is variable in both thickness and composition with the same paleosol expressed as a $<0.2 \mathrm{~m}$ thick, fibrous peat deposit near VQ-3.

Overlying the paleosol, the normally graded, fine sand to silt unit is interpreted to be a basal sole layer (Figure 45) deposited by the wave of water pushed in front of the head of the debris flow. At Vickers Quarry the paleosol and basal sole layer are often absent with the overlying coarse grained deposits unconformably overlying the Inglewood.b subunit (e.g. VQ-1 and VQ-2). The $<5.0 \mathrm{~m}$ thick, massive, monolithologic, coarse textured, pebble, cobble and boulder unit (VQ-1, Unit 6; VQ-2, Unit 7; VQ-3, Unit 8) is interpreted to be proximal debris flow deposits. This unit vertically grades to a massive, monolithologic, pebble and cobble-rich debris flow deposits (VQ-1, Unit 7). Based on the underlying Inglewood Tephra (c. 3,600 ${ }^{14} \mathrm{C}$ yrs B.P), the debris flow deposits are interpreted to be proximal exposures of the Ngatoro Formation (Figure 46). The top of these debris flow deposits is marked by a leaf litter accumulation that laterally transforms to an organic rich silt (VQ-1, Unit 8) interpreted to be a paleosol. This represents a period of stability in the landscape after the emplacement of the Ngatoro Formation. Overlying the leaf litter accumulation, the normally graded, and massive to stratified sand unit is interpreted to be fluvial reworked deposits (VQ-1, Unit 9) (Figure 47). The fluvial reworked deposits are laterally discontinuous suggesting an alluvial system formed on the upper surface of the Ngatoro Formation. This is supported by another leaf litter accumulation on the upper contact of the fluvial reworked deposits (VQ-1, Unit 10).

The paleosol and fluvial reworking sequence (VQ-1, Units 8, 9 \& 10) is laterally variable with the fluvial reworked deposits expressed as a massive, monolithologic, pebble and sand rich debris flow deposit overlain by a laterally continuous fine textured, fine sand to silt unit (VQ1 , Unit 11) interpreted to be a sole layer. The sole layer is overlain by another $<4.0 \mathrm{~m}$ thick, massive, monolithologic, reversely graded, pebble, cobble and boulder unit (VQ-1, Unit 12) vertically grading to gravelly fine to coarse sand unit (VQ-1, Units $13 \& 14$ ) are interpreted to 
be proximal debris flow deposits of the Te Popo Formation (Figure 46). These deposits laterally vary in thickness from $<4.0 m$ (VQ-1, Unit 12) to 7.0m thick (VQ-2, Units $7 \& 8$ ) where it infill's erosional channels into the underlying deposits.

The top of the Vickers Quarry sections are marked by a laterally continuous, medium to coarse pumiceous lapilli with some charred wood fragments (VQ-1, Unit 15; VQ-2, Unit 9). This is overlain by a massive, silty, fine to medium sand unit (VQ-1, Unit 16) interpreted to be a sole layer overlain by another $>0.5 \mathrm{~m}$ thick, monolithologic, reversly graded, sandy pebble and cobble unit (VQ-1, Unit 17) interpreted to be a proximal debris flow deposit. Major element composition analysis (VQ-1, TS-28) indicates the pumiceous lapilli has a composition indistinguishable from the Inglewood Tephra; however its stratigraphic position 9.6m above the Inglewood.a and Inglewood.b subunits (VQ-1, Units 3 \& 5) does not fit within the existing stratigraphic framework (Alloway et al,. 1995; Lowe, 1988). There are three possible explanations for the occurrence of TS-28 with its Inglewood glass chemistry. It may represent: 1) a layer of reworked Inglewood pumice occurring higher in the volcaniclastic stratigraphy; 2 ) an additional Inglewood eruptive subunit not recognised at other sections; or 3) an incorrectly labelled or inadvertently swapped sample during preparation and analysis. Irrespective of these possible explanations to account for the position of TS-28, Korito and Inglewood subunits $a$ and $b$ are identified in the correct sequence in the lower stratigraphy of the same vertical section. This issue is expected to be resolved after submission of this thesis by tephra resampling and further EMP analysis as well as submission of associated wood fragments for radiocarbon dating.

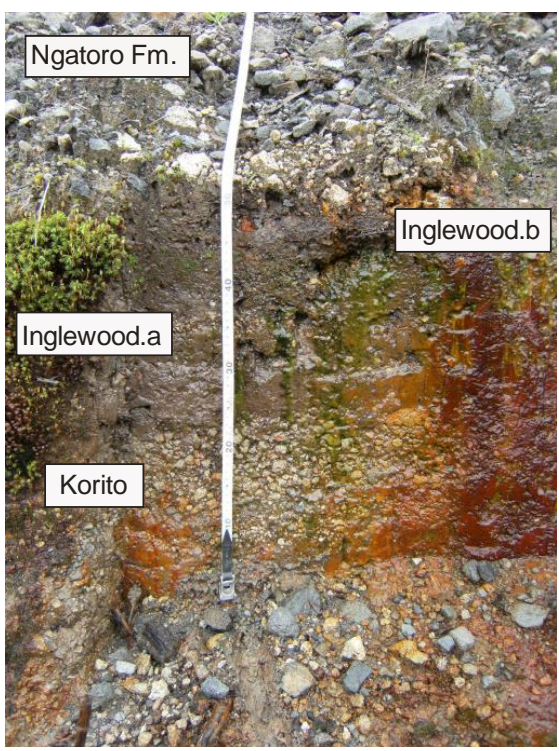

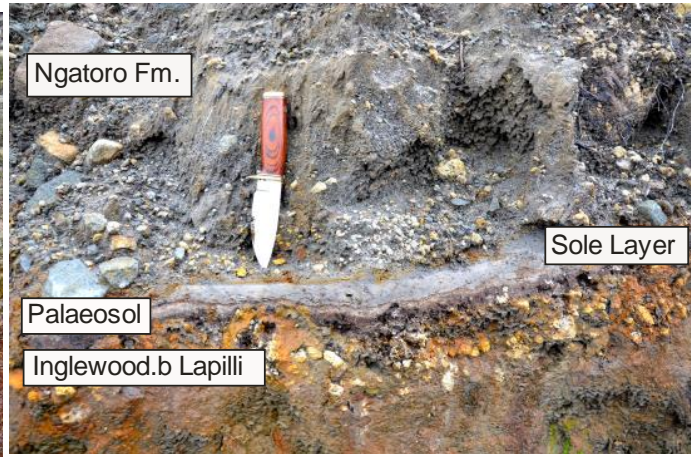

Figure 44 (Left): Photograph showing the Korito Tephra and Inglewood.a and Inglewood.b subunits at the base of sections VQ-1 and VQ-2.

Figure 45 (Above): Photograph showing the discontinuous basal sole layer at Vickers Quarry. 


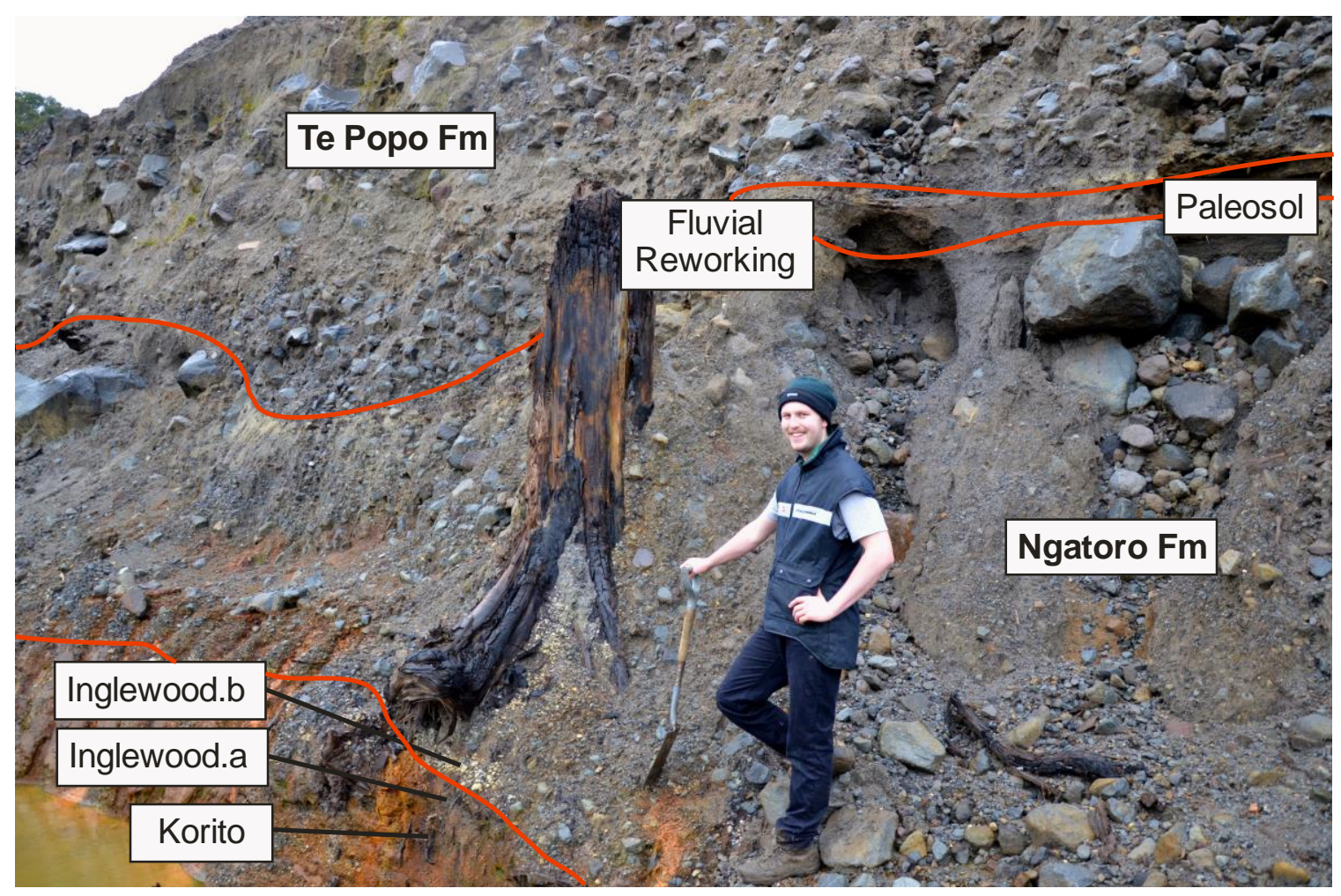

Figure 46: Photograph show the Ngatoro Formation overlying the Korito Tephra and Inglewood.a and Inglewood.b subunits at sections VQ-1 and VQ-2. The upper boundary is marked with a laterally discontinuous paleosol and fluvial reworked deposits. The overlying Te Popo Formation has eroded and infilled a channel into the underlying Ngatoro Formation. Note the charred tree truncated at the boundary between the Ngatoro Formation and Te Popo Formation. Photo courtesy of A/Prof Brent Alloway.

As previously discussed, a prominent feature of the Vickers Quarry site is the presence of truncated large podocarp-hardwood trees extending upwards from a paleosurface buried by rapid and catastrophic emplacement of the Ngatoro Formation (VQ-1, Units 6 \& 7) (Figure 47). The trees show two key features that provide insight into the emplacement of the Ngatoro Formation:

- Charred Outer Veneer - The outer edge of the truncated tree trunks are surficially charred to a penetration depth of $<0.1 \mathrm{~m}$. The charred outer is dark black in colour, with prominent desiccation cracks. This is evidence for an emplacement of the Ngatoro Formation or any pre-cursor event above ambient temperature - hot enough to char the trees but not enough to completely burn them. The outside and top of the truncated trees also show evidence of impacts from debris including rounded off tops, upslope removal and downslope preservation of bark, and fine material encased around the trunks. 
- Correlation of Truncation Height - The height at which the trees have been truncated ranges from $1.9 \mathrm{~m}$ to $3.3 \mathrm{~m}$ above the buttress of the tree. This height correlated with the boundary between the upper and lower flow units exposed in the quarry walls (VQ-1 and VQ-2).

\begin{tabular}{|c|c|c|c|}
\hline \multicolumn{4}{|c|}{ Vickers Quarry - Truncated Trees } \\
\hline Tree & Height (From Base) & $\begin{array}{c}\text { Height (From Top of } \\
\text { Buttress) }\end{array}$ & $\begin{array}{c}\text { Circumfrence } \\
(\mathrm{m})\end{array}$ \\
\hline 1 & 3.8 & - & 5.2 \\
\hline 2 & 4.3 & - & 3.4 \\
\hline 3 & 3.1 & 2.0 & 1.8 \\
\hline 4 & 4.5 & 3.5 & 4.2 \\
\hline 5 & 4.1 & 2.9 & 3.3 \\
\hline 6 & 3.9 & 3.3 & 5.9 \\
\hline 7 & 3.3 & 2.5 & 2.0 \\
\hline 8 & 3.5 & 2.0 & 5.2 \\
\hline 9 & 3.2 & 2.5 & 2.8 \\
\hline 10 & 3.9 & 3.3 & 3.8 \\
\hline 11 & 2.3 & 1.9 & 2.4 \\
\hline
\end{tabular}

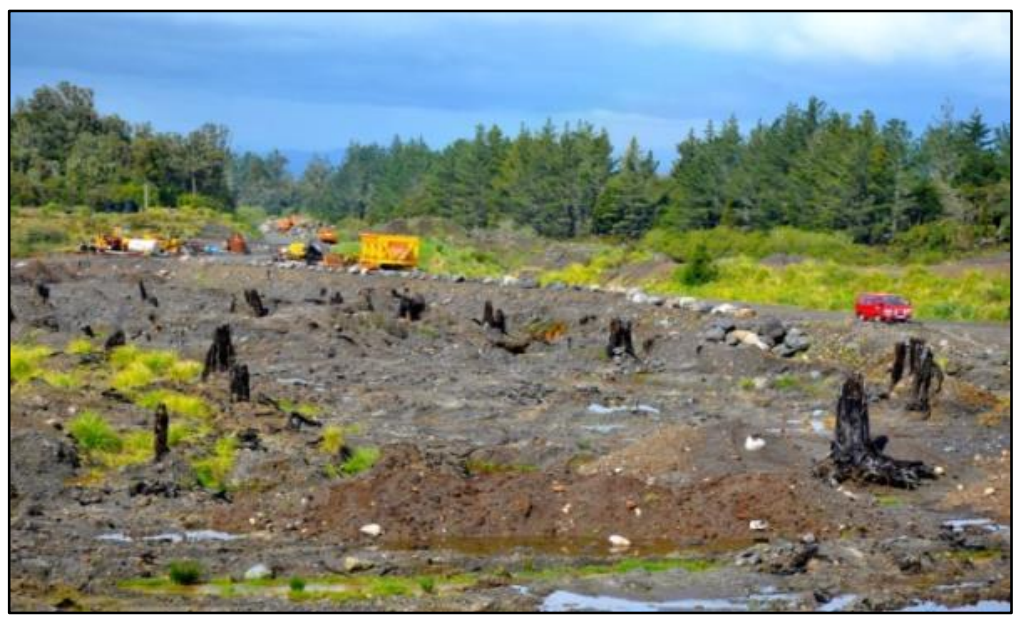

Figure 47: Table of truncated tree heights with accompanying photographs showing the excavated charred and desiccated in situ trees. Note the rounded tops and sand/cobbles forming a veneer
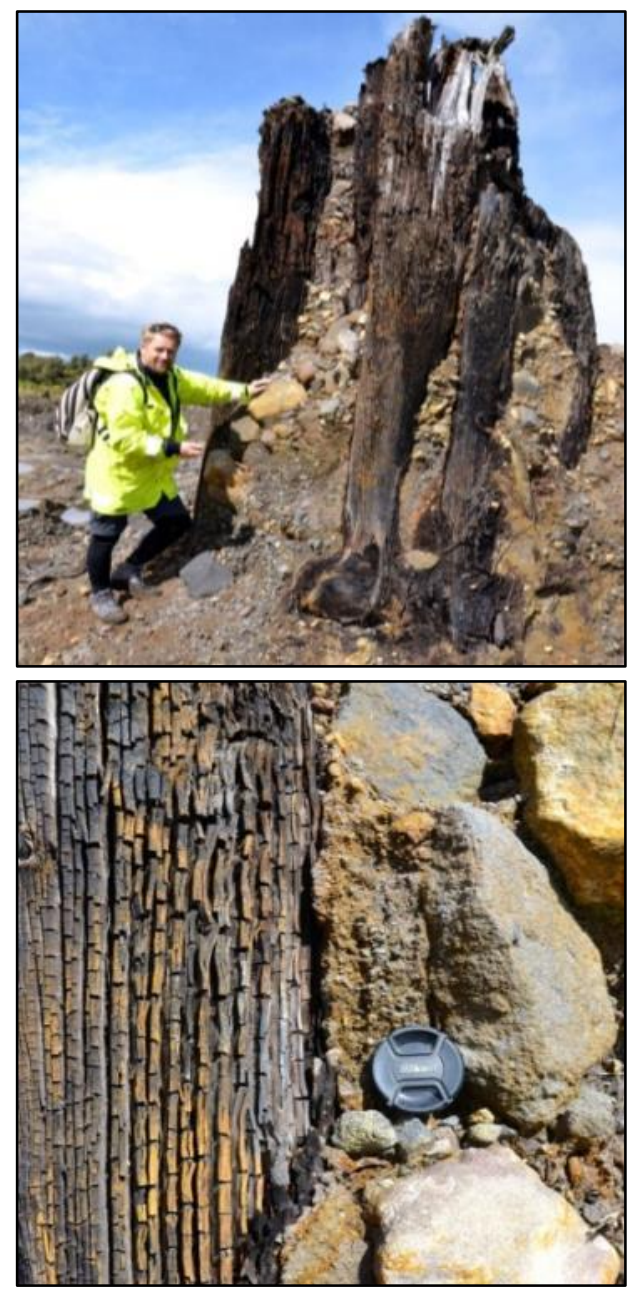
around the upslope side of trunk. Photographs courtesy of A/Prof Brent Alloway. 


\section{Surrey Road Quarry (SQ-1, SQ-2 and SQ-3)}

The Surrey Road Quarry sections are located is $10 \mathrm{~km}$ east from the present-day summit of Egmont Volcano on the banks of the Mangamawhete Stream (Figure 48). At this site three measured section were carried out (Figure 49).

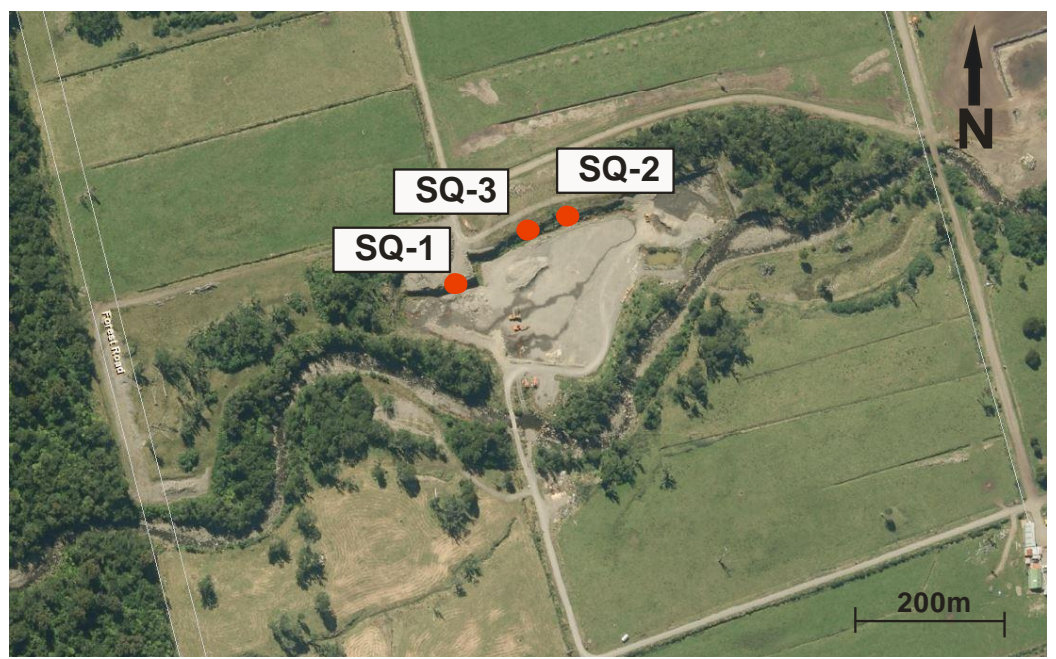

Figure 48: Aerial photograph showing the location of sections SQ-1, SQ-2 and SQ-3. Photo courtesy of Taranaki Regional Explorer (2014).

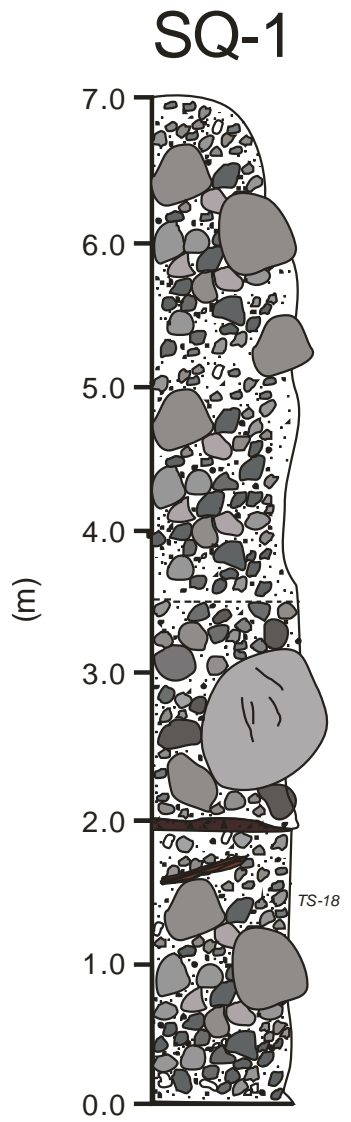

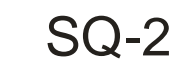

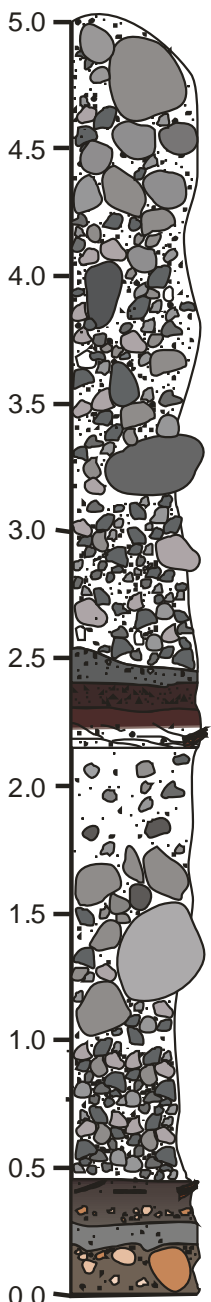

SQ-3

8.0

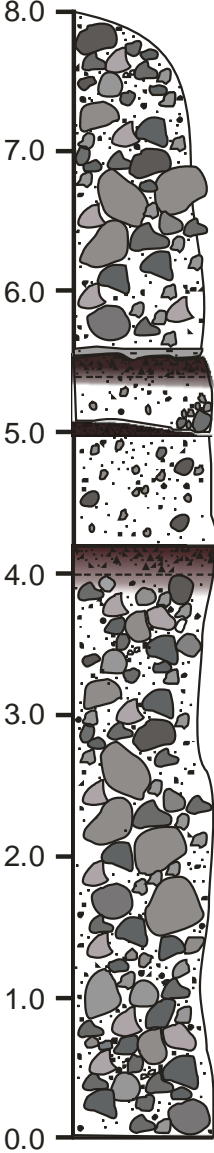

Figure 49: Stratigraphy of sections $S Q-1, S Q-2$ and SQ-3. 

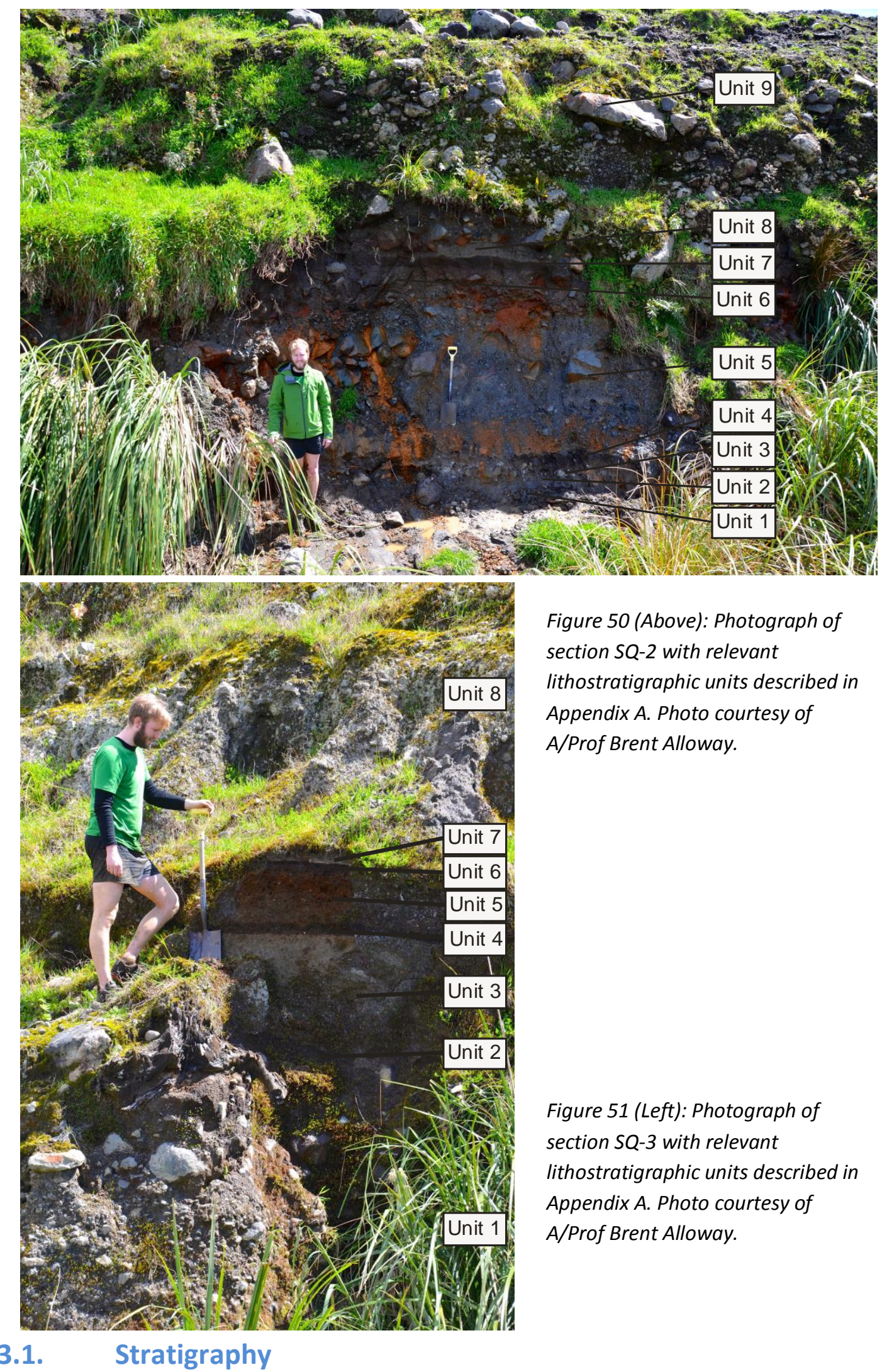

Figure 50 (Above): Photograph of section SQ-2 with relevant lithostratigraphic units described in Appendix A. Photo courtesy of A/Prof Brent Alloway.

Figure 51 (Left): Photograph of section SQ-3 with relevant lithostratigraphic units described in Appendix A. Photo courtesy of A/Prof Brent Alloway.

The stratigraphy described at Surrey Road Quarry sections VQ-1, 2 \& 3 (Appendix A) comprises up to $10 \mathrm{~m}$ of cobble-and boulder-rich deposits overlying a basal pumiceous lapilli sequence with interbedded basaltic, scoriaceous lapilli beds. Two closely spaced, $\mathrm{cm}$-to dmscale pumiceous lapilli beds (SQ-2, Units 1 \& 3) were observed at the base of the Surrey 
Road Quarry walls (Figure 50). These pumiceous lapilli beds are separated by a $<0.1 \mathrm{~m}$ thick, massive sand unit (SQ-2, Unit 2). The first lapilli bed (SQ-2, Unit 1 ) is $<0.2 \mathrm{~m}$ thick, very coarse (up to $0.3 \mathrm{~m}$ ) pumiceous lapilli and blocks, with the second lapilli bed (SQ-2, Unit 3) a $0.1 \mathrm{~m}$ thick, fine to medium, pumiceous lapilli in a sandy matrix. This is overlain by a $<0.1 \mathrm{~m}$ thick, dark brown, organic rich, fine to medium, sandy silt with common wood fragments (SQ-2, Unit 4). The two lapilli beds are only observed at section SQ-2.

The basal pumiceous lapilli sequence is typically overlain by $a<2.0 \mathrm{~m}$ thick, massive, monolithologic, pebble, cobble-and boulder-rich unit containing wood fragments $(0.2 \mathrm{~m})$, exhibiting a reversely graded lower to ungraded middle and normally graded upper (SQ-2, Unit 5) (Figure 50). In places the base of this unit is marked by a $<0.3 \mathrm{~m}$ thick, massive, poorly sorted fine to coarse sand. The cobble-and boulder-rich unit is subsequently overlain by a $\leq 0.15 \mathrm{~m}$ thick cross-stratified, sandy deposit normally grading to massive, dark brown sandy silt (SQ-2, Unit 6) and a $<0.1 \mathrm{~m}$ thick, massive to faintly stratified, fine to medium basaltic, scoriaceous lapilli in a sandy/silt matrix (SQ-1, Unit 2; SQ-2, Unit 7; SQ-3, Unit 2).

The basaltic lapilli is overlain by a laterally and vertically variable unit of massive, homolithogic, clast-supported, angular to sub-rounded, fine to coarse pebble-rich to pebble, cobble-and boulder-rich deposits (SQ-1, Units 3 \& 4; SQ-2, Units 8 \& 9; SQ-3, Units 3, 5 \& 8) with two $<0.2 \mathrm{~m}$ thick, interbeded basaltic, scoriaceous lapilli beds (SQ-3, Units $4 \& 6$ ). The two lapilli beds (SQ-3, Units $4 \& 6$ ) are comprised of massive, fine to medium basaltic, scoriaceous lapilli with the uppermost in a dark brown silt matrix. The sandy pebble, cobble and boulder units are channelised with erosional lower boundaries cutting into underlying units, and lateral textural and thickness variations $(0.3-2.5 \mathrm{~m}$ thick). This is evident in the three scoriaceous lapilli beds exposed at SQ-3 (Units 2, 4 \& 6), whereas only one scoriaceous lapilli bed is preserved at SQ-1 (Unit 2) where overlying units have incised and eroded out the second and third scoriaceous lapilli beds.

\subsection{Tephrochronology}

The pumiceous and scoriaceous lapilli beds (SQ-2, Units 1 \& 3; SQ-3, Units 2, 4 \& 6) exposed at Surrey Road Quarry were correlated with the existing tephrostratigraphic record on the basis of stratigraphic association augmented by glass shard chemistry (Section B1, Appendix B). The basal pumiceous lapilli beds (SQ-2, Unit 1 \& 3) are correlated with the lower and 
upper subunits of the Inglewood Tephra (c. 3,600 ${ }^{14} \mathrm{C}$ yrs B.P). The three basaltic, scoriaceous lithic lapilli beds (SQ-3, Units 2, 4 \& 6) have been correlated with the Manganui.a, Manganui.b and Manganui.c beds of the Manganui Tephra (c. 3,100 ${ }^{14} \mathrm{C}$ yrs B.P) (Alloway et al., 1995).

\subsection{Interpretation}

The basal pumiceous lapilli beds (SQ-2, Units $1 \& 3$ ) are interpreted to be the Inglewood.a and Inglewood.b subunits of the Inglewood Tephra (c. 3,600 ${ }^{14} \mathrm{C}$ yrs B.P) based on stratigraphic position, colour and coarse texture. The Inglewood Tephra is subsequently overlain by an organic-rich, sandy silt interpreted to be a paleosol (SQ-2, Unit 4) representing a period of stability in the landscape following the Inglewood eruptive event. The massive, poorly sorted sandy unit rarely preserved at Surrey Road Quarry (Figure 52) is interpreted to be a basal sole layer deposited by the wave of alluvial water pushed in front of the head of the debris flow.

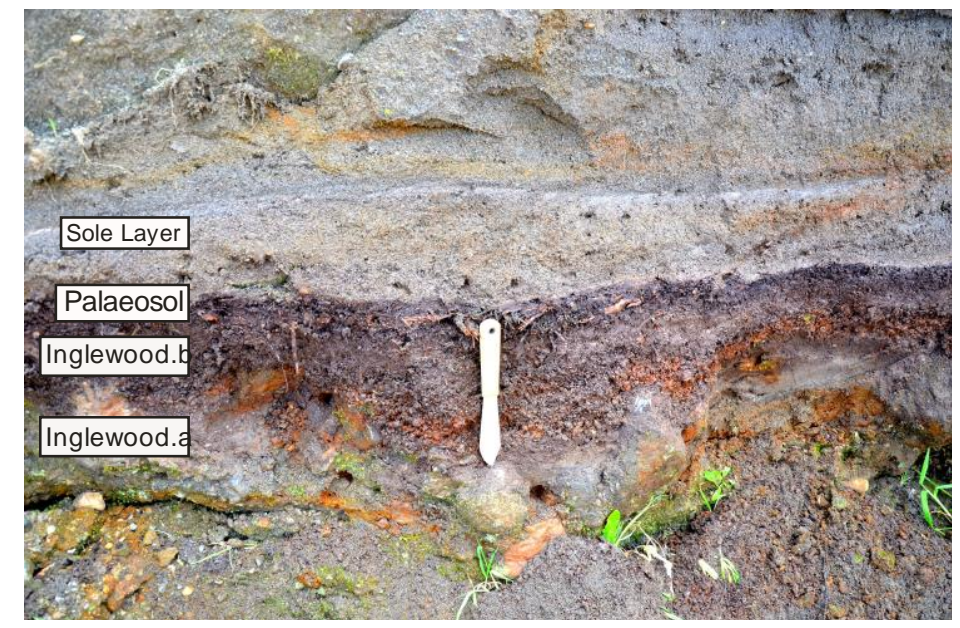

Figure 52: Interpretation of the lithostratigraphic units (Figure 50). This section exposes the Inglewood.b subunit, organic rich paleosol with wood fragments and the basal sole layer.

The lower massive, pebble, cobble-and boulder-rich unit (SQ-1, Unit 1; SQ-2, Unit 5 \& 6; and SQ-3, Unit 1) is interpreted to be a proximal debris flow deposit based on its coarse-grained texture, homogeneous composition, massive structure and poorly sorted nature. This is unconformably overlain by a cross-stratified, fine to coarse sandy unit (SQ-2, Unit 6) interpreted to be hyperconcentrated flow deposits vertically transforming into a massive, dark brown silt with abundant basaltic, scoriaceous lapilli (SQ-1, Unit 2; SQ-2, Unit 7; and SQ-3, Unit 2). The scoriaceous lapilli bed stratigraphically correlates with the Manganui.a subunit of the Manganui Tephra (c. $3,100{ }^{14} \mathrm{C}$ yrs B.P) and as a paleosol. This palaeosol 
represents a period of stability in the landscape following the first Manganui eruptive event. The enveloping Inglewood and Manganui Tephra correlate the proximal debris flow deposits and hyperconcentrated flow deposits (SQ-2, Units $5 \&$ 6) with the Ngatoro Formation (c. $3,600{ }^{14} \mathrm{C}$ yrs B.P) (Figure 53).

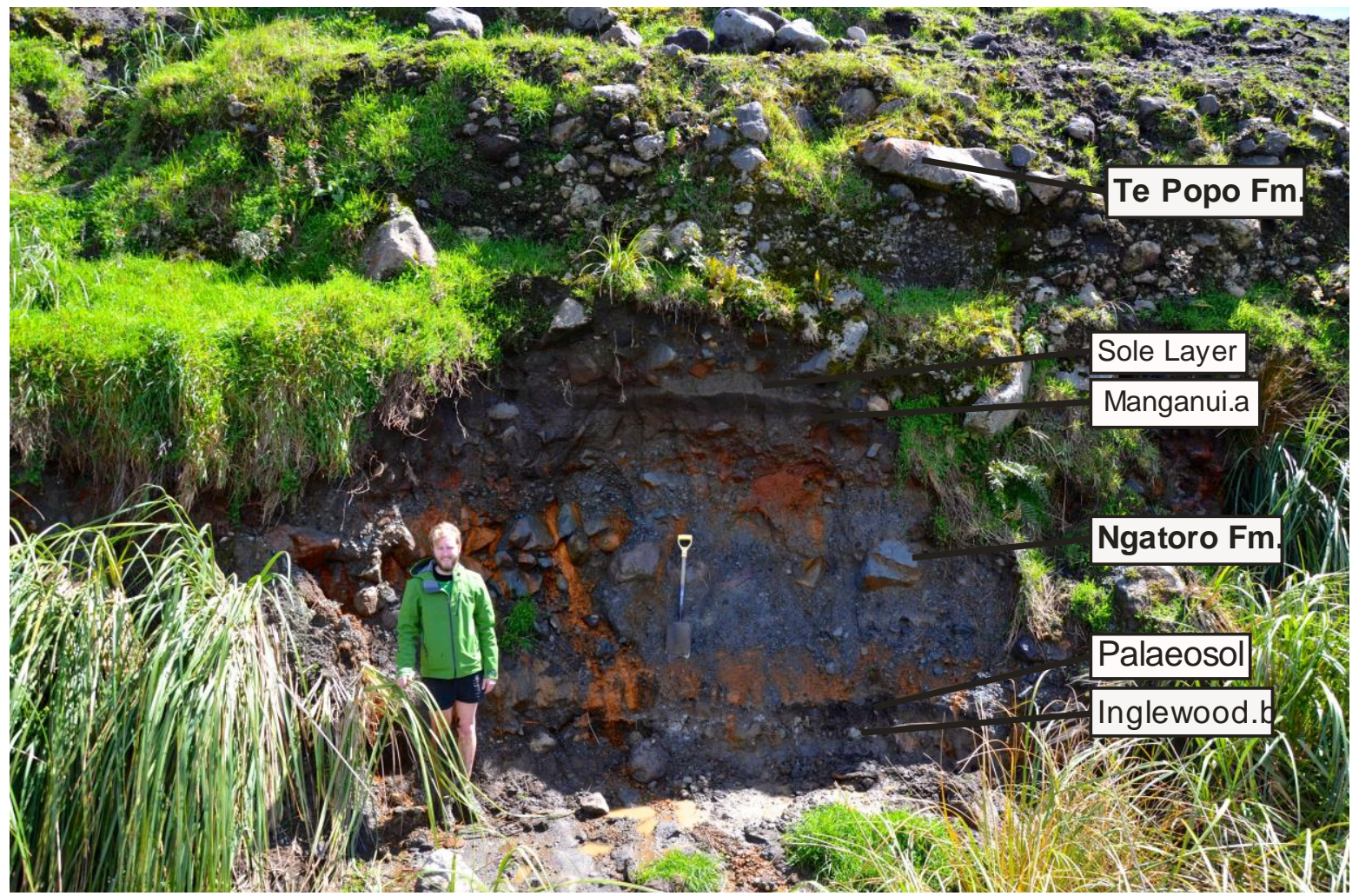

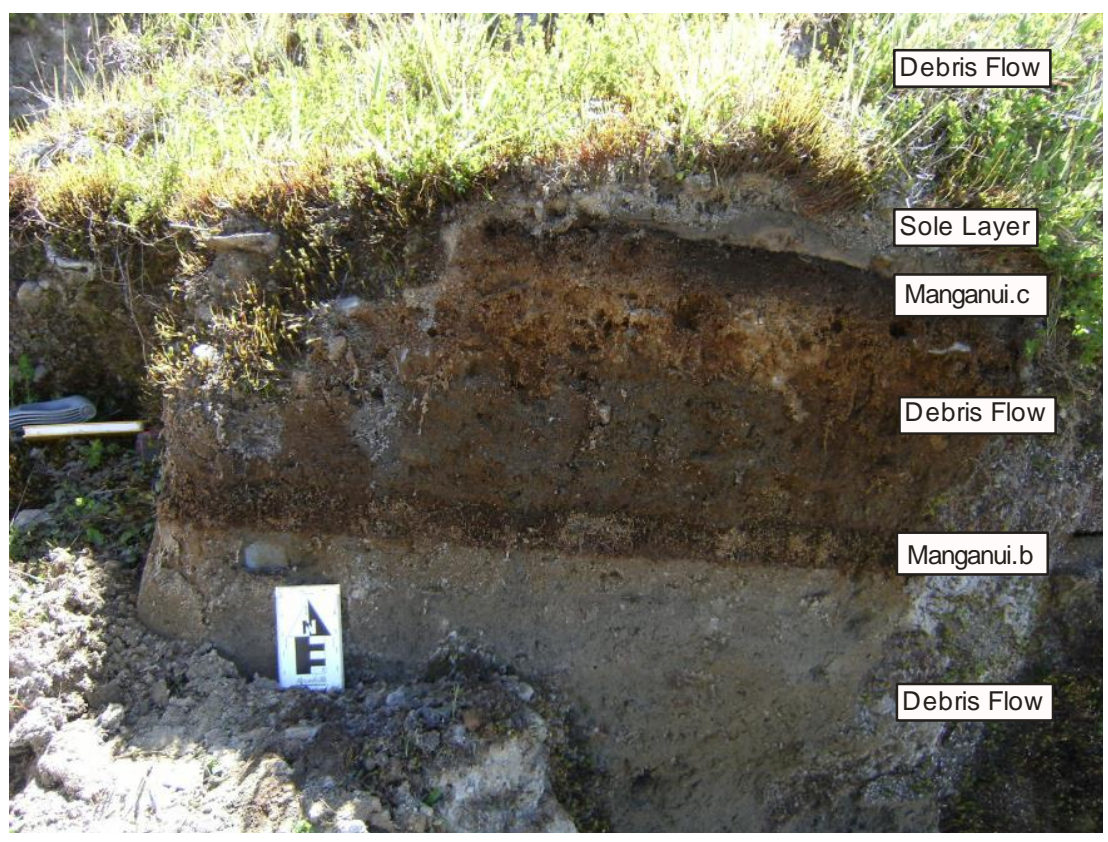

Figure 54: Photograph showing the Manganui.b and Manganui.c subunits with interbedded overbank pebbly sand debris flow deposits interpreted from lithostratigraphic units (Figure 51) at section SQ-3
Figure 53 (Above):

Photograph showing the Ngatoro Formation enveloped by the Inglewood.b subunit and paleosol and the overlying Manganui.a subunit interpreted from lithostratigraphic units (Figures 50 and 51) section SQ-2. The upper most debris flow deposits are proximal Te Popo Formation. Photo courtesy of A/Prof Brent Alloway. 
Above the Manganui.a subunit, the pebble, cobble-and boulder-rich unit (SQ-1, Unit 3; SQ-2, Unit 9; and SQ-3, Unit 3) is interpreted to be proximal debris flow deposits of the Te Popo Formation (c. 2.9 to $3.1 \mathrm{kyr}$ B.P) based on its coarse gravelly texture, homogeneous composition, massive structure and poorly sorted nature. This unit varies in thickness from $0.8 \mathrm{~m}$ (SQ-3, Unit 3) to $<2.5 \mathrm{~m}$ thick (SQ-2, Unit 9) as it basally erodes and forms channels in the underlying volcaniclastic deposits. Within the channels, the debris flow deposits are typically massive, clast-supported, and have cobble-and boulder-dominated textures (SQ-1, Unit 3; SQ-2, Unit 9), whereas the thinner overbank deposits are massive, matrix-supported and have sand-and pebble-dominated textures (SQ-3, Unit 3) (Figure 54). At section SQ-2, the base of the debris flow deposit (SQ-2, Unit 9) is marked by a massive, pebbly coarse sand layer (SQ -2, Unit 8) interpreted as a sole layer deposited by the wave of alluvial water pushed downstream at the head of the debris flow. The sole layer is not preserved at SQ-1 and SQ-3 through subsequent erosion by the main body of the debris flow.

At sections SQ-1 and SQ-2, the debris flow deposits extend up to the top of the quarry walls, however at section SQ-3 a second and third basaltic scoriaceous lapilli bed (SQ-3, Units 5 \& 6) are interbedded between the volcaniclastic deposits (Figure 54). The second scoriaceous lapilli bed (SQ-3, Unit 4) stratigraphically correlates with the Manganui.b subunit of the Manganui Tephra (c. $3,100{ }^{14} \mathrm{C}$ yrs B.P).This Manganui Tephra is not laterally continuous and variable in thickness where overlying deposits have eroded it out (Figures 55 and 56). The Manganui.b subunit is overlain by a laterally variable pebbly sand to pebble, cobble-and boulder-rich unit (SQ-3, Unit 5) is interpreted to be proximal debris flow deposits of the Te Popo Formation based on its coarse-grained texture, homogeneous composition, massive structure and poorly sorted nature. The debris flow deposits vary in thickness with coarsetextured infilled channels and finer textured overbank deposits (Figure 55 and 56) similar to the previous Te Popo Formation debris flow deposits (SQ-2, Unit 9; SQ-3, Unit 3).

The debris flow deposits (SQ-3, Unit 5) vertically transform into a basaltic, scoriaceous lapilli in a dark brown silt matrix (SQ-3, Unit 6) which stratigrapically correlates with the Manganui.c subunit of the Manganui Tephra (c. 3,100 ${ }^{14} \mathrm{C}$ yrs B.P) within a paleosol. This paleosol represents a period of stability in the landscape following the third Manganui eruptive event. Overlying the Manganui.c subunit, is another pebble, cobble-and boulderrich unit (SQ-3, Unit 8) interpreted to be proximal debris flow deposits of the Te Popo 
Formation based on its coarse-grained texture, homogeneous composition, massive structure and poorly sorted nature. The base of the debris flow deposits are marked by a massive silt layer (SQ-3, Unit 7) interpreted to be a sole layer deposited by the wave of alluvial water pushed in front of the head of the debris flow.

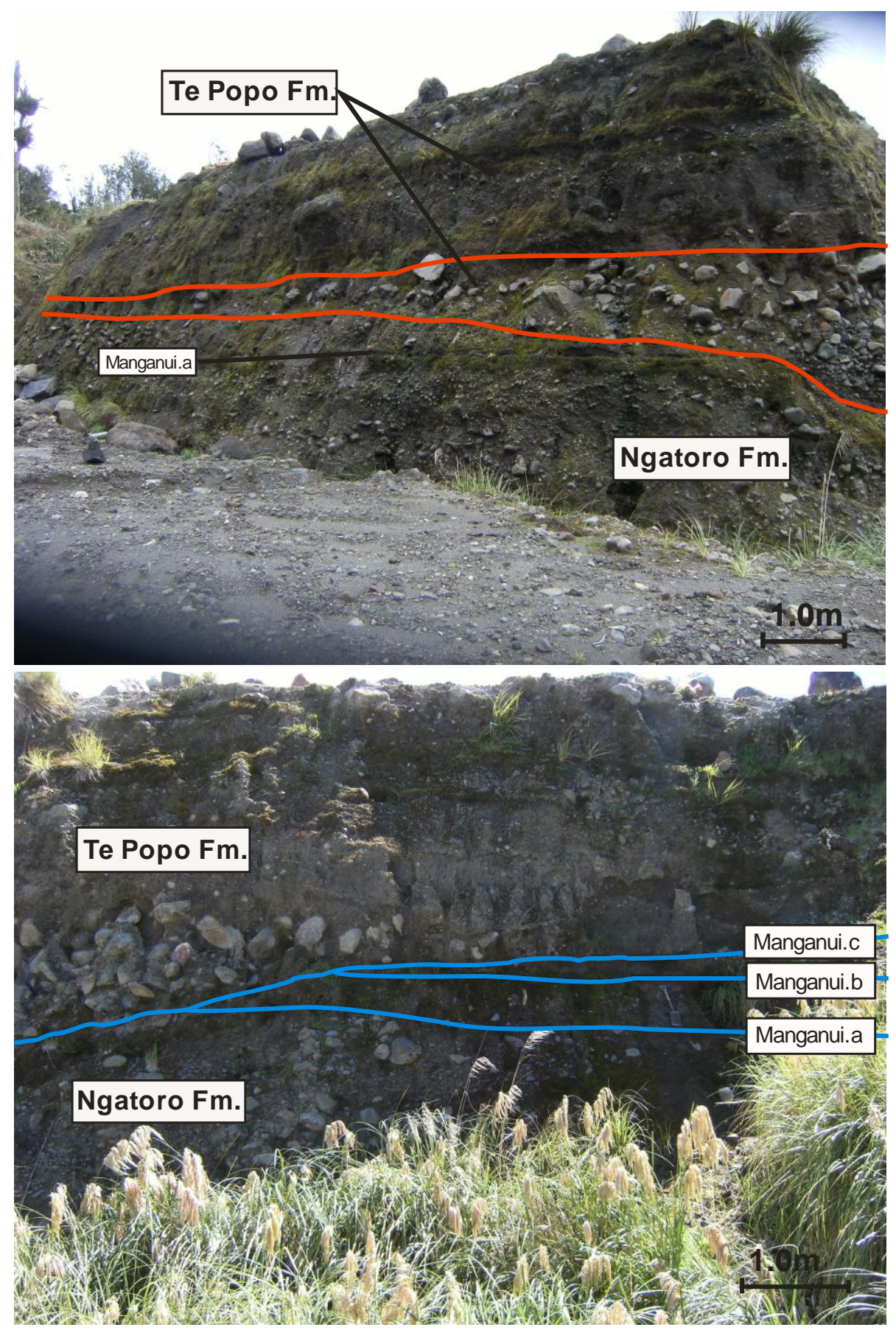

Figure 55 (Top): Photograph showing a debris flow deposit of the Te Popo Formation incised (orange line) into the underlying Ngatoro Formation and Manganui.a subunit forming a boulder-rich channel deposit.

Figure 56 (Bottom): Photograph showing the subunits of the Manganui Tephra (light blue) eroded away by channel deposits of the overlying Te Popo Formation. 


\section{York Road (YR-1 and YR-2)}

The York Road sections are located $13.6 \mathrm{~km}$ east from the present-day summit of Egmont Volcano at the cut slopes of a cow underpass on York Road (Figure 57). At this site two measured sections (Figure 58), and sampling for EMP analysis and grain size/shape analysis was carried out.

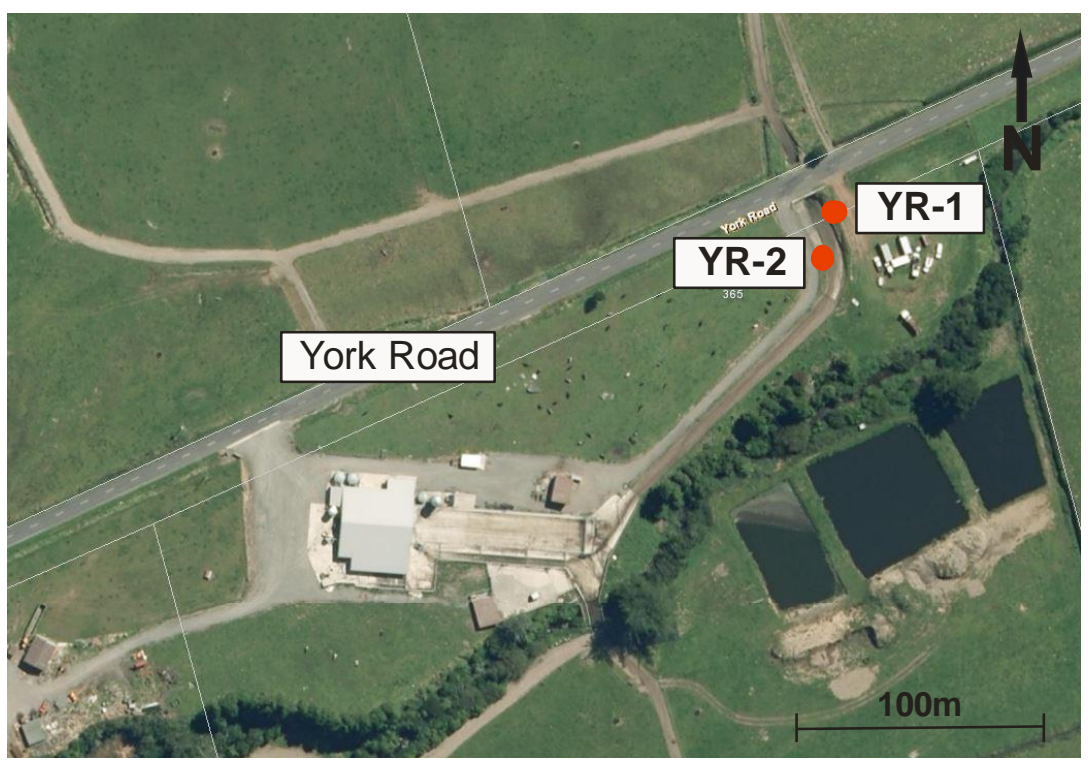

Figure 57 (Left): Aerial photograph showing the location of sections YR-1 and $Y R$-2. Photo courtesy of Taranaki Regional Explorer (2014).

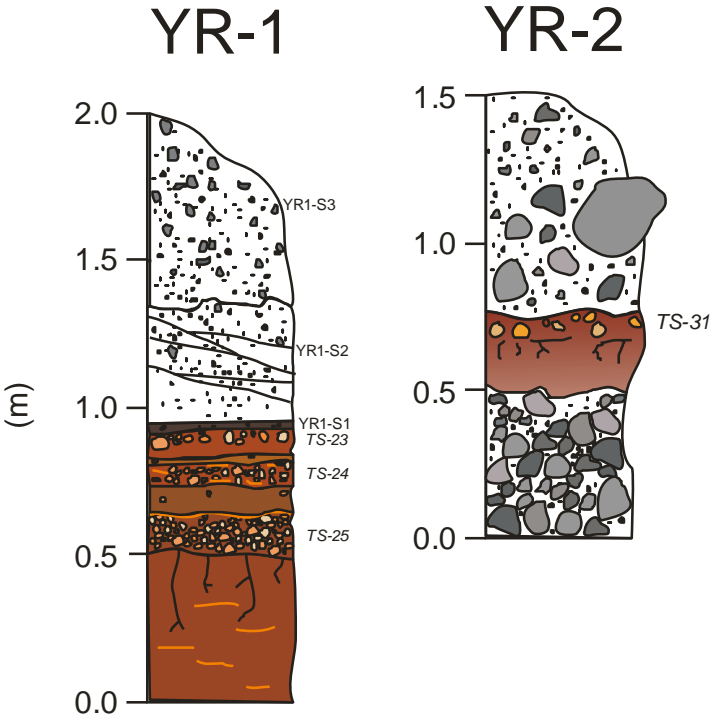

Figure 58: Stratigraphy of sections $Y R-1$ and YR-2.

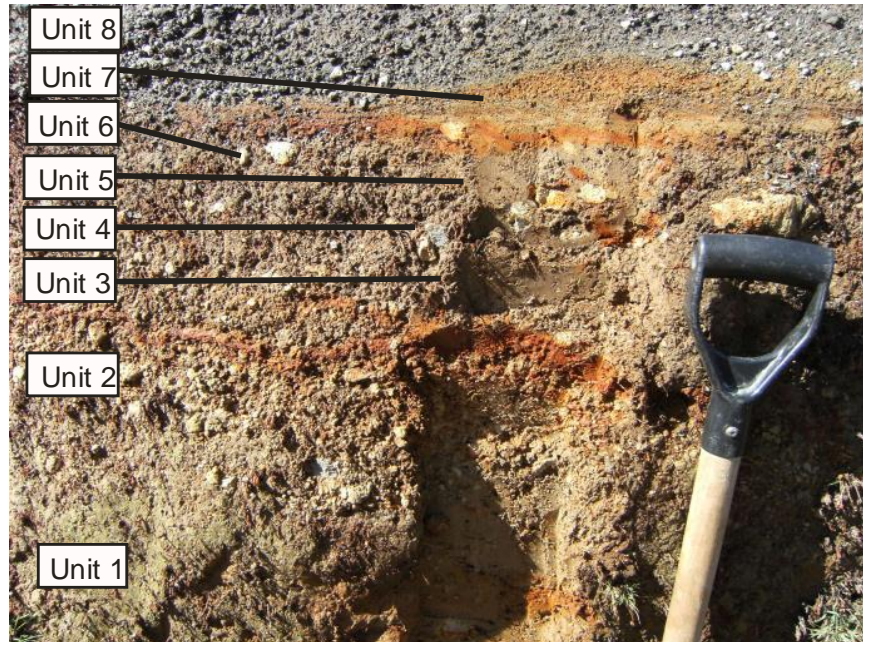

Figure 59: Photograph of the basal pumiceous lapilli sequence at $Y R-1$ with relevant lithostratigraphic units described in Appendix A. 


\subsection{Stratigraphy}

The stratigraphy described at York Road sections YR-1 and 2 (Appendix A) comprises $2 \mathrm{~m}$ of sandy pebble-and cobble-rich deposits overlying a basal pumiceous lapilli sequence. Section YR-1 exposes three cm-scale pumiceous lapilli beds (YR-1, Units 2, 4 \& 6) overlying a massive, yellow-brown soil (YR-1, Unit 1) (Figure 60). The first basal lapilli bed (YR-1, Unit 2) is a $<0.2 \mathrm{~m}$ thick, fine to medium, pumiceous lapilli in a sandy ash matrix overlain by massive, yellow-brown silt with few, fine to medium pumiceous clasts (YR-1, Unit 3). The second lapilli bed (YR-1, Unit 4) is a $<0.1 \mathrm{~m}$ thick, massive, fine to medium pumiceous lapilli and subangular, fine to medium lithic lapilli in a silty ash matrix. This is overlain by massive, yellowbrown silt with few, fine to medium, pumiceous clasts (YR-1, Unit 5). The third basal lapilli bed (YR-1, Unit 6 ) is a $\leq 0.1 \mathrm{~m}$ thick, massive, dominantly coarse, pumiceous lapilli and fine lithic lapilli in a brown sandy ash matrix.

The basal lapilli beds are overlain by a $<0.05 \mathrm{~m}$ thick, massive, monolithologic, fine to medium, pebbly sand (YR-1, Unit 7) and a $<0.5 \mathrm{~m}$ thick sequence of faintly stratified, pebblerich, fine to coarse sand (YR-1, Unit 8). This is subsequently overlain by a $<0.4 \mathrm{~m}$ thick, massive, monolithologic, fine to coarse sand and sub-angular to sub-rounded, fine to coarse pebbles (YR-1, Unit 9).

Approximately 5.0m along section, Units 8 and 9 from section YR-1 laterally transform to a $>0.5 \mathrm{~m}$ thick, massive, monolithologic, channelised, clast-supported, fine to coarse sand with some angular to sub-angular, fine to coarse pebbles with some cobbles (YR-2, Unit 1) (Figure 60). This unit erodes into the underlying pumiceous lapilli beds (YR-1, Units $2,4 \& 6$ ) and is overlain by a $<0.25 \mathrm{~m}$ thick, massive, fine to medium, sandy silt with abundant, medium to very coarse, pumiceous lapilli in the upper $0.1 \mathrm{~m}$ (YR-2, Unit 2). This pumiceous lapilli bed is subsequently overlain by a $>1.5 \mathrm{~m}$ thick, massive, monolithologic, faintly normally graded, matrix-supported, fine to coarse sand with angular to sub-angular, fine to coarse pebbles and cobbles (YR-2, Unit 3) (Figure 61). Along section YR-2 Unit 1 correlates with YR-1 Units 9 and 10. 


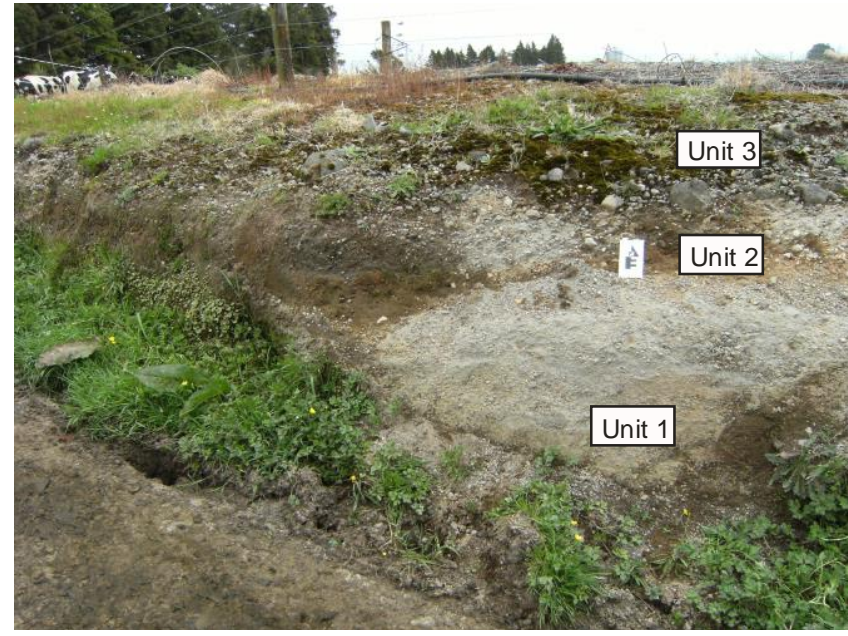

Figure 60: Photograph showing the two pebble- and cobble-rich sand units with interbedded pumiceous lapilli at section YR-2 with relevant lithostratigraphic units described in Appendix A.

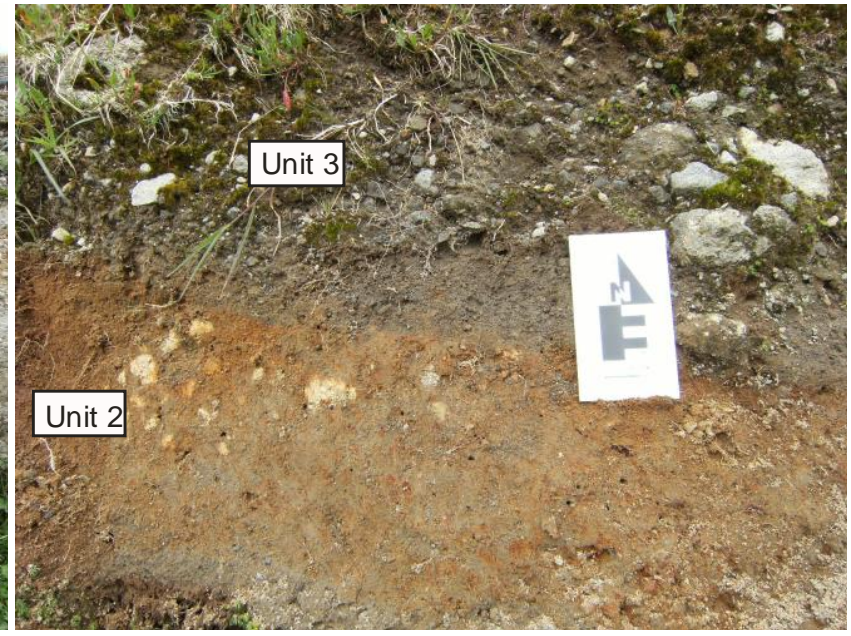

Figure 61: Photograph showing the pumiceous lapilli overlain by a pebble and cobble-rich sand unit at section YR-2 with relevant lithostratigraphic units described in Appendix $A$.

\subsection{Tephrochronology}

Glass shards of the three basal pumiceous lapilli beds (YR-1, Units 2, 4 \& 6) were analysed for major element composition and then correlated with the reference tephra dataset (Section B1, Appendix B) as well as stratigraphic logs published in Alloway et al., (1995). Major element glass analyses from the first pumiceous lapilli bed (YR-1, TS-25) is indistinguishable from those determined for Korito Tephra (c. $4,100{ }^{14} \mathrm{C}$ yrs B.P). The second and third pumiceous lapilli beds (YR-1, TS-24 \& 23 respectively) correlate with the lower and upper subunits (Inglewood.a and b, respectively) of Inglewood Tephra dated at c. 3,600 ${ }^{14} \mathrm{C}$ yrs B.P (Alloway et al., 1995). The lapilli bed exposed at YR-2 (Unit 2) correlates with the unknown uppermost lapilli bed at Vickers Quarry (VQ-1, Unit 15).

\subsection{Sedimentology}

Grain size analysis from sample YR1-S1 within the thin, fine-textured sand unit (YR-1, Unit 7) overlying the basal lapilli sequence exhibits a modal peak at $-0.5 \phi$ showing near normal distribution and has a mean of $-0.05 \phi$. The sample is very poorly sorted $(S . D=2.15 \phi)$, fine skewed $\left(\mathrm{SK}_{\mathrm{t}}=0.26\right)$ and has a fine constituent of $7.59 \mathrm{wt} \%<4 \phi$. Sample YR1-S2 sampled from the overlying pebbly sand unit (YR-1, Unit 8) exhibits a modal peak at $-0.5 \phi$ showing normal distribution and a mean of $-0.08 \phi$. The sample is poorly to very poorly sorted (S.D = $2.00 \phi)$, near symmetrical $\left(\mathrm{SK}_{\mathrm{t}}=0.02\right)$ and has a fine constituent of $4.74 \mathrm{wt} \%<4 \phi$. The top of 
the section exhibits an upwards coarsening and more poorly sorted nature with sample YR1S3 (YR-1, Unit 9) exhibiting a poorly defined peak at $-4.5 \phi$ and a mean of $-1.23 \phi$. The sample is very poorly sorted $(S . D=2.67 \phi)$, fine skewed $\left(S_{t}=2.99\right)$ and has a fine constituent of $5.00 w t \%<4 \phi$

Clast form analysis of YR1-S3 (YR-1, Unit 9) indicates the deposit comprises dominantly bladed and sub-rounded clasts. The analysis shows a main shape distribution of bladed (33\%), compact-bladed (23\%) and compact-elongate (18\%) with a range from compact-platy to very-elongate. The roundness estimates for YR1-S3 (YR-1, Unit 9) exhibit a peak, mean and median of sub-rounded (0.4), and a range from angular (0.2) to well-rounded (0.8).

\subsection{Interpretation}

The basal pumiceous lapilli beds (YR-1, Units 2, 4 \& 6) are interpreted to be the Korito Tephra (c. 4,100 ${ }^{14} \mathrm{C}$ yrs B.P) and Inglewood.a and Inglewood.b subunits of the Inglewood

Tephra (c. $3,600{ }^{14} \mathrm{C}$ yrs B.P) based on stratigraphic interpretation and geochemical composition. The andic soils that separate the pumiceous lapilli beds represent a period of stability in the landscape between the three eruptive events. The Inglewood Tephra constrains the overlying deposits to a maximum age of c. $3,600{ }^{14} \mathrm{C}$ yrs B.P.

The $<20 \mathrm{~mm}$ thick, pebbly sand deposit (YR-1, Unit 7) overlying the basal tephra is interpreted to be a sole layer deposited by the wave of alluvial water pushed in front of the head of the debris flow. This is overlain by the $\mathrm{cm}$-scale bedded to massive, sandy pebble deposits (YR-1, Units 8, 9 \& 10) interpreted to be coarse-textured marginal debris flow deposits exhibiting multiple cut and fill sequences. At section YR-2, the coarse-grained sand, pebble-and cobble-rich deposits exposed at the base of the section (YR-2, Unit 1) are interpreted to be debris flow deposits based on the coarse-texture, homogeneous composition, and massive structure and poorly sorted natured of the deposits. These coarse-grained debris flow deposits stratigraphically correlate with the Ngatoro Formation (Figure 62). Overlying the Ngatoro Formation is a massive, sandy silt soil with the upper boundary marked by a pumiceous lapilli bed (YR-2, Unit 2) which stratigraphically correlates with the unknown uppermost tephra at the Vickers Quarry sections (VQ-1, Unit 15 and VQ2 , Unit 10) based on texture, colour and relative stratigraphic position within enveloping volcaniclastic deposits. The soil beneath and within the tephra (YR-2, Unit 2) indicates a 
period of quiescence and stability in the landscape leading up to the deposition of the tephra and the deposition of the overlying volcaniclastic deposits (YR-2, Unit 3). The massive, fine to coarse pebble and cobble unit at the top of the section (YR-2, Unit 3) is interpreted to be a debris flow deposit based on coarse-grained texture, homogeneous composition, massive structure and poorly sorted nature.

The deposits described at YR-2 are much more coarsely grained in comparison to those at YR-1, in particular YR-2 Unit 2, which has cut into the underlying debris flow deposits (YR-1, Units 9 \& 10; YR-2, Unit 1) and basal tephra sequence (YR-1, Units 2, 4 \& 6) depositing a cobble-rich, massive, channelised debris flow unit (YR-2, Unit 3). This suggests that deposits at YR-1 are marginal deposits whereas YR-2 exposes deposits within a debris flow channel.

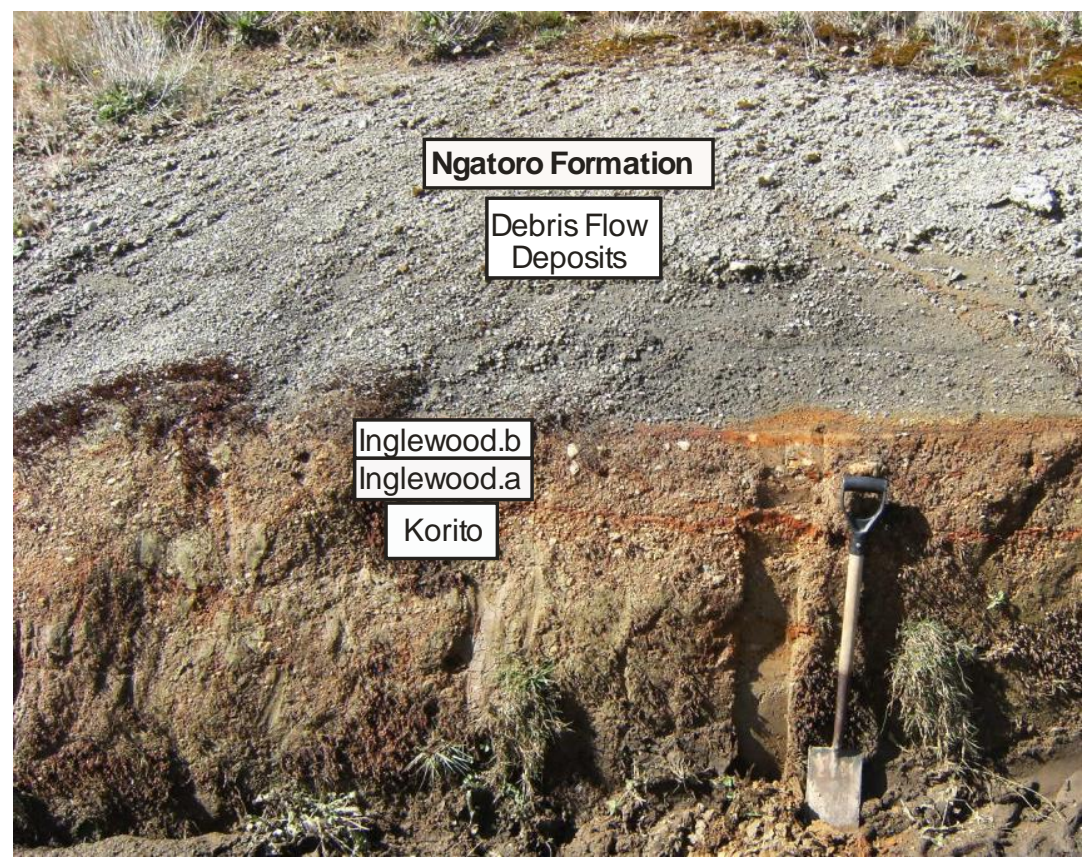

Figure 62: Interpretation of lithostratigraphic units (Figure 59) exposed at section YR-1. This section exposed the marginal debris flow deposits of the Ngatoro Formation overlying the Korito Tephra, and Inglewood.a and Inglewood.b sub-units. 


\section{Tariki - SH3 (TR-1)}

The Tariki - SH3 section is located $17.1 \mathrm{~km}$ east from the present-day summit of Egmont Volcano near the SH3 Mangmawhete Stream Bridge (Figure 63). At this site one measured section (Figure 64) was carried out.

Figure 63: Aerial photograph showing the location of section TR-1. Photo courtesy of Taranaki Regional Explorer (2014).

\section{TR-1}

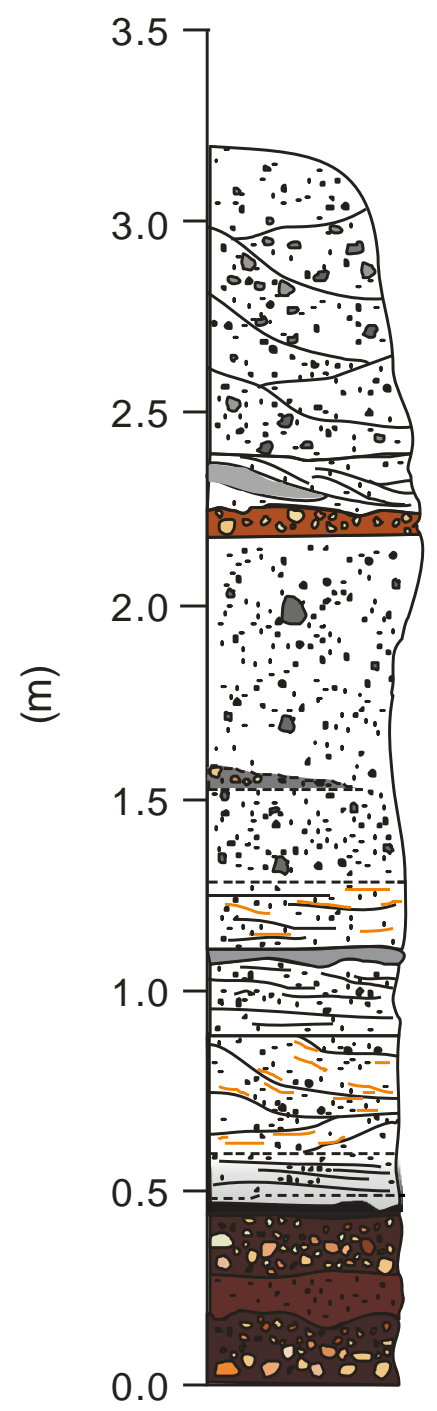

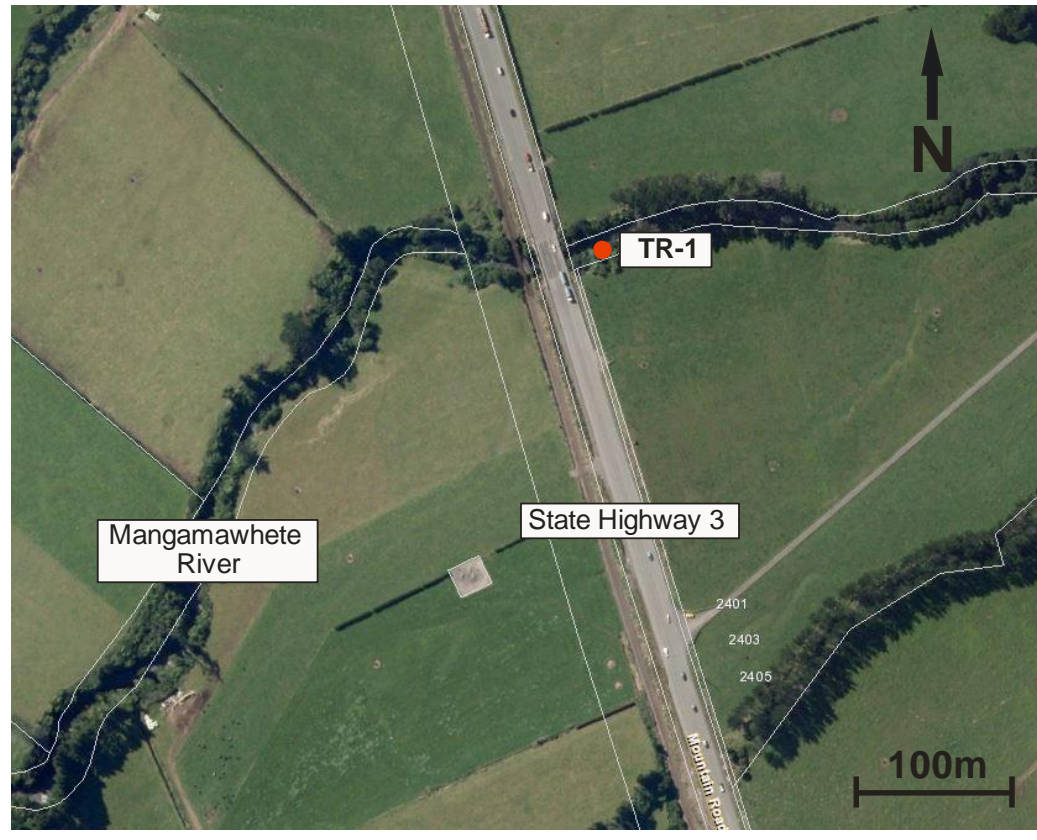

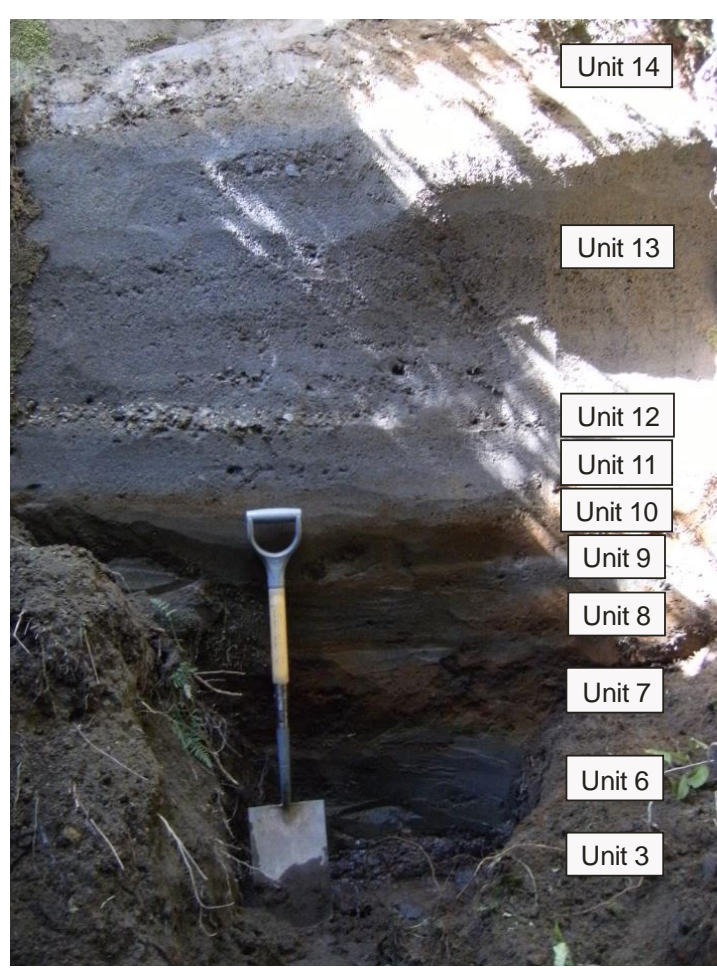

Figure 64 (Far Left): Stratigraphy of section $T R-1$

Figure 65: Photograph of section TR-1 with relevant lithostratigraphic units described in Appendix A. 


\subsection{Stratigraphy}

The stratigraphy described at Tariki-SH3 section (Appendix A) comprises $<3.0 \mathrm{~m}$ of pebbleand sand-rich deposits overlying a basal pumiceous lapilli sequence (Figure 65). Two cmscale pumiceous lapilli beds (TR-1, Units $1 \& 3$ ) are observed at the base of the section separated by a $\leq 0.1 \mathrm{~m}$ thick massive, dark brown, fine to coarse sandy silt (TR-1, Unit 2 ). The lower lapilli bed (TR-1, Unit 1 ) is a $<0.2 \mathrm{~m}$ thick, massive, normally graded, fine to medium pumiceous lapilli. The second lapilli bed (TR-1, Unit 3) is a $<0.15 \mathrm{~m}$ thick, massive, fine to coarse lapilli in a clayey silt matrix. This is overlain by $0.02 \mathrm{~m}$ thick, organic rich, dark brown silty clay (TR-1, Unit 4) (Figure 66).

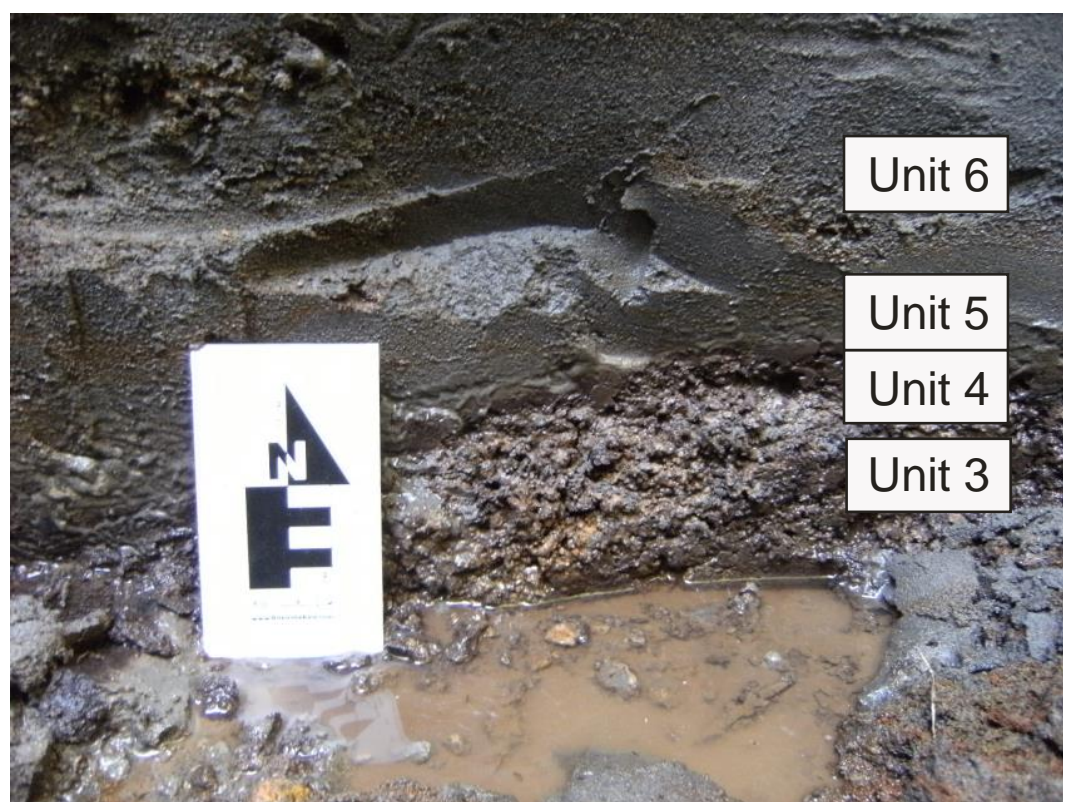

Figure 66: Photograph of the basal pumiceous lapilli and overlying organic-rich clay at section TR-1 with relevant lithostratigraphic units described in Appendix $A$. The arrow used for scale is $0.15 \mathrm{~m}$ long.

The basal pumiceous lapilli sequence is overlain by a $<0.03 \mathrm{~m}$ thick, massive, silty fine sand (TR-1. Unit 5) and $<0.7 \mathrm{~m}$ sequence of stratified/cross-stratified, fine to medium sand and channelised, fine to coarse pebbly sand (TR-1, Unit 6, $7 \& 8$ ). This sequence is overlain by a $<0.03 \mathrm{~m}$ thick, massive, silty fine sand (TR-1, Unit 9). This is subsequently overlain by $\leq 0.5 \mathrm{~m}$ of stratified, fine to medium sand (TR-1, Unit 10) vertically grading to massive, pebbly fine to medium sand (TR-1, Unit 11 \& 13), interbedded with a laterally discontinuous accumulation of fine to medium pumice clasts in a pebbly sand matrix (TR-1, Unit 12). Above this is a $<0.1 \mathrm{~m}$ thick, massive, fine to medium pumiceous lapilli in a silty sand matrix (TR-1, Unit 14) overlain by cross-stratified, fine to medium sand (TR-1, Unit 15) vertically grading to 
massive, channelised, alternating fine to coarse sand and fine to coarse, pebbly sand (TR-1, Unit 16). Approximately $10 \mathrm{~m}$ eastward of TR-1, Unit 16 is exposed as a massive, poorly sorted, clast-supported, gravel and cobble unit with a fine to coarse sand matrix.

\subsection{Tephrochronology}

The pumiceous lapilli beds exposed at the Tariki-SH3 section were correlated with the existing tephrostratigraphic record on the basis of stratigraphic association augmented by glass shard chemistry (Section B1, Appendix B). The two basal pumiceous lapilli beds (TR-1, Units 1 \& 3) are correlated with the Inglewood.a and Inglewood.b subunits of the Inglewood Tephra (c. 3,600 ${ }^{14} \mathrm{C}$ yrs B.P). The pumiceous lapilli at the top of the section (TR-1, Unit 14) within a silty sand matrix stratigraphically correlates with the tephra described at the top of the York Road (YR-2, Unit 2) and Vickers Quarry (VQ-1, Unit 15) sections.

\subsection{Interpretation}

The two basal pumiceous lapilli beds (TR-1, Units $1 \& 3$ ) are interpreted to be the Inglewood.a and Inglewood.b subunits of the Inglewood Tephra (c. 3,600 ${ }^{14} \mathrm{C}$ yrs B.P) separated by a paleosol (TR-1, Unit 2) based on relative stratigraphic position and field description. The Inglewood.a subunit is overlain by an organic rich, sandy silt paleosol (TR-1, Unit 4) (Figure 67) indicating a period of time between the Inglewood eruptive event and the emplacement of the overlying units.

The paleosol is overlain by a silty, fine sand layer (TR-1, Unit 5) interpreted to be a sole layer deposited by the wave of alluvial water pushed in front of the head of the next debris/hyperconcentrated flow (Figure 67). This vertically grades to stratified/low-angle cross-stratified to channelised, pebbly, fine to coarse sand units (TR-1, Units 6,7 \& 8)

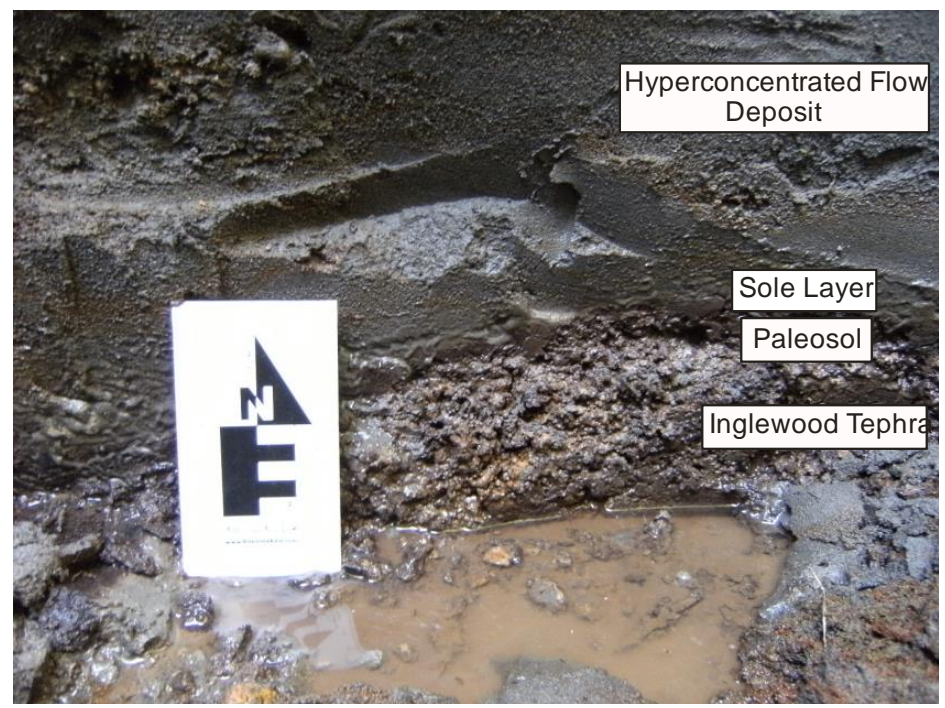

Figure 67: The interpretation of the lithostratigraphic units (Figure 66) at section TR-1. This section exposes the basal Inglewood Tephra overlain by the organic-rich paleosol. This is subsequently overlain by hypercocnentrated flow deposits of the Ngatoro Formation. 
interpreted to be hyperconcentrated flow deposits (Figure 68). This is subsequently unconformably overlain by a second silty, fine sand sole layer (TR-1, Unit 9). Above the second sole layer is a sequence of stratified, fine to medium sandy hyperconcentrated flow deposits (TR-1, Unit 10) vertically grading to the massive, fine to coarse, pebbly sand units (TR-1, Units 11 \& 13) interpreted to be debris flow deposits. These debris flow deposits are interbedded with a laterally discontinuous accumulation of pumiceous clasts (TR-1, Unit 12) (Figure 68).

The debris flow deposits are overlain by the massive, fine to medium, pumiceous lapilli (TR1, Unit 14) interpreted to be a pumiceous tephra which stratigraphically correlates with the tephra described at the top of the York Road (YR-2, Unit 2) and Vickers Quarry (VQ-1, Unit 15) sections. The silty, fine to medium sandy matrix is interpreted to be a paleosol indicating a period of time between the deposition of the tephra and the deposition of the overlying units. Above the tephra, the cross-stratified, fine to medium sand (TR-1, Unit 15) overlain by channelised, alternating pebbly, fine to coarse sand and gravelly, fine to coarse sand (TR-1, Unit 16) are interpreted to be hyperconcentrated flow deposits overlain by cut and fill debris flow deposits.

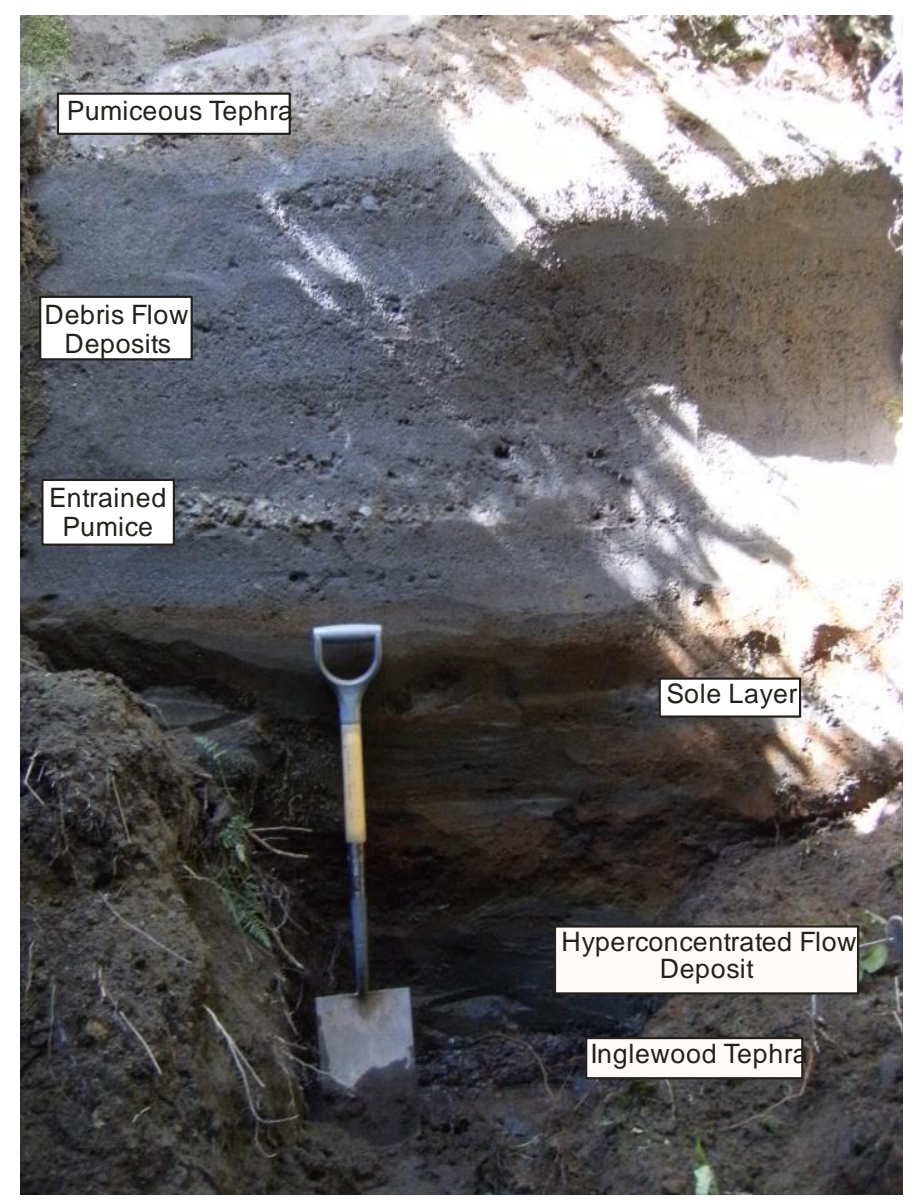

Figure 68: The interpretation of the lithostratigraphic units (Figure 65) at section TR-1. This section exposes hyperconcentrated flow deposits and debris flow deposits. Note the entrained pumice clasts and unknown pumiceous tephra at the top of the section. 


\section{Tariki Underpass (TU-1, TU-2, TU-3 and TU-4)}

The Tariki Underpass sections are located is $17.4 \mathrm{~km}$ east from the present-day summit of Egmont Volcano at the junction of Johns Road and SH3 (Figure 69). At this site four measured sections (Figure 71), and sampling for EMP analysis and grain size/shape analysis was carried out.

Figure 69: Aerial photograph showing the location of sections TU-1, TU-2, TU-3 and TU-4. Photo courtesy of Taranaki Regional Explorer (2014).
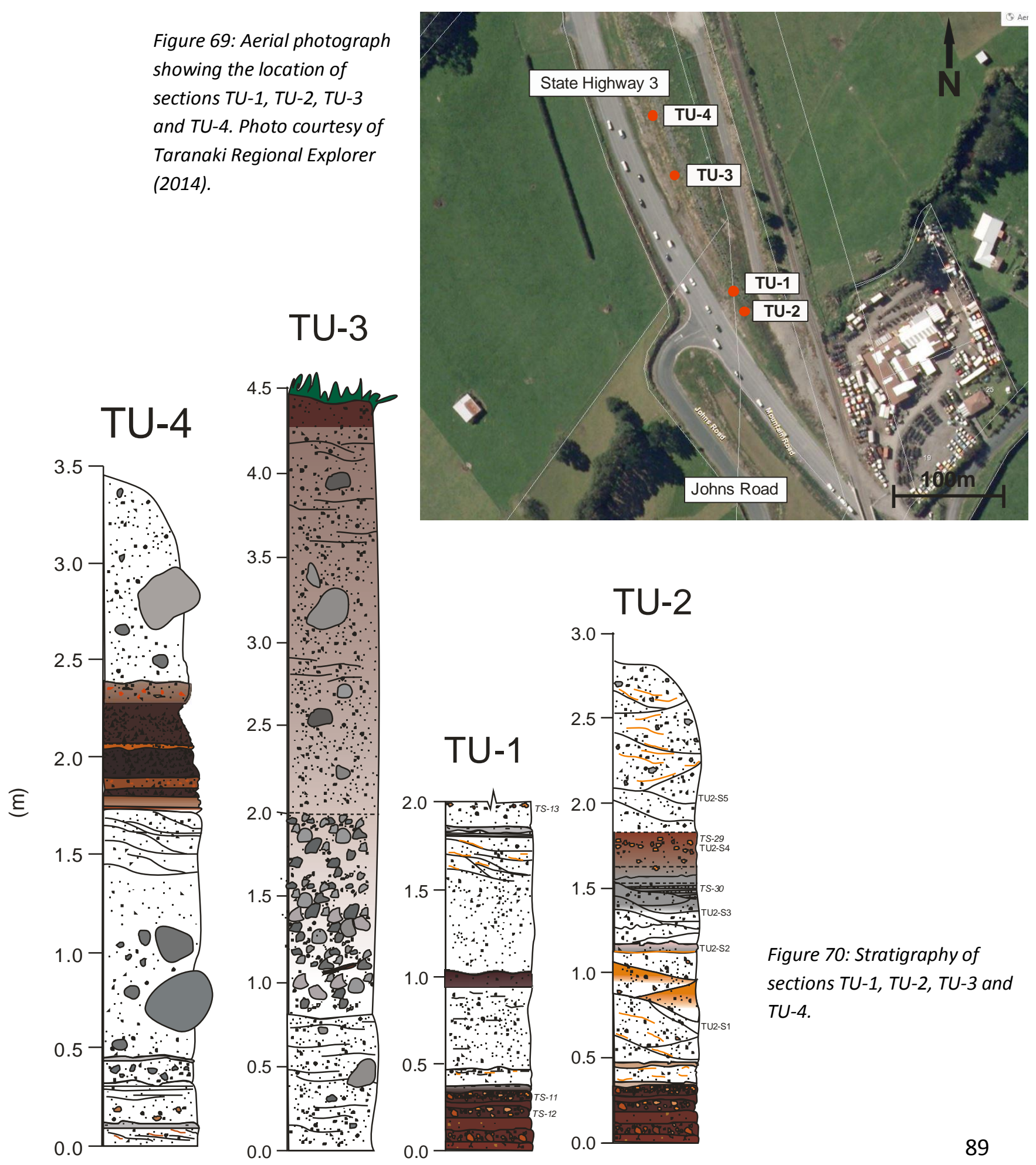

Figure 70: Stratigraphy of sections TU-1, TU-2, TU-3 and TU-4. 


\subsection{Stratigraphy}

The Tariki Underpass location exposes three distinct and stratigraphically variable sections (Appendix A) - TU-1 \& 2, TU-3 and TU-4 (Figure 69).

\section{Southern Sections (TU-1 and TU-2)}

The southern TU-1 and TU-2 sections expose three $\mathrm{cm}$-scale pumiceous lapilli beds with interbedded massive, dark brown, sandy/silty loam soils (TU-2, Units 1, 3 \& 5) (Figure 71). The first lapilli bed (TU-1, Unit 2; TU-2, Unit 2) is a $<0.07 \mathrm{~m}$ thick, massive, faintly normally graded, fine to coarse pumiceous lapilli in a coarse pumiceous sandy ash matrix. The second lapilli bed (TU-1, Unit 4; TU-2, Unit 4) is a $<0.07 m$ thick, massive, fine to coarse pumiceous lapilli and few pale grey fine to medium lithic lapilli in a dark brown silt/sand ash matrix. The third lapilli bed (TU-1, Unit 6; TU-2, Unit 6) is a $<0.05 m$ thick, massive, fine to coarse pumiceous lapilli.

Overlying the basal pumiceous lapilli sequence is a $<0.04 \mathrm{~m}$ thick, massive, well sorted silt with organic fragments (TU-1, Unit 7; TU-2, Unit 7) overlain by a $0.1 \mathrm{~m}$ thick, massive, fine sand with few pumiceous clasts and rip-ups of the underlying silt (TU-2, Unit 8). Approximately $1.0 \mathrm{~m}$ along section from TU-1, the $<0.04 \mathrm{~m}$ thick silt unit (TU-1, Unit 7) becomes deformed, forming convolute dewatering structures (Figure 71). Units $7 \& 8$ at section TU-2 is overlain by a $<0.02 \mathrm{~m}$ thick, massive silt (TU-2, Unit 9) and a $<0.7 \mathrm{~m}$ thick, $\mathrm{mm}$ to $\mathrm{cm}$-scale stratified and chanelised, fine to coarse sand with rare, medium pumiceous clasts (TU-2, Unit 10). Approximately $2.0 \mathrm{~m}$ along section from TU-1, the stratified sandy unit erodes down into the underlying sand units and pumiceous lapilli beds (TU-2, Units 1 to 9).

Overlying the stratified sandy unit (TU-2, Unit 10) is a $<0.05 \mathrm{~m}$ thick, massive, fine to medium sand vertically grading to silt (TU-2, Unit 11). This laterally transforms along section to massive, dark brown, organic rich sand with preserved leaf litter (TU-1, Unit 10) (Figure 72). This is overlain by a $<0.5 \mathrm{~m}$ thick, channelised lower to laminated upper, fine to coarse sand (TU-2, Unit 12). This unit exhibits sharp erosional scour features and silt rip-ups at the basal contact, flame dewatering structures within the lower part of the unit and vertically grades to a $<0.03 m$ thick, massive, fine sandy silt (TU-2, Unit 13) (Figure 73). This silt unit is overlain 
by a $<0.1 \mathrm{~m}$ thick, massive, medium sand with few pumiceous clasts (TU-2, Unit 14) vertically grading to a $<0.2 \mathrm{~m}$ thick, massive, abundant fine to coarse pumiceous clasts in a medium to coarse sand matrix (TU-2, Unit 15). The top of the sections comprise stratified and channelised, fine to coarse sand with some pebbles (TU-2, Unit 16).

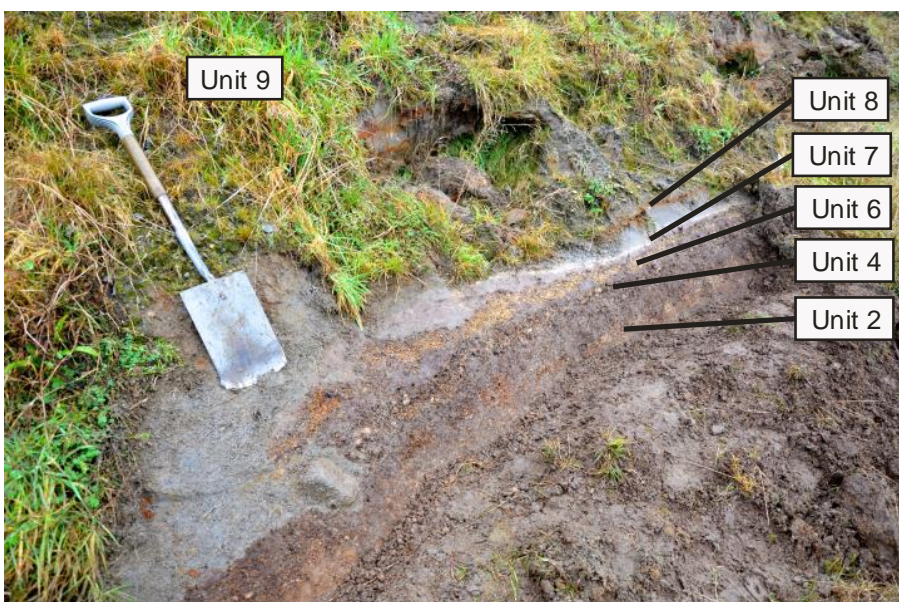

Figure 71 (Above): Photograph showing the basal pumiceous lapilli sequence at section TU-1 with relevant lithostratigraphic units described in Appendix A. Note the overlying deposits incised into the lapilli sequence. Photo courtesy of A/Prof Brent Alloway.

Figure 72 (Right): Photograph showing the organic-rich sand unit at section TU-1. Photo courtesy of A/Prof Brent Alloway.

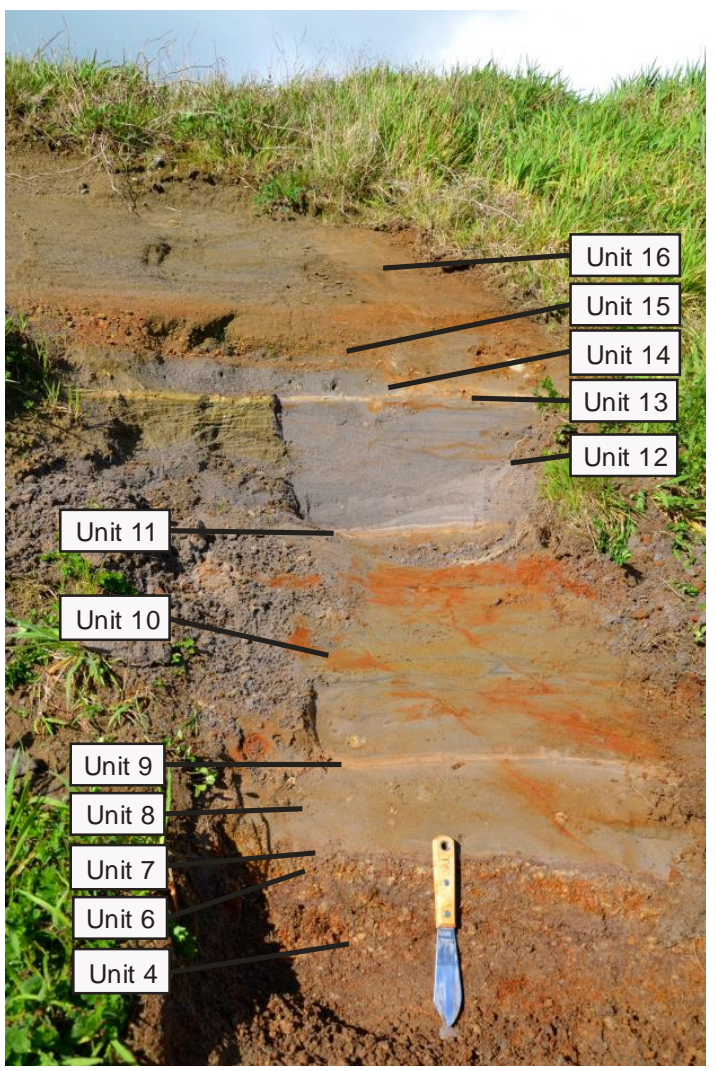

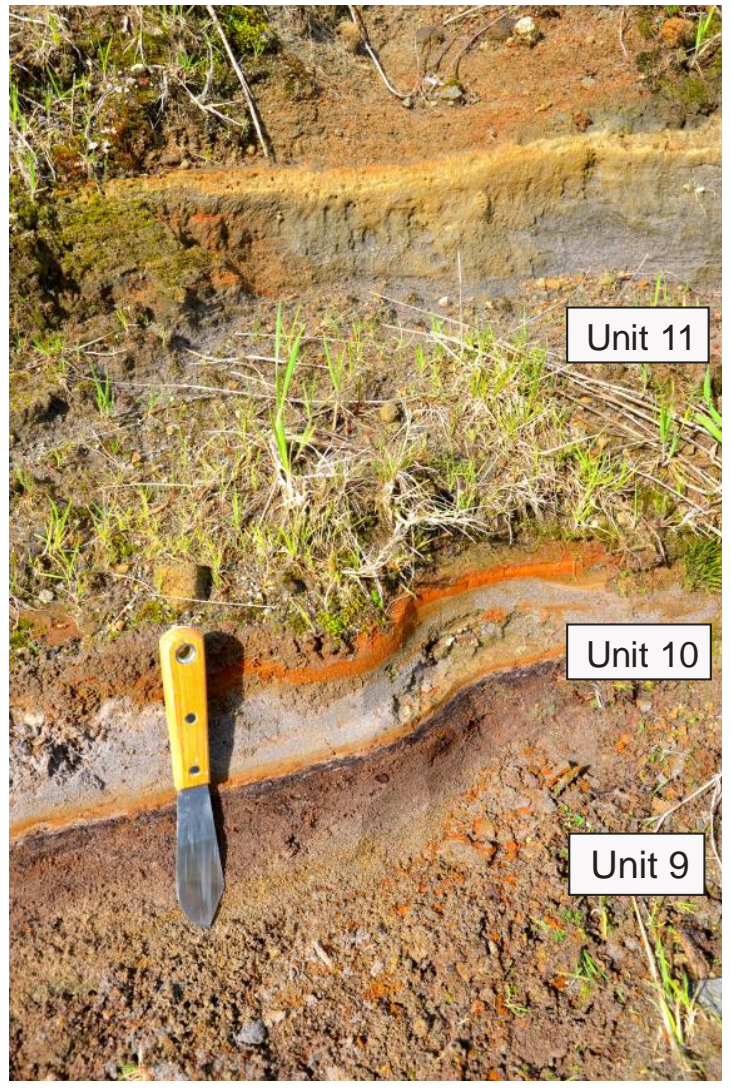

Figure 73 (Left): Photograph showing the stratified sandy units overlying the basal pumiceous lapilli sequence at section TU-2 with relevant lithostratigraphic units described in Appendix A. Photo courtesy of A/Prof Brent Alloway. 
Central Section (TU-3)

The central TU-3 section exposes a $<1.0 \mathrm{~m}$ thick, faintly $\mathrm{mm}$-to-cm scale stratified, poorly sorted, fine to coarse sand with some sub-angular to sub-rounded pebbles with rare boulders and wood fragments (TU-3, Unit 1). This is overlain by a $<1.2 \mathrm{~m}$ thick, massive, monolithologic, poorly sorted, fine to coarse pebbles and cobbles matrix supported in fine to coarse sand (TU-3, Unit 2) vertically grading to a $4.0 \mathrm{~m}$ thick, massive to faintly stratified, medium to coarse sand with some fine to medium pebbles and few boulders (TU-3, Unit 3). The top of the section is marked by the modern topsoil (TU-3, Unit 4) formed following the cutting and construction of the existing batter slopes.

\section{Northern Section (TU-4)}

The northern TU-4 section exposes a >0.1m thick, low angle cross-stratified, fine to coarse sand (TU-4, Unit 1) overlain by $0.02 \mathrm{~m}$ thick, massive silt with fibrous organic material (TU-4, Unit 2) (Figure 74). Above this is a $0.1 \mathrm{~m}$ thick, massive, medium to coarse sand with some coarse to very coarse pumiceous lapilli (TU-4, Unit 3) overlain by a $0.1 \mathrm{~m}$ thick, faintly stratified, fine to medium sand grading to fine to coarse sand (TU-2, Unit 4). Unconformably overlying the sandy unit is a massive, fine to coarse sandy, fine to medium pebbles with the upper boundary marked by a $0.02 \mathrm{~m}$ thick, massive, silt (TU-4, Unit 5). Above this a $1.3 \mathrm{~m}$ thick, massive, fine to medium sand with fine to coarse pebbles, some cobbles and boulders vertically grades to faintly cross-stratified, fine to medium sand (TU-4, Unit 6). The top of this unit is marked by massive silt.

Above the lower sandy units, TU-4 exposes a sequence of three cm-to-dm thick, basaltic, scoriaceous lapilli beds (TU-4, Units 8, $10 \& 12$ ) (Figure 74). The base of the sequence is marked by a $<0.1 \mathrm{~m}$ thick, massive, sandy silty soil (TU-4, Unit 7) overlain by the first $0.03 \mathrm{~m}$ thick lapilli bed (TU-4, Unit 8) comprised of massive, fine basaltic, scoriaceous lapilli. Overlying this is a $<0.1 \mathrm{~m}$ thick, massive, fine to medium sandy soil (TU-4, Unit 9) and the second $0.15 \mathrm{~m}$ thick, massive, fine, basaltic, scoriaceous lapilli (TU-4, Unit 10). The third lapilli bed (TU-4, Unit 12) is a $<0.2 \mathrm{~m}$ thick, massive, normally graded, fine to medium basaltic, scroiaceous lapilli with the upper $0.02 \mathrm{~m}$ marked by an orange iron pan. The third lapilli is subsequently overlain by a $<0.15 \mathrm{~m}$ thick, massive, fine sandy silt with lenses of clay (TU-4, Unit 13) then unconformably overlain by a $>1.1 \mathrm{~m}$ thick, massive, matrix supported, fine to 
coarse sand with fine to coarse pebbles, some cobbles and boulders (TU-4, Unit 14). The lower $0.2 \mathrm{~m}$ has rip-ups of silt with fibrous organics.

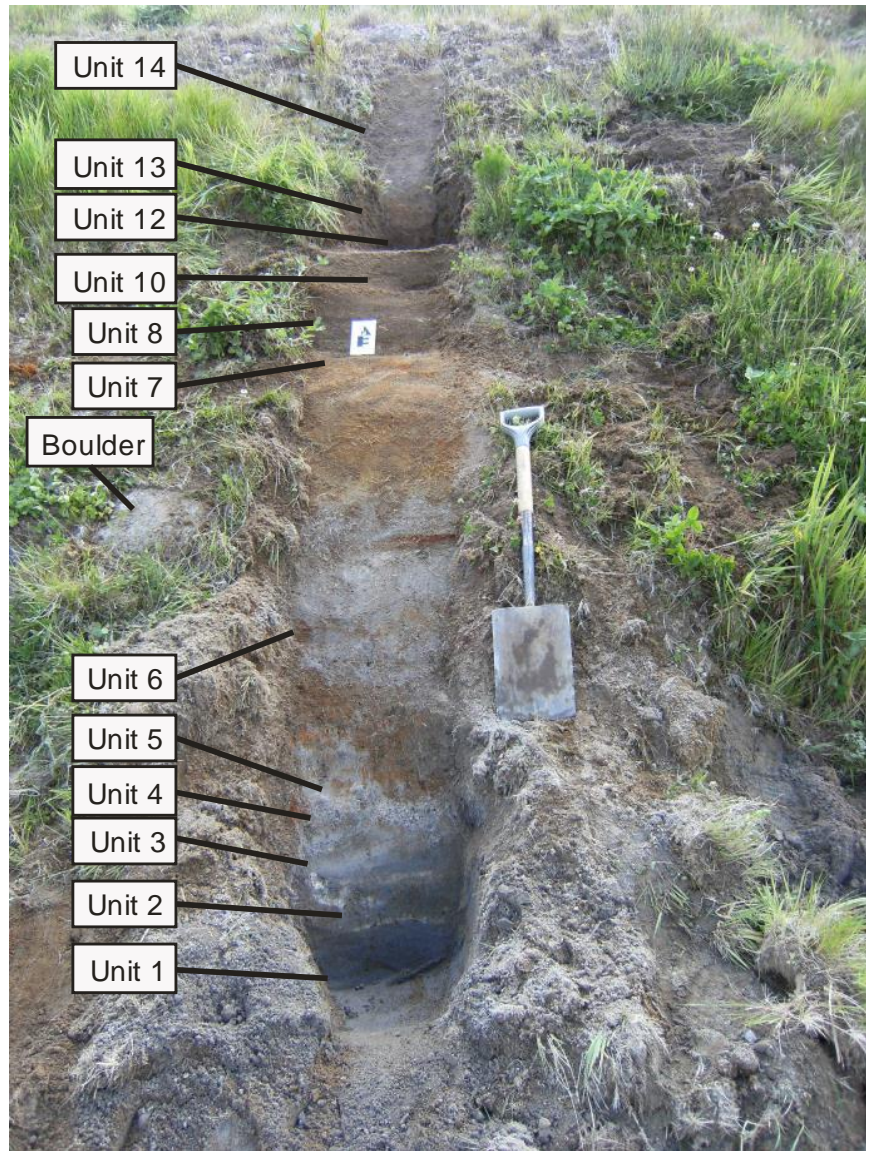

Figure 74 (Left): Photograph showing the three basaltic, scoriaceous lapilli beds overlying pebbly sand basal deposits at TU-4 with relevant lithostratigraphic units described in Appendix A.

\subsection{Tephrochronology}

Glass shards of the three pumecious lapilli beds at the base of TU-1 were analysed for major element composition and then correlated with the reference tephra dataset (Section B1, Appendix B) and stratigraphic logs published in Alloway et al (1995). Major element glass analyses from the first pumiceous lapilli bed (TU-1, TS-12) and second pumiceous lapilli bed (TU-1, TS-11) correlate with the lower and upper subunits (Inglewood.a and b, respectively) of Inglewood Tephra dated at c. 3,600 ${ }^{14}$ C yrs B.P (Alloway et al., 1995). The three basaltic, scoriaceous lapilli beds (TU-4, Units 8, 10 \& 12) stratigraphically correlate with the Manganui.a, Manganui, b and Manganui,c subunits of the Manganui Tephra dated at $c$. $3,100{ }^{14}$ C yrs B.P (Section 1: Alloway et al., 1995). 


\subsection{Sedimentology}

Sample TU2-S1 (TU-2, Unit 10) exhibits a single modal peak at $2.0 \phi$ to $2.5 \phi$, with a mean of $2.16 \phi$. The sample is poorly sorted $(S . D=1.20 \phi)$, strongly fine skewed $\left(\mathrm{SK}_{t}=0.70\right)$ and has a fine constituent of $6.89 \mathrm{wt} \%<4 \phi$. Sample TU2-S2 (TU-2, Unit 11) taken from the thin, fine sandy silt unit exhibits an asymmetric, single modal peak at $4.0 \phi$, with a mean of $4.49 \phi$. The sample is poorly sorted $(S . D=1.49 \phi)$, strongly fine skewed $\left(S_{\mathrm{t}}=0.99\right)$ and has a fine constituent of 53.97wt\% < 4\$. Sample TU2-S3 (TU-2, Unit 12) exhibits a well-defined, single modal peak at $2.0 \phi$ and has a mean of $2.02 \phi$. The sample is poorly sorted (S.D $=1.29 \phi)$, strongly fine skewed $\left(\mathrm{SK}_{\mathrm{t}}=0.65\right)$ and has a fine constituent of $7.90 \mathrm{wt} \%<4 \phi$. This sandy unit vertically grades to a pumice and sand unit where sample TU2-S4 (TU-2, Unit 15) exhibits a bimodal distribution with peaks at $-4.5 \phi$ and $2.0 \phi$, and a mean of $-0.31 \phi$. The sample is very poorly sorted $(S . D=3.02 \phi)$, strongly fine skewed $\left(S K_{t}=2.55\right)$ and has a fine constituent of $5.38 w t \%<4 \phi$. Sample TU2-S5 from the upper most unit (TU-2, Unit 16) exhibits a single, broad modal peak at $1.0 \phi$ and has a mean of $1.44 \phi$. The sample is poorly sorted (S.D = $1.33 \phi)$, strongly fine skewed $\left(\mathrm{SK}_{\mathrm{t}}=0.71\right)$ and has a fine constituent of $5.26 \mathrm{wt} \%<4 \phi$.

\subsection{Interpretation}

\section{Southern Sections (TU-1 and TU-2)}

The first basal pumiceous lapilli bed (TU-2, Unit 2) is interpreted to be the Korito Tephra (c. $4,100{ }^{14} \mathrm{C}$ yrs B.P) based on stratigraphic position. The overlying second and third lapilli beds (TU-2, Unit 4 \& 6) are interpreted to the Inglewood.a and Inglewood.b subunits of the Inglewood Tephra (c. 3,600 ${ }^{14} \mathrm{C}$ yrs B.P) (Figure 75) based on stratigraphic interpretation and geochemical composition. This is overlain by a massive, organic rich silt unit (TU-2, Unit 7) interpreted to be a sole layer deposited by the wave of alluvial water pushed in front of the head of the debris/hyperconcentrated-flow. This is overlain by a massive, fine sand unit with few fine pumice clasts (TU-2, Unit 8). This unit has an erosional lower contact with rip-ups of the underlying sole layer. Above this is a second massive silt unit (TUI-2, Unit 9) interpreted to be another sole layer (Figure 75). 


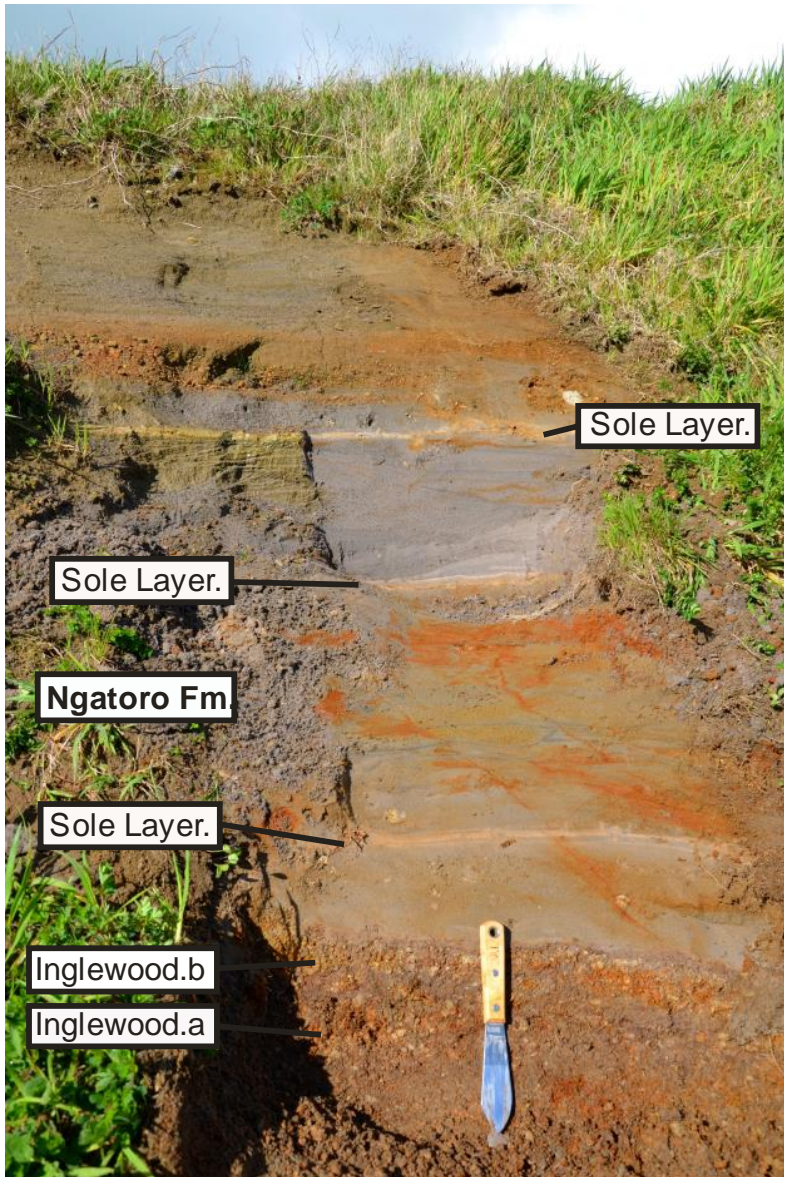

Figure 75: Interpretation of the lithostratigraphic units (Figure 73) at section TU-2. This section exposes sandy hypercocnentrated-flow deposits of the Ngatoro Formation overlying the Korito Tephra, and the Inglewood.a and Inglewood.b subunits. Note the three interbedded sole layers.

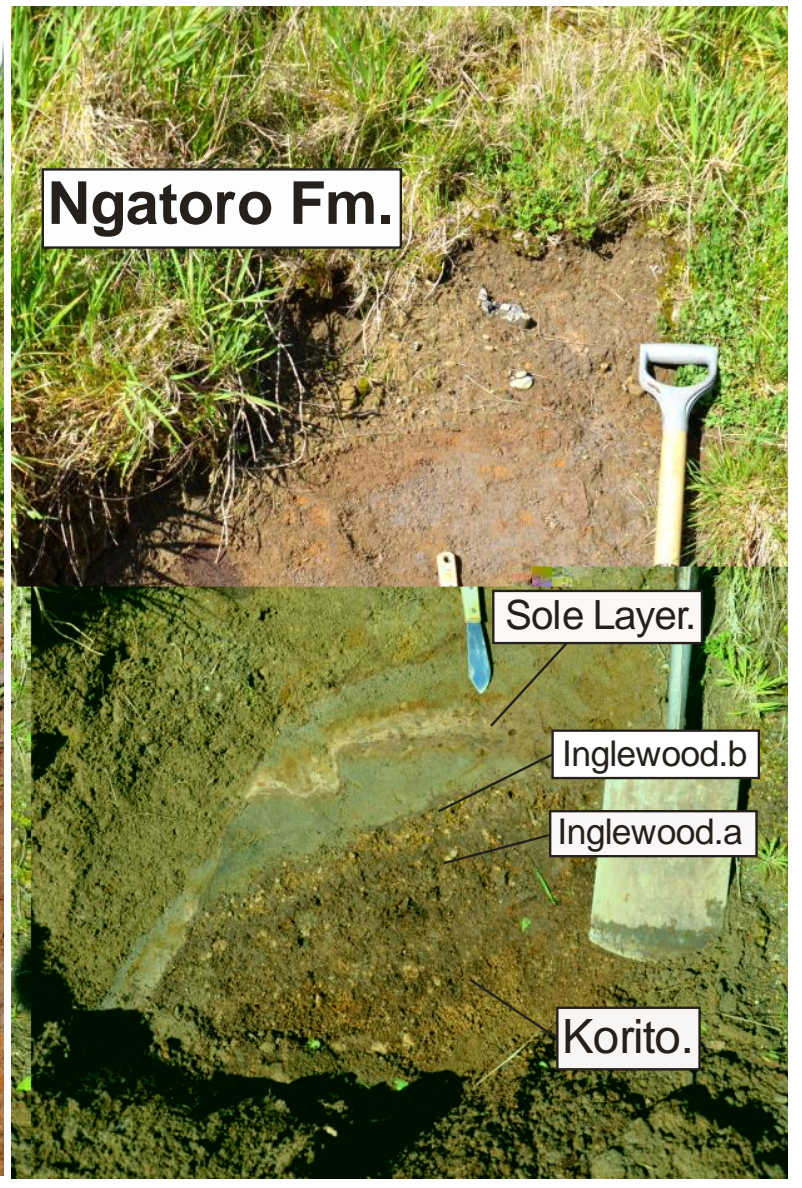

Figure 76: Interpretation of the lithostratigraphic units (Figure 71) at section TU-1. This section exposes load deformation of the sole layer and the incised hypercocnentrated-flow deposits of the Ngatoro Formation in to the basal lapilli. Photo courtesy of A/Prof Brent Alloway.

The overlying $<0.7 \mathrm{~m}$ thick sequence of stratified and channelised fine to coarse sand unit (TU-2, Unit 10) interpreted to be hyperconcentrated-flow deposits of the Ngatoro Formation. The deposition of this unit resulted in the deformation of the underlying sole layers forming convolute dewatering structures and the erosion of the underlying basal pumiceous lapilli beds (Figure 77). Above the hyperconcentrated-flow deposits, the massive, normally graded fine to medium sand to silt unit (TU-2, Unit 11) is interpreted to be a third sole layer which laterally transforms to an organic rich, sandy paleosol (TU-1, Unit 10). The overlying channelised to laminated fine to coarse sand unit (TU-2, Unit 12) is interpreted to a sequence of debris-flow deposits vertically grading to laminated hyperconcrated flow deposits. This unit has rip-ups of the underlying sole layer and flame dewatering structures (Figure 77) which develop as the flow transitions from a single phase debris flow to the two 
phased hyperconcentrated flow phase. This unit vertically grades to a massive, fine sandy silt unit (TU-2, Unit 13) interpreted to be a fourth sole layer.

The overlying, laterally discontinuous accumulation of pumice clast in a medium to coarse sand matrix (TU-2, Units 14 \& 15) are interpreted to be a pumice "train" deposited on the margins of the mass flow. This is subsequently overlain by stratified and channelised, fine to coarse sand with few pebbles (TU-2, Unit 16) interpreted to be hyperconcentrated flow deposits.

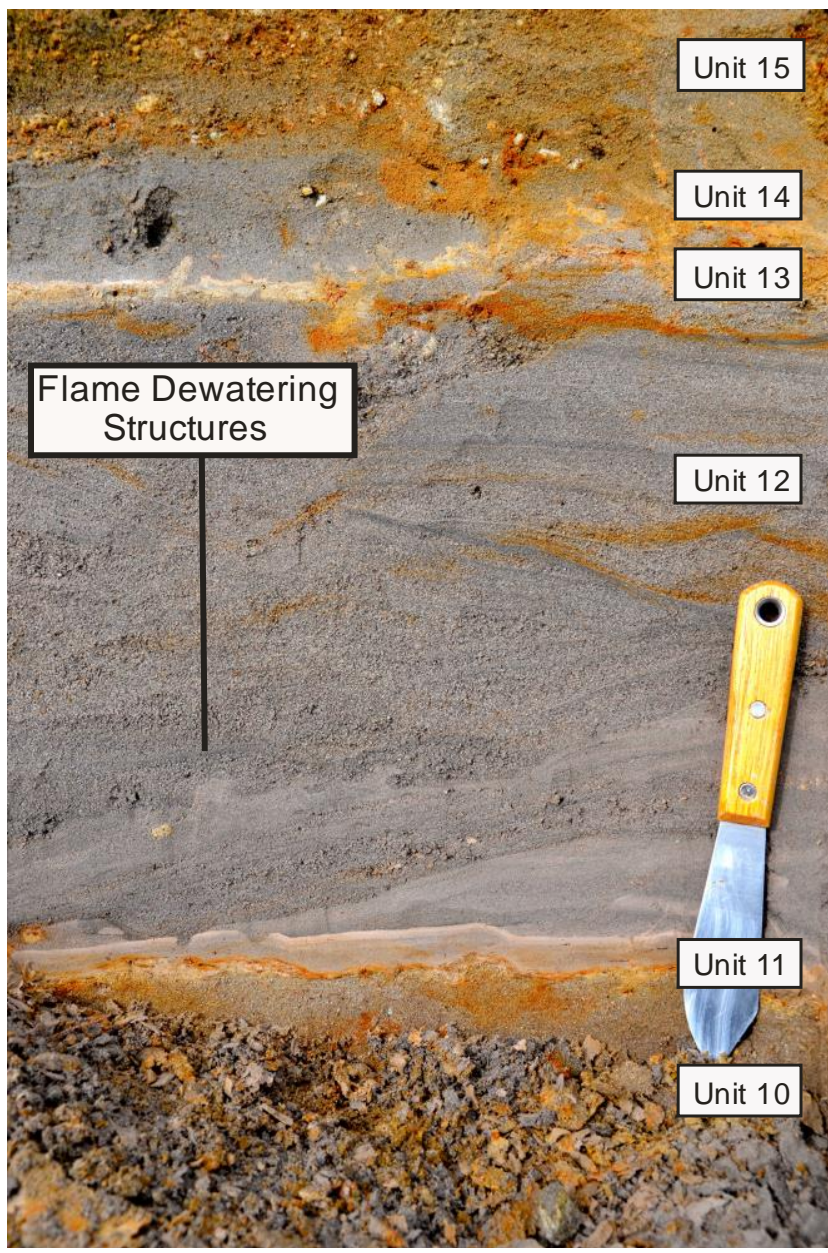

Figure 77: Photograph showing the flame dewatering structures in the hypercocnentrated flow deposits at section TU-1. Photo courtesy of A/Prof Brent Alloway.

\section{Central Section (TU-3)}

The lower faintly stratified, fine to coarse sandy unit with pebbles and rare boulders (TU-3, Unit 1) is interpreted to hyperconcentrated flow deposits based on the stratification formed indicative of a flow with a solid and fluid phase. This is unconformably overlain by a massive matrix supported pebble and cobble unit (TU-3, Unit 2) interpreted to be a debris flow deposit. This unit vertically grades to a massive to faintly stratified, medium to coarse sand 
unit with some gravel and few boulders (TU-3, Unit 4) is interpreted to be a

hyperconcentrated flow deposit with its upper contact forming the modern day topsoil (TU3, Unit 4).

\section{Northern Section (TU-4)}

The low angle cross-stratified, fine to coarse sand unit (TU-4, Unit 1) at the base of the section is interpreted to be a hyperconcentrated flow deposit overlain by a massive silt with some fine sand and fibrous organics (TU-4, Unit 2) interpreted to be a basal sole layer. Above this, a massive, medium to coarse sand unit with some pumiceous lapilli (TU-4, Unit 3) interpreted to be a debris flow deposit is unconformably overlain by faintly stratified sandy (TU-4) hyperconcentrated flow deposits. Overlying this is a massive, sandy pebble unit (TU-4, Unit 5) interpreted to a debris flow deposit with an upper contact marked by a second massive, silt sole layer.

Overlying the second sole layer is a $1.3 \mathrm{~m}$ thick, massive lower to stratified upper, fine to medium sand unit with common pebbles, some cobbles and few boulders (TU-4, Unit 6). This is interpreted to be a massive debris flow deposit vertically grading to stratified hyperconcentrated flow deposits. This is overlain by a sequence of three basaltic, scoriaceous lapilli beds (TU-4, Units 8, 10 \& 12) with interbedded silty, fine to medium sandy soils (TU-4, Units 7 \& 9) (Figure 78). The lapilli beds are interpreted to be the Manganui.a, Manganui.b and Manganui.c subunits of the Manganui Tephra (c. 3,100 ${ }^{14} \mathrm{C}$ yrs B.P) based on stratigraphic interpretation and field descriptions. These soils indicate a period of stability in the landscape between the Manganui.a and Manganui.b eruptive events. Above the Manganui.c lapilli is massive, fine sandy silt paleosol with lenses of clay (TU-4, Unit 13). This indicates a period of time between the Manganui.c eruptive event and the emplacement of the overlying massive, pebble, cobble and boulder unit (TU-4, Unit 14) interpreted to be a debris flow deposit.

The complex stratigraphic relationships between the stratigraphic sections at the Tariki Underpass makes correlation between stratigraphic units complicated. However the hyperconcentrated flow deposits (TU-2, Unit 10; TU-1, Unit 9) incising into the underlying basal lapilli beds indicates that an erosional channel is observed at this location with TU1 
and TU-2 indicating the southern margin, TU-3 indicating the axis and TU-4 indicating the northern margin of the mass flow channel.

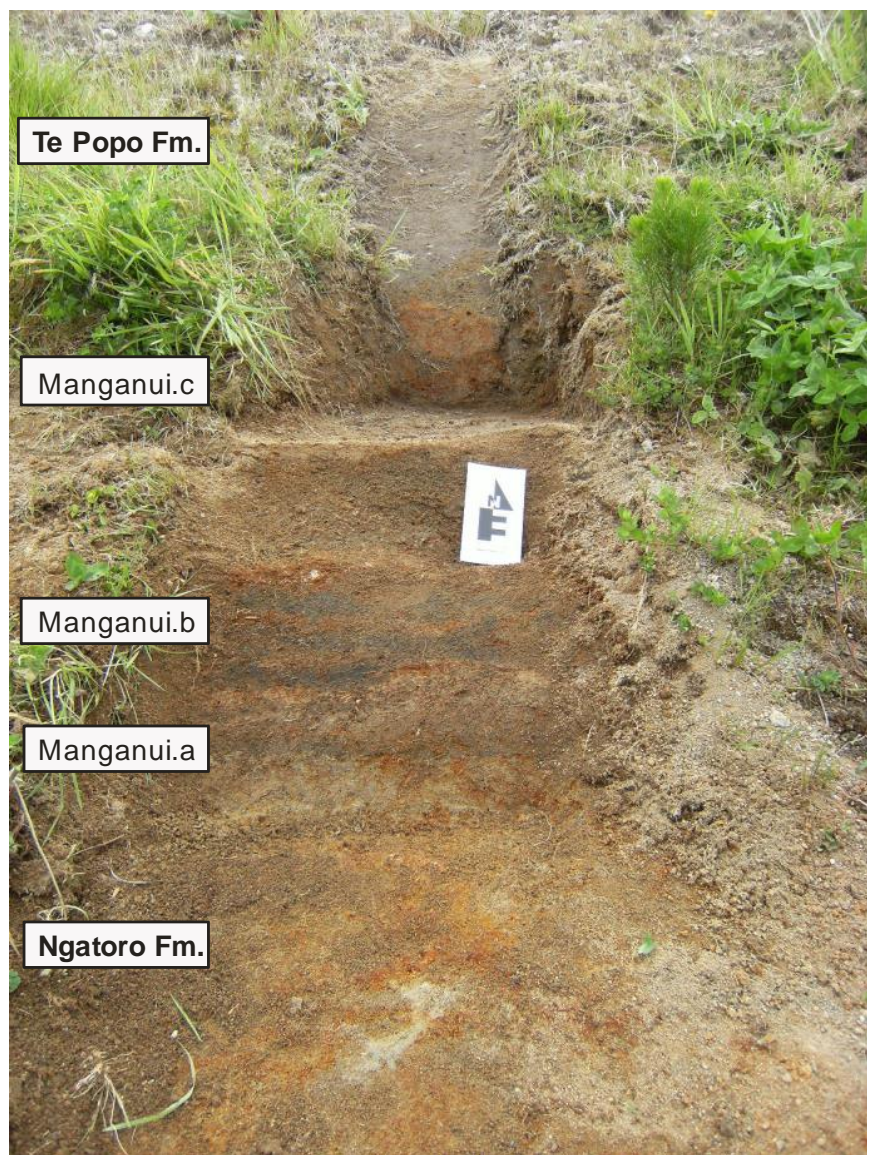

Figure 78: Interpretation of the lithostratigraphic units (Figure 74) at section TU-4. This section exposes the Manganui.a, Manganui.b and Manganui.c subunits overlying hyperconcentrated flow deposits of the Ngatoro Formation. 


\section{Suffolk Road Junction (SF-1)}

The Suffolk Road section is located $22.8 \mathrm{~km}$ north-east from the present-day summit of Egmont Volcano near the Waitepuke Stream Bridge (Figure 79). At this site one measured section (Figure 80) and sampling for EMP analysis was carried out.

Figure 79 (Right): Aerial photograph showing the location of section SF-1. Photo courtesy of Taranaki Regional Explorer (2014).

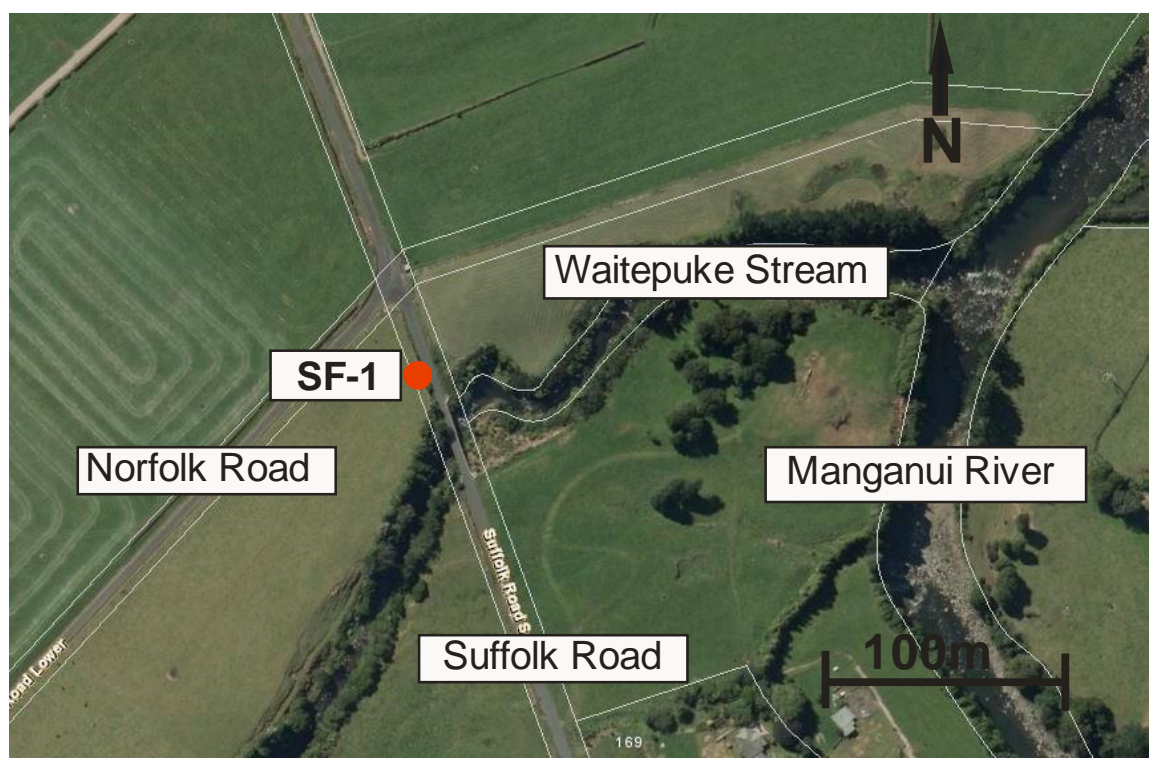

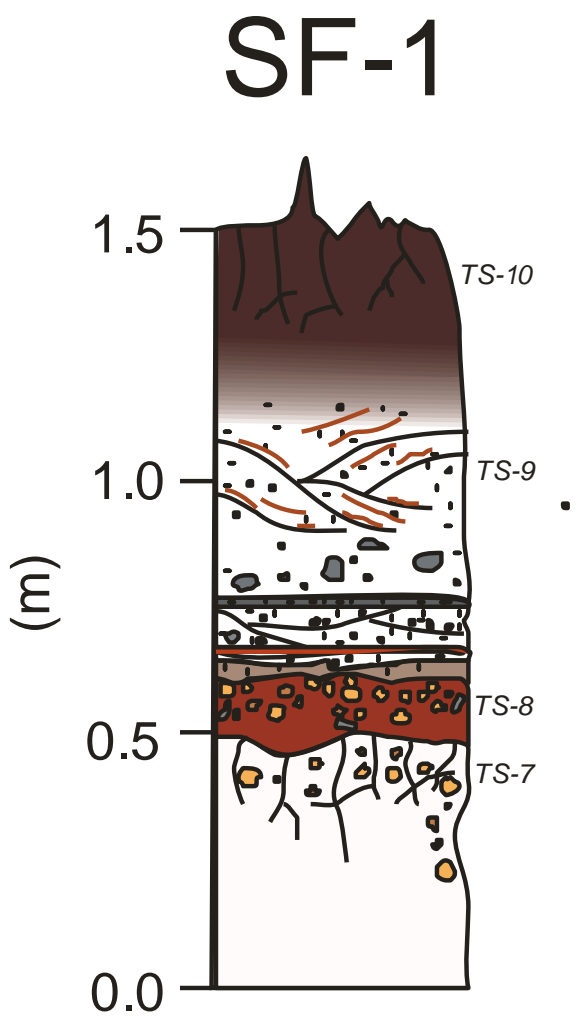

Figure 80: Stratigraphy of section SF-1.

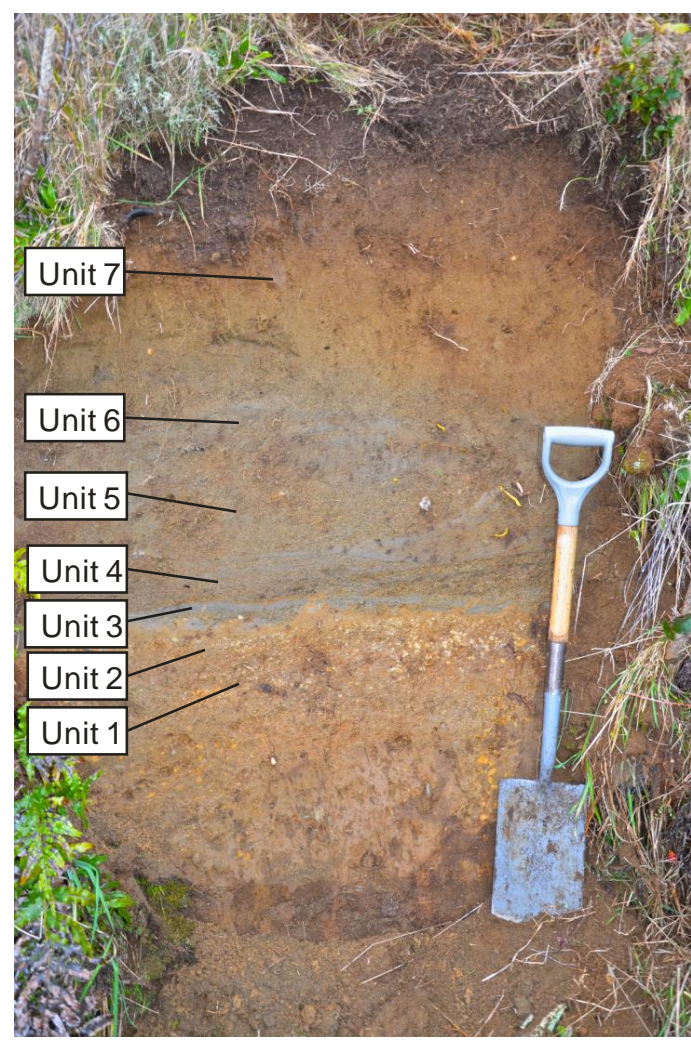

Figure 81: Photograph of section SF-1 with relevant lithostratigraphic units described in Appendix A. 


\subsection{Stratigraphy}

The stratigraphy described at Suffolk Road section (Appendix A) comprises $>1.0 \mathrm{~m}$ thick sand and pebbly sand deposits overlying a basal pumiceous lapilli sequence (Figure 81). The SF-1 section exposes two laterally continuous, $\mathrm{cm}$-scale pumiceous lapilli beds overlying $>0.3$ thick massive, firm, friable fine to medium sand and silt. The first pumiceous lapilli bed (SF1 , Unit 1 ) is a $<0.5 \mathrm{~m}$ thick, massive, firm and friable, fine to medium sand and silt with fine to coarse pumiceous lapilli and few lithic lapilli concentrated at the upper boundary. The second lapilli bed (SF-1, Unit 2) is a $\leq 0.1 \mathrm{~m}$ thick, massive, fine to coarse pumiceous lapilli with few fine to coarse lithic lapilli.

The basal tephra sequence is overlain by a lower unit comprising massive, fine sand that laterally pinches and swells (SF-1, Unit 3) (Figure 81). This is subsequently overlain by massive, fine to coarse sand with few pebbles grading to laminated, medium sand (SF-1, Unit 4) and channelised, fine to coarse sand with pumiceous and lithic clasts in the channels (SF-1, Unit 5). The lower unit is overlain by massive, fine to coarse sand with some fine to medium pebbles grading to channelised, stratified, fine to medium sand (SF-1, Unit 6).The top of the section is marked by massive, loamy fine sand (SF-1, Unit 7).

\subsection{Tephrochronology}

Glass shards of the two pumiceous lapilli beds and entrained pumice clasts from SF-1 were analysed for major element composition and then correlated with the reference tephra dataset (Section B1, Appendix B) and stratigraphic logs published in Alloway et al,. (1995). Major element glass composition from the first pumiceous lapilli bed (SF-1, TS-7) is indistinguishable from the Korito Tephra (c. $4,100{ }^{14} \mathrm{C}$ yrs B.P). The second lapilli bed (SF-1, TS-8) correlates with the Inglewood Tephra (c. 3,600 ${ }^{14} \mathrm{C}$ yrs B.P).

Pumice clasts sampled from within Unit 6 (SF-1, TS-9) have a broader range of major element compositions but are generally indistinguishable from the Inglewood Tephra (c. $3,600{ }^{14} \mathrm{C}$ yrs B.P). Pumice clasts sampled from within the soil in Unit 7 at the top of the section (SF-1, TS-10) has a well constrained major element composition indistinguishable from the Burrell Lapilli (A.D. 1655). 


\subsection{Interpretation}

The first basal pumiceous lapilli bed (SF-1, Unit 1) is interpreted to be the Korito Tephra (c. $4,100{ }^{14} \mathrm{C}$ yrs B.P) based on stratigraphic interpretation and geochemical composition. The vertical accumulation of pumiceous lapilli within the laterally continuous lapilli bed is most likely an in-filled tree root or a localised depression in the paleotopography. The second basal pumiceous lapilli bed (SF-1, Unit 2) is interpreted to be a distal deposit of the Inglewood Tephra (c. 3,600 ${ }^{14} \mathrm{C}$ yrs B.P). At these distal distances the Inglewood.a and Inglewood.b subunits have been described as merging into a single lapilli bed (Alloway et al., 1995). A thin bed of reddish brown andic soil seperates the Korito and Inglewood Tephra distinguishing the eruptive events both stratigraphically and temporally. Constrained by the basal tephra (Figure 83), the overlying deposits are interpreted to have a maximum age of $c$. $3,600{ }^{14} \mathrm{C}$ yrs B.P.

The $<0.05 \mathrm{~m}$ thick, fine sand bed (SF-1, Unit 3) is interpreted to be a fine grained sole layer deposited by the wave of alluvial water pushed in front of the head of the debris/hyperconcentrated flow. The overlying lower sandy deposits (SF-1, Unit 4) are interpreted to be an erosional cut and fill debris flow deposit vertically grading to laminated hyperconcentrated stream flow deposits indicating a transition from en masse sediment deposition to grain by grain deposition from a solid and liquid phased flow. The overlying massive, poorly sorted, pebbly sand (SF-1, Unit 5) is interpreted to be a fine textured distal debris flow deposit vertically grading to channelised to laminated hyperconcentrated flow deposits (SF-1, Unit 6). The basal Inglewood Tephra, and entrained pumice clasts sourced from the Inglewood Tephra, indicates that Units 3 to 6 are distal deposits of the Ngatoro Formation (Figure 82). The pumice clasts within the soil at the top of the section (SF-1, Unit 7) geochemically correlated with the Burrell Lapilli gives a minimum age of the underlying deposits of 1600 A.D. When compared to the reference stratigraphy (Alloway et al., 1995) several tephra were not identified at the Suffolk Road section (eg. Manganui and Maketawa Tephras). This could be due to deposition then subsequent erosion or that these distal tephra have been dispersed by biological agents (vegetation and/or invertebrate insects) in the andic soil coverbeds and are no longer recognisable as discrete layers. 


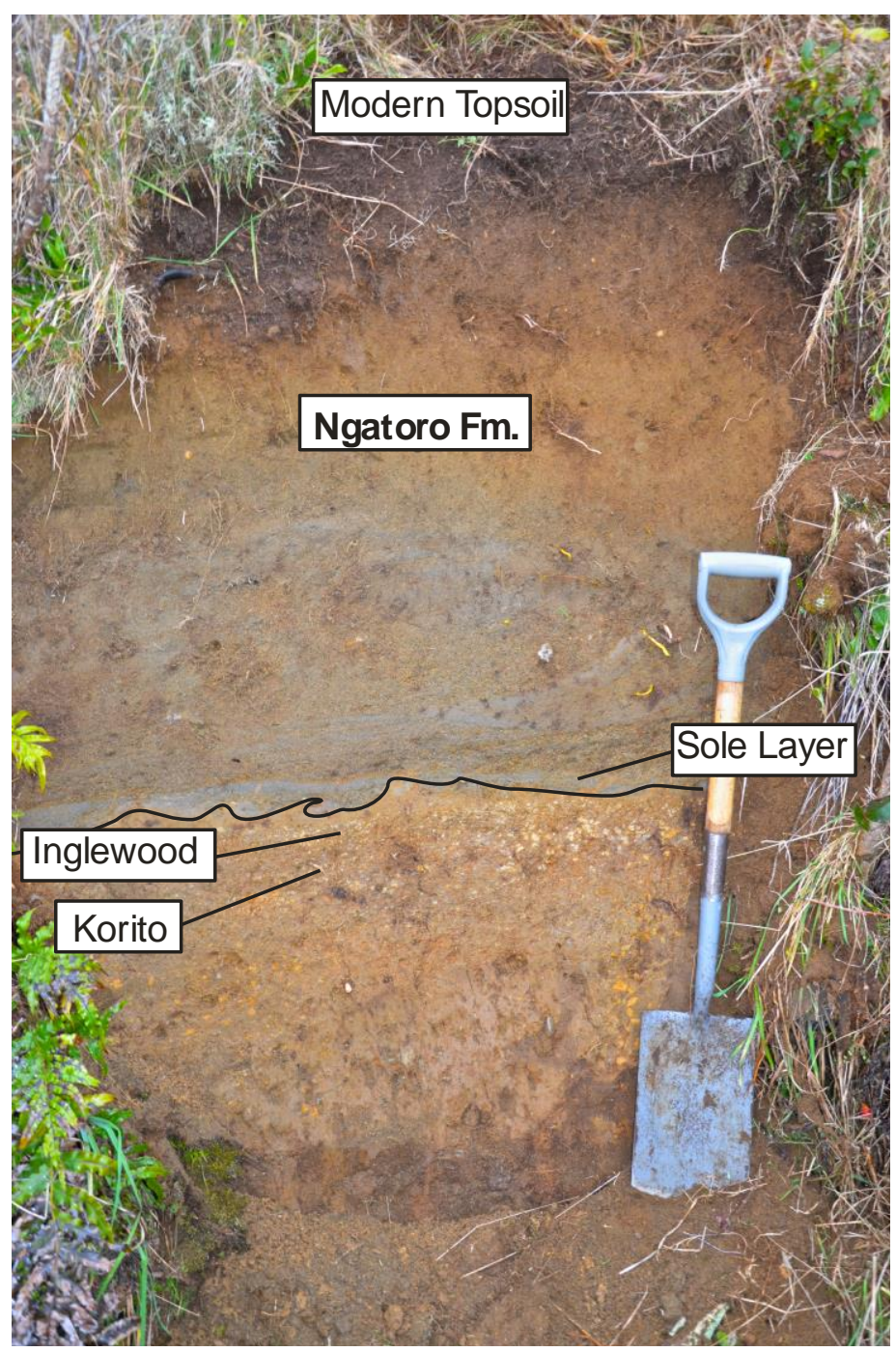

Figure 82: Interpretation of the lithostratigraphic units (Figure 81) at section SF-1. This section exposes sandy hypercocnentrated flow and pebbly sand debris flow deposits of the Ngatoro Formation overlying the Korito and Inglewood Tephra. 


\section{Kaimata Sawmills (MG-1)}

The Kaimata Sawmills section is located $23.8 \mathrm{~km}$ north-east from the present-day summit of Egmont Volcano on the banks of the Manganui River (Figure 83). At this site one measured section (Figure 84), and sampling for EMP analysis and grain size analysis was carried out.

Figure 83 (Right): Aerial photograph showing the location of section MG-1. Photo courtesy of Taranaki Regional Explorer (2014).

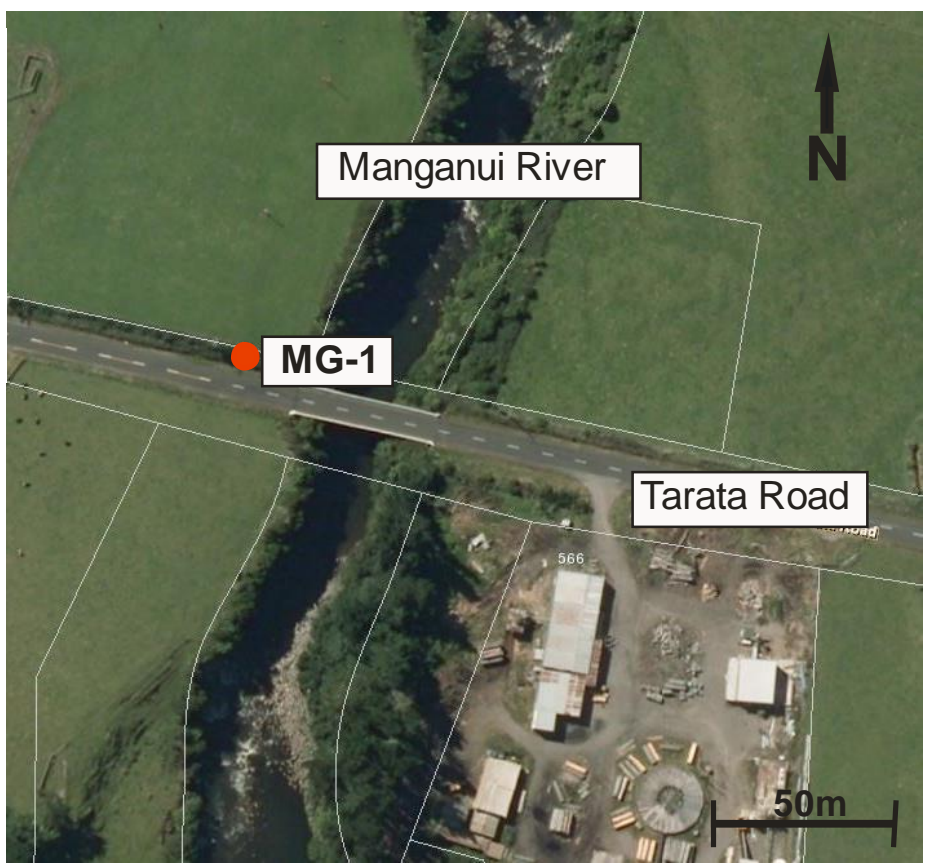

MG-1
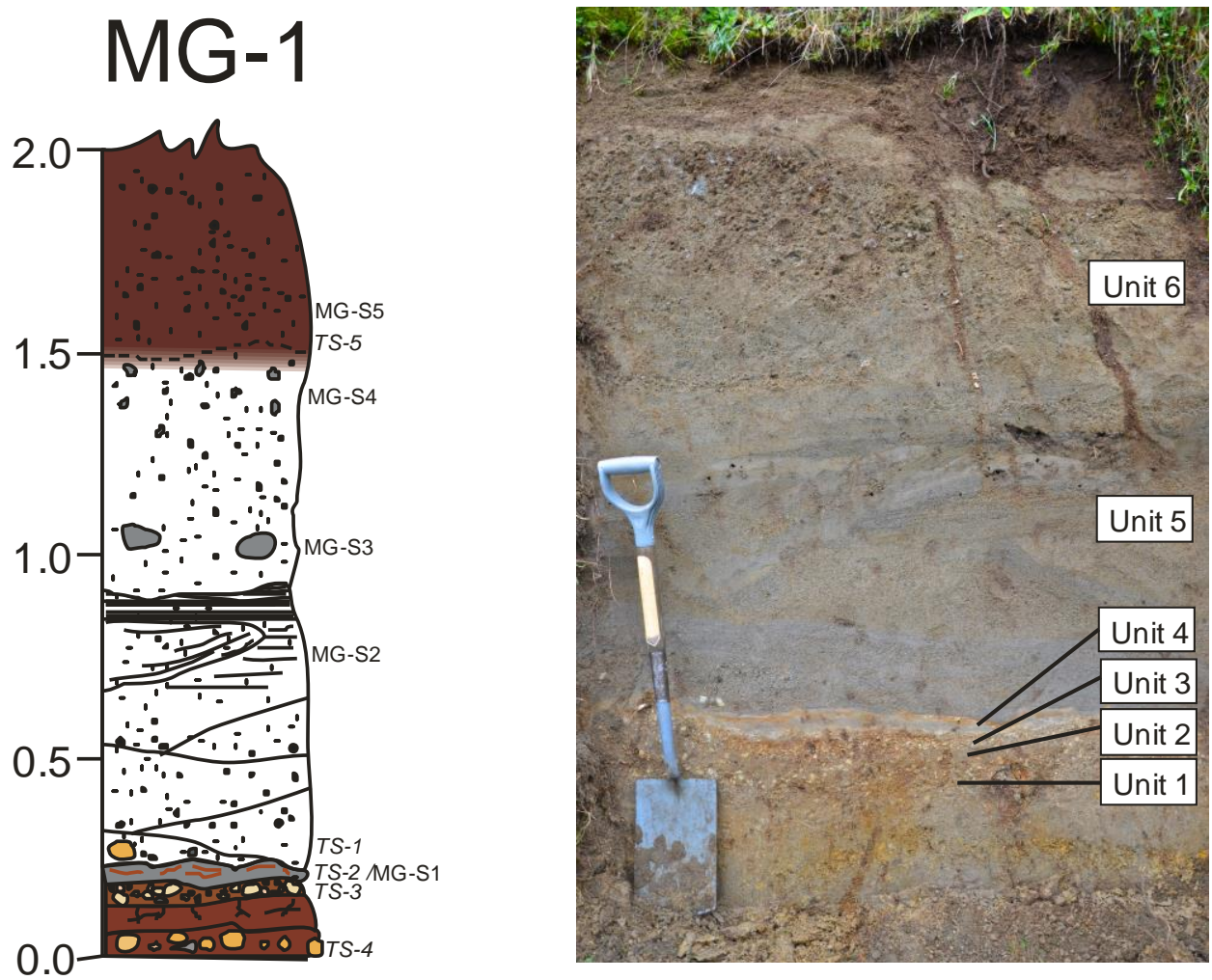

Figure 84: Stratigraphy of section MG-1.

Figure 85: Photograph of section MG-1 with relevant lithostratigraphic units described in Appendix A. 


\subsection{Stratigraphy}

The stratigraphy described at Kaimata Sawmills section (Appendix A) comprises $>1.5 \mathrm{~m}$ thick sand and pebbly sand deposits overlying a basal pumiceous lapilli sequence (Figure 85 ). The MG-1 section exposes two cm-scale, pumiceous lapilli beds (MG-1, Units 1 \& 3 ) separated by a $<0.05 \mathrm{~m}$ thick, massive, loamy silt (MG-1, Unit 2) (Figure 86). The lower lapilli bed (MG-1, Unit 1 ) is a $<0.1 \mathrm{~m}$ thick, massive, fine to coarse pumiceous lapilli and very fine to fine lithic lapilli in an ash matrix. The second lapilli bed (MG-1, Unit 3) is a $\leq 0.05 \mathrm{~m}$ thick, massive, fine to coarse pumiceous lapilli and few fine lithic lapilli in a fine ash matrix.

These pumiceous lapilli beds are overlain by a $<0.05 \mathrm{~m}$ thick, massive, fine sand and silt vertically grading to silt (MG-1, Unit 4) (Figure 86). This is subsequently overlain by a $0.7 \mathrm{~m}$ thick sequence of alternating channelised, fine to coarse sand and very fine to fine sand vertically grading to laminated, fine to very coarse sand (MG-1, Unit 5). The lower sandy deposits are overlain by a $1.0 \mathrm{~m}$ thick unit (MG-1, Unit 6) comprising massive, medium to coarse sand with few pebbles vertically grading to massive, medium to coarse sandy pebble deposits and fine to very coarse sand. This unit is gradationally overlain by massive, friable, fine to very coarse sand (MG-1, Unit 7).

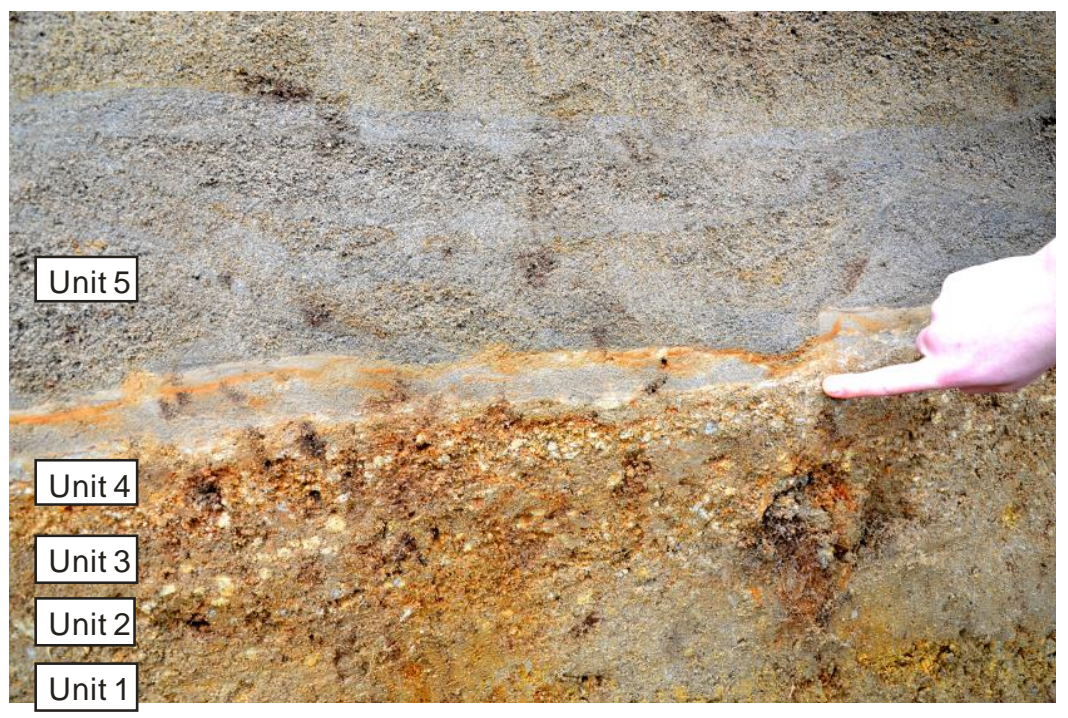

Figure 86: Photograph showing the basal pumiceous lapilli sequence at section MG-1 with relevant lithostratigraphic units described in Appendix A. 


\subsection{Tephrochronology}

Glass shards of the two basal lapilli beds at the base and three samples from within the sandy deposits at MG-1 were analysed for major element composition and then correlated with the reference tephra dataset (Section B1, Appendix B) and stratigraphic logs published by Alloway et al., (1995). Major element glass analysis from the first pumiceous lapilli bed (MG-1, TS-4) is indistinguishable from those determined for the Korito Tephra (c. 4,100 ${ }^{14} \mathrm{C}$ yrs B.P). The second lapilli bed (MG-1, TS-3) can be geochemically correlated with the Inglewood Tephra (c. 3,600 ${ }^{14} \mathrm{C}$ yrs B.P). Pumice clasts sampled from the basal silt layer, Unit 4 (MG-1, TS-2) and lower unit sandy deposits, Unit 5 (MG-1, TS-1) can be geochemically correlated with the underlying Inglewood Tephra. Pumice clasts sampled from the upper fine to very coarse sandy deposits, Unit 7 (MG-1, TS-5) has a broader major elemental composition but can be correlated with the underlying Inglewood Tephra (c. 3,600 ${ }^{14} \mathrm{C}$ yrs B.P).

\subsection{Sedimentology}

Sample MG-S1 (MG-1, Unit 4) exhibits a single modal peak at 3.0 $\phi$ and has a mean of 3.23 $\phi$. The sample is poorly sorted $(S . D=1.41 \phi)$, strongly fine skewed $\left(\mathrm{SK}_{t}=0.82\right)$ and has a fine constituent of $20.17 w t \%<4 \phi$. Sample MG-S2 taken from the first sand and pebbly sand unit (MG-1, Unit 5) exhibits a broad, single modal peak from 1.0 $\phi$ to $2.0 \phi$ and has a mean of $1.53 \phi$. The sample is poorly sorted $(S . D=1.59 \phi)$, strongly fine skewed $\left(\mathrm{SK}_{t}=0.62\right)$ and has a fine constituent of $7.69 w t \%<4 \phi$. Sample MG-S3 (MG-1, Unit 6) exhibits a broad, single modal peak at $1.0 \phi$ with a mean of $0.96 \phi$. The sample is very poorly sorted $(S . D=2.01 \phi)$, strongly fine skewed $\left(\mathrm{SK}_{\mathrm{t}}=0.64\right)$ and has a fine constituent of $6.93 \mathrm{wt} \%<4 \phi$. This vertically grades to sample MG-S4 (MG-1, Top of Unit 6) which exhibits a bimodal distribution with peaks at $-2.5 \phi$ and $1.0 \phi$, and a mean of $-0.24 \phi$. The sample is very poorly sorted (S.D = $2.50 \phi)$, strongly fine skewed $\left(\mathrm{SK}_{t}=1.17\right)$ and has a fine constituent of $4.79 \mathrm{wt} \%<4 \phi$. Sample MG-S5 taken from the top of the section (MG-1, Unit 7) exhibits a well-defined, single modal peak at $2.5 \phi$ and has a mean of $1.10 \phi$. The sample is poorly sorted ( $S . D=1.40 \phi)$, strongly fine skewed $\left(\mathrm{SK}_{\mathrm{t}}=0.80\right)$ and has a fine constituent of $4.12 \mathrm{wt} \%<4 \phi$. 


\subsection{Interpretation}

The two basal pumiceous lapilli beds (MG-1, Unit $1 \& 3$ ) are correlated with Korito Tephra (c. $4,100{ }^{14} \mathrm{C}$ yrs B.P) and Inglewood Tephra (c. 3,600 ${ }^{14} \mathrm{C}$ yrs B.P) based on stratigraphic association and confirmed by the reference dataset (Section B1, Appendix B). The interbedded loamy silt represents a period of andic soil formation and site stability. The basal pumiceous lapilli beds constrain the base of section (MG-1) to a maximum age of C. 3,600 ${ }^{14} \mathrm{C}$ yrs B.P. with the overlying Units 5,6 and 7 being interpreted as the Ngatoro Formation.

The base of the Ngatoro Formation is marked by massive, fine sandy silt (MG-1, Unit 4) unconformably overlying the Inglewood Tephra. This unit is interpreted to be a basal sole layer deposited by the wave of alluvial water pushed in front of the head of the debris/hyperconcentrated flow. The lowermost sandy deposits of the Ngatoro Formation (MG-1, Unit 5) are interpreted to be hyperconcentrated flow deposits based on the cut and fill, and laminated sedimentary structures within the fine grained sandy deposit indicative of flows with both a solid and fluid phase. The vertical transition from cut and fill structures to laminations indicate transformation to a higher flow regime. The overlying units $6 \& 7$ are interpreted to be distal debris flow deposits with a dominantly massive, sandy texture.

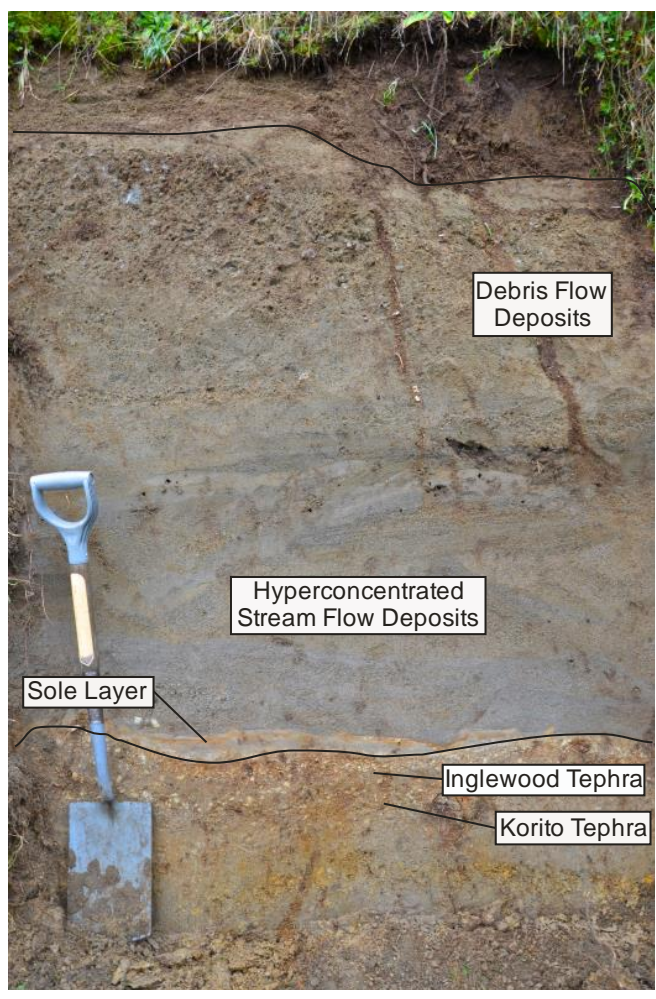

Figure 87: Interpretation of the lithostratigraphic units (Figure86) at section MG-1. This section exposes hyperconcentrated flow and debris flow deposits. 


\section{Palaeomagnetic Analysis}

The following section presents the results of the magnetic susceptibility and thermal demagnetisation studies carried out on andesite clasts sampled at Vickers Quarry and Surry Road Quarry.

- Preliminary Investigation (VQ-1, Unit 6)

- Main Lower Unit Investigation (VQ-1, Unit 6 and SQ-1, Unit 1)

- Preliminary Upper Unit Investigation (VQ-1, Unit 12)

This includes identification and calculation of distinct components of natural remanent magnetisation (NRM) by principal component analysis (PCA) of progressive specimen demagnetisation data, averaging these components by clast and estimation of emplacement temperatures. Full specimen analysis with relevant Zijderveld plots and plots of magnetisation intensity versus temperature are presented in Appendix D.

\subsection{Preliminary Investigation}

The preliminary alternating field demagnetisation investigations show the andesite clasts having a strong, stable remanent magnetisation suitable for palaeomagnetic studies, with intensities ranging from 5.43 to $9.28 \mathrm{~A} / \mathrm{m}$. Throughout the demagnetisation, specimen VQ2$3 C$ exhibits a north east $\left(D=66.0^{\circ}\right)$ and downward $\left(I=20.8^{\circ}\right)$ trending component of magnetisation with a Maximum Angular Deviation (MAD) of $2.0^{\circ}$ (Figure 88). Specimens VQ3-1C and VQ3-2B exhibit a north and downward component. All three specimens showed a slight deviance from the ChRM at low field strength demagnetisation steps (NRM and $5 \mathrm{mT}$ ) but this can be attributed to a viscous component rather than a secondary component of magnetisation formed during emplacement. These results (being alternating field demagnetisation) do not give any direct indication of thermal history or emplacement temperature, but they do suggest a simple emplacement history. 

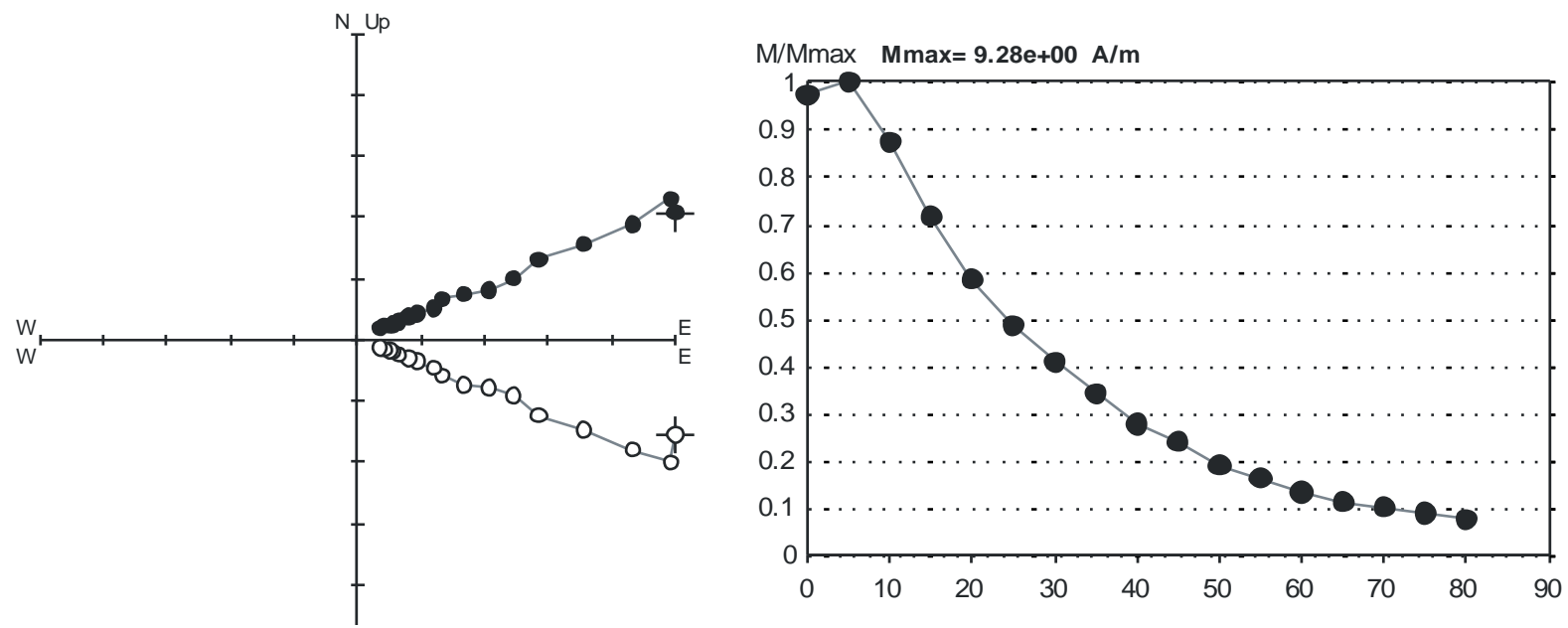

Figure 88: Zijderveld diagram and magnetic intensity plots showing the demagnetisation of specimen VQ2-3C. The specimen exhibits a single component of magnetisation. 


\subsection{Main Lower Unit Investigation (S3, S4, S5, S7, S10, S11, S12 \& S14)}

\subsubsection{Magnetic Susceptibility}

The magnetic susceptibility with temperature measurements indicate that the ferrimagnetic minerals in the sample (S10.3, S11.2 and S12.1)lose their magnetic susceptibility by $550^{\circ} \mathrm{C}$ suggesting curie temperatures in the order of $550^{\circ} \mathrm{C}$ and a composition within the titanomagnetite series $\left(20 \% \mathrm{Fe}_{3} \mathrm{O}_{4}\right.$ to $\left.80 \% \mathrm{Fe}_{2} \mathrm{TiO}_{4}\right)$ (Butler, 2004). The results of temperature susceptibility analysis are presented in Section D1, Appendix D. The room temperature magnetic susceptibility results cluster into four distinct susceptibility groups centred around 0.065-0.1 SI, 0.06 SI, 0.4 SI and 0.002 SI (Figure 89). Although there is a range between specimens, there are no significant changes in room temperature magnetic susceptibility over the thermal demagnetisation temperature range $\left(0-550^{\circ} \mathrm{C}\right)$. This suggests no major thermally induced alteration of the ferrimagnetic minerals during the demagnetisation and a Curie temperature $\left(T_{c}\right)$ higher than $550^{\circ} \mathrm{C}$. The range in magnetic susceptibility between specimens could be attributed to varying concentrations of titanomagnetite, however the high Curie temperature $\left(>550^{\circ} \mathrm{C}\right)$ suggests a dominantly low titanium (Ti) content with compositions close to magnetite. Clast S12 has the lowest susceptibility and also is the most mafic clast sampled; dark grey in colour rather than light grey.

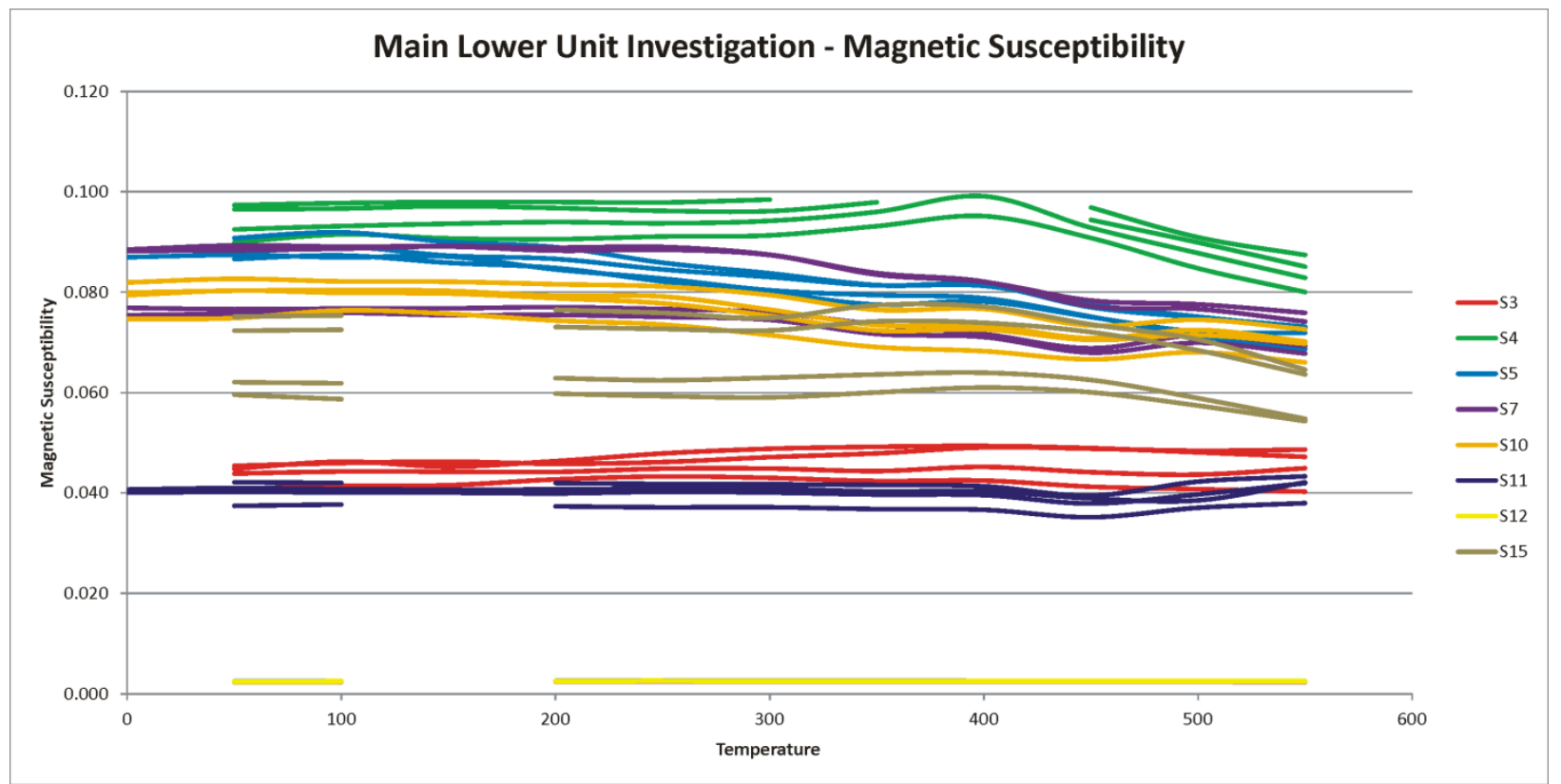

Figure 89: Room temperature magnetic susceptibility versus temperature plot for the main lower unit investigations specimens. Specimens plots are distinguished by colour based on clast. 


\subsubsection{Palaeomagnetic Directions}

Specimens sampled exhibit strong and stable remanent magnetisations, with NRM intensities ranging from 1.07 to $10.6 \mathrm{~A} / \mathrm{m}$. During thermal demagnetisation $90 \%$ of the NRM was generally removed after the $550^{\circ} \mathrm{C}$ step. The NRM intensity decreased with each temperature step in two main ways (Figure 90) - Specimens from clasts S3, S4 and S15 exhibited an almost linear decrease in intensity with temperature whereas specimens from clasts S5, S7, S10, S11 and S12 only lost $30-40 \%$ of their TRM intensity up to $450-500^{\circ} \mathrm{C}$ before decreasing rapidly by the final $550^{\circ} \mathrm{C}$ heating step. The former, more linear (un)blocking temperature spectrum could be attributed to a greater range of ferrimagnetic grain size.

\section{S3-3A}

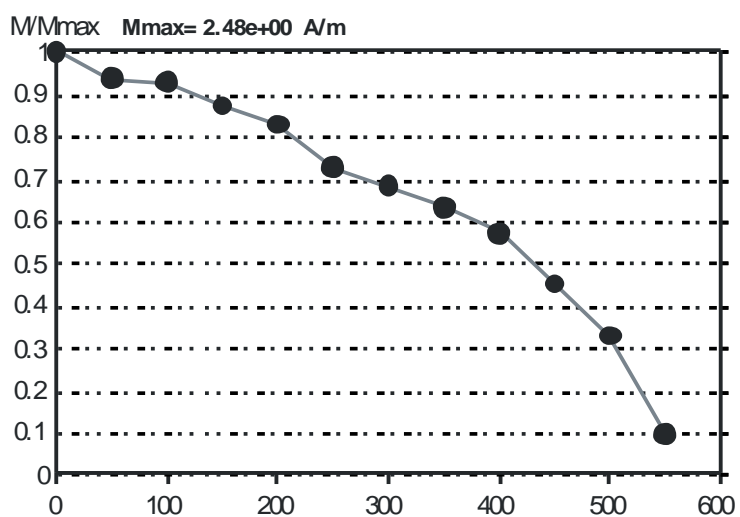

S10-3A

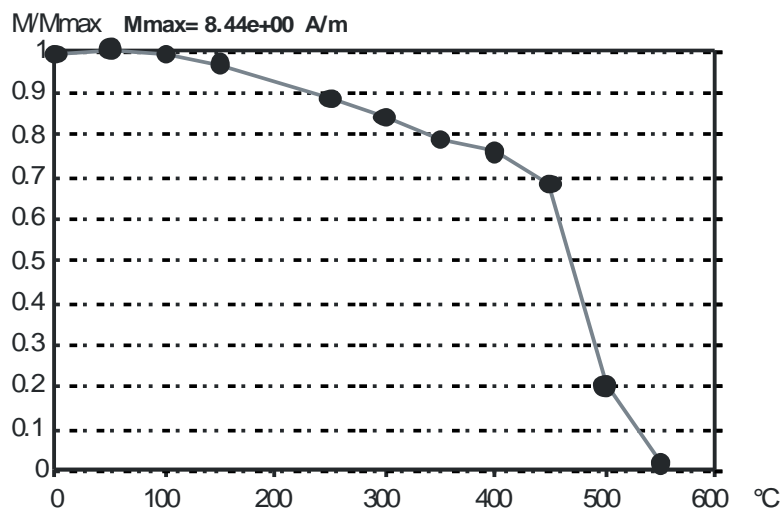

Figure 90: Remanent magnetisation intensity versus temperature plots showing examples of a gradual, almost linear loss in intensity (S3.3A) and a relatively stable intensity before a rapid loss at $450^{\circ} \mathrm{C}(\mathrm{S} 10.3 \mathrm{~A})$.

Principal component analysis (PCA) was carried out on the demagnetisation data of thirty two specimens to identify components of magnetisation carried in different intervals of the blocking temperature spectrum. The suite of specimens predominantly exhibits a welldefined $C_{\mid}$and $C_{h}$ component. The $C_{\mid}$components have MAD's ranging from $2.2^{\circ}$ to $10.3^{0}$ and the $C_{c}$ components have MAD's ranging from $0.4^{0}$ to $4.7^{0}$. This is exhibited by twenty of thirty two specimens. Demagnetisation data of typical specimens are shown in figure 91 and discussed below:

- S3.3A has an NRM intensity of $2.48 \mathrm{~A} / \mathrm{m}$. It has a $\mathrm{C}_{1}$ component in a north-easterly and downward direction (declination, $D=17.1^{\circ}$, inclination, $I=-51.9^{\circ}$, intensity of remanence analysed by $P C A=0.42 A / m$ ), isolated between 50 and $200^{\circ} \mathrm{C}$, and a $C_{h}$ 
component in a more easterly and shallower direction $\left(D=79.3^{0}, I=-19.6^{\circ}\right.$, intensity $=1.82 \mathrm{~A} / \mathrm{m}$ ) isolated between 200 and $550^{\circ} \mathrm{C}$. Overall the remanence exhibits a near linear decrease with temperature.

- S4.3C has an NRM intensity of $2.59 \mathrm{~A} / \mathrm{m}$. It has a $\mathrm{C}_{1}$ component in a north-westerly and downward direction $\left(D=312.3^{\circ}, I=-64.1^{\circ}\right.$, intensity of remanence analysed by $P C A=0.64 A / m)$, isolated between 50 and $200^{\circ} \mathrm{C}$, and a $C_{h}$ component in a southwesterly and steeper direction $\left(D=213.1^{\circ}, I=-73.5^{\circ}\right.$, intensity $\left.=1.69 \mathrm{~A} / \mathrm{m}\right)$ isolated between 250 and $550^{\circ} \mathrm{C}$. Overall the remanence exhibits a near linear decrease with temperature, except for the 350 and $400^{\circ} \mathrm{C}$ steps where it remains stable.

- $\mathrm{S7.1 \textrm {A }}$ has an NRM intensity of $9.81 \mathrm{~A} / \mathrm{m}$. It has a $\mathrm{C}_{\text {I }}$ component in a south-westerly and downward direction $\left(D=231.7^{\circ}, I=-64.4^{\circ}\right.$, intensity of remanence analysed by $P C A=0.99 A / m)$, isolated between 50 and $250^{\circ} \mathrm{C}$, and a $C_{h}$ component in a southerly and upwards direction $\left(D=164.0^{\circ}, I=39.5^{\circ}\right.$, intensity $\left.=9.35 \mathrm{~A} / \mathrm{m}\right)$ isolated between 300 and $550^{\circ} \mathrm{C}$. The overall remanence remains stable until $450^{\circ} \mathrm{C}$, after which $90 \%$ has been removed by $550^{\circ} \mathrm{C}$.

- $\mathrm{S} 15.3 \mathrm{~A}$ has an NRM intensity of $2.68 \mathrm{~A} / \mathrm{m}$. It has a $\mathrm{C}_{1}$ component in a westerly and downward direction $\left(D=291.0^{\circ}, I=-73.3^{\circ}\right.$, intensity of remanence analysed by PCA = $0.79 \mathrm{~A} / \mathrm{m}$ ), isolated between 100 and $300^{\circ} \mathrm{C}$, and a $\mathrm{C}_{\mathrm{h}}$ component in a south-westerly and downward direction $\left(\mathrm{D}=225.0^{\circ}, \mathrm{I}=-72.5^{\circ}\right.$, intensity $=1.16 \mathrm{~A} / \mathrm{m}$ ) isolated between 350 and $550^{\circ} \mathrm{C}$. Overall the remanence exhibits a near linear decrease with temperature, except for the 500 and $550^{\circ} \mathrm{C}$ steps where it remains stable. 

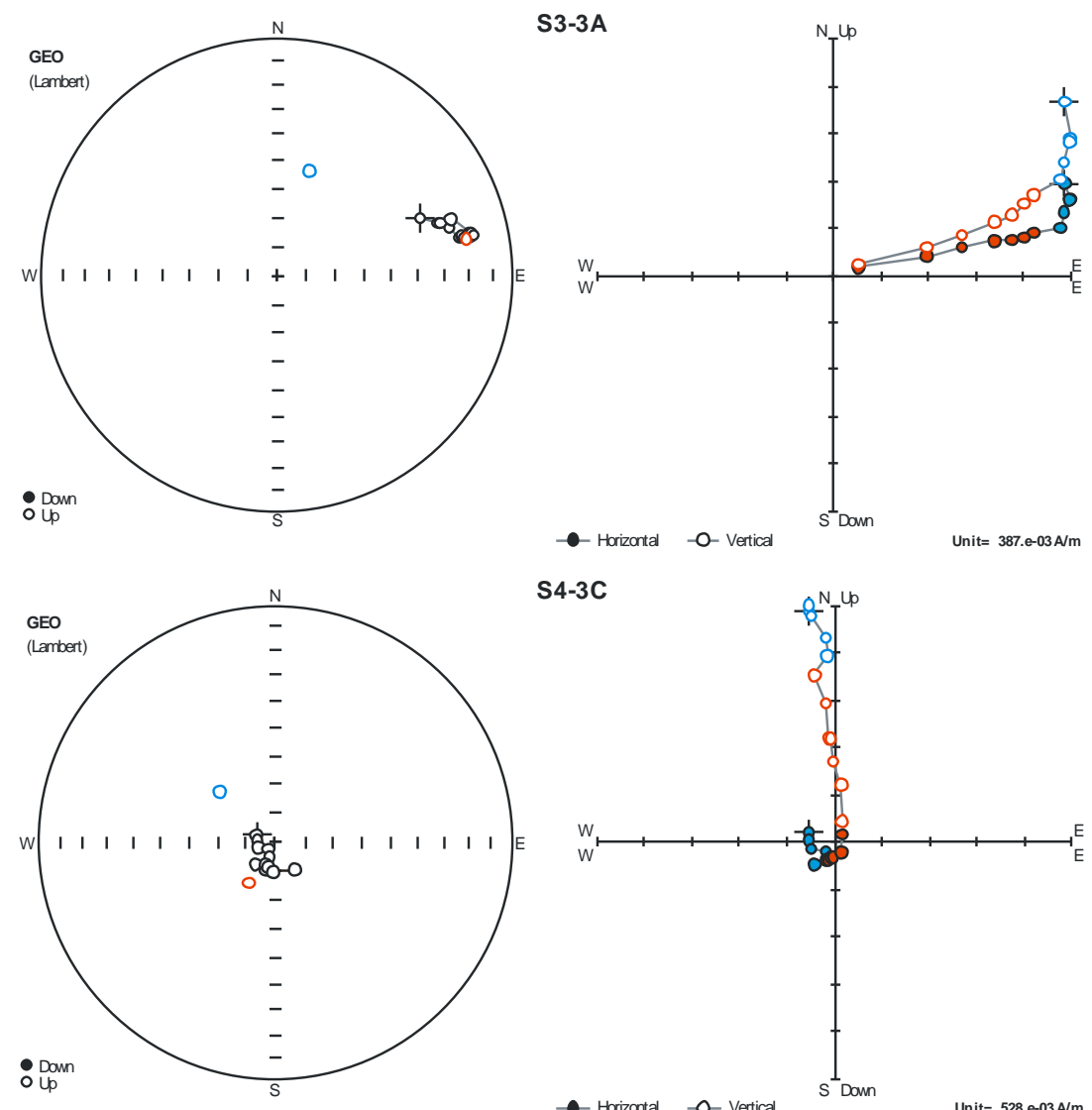

S4-3C
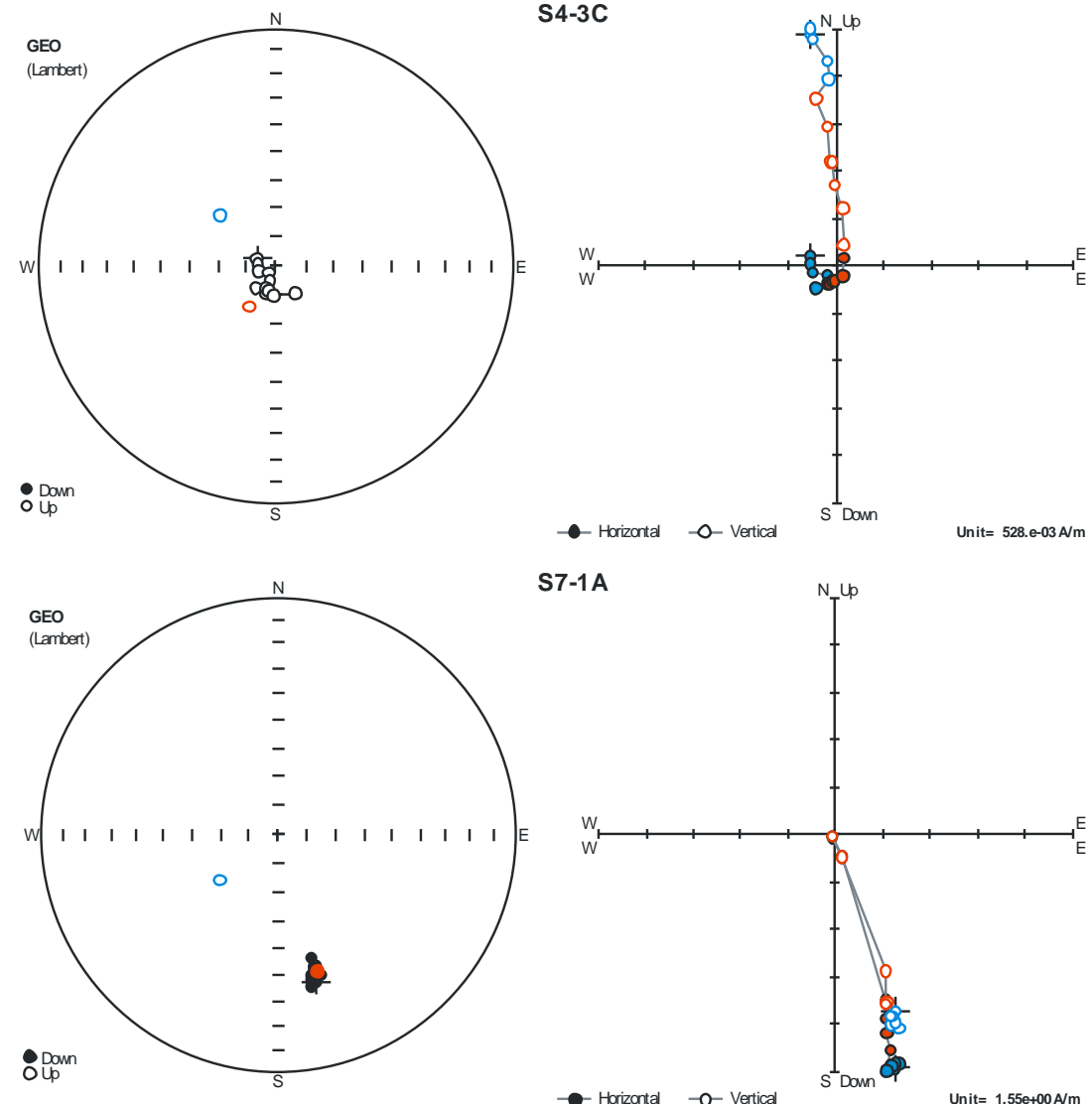

S7-1A
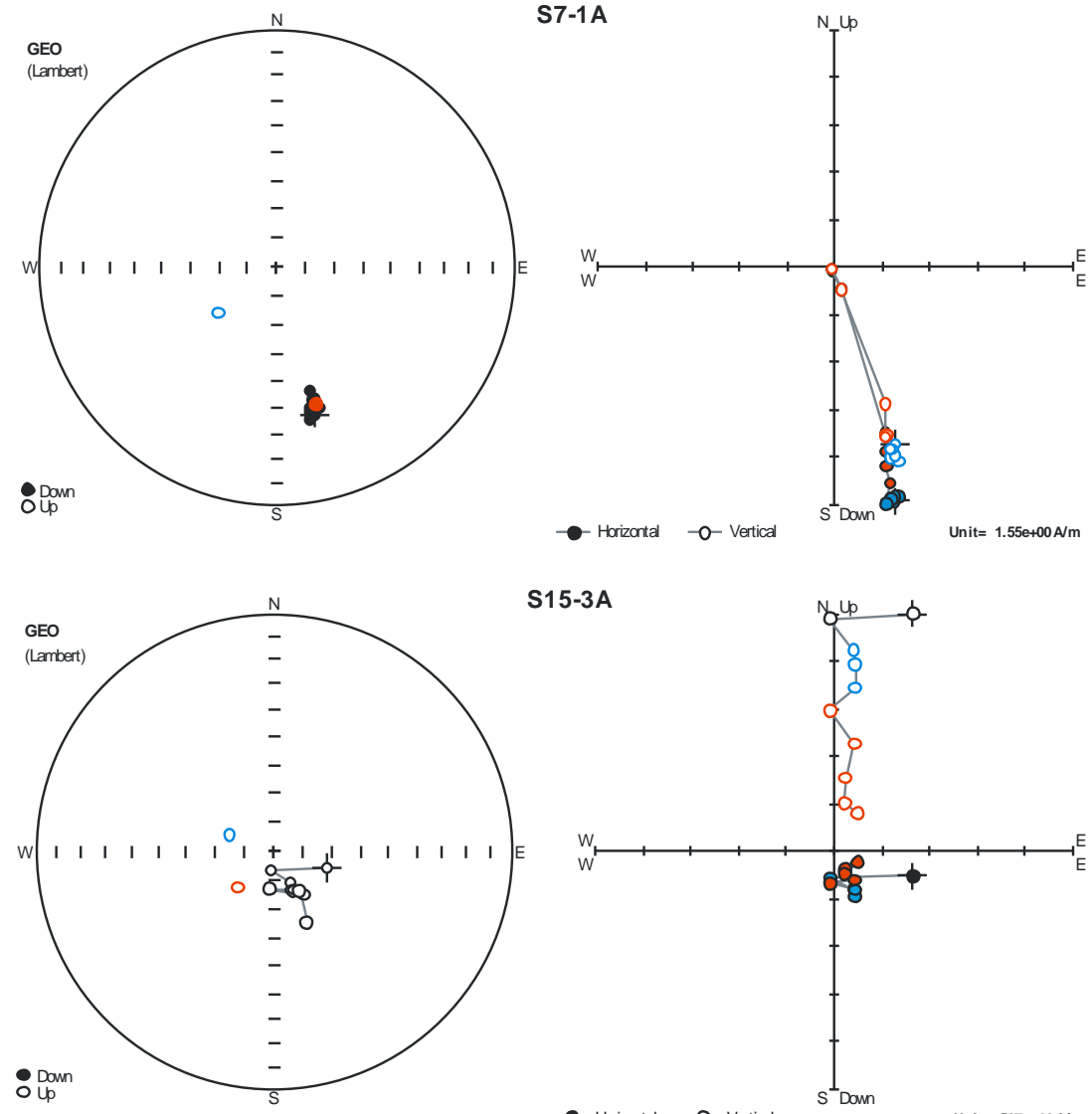

S15-3A

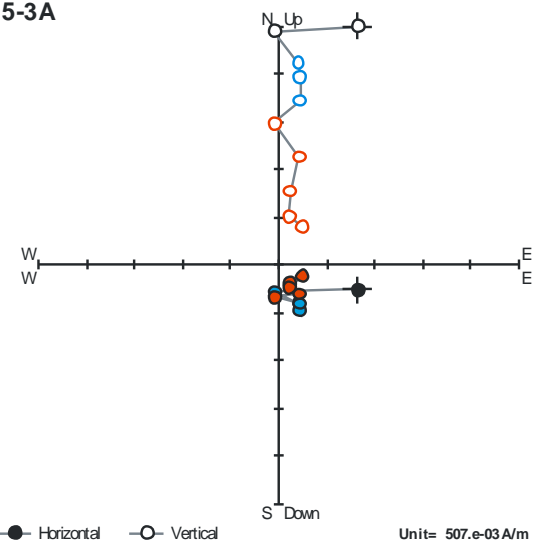

Figure 91: Lambert (equal area) stereoplots and Zijderveld diagrams showing the predominant styles of behaviour of specimens during thermal 
Some specimens exhibit behaviour which differs from this predominant behaviour. Eight of the thirty two specimens exhibit a poorly-defined $C_{I}$ and a well-defined $C_{h}$ component. The $C_{l}$ components have Maximum Angular Deviations (MAD) ranging from $12.5^{\circ}$ to $23.0^{\circ}$ and the $C_{h}$ components have MAD's ranging from $1.9^{\circ}$ to $8.9^{\circ}$. Three of specimens sampled from clast S3 exhibit curvature between the $C_{1}$ and $C_{h}$ components. The curvature is attributed to the overlapping blocking temperature ranges of the two components. These include (Figure 92):

- S5.1A has an NRM intensity of $2.05 \mathrm{~A} / \mathrm{m}$. It has a $C_{1}$ component in a north-westerly and downward direction (declination, $\mathrm{D}=348.4^{\circ}$, inclination, $\mathrm{I}=-61.9^{\circ}$, intensity of remanence analysed by $P C A=0.11 \mathrm{~A} / \mathrm{m}$ ), isolated between 50 and $200^{\circ} \mathrm{C}$, and a $C_{h}$ component in a more north-westerly and shallower direction $\left(D=329^{\circ}, I=-5.2^{0}\right.$, intensity $=1.62 \mathrm{~A} / \mathrm{m}$ ) isolated between 300 and $550^{\circ} \mathrm{C}$. The overall remanence remains stable until $300^{\circ} \mathrm{C}$ after which it exhibits a near-linear decrease with temperature until $85 \%$ is lost by the $550^{\circ} \mathrm{C}$ demagnetisation step.

- $\mathrm{S} 11.1 \mathrm{C}$ has an NRM intensity of $1.15 \mathrm{~A} / \mathrm{m}$. It has a $\mathrm{C}_{\text {I }}$ component in a north-westerly and downward direction (declination, $D=319.6^{\circ}$, inclination, $I=\quad-66.5^{\circ}$, intensity of remanence analysed by PCA $=0.10 \mathrm{~A} / \mathrm{m}$ ), isolated between 50 and $200^{\circ} \mathrm{C}$, and a $\mathrm{C}_{\mathrm{h}}$ component in a more south-westerly and shallower direction $\left(D=214.2^{0}, I=-20.1^{0}\right.$, intensity $=0.26 \mathrm{~A} / \mathrm{m}$ ) isolated between 250 and $550^{\circ} \mathrm{C}$. The overall remanence exhibits a near-linear decrease with temperature until $450^{\circ} \mathrm{C}$ after which it decreases rapidly with $90 \%$ lost by $550^{\circ} \mathrm{C}$.

- S3.1A has an NRM intensity of $2.87 \mathrm{~A} / \mathrm{m}$. It has a $C_{1}$ component in a northerly and downward direction (declination, $D=23.7^{0}$, inclination, $\mathrm{I}=-57.2^{0}$, intensity of remanence analysed by $P C A=0.51 \mathrm{~A} / \mathrm{m}$ ), isolated between 50 and $200^{\circ} \mathrm{C}$, and $\mathrm{C} \mathrm{C}_{\mathrm{h}}$ component in a more easterly and shallower direction $\left(D=80.9^{\circ}, I=-20.2^{0}\right.$, intensity $=1.80 \mathrm{~A} / \mathrm{m}$ ) isolated between 250 and $550^{\circ} \mathrm{C}$. The overall remanence exhibits a nearlinear decrease with temperature until $450^{\circ} \mathrm{C}$ after which it decreases rapidly with $85 \%$ lost by $550^{\circ} \mathrm{C}$.

In most specimens there is a short interval of the blocking temperature spectrum between the removal of the $C_{l}$ component and the clear isolation of the $C_{h}$ component. In only a few specimens (e.g. S10.3A, Figure 92) is it possible to isolate and determine a 
distinct component of remanence in this blocking temperature interval. However, the presence of such an intermediate interval suggests an intermediate stage in the thermal history of the clasts. This is thought to represent a time interval between the acquisition of the high and low blocking temperature components, during which the clasts were in a state of turbulent transport. This intermediate component is clearly seen in Figure 93:

- $\mathrm{S} 10.3 \mathrm{~A}$ has an NRM intensity of $8.34 \mathrm{~A} / \mathrm{m}$. It has a $\mathrm{C}_{1}$ component in a south-easterly and upwards direction (declination, $D=154.8^{\circ}$, inclination, $\mathrm{I}=15.7^{\circ}$, intensity of remanence analysed by $P C A=0.51 \mathrm{~A} / \mathrm{m}$ ) isolated between 50 and $150^{\circ} \mathrm{C}$, a $\mathrm{C}_{\mathrm{i}}$ component in a south-westerly and downward direction $\left(D=248.7^{0}, I=-16.6^{0}\right.$, intensity of remanence analysed by PCA $=1.42 \mathrm{~A} / \mathrm{m}$ ) isolated between 150 and $450^{\circ} \mathrm{C}$, and a $\mathrm{C}_{\mathrm{h}}$ component in a in a south-westerly and downward direction ( $\mathrm{D}=$ $216.1^{0}, I=-11.4^{0}$, intensity of remanence analysed by PCA $=3.22 \mathrm{~A} / \mathrm{m}$ ) isolated between 450 and $550^{\circ} \mathrm{C}$. 

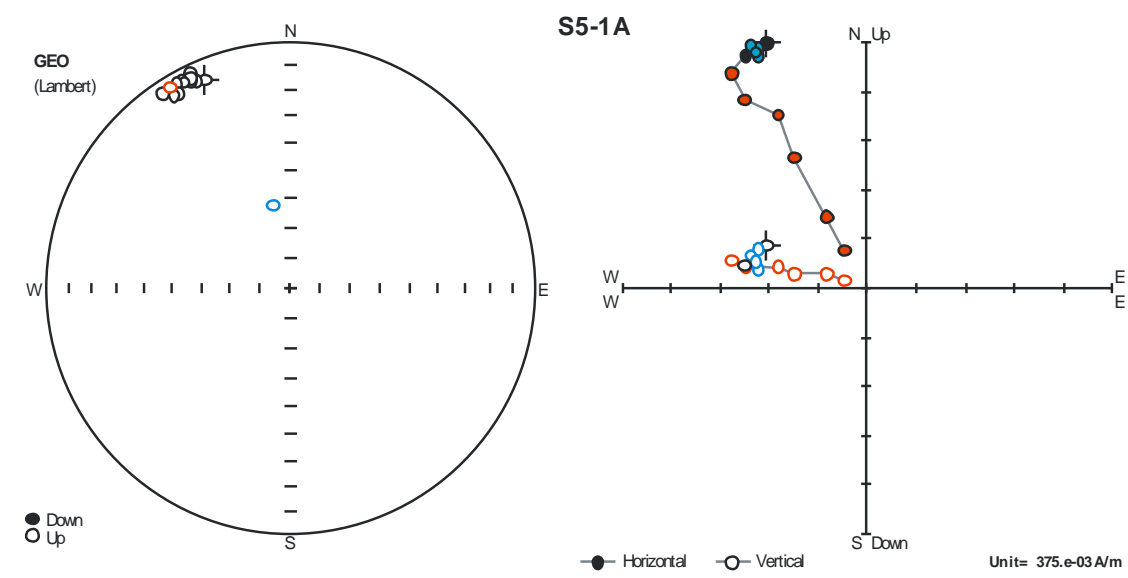

Figure 92: Lambert (equal area) stereoplots and Zijderved diagrams showing the behaviour of specimens which differes from the predominant behaviour shown in Figure 91.

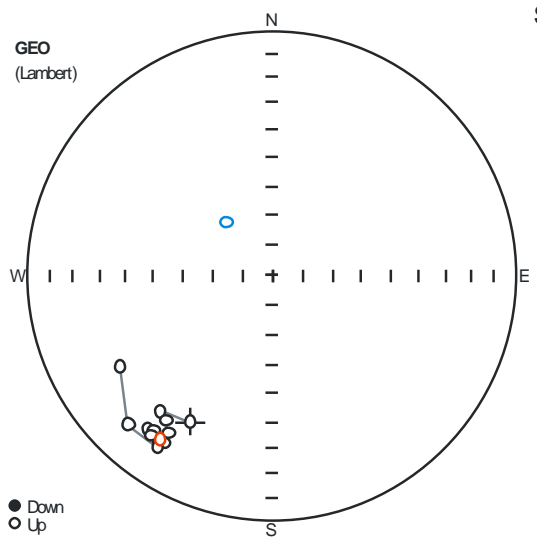

S11-1C
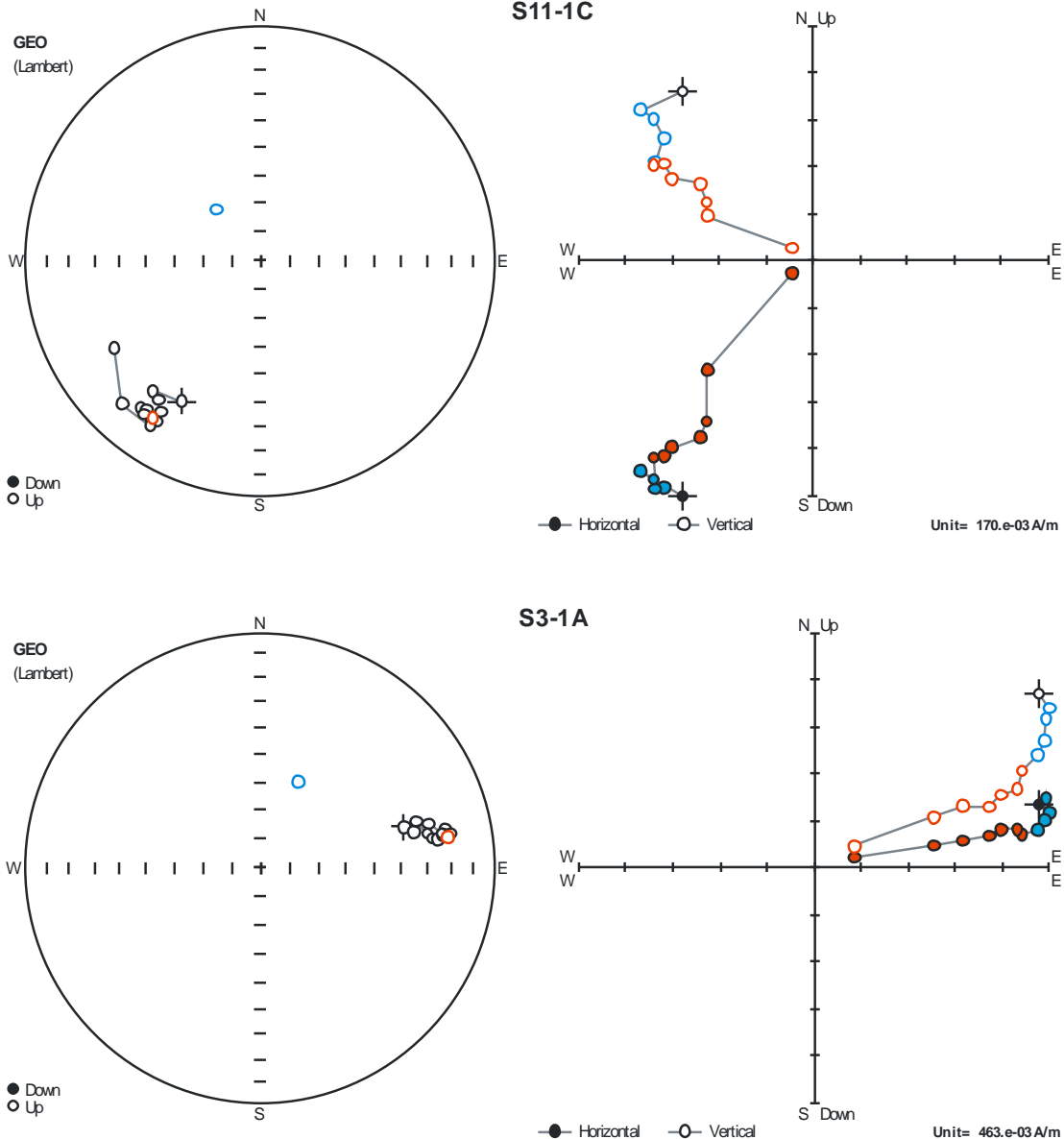

S3-1A
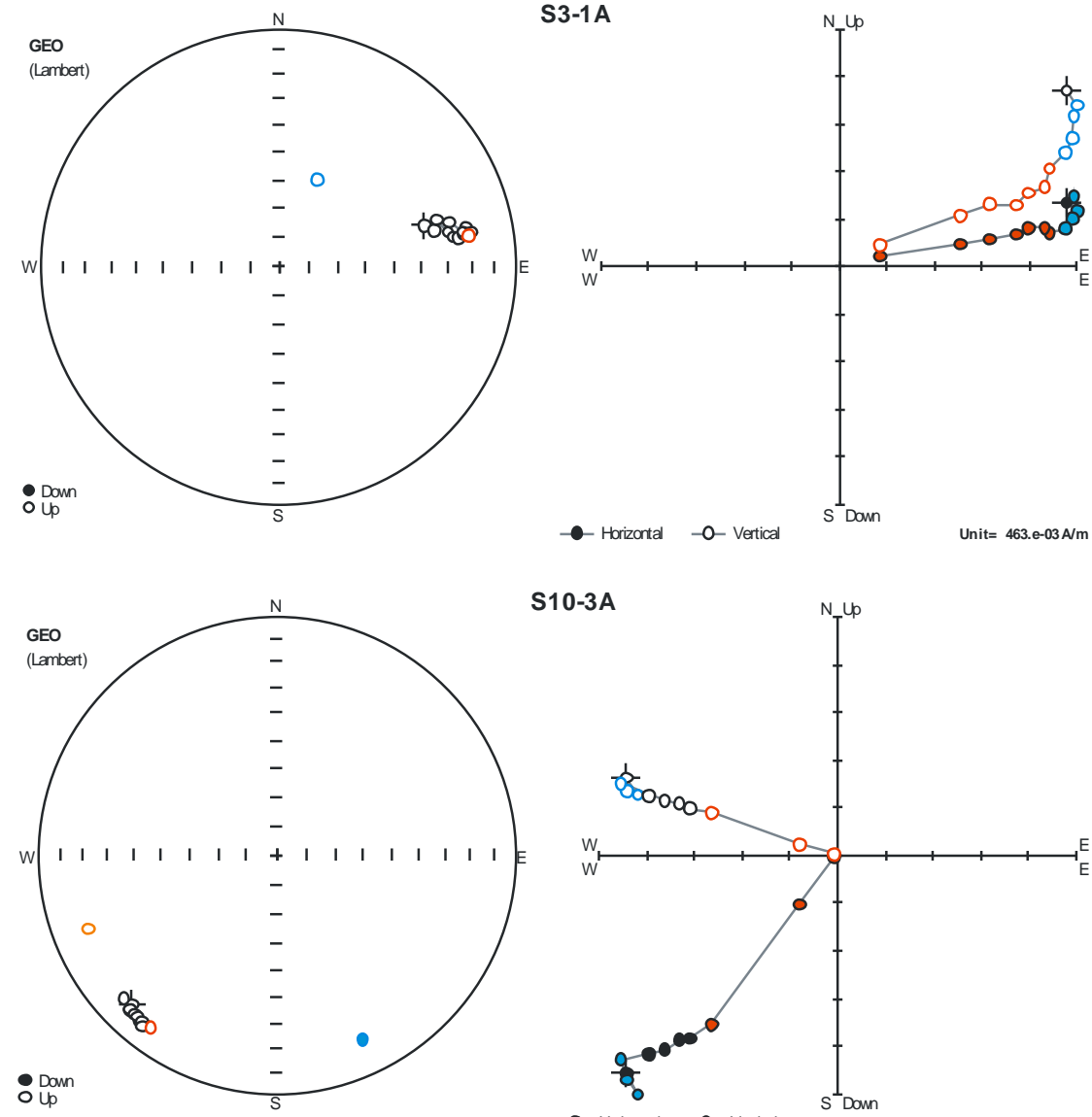

S10-3A

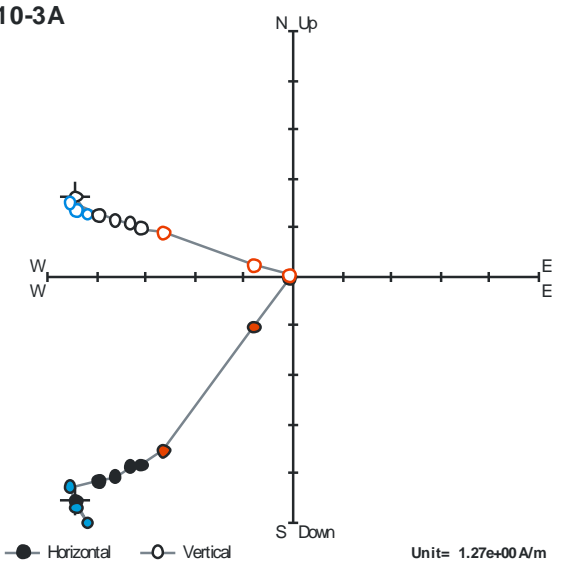


Of the thirty two specimens, S12.2A was excluded from the suite as it exhibited unstable behaviour during thermal demagnetisation - PCA did not identify any coherent component of magnetisation. Specimen S12.1A was only used in the analysis of high temperature components as it exhibits a well-defined high temperature component $\left(C_{h}\right)$ but an undefined low temperature component $\left(C_{1}\right)$.

The presence of two and in some cases three, components of magnetisation suggests that the thermal history of the clasts involves more than simply one cooling episode. This is more complicated than the preliminary alternating field demagnetisation investigation suggested. The directions of the $C_{h}$ components show strong correlation between specimens within clasts but no correlation between clasts. The $\mathrm{C}_{\mid}$components are generally less welldetermined, but show some correlation, both within and between clast (Figure 93).
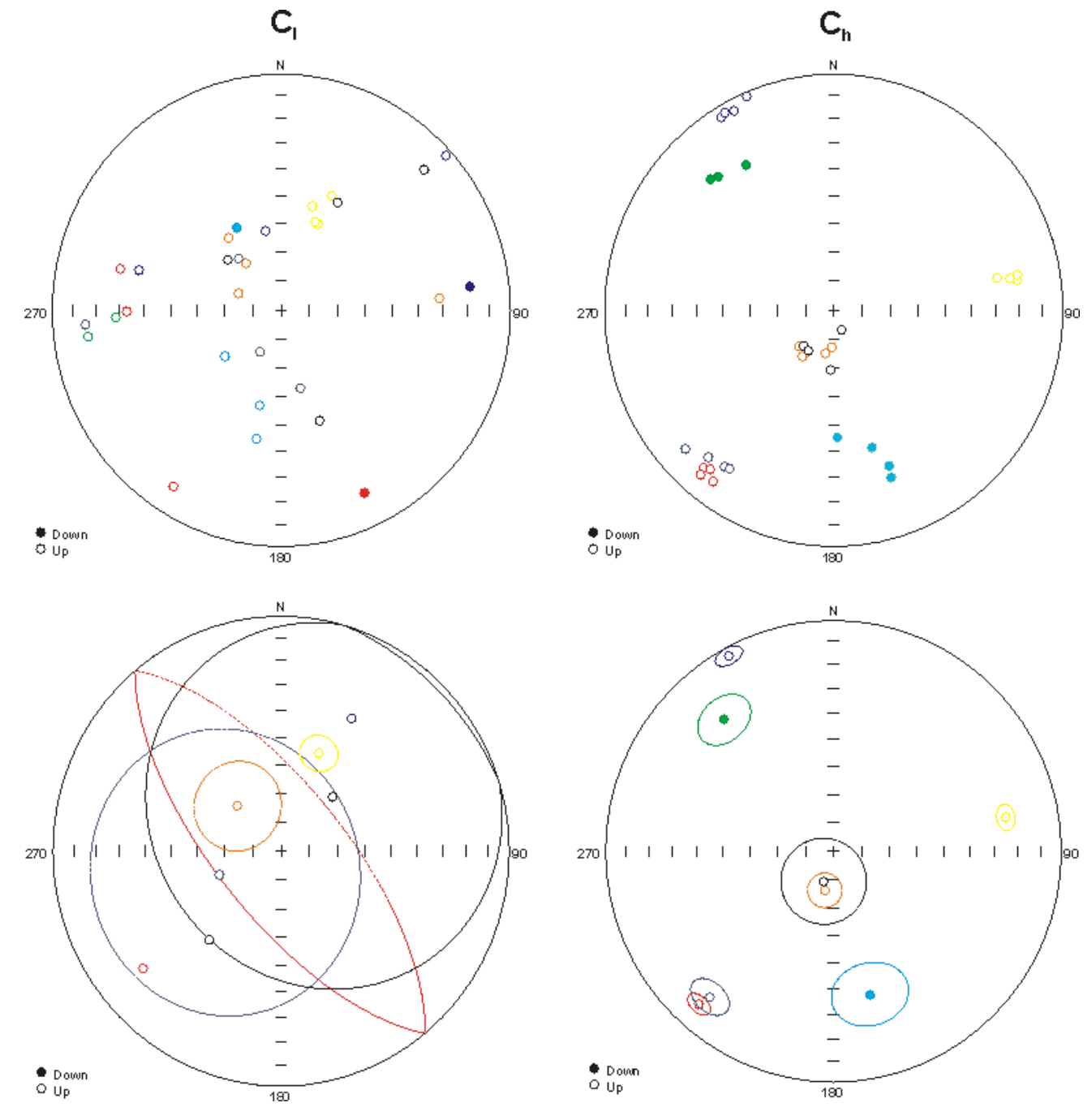

Figure 93: Lambert (equal area) stereoplots showing the low temperature ( $\left.C_{l}\right)$ (left) and high temperature $\left(C_{h}\right)$ (right) components of each specimen (top) and as a clast mean (bottom) - Clast S3 (yellow); S4 (black); S5 (purple); S7 (light blue); S10 (red); S11 (dark blue); S12 (green); and S15 (orange). 
The lower quality of the $C_{\mid}$components of magnetisation can be attributed to (1) a low blocking temperature viscous component of magnetisation (VRM) overprinting the thermoremanent magnetisation (TRM) acquired during emplacement and/or (2) statistical limitations of analysis due to the small number of demagnetisation steps (generally $\leq 5$ ) used to calculate the low temperature component of magnetisation.

- (1) VRM: Acquired gradually overtime, VRM is due to the relaxation of the ferrimagnetic moments of magnetic grains to align with the ambient field. The VRM is dependent on the relaxation of time of the magnetic grains, with the magnetic moments of any grains having a relaxation time $(\tau)$ shorter than the age of the deposit sampled tending to become unblocked and realigned with earth's modern geomagnetic field.

- (2) The maximum angular deviation (MAD) of a component is increased by both increased deviation of points from the calculated mean but also by reductions in points used in the calculation of the mean. With the low temperature component generally removed by $100^{\circ} \mathrm{C}$ to $300^{\circ} \mathrm{C}$ leaving minimal data points available to calculate a statistically reasonable low temperature component.

\subsubsection{Thermal History}

As previously discussed a modification of the conglomerate test is being used to decipher the thermal history and estimate the temperature at which clasts were deposited. This is considered the lowest temperature at which the $T_{h}$ component has been removed. To estimate the temperature at which the whole deposit was emplaced Paterson et al (2010) recommends the equilibrium temperature method of Bardot and McClelland (2000). The equilibrium temperature is considered the lowest emplacement of the sampled clasts. This method however commonly underestimates true deposit temperature in thin deposits or where clasts at flow boundaries experience adverse cooling (Cioni et al, 2004).

Based on the behaviour of the specimens and the PCA I consider a single emplacement event does not adequately describe the variability in the palaeomagnetic demagnetisation data. This variability can be attributed to differing thermal histories, clast incorporation temperatures and time of deposition during the flow process. I have taken the approach of 
determining separately, a mean incorporation and emplacement temperature based on the $C_{I}$ and $C_{h}$ components. The three temperature intervals and two remanence components identified in these specimens represent three stages of the clasts thermal history. These have been interpreted as the following (Figure 94):
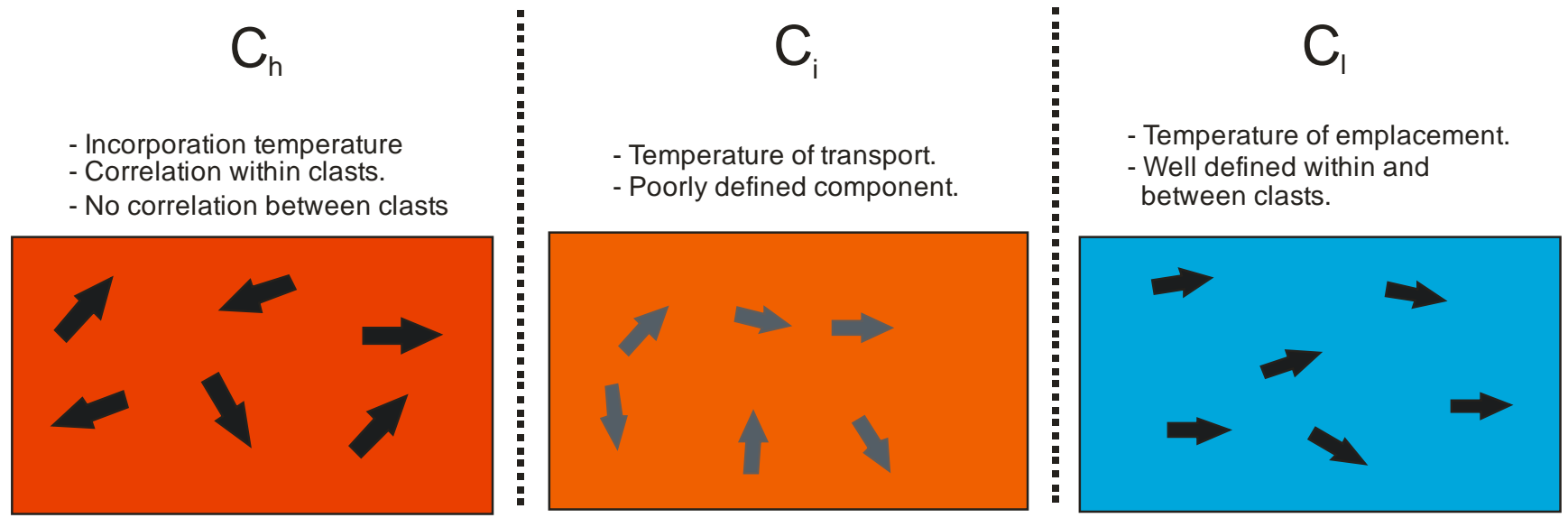

Figure 94: Idealised illustration providing a visual representation of the high, intermediate and low temperature components of magnetisation.

- The lowest temperature at which the $C_{h}$ component is preserved as an estimate of the temperature at which the clast was incorporated into the flow. The high temperature component is the component remaining from the parent rock's formation or a previous process which heated the clast above the Curie temperature of the magnetic minerals (c. $585^{\circ}$ ). This component has been removed from lower blocking temperature grains during the deposition of the Ngatoro Formation.

- The temperature range over which the randomly defined $C_{i}$ component is preserved as an estimate of the clasts cooling during incorporation and transport. The component is poorly defined as it represents the clast cooling during transport within the flow from the time of its incorporation until emplacement.

- The highest temperature at which the $C_{\mid}$component is preserved as an estimate of the emplacement temperature of that clast. This is interpreted to be the temperature at which the clast became stationary within the flow deposit, resulting in a well-defined $C_{\mid}$component. 
The emplacement temperature of the deposit is based on principal component analysis from 31 specimens representing 8 clasts from two locations. The stepwise thermal demagnetisation limits the maximum accuracy of any temperature estimate to the minimum demagnetisation step, which in this study is $50^{\circ} \mathrm{C}$. The highest temperature at which the $\mathrm{C}_{1}$ component is preserved ranges from $100^{\circ} \mathrm{C}$ to $350^{\circ} \mathrm{C}$ (Table 8 ) and has a modal peak, mean and median of $200^{\circ} \mathrm{C}$. The lowest temperature at which the $\mathrm{C}_{\mathrm{h}}$ component is preserved ranges from $100^{\circ} \mathrm{C}$ to $450^{\circ} \mathrm{C}$ (Table 8 ) and has a modal peak, mean and median of $300^{\circ} \mathrm{C}$. Based on these results, the Ngatoro Formation is considered to have a mean incorporation temperature estimate of $300^{\circ} \mathrm{C}$ and a mean emplacement temperature estimate of $200^{\circ} \mathrm{C}$ (Figure 95). The mean amount the clast cooled between incorporation and emplacement is estimated to be $80^{\circ} \mathrm{C}$. 
Main Lower Unit Investigation - Principal Component Analysis

\begin{tabular}{|c|c|c|c|c|c|c|c|c|c|c|c|c|}
\hline \multicolumn{13}{|c|}{ Main Lower Unit Investigation - Principal Component Analysis } \\
\hline Specimen & Declination & Inclination & MAD & Intensity & Temperature & Declination & Inclination & MAD & Intensity & Range & $\mathrm{Cl}$ & $\mathrm{Ch}$ \\
\hline S3.1A & 23.7 & -57.2 & 10.5 & 0.51 & $50-200$ & 80.9 & -20.2 & 2.7 & 1.83 & $250-550$ & 200 & 250 \\
\hline S3.1D & 24.3 & -45.8 & 4.2 & 0.55 & $50-200$ & 79.1 & -28.3 & 2.3 & 2.75 & $250-550$ & 200 & 250 \\
\hline S3.3A & 17.1 & -51.9 & 2.2 & 0.42 & $50-200$ & 79.3 & -19.6 & 2.6 & 1.82 & $200-550$ & 200 & 200 \\
\hline S3.3C & 21.4 & -56.9 & 8 & 0.45 & $50-200$ & 80 & -23.1 & 1.4 & 2.25 & $250-550$ & 200 & 250 \\
\hline S4.2A & 28.3 & -47.1 & 3.3 & 0.4 & $50-150$ & 221.1 & $\begin{array}{l}-73.7 \\
\end{array}$ & 4.9 & 1.65 & $200-550$ & 150 & 200 \\
\hline S4.2C & 46.4 & -14.9 & 14.5 & 0.43 & $0-100$ & 157.8 & -82.8 & 6.3 & 1.89 & $200-550$ & 100 & 200 \\
\hline S4.3A & 160.3 & -49 & 5.2 & 1.15 & $50-250$ & 183.2 & -69.5 & 4.5 & 1.36 & $300-550$ & 250 & 300 \\
\hline S4.3C & 312.3 & -64.1 & 5.2 & 0.64 & $50-200$ & 213.1 & -73.5 & 3.7 & 1.69 & $250-550$ & 200 & 250 \\
\hline S5.1A & 348.4 & -61.9 & 23 & 0.11 & $50-200$ & 329 & -5.2 & 3 & 1.62 & $300-550$ & 200 & 300 \\
\hline S5.1B & 285.3 & -35.8 & 12.5 & 0.29 & $50-200$ & 337.2 & -2 & 6.4 & 1.59 & $300-550$ & 200 & 300 \\
\hline S5.2A & 82.9 & 18.2 & 12.8 & 0.23 & $50-250$ & 330.4 & -4.3 & 2.6 & 1.19 & $300-550$ & 250 & 300 \\
\hline S5.2B & 47.6 & -3.1 & 8.4 & 0.28 & $50-200$ & 332.7 & -5.5 & 4.4 & 1.57 & $300-550$ & 200 & 300 \\
\hline S7.1A & 231.7 & -64.4 & 5.8 & 0.99 & $50-250$ & 164 & 39.5 & 1.6 & 9.35 & $300-550$ & 250 & 300 \\
\hline S7.1C & 330.9 & 57 & 4.4 & 1.09 & $50-200$ & 178.4 & 45.3 & 2.3 & 9.07 & $400-550$ & 200 & 400 \\
\hline S7.3A & 191.3 & -43.8 & 4.4 & 1.6 & $50-250$ & 159.9 & 30.6 & 3.2 & 8.28 & $300-550$ & 250 & 300 \\
\hline S7.3B & 193.1 & -56 & 5.5 & 1.02 & $50-200$ & 160.5 & 26 & 4.6 & 9.09 & $250-550$ & 200 & 250 \\
\hline $\mathrm{S} 10.1 \mathrm{~A}$ & 212.3 & -12.9 & 5.7 & 1.08 & $50-250$ & 220.4 & -13.5 & 2 & 7 & $300-550$ & 250 & 300 \\
\hline $\mathrm{S} 10.1 \mathrm{~B}$ & 269.6 & -33 & 3.5 & 0.58 & $50-150$ & 219.9 & -10.3 & 1.1 & 7.37 & $300-550$ & 150 & 300 \\
\hline S10.3A & 154.8 & 15.7 & 5.6 & 0.51 & $50-150$ & 216.1 & -11.4 & 0.7 & 3.22 & $450-550$ & 150 & 450 \\
\hline $\mathrm{S} 10.3 \mathrm{C}$ & 284.1 & -28.5 & 5.8 & 0.36 & $50-150$ & 218.8 & -14.9 & 0.4 & 3.58 & $450-550$ & 150 & 450 \\
\hline $\mathrm{S} 11.1 \mathrm{~A}$ & 208.1 & -73.9 & 16.7 & 0.13 & $50-150$ & 215.8 & -19.6 & 2.9 & 0.82 & $300-550$ & 150 & 300 \\
\hline S11.1C & 319.6 & -66.5 & 17.8 & 0.1 & $50-200$ & 214.2 & -20.1 & 8.9 & 0.26 & $250-550$ & 200 & 250 \\
\hline $\mathrm{S} 11.2 \mathrm{~A}$ & 266 & -15.4 & 7.2 & 0.21 & $50-200$ & 221.4 & -18.3 & 5.7 & 0.28 & $350-550$ & 200 & 350 \\
\hline S11.2D & 165.8 & -62.2 & 13.4 & 0.25 & $50-250$ & 227.9 & -13.7 & 1.9 & 1 & $300-550$ & 250 & 300 \\
\hline $\mathrm{S} 12.1 \mathrm{~A}$ & - & - & - & - & - & 318.3 & 25.2 & 0.9 & 6.2 & $400-550$ & - & 400 \\
\hline $\mathrm{S} 12.1 \mathrm{C}$ & 262.6 & -16 & 19.5 & 0.85 & $50-350$ & 314.9 & 23.8 & 2.1 & 6.48 & $400-550$ & 350 & 400 \\
\hline $\mathrm{S} 12.2 \mathrm{~A}$ & - & - & - & - & - & - & - & - & - & - & - & - \\
\hline S12.2B & 267.7 & -28.4 & 5.1 & 1.52 & $50-300$ & 328.1 & 28.3 & 2.5 & 6.53 & $350-550$ & 300 & 350 \\
\hline S15.1A & 85.7 & -31.3 & - & 0.39 & $50-100$ & 215.1 & -70.6 & 3.4 & 2.46 & $100-550$ & 100 & 100 \\
\hline S15.1C & 322.3 & -69.5 & 2.9 & 0.57 & $50-200$ & 183.1 & $\begin{array}{l}-77.3 \\
\end{array}$ & 3.6 & 1.71 & $250-550$ & 200 & 250 \\
\hline S15.3A & 291 & -73.3 & 10.3 & 0.79 & $100-300$ & 225 & -72.5 & 8.1 & 1.16 & $350-550$ & 300 & 350 \\
\hline S15.3C & 323.1 & -58.5 & 3.2 & 0.47 & $0-200$ & 191.5 & -74.9 & 2.9 & 1.87 & $200-550$ & 200 & 200 \\
\hline
\end{tabular}

\begin{tabular}{|c|c|c|c|c|c|c|}
\hline Specimen & Declination & Inclination & $\alpha 95$ & Declination & Inclination & $\alpha 95$ \\
\hline S3 & 21.7 & -53 & 6.5 & 79 & -24 & 3.9 \\
\hline S4 & 44.3 & -63.5 & 66.9 & 198.4 & -78.8 & 15.2 \\
\hline S5 & 28.7 & -35.9 & 127.6 & 331.5 & -4.2 & 3.9 \\
\hline S7 & 219.9 & -49.3 & 124.7 & 165.5 & 35.9 & 12.4 \\
\hline S10 & 230.5 & -22.6 & 89.7 & 221.7 & -12.2 & 3.7 \\
\hline S11 & 249.6 & -66.5 & 50.3 & 220.7 & -17.8 & 6.4 \\
\hline S12 & - & - & - & 319.9 & 26.2 & 9 \\
\hline S15 & 315.2 & -67.8 & 15.5 & 192.6 & -75.9 & 6.1 \\
\hline Mean & 306.7 & -78.7 & 36.5 & - & - & - \\
\hline
\end{tabular}

Table 8: Table of the Principle Component Analysis (PCA)

results for the main lower unit investigation. The table

includes the $C_{l}$ and $C_{h}$ components with their declination, inclination and $\alpha 95$ angles. 


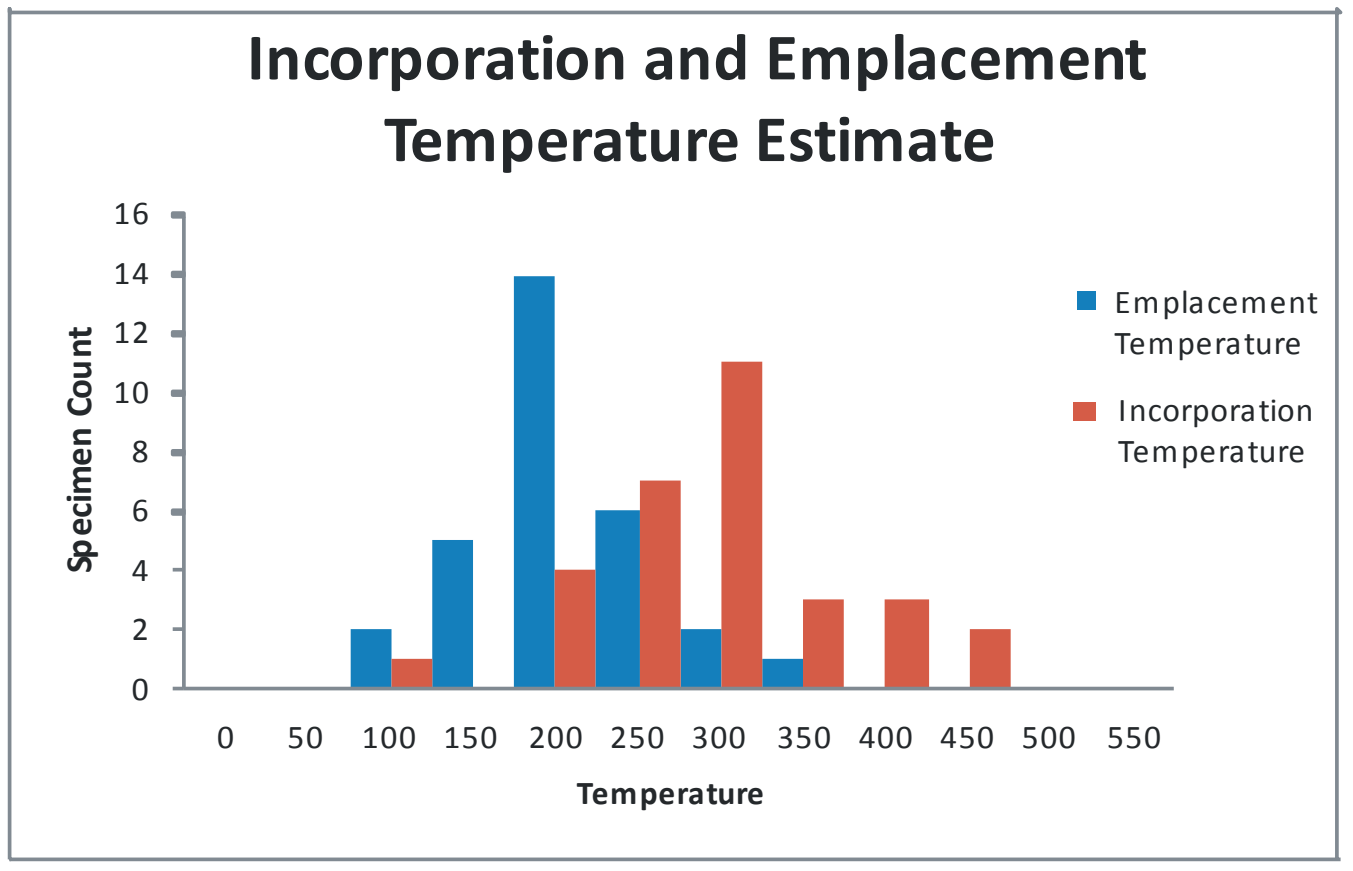

Figure 95: Plot showing the incorporation and emplacement temperature estimates based on PCA outlined in Table 8. 


\subsection{Preliminary Upper Unit Investigation (S16, S17, S18 \& S19)}

\subsubsection{Magnetic Susceptibility}

The magnetic susceptibility with temperature measurements indicates that the ferrimagnetic minerals in the sample (S19.1) loses its magnetic susceptibility by $550^{\circ} \mathrm{C}$ suggesting a Curie temperatures in the order of $550^{\circ} \mathrm{C}$ and a composition within the titanomagnetite series $\left(20 \% \mathrm{Fe}_{3} \mathrm{O}_{4}\right.$ to $\left.80 \% \mathrm{Fe}_{2} \mathrm{TiO}_{4}\right)$ (Butler, 2004). The results of temperature susceptibility analysis are presented in Section D1, Appendix D.

The room temperature magnetic susceptibility results show no significant changes in susceptibility with demagnesitation temperature (Figure 96). The samples show a range from $0.03 \mathrm{SI}$ to $0.09 \mathrm{SI}$ and exhibit a $\approx 0.01 \mathrm{SI}$ decrease in susceptibility above $400^{\circ} \mathrm{C}$. These results suggest no major thermally induced alteration of the ferrimagnetic minerals. As with the Main Lower Unit investigation, the high Curie temperature $\left(>550^{\circ} \mathrm{C}\right)$ suggests a low titanium (Ti) content with compositions close to magnetite.

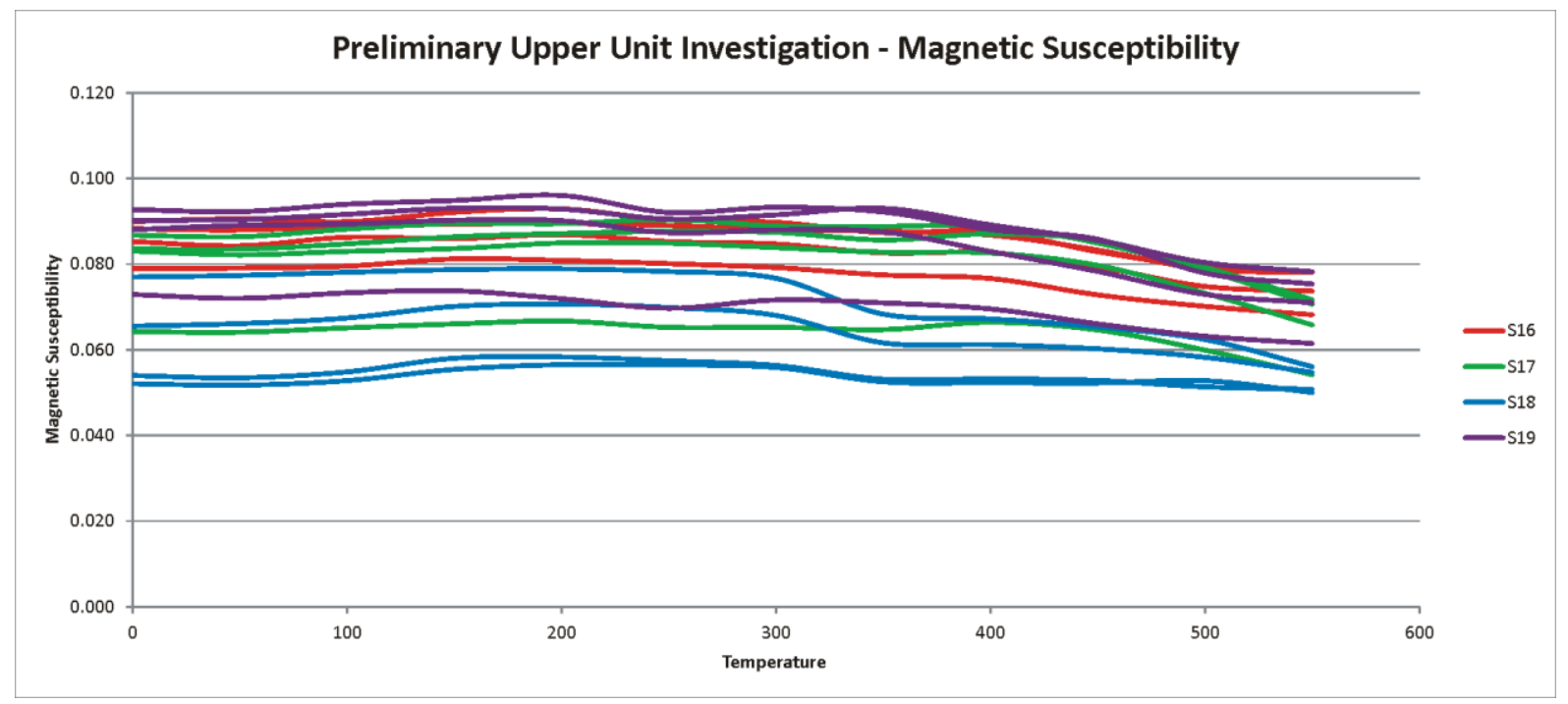

Figure 96: Room temperature magnetic susceptibility verses temperature plot for the preliminary upper unit investigations specimens. Specimens plots are distinguished by colour based on clast.

\subsubsection{Palaeomagnetic Directions}

The 16 specimens demagnetised from the upper unit exhibit strong, stable magnetisations with NRM intensities ranging from 1.31 to $2.27 \mathrm{~A} / \mathrm{m}$. During thermal demagnetisation, $80-$ $90 \%$ of the TRM was generally removed after the $550^{\circ} \mathrm{C}$ step and the NRM intensity generally decreasing with each demagnetisation step, however some specimens show small increases at certain demagnetisation temperature steps (Figure 97). Clasts S16 and S18 have 
a stable NRM at low temperatures, only losing $20-40 \%$ of their TRM intensity prior to the $450^{\circ} \mathrm{C}$ demagnetisation step after which the intensity is rapidly lost with each temperature step (Figure 97 ). Clasts $\mathrm{S} 17$ gradually lose $10-20 \%$ of their NRM intensity by $300^{\circ} \mathrm{C}$, after which the intensity decreases almost linearly until the $550^{\circ} \mathrm{C}$ demagnetisation step (Figure 97).

S16-1A

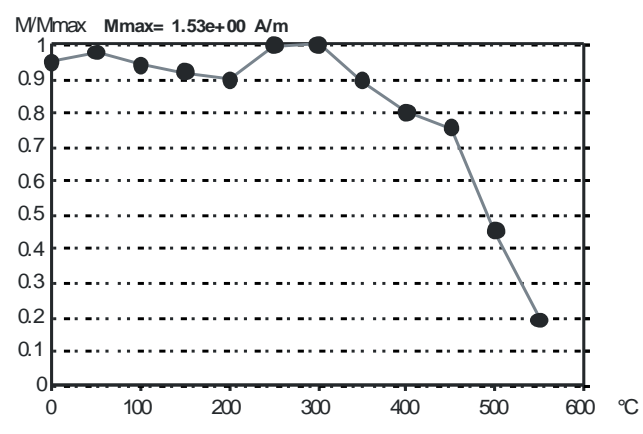

S17-3B
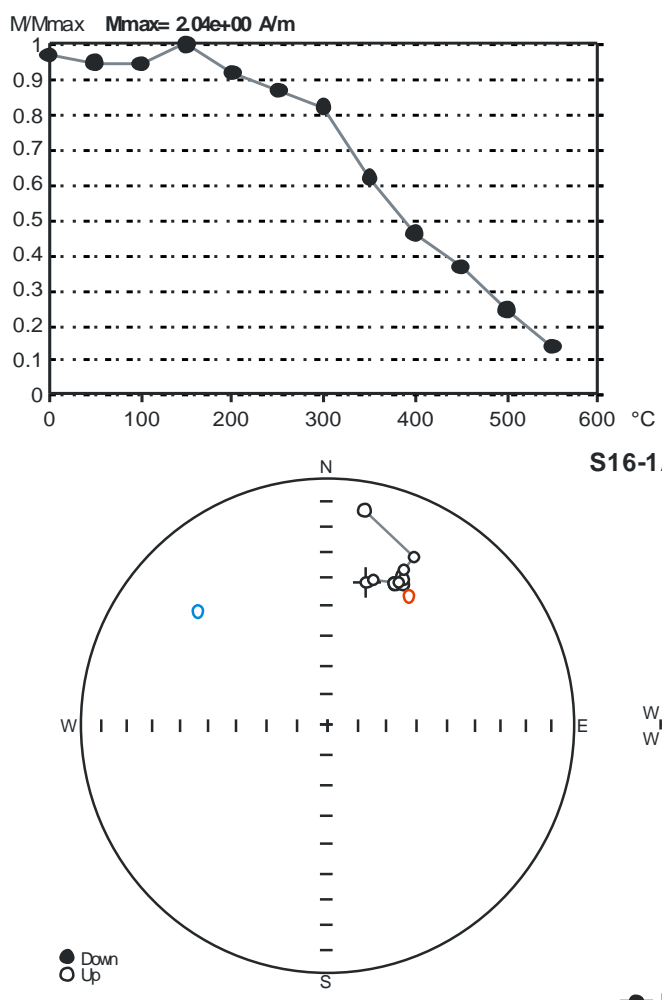

S16-1A
S18-1C

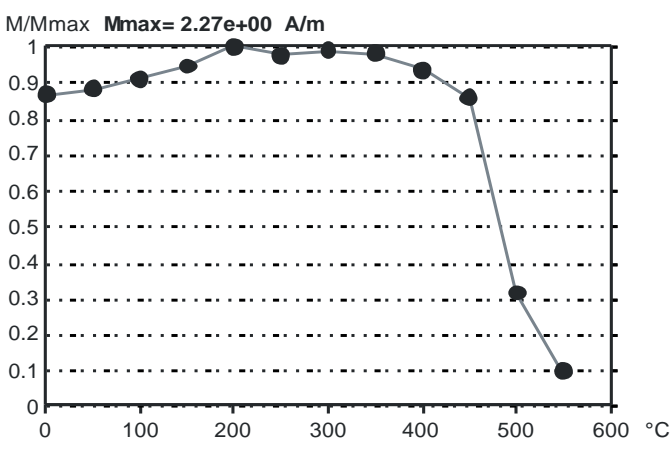

Figure 97: Remanent magnetisation intensity versus temperature plots showing demagnetisation behaviour exhibited by the specimens.

Figure 98 (below): Lambert (equal area) stereoplots and Zijderveld diagrams showing the predominant behaviour of specimens during thermal demagnetisation.
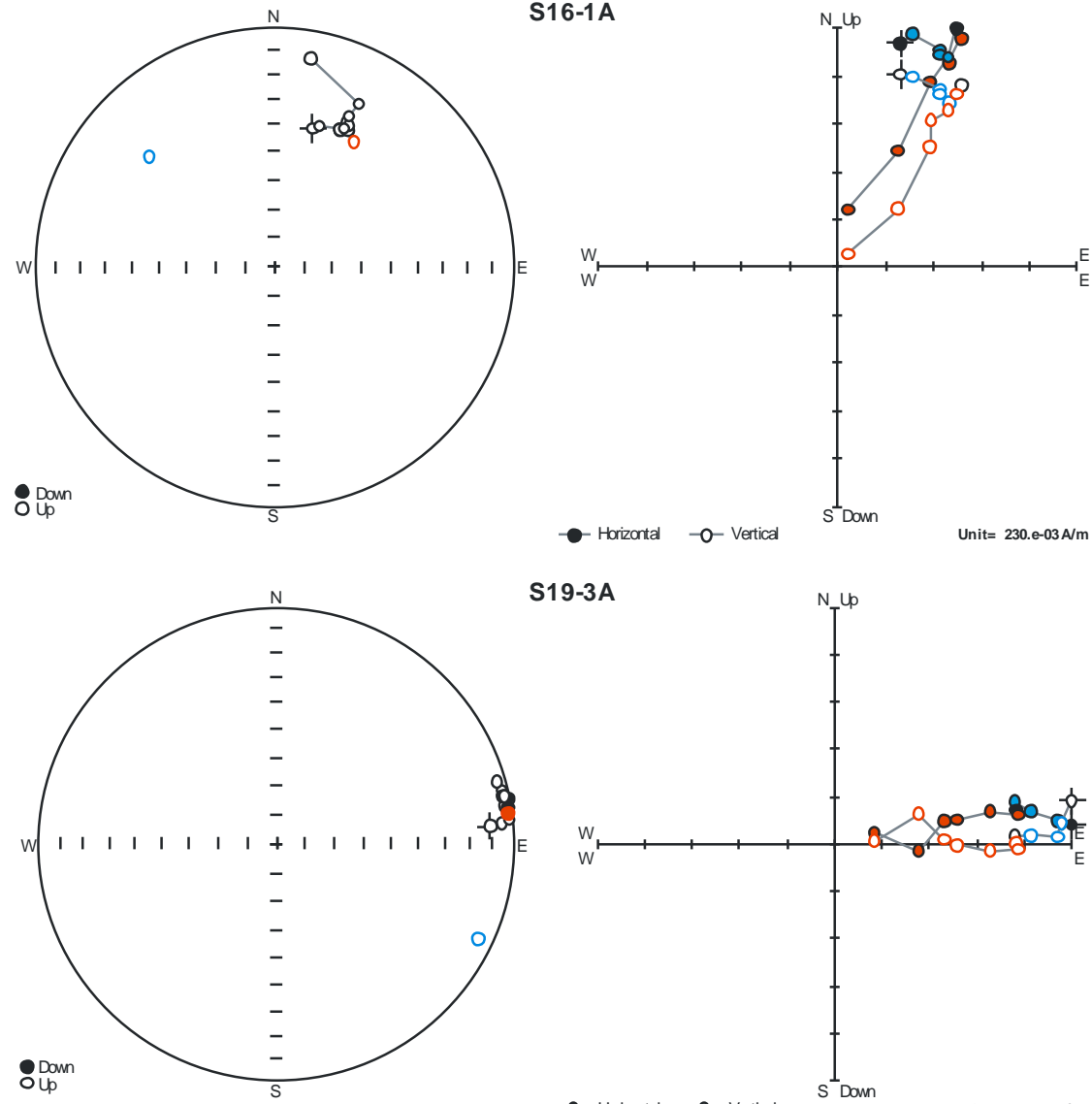

S19-3A

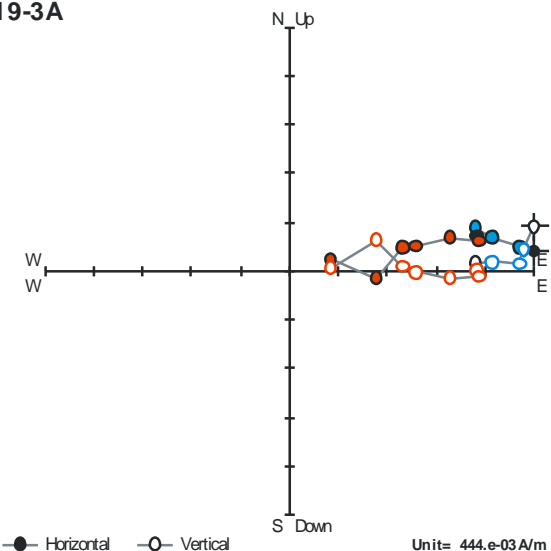


Principal component analysis (PCA) was carried out on sixteen specimens to identify high and/or low temperature components of magnetisation. The predominant behaviour of the suite of specimens is well-defined with a $C_{I}$ and $C_{h}$ component. The $C_{I}$ components have MAD's ranging from $6^{0}$ to $9.9^{\circ}$ and $T_{h}$ components have MAD's ranging from $0.5^{0}$ to $9.9^{0}$ (Figure 98):

- S16.1A has an NRM intensity of $1.45 \mathrm{~A} / \mathrm{m}$. It has a $\mathrm{C}_{1}$ component in a north-westerly and downward direction (declination, $D=311.5^{\circ}$, inclination, $\mathrm{I}=-30.8^{\circ}$, intensity of remanence analysed by PCA $=0.26 \mathrm{~A} / \mathrm{m}$ ), isolated between 50 and $200^{\circ} \mathrm{C}$, and a $\mathrm{C}_{\mathrm{h}}$ component in a more north-easterly and steeper direction $\left(D=32.5^{\circ}, I=-37.7^{0}\right.$, intensity $=1.28 \mathrm{~A} / \mathrm{m}$ ) isolated between 300 and $550^{\circ} \mathrm{C}$. Overall the remanence exhibits an increase at the 250 and $300^{\circ} \mathrm{C}$ temperature intervals before rapidly decreasing with temperature after the $450^{\circ} \mathrm{C}$ temperature step.

- S19.3A has an NRM intensity of $2.27 \mathrm{~A} / \mathrm{m}$. It has a $\mathrm{C}_{1}$ component in an easterly and downward direction $\left(D=115.1^{0}\right.$, inclination, $I=-6.7^{0}$, intensity of remanence analysed by PCA $=0.49 \mathrm{~A} / \mathrm{m}$ ), isolated between 50 and $200^{\circ} \mathrm{C}$, and $\mathrm{a} \mathrm{C}_{\mathrm{h}}$ component in a more easterly and upward direction $\left(D=82.5^{\circ}, I=1.5^{\circ}\right.$, intensity $=1.36 \mathrm{~A} / \mathrm{m}$ ) isolated between 300 and $550^{\circ} \mathrm{C}$. Overall the remanence exhibits a near linear decrease with temperature.

Some specimens do exhibit behaviour which differs from this predominant behaviour. Six of the 16 specimens exhibit a poorly-defined $C_{l}$ but well-constrained $C_{h}$ component. The $C_{l}$ components have MAD's ranging from $9.6^{\circ}$ to $17.1^{\circ}$ and the $C_{h}$ components have MAD's ranging from $0.5^{0}$ to $3.9^{0}$. All sixteen of the specimens exhibit some form of $C_{i}$ component, in most cases just a poorly-defined component occupying a blocking temperature interval of at least $50^{\circ} \mathrm{C}$ between the $\mathrm{C}_{\mathrm{I}}$ and $\mathrm{C}_{\mathrm{h}}$ components. Two of the specimen (S18.2B and S18.2C) exhibit well-defined $C_{i}$ components with MAD's of $1.9^{\circ}$ and $4.3^{\circ}$. Exceptions to the predominant behaviour include (Figure 99):

- S16.3A has an NRM intensity of $1.61 \mathrm{~A} / \mathrm{m}$. It has a $\mathrm{C}_{1}$ component in a north-westerly and downward direction (declination, $\mathrm{D}=286.1^{\circ}$, inclination, $\quad \mathrm{I}=-56.6^{\circ}$, intensity of remanence analysed by PCA $=0.31 \mathrm{~A} / \mathrm{m}$ ), isolated between 50 and $200^{\circ} \mathrm{C}$, and a $C_{h}$ component in a more easterly and shallower direction $\left(D=30.8^{\circ}, I=-37.7^{\circ}\right.$, 
intensity $=1.47 \mathrm{~A} / \mathrm{m}$ ) isolated between 300 and $550^{\circ} \mathrm{C}$. Overall the remanence exhibits an increase at the 250 and $300^{\circ} \mathrm{C}$ temperature intervals before rapidly decreasing with temperature after the $450^{\circ} \mathrm{C}$ temperature step.

- $\mathrm{S} 17.1 \mathrm{~B}$ has an NRM intensity of $2.08 \mathrm{~A} / \mathrm{m}$. It has a $\mathrm{C}_{\mathrm{I}}$ component in a easterly and downward direction $\left(D=72.2^{\circ}, I=-18.2^{\circ}\right.$, intensity of remanence analysed by $P C A=$ $0.16 \mathrm{~A} / \mathrm{m}$ ), isolated between 50 and $150^{\circ} \mathrm{C}$, and a $\mathrm{C}_{\mathrm{h}}$ component in a more northerly and upward direction $\left(D=30.0^{\circ}, I=51.5^{\circ}\right.$, intensity $\left.=1.41 \mathrm{~A} / \mathrm{m}\right)$ isolated between 300 and $550^{\circ} \mathrm{C}$. Overall the remanence remains stable until $100^{\circ} \mathrm{C}$ after which it exhibits a near linear decrease with temperature.

- $\mathrm{S} 18.2 \mathrm{~B}$ has an NRM intensity of $1.83 \mathrm{~A} / \mathrm{m}$. It has a $\mathrm{C}_{1}$ component in a north-easterly and downwards direction (declination, $D=39.4^{0}$, inclination, $I=-60.2^{0}$, intensity of remanence analysed by $P C A=0.27 \mathrm{~A} / \mathrm{m}$ ) isolated between 50 and $150^{\circ} \mathrm{C}$, a $\mathrm{C}_{\mathrm{i}}$ component in a southerly and upward direction $\left(D=197.9^{\circ}, I=43.2^{\circ}\right.$, intensity of remanence analysed by $P C A=0.48 \mathrm{~A} / \mathrm{m}$ ) isolated between 300 and $450^{\circ} \mathrm{C}$, and a $\mathrm{C}_{\mathrm{h}}$ component in a in a south-easterly and upward direction $\left(D=154.7^{\circ}, I=46.0^{\circ}\right.$, intensity of remanence analysed by PCA $=1.34 \mathrm{~A} / \mathrm{m}$ ) isolated between 450 and $550^{\circ} \mathrm{C}$.

As with the Lower Unit Investigation, the presence of two and in some cases three, components of magnetisation suggests that the clasts have a three stage thermal history. The $C_{h}$ components show strong correlation between specimens within clasts but no correlation between clasts, where the $C_{\mid}$components show some correlation both within and between clast but is much less well-defined (Figure 100). The $C_{\mid}$component has a mean direction of $28.6^{\circ}$ declination and $-66.6^{\circ}$ inclination with an $\alpha-95$ of $37.3^{0}$. It is most probably that this represents the ambient geomagnetic field at the time of emplacement (c. 3,600 ${ }^{14} \mathrm{C}$ yr B.P). There is no published palaeomagnetic data for this date from New Zealand, however one would expect a direction that deviates from that of a Geocentric Axial Dipole (GAD) field by no more that the generally accepted amplitude if secular variation i.e. declination of $0 \pm 15^{\circ}$ and an inclination of $58.5 \pm 15^{\circ}$. Despite the large $\alpha-95$, the mean $C_{\mid}$component is consistent with this. 

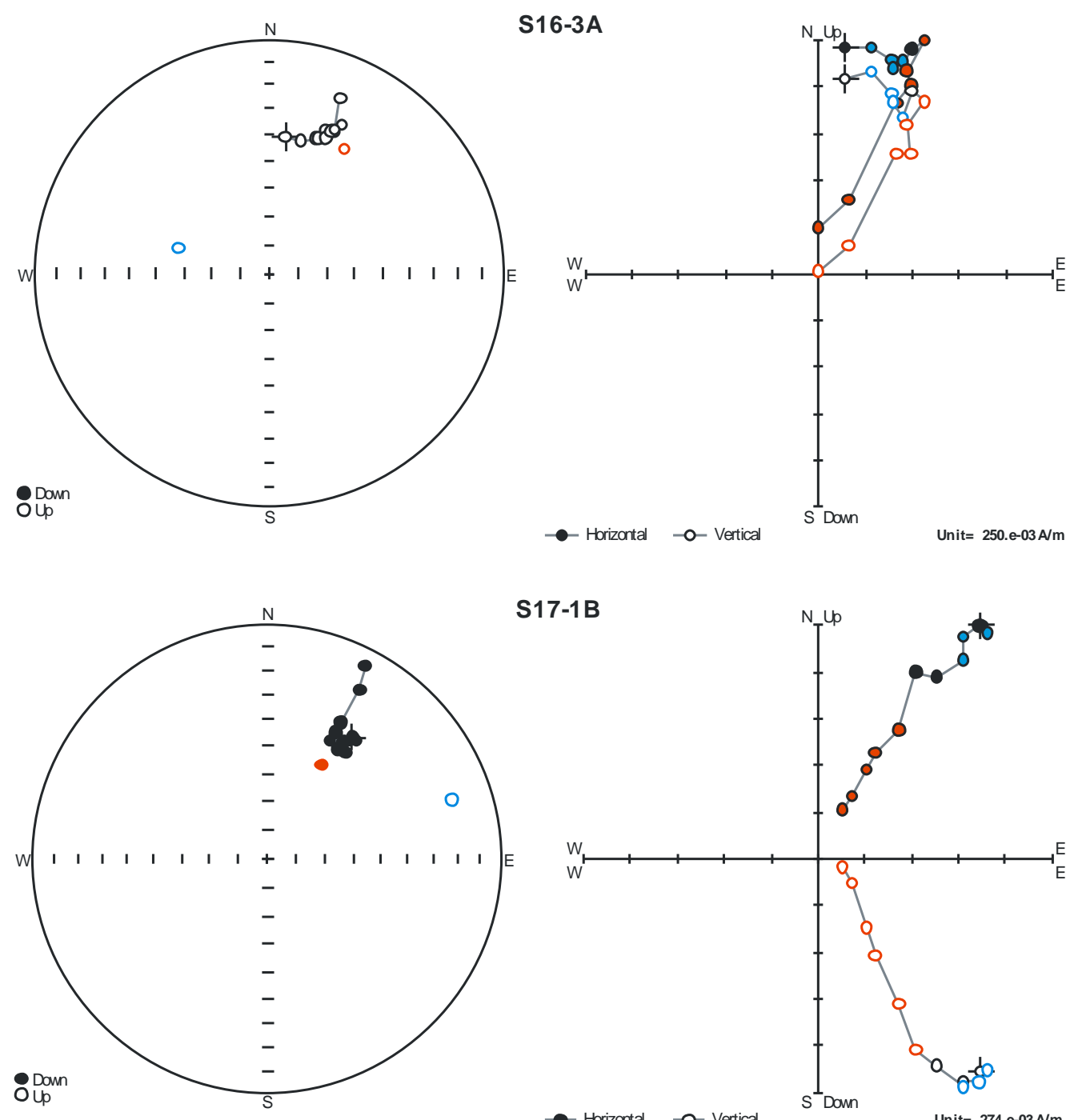

S17-1B
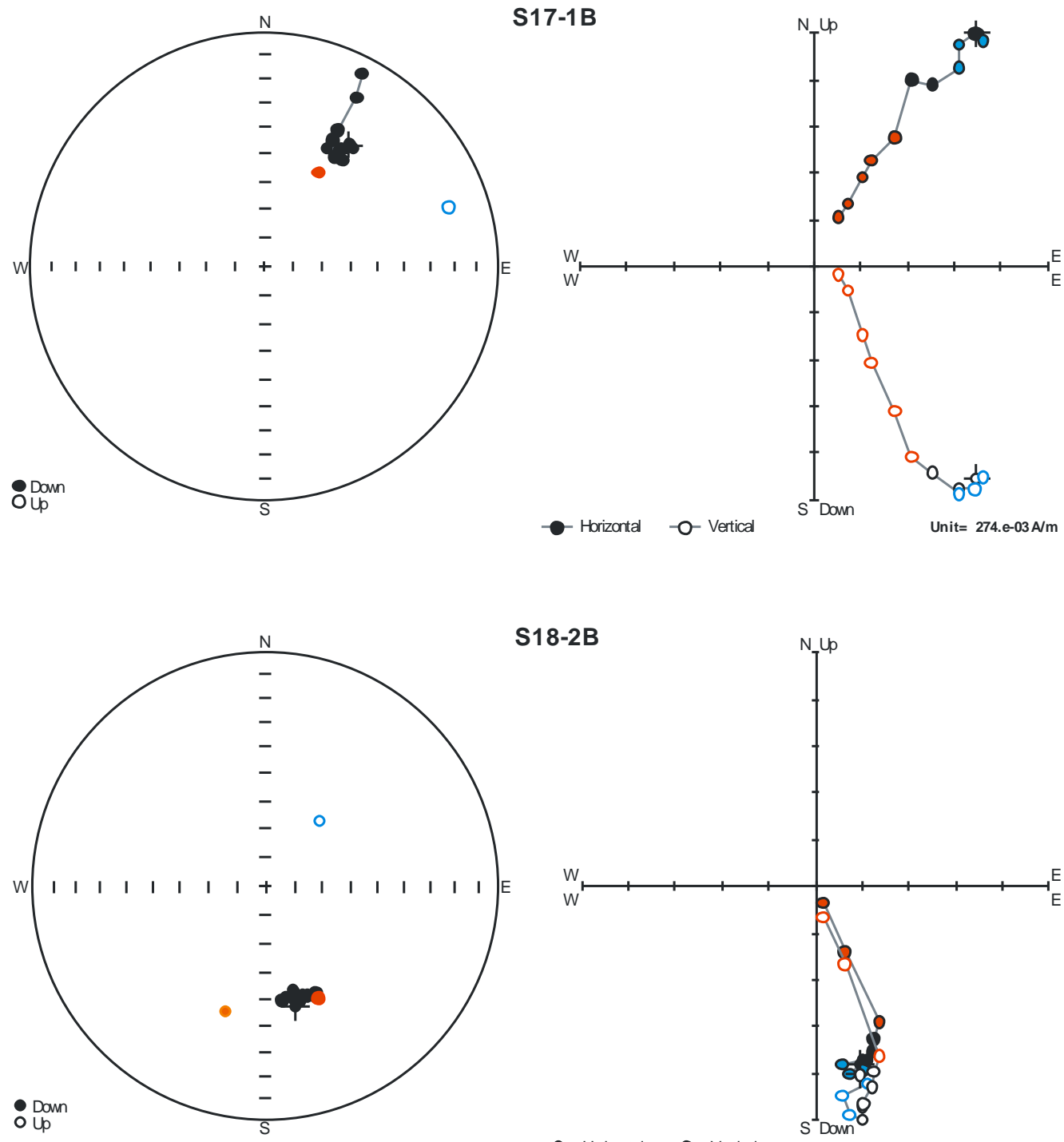

S18-2B

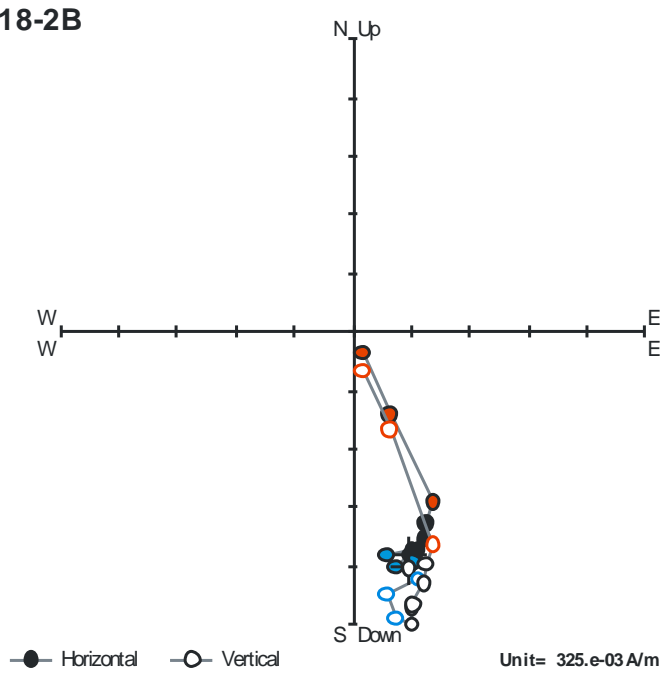

Figure 99: Lambert (equal area) stereoplots and Zijderved diagrams showing the behaviour of specimens which differs from the predominant behaviour shown in figure 98. 

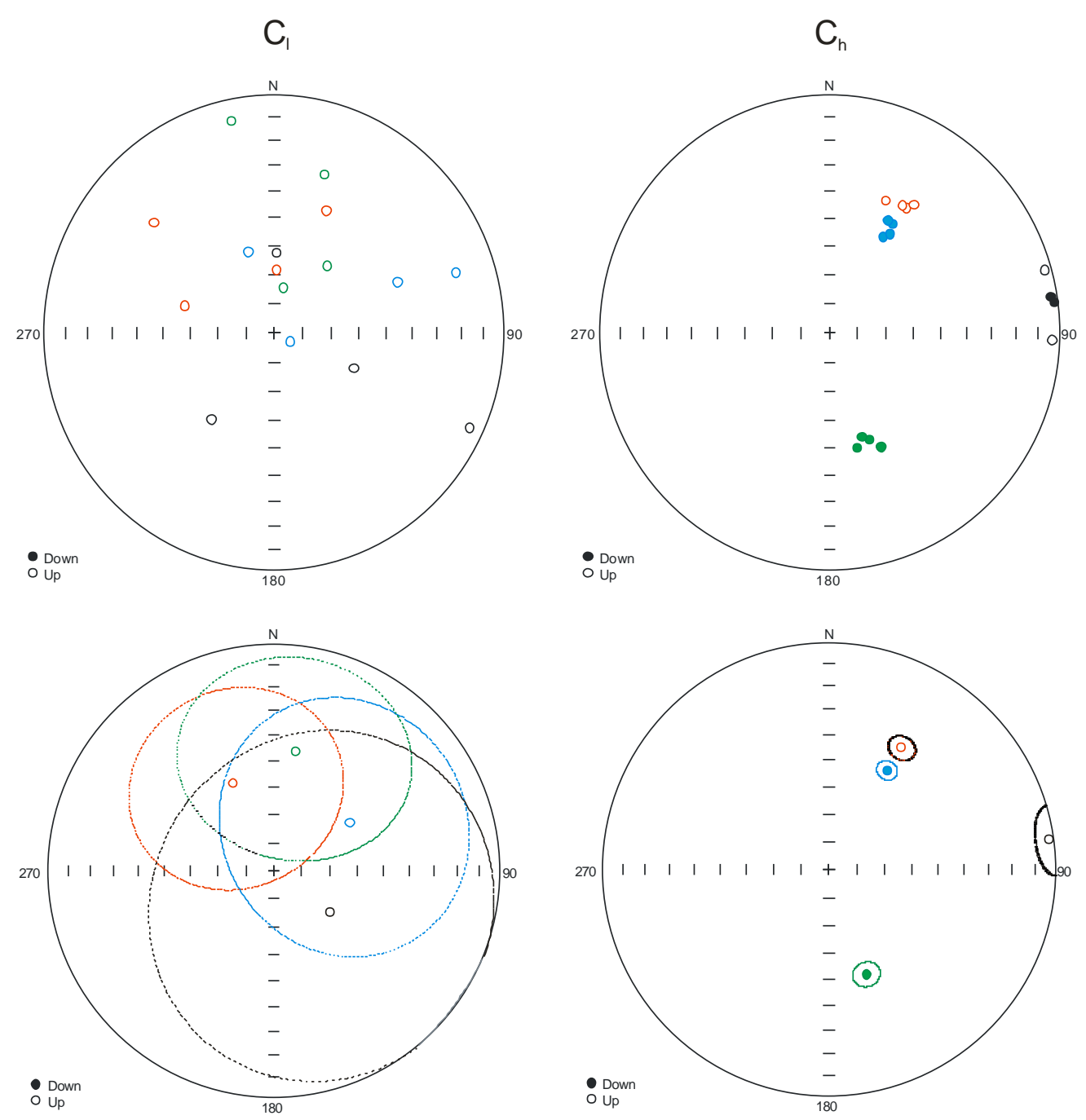

Figure 100: Stereoplots showing the low temperature $\left(C_{l}\right)$ (left) and high temperature $\left(C_{h}\right)$ (right) components of each specimen (top) and as a clast mean (bottom) - Clast S16 (orange); S17 (light blue); S18 (green); and S19 (black).

\subsubsection{Thermal History}

As with the Lower Unit Investigation, the thermal history of the deposit is based on principal component analysis from 16 specimens representing 4 clasts from Vickers Quarry. The stepwise thermal demagnetisation limits the maximum precision of any temperature estimate to the minimum demagnetisation step, which in this study is $50^{\circ} \mathrm{C}$. As previously discussed a modification of the conglomerate test is being used to determine the temperature at which a clast was deposited. This is considered the lowest temperature at which the $C_{h}$ component has been removed.

The temperature estimates are based of the method outline in the Lower Unit Investigation (Section 9.2.3) where an incorporation and emplacement temperature is estimated based on the $C_{1}, C_{i}$ and $C_{h}$ components. The highest temperature at which the $C_{1}$ component is preserved ranges from $100^{\circ} \mathrm{C}$ to $200^{\circ} \mathrm{C}$ (Table 9) and has a modal peak of $200^{\circ} \mathrm{C}$, mean of 
Preliminary Upper Unit Investigation - Principal Component Analysis

\begin{tabular}{|c|c|c|c|c|c|c|c|c|c|c|c|c|}
\hline \multicolumn{13}{|c|}{ Preliminary Upper Unit Investigation - Principal Component Analysis } \\
\hline Specimen & Declination & Inclination & MAD & Intensity & Temperature & Declination & Inclination & MAD & Intensity & Temperature & $\mathrm{Cl}$ & $\mathrm{Ch}$ \\
\hline $\mathrm{S} 16.1 \mathrm{~A}$ & 311.50 & -30.80 & 6.00 & 0.26 & $50-200$ & 32.50 & -37.70 & 2.80 & 1.28 & $300-550$ & 200 & 300 \\
\hline S16.1B & 23.90 & -43.20 & 6.40 & 0.34 & $50-200$ & 23.70 & -39.10 & 1.70 & 1.43 & $250-550$ & 200 & 250 \\
\hline S16.3A & 286.10 & -56.60 & 10.20 & 0.31 & $50-200$ & 30.80 & -37.70 & 2.50 & 1.47 & $300-550$ & 200 & 300 \\
\hline S16.3B & 1.90 & -62.40 & 11.20 & 0.21 & $50-200$ & 34.30 & -35.10 & 2.40 & 1.43 & $300-550$ & 200 & 300 \\
\hline S17.1B & 72.20 & -18.30 & 17.10 & 0.16 & $50-150$ & 30.10 & 51.50 & 2.90 & 1.41 & $300-550$ & 150 & 300 \\
\hline $\mathrm{S} 17.1 \mathrm{C}$ & 68.30 & -41.80 & 7.80 & 0.53 & $50-150$ & 30.90 & 45.50 & 3.20 & 0.98 & $250-550$ & 150 & 250 \\
\hline S17.3B & 118.40 & -83.50 & 11.50 & 0.23 & $50-150$ & 28.40 & 45.30 & 1.90 & 1.66 & $200-550$ & 150 & 200 \\
\hline $\mathrm{S} 17.3 \mathrm{C}$ & 341.60 & -60.60 & 11.80 & 0.22 & $50-200$ & 32.40 & 49.20 & 3.90 & 1.27 & $300-550$ & 200 & 300 \\
\hline $\mathrm{S} 18.1 \mathrm{~A}$ & 348.10 & -9.90 & 0.00 & 0.19 & $50-100$ & 166.20 & 48.70 & 2.30 & 1.31 & $250-550$ & 100 & 250 \\
\hline $\mathrm{S} 18.1 \mathrm{C}$ & 18.20 & -30.50 & 9.60 & 0.35 & $50-200$ & 158.70 & 50.40 & 0.50 & 2.02 & $350-550$ & 200 & 350 \\
\hline S18.2B & 39.40 & -60.20 & 19.20 & 0.27 & $50-150$ & 154.70 & 46.00 & 1.80 & 1.34 & $450-550$ & 150 & 450 \\
\hline $\mathrm{S} 18.2 \mathrm{C}$ & 11.70 & -74.30 & 6.00 & 0.27 & $50-150$ & 161.90 & 52.00 & 4.30 & 1.17 & $300-550$ & 150 & 300 \\
\hline S19.1A & 216.80 & -52.40 & 9.90 & 0.24 & $50-150$ & 74.30 & -3.00 & 3.50 & 0.85 & $350-550$ & 150 & 350 \\
\hline S19.1B & 113.30 & -59.00 & 9.20 & 0.57 & $50-200$ & 91.80 & -3.50 & 7.30 & 1.54 & $300-550$ & 200 & 300 \\
\hline S19.3A & 115.10 & -6.70 & 8.30 & 0.49 & $50-200$ & 82.50 & 1.50 & 9.90 & 1.36 & $300-550$ & 200 & 300 \\
\hline S19.3B & 1.80 & -68.50 & 0.00 & 0.15 & $50-100$ & 81.10 & 2.90 & 1.50 & 1.40 & $300-550$ & 100 & 300 \\
\hline
\end{tabular}

\begin{tabular}{|c|c|c|c|c|c|c|}
\hline Specimen & Declination & Inclination & $\alpha 95$ & Declination & Inclination & $\alpha 95$ \\
\hline S16 & 335.00 & -55.00 & 37.90 & 30.40 & -37.50 & 4.60 \\
\hline S17 & -57.60 & -57.30 & 46.70 & 30.40 & 47.90 & 3.60 \\
\hline S18 & 10.20 & -45.50 & 39.90 & 160.30 & 49.40 & 4.70 \\
\hline S19 & 126.30 & -64.90 & 65.70 & 82.40 & -0.50 & 9.00 \\
\hline Mean & 28.60 & -66.60 & 37.30 & 68.20 & 22.80 & 107.00 \\
\hline
\end{tabular}

Table 9: Table of the Principle Component Analysis (PCA) results for the main lower unit investigation. The table includes the $C_{l}$ and $C_{h}$ components with their declination, inclination and $\alpha 95$ angles. 
$170^{\circ} \mathrm{C}$ and median of $175^{\circ} \mathrm{C}$. The lowest temperature at which the $\mathrm{C}_{\mathrm{h}}$ component is preserved ranges from $200^{\circ} \mathrm{C}$ to $450^{\circ} \mathrm{C}$ (Table 9) and has a modal peak, mean and median of $300^{\circ} \mathrm{C}$. Based on these results, the Te Popo Formation is considered to have a mean incorporation temperature estimate of $300^{\circ} \mathrm{C}$ and a mean emplacement temperature estimate of $170-200^{\circ} \mathrm{C}$ (Figure 101). The mean amount the clast cooled between incorporation and emplacement is estimated to be $130^{\circ} \mathrm{C}$.

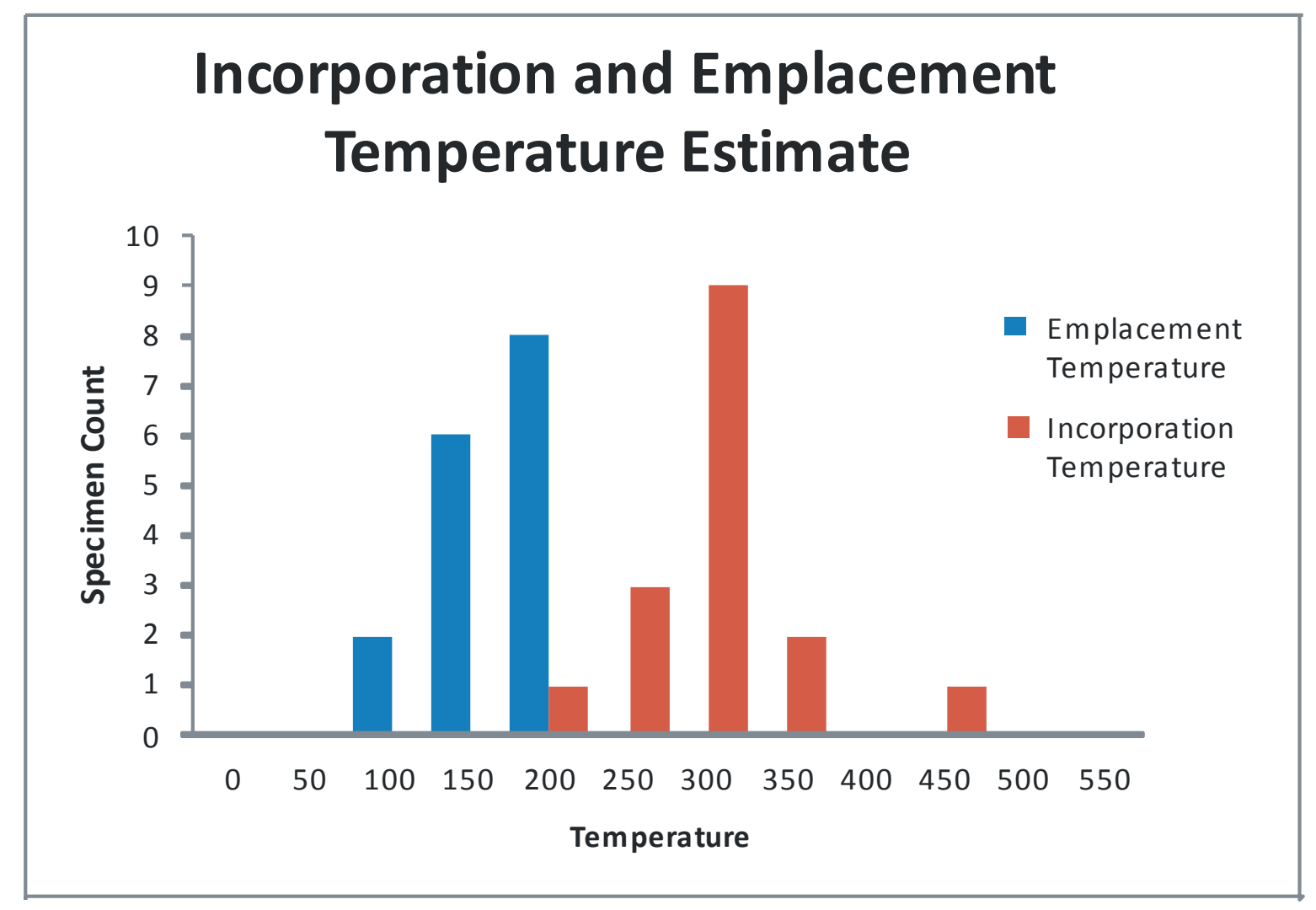

Figure 101: Plot showing the incorporation and emplacement temperature estimates based on PCA outlined in Table 9. 


\section{Chapter Four: Discussion}

\section{Internal Architecture}

\subsection{Distribution}

In this study, deposits of the Ngatoro Formation were described at eight locations within Egmont National Park and the surrounding ring plain ranging between 2 and $24 \mathrm{~km}$ from the present day Egmont Volcano summit (Figure 20, Section 1, Chapter Two). These included catchments of the:

- Manganui River from the Manganui Ski Field, down through Vickers Quarry to the Manganui River Bridge on Tarata Road.

- Mangawhete Stream from the boundary of Egmont National Park on Surrey Road to the junction of the Mangawhete Stream with the Manganui River.

These locations confirm the distribution of the Ngatoro Formation outlined by Alloway et al. (1989) and presented by Neall and Alloway (2004) who described the Ngatoro Formation within the Ngatoro, Ngatoroiti, Maketawa, Mangatengehu Streams and the Manganui River.

\subsection{Deposit Characteristics}

The textural and bedding characteristics of mass flow deposits provide a means for determining the emplacement mechanisms, flow types and transformations, and stratigraphic correlation of the Ngatoro Formation. These characteristics include stratigraphic position, texture, sorting, bedding, sedimentological features and contact geometry. The characteristics of deposits of the Ngatoro Formation are presented in the Table 10 below: 
Table 10: Block-and-ash, debris and hyperconcentrated flow deposit characteristics of the Ngatoro Formation described in this study. Modification of the Table 2 presented in Section 2, Chapter One.

\begin{tabular}{|c|c|c|}
\hline Deposit Type & Sedimentary Characteristics & Other Features \\
\hline $\begin{array}{l}\text { Block and Ash Flows } \\
\text { Channel } \\
\text { Overbank Surge }\end{array}$ & $\begin{array}{l}\text { - } \quad \text { Dominantly clast supported. } \\
\text { - } \quad \text { Predominantly monolithologic. } \\
\text { - } \quad \text { Mngular to sub-angular pebble-to boulder-sized } \\
\text { - } \\
\text { - } \quad \text { Fine to medium sand and silt } \\
\text { - } \quad \text { Well sorted } \\
\text { - } \quad \text { Alternating silt/fine to medium sand and fine to } \\
\text { - } \quad<0.3 m \text { thick. }\end{array}$ & $\begin{array}{l}\text { Basally erosive contact overlying } \\
\text { lava flow and auto-breccia } \\
\text { deposits. } \\
\text { Repeating undifferentiated units. } \\
\text { Sharp and irregular basal contact. } \\
\text { Deposited on margins of the } \\
\text { Manganui Valley. }\end{array}$ \\
\hline $\begin{array}{l}\text { Debris Flow Deposits (Non-cohesive mass } \\
\text { flow deposits) }\end{array}$ & 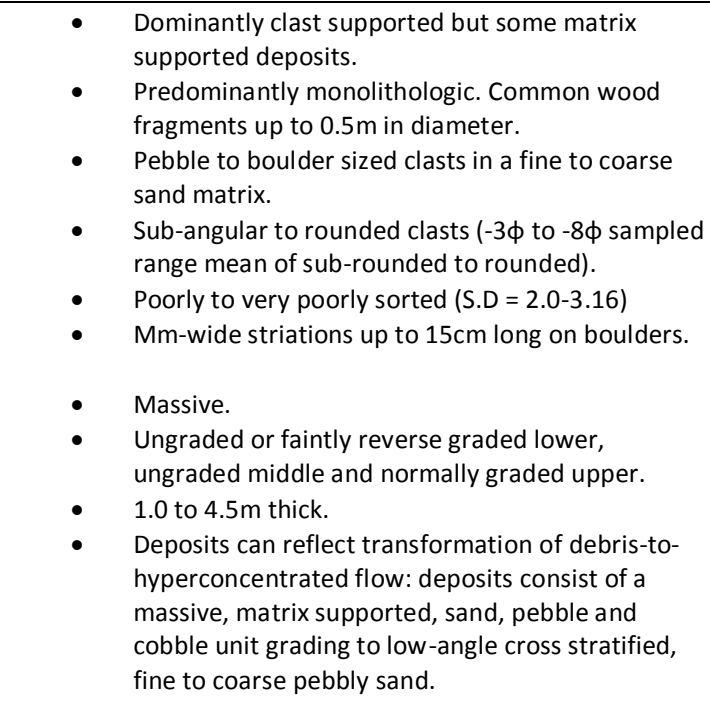 & \\
\hline 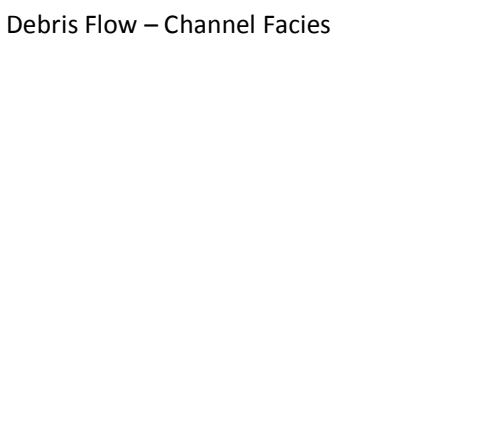 & $\begin{array}{l}\text { Dominantly clast supported with subordinate } \\
\text { pebble and sand matrix. } \\
\text { Very coarse, pebble to boulder sized clasts (up to } \\
\text { - } 2.0 \mathrm{~m} \text { ). } \\
\text { - } \quad \text { Very poorly to extremely poorly sorted. } \\
\text { - } \quad \text { Up to } 5.0 \mathrm{~m} \text { thick. } \\
\text { - } \quad \text { Grades upwards to weakly low angle cross- } \\
\text { - } \quad \text { Lenses of massive to faintly stratified, normally } \\
\text { graded, pebbly fluvial sand deposits due to rapid } \\
\text { post-depositional reworking. }\end{array}$ & $\begin{array}{l}\text { Erosional basal contact. } \\
\text { Confined to the erosive channels. }\end{array}$ \\
\hline Debris Flow - Marginal Facies & $\begin{array}{l}\text { - } \quad \text { Moderately to poorly sorted, sandy pebble and } \\
\text { pebbly sand deposits becoming progressively } \\
\text { coarser and more poorly sorted towards the } \\
\text { channel. } \\
\text { - } \quad \text { Faintly stratified to massive repeating units. } \\
\text { - Ungraded } \\
\text { Up to } 1.0 \mathrm{~m} \text { thick - becoming thinner with distance } \\
\text { from the channel. }\end{array}$ & $\begin{array}{l}\text { Non-erosive. } \\
\text { Wedge shaped - thins away from } \\
\text { channel. }\end{array}$ \\
\hline $\begin{array}{l}\text { Hyperconcentrated Flow Deposits } \\
\text { HCF - Channel Facies }\end{array}$ & $\begin{array}{l}\text { - } \quad \text { Fine to coarse sand with some pebbles and rare } \\
\text { boulders }(0.5 \mathrm{~m}) \text {. } \\
\text { - } \quad \text { Moderately to poorly sorted. } \\
\text { - } \quad>0.5 \mathrm{~m} \text { thick. } \\
\text { - }\end{array}$ & $\begin{array}{l}\text { Erosional basal and contacts. } \\
\text { Confined to erosional channels. }\end{array}$ \\
\hline
\end{tabular}




\begin{tabular}{|c|c|c|}
\hline HCF - Marginal Facies & $\begin{array}{l}\text { - } \quad \text { Fine to coarse sand with some pebbles and few } \\
\text { cobble sized clasts. } \\
\text { - } \quad \text { Poorly to moderately sorted. } \\
\text { - } \quad \text { dm to cm-bedded cross-stratified to planar parallel } \\
\text { sands. } \\
\text { - } \quad \text { Normally graded to ungraded. } \\
\text { - } \quad \text { Typically } 0.1 \text { to } 0.8 m \text { thick } \\
\text { - } \quad \text { Occurence of pumice "trains" and aligned clasts. } \\
\text { - } \quad \text { Flame and convolute dewatering structures. } \\
\text { - } \quad \text { Rip-ups of underlying deposits. }\end{array}$ & $\begin{array}{l}\text { Typically non-erosive, although } \\
\text { rip-up indicate minor erosion. }\end{array}$ \\
\hline Sole Layer & $\begin{array}{l}\text { - } \quad \text { Massive to low angle cross stratified. } \\
\text { - } \quad \text { Fine to coarse sand (proximal) to silty fine sand } \\
\text { - } \quad \text { Ungrermediate/distal). } \\
\text { - } \quad \text { Repeated to normally graded. } \\
\text { - }\end{array}$ & $\begin{array}{l}\text { Non-erosional and typically at } \\
\text { the base of a } \\
\text { debris/hyperconcentrated flow } \\
\text { deposit. Discontinuous and often } \\
\text { truncated by overlying df and hcf } \\
\text { deposits }\end{array}$ \\
\hline
\end{tabular}

\subsubsection{Debris Flow Deposits}

Debris flow deposits of the Ngatoro Formation are generally confined to the proximal locations within 14 km from source (Vickers Quarry, Surrey Road Quarry and York Road). These deposits are typically massive, poorly to very poorly sorted (S.D = 2.0-3.16), clast supported, monolithologic. pebble to boulder sized, sub-angular andesite clasts in a fine to coarse sand matrix (VQ-1, Unit 6; VQ-2, Unit 7; SQ-2, Unit 5). Deposits have an ungraded or faintly reverse graded lower, ungraded middle and normally graded upper, ranging from 1.0 to $4.5 \mathrm{~m}$ in thickness and associated with charred wood, both entrained and as in situ tree trunks. Deposits can reflect the transformation from debris-to-hyperconcentrated flows with massive, matrix-supported, sand-, pebble- and cobble-rich deposits grading to lowangle cross stratified, fine to coarse pebbly sand (SQ-2, Unit 6). The base of debris flow deposits are commonly underlain by a sole layer comprising massive to low angle crossstratified, fine to coarse sand and silt (Figure 102). These layers are typically less than $0.1 \mathrm{~m}$ thick but in some instances up to $0.3 \mathrm{~m}$ thick. The sole layer is not preserved at all locations either due to non-deposition but more commonly through erosion by the downstream passage of subsequent debris flow events. Sandy-textured debris flow deposits are also observed at distal locations (Suffolk Road and Kaimata Sawmills). These distal deposits are typically massive, poorly sorted, pebbly fine to very coarse sand (MG-1, Unit 6). Deposits are normally graded to ungraded and up to $0.5 \mathrm{~m}$ in thickness. 


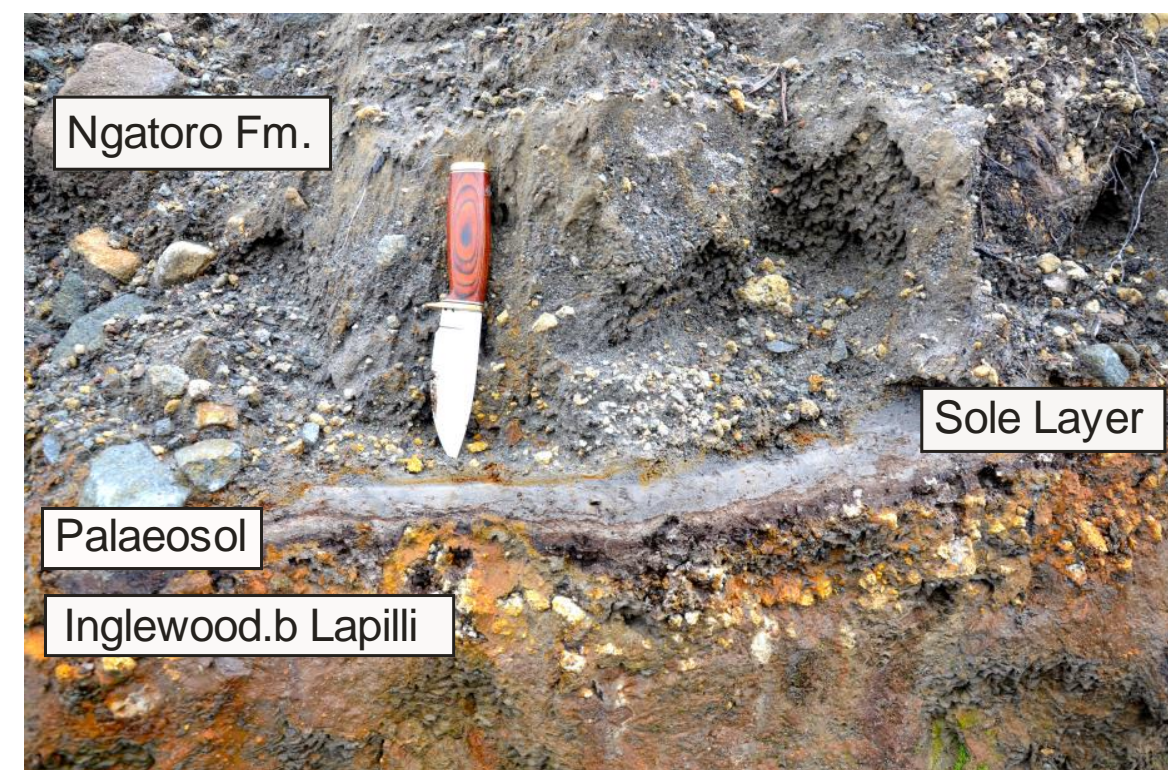

Figure 102 (Left): Normally graded, fine sand to silt, sole layer at the base of the Ngatoro Formation

\subsubsection{Hyperconcentrated Flow Deposits}

Hyperconcentrated flow deposits of the Ngatoro Formation are constrained to the intermediate and distal localities $>10 \mathrm{~km}$ from the modern summit (Tariki-SH3, Tariki Underpass, Suffolk Road and Kaimata Sawmills). These deposits are typically poorly to moderately sorted sands with some pebbles and a few cobble-sized clasts. Deposits are 0.1 to $0.8 \mathrm{~m}$ thick, repeated units of channelised, cross-stratified lower to laminated upper, normally graded to ungraded with sedimentary structures such as flame dewatering structures, convolute bedding, rip-ups of underlying deposits, pumice 'trains' and aligned clasts (TR-1, Units 6, 7 \& 8; TU-2, Units 10 \& 12). The repeated units are underlain and interbedded with $<0.05 \mathrm{~m}$ thick, massive, fine sandy silt sole layers that exhibit load deformation structures (TU-2, 7, 9 \& 11; SF-1, Unit 3; MG-1, Unit 4).

\subsection{Lateral and Longitudinal Variability}

\subsubsection{Proximal}

Deposits of the Ngatoro Formation exhibit lateral textural variability with distance from Egmont Volcano. Within the confines of the Manganui Valley inside Egmont National Park (EE-1, $2.7 \mathrm{~km}$ from the modern summit) the Ngatoro Formation is manifested as a $<0.2 \mathrm{~m}$ thick, bedded to low angle cross-stratified, alternating silt/fine sand and fine to medium sand interpreted to be an overbank surge deposits (EE-1, Unit 8) (Figure 103). These surge deposits mantle the topographically high margins of the Manganui River and extend down 
the valley towards the ring plain. At the boundary of Egmont National Park at the Vickers Quarry (VQ-1, VQ-2 \& VQ-3, 10 km from the modern summit) and Surrey Road Quarry (SQ1, SQ-2 and SQ-3, $10 \mathrm{~km}$ from the modern summit) the Ngatoro Formation is manifested as a 2.0 to 5.0 m thick, massive, poorly to very poorly sorted, monlithologic, pebble to boulder (up to $2.0 \mathrm{~m}$ ) channel debris flow deposits with common charred wood fragments (VQ-1, Unit 6; SQ-2, Unit 5) (Figure 103 and 104). The debris flow deposits typically overly a $<0.1 \mathrm{~m}$ thick, organic rich well-developed paleosol and in places a massive, normally graded, fine sand to silt sole layer. In places the debris flow deposits are overlain by $<0.15 \mathrm{~m}$ thick, low angle cross-stratified, fine to coarse sand with some pebbles interpreted to be hyperconcentrated flow deposits (SQ-2, Unit 6).

Marginal deposits of the proximal Ngatoro Formation (800m from Vickers Quarry) occur at York Road as $<2.0 m$ thick, massive, poorly sorted, fine to coarse sand with some matrixsupported sandy deposits (YR-1, Unit 9 \& 10) (Figure 104). The basal contact is non-erosive with the debris flow deposits overlying $<0.05 \mathrm{~m}$ thick, massive, fine to coarse sand and fine pebble sole layer (YR-1, Unit 7).

The marginal deposits are typically thinner, matrix supported, better sorted and finer textured with a unimodal grainsize peak and predominantly bladed clasts in comparison to the clast supported, very coarse textured, channel deposits which exhibit a bimodal grainsize distribution and comprise predominantly of compact-bladed clasts (Figure 104). Both channel and marginal deposits are massive and poorly sorted without sedimentary structures indicative of a single phase flow.

\subsubsection{Intermediate}

On the Egmont ring plain (TU-1, TU-2, TU-3 \& TU-4, 17.1 to $17.3 \mathrm{~km}$ from the modern summit) Ngatoro Formation at Tariki Underpass occurs predominantly as channel deposits comprising 1.0 to $2.0 \mathrm{~m}$ thick, massive to faintly stratified, poorly sorted fine to coarse sandy hyperconcentrated flow deposits with some pebbles, cobbles and a few boulders $(0.5 \mathrm{~m})$ (TU-3, Units 1 \& 3) (Figure 105). In places the channel deposits are massive, poorly sorted, pebble and cobble debris flow deposits, matrix-supported in a fine to coarse sand matrix (TU-3, Unit 2). The channel deposits typically have erosional lower contacts. 


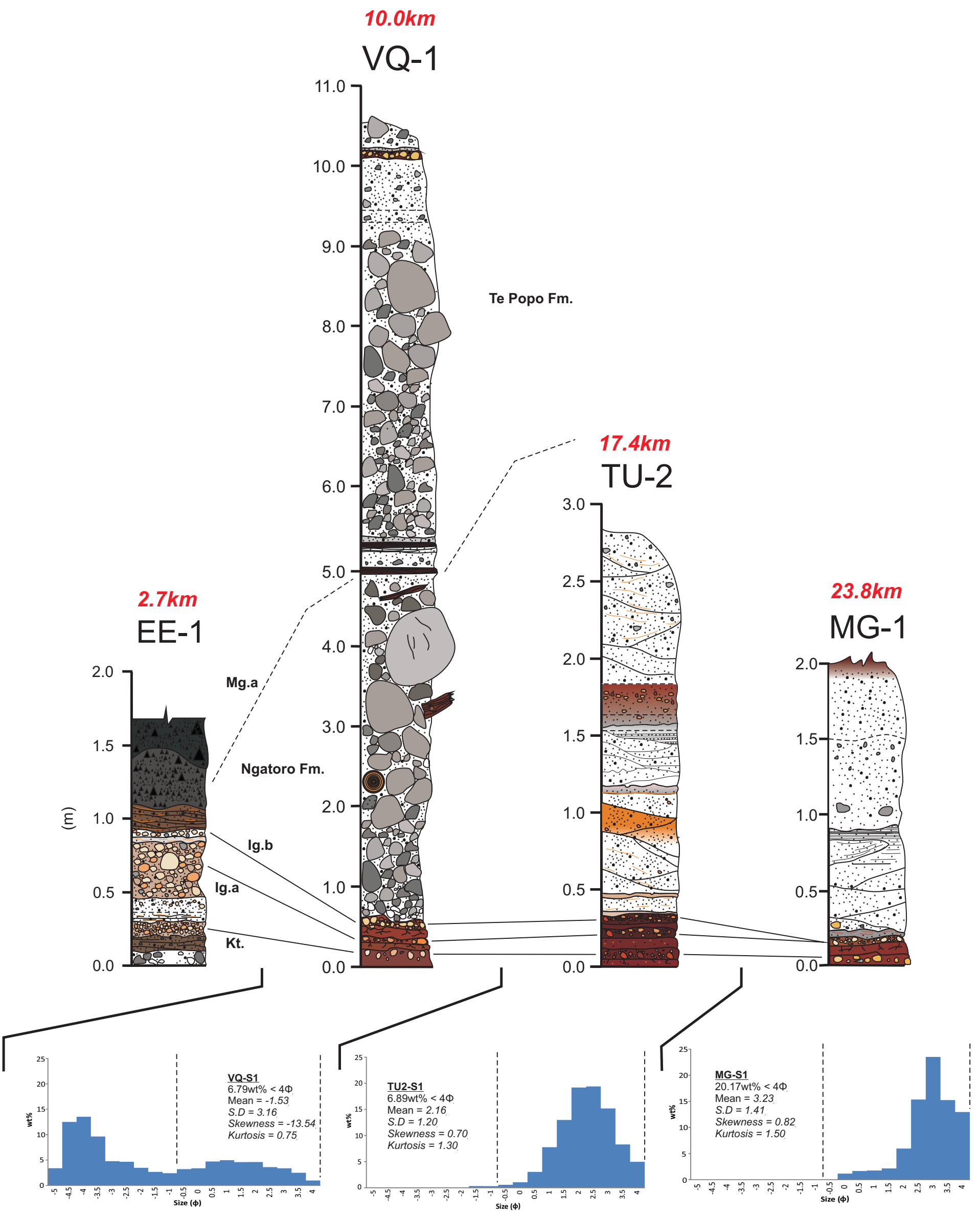

Proximal

Figure 103: Measured sections indicating the transition from proximal pyroclastic surge and debris flow deposits to intermediate and distal hypercocnentrated flow deposits. Grain size histograms show the deposits becoming more sorted and fine grained with distance from Egmont Volcano. 


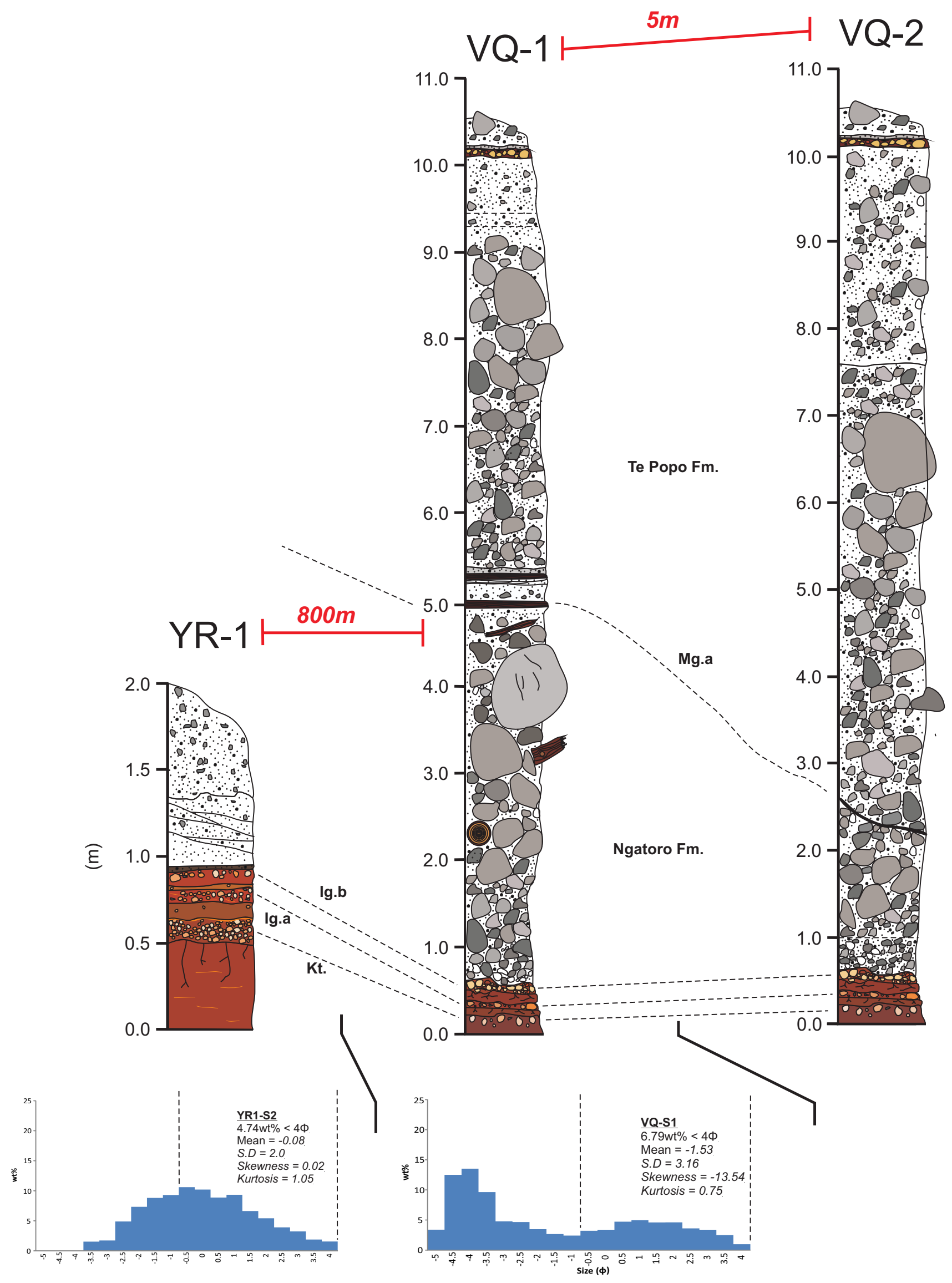

Marginal

Figure 104: Measured sections indicating the transition from thick, axial cobble and boulder rich debris flow deposits to thin, marginal pebbly sand debris flow deposits. Grain size histograms show the deposits becoming more sorted and fine grained with distance from the channel axis. 

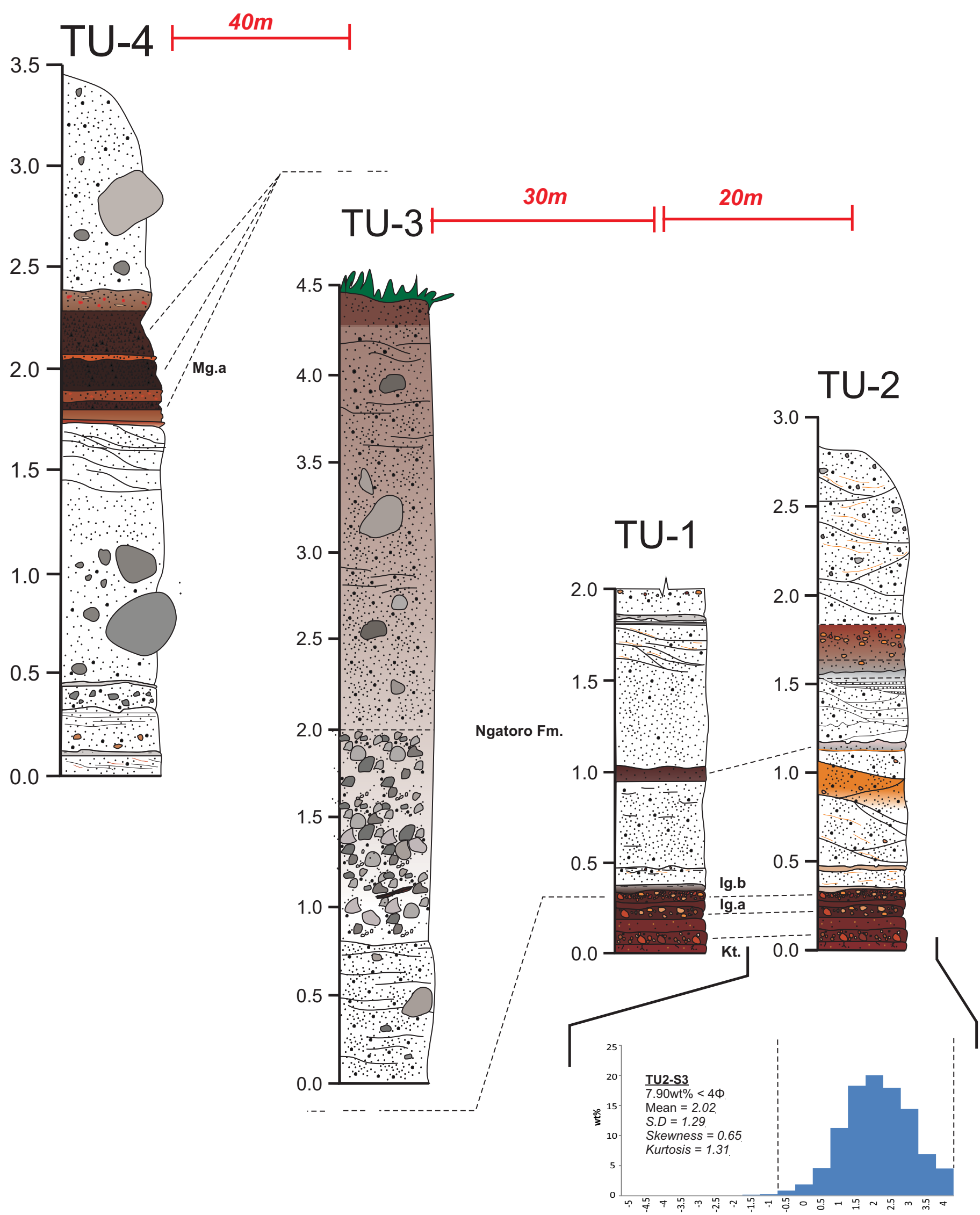
The marginal deposits of the intermediate Ngatoro Formation (TU-1 \& TU-2) are typically 0.1 to $0.8 \mathrm{~m}$ thick, low angle cross-stratified to laminated, poorly to moderately sorted, sandy deposits with some pebbles (TR-1, Units 6, 7 \& 8; TU-2, Units 10 \& 12) (Figure 105). These marginal deposits exhibit unimodal and bimodal grain size distributions, and sedimentary structures such as flame dewatering structures, convolute bedding, rip-ups of underlying deposits, pumice 'trains' and aligned clasts that are interpreted as hyperconcentrated flow deposits. These deposits are underlain and interbedded with massive to normally graded, well sorted, unimodal fine sand to silt sole layers.

Marginal deposits are typically thinner, cross-stratified to laminated, better sorted and finer textured with single and bimodal grainsize distributions in comparison to the thicker, massive to faintly stratified, poorly sorted, coarser textured channel deposits (Figure 105). In comparison to the proximal debris flow deposits at Vickers Quarry and Surrey Road Quarry (Figure 103), the intermediate deposits are thinner, finer textured, better sorted, stratified and exhibit sedimentary structures indicative of a flow with both a solid and fluid phase.

\subsubsection{Distal}

At distal locations (SF-1 \& MG-1, c. $22 \mathrm{~km}$ from the modern summit) the Ngatoro Formation occurs as a $<0.7 \mathrm{~m}$ thick, stratified fine to coarse sandy deposit with some entrained fine to coarse pumice lapilli eroded from the underlying Inglewood Tephra and repeating cut and fill structures, interpreted as hyperconcentrated flow deposits (SF-1, Unit 6; MG-1, Unit 5). The deposits exhibit a generally unimodel and fine textured grain size distribution. These are overlain by a massive, fine textured, bimodally distributed, poorly sorted fine to medium pebbly sand debris flow deposit (SF-1, Unit 5; MG-1, Units 6 \& 7). The distal Ngatoro Formation is typically underlain by a $<0.05 \mathrm{~m}$ thick, massive, fine sand and silt normally grading to silt deposit interpreted as a sole layer (SF-1, Unit 3; MG-1, Unit 4). The sole layer is well-sorted and exhibits a fine textured, unimodal grainsize distribution. In comparison to the intermediate deposits at Tariki-SH3 and Tariki Underpass (Figure 103), distal deposits are typically thinner, finer textured and better sorted. 


\section{Emplacement History}

\subsection{Precursory Events}

The existing tephra framework for Holocene eruptive events on Egmont Volcano indicates that the Ngatoro Formation is underlain by two closely spaced pumiceous lapilli beds (Alloway et al., 1995; Neall, 1972). These lapilli beds are the widely dispersed informal Inglewood.a and Inglewood.b subunits of the Inglewood Tephra (c. $3,600{ }^{14} \mathrm{C}$ yrs B.P.). The Inglewood tephra is associated with two closely spaced plinian eruptions from Egmont Volcano that deposited juvenile pumiceous material throughout north-east Taranaki and extending to the Waikato (Lowe, 1988). The Inglewood Tephra was described at all eight of the locations studied, either as the Inglewood.a and Inglewood.b subunits at proximal sections (East Egmont, Vickers Quarry, Surrey Road Quarry and York Road) and intermediate sections (Tariki - SH3 and Tariki Underpass) or as a single, pumiceous lapilli bed at distal sections (Suffolk Road and Kaimata Sawmills). The current understanding of the deposition of the Ngatoro Formation is that is "closely followed" the eruption of the Inglewood Tephra (Alloway et al., 1995). However, well-developed paleosols consistently identified between the Inglewood Tephra and overlying Ngatoro Formation suggests that that these events are closely related in time but represent separate events (Figure 106).

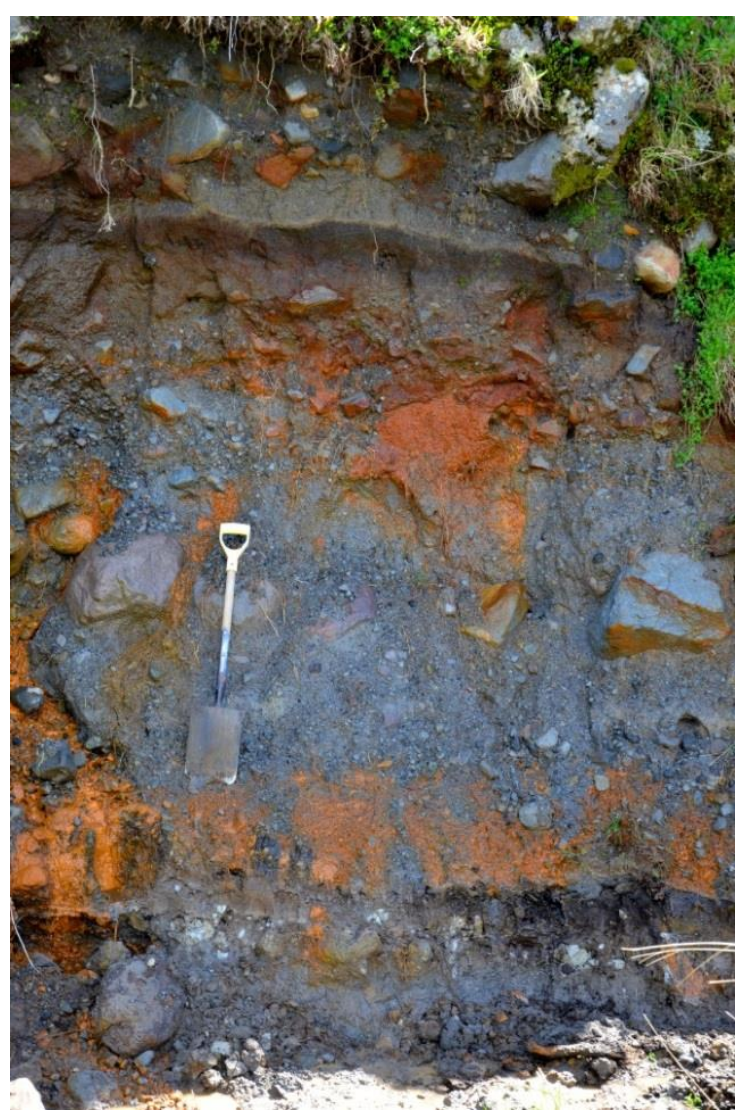

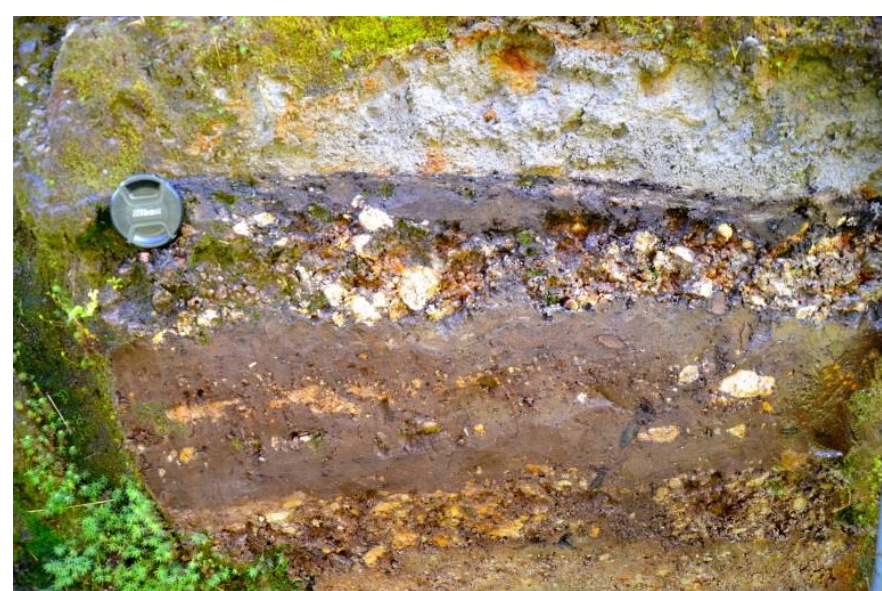

Figure 106: Photographs of the well-developed paleosol between the underlying Inglewood.b subunit and overlying Ngatoro Formation debris flow deposits. The paleosol is shown at Surrey Road Quarry (Left) at the base of the spade and at Vickers Quarry marked by the camera lense cap (Photo courtesy of B. Alloway). 
This paleosol represents an intervening hiatus between deposition of Inglewood and Ngatoro Formation where pedogenic processes predominated in favour of volcanigenic deposition. Organic rich paleosols were described at Vickers Quarry (VQ-1, Unit 7), Surrey Road Quarry (SQ-2, Unit 4) and Tariki-SH3 (TR-1, Unit 4), and at the remaining sections the Inglewood Tephra was expressed as a pumiceous lapilli within a silty, ash soil (e.g. MG-1, Unit 3). As this prominent paleosol is observed at multiple locations, both proximal and distal, it is evidence to suggest the emplacement of the Ngatoro Formation is not a syneruptive process directly related to the deposition of the Inglewood Tephra, but rather a separate volcaniclastic event and may be attributed to a hitherto previously unrecognised extended phase of the Inglewood eruption event.

\subsection{Emplacement Mechanism}

With evidence such as the underlying paleosol and absence of juvenile pumiceous clasts within its deposits suggesting the emplacement of the Ngatoro Formation occurred sometime after the emplacement of the Inglewood.a and Inglewood.b lapilli beds an emplacement mechanism must be determined. Common mass flow generating mechanisms outlined in Section 2.3, Chapter One include; transformation of edifice collapse generated debris avalanches; lateral transformation of pyroclastic flows; and rainfall-induced destabilisation of unstable volcaniclastic material.

Within Egmont National Park at section EE-1 the Ngatoro Formation is expressed as fine grained pyroclastic surge deposit (EE-1, Unit 8) enveloped by the Inglewood.b and Manganui.a subunits (EE-1, Units 7 \& 9). The pyroclastic surge deposit may be an overbank surge deposits associated with one of the many undifferentiated, massive, monolithologic, cobble- and boulder-rich block-and-ash flow deposits within the Manganui Valley. This suggests that the debris and hyperconcentrated flow deposits described beyond the confines of Egmont National Park transformed from proximal block-and-ash flows. Debris flow deposits described at Vickers Quarry (VQ-1, Units 6 \& 7) and Surrey Road Quarry (SQ-2, Unit 5) indicate the block-and-ash flows within the Manganui and Mangatenghu Rivers transformed to water supported debris flows within $10 \mathrm{~km}$ of the summit of Egmont Volcano. 
The generation of block-and-ash flows not directly related to volcanic events such as the emplacement of the Inglewood Tephra is generally through the gravitational collapse of an effusive lave dome. The collapse of lava domes is identified in the eruptive history of Egmont Volcano (Platz et al., 2007) and also has been observed at Soufriere Hills Volcano (Cole et al., 2002; Stinton et al., 2014; Wadge et al., 2014), Merapi Volcano (Charbonnier and Gertisser, 2008) and Unzen Volcano (Ui et al., 1999). The period of lava dome growth and subsequent collapse observed at Unzen Volcano, Japan, between 1990 and 1995 can be used as an analogue for the generation of the proximal block-and-ash flow deposits of the Ngatoro Formation. The generated lava dome formed exogenous lobes up to $300 \mathrm{~m}$ long, $150 \mathrm{~m}$ wide and advanced less than $20 \mathrm{~m}$ per day (Ui et al., 1999). Prior to the collapse, gas plumes were observed on the lobes at the points where the block and ash flows emanated (Figure $107 \mathrm{~A}$ ). As the dome collapsed lava blocks from the frontal cliffs of the lobes or from the cliffs formed as new lava is extruded from the vent separated (Figure $107 \mathrm{~B}-\mathrm{C}$ ) and disintegrated instantaneously resulting in catastrophic block and ash flows (Figure 107 D-F). In photo $\mathrm{G}$ (Figure 107) the ash cloud and pyroclastic surge is clearly visible moving down the flanks of the cone. This is similar the type of surge that would have deposited the overbank surge deposits described within Egmont National Park (EE-1, Unit 8). 

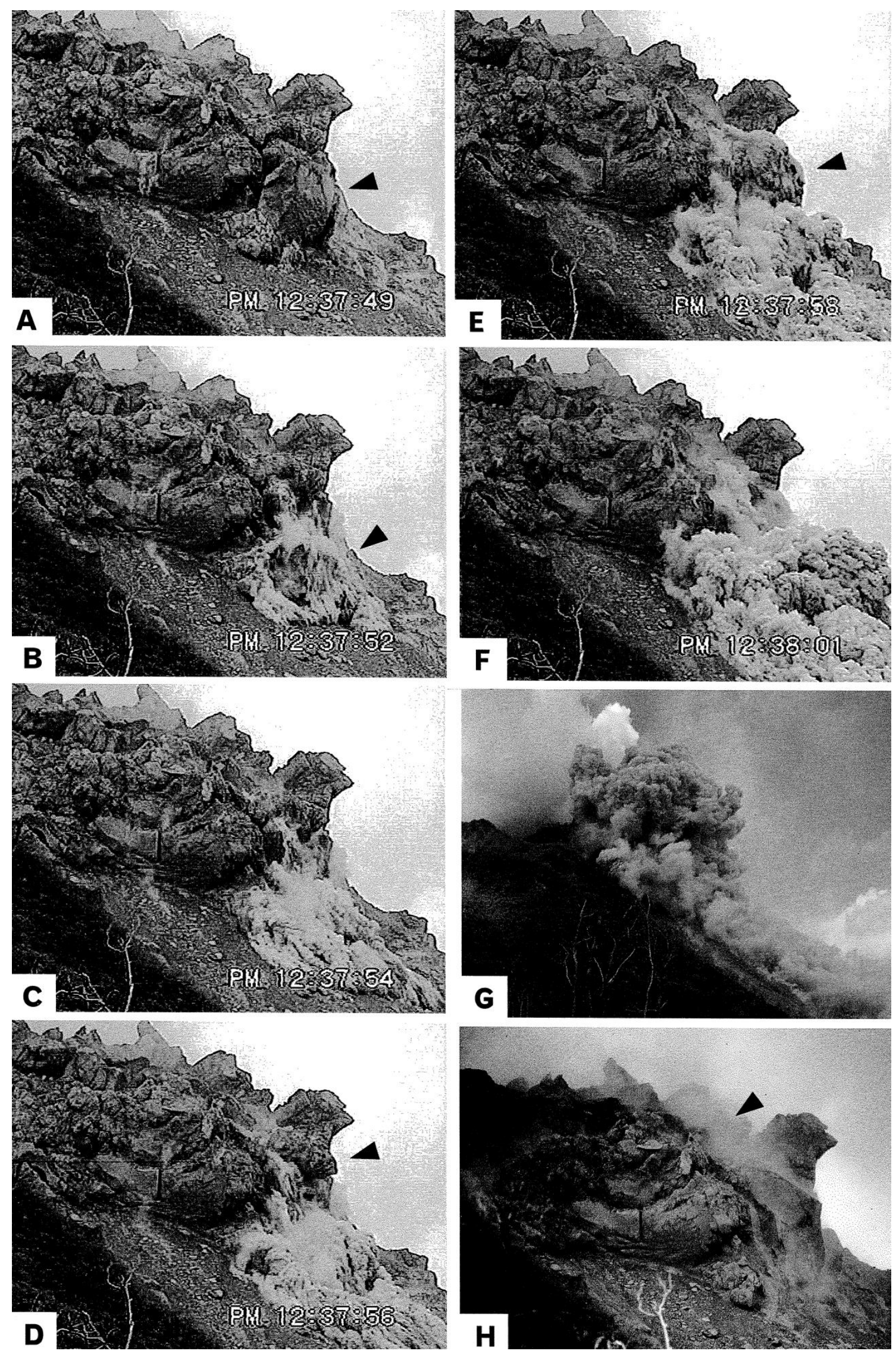

Figure 107: Photographs of block-and-ash flow generation from the collapse of an effusive lava dome on Unzen Volcano, February 251992 (Ui et al., 1999). This generated block-and-ash flows similar to the proximal pyroclastic surge deposits of the Ngatoro Formation at section $E E-1(A, B$ \& C). The frontal lobe of the lava dome detached (indicated by arrows), disintegrated and subsequently generated a block-and-ash flow followed by the collapse (D \& E) of a second slab of lava ( $F \& G$ ). Close up and distant view of the generated block and ash flow and $(H)$ the remains of the lava dome 10 minutes after the collapse. 


\subsection{Emplacement Temperature}

Initial evidence for elevated emplacement temperatures for the Ngatoro Formation was the charred and desiccated outer podocarp-hardwood tree trunks observed at Vickers Quarry. The charring is limited to a $<0.1 \mathrm{~m}$ thick veneer on the outside of the tree stumps while the interior remains well preserved. This suggests that the debris flow was hot enough to char the trees but not hot enough, or lacked the oxygen supply to completely burn the trees. This is a phenomenon associated with other mass flows that have originated as pyroclastic flows. Crandell (1971) and Scott (1988) both describe charred or carbonised wood associated with lahars on Mt Rainier and Mt St Helens respectively. Crandell (1971) also references the observations of Kemmerling (1921) on Mt Merapi where a temperature of $92^{\circ} \mathrm{C}$ was measured one foot below the surface of the mass flow deposit a few days after deposition. Kemmerling also observed a gas vent from the mass flow deposits with a temperature of $360^{\circ} \mathrm{C}$ and subsequent temperature of $100^{\circ} \mathrm{C}$ at the same point one year later. This same heat retention within volcaniclastic deposits is observed in block-and-ash flow deposits on Volcan de Colima, Mexico where a temperature of $128^{\circ} \mathrm{C}$ was recorded $0.3 \mathrm{~m}$ below the surface six days after deposition (Rodriguez-Elizarraras et al., 1991).

The results of the palaeomagnetic investigation of the Ngatoro Formation and overlying Te Popo Formation (Section 9, Chapter Three) give both incorporation and emplacement temperature estimates for the sampled clasts. For sampled clasts from Ngatoro Formation, the incorporation temperature is considered the temperature of the clasts at the time they were entrained within the block and ash flow, and the emplacement temperature refers to the temperature at which the clasts were deposited at the Vickers Quarry and Surrey Road Quarry.

The main lower unit investigation (VQ-1, Unit 6; SQ-1, Unit 1) gives a mean incorporation temperature estimate of $300^{\circ} \mathrm{C}$ for the proximal block-and-ash flow phase of the Ngatoro Formation. This indicates a lower temperature block-and-ash flow generated the Ngatoro Formation than comparable pyroclastic flows on typical andesitic volcanoes (Table 11): 
Table 11: Incorporation temperature estimate of the Ngatoro Formation from this study compared with block and ash flow temperatures from comparable volcanoes.

\begin{tabular}{|c|c|c|c|}
\hline Event / Location & Temperature & Method & Reference \\
\hline $\begin{array}{l}\text { Ngatoro Formation, } \\
\text { Egmont Volcano }\end{array}$ & $\begin{array}{c}\text { Incorporation } \\
\text { Temperature of } 300^{\circ} \mathrm{C} .\end{array}$ & $\begin{array}{c}\text { Palaeomagnetic } \\
\text { temperature estimates. }\end{array}$ & This study. \\
\hline $\begin{array}{l}\text { Te Popo Formation, } \\
\text { Egmont Volcano }\end{array}$ & $\begin{array}{c}\text { Incorporation } \\
\text { Temperature of } 300^{\circ} \mathrm{C} .\end{array}$ & $\begin{array}{c}\text { Palaeomagnetic } \\
\text { temperature estimates. }\end{array}$ & This study. \\
\hline $\begin{array}{c}\text { Merapi Volcano, Central } \\
\text { Java }\end{array}$ & $\begin{array}{l}\text { Minimum temperatures } \\
\text { range from } 400^{\circ} \mathrm{C} \text { for the } \\
\text { basal avalanche and } \\
165^{\circ} \mathrm{C} \text { for the ash cloud. }\end{array}$ & $\begin{array}{c}\text { Fourier-transform } \\
\text { infrared spectro-scopic } \\
\text { measurement of plastic } \\
\text { buried in the flow } \\
\text { deposits and from direct } \\
\text { temperature } \\
\text { measurements of the } \\
\text { flow deposits. }\end{array}$ & $\begin{array}{l}\text { Charbonnier and } \\
\text { Gertisser (2008) }\end{array}$ \\
\hline $\begin{array}{c}\text { Soufiere Hills Volcano, } \\
\text { Montserrat }\end{array}$ & $365-640^{\circ} \mathrm{C}$ & $\begin{array}{c}\text { Direct measurement with } \\
\text { a thermocouple and } \\
\text { temperature patches. }\end{array}$ & Cole et al. (2002) \\
\hline Unzen Volcano, Japan & $300-600^{\circ} \mathrm{C}$ & $\begin{array}{c}\text { Palaeomagnetic } \\
\text { temperature estimates. }\end{array}$ & Tanaka et al. (2004) \\
\hline $\begin{array}{l}\text { Mt St Helens, } \\
\text { Washington }\end{array}$ & $550-600^{\circ} \mathrm{C}$ & $\begin{array}{c}\text { Palaeomagnetic } \\
\text { temperature estimates. }\end{array}$ & $\begin{array}{c}\text { Hoblitt and Kellogg } \\
\text { (1979) }\end{array}$ \\
\hline
\end{tabular}

The main lower unit investigation also gives a mean emplacement temperature estimate of $200^{\circ} \mathrm{C}$ for the proximal block-and-ash flow phase of the Ngatoro Formation. As with the incorporation temperature, this temperature estimate is lower than the palaeomagnetic temperature estimate of $375 \pm 25^{\circ} \mathrm{C}$ for comparable mass flows at Mt St Helens, Washington (Hoblitt and Kellogg, 1979).

Based on palaeomagnetic analysis and field observations of proximal deposits at Vickers Quarry and Surrey Road Quarry, the Ngatoro Formation was initiated as a low temperature block-and-ash flow with an estimated temperature of $300^{\circ} \mathrm{C}$. As this mass flow laterally transformed into a water-supported debris flow it was emplaced with an estimated temperature of $200^{\circ} \mathrm{C}$. As the trees in the vicinity of Vickers Quarry were inundated and buried, the Ngatoro Formation retained sufficient heat to surfically burn and desiccate the exterior of mature podocarp-hardwood tree trunks but did not have sufficient heat or oxygen to completely burn them. 


\subsection{Flow Transformations}

The transformation from gas-supported block and ash flows to water-supported debris flows requires the incorporation of large volumes of water, sufficient unconsolidated debris, steep slopes and a triggering mechanism. With the proposed mechanism of gravitational collapse of an effusive lava dome and the abundant unconsolidated block and ash flow deposits within the steep Manganui Valley, the question of source water remains.

The most likely source of water for the transformation of the Ngatoro Formation was the incorporation of steam and water from the source rocks, ice and snow from the flanks of the volcano and alluvial water within the catchments down which the pyroclastic flows travelled (Scott, 1988; Vallance, 2000; Vallance 2005). The block and ash flows typically come to rest and form the melt water which subsequently erodes the pyroclastic material forming the water-supported mass flows (Vallance, 2000).

The transition from gas-supported block-and-ash flows to water supported debris flows occurs within the upper confinements of the Manganui Valley and Mangawhete Stream $<2.0$ $\mathrm{km}$ from the modern day summit. Evidence for the bulking or incorporation of previously deposited loose sediment is generally evident in the presence of foreign clasts within the flow deposits. Determining the amount of sediment bulking for the Ngatoro Formation is challenging due to the $>70 \mathrm{~m}$ thick, monolithologic, undifferentiated, block-and-ash flow deposits upstream within the Manganui Valley. This material makes it challenging to differentiate between andesite cobbles and boulders sourced from the dome collapse event and the same type of andesite clasts incorporated into the Ngatoro debris flow from the underlying deposits. The use of palaeomagnetic investigations however provide some insight into the sediment bulking during the emplacement of the Ngatoro Formation. The clasts sampled in the main lower unit Investigation (VQ-1, Unit 6; SQ-2, Unit 5) exhibit a range in incorporation and emplacement temperatures $\left(100-450^{\circ} \mathrm{C}\right.$ and $100-350^{\circ} \mathrm{C}$ respectively) as discussed in Chapter Three, Section 9.0. These results suggest differing thermal histories, and therefor differing incorporation and emplacement processes between the sampled clasts. For example, specimen S15.1A has an incorporation and emplacement

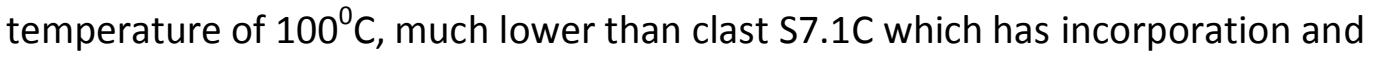
emplacement temperatures of $400^{\circ} \mathrm{C}$ and $200^{\circ} \mathrm{C}$. This suggests that clasts $\mathrm{S} 15$ was incorporated or bulked into the debris flow at a lower temperature and did not significantly 
cool during transportation, in comparison to clast S7 which was incorporated at a high temperature and subsequently cooled during transportation.

The coarse-textured deposits exposed at Vickers Quarry (VQ-1, Unit 6) and Surrey Road Quarry (SQ-2, Unit 5) contain clasts up to 2.0 in diameter, are predominantly cobble and boulder and lack any internal stratification or sedimentary structures. This type of mass flow deposit is indicative of a single phase debris flow with very high sediment concentrations (>80wt\%) and sufficient energy to transport these large clasts in its primary axis of flow. The largest boulders are located at the top of the debris flow deposit (VQ-1, Unit 6) indicating that these clasts were buoyed on top of the sediment water mixture until which point the flow no longer has sufficient energy, sediment concentration, and yield strength to support them any longer. At Surrey Road Quarry there is an upward transformation from coarsetextured debris flow deposits (SQ-2, Unit 5) to cross-stratified sandy deposits interpreted as hyperconcentrated flow deposits in the dilute waning stage of flow (Zernack et al., 2009).

Downstream there is evidence to indicate a progressive reduction in the carrying capacity of the mass flow with the predominance of stratified, sandy and pebbly sand-textured deposits at Tariki - SH3 and Tariki Underpass sections $17 \mathrm{~km}$ from the modern day summit. These features are indicative of a hyperconcentrated stream flow, with intermediate sediment concentrations (40-80wt\%) and a solid and fluid phase. The hyperconcentrated flows deposited sediment in multiple pulses indicated by multiple intervening sole layers (TU-2, Units 7, 9 \& 11; TR-2, Units 5 \& 9) and repeated stratified units (TU-2, Unit 10), and in variable flow regimes depositing features from low angle cross-stratified (TR-1, Unit 8) to laminated sands (TU-2, Unit 12).

\subsection{Emplacement of the Manganui Tephra and Te Popo Formation} The existing tephra framework for Holocene eruptive events on Egmont Volcano indicates that the Ngatoro Formation is overlain by four basaltic, scoriaceous lapilli beds (Alloway et al., 1995; Neall, 1972). These lapilli beds are considered informal subunits of the Manganui Tephra (c. $3,100{ }^{14} \mathrm{C}$ yrs B.P.) related to a period of activity on Fanthams Peak (Alloway et al., 1995). Associated with these lapilli beds are mass flow deposits of the Te Popo Formation. The Manganui.a, Manganui.b and Manganui.c subunits were described at three of the locations in this study (East Egmont, Surrey Road Quarry and Tariki Underpass). At proximal 
locations (Surrey Road Quarry) the Manganui subunits are associated with massive, poorly sorted, cobble and boulder rich debris flow deposits. A preliminary palaeomagnetic study on the Te Popo Formation at Vickers Quarry (VQ-1, Unit 12) gives an incorporation temperature estimate of $300^{\circ} \mathrm{C}$ and emplacement temperature estimate of $170-200^{\circ} \mathrm{C}$. These are comparable temperature estimates to those of Ngatoro Formation.

The stratigraphy described in this thesis supports the existing stratigraphic framework of Alloway et al., 1995, however as with the Ngatoro Formation paleosols the Manganui.a and Manganui.c subunits (SQ-3, Units 2 \& 6) indicate a separation in time between the Manganui eruptive events and subsequent emplacement of the Te Popo debris flow deposits. This suggests that eruptive events such as the Inglewood and Manganui events being followed sometime after by low temperature, water supported mass flows are not an isolated sequence of events on Egmont Volcano but repeated in the stratigraphic record.

\subsection{Summary of Emplacement}

The summary of precursor events and emplacement of the Ngatoro Formation is as follows:

1. Emplacement of the Inglewood.a lapilli during the first eruptive phase of the Inglewood eruptive event at c. 3,600 ${ }^{14}$ C yrs B.P (e.g. VQ-1, Unit 3; Tu-2, Unit 4).

2. Period of quiescence and stability in the landscape enabling the formation of andic soils (e.g. VQ-1, Unit 4; TU-2, Unit 5).

3. Emplacement of the Inglewood.b lapilli during the second phase of the Inglewood eruptive event at least several decades after c. 3,600 ${ }^{14}$ C yrs B.P (e.g. VQ-1, Unit 5; TU-2, Unit 6).

4. Period of quiescence and stability in the landscape enabling the formation of a welldeveloped, organic rich paleosol (e.g. VQ-3, Unit 7).

5. Effusive growth of a post-Inglewood lava dome - presumably near the summit of the present-day Egmont Volcano

6. Subsequent collapse of this effusive lava dome generating a block-and-ash flow at a temperature of $300^{\circ} \mathrm{C}$. This deposited cobble- and boulder-rich block-and-ash flow deposits in the Manganui Valley and overbank surge deposits of the valley margins (e.g. EE-1, Unit 8). 
7. Snow, ice and alluvial water incorporated into the flow transformed the block-andash flow into single phase, water-supported, sediment rich, coarse-textured debris flows with temperatures of $200^{\circ} \mathrm{C}$ (e.g. VQ-1, Units 6-7; SQ-2, Units 5-6). This event inundated, buried and partially burned the podocarp-hardwood forest occurring on the lower eastern flanks in the vicinity of Vickers Quarry (e.g. VQ-1, Units 6 \& 7).

8. Syn-depositional lateral transformation from debris flows to finer-textured, more dilute, solid and fluid phase hyperconcentrated flows (e.g. TR-1, Units 6-8; TU-2, Unit 10; MG-1, Unit 5).

9. Period of quiescence then the emplacement of the Fanthams Peak sourced Manganui.a scoriaceous lapilli of the Manganui Tephra at $3,100{ }^{14} \mathrm{C}$ yrs B.P. (e.g. EE1, Unit 9; SQ-2, Unit 7; TU-4, Unit 8).

10. Following the emplacement of the Manganui.a lapilli was a period of quiescence enabling the formation of a well-developed paleosol (e.g. SQ-3, Unit 6 \& 7).

11. Emplacement of the first coarse-textured, water-supported debris flow deposit of the Te Popo Formation (e.g. SQ-2, Units 8 \& 9). This unit decapitated the partially buried and burnt podocarp-hardwood forest remnants at Vickers Quarry (e.g. VQ-1, Unit 12).

12. Subsequently deposition of another two scoriaceous lapilli beds, Manganui.b and Manganui.c lapilli (e.g. SQ-3, Units 4 \& 6; TU-4, Units 10 \& 12), and associated debris flow units of the Te Popo Formation (e.g. SQ-3, Units 5, 7 \& 8). 


\section{Hazards}

Egmont Volcano is an active andesite stratovolcano with 76 Egmont-sourced tephra intermittently erupted between c. 3,000 and C. $28,000{ }^{14} \mathrm{C}$ yrs B.P. and an eruptive periodicity of c. 330 years (Alloway et al., 1995). Recent work by Turner at al. (2009) identified 138 separate ash-forming eruptions between 96 and 10,150 yrs B.P. Using this record Turner et al. (2009) used the Weibulls renewal model to forecast a probability of 0.52 for an eruption in the next 50 years on Egmont Volcano. Along with tephra emission, Egmont Volcano also has a history of pycroclastic flows, water-supported debris/hyperconcentrated flows, lava flows and edifice collapse induced debris avalanches (Alloway, 1989; Neall and Alloway, 2004). In order to assess the risk posed by these range of processes requires an understanding of:

- The emplacement mechanisms.

- Spatial extent and duration of the event.

- The return period.

- The amount of forewarning.

- Potential social and economic effects.

Water-supported mass flows similar to the Ngatoro Formation are recorded throughout the eruptive history of Egmont Volcano (Alloway, 1989; Zernack et al., 2009). The many truncated and charred trees exposed at Vicker Quarry (circumferences up to $5.9 \mathrm{~m}$ ) and the rapid accumulations of coarse-textured cobble- and boulder-rich (up to $2.0 \mathrm{~m}$ in diameter) deposits depict the extreme risk posed to any person or structure directly in the path of water-supported mass flow events such as the Ngatoro event. The catastrophic effects of debris/hyperconcentrated flows was highlighted in the 1985 inundation of the town of Armero, Colombia by a lahar following the eruption of Nevado del Ruiz volcano, resulting in 22,000 deaths (Voight, 1996). This was a disaster that with a better understanding of the hazards and behaviour of mass flows, and adequate warning systems in place could have been avoided.

The current hazard monitoring system on Egmont Volcano by GNS Science includes 1 continuous feed web cam, 9 seismographs and 1 continuous GPS site (Figure 108) (Johnston et al., 2011). This is a less comprehensive monitoring than on Mt Ruapehu, New Zealand 
which is equipped with 2 continuous feed web cameras, 10 seismographs, 6 microphones, 9 continuous GPS stations and regular water and gas monitoring visits to the Crater Lake as well as airborne gas surveys (www.gns.cri.nz). This is comprehensive monitoring system was implemented in response to an eruptive history, including the 1953 Tangiwai disaster in which the Christmas Eve Wellington to Auckland express train crashed into the Whangaehu River killing 151 people after a water-supported mass flow destroyed the rail bridge (Neall, 1976).

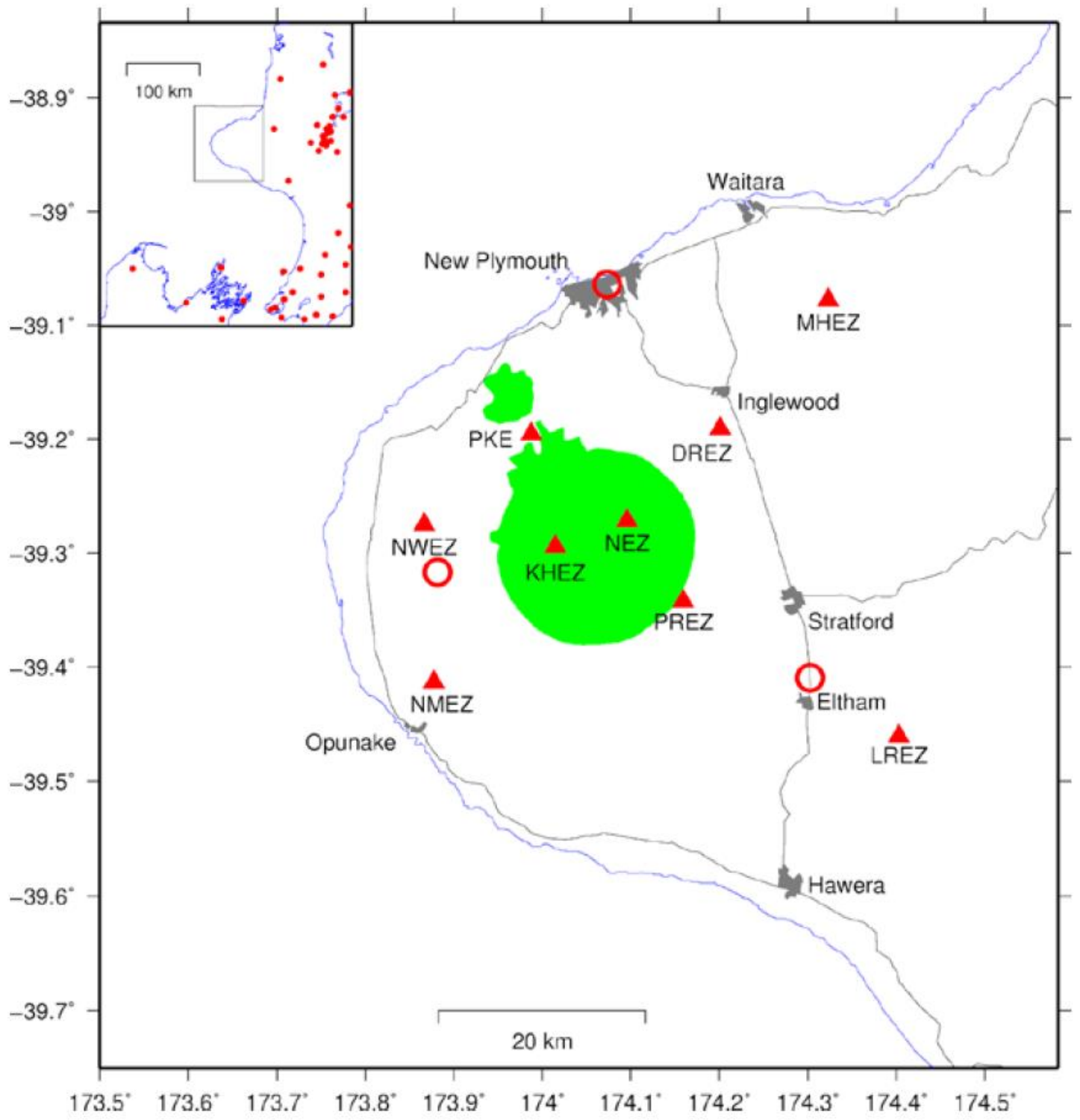

Figure 108: Schematic map indication the positions of the seismographs and continuous GPS site as part of the Egmont Volcano monitoring program (Johnston et al., 2011) 
However Egmont Volcano and Mt Ruapehu both have a highly active and intermittent eruptive record comprising pyroclastic flows, debris/hyperconcentrated flows and debris avalanches. The difference in monitoring system between Egmont Volcano and Mt Ruapehu may indicate an underestimation of the risk posed by Egmont Volcano due to the most recent eruption occurring in 1755 A.D. (Alloway et al., 1995), before anecdotal or written record.

A combined volcanic hazard zone map published by the Taranaki Regional Council (Figure 109) indicates areas to the north-east, north-west and south-west of Egmont Volcano at risk of water-supported mass flows (in purple) - This includes the area of the Ngatoro Formation. The distribution of the Ngatoro Formation described in this thesis supports that of Alloway et al. (1995) and Neall and Alloway (2004), and reinforces the existing understanding of hazards posed by debris/hyperconcentrated flow distribution. The findings of this thesis add to the current understanding of these mass flow events and the timing of mass flow emplacement relative to precursory eruptive events. The emplacement of the Ngatoro Formation has been found to occur sometime after the emplacement of the Inglewood Tephra (c. 3,600 ${ }^{14} \mathrm{C}$ yrs B.P) as part of an extended and previously unidentified phase of the Inglewood eruptive event involving the steady growth and subsequent collapse of an effusive lava dome. This timing suggests that for future eruptions there is still significant risk of catastrophic emplacement of gas- to water-supported mass flows for an extended period of time after a paroxsymal eruptive event similar to that which emplaced the Inglewood Tephra. 


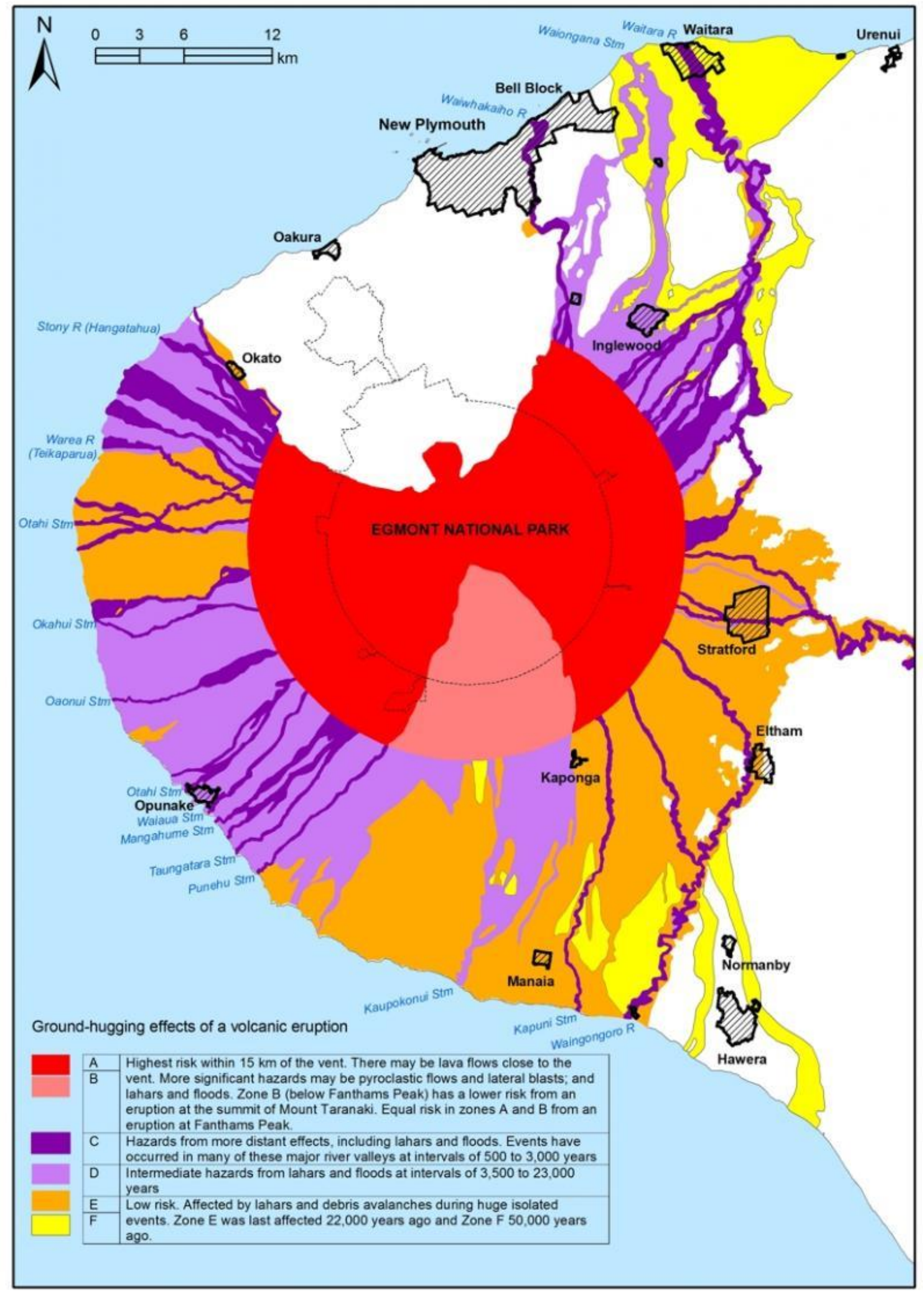

Figure 109: Combined volcanic hazard zone map (Neall and Alloway, 1995). The areas classified as being at risk of debris/hyperconcentrated flows and associated flood flows are identified in purple to the north-east, north-west and south-west of Egmont Volcano. 


\section{Chapter Four: Conclusions}

\section{Conclusions}

This thesis has used a combination of field mapping, stratigraphic descriptions, grain size and shape analysis, tephrochronology and palaeomagnetic analysis to determine the stratigraphy, facies architecture and emplacement history of the c. 3.6 ka B.P. Ngatoro Formation on the eastern flanks of Egmont Volcano, western North Island, New Zealand.

Based on this the following conclusions have been drawn:

- The Ngatoro Formation comprises two closely spaced mass flow events whose flow \& emplacement characteristics- have undergone both proximal to distal and axial to marginal transformations. On surfaces adjacent the Manganui Valley on the incised flanks of Egmont Volcano the Ngatoro Formation is identified as $<0.2 \mathrm{~m}$ thick overbank surge deposits. These surge deposits mantle the topographically high margins of the Manganui River and extend down-valley towards the ring plain. Within the Manganui River valley itself Ngatoro Formation deposits couldn't be identified with any certainty on account of intra-channel cut and fill and the lack of any intervening stratigraphic marker beds. At the boundary of Egmont National Park the Ngatoro Formation occurs as 2.0 to $5.0 \mathrm{~m}$ thick, pebble- to boulder-rich debris flow deposits with common charred wood fragments laterally transforming to $<2.0 \mathrm{~m}$ thick, massive, poorly sorted, fine to coarse sand with some matrix-supported pebble marginal debris flow deposits. At intermediate and distal sections the Ngatoro Formation occurs as $<0.8 \mathrm{~m}$ thick sequence of at least two, low angle crossstratified to laminated, pebbly sandy hyperconcentrated flow deposits. These deposits exhibit sedimentary structures such as flame dewatering structures, convolute bedding, rip-ups of underlying deposits, pumice 'trains' and aligned clasts.

- This lateral and longitudinal variability in the Ngatoro Formation reflects the transformation from gas-supported block and ash flows within the valley confines of Egmont National Park to transitional gas/water-supported debris flows at the Vickers 
Quarry, Surrey Road Quarry and York Road sections. These debris flows had high sediment concentrations, flowed as a single phase and deposited sediment en-masse as evidenced by the massive, very coarse-textured deposits. The debris flows laterally transformed to turbulent finer grained, gravelly sand-dominated hyperconcentrated flows with a solid and fluid phase and lower yield strength than the debris flow from which it transformed. This is evident in the stratified, finer textured deposits with flame dewatering structures, convolute bedding, rip-ups of underlying deposits, pumice 'trains' and aligned clasts.

- Palaeomagnetic temperature estimates for Ngatoro Formation in the vicinity of the National Park boundary (c.9.6 km from the present day summit; Vickers Quarry and Surrey Road Quarry sites) indicate clast incorporation temperatures of c. $300^{\circ} \mathrm{C}$ and emplacement temperatures of c. $200^{\circ} \mathrm{C}$.

- The Ngatoro Formation manifests as a single pyroclastic deposit within Egmont National Park, has an underlying well-developed paleosol and monolithologic composition, and an above ambient incorporation temperature. This evidence suggest the Ngatoro Formation was emplaced by the lateral transformation of a block and ash flow generated by collapse of an effusive lava dome sometime after the Inglewood eruptive event (c. 3,600 ${ }^{14} \mathrm{C}$ yrs B.P.).

- The overlying Te Popo Formation exhibits similar debris and hyperconcentrated flow deposits overlying well-developed andic paleosols with ash and lapilli interbeds with comparable incorporation and emplacement temperatures. This suggests that eruptive events such as the Inglewood and Manganui tephra events being followed sometime after by low temperature, rapidly transforming water-supported mass flows are not isolated occurrences on Egmont Volcano but apparently are repeated in the aftermath of sustained eruptive activity or paroxysmal eruption. On this basis, such similar events could conceivably be expected in the years and decades following a future Egmont Volcano eruptive phase. 


\section{Future Work}

The complex and laterally variable nature of volcaniclastic deposits and their spatial and temporal relationship with enveloping tephra generally leads to a wide range of potential future work. Upon completion of this study some specific recommendations for future work are summarised below:

- The key to describing and correlating rapidly transforming volcaniclastic deposits between sections is through the correlation of tephra units. In this study, Korito, Inglewood and Manganui Tephras were successfully correlated using a combination of field descriptions as well as major element glass composition determined from EMP analysis. Some stratigraphic complexity encountered in the upper part of the Vickers Quarry and York Road sections do not currently fit within the existing stratigraphic framework (Alloway et al,. 1995). This issue is expected to be better clarified after submission of this thesis by tephra resampling, further EMP analysis and the submission of associated wood fragments for radiocarbon dating.

- This thesis has identified that the emplacement of the Ngatoro Formation does not strictly correspond in age with the Inglewood Tephra eruption (c. 3,600 yrs ${ }^{14}$ C B.P.). with suficient intervening time between the two events as evidenced by the formation of a prominent intervening soil. The challenge from this revelation is to precisely estimate the time between the emplacement of the Inglewood Tephra and the Ngatoro Formation. This may be best done through more intensive radiocarbon dating of the interval that separates the Inglewood Tephra from the closely overlying Ngatoro Formation.

- This thesis has successfully used palaeomagnetic analysis to estimate clast incorporation and emplacement temperatures for Ngatoro Formation using a modification of the conglomerate test. We suggest the comparison of the Ngatoro Formation temperature estimates to those calculated at similar volcanoes elsewhere in order to understand the temperatures at which water-supported mass flows are initially generated and emplaced. 


\section{References}

Alloway BV 1989. The Late Quaternary cover bed stratigraphy and tephrochronology of northeastern and central Taranaki, New Zealand. Unpublished PhD Thesis, Massey University, Palmerston North, New Zealand.

Alloway BV, Fyfe R, Neall VE 1990. Further evidence of early Maori occupation on the flanks of Egmont Volcano. Archaeology in New Zealand 33: 40 - 48.

Alloway BV, McComb P, Neall VE, Vucetich CG, Gibb J, Sherburn S, Stirling M 2005. Stratigraphy, age and correlation of voluminous debris-avalanche events from ancestral Egmont Volcano: Implications for coastal plain construction and regional hazard assessment. Journal of the Royal Society of New Zealand 35: 229-267.

Alloway BV, Neall VE, Vucetich CG 1995. Late Quaternary (post 28,000 year B.P) tephrostratigraphy of northeast and central Taranaki, New Zealand. Journal of the Royal Society of New Zealand 25: 385-458.

Boggs S 2006. Principals of sedimentology and stratigraphy. $4^{\text {th }}$ ed. New Jersey, Prentice Hall.

Butler RF 1992. Paleomagnetism: Magnetic Domains to Geological Terranes. Portland, Blackwell Scientific Publications.

Capra L, Marcias JL 2002. The cohesive Naranjo debris-flow deposit (10 km3):: A dam breakout flow derived from the Pleistocene debris-avalanche deposit of Nevado de Colima Volcano (México). Journal of Volcanology and Geothermal Research 117: 213-235.

Charbonnier SJ, Getisser R 2008. Field observations and surface characteristics of pristine block-and-ash flow deposits from the 2006 eruption of Merapi Volcano, Java, Indonesia. Journal of Volcanology and Geothermal Research 177: 971-982.

Cioni R, Gurioli L, Lanza R, Zanella E 2004. Temperatures of the AD 79 pyroclastic density current deposits (Vesuvius, Italy). Journal of Geophysical Research 109:B02207.

Clement BM, Connor CB, Graper G 1993. Paleomagnetic estimate of the emplacement temperature of the long-runout Nevado de Colima volcanic debris avalanche deposit, Mexico. Earth and Planetary Science Letters 120: 499-510.

Cole PD, Calder ES, Sparks RSJ, Clarke AB, Druitt TH, Young SR, Herd RA, Harford CL, Norton GE 2002. Deposits from dome-collapse and fountain-collapse pyroclastic flows at Soufrière Hills Volcano, Montserrat. London Geological Society Memoirs 21: 231-262.

Cox A 1969. A palaeomagnetic study of secular variation in New Zealand. Earth and Planetary Science Letters 6: 257-267. 
Crandell DR 1971. Postglacial lahars from Mount Rainier Volcano, Washington. U.S. Geological Survey Professional Paper 677: 75p.

Cronin SJ, Neall VE, Lecointe JA, Palmer AS 1997a. Changes in Whangaehu river lahar characteristics during the 1995 eruption sequence, Ruapehu volcano, New Zealand. Journal of Volcanology and Geothermal Research 76: 47-61.

Cronin SJ, Hodgeson KA, Neall VE, Palmer AS, Lecointre JA 1997b. 1995 Ruapehu lahars in relation to the late Holocene lahars of the Whangaehu River, New Zealand. New Zealand Journal of Geology and Geophysics 40: 507-520.

Downey WS, Kellett RJ, Smith IEM, Price RC, Stewart, RB 1994. New palaeomagnetic evidence for the recent eruptive activity on Mt Taranaki, New Zealand. Journal of Volcanology and Geothermal Research 60: 15-27.

Druce AP 1966. Tree ring dating of recent volcanic ash and lapilli, Mount Egmont. New Zealand Journal of Botany 4: 3-41.

Fairchild LH 1984. Initiation of the North Fork Toutle River lahar by liquefaction of debris avalanche deposits during the May 18, 1980 Mount St. Helens eruptions. Geological Society of America Abstracts with Programs 16: p105.

Folk RL 1966. A review of grain-size parameters. Sedimentology 6: 73-93.

Folk RL 1980. Petrology of Sedimentary Rocks. Austin Texas, Hemphill Publishing Company.

Folk RL, Ward WC 1957. Brazos River Bar: A study in the significance of grain size parameters. Journal of Sedimentary Petrology 27: 3-26.

Fritz WJ, Harrison S 1983b. Giant armoured mud boulder from the 1982 Mount St Helens mudflows - Reply. Journal of Sedimentary Petrology 53: 1358-1359.

Glicken H 1998. Rockslide-debris avalanche of May 18, 1980, Mount St Helens volcano, Washington. Geological Survey of Japan Bulletin 49: 55-106.

Graettinger AH, Manville V, Briggs RM 2010. Depositional record of historic lahars in the upper Whangaehu Valley, Mt Ruapehu, New Zealand: implications for trigger mechanisms, flow dynamics and lahar hazards. Bulletin of Volcanology 72: 279-296.

Hanenkamp E 2011. Decoupling processes in block and ash flows: field evidence and analogue modelling. Unpublished PhD thesis, University of Canterbury, Christchurch, New Zealand.

Hoblitt RP, Kellogg KS 1979. Emplacement temperatures of unsorted and unstratified deposits of volcanic rock debris as determined by paleomagnetic techniques. Geological Society of America Bulletin 90: 633-642. 
Hodgson KA 1993. Late Quaternary lahars from Mount Ruapehu in the Whangaehu River Valley, North Island, New Zealand. Unpublished PhD thesis, Massey University, Palmerston North, New Zealand.

Hyde JH 1975. Upper Pleistocene pyroclastic flow deposits and lahars south of Mt St Helens volcano, Washington. U.S. Geological Survey Bulliten 1383-B: 20 p.

Inman DL 1952. Measures for describing the size distribution of sediments. Journal of Sedimentary Petrology 22: 125-145.

Johnston D, Becker J, Jolly G, Potter S, Wilson T, Stewart C, Cronin S 2011. Volcanic Hazards Management at Taranaki Volcano: Information Source Book, GNS Science Report 2011/37.

Kellerhals R, Bray BI 1971. Sampling procedures for coarse fluvial sediments: Proceedings of the American Society of Civil Engineers. Journal of the Hydraulics Division 97: 1165-1180.

Kemmerling, G. L. L. 1921: Crandell DR 1971. Postglacial lahars from Mount Rainier Volcano, Washington. U.S. Geological Survey Professional Paper 677: 75p.

Kirschvink JL 1980. The least squares line and plane and the analysis of palaeomagnetic data. Geophysical Journal of the Royal Astronomical Society 62: 699-718.

Krumbein WC 1941. Measurement and geological significance of shape and roundness of sedimentary particles. Journal of Sedimentary Petrology 11: 64-72.

Lavigne F, Suwa H 2004. Contrasts between debris flows, hyperconcentrated flows and stream flows at a channel of Mount Semeru, East Java, Indonesia. Geomorphology 61: 4158.

Lavigne F, Thouret JC 2002. Sediment transportation and deposition by rain-triggered lahars at Merapi Volcano, Central Java, Indonesia. Geomorphology 49: 45-69.

Lavigne F, Thouret JC, Voight B, Suwa H, Sumaryono A 2000. Lahars at Merapi volcano, Central Java: an overview. Journal of Volcanology and Geothermal Research 100: 423-456.

Lecointre J, Hodgeson KA, Neall VE, Cronin S 2004. Lahar-Triggering Mechanisms and Hazard at Ruapehu Volcano, New Zealand. Natural Hazards 31: 85-109.

Lowe DJ 1988. Stratigraphy, age, composition, and correlation of late Quaternary tephras interbedded with organic sediments in Waikato lakes, North Island, New Zealand. New Zealand Journal of Geology and Geophysics 31: 125-165.

Major JJ, Pierson TC, Scott KM 2005. Debris flows at Mount St. Helens, Washington, USA. In: Jakob M, Hungr O ed. Debris-flow Hazards and Related Phenomena. Heidelberg, Springer Praxis: 685-731. 
Michol KA, Russell JK, Andrews GDM 2008. Welded block and ash flow deposits from Mount Meager, British Columbia, Canada. Journal of Volcanology and Geothermal Research 169: 121-144.

Murcia HF, Hurtado BO, Cortes GP, Macias JL, Cepeda H 2008. The 2500 yr B.P. Chicoral non-cohesive debris flow from Cerro Machín Volcano, Colombia. Journal of Volcanology and Geothermal Research 171: 201-214.

Neall VE 1972. Tephrochronology and tephrostratigraphy of western Taranaki (N108-109), New Zealand. New Zealand Journal of Geology and Geophysics 15: 507-557.

Neal VE 1976. Lahars as a major geological hazard. Bulletin of the International Association of Engineering Geology 14: 233-240.

Neall VE 1979. Sheets P19, P20 and P21 - New Plymouth, Egmont and Mania. Geological Map of New Zealand 1:50 000. New Zealand, DSIR. 3 sheets +36 p.

Neall VE, Alloway BV 1986. International Volcanological Congress, New Zealand. Tour Guide C3: Quaternary volcaniclastics and hazards of Taranaki. N.Z. Geological Survey record 12.

Neall, VE, Alloway BV 1995. Volcanic hazard map of Taranaki 1:100,000. Massey University Soil Science Department Occasional Report 12, Massey University, Palmerston North.

Neall VE, Alloway BV 2004. Quaternary Geological Map of Taranaki. 1: 100 000. Institute of Natural Resources - Massey University, Soil and Earth Sciences Occasional Publication No. 4. Palmerston North, New Zealand.

Neall VE, Birks DL 2004. Understanding the pre-1000 year B.P volcanic diamictons in Egmont National Park. Geological Society of New Zealand Miscellanceous Publication 117A: 72.

Neall VE, Hogg AG, Zernack AV 2012. Revision of Volcaniclastic Stratigraphy in Eastern Egmont National Park, Taranaki. Geoscience Society of New Zealand 2012 Conference.

Oldrich H, McDougall S, Bovis M 2005. Entrainment of matrial by debris flows. In: Jakob M, Hungr O. ed. Debris-flow Hazards and Related Phenomena. Heidelberg, Springer Praxis: 136157.

Oliver WR 1931. An ancient Maori oven on Mount Egmont. Journal of the Polynesian Society 40: 73-79.

Paintin IK 1982. Paleomagnetism of two flow deposits, Mt Egmont, New Zealand. A preliminary investigation. BSc (Hons) dissertation. Victoria University of Wellington.

Palmer BA, Neall VE 1989. The Murimoto Formation - 9500 year old deposits of a debris avalanche and associated lahars, Mount Ruapehu, North Island, New Zealand. New Zealand Journal of Geology and Geophysics 32: 477-486. 
Parffit L, Wilson L 2008. Fundamentals of Physical Volcanology. Oxford, United Kingdom, Blackwell Publishing.

Paterson GA, Roberst AP, Miocaill CM, Muxworthy AR, Gurioli L, Viramonte JG, Navarro C, Weider S 2010. Paleomagnetic determination of emplacement temperatures of pyroclastic deposits: an under-utilized tool. Bulletin of Volcanology 72: 309-330.

Petrie RA 1988. The Manganui Tephra. A 3,200 year old eruptive from Fanthams Peak, Mt. Egmont. BSc (Hons) dissertation. Massey University.

Pierson TC 2005. Hyperconcentraed flow - transitional process between water flow and debris flow. In: Jakob M, Hungr O ed. Debris-flow Hazards and Related Phenomena. Heidelberg, Springer Praxis: 159-202.

Platz T, Cronin SJ, Cashman KV, Stewart RB, Smith IEM 2007. Transition from effusive to explosive phases of andesite eruptions - A case-study from the AD1655 eruption of Mt. Taranaki, New Zealand. Journal of volcanology and geothermal research 161: 15-34.

Price RC, McCulloch MT, Smith IE, Stewart RB 1992. Pb-Nd-Sr isotopic compositions and trace element characteristics of young volcanic rocks from Egmont Volcano and comparisons with basalts and andesites from the Taupo Volcanic Zone, New Zealand. Geochemica et Cosmochemica Acta 56: 941-953.

Price RC, Turner S, Cook C, Hobden B, Smith IEM, Gamble JA, Handley H, Maas R, Mobis A 2010. Crustal and mantle influences and U-Th-Ra disequilibrium in andesitic lavas of Ngauruhoe volcano, New Zealand. Chemical Geology 277: 355-373.

Rodolfo KS, Arguden AT 1991. Rain-Lahar generation and sediment-delivery systems at Mayon Volcano. In: Fisher RV, Smith GA ed. Sedimentation in volcanic settings. Society for Sedimentary Geology (SEPM) Special Publication 45: 71-88.

Rodriguez-Elizarraras S, Siebe C, Komorowski JC, Espindola JM, Saucedo R 1991. Field observations of pristine block and ash flow deposits emplaced April 16-17, 1991 at Volcan de Colima, Mexico. Journal of Volcanology and Geothermal Research 48: 399-412

Sandiford A, Alloway BV, Shane P 2001. A 28 000-6600 cal. yr record of local and distal volcanism preserved in a paleolake, Auckland, New Zealand. New Zealand Journalof Geology and Geophysics 44: 323-336.

Schiano P, Monzier M, Eissen JP, Martin H, Koga KT 2010. Simple mixing as the major control of the evolution of volcanic suites in Equadorian Andes. Contrib Mineral Petrol 160: 297312.

Schmidt R 1981. Descriptive nomenclature and classification of pyroclastic deposits and fragments: Recommendations of the IUGS Subcommission on the Systematics of Igneous Rocks. Geology 9: 41-43. 
Scott KM 1988. Origins, Behavior, and Sedimentology of Lahars and Lahar-Runout Flows in the Toutle-Cowlitz River System. U.S. Geological Survey Professional Paper 1447-A: A1-A74.

Scrivenor JB 1929. The mudstreams (lahars) of Gunong Keleot in Java. Geology Magazine 66: 433-434.

Sigurdsson H, Houghton B, McNutt SR, Rymer H, Stix J 2000. The Encyclopaedia of Volcanoes. $1^{\text {st }}$ ed. USA, Academic Press.

Smith GA 1986. Coarse-grained nonmarine volcaniclastic sediment: Terminology and depositional process. Geological Society of America Bulliten 97: 1-10.

Smith GA, Fritz WJ 1989. Penrose Conference report: volcanic influences on terrestrial sedimentation. Geology 17: 376 (abstract).

Sneed ED, Folk RL 1958. Pebbles in the Lower Colorado River, Texas a Study in Particle Morphogenesis. The Journal of Geology 66: 114-150.

Sparks RSJ, Wilson L 1976. A model for the formation of ignimbrite by gravitational column collapse. Journal of the Geological Society 132: 441-451.

Sparks RSJ, Bursik ML, Carey SN, Gilbert JS, Glaze L, Sigurdsson H, Woods AW 1997. Volcanic Plumes. Chichester, Wiley.

Statistics New Zealand 2006. The New Zealand Census. New Zealand, Statistics New Zealand.

Stinton AJ, Cole PD, Stewart RC, Odbert HM, Smith P 2014. The 11 February 2010 partial collapse at Soufriere Hills Volcano, Montserrat. Geological Society of London Memoirs: 39

Suryo I, Clarke MCG 1985. The occurrence and mitigation of volcanic hazards in Indonesia as exemplified at the Mount Merapi, Mount Kelut and Mount Galunggung volcanoes. Quarterly Journal of Engineering Geology 18: 79-98.

Taranaki Regional Council 2012. Report on Land Management and Dairying. Taranaki, Taranaki Regional Council.

Tarbuck EJ, Lutgens FK 2009. Earth Science. New jersey, Pearson Education Inc.

Townsend D, Vonk A, Kamp PJ 2008. Geology of the Taranaki Area 1:250 000. Institute of Geological \& Nuclear Sciences Geological Map 7. Lower Hutt, New Zealand, Institute of Geological \& Nuclear Sciences Ltd. 1 sheet +77 p.

Turner MB 2008. Eruption cycles and magmatic processes at a reawakening volcano, Mt Taranaki, New Zealand. Unpublished PhD thesis, Massey University, Palmerston North, New Zealand. 
Ui T, Matsuwo N, Sumita M, Fujinawa A 1999. Generation of block and ash flows during the 1990-1995 eruption of Unzen Volcano, Japan. Journal of Volcanology and Geothermal Research 89: 123-137.

Vallance JW 2005. Volcanic debris flows. In: Jakob M, Hungr O ed. Debris-flow Hazards and Related Phenomena. Heidelberg, Springer Praxis: 247-274.

Van Bremmelen RW 1949. The Geology of Indonesia. Vol 1(A). The Hague, Government Printing Office. $732 \mathrm{p}$.

Vignaux M, Weir GJ 1990. A general model for Mt Ruapehu lahars. Bulletin of Volcanology 52: 381-390.

Wadell H 1932. Volume, shaoe and roundness of rock particels. Journal of Geology 40: 443451.

Wadge G, Voight B, Sparks RS, Loughin SC, Robertson REA 2014: Chapter 1, An overview of the eruption at Soufriere Hills Volcano, Montserrat from 2000 to 2010: 39.

Wentworth CK 1922. A scale of grade and class terms for clastic sediments. Journal of Geology 30: 377-392.

Williams H, McBirney AR 1979. Volcanology. San Francisco, Freeman, Cooper and Company. $397 \mathrm{p}$.

Wilson L 1958. Explosive Volcanic Eruptions-III. Plinian Eruption Columns. Geophysical Journal of the Royal Astronomical Society 1: 543-556.

Wohletz K, Heiken G 1992. Volcanology and Geothermal Energy. California, University of California Press.

Wolman MG 1954. A Method of Sampling Coarse River-Bed Material. American Geophysical Union 35: 951-956.

Zerback AV, Procter JN, Cronin SJ 2009. Sedimetary signatures of cyclic growth and destruction of stratovolcanoes: A case study from Mt Taranaki, New Zealand. Sedimentary Geology 220, 288-305 


\section{Appendix A: Stratigraphy, Sedimentology and Electron Microprobe Results}

\section{A1 - Field and laboratory Results}

Sixteen measured sections, field descriptions, Electron Microprobe results and grain size and shape analysis result presented by stratigraphic section. 


\section{EE-1}

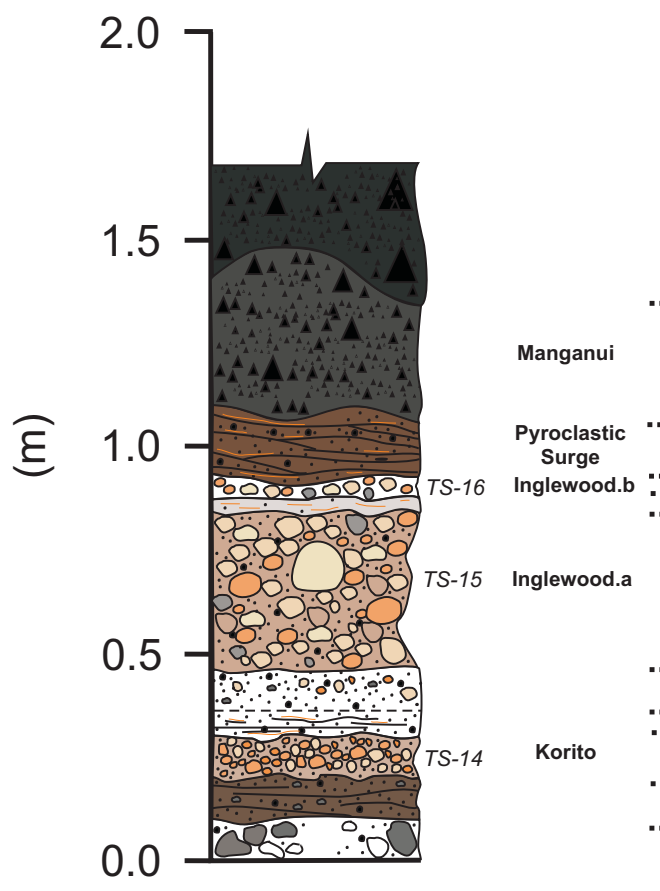

\section{Description}

UNIT 10, 1.48m: Lower boundary is sharp and irregular. Massive, very poorly sorted, dark blackish grey, fine to coarse, basaltic, scoriaceous lapilli and blocks.

UNIT 9, 1.1m: Lower boundary is sharp and wavy. Faintly stratified, orange coated dark grey, scoriaceous basaltic lapilli. [TEPHRA] UNIT 8, 0.92m: Lower boundary abrupt and irregular. Bedded and low
angle cross bedded (cm scale), sorted, brown and dark grey with orange streaked, alternating silt and fine sand, and fine to medium sand. [PYROCLASTIC SURGE DEPOSIT]

\section{$\because \quad$ [PYROCL}

UNIT 7, 0.87m: Lower boundary abrupt and wavy. Abundant, fine to coarse, yellowish white pumiceous lapilli and few to common angular, grey lithic lapilli. Clast supported in a light brownish grey silt matrix. [TEPHRA]

UNIT 6, 0.84m: Lower boundary sharp and wavy. Well sorted, light grey with orange streaked, fine sand and silt.

UNIT 5, 0.46m: Lower boundary distinct and irregular. Profuse, massive, moderately sorted, coarse to very coarse pumiceous lapilli and bombs $(14.0 \mathrm{~cm})$ and few angular to sub-angular lithic pebbles and cobbles $(10.0 \mathrm{~cm})$. Clast supported in a fine to coarse sandy pebble matrix. [TEPHRA]

UNIT 4, 0.34m: Lower boundary is gradational $(3.0 \mathrm{~cm})$ and irregular. Massive, fine to coarse sand with few to common creamy white
UNIT 3, 0.30m: Lower boundary sharp and undulating. Well sorted, faintly laminated, grey with orange streaked, fine sand and silt. Few faintly laminated, grey with orange streaked, fine sand and $\because$ UNIT 2,

$20 \mathrm{~m}$ : Lower boundary abrupt and irregular. Abundant medium to coarse, yellowish white pumiceous lapilli in a fine to coarse pumiceous sand matrix. [TEPHRA]

UNIT 1, 0.10m: Lower boundary abrupt and wavy. Bedded (cm scale),

alternating light brown and grey fine sand and silt, and fine to coarse

sand with few angular to sub-angular andesite pebbles and coarse pumiceous lapilli.

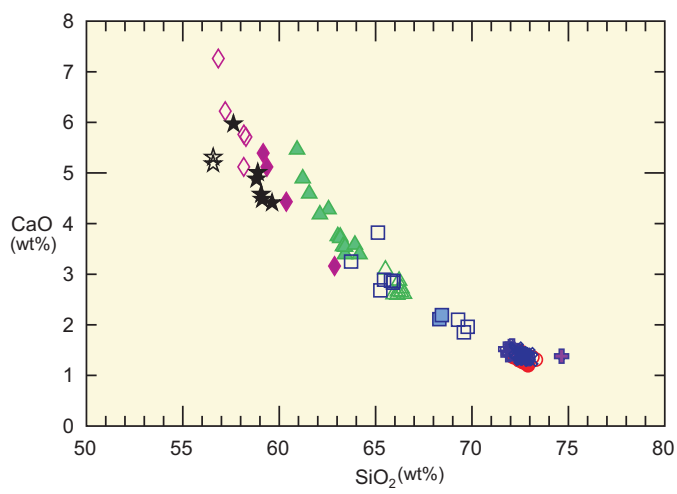

\section{EMP Analysis}

\section{East Egmont Reference:}

$\triangle$ Burrell Lapilli

$\triangle$ Kaupokonui Tephra

$\square$ unnamed Vulcanian tephra

$\square$ Maketawa Tephra

$\diamond$ Mg.d, Manganui Tephra

- Mg.c, Manganui Tephra

is Mg.b, Manganui Tephra

$\star$ Mg.d, Manganui Tephra

○ II.b, upper Inglewood Tephra

- Il.a, upper Inglewood Tephra

\& Korito Tephra
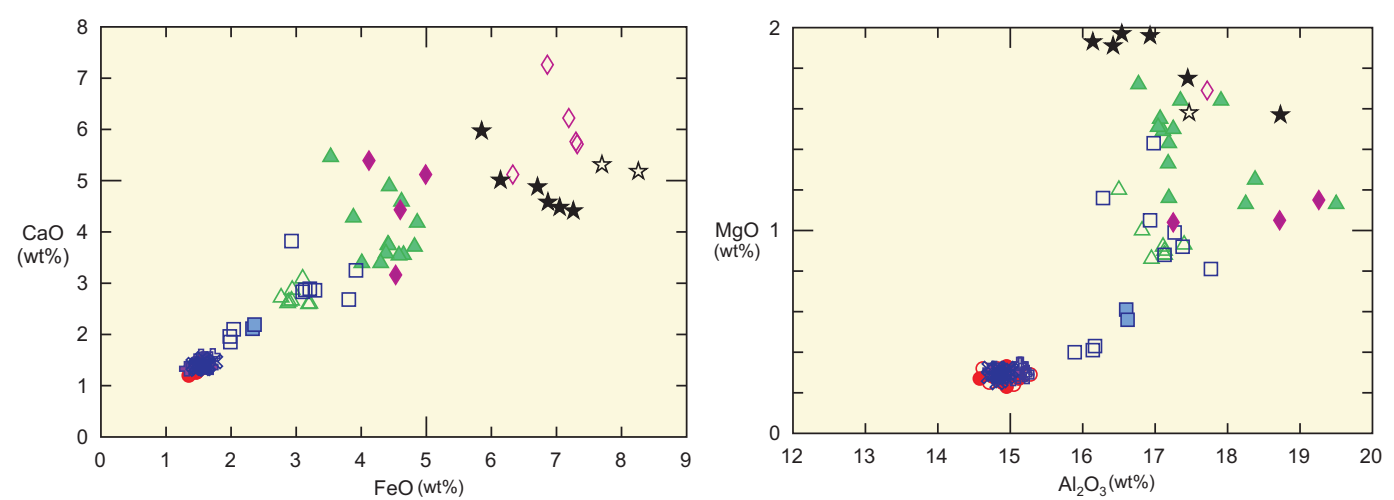

EE-1: Measured section showing relevant descriptions and sample locations. Electron Microprobe Analysis results compared with East Egmont and Dawson Falls reference sections (Section B1, Appendix B). 


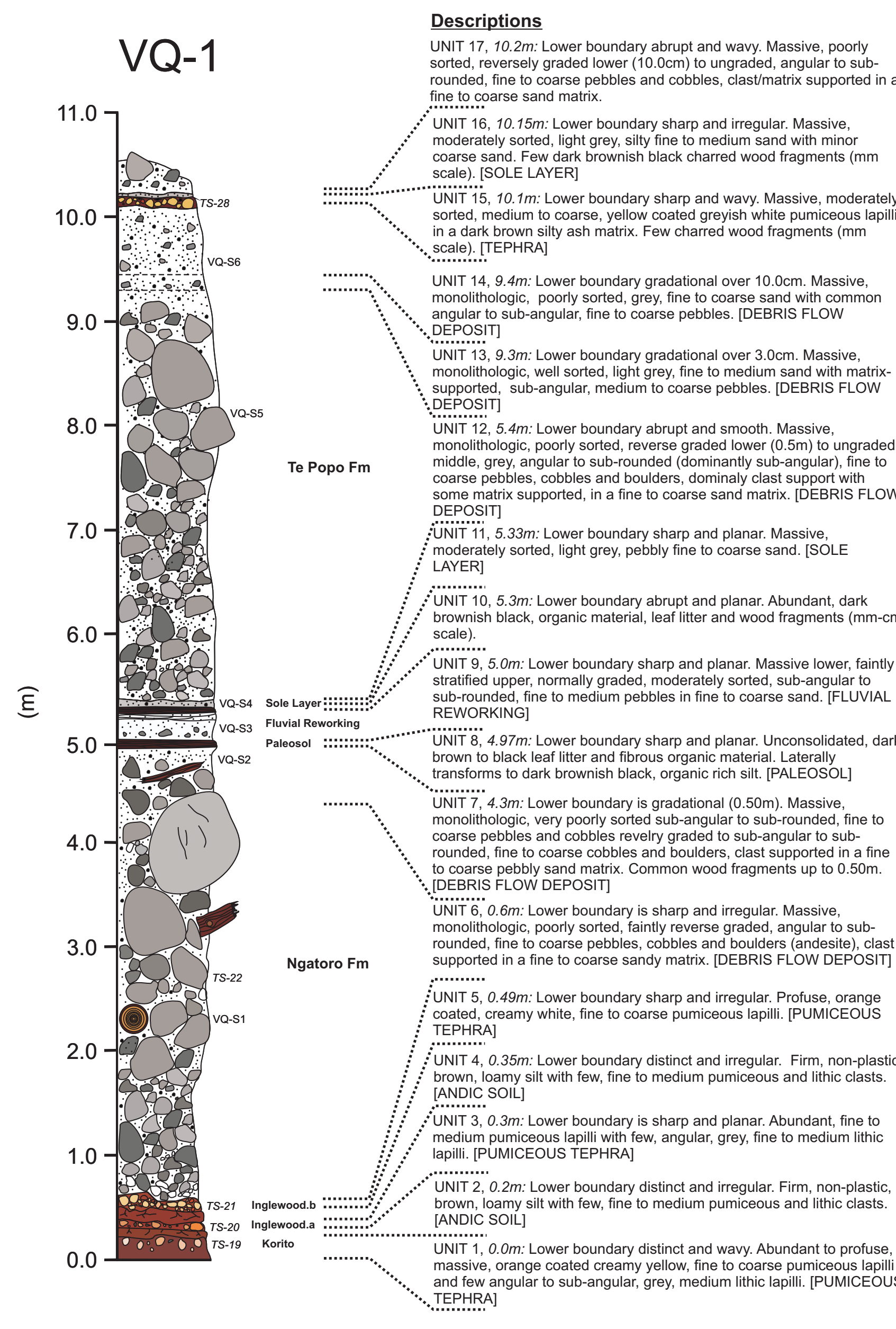

VQ-1: Measured section with relevant descriptions and sample locations. Grain size histograms, clast shape and roundness histograms, and Electron Microprobe Analysis results compared with the East Egmont and Dawson Falls reference Section (Section B1, Appendix B).
Grainsize Histograms
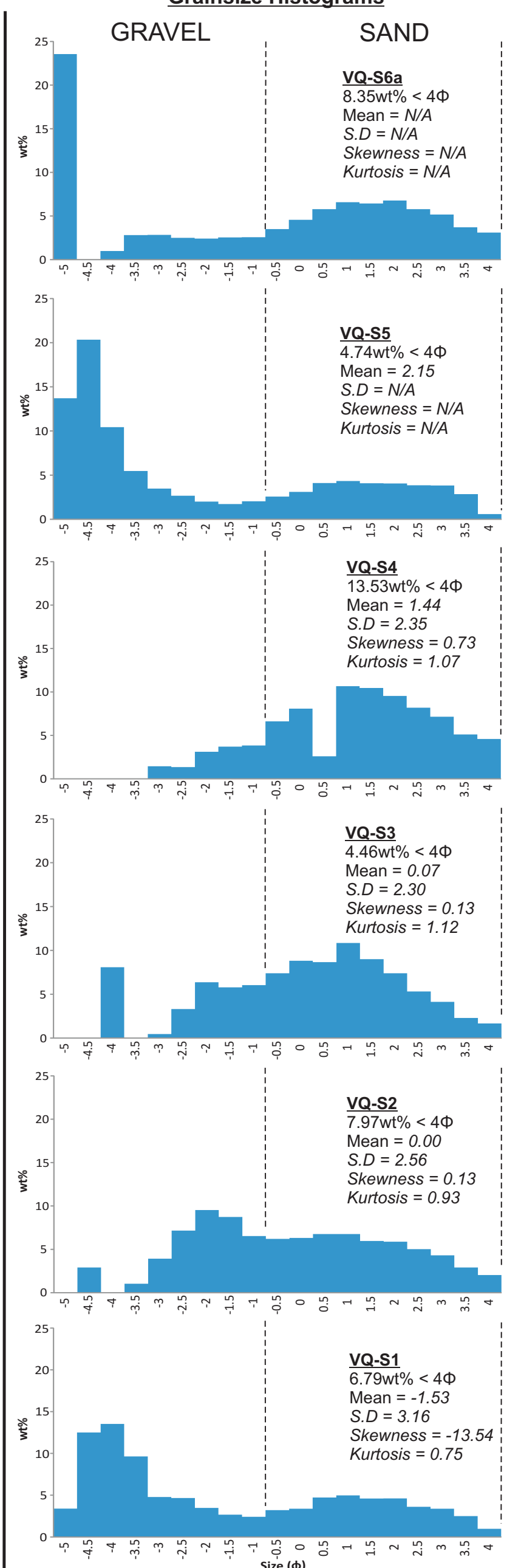

Size (\$)
Clast Shape and Roundness

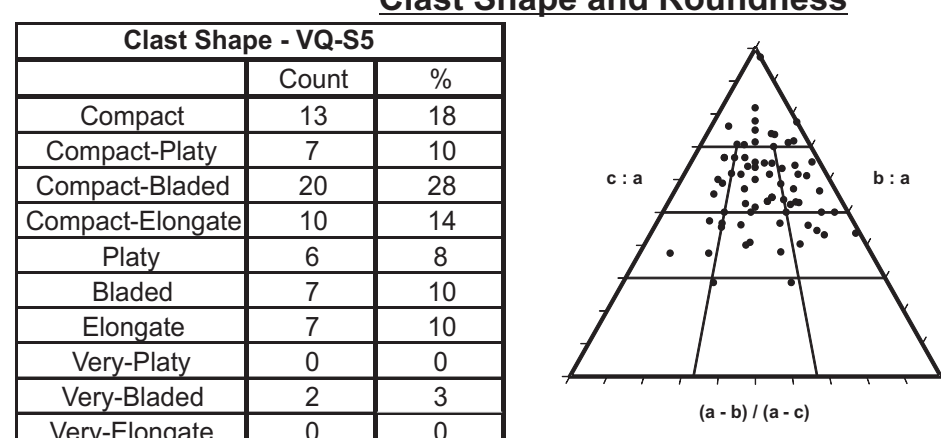

\section{\begin{tabular}{|c|c|c|}
\hline Very-Elongate & 0 & 0 \\
\hline
\end{tabular}}
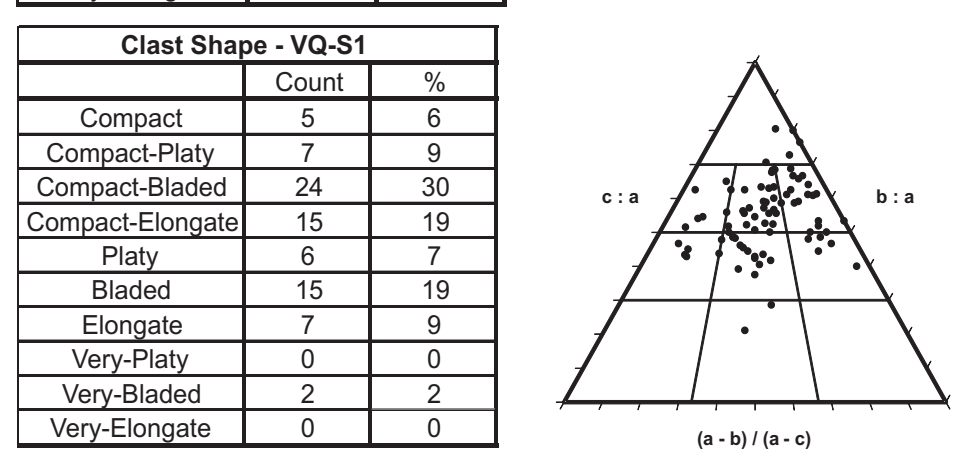

Clast Roundness
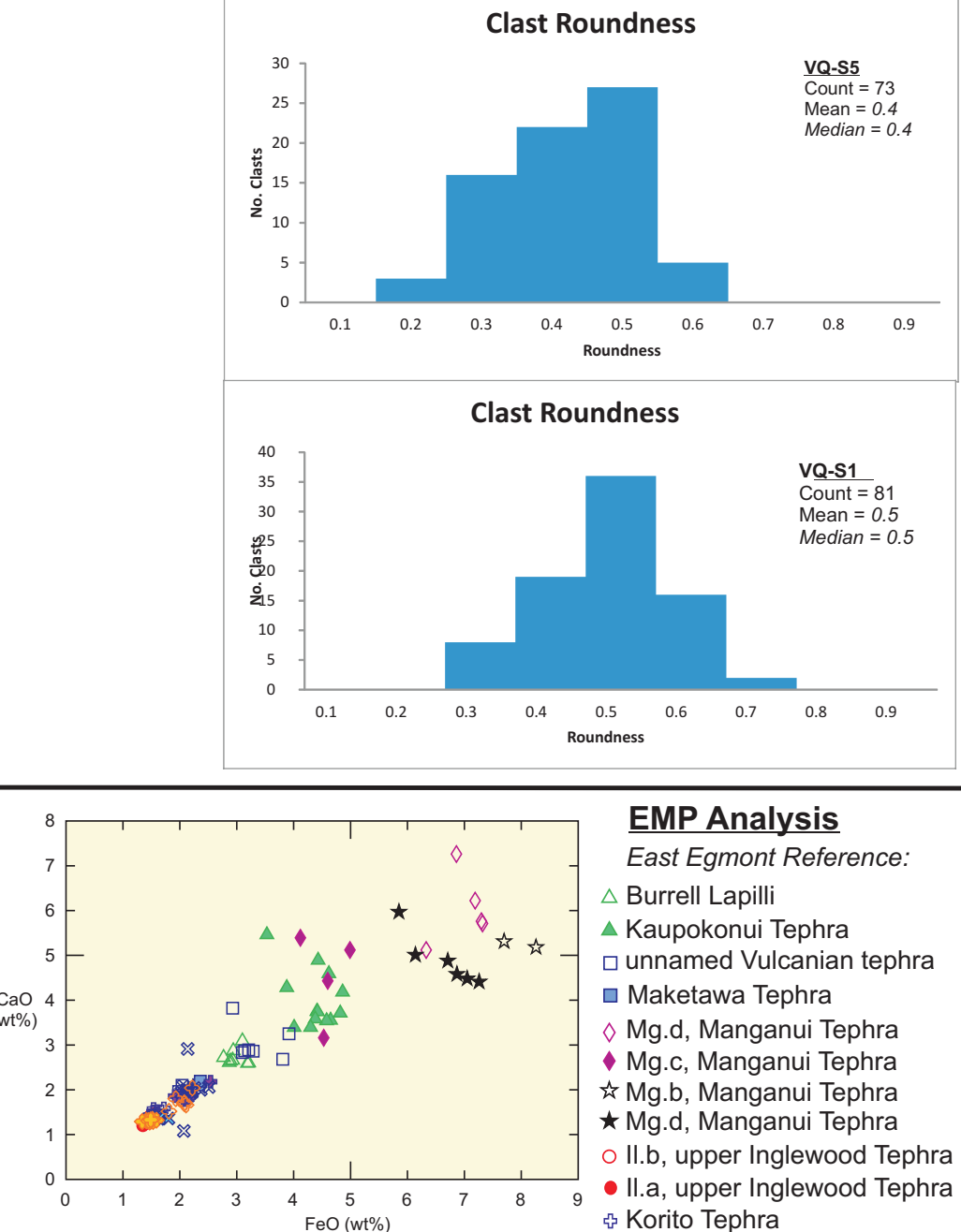

EMP Analysis

East Egmont Reference:
Burrell Lapilli
*TS 19 -19

$\triangle$ Kaupokonui Teph

D unnamed Vulcanian te

a Maketawa Tephra

$\leftrightarrow \mathrm{TS}-28$

is Mg.c, Manganui Tephra

* Mg.d, Manganui Tephra

○ ll.b, upper Inglewood Tephra
- Il.a, upper Inglewood Tephra
६ Korito Tephra
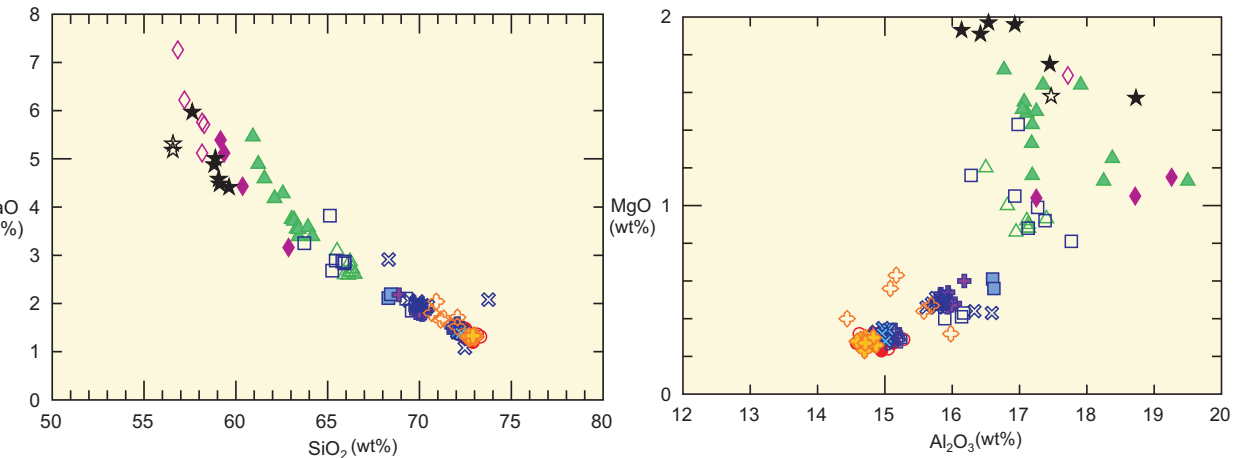


\section{Descriptions}

\section{VQ-2}

Eี

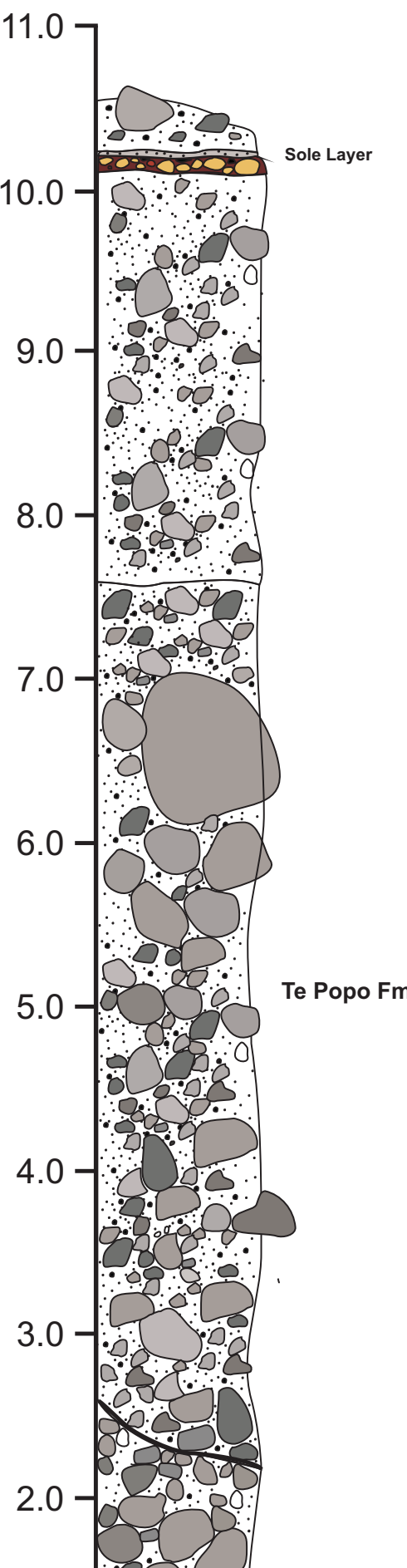




\section{VQ-3}

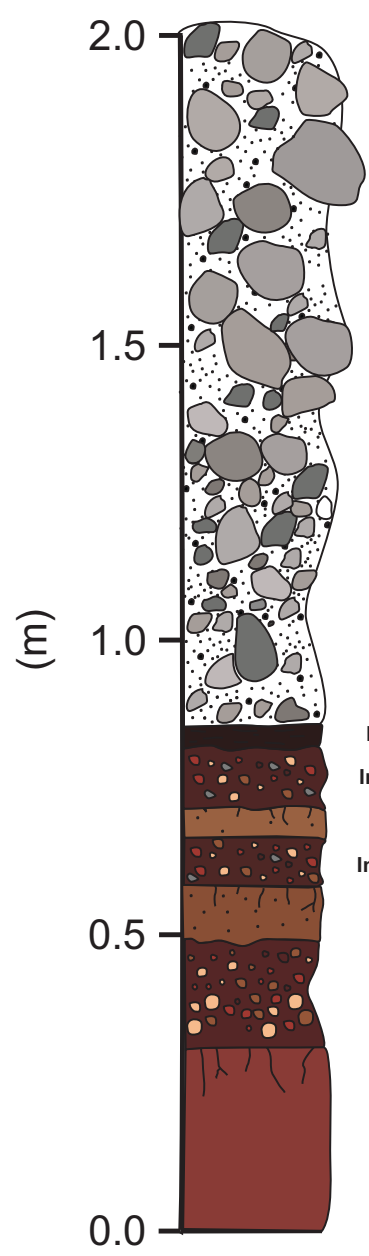

\section{Descriptions}

UNIT 8, 0.84m: Lower boundary is sharp and smooth. Massive, monolithologic, moderately sorted, light grey, fine to medium sand with some sub-angular to sub-rounded andesite pebbles grading over $20 \mathrm{~cm}$ to massive, poorly sorted, angular to sub-angular, fine to coarse andesite pebbles and cobbles with some boulders, clast supported in a grey, fine to coarse sand matrix. [DEBRIS FLOW DEPOSIT]

UNIT 7, 0.8m: Lower boundary sharp and wavy. Massive, , dark blackish brown, organic rich silt. Firm, semi-deformable, non-plastic. [CARBONACEOUS PALEOSOL]

UNIT 6, 0.7m: Lower boundary is abrupt and wavy. Massive, profuse, poorly sorted, dark brown coated greyish white to creamy white, fine to coarse pumiceous lapilli and few to common grey, fine to medium lithic lapilli, in a dark brown ash matrix. [TEPHRA]

UNIT 5, 0.65m: Lower boundary is distinct and smooth. Massive, dark brown silt. Slightly firm, semi-deformable, semi-plastic and stains fingers. [ANDIC SOIL]

$$
\text { ............ }
$$

UNIT 4, 0.57m: Lower boundary distinct and smooth. Massive, abundantant, moderately sorted, reddish brown coated greyish white, fine to medium pumiceous lapilli and few grey, angular to sub-angular, fine to medium lithic lapilli, in a dark brown ash matrix. Rare wood fragments $(\mathrm{mm})$. [TEPHRA]

Inglewood.a

Korito

UNIT 3, 0.48m: Lower boundary abrupt and irregular. Massive, greyish brown silt. Slightly firm, semi-deformable and slightly plastic. [ANDIC SOIL]

UNIT 2, 0.3m: Lower boundary is distinct and wavy. Profuse, reverse graded, brown coated creamy white, fine to coarse pumiceous lapilli in a dark brown ash matrix. [TEPHRA]

UNIT 1, 0.0m: Lower boundary not observed. Massive, greyish brown silt. Slightly firm, semi-deformable and slightly plastic. [SOIL]

VQ-3: Measured section with relevant descriptions and sample locations. 


\section{SQ-1}

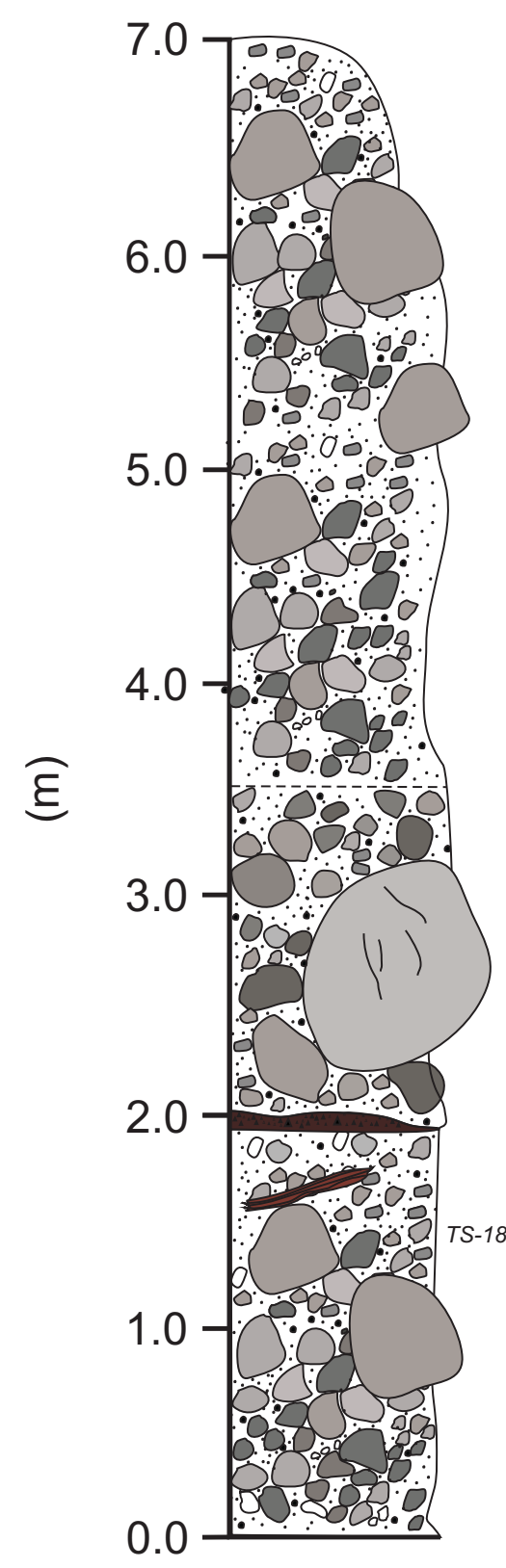

\section{Descriptions}

UNIT 4, 3.5m: Lower boundary is gradational over $0.3 \mathrm{~m}$. Massive, monolithologic, moderately sorted, sub-angular to sub-rounded, fine to coarse pebbles with few cobbles and rare boulder, matrix supported in a grey, fine to coarse, sand matrix. [DEBRIS FLOW DEPOSIT]

UNIT 3, 2.0m: Lower boundary is distinct and wavy. Massive, monolithologic, very poorly sorted, sub-angular to sub-rounded, fine to very coarse pebbles, cobbles and boulders clast supported in a fine to coarse sand matrix. Channelised with erosional lower contact. [DEBRIS Te Popo Fm FLOW DEPOSIT]

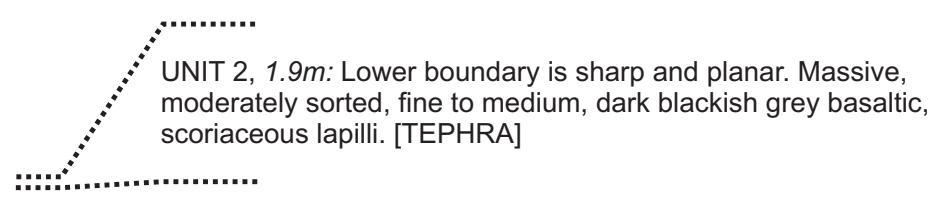

UNIT 1, 0.0m: Lower boundary not observed. Massive, monolithologic, ungraded lower to normally graded upper, poorly sorted, angular to sub-rounded, fine to coarse pebbles and cobbles clast supported in a grey, fine to coarse, pebbly sand. Becoming matrix supported in upper $0.5 \mathrm{~m}$. Common wood fragments up to $0.2 \mathrm{~m}$. [DEBRIS FLOW DEPOSIT]

SQ-1: Measured section with relevant descriptions and sample locations. 


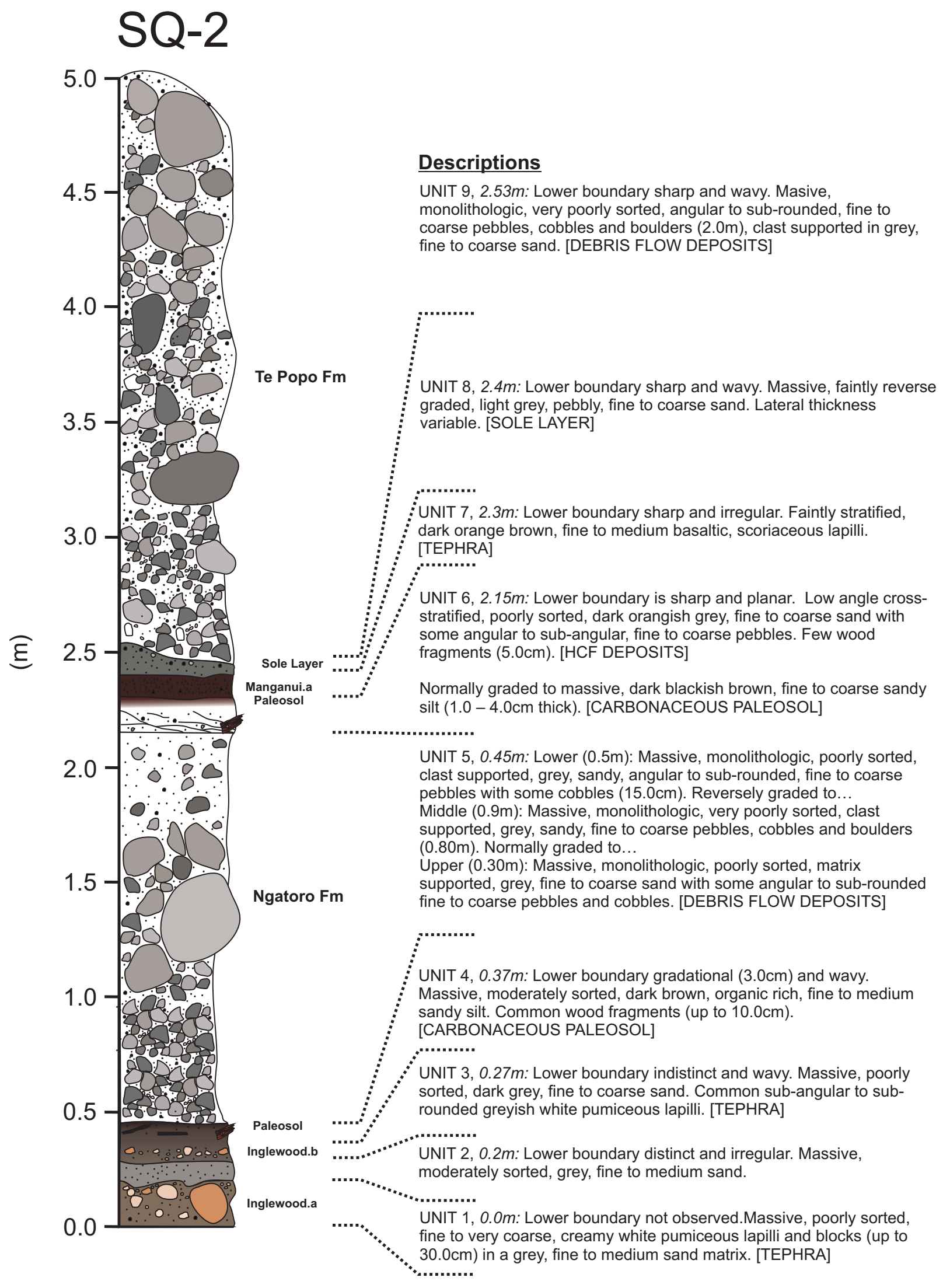

SQ-2: Measured section with relevant descriptions and sample locations. 


\section{SQ-3}

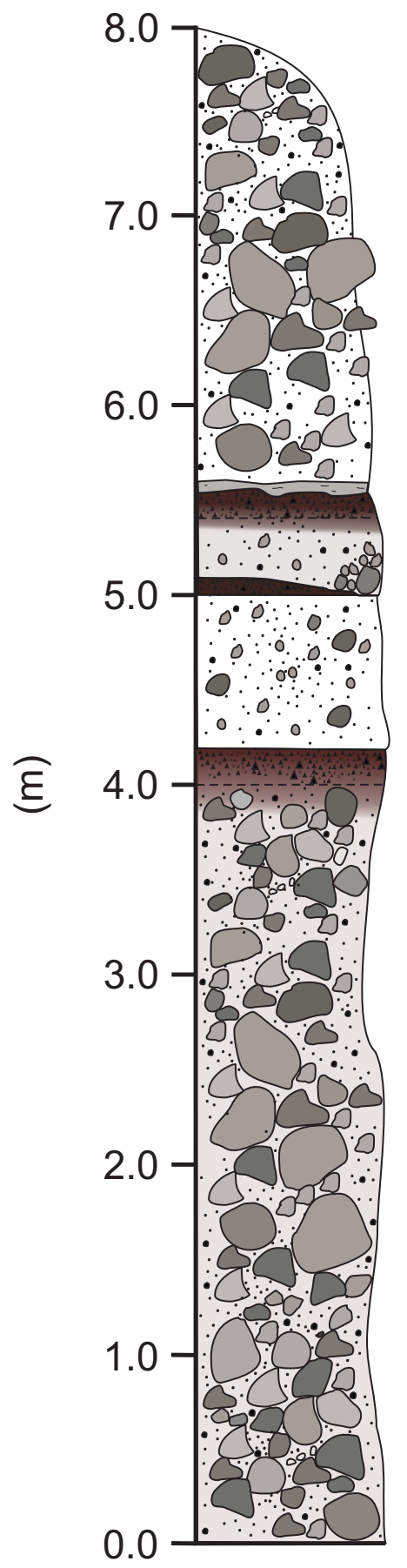

\section{Descriptions}

UNIT 8, 5.48m: Lower boundary sharp and irregular. Massive, monolithologic, very poorly sorted, dark grey, sub-angular to subrounded, fine to coarse pebbles and cobbles with few boulders, clast/matrix supported in a fine to coarse sand matrix. [DEBRIS FLOW DEPOSIT]

Te Popo Fm

Sole Layer

Manganui.c

\section{$\because: 3$} (.........

UNIT 7, 5.45m: Lower contact sharp and wavy. Massive, light grey, silt with trace of black organics. [SOLE LAYER]

UNIT 6,5 .......

UNIT 6, 5.38m: Lower boundary gradational $(4.0 \mathrm{~cm})$ and irregular. Massive, moderately sorted, dark brown, silty fine to medium basaltic, scoriaceous lapilli. [TEPHRA/CARBONACEOUS PALEOSOL]

$$
\text { UNIT } 5 \text {, }
$$

UNIT 5, 5.08m: Lower boundary sharp and planar. Massive, monolithologic, poorly sorted, dark orange brown, fine to coarse sand with some angular to sub-rounded, fine to medium pebbles. Laterally

Te Popo Fm transforms (metre scale) to massive, very poorly sorted, sub-angular to

Manganui.b sub-rounded, fine to coarse, pebble, cobble and boulders clast

Te Popo Fm supported in a sandy matrix. [DEBRIS FLOW DEPOSITS]

U..........

UNIT 4, 5.0m: Lower boundary sharp and planar. Massive, moderately sorted, dark brown, fine to medium basaltic, scoriaceous lapilli. [TEPHRA]

Manganui.a

UNIT 3, 4.2m: Lower boundary sharp and planar. Massive, monolithologic, poorly sorted, fine to coarse sand with few angular to sub-angular, fine to medium pebbles and cobbles. [DEBRIS FLOW DEPOSIT]

UNIT 2, 4.0m: Lower boundary gradational $(10.0 \mathrm{~cm})$. Massive, dark brown, fine to medium sandy silt with upper $10.0 \mathrm{~cm}$ abundant in in dark

blackish brown, fine to medium basaltic, scoriaceous lapilli. Few wood fragments (up to $20.0 \mathrm{~cm}$ ). [CARBONACEOUS PALEOSOL/TEPHRA] :

Ngatoro Fm

UNIT 1, 0.0m: Lower boundary not observed. Massive, monolithologic, poorly sorted, sub-angular to sub-rounded, fine to coarse pebbles, cobbles and boulders $(40.0 \mathrm{~cm})$, clast supported in a fine to coarse sand matrix. [DEBRIS FLOW DEPOSITS]

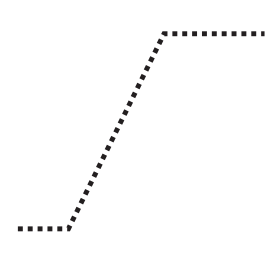

SQ-3: Measured section with relevant descriptions and sample locations. 
Grainsize Histograms

\section{Descriptions}

UNIT 10, 1.3m: Lower boundary is distinct and irregular. Massive, some, sub-angular to sub-rounded, cobbles. [DEBRIS FLOW

DEPOSITS

UNIT 9, 0.942m: Lower boundary is sharp and wavy. Faintly stratified, monolithologic, moderate to poorly sorted, grey, fine to coarse sand and with few angular to sub-angular, pebbles. [DEBRIS FLOW DEPOSIT]

UNIT 8, 0.94m: Lower boundary sharp and irregular. Massive, monolithologic, moderately sorted, consolidated, orange grey fine

medium sand. [DEBRIS FLOW DEPOSIT

UNIT 7, 0.9m: Lower boundary sharp and planar, marked by $<2.0 \mathrm{~mm}$ reddish orange iron pan. Massive, moderately sorted, orange brown and grey, fine to coarse sand and angular to sub-angular, fine to
medium pebbles. [SOLE LAYER]

$\widehat{\varepsilon}$

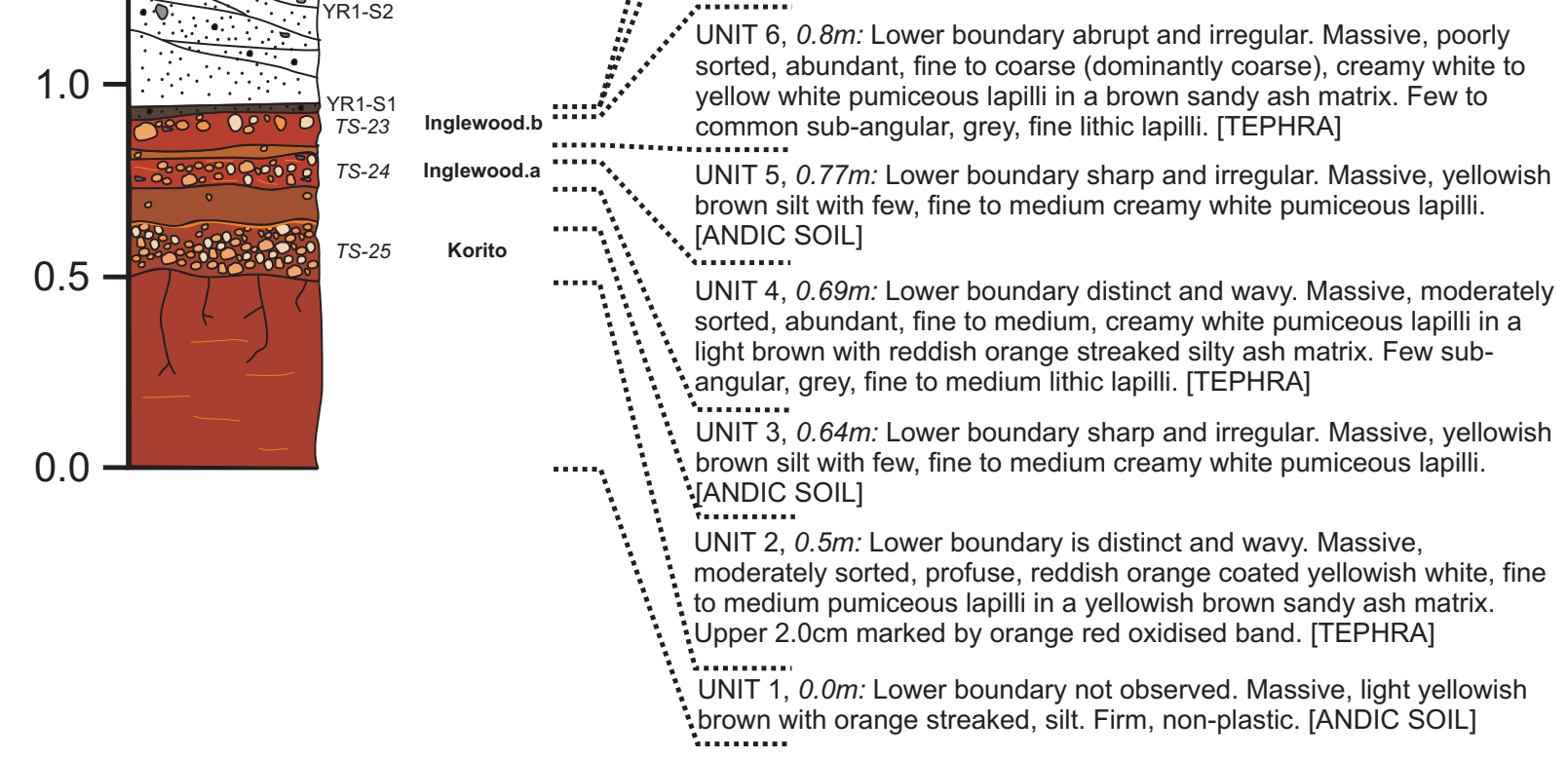

YR-1: Measured section with relevant descriptions and sample locations. Grain size histograms, clast .
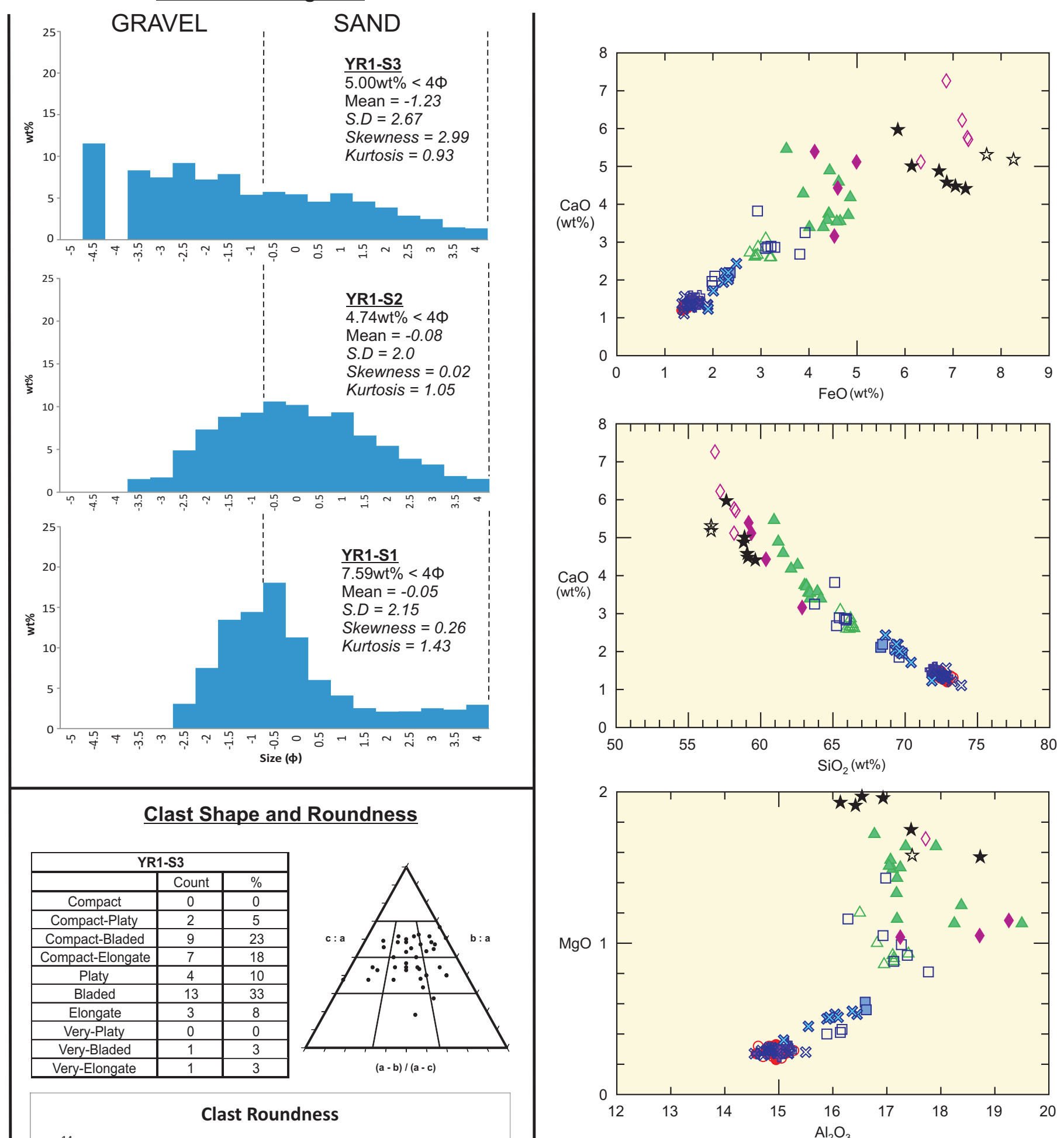

Clast Roundness

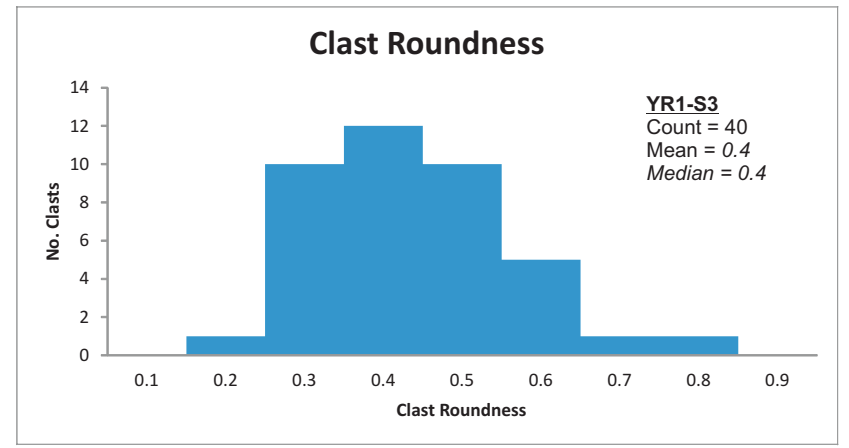

EMP Analysis

East Egmont Reference:

$\triangle$ Kaupokonui Teph

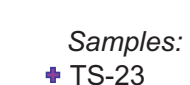

Kaupokonui Tephra

$*$ TS-23
$*$ TS-24

Maketawa Tephra

$\times$ TS -25

$\diamond$ Mg.d, Manganui Tephr

Mg.c, Manganui Tephra

« Mg.d, Manganui Tephra

II.b, upper Inglewood Tephra

- Il.a, upper Inglewood Tephra

s. Korito Tephra 


\section{YR-2}

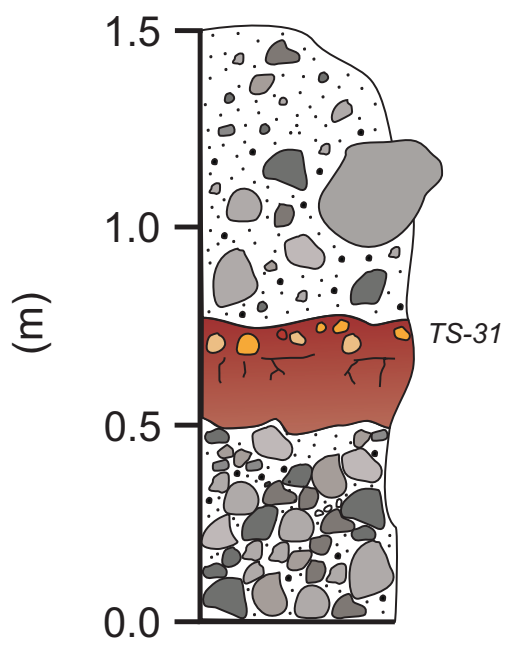

\section{Descriptions}

UNIT 3, 0.75m: Lower boundary is sharp and wavy. Massive, monolithologic, faintly normally graded, matrix supported, dark grey, fine to coarse sand with angular to sub-angular, pebbles and cobbles $(25.0 \mathrm{~cm})$. [DEBRIS FLOW DEPOSITS]

$\therefore$ UNIT 2, 0.5m: Lower boundary is distinct and wavy. Massive, orange brown, fine to medium sandy silt. Upper boundary marked with abundant, medium to very coarse, yellowish white pumiceous lapilli. [PUMICEOUS TEPHRA/ANDIC SOIL]

UNIT 1, 0.0m: Lower boundary not observed. Massive, monolithologic, poorly sorted, clast supported, dark grey, fine to coarse sand with some angular to sub-angular, fine to coarse pebbles. [DEBRIS FLOW DEPOSITS]

YR-2: Measured section with relevant descriptions and sample locations. 


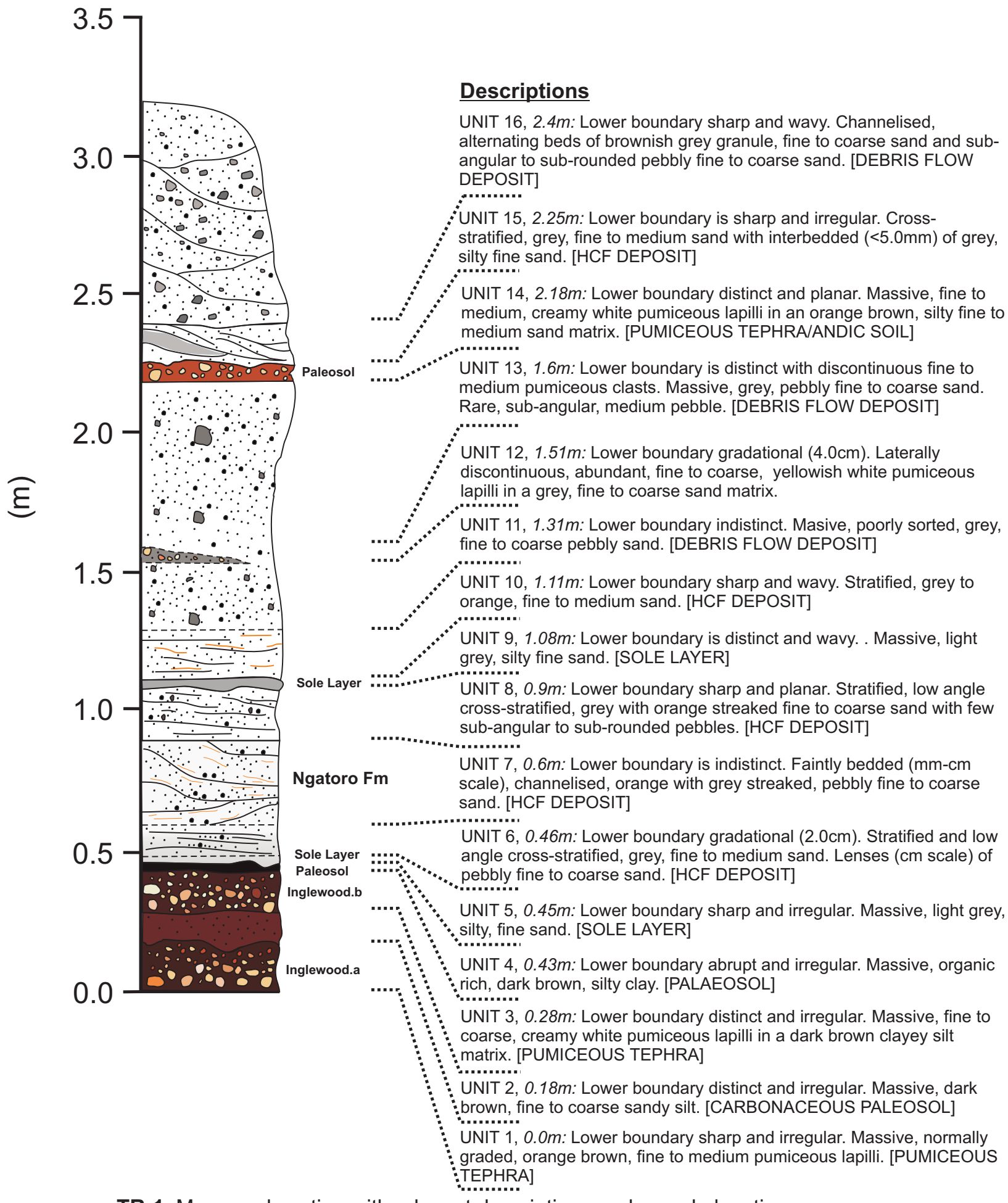

TR-1: Measured section with relevant descriptions and sample locations. 


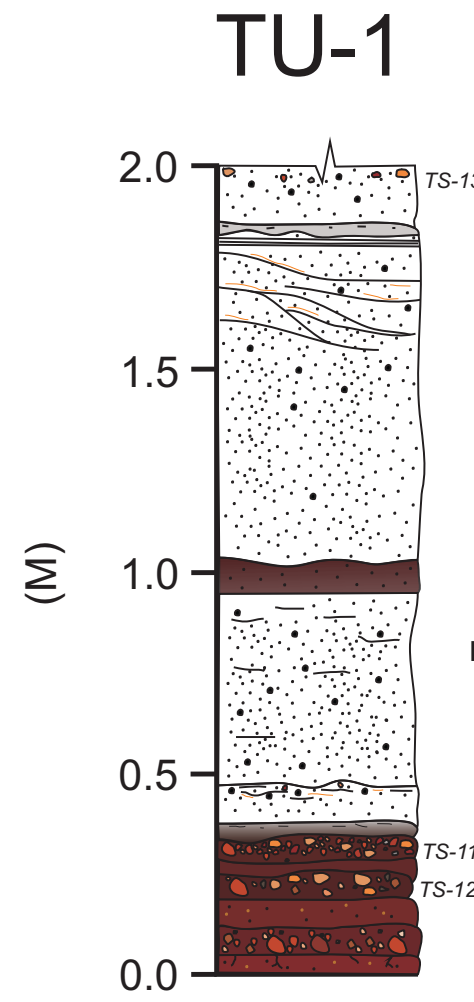

Paleosole

Ngatoro Fm

TU-1: Measured section with relevant descriptions and sample locations. Electron Microprobe Analysis results compared with the East Egmont and Dawson Falls reference Section (Section B1, Appendix B).

Korito

\section{Descriptions}

UNIT 13, 1.88m: Lower boundary sharp and irregular. Massive, poorly sorted, grey and orange brown, fine to coarse sand with few to common fine to coarse, grey to reddish orange coated, grey to creamy white pumiceous lapilli.

UNIT 12, 1.85m: Lower boundary sharp and wavy. Massive, well

sorted, light grey with orange mottled silt. Firm and friable. Some fibrous organics. [SOLE LAYER]

...........

$\therefore$ UNIT 11, 1.04m: Lower boundary distinct and irregular. Massive, moderately sorted, grey, fine to medium sand grading to low angle cross-stratified, grey with reddish orange streaked, fine to coarse sand (Upper $20.0 \mathrm{~cm}$ ). Upper $4.0 \mathrm{~cm}$ laminated, normally graded sand. [HCF DEPOSIT

UNIT 10, 0.94m: Lower boundary abrupt and planar. Massive, fine to

medium, dark brown organic rich sand. [CARBONACEOUS PALEOSOL]

UNIT.............

UNIT 9, 0.47m: Lower boundary sharp and wavy. Massive, moderately sorted, dark grey, fine to coarse sand. Localised faint laminations.

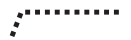

UNIT 8, 0.365m: Lower boundary abrupt and wavy. Massive, well sorted, well sorted, fine to medium sand grading to faintly stratified,
grey with orange streaked, medium to coarse sand. Upper $4.0 \mathrm{~cm}$ has few medium to coarse, creamy white pumiceous lapilli. Few pinkish grey silt rip-ups in lower $2.0 \mathrm{~cm}$. [HCF DEPOSIT]

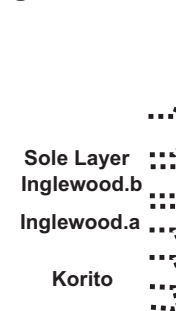

UnIT $7,0.3$

$\therefore$

UNIT 7, 0.33m: Lower boundary sharp and wavy. Massive, dark brownish grey grading to light grey silt. Firm, semi-deformable, slightly plastic. Trace of fine, black organics. [SOLE LAYER]

UNIT 6, 0.285m: Lower boundary abrupt and wavy. Massive, moderately sorted, abundant fine to coarse orange brown coated pale grey to creamy white pumiceous lapilli. [PUMICEOUS TEPHRA] UNIT 5, 0.25m: Lower boundary distinct and irregular. Massive, dark brown silty loam. Firm, friable, non-plastic. [ANDIC SOIL]

UNIT 4, 0.18m: Lower boundary distinct and wavy. Massive, poorly sorted, abundant, fine to very coarse red brown to orange brown coated pale grey pumiceous lapilli in a dark brown silty sand and ash matrix.

Very few pale grey, fine to medium lithic lapilli. [PUMICEOUS TEPHRA] ..........

UNIT 3, 0.12m: Lower boundary abrupt and wavy. Massive, dark brown, sandy loam with some coarse yellowish white pumiceous sand, firm, semi-deformable, non-plastic. [ANDIC SOIL]

:.........

UNIT 2, 0.05m: Lower boundary sharp and smooth. Moderately sorted, faintly normally graded, fine to coarse (few very coarse), light brown coated yellowish white pumiceous lapilli in a coarse pumiceous sandy ash matrix. [PUMICEOUS TEPHRA]

"uNIT 1, O."

UNIT 1, 0.0m: Lower boundary not observed. Massive, dark brown, loamy sand with some well sorted, pumiceous sand. Very firm, semideformable, slightly plastic. [ANDIC SOIL]
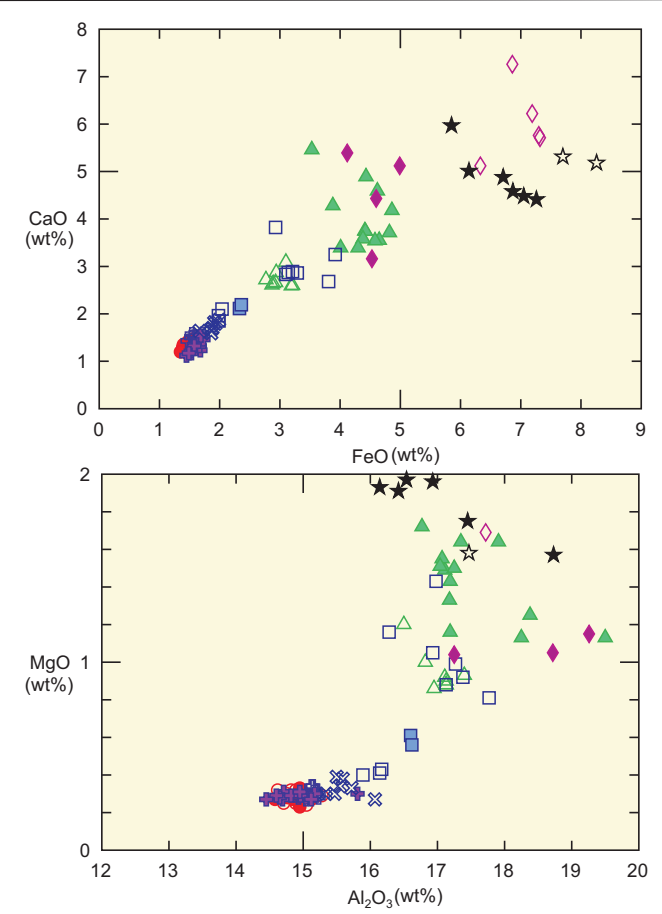

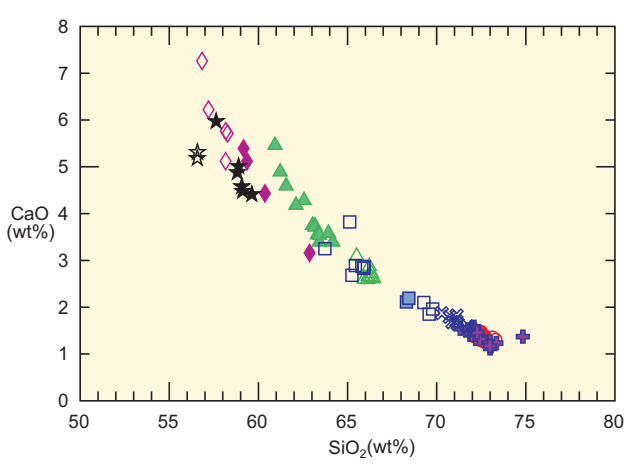

\section{EMP Analysis}

East Egmont Reference:

$\triangle$ Burrell Lapilli

$\triangle$ Kaupokonui Tephra

$\square$ unnamed Vulcanian tephra

$\square$ Maketawa Tephra
Samples:

+ TS-11

is -12 $\diamond$ Mg.d, Manganui Tephra - Mg.c, Manganui Tephra ฟ Mg.b, Manganui Tephra $\star$ Mg.d, Manganui Tephra - II.b, upper Inglewood Tephra - II.a, upper Inglewood Tephra ↔ Korito Tephra 
Grainsize Histograms

UNIT 14, 1.55m: Lower boundary is sharp and irregular. Massive, moderately sorted, grey lower to orange brown upper, fine to medium
sand. Few, orange brown coated creamy white pumiceous clasts at top of unit.

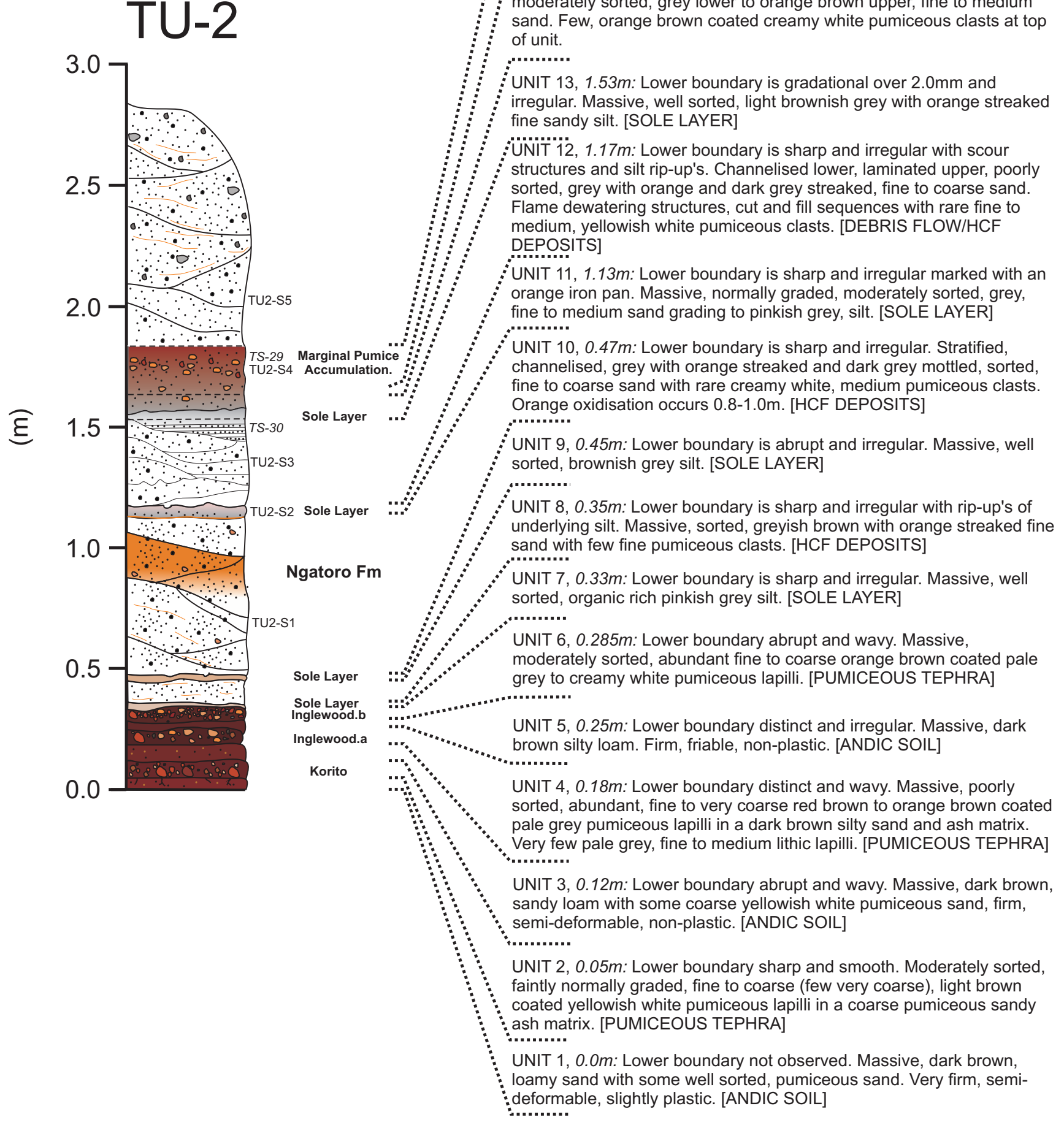

TU-2: Measured section with relevant descriptions and sample locations. Grain size histograms and Electron Microprobe Analysis results compared with the East Egmont and Dawson Falls reference Section (Section B1, Appendix B).

\section{GRAVEL \\ SAND}

$\frac{\text { TU2-S5 }}{5.26 \mathrm{wt} \%}<40$

Mean $=1.44$
$S . D=1.33$

Skewness $=0.71$
Kurtosis $=1.13$

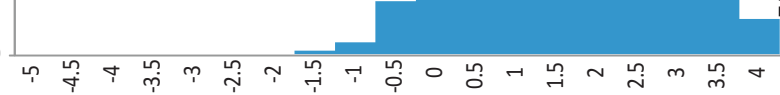

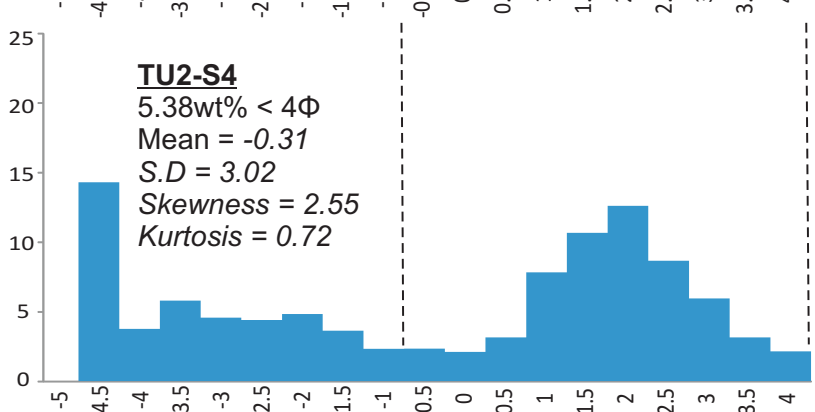

TU2-S3

$7.90 w+\%<40$
Mean $=2.02$

Skewness $=0$.

Kurtosis $=1.31$

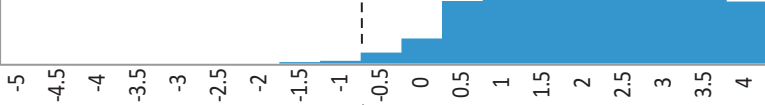

${ }^{25}$

TU2-S2

TU2-S2
53.97wt $\%<4 \Phi$
Mean $=4.49$

Mean $=4.49$
$S . D=1.45$

Skewness $=0.99$
Kurtosis $=0.87$

Kurtosis $=0.87$

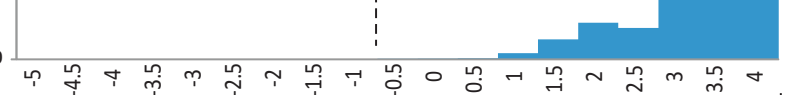

${ }^{25}$

TU2-S1

$\frac{1.29 \mathrm{wt} \%}{6.89 \Phi}$
Mean $=2.16$

Mean $=2.16$
$S . D=1.20$
$S K u$

Skewness $=0.70$
Kurtosis $=1.30$

5.

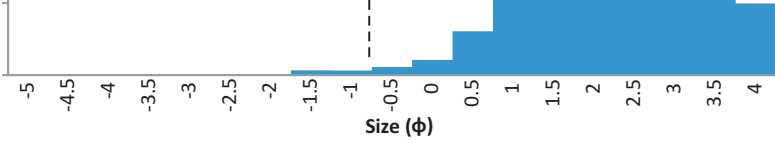

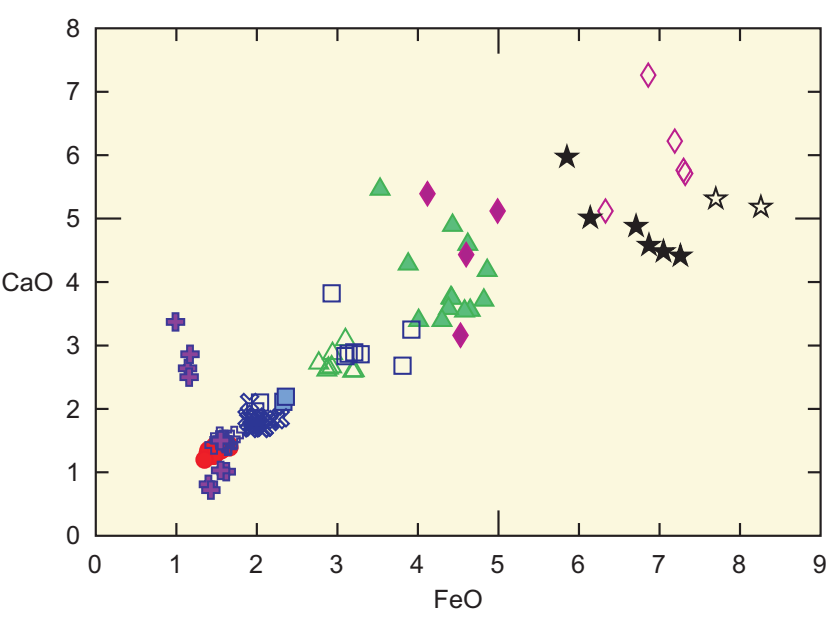
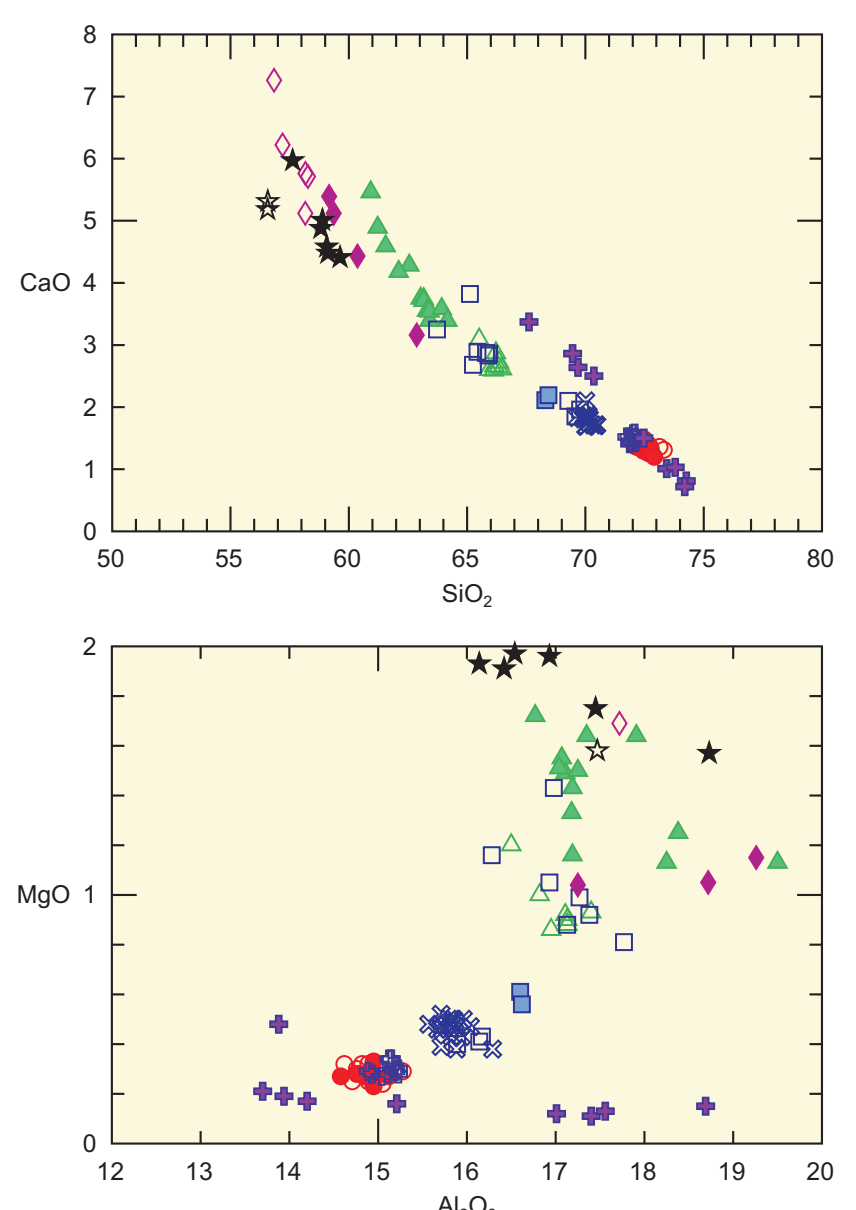

\section{EMP Analysis}

East Egmont Reference:

$\triangle$ Burrell Lapili
$\triangle$ Kaupokonui Teph

Samples:

$\triangle$ Kaupokonui Tephra

- Maketawa Tephra

- Mg.d, Manganui Tephra

iz Mg.b, Manganui Tephra
$\star$ Mg.d. Manganui Tephra

* ll. upper Ingu Tephra

- Il.a, upper Inglewood Tephra

\$ Korito Tephra 


\section{TU-3}

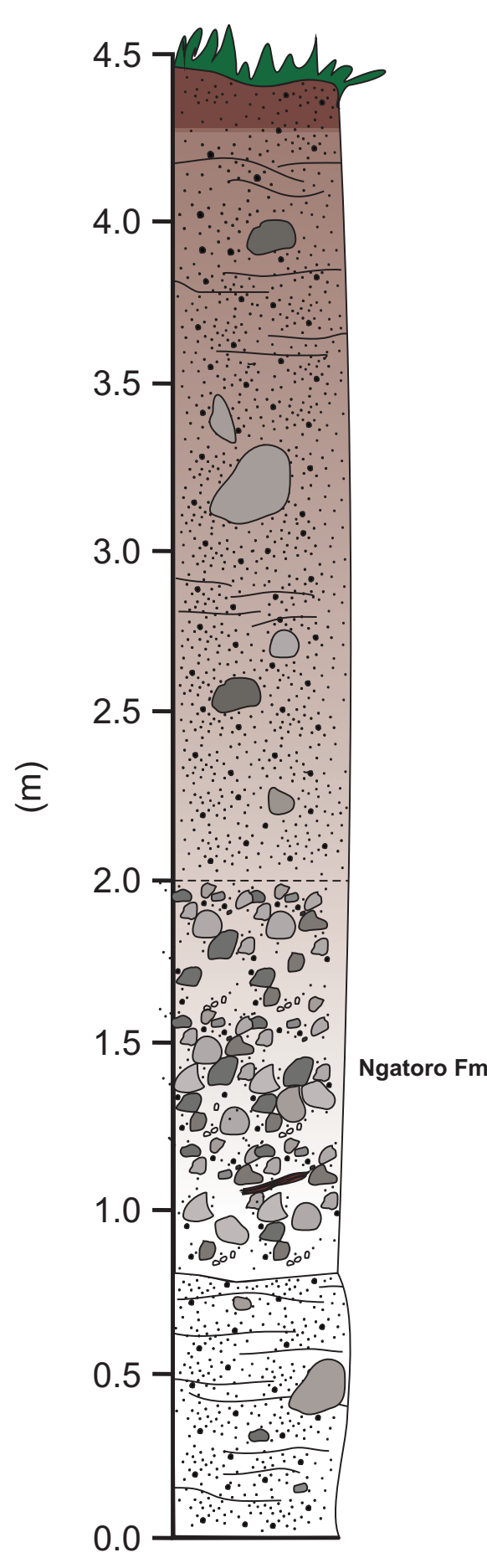

\section{Descriptions}

UNIT 4, > 4.5m: Vegetated, modern topsoil.

UNIT 3, 2.0m: Lower boundary gradational over 0.5m. Massive, moderately sorted, dark grey with few bron mottles, medium to coarse sand with some sub-rounded, fine to medium pebbles forming faintly stratified units $(0.1 \mathrm{~m})$ in some places. Few boulders $(0.5 \mathrm{~m})$ in upper part of unit.

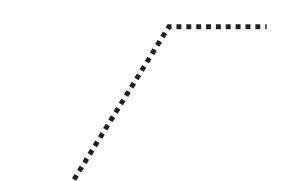

UNIT 2, 0.8m: Lower boundary is abrupt and wavy.Massive, poorly sorted, grey, sub-angular to sub-rounded, fine to coarse pebbles and cobbles matrix supported in brownish grey, fine to coarse sand matrix.

TU-3: Measured section with relevant descriptions and sample locations. 

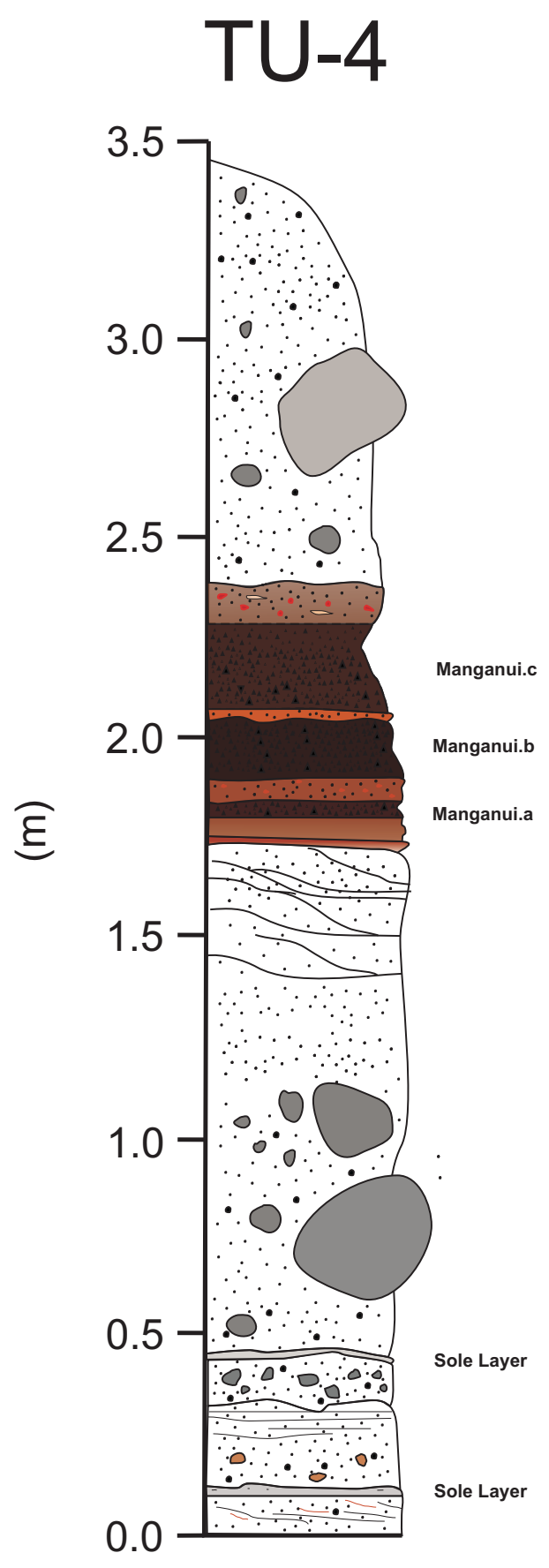

\section{Descriptions}

UNIT 14, 2.39m: Lower boundary is indistinct. Massive, poorly sorted, matrix supported, brownish grey, fine to coarse sand with few subangular to sub-rounded, fine to coarse pebbles, cobbles and boulders $(50.0 \mathrm{~cm})$. Few rip ups of light grey silt with fibrous organics. [DEBRIS FLOW DEPOSITS]

UNIT 13, 2.27m: Lower boundary gradational $(5.0 \mathrm{~cm})$. Massive, light brown with orange mottled, fine sandy silt with lenses of some clay. [PALEOSOL]

UNIT 12, 2.09m: Lower boundary is distinct and wavy. Massive, normally graded, dark brownish black, fine to medium basaltic,

scoriaceous lapilli. Upper $2.0 \mathrm{~cm}$ marked by brownish orange iron pan. [SCORIACEOUS TEPHRA]

UNIT 11,20

UNIT 11, 2.05m: Lower boundary is distinct and wavy. Massive, moderately sorted, orange, fine to medium sandy silt iron pan.

moderate

UNIT 10, 1.9m: Lower boundary is distinct and wavy. Massive, fine, black basaltic, scoriaceous lapilli. [SCORIACEOUS TEPHRA] UNIT 9, 1.83m: Lower boundary abrupt and smooth. Massive, light
brown with orange mottled, silty fine to medium sandy soil. [ANDIC SOIL]
$\therefore: 8$
...........* UNIT 8, 1.8m: Lower boundary sharp and planar. Massive, fine, black basaltic, scoriaceous lapilli. [SCORIACEOUS TEPHRA]

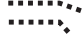

UNIT 7, 1.74m: Lower boundary abrupt and smooth. Massive, light

brown, fine to medium sandy silty soil. [ANDIC SOIL]

UNIT 6, 0.44m: Lower boundary is sharp and irregular. Massive, poorly sorted, light grey with orange mottled and streaked, fine to medium sand with common sub-angular to sub-rounded, fine to coarse pebbles, some cobbles and few boulders $(50.0 \mathrm{~cm})$. Graded to faintly crossstratified, moderately sorted, orange, fine to medium sand. Upper boundary marked with sharp and wavy, massive, light brown, silt. DEBRIS/HCF DEPOSITS
UNIT 5, 0.32m: Lower boundary is distinct and irregular. Massive,
UNIT 5, 0.32m: Lower boundary is distinct and irregular. Massive, poorly sorted, fine to coarse sandy, angular to sub-angular, fine to medium pebbles. Erosive channels at base with upper boundary

marked with 2.0mm light grey silt bed. [SOLE LAYER]
UNIT 4, 0.22m: Lower boundary sharp and planar. Faintly stratified,
moderately sorted, fine to medium sand grading to fine to coarse sand :::::- moderately sorted, fine to medium sand grading to fine to coarse sand. ............. ÜITIT 3, 0.12m: Lower boundary is sharp and irregular. Massive, moderately sorted, grey, medium to coarse sand with some, coarse to very coarse, creamy white pumiceous lapilli.

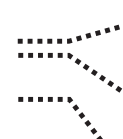

UNIT 2, 0.1m: Lower boundary sharp and planar. Massive, light grey, silt with some fine sand and a few, fine, dark brown, fibrous organics. silt with some fine

UNIT 1, 0.0m: Lower boundary not observed. Low angle cross-stratified, moderately sorted, dark grey with orange streaked, fine to coarse sand. HCF DEPOSITS]

TU-4: Measured section with relevant descriptions and sample locations. 


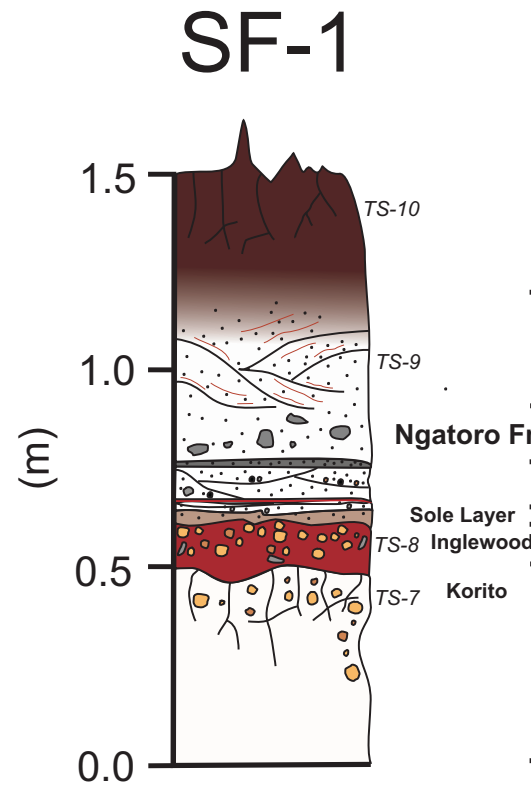

SF-1: Measured section with relevant descriptions and sample locations. Electron Microprobe Analysis results compared with the East Egmont and Dawson Falls reference Section (Section B1, Appendix B).

\section{m}

\section{Descriptions}

UNIT 7, 1.1m: Lower boundary is diffuse. Massive, weak, friable, loamy fine sand. [TOPSOIL]

UNIT 6, 0.72m: Lower boundary sharp and smooth, marked by thin (2mm), discontinuous, fine to medium sand bed. Masive, poorly sorted, grey, fine to coarse sand with some sub-rounded, fine to medium pebbles grading to stratified, sorted, grey with orange streaked medium to coarse channelised sand. [HCF DEPOSITS]

UNIT 5, 0.66m: Lower boundary is sharp and smooth, marked by an orange iron pan $(<0.01 \mathrm{~cm})$. Channelised, poorly sorted, friable, grey, fine to coarse sand with some abundant pumice and lithic pebbles in channels. [DEBRIS FLOW DEPOSITS]

UNIT 4, 0.63m: Lower boundary is sharp and wavy. Massive, poorly

$$
\begin{aligned}
& \text { sorted, fine to coarse sand with few pebbles vertically grading to a } \\
& \text { laminated, well sorted, grey with orange streaked medium sand. [HCF }
\end{aligned}
$$

UNIT 3, 0.6m: Lower boundary is sharp and irregular. Massive, well sorted, friable, orange brown fine sand. Laterally swells and pinches. :[SOLE LAYER]

UNIT 2, 0.5m: Lower boundary is distinct and irregular. Abundant,

moderately sorted, reddish brown coated creamy white, fine to coarse

pumiceous lapilli and few fine, grey, sub-angular to sub-rounded, fine to coarse lithic lapilli in a reddish brown sandy ash matrix. [PUMICEOUS TEPHRA]

UNIT 1, 0.0m: Lower boundary not observed. Massive, firm, friable, reddish brown fine to medium sand and silt. Few fine to coarse pale brownish white pumiceous lapilli and grey, sub-angular to sub-rounded lithic lapilli. Vertical infilled accumulation of pale brownish white, medium to coarse pumiceous lapilli. [PUMICEOUS TEPHRA]
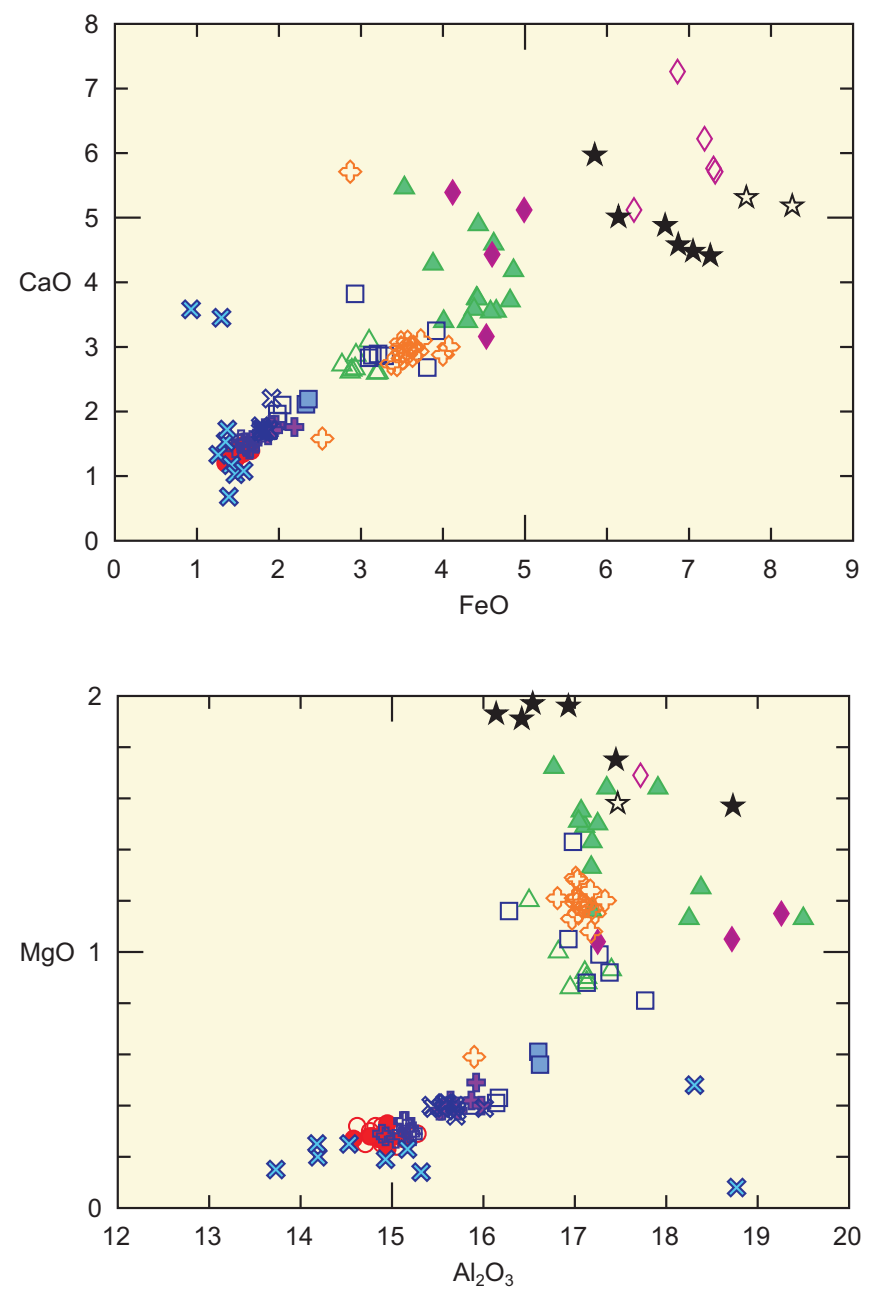

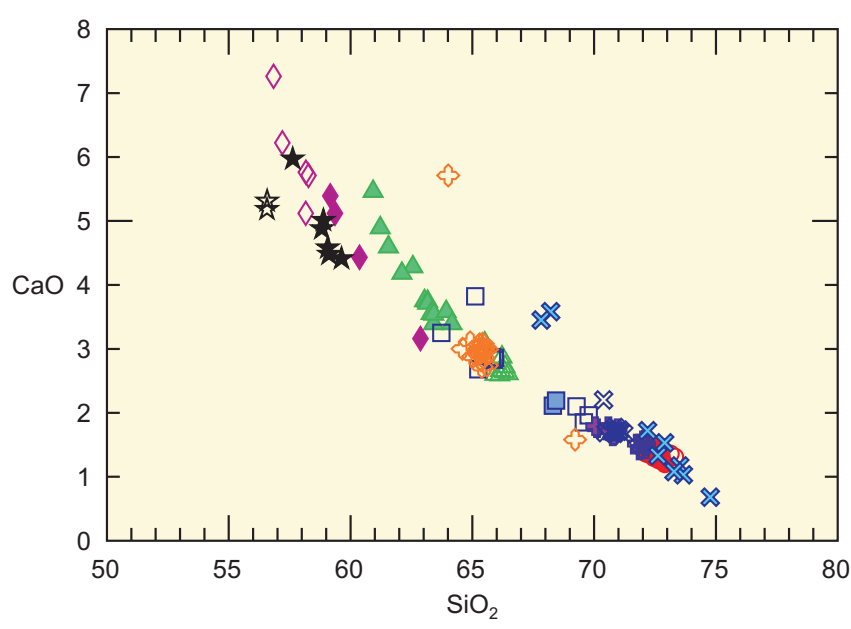

\section{EMP Analysis}

East Egmont Reference:

$\triangle$ Burrell Lapilli

Samples:

$\triangle$ Kaupokonui Tephra

ч unnamed Vulcanian tephra

+ TS-7

$\approx$ TS-8

$\approx$ TS -9

- Maketawa Tephra

\& TS-10

$\diamond$ Mg.d, Manganui Tephra

- Mg.c, Manganui Tephra

it Mg.b, Manganui Tephra

$\star$ Mg.d, Manganui Tephra

o II.b, upper Inglewood Tephra

- II.a, upper Inglewood Tephra

↔ Korito Tephra 


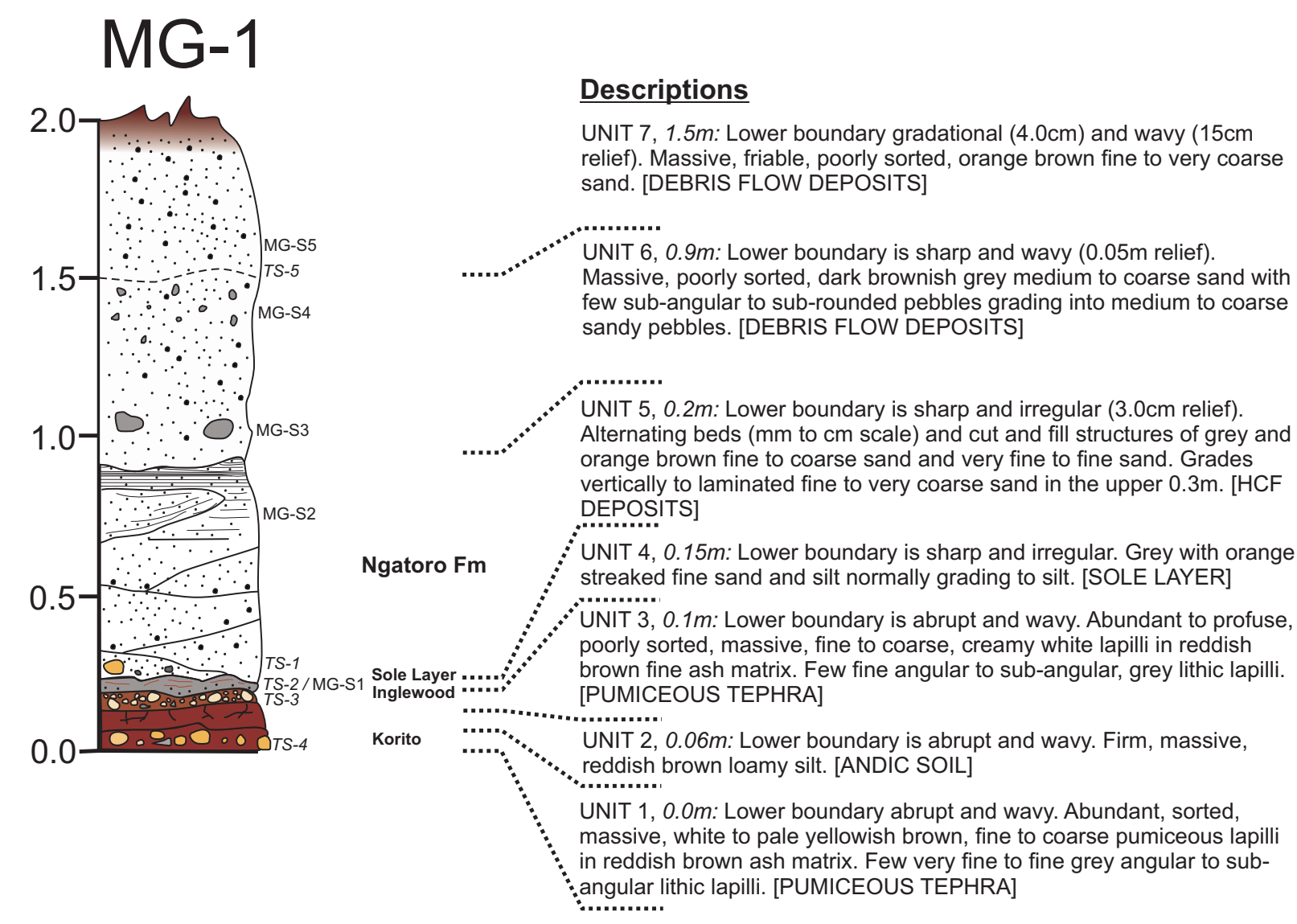

MG-1: Measured section with relevant descriptions and sample locations. Grain size histograms and

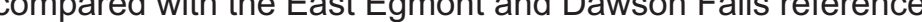
Section (Section B1, Appendix B).

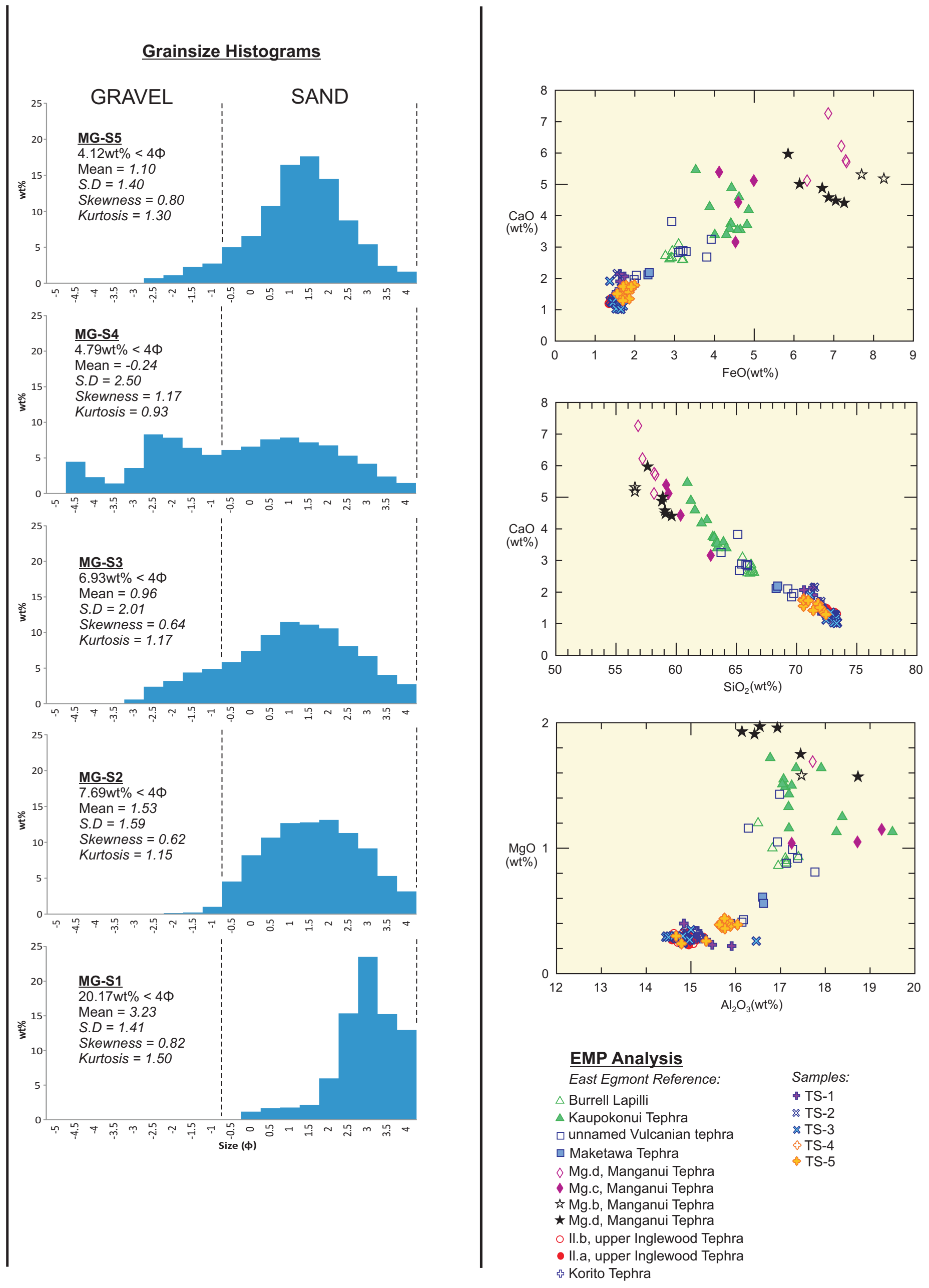




\section{A2 - Stratigraphic Correlation}

The measured sections presented in section A1 are correlated using well-developed paleosols and laterally continuous tephra marker beds supported by EMP analysis. 


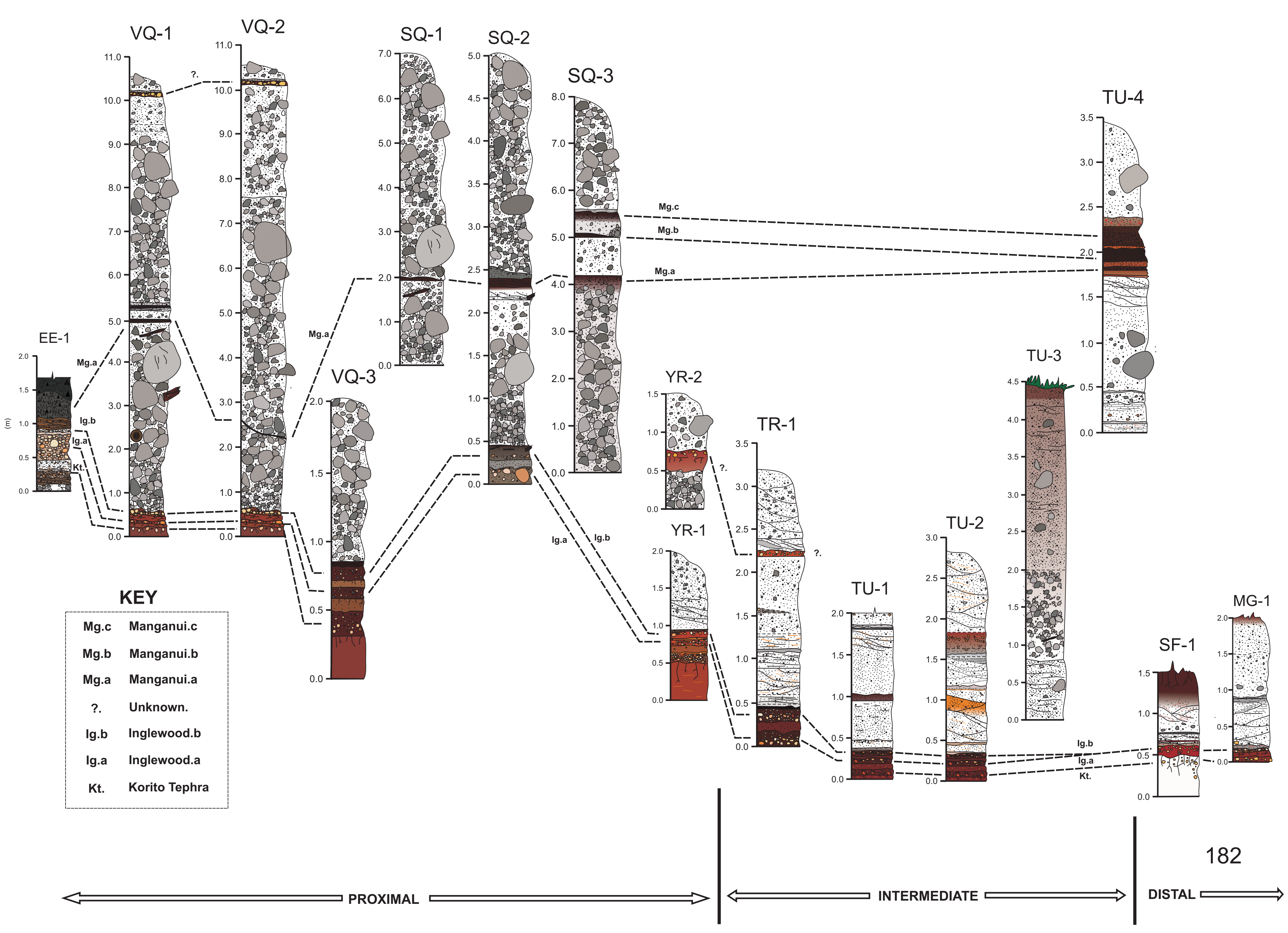




\section{Appendix B: Electron Microprobe Dataset}

\section{B1 - Reference Major Elemental Glass Composition}

Presented is the reference Electron Microprobe Analysis dataset showing the major elemental glass compositions of the sampled reference tephra sections at East Egmont and Dawson Falls. This is unpublished data provided by A/Prof Brent Alloway for the correlation of tephra beds identified in this study with the existing stratigraphic and tephrochronologic framework.
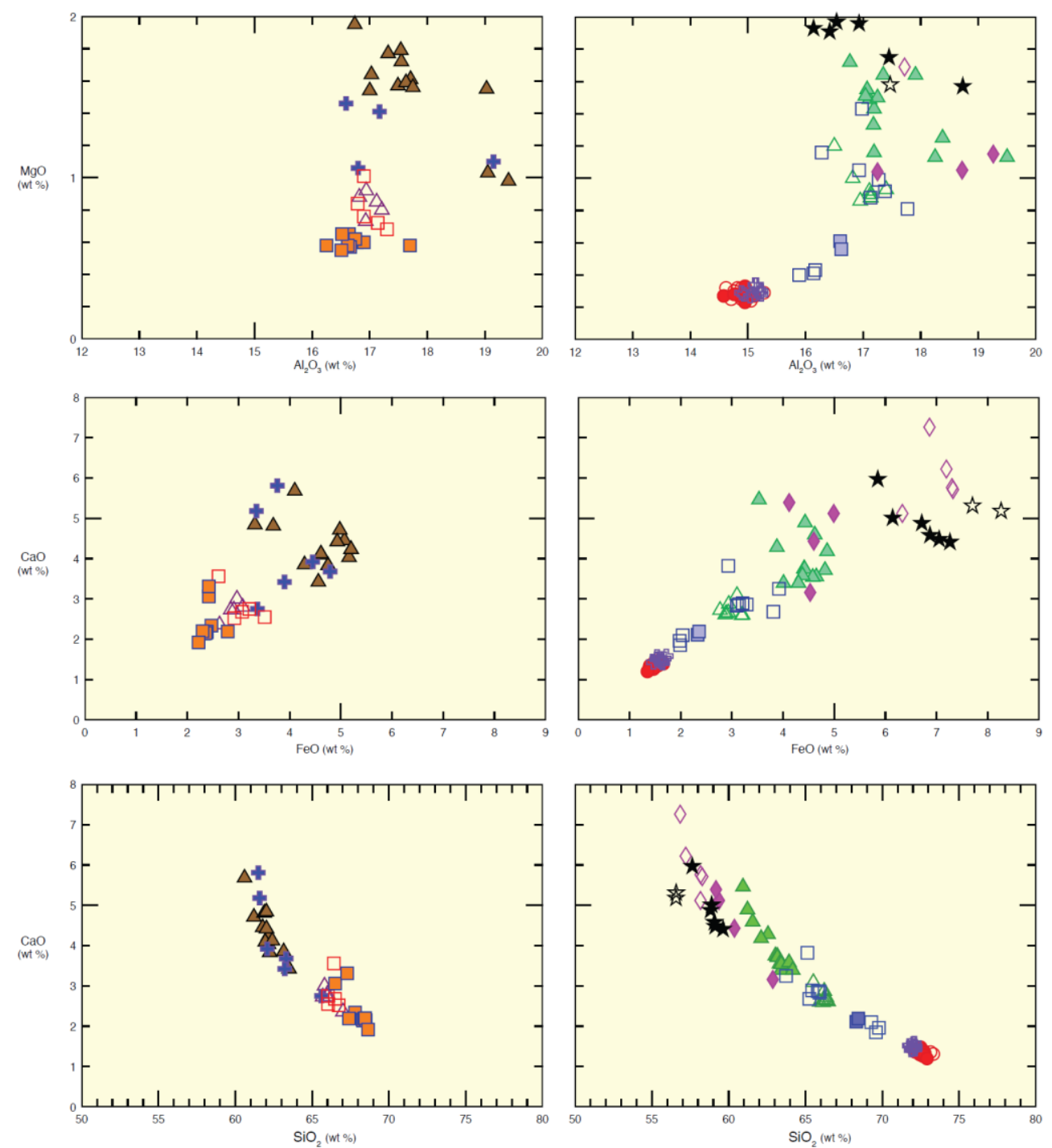

Dawson Falls

Burrell Lapilli

Kapokonui Tephra

upper unnamed Vulcanian tephra

Iwr unnamed Vulcanian tephra

Maketawa Tephra

\section{East Egmont}

Burrell Lapilli

Kapokonui Tephra

upper unnamed Vulcanian tephra

Maketawa Tephra

Mg.d, Manganui Tephra

Mg.c, Manganui Tephra

Mg.b, Manganui Tephra

Mg.a, Manganui Tephra

II.b, upper Inglewood Tephra

Il.a, lower Inglewood Tephra

Korito Tephra 
East Egmont EMP Reference Dataset

\begin{tabular}{|c|c|c|c|c|c|c|c|c|c|c|c|}
\hline Sample & $\mathrm{SiO}_{2}$ & $\mathrm{Al}_{2} \mathrm{O}_{3}$ & $\mathrm{TiO}_{2}$ & $\mathrm{FeO}$ & $\mathrm{MgO}$ & MnO & $\mathrm{CaO}$ & $\mathrm{Na}_{2} \mathrm{O}$ & $\mathrm{K}_{2} \mathrm{O}$ & $\mathrm{NA}_{2} \mathrm{O}+\mathrm{K}_{2} \mathrm{O}$ & Correlative \\
\hline 498 & 66.22 & 17.13 & 0.46 & 2.94 & 0.88 & 0.11 & 2.87 & 4.61 & 4.57 & 9.18 & Burrell_1 \\
\hline 485 & 66.13 & 16.50 & 0.71 & 3.19 & 1.20 & 0.15 & 2.59 & 4.55 & 4.71 & 9.26 & Burrell_2 \\
\hline 486 & 65.93 & 16.82 & 0.49 & 3.21 & 1.00 & 0.13 & 2.60 & 4.95 & 4.63 & 9.58 & Burrell_3 \\
\hline 489 & 66.16 & 17.13 & 0.60 & 2.93 & 0.88 & 0.15 & 2.66 & 4.53 & 4.75 & 9.28 & Burrell_4 \\
\hline 490 & 66.35 & 17.13 & 0.38 & 2.77 & 0.90 & 0.00 & 2.72 & 4.74 & 4.76 & 9.50 & Burrell_5 \\
\hline 493 & 66.32 & 17.11 & 0.48 & 2.89 & 0.92 & 0.10 & 2.64 & 4.63 & 4.64 & 9.27 & Burrell_6 \\
\hline 494 & 66.47 & 16.95 & 0.37 & 2.87 & 0.86 & 0.18 & 2.61 & 4.73 & 4.65 & 9.38 & Burrell_7 \\
\hline 495 & 65.51 & 17.40 & 0.53 & 3.10 & 0.93 & 0.11 & 3.09 & 4.55 & 4.57 & 9.11 & Burrell_8 \\
\hline 404 & 62.56 & 18.25 & 0.77 & 3.88 & 1.13 & 0.19 & 4.28 & 5.25 & 3.59 & 8.84 & Kp-1 \\
\hline 405 & 63.04 & 17.19 & 0.83 & 4.41 & 1.43 & 0.19 & 3.75 & 4.90 & 4.09 & 8.99 & Kp-2 \\
\hline 406 & 63.17 & 17.11 & 0.80 & 4.42 & 1.49 & 0.26 & 3.74 & 4.78 & 4.01 & 8.79 & Kp-3 \\
\hline 407 & 63.41 & 17.18 & 1.00 & 4.01 & 1.33 & 0.14 & 3.39 & 5.00 & 4.35 & 9.36 & Kp-4 \\
\hline 408 & 62.11 & 17.35 & 0.57 & 4.86 & 1.64 & 0.23 & 4.18 & 4.88 & 4.01 & 8.89 & Kp-5 \\
\hline 409 & 61.56 & 17.91 & 0.76 & 4.62 & 1.64 & 0.16 & 4.59 & 5.24 & 3.39 & 8.64 & Kp-6 \\
\hline 410 & 63.17 & 16.77 & 0.73 & 4.82 & 1.72 & 0.12 & 3.71 & 4.79 & 4.12 & 8.91 & Kp-7 \\
\hline 411 & 60.93 & 19.50 & 0.58 & 3.53 & 1.13 & 0.12 & 5.46 & 5.88 & 2.74 & 8.62 & Kp-8 \\
\hline 413 & 63.31 & 17.25 & 0.80 & 4.65 & 1.50 & 0.12 & 3.55 & 4.50 & 4.06 & 8.57 & Кp-9 \\
\hline 414 & 63.42 & 17.07 & 0.81 & 4.58 & 1.55 & 0.16 & 3.54 & 4.62 & 4.01 & 8.62 & Kp-10 \\
\hline 415 & 63.93 & 17.04 & 0.61 & 4.38 & 1.51 & 0.03 & 3.58 & 4.57 & 4.20 & 8.76 & Kp-11 \\
\hline 417 & 64.17 & 17.19 & 0.56 & 4.30 & 1.16 & 0.16 & 3.39 & 4.52 & 4.34 & 8.86 & Kp-12 \\
\hline 418 & 61.22 & 18.38 & 0.75 & 4.43 & 1.25 & 0.09 & 4.89 & 5.51 & 3.31 & 8.82 & Kp-13 \\
\hline 420 & 63.73 & 16.98 & 0.53 & 3.92 & 1.43 & 0.10 & 3.25 & 5.11 & 4.70 & 9.81 & Vulc_1 \\
\hline 422 & 65.90 & 17.27 & 0.46 & 3.10 & 0.99 & 0.14 & 2.83 & 4.88 & 4.16 & 9.04 & Vulc_2 \\
\hline 423 & 65.80 & 17.13 & 0.72 & 3.14 & 0.88 & 0.19 & 2.87 & 4.89 & 4.19 & 9.08 & Vulc_3 \\
\hline 424 & 65.25 & 16.28 & 0.70 & 3.81 & 1.16 & 0.11 & 2.68 & 5.30 & 4.45 & 9.75 & Vulc_4 \\
\hline 425 & 69.58 & 16.17 & 0.39 & 1.99 & 0.43 & 0.00 & 1.85 & 4.43 & 4.89 & 9.32 & Vulc_5 \\
\hline 426 & 65.93 & 16.93 & 0.46 & 3.29 & 1.05 & 0.11 & 2.86 & 4.89 & 4.21 & 9.10 & Vulc_6 \\
\hline 427 & 65.44 & 17.38 & 0.48 & 3.21 & 0.92 & 0.25 & 2.89 & 4.83 & 4.42 & 9.26 & Vulc_7 \\
\hline 428 & 69.28 & 16.14 & 0.23 & 2.04 & 0.41 & 0.08 & 2.10 & 4.66 & 4.82 & 9.49 & Vulc_8 \\
\hline 429 & 65.12 & 17.77 & 0.43 & 2.93 & 0.81 & 0.14 & 3.82 & 5.28 & 3.52 & 8.80 & Vulc_9 \\
\hline 432 & 69.78 & 15.89 & 0.39 & 1.98 & 0.40 & 0.19 & 1.96 & 4.38 & 4.78 & 9.15 & Vulc_10 \\
\hline 438 & 68.31 & 16.60 & 0.50 & 2.33 & 0.61 & 0.13 & 2.11 & 4.71 & 4.46 & 9.17 & Mk_1 \\
\hline 443 & 68.44 & 16.62 & 0.41 & 2.36 & 0.56 & 0.11 & 2.19 & 4.63 & 4.49 & 9.12 & Mk_2 \\
\hline 510 & 56.84 & 17.34 & 0.68 & 6.86 & 2.66 & 0.25 & 7.26 & 5.08 & 2.86 & 7.94 & Mg4_1 \\
\hline 506 & 57.20 & 17.29 & 0.90 & 7.19 & 2.84 & 0.19 & 6.22 & 5.03 & 2.98 & 8.02 & Mg4_2 \\
\hline 508 & 58.16 & 17.72 & 1.17 & 6.33 & 1.69 & 0.12 & 5.12 & 5.67 & 3.87 & 9.53 & Mg4_3 \\
\hline 513 & 58.17 & 15.84 & 1.21 & 7.30 & 2.46 & 0.32 & 5.76 & 5.01 & 3.77 & 8.78 & Mg4_4 \\
\hline 514 & 58.28 & 16.31 & 1.16 & 7.32 & 2.24 & 0.26 & 5.71 & 4.67 & 3.79 & 8.46 & Mg4_5 \\
\hline 530 & 60.37 & 18.72 & 0.85 & 4.60 & 1.05 & 0.12 & 4.43 & 5.98 & 3.66 & 9.63 & Mg3_1 \\
\hline 525 & 59.36 & 19.26 & 0.63 & 4.99 & 1.15 & 0.14 & 5.12 & 6.41 & 2.82 & 9.24 & Mg3_2 \\
\hline 528 & 62.87 & 17.25 & 0.95 & 4.53 & 1.04 & 0.18 & 3.16 & 5.25 & 4.56 & 9.81 & Mg3_3 \\
\hline 523 & 59.17 & 20.26 & 0.67 & 4.12 & 0.95 & 0.15 & 5.39 & 6.18 & 2.92 & 9.10 & Mg3_4 \\
\hline 537 & 56.57 & 16.24 & 1.29 & 8.26 & 2.46 & 0.31 & 5.18 & 5.16 & 4.31 & 9.47 & Mg2_1 \\
\hline 540 & 56.58 & 17.47 & 1.52 & 7.70 & 1.58 & 0.16 & 5.31 & 5.57 & 3.86 & 9.43 & Mg2_2 \\
\hline
\end{tabular}




\begin{tabular}{|c|c|c|c|c|c|c|c|c|c|c|c|}
\hline Sample & $\mathrm{SiO}_{2}$ & $\mathrm{Al}_{2} \mathrm{O}_{3}$ & $\mathrm{TiO}_{2}$ & FeO & MgO & MnO & $\mathrm{CaO}$ & $\mathrm{Na}_{2} \mathrm{O}$ & $\mathrm{K}_{2} \mathrm{O}$ & $\mathrm{NA}_{2} \mathrm{O}+\mathrm{K}_{2} \mathrm{O}$ & Correlative \\
\hline 551 & 59.63 & 16.14 & 1.03 & 7.26 & 1.93 & 0.20 & 4.41 & 4.93 & 4.24 & 9.16 & Mg1_1 \\
\hline 552 & 59.07 & 16.93 & 1.09 & 6.87 & 1.96 & 0.15 & 4.58 & 5.03 & 4.11 & 9.14 & Mg1_2 \\
\hline 560 & 58.82 & 16.54 & 1.29 & 6.71 & 1.97 & 0.18 & 4.88 & 5.38 & 3.95 & 9.33 & Mg1_3 \\
\hline 561 & 59.12 & 16.42 & 1.24 & 7.05 & 1.91 & 0.28 & 4.48 & 5.09 & 4.16 & 9.26 & Mg1_4 \\
\hline 558 & 58.89 & 17.45 & 1.00 & 6.14 & 1.75 & 0.36 & 5.01 & 5.61 & 3.68 & 9.29 & Mg1_5 \\
\hline 553 & 57.63 & 18.73 & 1.00 & 5.85 & 1.57 & 0.21 & 5.97 & 5.50 & 3.33 & 8.83 & Mg1_6 \\
\hline 454 & 72.65 & 14.71 & 0.41 & 1.46 & 0.25 & 0.07 & 1.26 & 4.25 & 4.63 & 8.88 & $\| 2.1$ \\
\hline 455 & 72.35 & 15.05 & 0.30 & 1.49 & 0.24 & 0.16 & 1.35 & 4.17 & 4.67 & 8.84 & $\| 12.2$ \\
\hline 457 & 72.17 & 15.28 & 0.35 & 1.57 & 0.29 & 0.02 & 1.36 & 4.31 & 4.43 & 8.74 & 112.3 \\
\hline 459 & 72.45 & 14.62 & 0.32 & 1.65 & 0.32 & 0.15 & 1.44 & 4.27 & 4.60 & 8.87 & 112.4 \\
\hline 460 & 72.44 & 14.89 & 0.41 & 1.39 & 0.25 & 0.10 & 1.30 & 4.13 & 4.79 & 8.92 & 112.5 \\
\hline 463 & 72.47 & 14.76 & 0.39 & 1.40 & 0.30 & 0.15 & 1.30 & 4.36 & 4.57 & 8.93 & 112.6 \\
\hline 464 & 73.14 & 14.89 & 0.26 & 1.48 & 0.32 & 0.05 & 1.36 & 3.63 & 4.68 & 8.31 & 112.7 \\
\hline 465 & 73.32 & 14.79 & 0.40 & 1.44 & 0.28 & 0.06 & 1.31 & 3.59 & 4.63 & 8.22 & $1 \mid 2.8$ \\
\hline 466 & 72.42 & 14.82 & 0.21 & 1.55 & 0.32 & 0.14 & 1.34 & 4.26 & 4.72 & 8.98 & 112.9 \\
\hline 468 & 72.49 & 14.93 & 0.32 & 1.58 & 0.30 & 0.09 & 1.48 & 4.16 & 4.42 & 8.58 & II_1 \\
\hline 469 & 72.45 & 14.97 & 0.43 & 1.57 & 0.27 & 0.19 & 1.39 & 3.94 & 4.48 & 8.42 & $\| 1 \_2$ \\
\hline 470 & 72.77 & 14.95 & 0.35 & 1.42 & 0.33 & 0.09 & 1.33 & 3.81 & 4.66 & 8.47 & II_3 \\
\hline 471 & 72.52 & 14.92 & 0.02 & 1.61 & 0.29 & 0.21 & 1.41 & 4.10 & 4.59 & 8.69 & $\| 1 \_4$ \\
\hline 472 & 72.68 & 14.87 & 0.43 & 1.47 & 0.27 & 0.01 & 1.26 & 4.12 & 4.63 & 8.75 & 111_5 \\
\hline 474 & 72.68 & 14.95 & 0.29 & 1.66 & 0.23 & 0.05 & 1.39 & 3.98 & 4.50 & 8.49 & $\| 1 \_6$ \\
\hline 476 & 72.08 & 15.12 & 0.56 & 1.49 & 0.27 & 0.11 & 1.38 & 4.01 & 4.66 & 8.66 & II1_7 \\
\hline 478 & 72.74 & 14.85 & 0.41 & 1.40 & 0.27 & 0.02 & 1.35 & 3.97 & 4.70 & 8.67 & 111_8 \\
\hline 479 & 72.17 & 14.89 & 0.29 & 1.48 & 0.27 & 0.14 & 1.42 & 4.30 & 4.77 & 9.07 & II1_9 \\
\hline 481 & 72.75 & 14.58 & 0.34 & 1.48 & 0.27 & 0.18 & 1.28 & 4.16 & 4.67 & 8.83 & |l1_10 \\
\hline 482 & 72.91 & 14.76 & 0.30 & 1.35 & 0.28 & 0.05 & 1.20 & 4.01 & 4.84 & 8.85 & ||1_11 \\
\hline 567 & 71.96 & 15.15 & 0.18 & 1.65 & 0.34 & 0.11 & 1.43 & 4.31 & 4.64 & 8.95 & J_1 \\
\hline 568 & 71.89 & 15.19 & 0.36 & 1.61 & 0.31 & 0.05 & 1.45 & 4.36 & 4.55 & 8.91 & J_2 \\
\hline 569 & 71.85 & 15.14 & 0.39 & 1.68 & 0.34 & 0.15 & 1.52 & 4.11 & 4.54 & 8.64 & J_3 \\
\hline 570 & 72.04 & 15.23 & 0.30 & 1.53 & 0.28 & 0.19 & 1.51 & 4.17 & 4.52 & 8.69 & J_4 \\
\hline 571 & 72.13 & 15.20 & 0.60 & 1.54 & 0.29 & 0.15 & 1.50 & 3.94 & 4.43 & 8.37 & J_5 \\
\hline 572 & 72.01 & 14.89 & 0.34 & 1.54 & 0.29 & 0.17 & 1.57 & 4.25 & 4.63 & 8.88 & J_6 \\
\hline 573 & 71.75 & 15.11 & 0.59 & 1.60 & 0.28 & 0.23 & 1.52 & 4.32 & 4.40 & 8.72 & J_7 \\
\hline 574 & 72.11 & 15.04 & 0.32 & 1.47 & 0.27 & 0.05 & 1.43 & 4.44 & 4.68 & 9.13 & J_8 \\
\hline 575 & 72.09 & 14.93 & 0.39 & 1.58 & 0.28 & 0.15 & 1.52 & 4.31 & 4.51 & 8.82 & J_9 \\
\hline 578 & 72.14 & 15.23 & 0.28 & 1.60 & 0.30 & 0.09 & 1.47 & 4.13 & 4.54 & 8.67 & J_10 \\
\hline 579 & 71.87 & 15.12 & 0.35 & 1.64 & 0.34 & 0.20 & 1.41 & 4.27 & 4.61 & 8.88 & J_11 \\
\hline 580 & 72.09 & 15.15 & 0.23 & 1.72 & 0.31 & 0.03 & 1.58 & 4.26 & 4.38 & 8.64 & J_12 \\
\hline
\end{tabular}




\section{Dawson Falls EMP Reference Dataset}

\begin{tabular}{|c|c|c|c|c|c|c|c|c|c|c|c|}
\hline Sample & $\mathrm{SiO}_{2}$ & $\mathrm{Al}_{2} \mathrm{O}_{3}$ & $\mathrm{TiO}_{2}$ & $\mathrm{FeO}$ & MgO & MnO & $\mathrm{CaO}$ & $\mathrm{Na}_{2} \mathrm{O}$ & $\mathrm{K}_{2} \mathrm{O}$ & $\mathrm{NA}_{2} \mathrm{O}+\mathrm{K}_{2} \mathrm{O}$ & Correlative \\
\hline 396 & 65.99 & 16.94 & 0.73 & 2.91 & 0.92 & 0.11 & 2.73 & 4.79 & 4.61 & 9.40 & Burrell_2 \\
\hline 383 & 65.69 & 17.21 & 0.78 & 2.85 & 0.80 & 0.16 & 2.73 & 4.99 & 4.57 & 9.56 & Burrell_3 \\
\hline 387 & 66.00 & 16.82 & 0.54 & 3.08 & 0.88 & 0.10 & 2.80 & 4.84 & 4.71 & 9.55 & Burrell_4 \\
\hline 393 & 65.81 & 17.12 & 0.57 & 2.97 & 0.85 & 0.10 & 3.00 & 4.69 & 4.64 & 9.33 & Burrell_5 \\
\hline 394 & 67.01 & 16.93 & 0.34 & 2.63 & 0.73 & 0.12 & 2.36 & 4.93 & 4.74 & 9.67 & Burrell_6 \\
\hline 295 & 62.24 & 17.55 & 0.89 & 4.75 & 1.72 & 0.21 & 3.83 & 4.67 & 3.93 & 8.60 & Kp-1 \\
\hline 296 & 62.16 & 16.74 & 0.96 & 5.16 & 1.95 & 0.10 & 4.03 & 4.69 & 4.00 & 8.69 & Kp-2 \\
\hline 297 & 61.78 & 17.49 & 0.78 & 5.07 & 1.57 & 0.01 & 4.45 & 4.98 & 3.72 & 8.70 & Kp-3 \\
\hline 298 & 61.21 & 17.54 & 0.65 & 4.98 & 1.79 & 0.10 & 4.71 & 5.04 & 3.79 & 8.83 & Kp-4 \\
\hline 299 & 62.14 & 17.03 & 0.66 & 5.20 & 1.64 & 0.19 & 4.23 & 4.80 & 3.95 & 8.75 & Kp-5 \\
\hline 301 & 62.03 & 17.32 & 0.62 & 4.93 & 1.77 & 0.15 & 4.42 & 4.95 & 3.67 & 8.63 & Kp-6 \\
\hline 303 & 61.95 & 17.71 & 0.88 & 4.62 & 1.61 & 0.19 & 4.09 & 4.69 & 4.06 & 8.74 & Kp-7 \\
\hline 304 & 62.41 & 17.63 & 0.67 & 4.61 & 1.59 & 0.09 & 4.12 & 4.86 & 3.81 & 8.67 & Kp-8 \\
\hline 305 & 63.15 & 17.75 & 0.73 & 4.29 & 1.56 & 0.03 & 3.85 & 4.75 & 3.71 & 8.47 & Kp-9 \\
\hline 308 & 63.50 & 17.00 & 0.71 & 4.56 & 1.54 & 0.11 & 3.42 & 4.68 & 4.32 & 9.00 & Kp-10 \\
\hline 309 & 61.88 & 19.05 & 0.59 & 3.68 & 1.03 & 0.09 & 4.81 & 5.39 & 3.25 & 8.64 & Кр-11 \\
\hline 310 & 62.02 & 19.41 & 0.50 & 3.32 & 0.98 & 0.12 & 4.84 & 5.64 & 3.13 & 8.77 & Kp-12 \\
\hline 311 & 60.60 & 19.03 & 0.43 & 4.10 & 1.55 & 0.22 & 5.68 & 5.48 & 2.73 & 8.21 & $\mathrm{Kp}-13$ \\
\hline 320 & 61.58 & 19.15 & 0.55 & 3.35 & 1.10 & 0.12 & 5.18 & 5.78 & 3.00 & 8.79 & Up-Un-1 \\
\hline 321 & 62.08 & 17.08 & 0.75 & 4.45 & 2.02 & 0.13 & 3.92 & 4.46 & 4.90 & 9.36 & Up-Un-2 \\
\hline 318 & 63.31 & 16.59 & 0.50 & 4.79 & 1.46 & 0.16 & 3.68 & 5.88 & 3.39 & 9.26 & Up-Un-3 \\
\hline 326 & 65.61 & 16.80 & 0.67 & 3.37 & 1.06 & 0.12 & 2.75 & 5.21 & 4.19 & 9.41 & Up-Un-4 \\
\hline 327 & 63.22 & 17.17 & 0.81 & 3.90 & 1.41 & 0.09 & 3.42 & 6.05 & 3.72 & 9.76 & Up-Un-5 \\
\hline 328 & 61.50 & 17.52 & 0.65 & 3.76 & 2.34 & 0.19 & 5.81 & 5.56 & 2.56 & 8.12 & Up-Un-6 \\
\hline 345 & 66.03 & 16.90 & 0.47 & 3.21 & 1.01 & 0.24 & 2.75 & 4.91 & 4.33 & 9.24 & Lwr-Un-1 \\
\hline 330 & 66.41 & 17.30 & 0.29 & 2.61 & 0.68 & 0.08 & 3.56 & 5.26 & 3.54 & 8.80 & Lwr-Un-2 \\
\hline 334 & 66.49 & 17.14 & 0.38 & 3.07 & 0.72 & 0.09 & 2.68 & 5.01 & 4.12 & 9.13 & Lwr-Un-3 \\
\hline 337 & 66.73 & 16.79 & 0.76 & 2.92 & 0.84 & 0.16 & 2.52 & 4.74 & 4.26 & 8.99 & Lwr-Un-4 \\
\hline 341 & 66.04 & 16.90 & 0.54 & 3.51 & 0.76 & 0.12 & 2.55 & 5.26 & 4.09 & 9.34 & Lwr-Un-5 \\
\hline 364 & 67.79 & 16.64 & 0.38 & 2.47 & 0.65 & 0.09 & 2.34 & 4.82 & 4.53 & 9.35 & Mk-1 \\
\hline 365 & 68.29 & 16.77 & 0.25 & 2.38 & 0.60 & 0.10 & 2.17 & 4.87 & 4.36 & 9.22 & Mk-2 \\
\hline 351 & 67.40 & 16.90 & 0.52 & 2.79 & 0.60 & 0.15 & 2.19 & 4.93 & 4.30 & 9.24 & Mk-3 \\
\hline 353 & 66.50 & 17.70 & 0.63 & 2.42 & 0.58 & 0.13 & 3.06 & 4.95 & 3.86 & 8.80 & Mk-4 \\
\hline 354 & 68.31 & 16.75 & 0.39 & 2.33 & 0.62 & 0.08 & 2.14 & 4.73 & 4.41 & 9.14 & Mk-5 \\
\hline 355 & 68.39 & 16.66 & 0.30 & 2.38 & 0.57 & 0.12 & 2.19 & 4.70 & 4.44 & 9.14 & Mk-6 \\
\hline 357 & 68.49 & 16.25 & 0.57 & 2.36 & 0.58 & 0.01 & 2.15 & 4.89 & 4.46 & 9.35 & Mk-8 \\
\hline 358 & 68.46 & 16.62 & 0.48 & 2.30 & 0.58 & 0.05 & 2.20 & 4.64 & 4.42 & 9.07 & Mk-9 \\
\hline 361 & 68.64 & 16.51 & 0.38 & 2.22 & 0.55 & 0.09 & 1.92 & 4.83 & 4.51 & 9.34 & Mk-10 \\
\hline 362 & 67.29 & 16.52 & 0.55 & 2.42 & 0.65 & 0.06 & 3.31 & 4.71 & 4.31 & 9.02 & Mk-11 \\
\hline
\end{tabular}




\section{B2 - Study Electron Microprobe Dataset}

Presented is the Electron Microprobe Analysis dataset showing the major elemental glass compositions of tephra beds sampled at East Egmont (TS-14, TS-15 and TS-16), Vickers Quarry (TS19, TS-20, TS-21, TS-22 and TS-28), York Road (TS-23, TS-24 and TS-25), Tariki Underpass (TS-11, TS12, TS-13, TS-29 and TS-30), Suffolk Road (TS-7, TS-8, TS-9 and TS-10) and Kaimata Sawmills (TS-1, TS2, TS-3, TS-4 and TS-5) sections. The alternating blue and white cells discriminate between each tephra sample (i.e. TS-1, TS-2).

\section{Study EMP Dataset}

\begin{tabular}{|c|c|c|c|c|c|c|c|c|c|c|c|c|}
\hline Section & Sample & $\mathrm{SiO}_{2}$ & $\mathrm{Al}_{2} \mathrm{O}_{3}$ & $\mathrm{TiO}_{2}$ & $\mathrm{FeO}$ & MgO & MnO & $\mathrm{CaO}$ & $\mathrm{Na}_{2} \mathrm{O}$ & $\mathrm{K}_{2} \mathrm{O}$ & $\mathrm{NA}_{2} \mathrm{O}+\mathrm{K}_{2} \mathrm{O}$ & Correlative \\
\hline MG-1 & 108 & 71.87 & 14.84 & 0.36 & 1.84 & 0.40 & 0.18 & 1.62 & 4.28 & 4.60 & 8.89 & TS1_1 \\
\hline MG-1 & 110 & 71.39 & 15.48 & 0.35 & 1.63 & 0.23 & 0.15 & 1.90 & 4.31 & 4.53 & 8.84 & TS1_2 \\
\hline MG-1 & 115 & 70.62 & 15.91 & 0.34 & 1.74 & 0.22 & 0.11 & 2.06 & 4.68 & 4.30 & 8.98 & TS1_3 \\
\hline MG-1 & 119 & 71.93 & 14.72 & 0.41 & 1.92 & 0.28 & 0.13 & 1.69 & 4.32 & 4.58 & 8.90 & TS1_4 \\
\hline MG-1 & 120 & 71.37 & 15.34 & 0.35 & 1.62 & 0.27 & 0.10 & 2.14 & 4.73 & 4.07 & 8.80 & TS1_5 \\
\hline MG-1 & 122 & 72.80 & 14.67 & 0.35 & 1.51 & 0.28 & 0.08 & 1.28 & 4.33 & 4.69 & 9.02 & TS2_1 \\
\hline MG-1 & 123 & 72.98 & 14.80 & 0.34 & 1.48 & 0.30 & 0.08 & 1.23 & 4.29 & 4.48 & 8.78 & TS2_2 \\
\hline MG-1 & 124 & 71.49 & 14.87 & 0.33 & 1.56 & 0.33 & 0.15 & 2.15 & 4.44 & 4.65 & 9.09 & TS2_3 \\
\hline MG-1 & 125 & 72.85 & 14.92 & 0.31 & 1.42 & 0.26 & 0.16 & 1.23 & 4.25 & 4.59 & 8.83 & TS2_4 \\
\hline MG-1 & 128 & 72.54 & 14.72 & 0.31 & 1.58 & 0.28 & 0.08 & 1.25 & 4.67 & 4.56 & 9.23 & TS2_5 \\
\hline MG-1 & 129 & 73.18 & 14.83 & 0.33 & 1.38 & 0.25 & 0.05 & 1.29 & 3.90 & 4.76 & 8.66 & TS2_6 \\
\hline MG-1 & 130 & 73.24 & 14.85 & 0.33 & 1.46 & 0.29 & 0.10 & 1.27 & 3.79 & 4.64 & 8.42 & TS2_7 \\
\hline MG-1 & 131 & 73.07 & 14.89 & 0.31 & 1.53 & 0.27 & 0.11 & 1.29 & 3.97 & 4.54 & 8.51 & TS2_8 \\
\hline MG-1 & 132 & 73.10 & 14.82 & 0.33 & 1.60 & 0.24 & 0.05 & 1.26 & 3.87 & 4.73 & 8.59 & TS2_9 \\
\hline MG-1 & 134 & 72.02 & 14.92 & 0.35 & 1.66 & 0.32 & 0.08 & 1.70 & 4.24 & 4.68 & 8.92 & TS2_10 \\
\hline MG-1 & 135 & 72.91 & 14.93 & 0.34 & 1.50 & 0.28 & 0.11 & 1.27 & 4.03 & 4.62 & 8.65 & TS2_11 \\
\hline MG-1 & 136 & 73.01 & 14.78 & 0.31 & 1.45 & 0.30 & 0.10 & 1.28 & 4.16 & 4.58 & 8.74 & TS2_12 \\
\hline MG-1 & 143 & 73.26 & 14.82 & 0.36 & 1.52 & 0.30 & 0.10 & 1.17 & 3.62 & 4.80 & 8.43 & TS3_1 \\
\hline MG-1 & 144 & 72.46 & 14.44 & 0.37 & 1.71 & 0.29 & 0.09 & 1.12 & 4.41 & 5.09 & 9.51 & TS3_2 \\
\hline MG-1 & 145 & 73.39 & 14.46 & 0.36 & 1.60 & 0.30 & 0.11 & 1.04 & 3.94 & 4.79 & 8.73 & TS3_3 \\
\hline MG-1 & 146 & 73.28 & 14.53 & 0.37 & 1.65 & 0.30 & 0.13 & 1.09 & 3.94 & 4.69 & 8.63 & TS3_4 \\
\hline MG-1 & 148 & 72.54 & 15.00 & 0.34 & 1.45 & 0.35 & 0.14 & 1.23 & 4.29 & 4.64 & 8.93 & TS3_5 \\
\hline MG-1 & 150 & 73.37 & 14.50 & 0.32 & 1.60 & 0.29 & 0.10 & 1.02 & 4.15 & 4.64 & 8.79 & TS3_6 \\
\hline MG-1 & 152 & 73.10 & 14.63 & 0.35 & 1.53 & 0.30 & 0.18 & 1.03 & 4.09 & 4.76 & 8.85 & TS3_7 \\
\hline MG-1 & 153 & 72.83 & 14.97 & 0.37 & 1.53 & 0.27 & 0.07 & 1.36 & 4.23 & 4.36 & 8.58 & TS3_8 \\
\hline MG-1 & 154 & 73.33 & 14.69 & 0.36 & 1.65 & 0.30 & 0.09 & 1.01 & 3.81 & 4.75 & 8.56 & TS3_9 \\
\hline MG-1 & 155 & 71.13 & 16.46 & 0.29 & 1.37 & 0.26 & 0.09 & 1.91 & 4.40 & 4.08 & 8.47 & TS3_10 \\
\hline MG-1 & 157 & 70.68 & 15.88 & 0.43 & 1.91 & 0.38 & 0.11 & 1.74 & 4.50 & 4.36 & 8.86 & TS4_1 \\
\hline MG-1 & 158 & 71.78 & 16.04 & 0.40 & 1.75 & 0.39 & 0.15 & 1.63 & 3.44 & 4.40 & 7.84 & TS4_2 \\
\hline MG-1 & 159 & 70.55 & 15.69 & 0.42 & 1.79 & 0.41 & 0.12 & 1.74 & 4.72 & 4.54 & 9.27 & TS4_3 \\
\hline MG-1 & 164 & 70.58 & 15.69 & 0.39 & 1.85 & 0.37 & 0.12 & 1.56 & 5.13 & 4.30 & 9.43 & TS4_4 \\
\hline MG-1 & 165 & 70.60 & 15.84 & 0.40 & 1.78 & 0.42 & 0.10 & 1.77 & 4.71 & 4.36 & 9.07 & TS4_5 \\
\hline MG-1 & 166 & 70.59 & 15.74 & 0.41 & 1.99 & 0.41 & 0.10 & 1.78 & 4.60 & 4.36 & 8.96 & TS4_6 \\
\hline
\end{tabular}




\begin{tabular}{|c|c|c|c|c|c|c|c|c|c|c|c|c|}
\hline Section & Sample & $\mathrm{SiO}_{2}$ & $\mathrm{Al}_{2} \mathrm{O}_{3}$ & $\mathrm{TiO}_{2}$ & $\mathrm{FeO}$ & $\mathrm{MgO}$ & $\mathrm{MnO}$ & $\mathrm{CaO}$ & $\mathrm{Na}_{2} \mathrm{O}$ & $\mathrm{K}_{2} \mathrm{O}$ & $\mathrm{NA}_{2} \mathrm{O}+\mathrm{K}_{2} \mathrm{O}$ & Correlative \\
\hline MG-1 & 167 & 70.58 & 15.75 & 0.40 & 1.71 & 0.44 & 0.11 & 1.74 & 4.87 & 4.38 & 9.25 & TS4_7 \\
\hline MG-1 & 169 & 71.39 & 15.64 & 0.37 & 1.68 & 0.39 & 0.10 & 1.42 & 4.99 & 4.02 & 9.01 & TS4_8 \\
\hline MG-1 & 171 & 70.98 & 15.76 & 0.43 & 1.91 & 0.36 & 0.11 & 1.73 & 4.26 & 4.43 & 8.69 & TS4_9 \\
\hline MG-1 & 157 & 70.68 & 15.88 & 0.43 & 1.91 & 0.38 & 0.11 & 1.74 & 4.50 & 4.36 & 8.86 & TS5_1 \\
\hline MG-1 & 158 & 71.78 & 16.04 & 0.40 & 1.75 & 0.39 & 0.15 & 1.63 & 3.44 & 4.40 & 7.84 & TS5_2 \\
\hline MG-1 & 159 & 70.55 & 15.69 & 0.42 & 1.79 & 0.41 & 0.12 & 1.74 & 4.72 & 4.54 & 9.27 & TS5_3 \\
\hline MG-1 & 164 & 70.58 & 15.69 & 0.39 & 1.85 & 0.37 & 0.12 & 1.56 & 5.13 & 4.30 & 9.43 & TS5_4 \\
\hline MG-1 & 165 & 70.60 & 15.84 & 0.40 & 1.78 & 0.42 & 0.10 & 1.77 & 4.71 & 4.36 & 9.07 & TS5_5 \\
\hline MG-1 & 166 & 70.59 & 15.74 & 0.41 & 1.99 & 0.41 & 0.10 & 1.78 & 4.60 & 4.36 & 8.96 & TS5_6 \\
\hline MG-1 & 167 & 70.58 & 15.75 & 0.40 & 1.71 & 0.44 & 0.11 & 1.74 & 4.87 & 4.38 & 9.25 & TS5_7 \\
\hline MG-1 & 169 & 71.39 & 15.64 & 0.37 & 1.68 & 0.39 & 0.10 & 1.42 & 4.99 & 4.02 & 9.01 & TS5_8 \\
\hline MG-1 & 171 & 70.98 & 15.76 & 0.43 & 1.91 & 0.36 & 0.11 & 1.73 & 4.26 & 4.43 & 8.69 & TS5_9 \\
\hline MG-1 & 188 & 71.95 & 15.34 & 0.34 & 1.56 & 0.26 & 0.14 & 1.51 & 4.24 & 4.66 & 8.90 & TS5_10 \\
\hline MG-1 & 190 & 72.32 & 14.67 & 0.36 & 1.86 & 0.30 & 0.19 & 1.35 & 4.04 & 4.88 & 8.93 & TS5_11 \\
\hline MG-1 & 191 & 72.44 & 14.79 & 0.38 & 1.70 & 0.24 & 0.08 & 1.29 & 4.26 & 4.80 & 9.06 & TS5_12 \\
\hline SF-1 & 192 & 70.77 & 15.72 & 0.39 & 1.87 & 0.38 & 0.13 & 1.63 & 4.92 & 4.18 & 9.10 & TS-7_1 \\
\hline SF-1 & 193 & 70.12 & 15.92 & 0.43 & 2.19 & 0.49 & 0.14 & 1.76 & 4.68 & 4.25 & 8.93 & TS-7_2 \\
\hline SF-1 & 194 & 70.81 & 15.55 & 0.44 & 1.75 & 0.38 & 0.16 & 1.65 & 4.93 & 4.31 & 9.24 & TS-7_3 \\
\hline SF-1 & 196 & 70.63 & 15.87 & 0.39 & 1.83 & 0.42 & 0.11 & 1.74 & 4.71 & 4.27 & 8.98 & TS-7_4 \\
\hline SF-1 & 197 & 70.04 & 15.98 & 0.40 & 1.96 & 0.40 & 0.12 & 1.79 & 4.97 & 4.31 & 9.28 & TS-7_5 \\
\hline SF-1 & 198 & 70.59 & 15.64 & 0.44 & 1.91 & 0.42 & 0.12 & 1.79 & 4.83 & 4.23 & 9.05 & TS-7_6 \\
\hline SF-1 & 199 & 70.77 & 15.66 & 0.43 & 1.86 & 0.40 & 0.13 & 1.71 & 4.61 & 4.38 & 9.00 & TS-7_7 \\
\hline SF-1 & 200 & 70.97 & 15.52 & 0.42 & 1.91 & 0.38 & 0.04 & 1.76 & 4.81 & 4.17 & 8.98 & TS-7_8 \\
\hline SF-1 & 201 & 70.66 & 15.63 & 0.43 & 1.93 & 0.40 & 0.14 & 1.71 & 4.85 & 4.23 & 9.08 & TS-7_9 \\
\hline SF-1 & 81 & 70.88 & 15.45 & 0.44 & 1.88 & 0.39 & 0.15 & 1.71 & 4.77 & 4.30 & 9.07 & TS8_1 \\
\hline SF-1 & 82 & 70.85 & 15.69 & 0.40 & 1.82 & 0.40 & 0.10 & 1.68 & 4.76 & 4.28 & 9.05 & TS8_2 \\
\hline SF-1 & 83 & 70.88 & 15.43 & 0.41 & 1.78 & 0.40 & 0.20 & 1.77 & 4.70 & 4.41 & 9.11 & TS8_3 \\
\hline SF-1 & 84 & 70.39 & 16.01 & 0.37 & 1.91 & 0.39 & 0.14 & 2.20 & 4.66 & 3.89 & 8.56 & TS8_4 \\
\hline SF-1 & 85 & 71.22 & 15.60 & 0.42 & 1.82 & 0.41 & 0.08 & 1.67 & 4.49 & 4.28 & 8.77 & TS8_5 \\
\hline SF-1 & 86 & 71.06 & 15.54 & 0.42 & 1.79 & 0.39 & 0.08 & 1.73 & 4.67 & 4.32 & 8.98 & TS8_6 \\
\hline SF-1 & 87 & 70.48 & 15.70 & 0.40 & 1.78 & 0.36 & 0.15 & 1.69 & 5.01 & 4.42 & 9.43 & TS8_7 \\
\hline SF-1 & 89 & 70.73 & 15.71 & 0.42 & 1.87 & 0.38 & 0.10 & 1.71 & 4.76 & 4.29 & 9.05 & TS8_8 \\
\hline SF-1 & 90 & 71.01 & 15.58 & 0.41 & 1.80 & 0.41 & 0.14 & 1.71 & 4.52 & 4.41 & 8.93 & TS8_9 \\
\hline SF-1 & 91 & 72.62 & 15.17 & 0.30 & 1.26 & 0.23 & 0.08 & 1.33 & 4.28 & 4.71 & 9.00 & TS9_1 \\
\hline SF-1 & 92 & 68.22 & 18.77 & 0.22 & 0.93 & 0.08 & 0.04 & 3.58 & 4.80 & 3.36 & 8.16 & TS9_2 \\
\hline SF-1 & 93 & 73.52 & 14.53 & 0.34 & 1.42 & 0.25 & 0.06 & 1.17 & 3.69 & 5.01 & 8.70 & TS9_3 \\
\hline SF-1 & 94 & 74.77 & 13.73 & 0.38 & 1.39 & 0.15 & 0.10 & 0.68 & 3.49 & 5.29 & 8.79 & TS9_4 \\
\hline SF-1 & 95 & 73.67 & 14.19 & 0.35 & 1.47 & 0.20 & 0.12 & 1.03 & 3.85 & 5.09 & 8.94 & TS9_5 \\
\hline SF-1 & 96 & 72.90 & 14.93 & 0.32 & 1.35 & 0.19 & 0.05 & 1.53 & 4.13 & 4.58 & 8.71 & TS9_6 \\
\hline SF-1 & 99 & 72.20 & 15.32 & 0.33 & 1.37 & 0.14 & 0.12 & 1.72 & 4.69 & 4.10 & 8.79 & TS9_7 \\
\hline SF-1 & 100 & 73.28 & 14.18 & 0.35 & 1.57 & 0.25 & 0.10 & 1.08 & 3.99 & 5.18 & 9.17 & TS9_8 \\
\hline SF-1 & 105 & 67.83 & 18.31 & 0.23 & 1.30 & 0.48 & 0.08 & 3.45 & 5.28 & 3.05 & 8.33 & TS9_9 \\
\hline SF-1 & 112 & 65.03 & 17.04 & 0.61 & 4.00 & 1.15 & 0.17 & 2.88 & 4.91 & 4.18 & 9.09 & TS10_1 \\
\hline SF-1 & 113 & 65.60 & 17.18 & 0.63 & 3.37 & 1.08 & 0.17 & 2.74 & 4.94 & 4.28 & 9.22 & TS10_2 \\
\hline SF-1 & 114 & 65.61 & 17.08 & 0.59 & 3.49 & 1.18 & 0.15 & 2.99 & 4.74 & 4.17 & 8.91 & TS10_3 \\
\hline
\end{tabular}




\begin{tabular}{|c|c|c|c|c|c|c|c|c|c|c|c|c|}
\hline Section & Sample & $\mathrm{SiO}_{2}$ & $\mathrm{Al}_{2} \mathrm{O}_{3}$ & $\mathrm{TiO}_{2}$ & $\mathrm{FeO}$ & MgO & MnO & $\mathrm{CaO}$ & $\mathrm{Na}_{2} \mathrm{O}$ & $\mathrm{K}_{2} \mathrm{O}$ & $\mathrm{NA}_{2} \mathrm{O}+\mathrm{K}_{2} \mathrm{O}$ & Correlative \\
\hline SF-1 & 115 & 65.39 & 17.33 & 0.61 & 3.44 & 1.20 & 0.15 & 2.72 & 4.94 & 4.21 & 9.15 & TS10_4 \\
\hline SF-1 & 116 & 65.43 & 16.81 & 0.64 & 3.57 & 1.21 & 0.15 & 3.08 & 4.86 & 4.22 & 9.08 & TS10_5 \\
\hline SF-1 & 117 & 64.01 & 16.59 & 0.47 & 2.87 & 2.19 & 0.14 & 5.71 & 4.32 & 3.69 & 8.01 & TS10_6 \\
\hline SF-1 & 119 & 69.22 & 15.90 & 0.45 & 2.53 & 0.59 & 0.09 & 1.58 & 4.53 & 5.10 & 9.63 & TS10_7 \\
\hline SF-1 & 121 & 65.36 & 17.12 & 0.61 & 3.64 & 1.18 & 0.15 & 3.00 & 4.87 & 4.05 & 8.92 & TS10_8 \\
\hline SF-1 & 122 & 65.30 & 17.17 & 0.63 & 3.49 & 1.24 & 0.07 & 3.07 & 4.85 & 4.16 & 9.01 & TS10_9 \\
\hline SF-1 & 123 & 65.47 & 17.08 & 0.62 & 3.61 & 1.19 & 0.20 & 3.00 & 4.64 & 4.18 & 8.82 & TS10_10 \\
\hline SF-1 & 124 & 65.26 & 17.03 & 0.66 & 3.51 & 1.28 & 0.14 & 2.92 & 5.00 & 4.19 & 9.19 & TS10_11 \\
\hline SF-1 & 125 & 65.46 & 16.97 & 0.64 & 3.63 & 1.13 & 0.15 & 2.86 & 4.94 & 4.20 & 9.14 & TS10_12 \\
\hline SF-1 & 126 & 64.60 & 17.03 & 0.65 & 4.07 & 1.21 & 0.13 & 3.00 & 5.13 & 4.18 & 9.30 & TS10_13 \\
\hline SF-1 & 127 & 65.23 & 17.02 & 0.61 & 3.62 & 1.19 & 0.18 & 2.98 & 4.96 & 4.19 & 9.15 & TS10_14 \\
\hline SF-1 & 128 & 65.49 & 17.19 & 0.63 & 3.56 & 1.17 & 0.19 & 2.96 & 4.67 & 4.14 & 8.80 & TS10_15 \\
\hline SF-1 & 129 & 65.36 & 17.22 & 0.69 & 3.51 & 1.15 & 0.08 & 2.82 & 4.92 & 4.25 & 9.16 & TS10_16 \\
\hline SF-1 & 130 & 64.91 & 17.01 & 0.62 & 3.73 & 1.29 & 0.13 & 3.10 & 5.02 & 4.17 & 9.19 & TS10_17 \\
\hline SF-1 & 131 & 65.34 & 17.01 & 0.65 & 3.69 & 1.21 & 0.11 & 2.93 & 4.91 & 4.13 & 9.03 & TS10_18 \\
\hline TU-1 & 137 & 72.99 & 14.71 & 0.32 & 1.55 & 0.31 & 0.11 & 1.26 & 4.08 & 4.64 & 8.72 & TS11_1 \\
\hline TU-1 & 138 & 72.75 & 14.69 & 0.34 & 1.65 & 0.27 & 0.11 & 1.26 & 4.04 & 4.85 & 8.89 & TS11_2 \\
\hline TU-1 & 139 & 73.05 & 14.65 & 0.32 & 1.53 & 0.28 & 0.12 & 1.17 & 4.04 & 4.83 & 8.87 & TS11_3 \\
\hline TU-1 & 140 & 73.00 & 14.60 & 0.38 & 1.45 & 0.29 & 0.13 & 1.12 & 4.19 & 4.82 & 9.01 & TS11_4 \\
\hline TU-1 & 141 & 73.35 & 14.82 & 0.33 & 1.68 & 0.29 & 0.11 & 1.23 & 3.57 & 4.61 & 8.18 & TS11_5 \\
\hline TU-1 & 142 & 74.84 & 15.04 & 0.36 & 1.65 & 0.28 & 0.11 & 1.37 & 1.63 & 4.71 & 6.34 & TS11_6 \\
\hline TU-1 & 144 & 72.51 & 14.96 & 0.32 & 1.57 & 0.29 & 0.09 & 1.35 & 4.17 & 4.71 & 8.89 & TS11_7 \\
\hline TU-1 & 146 & 72.20 & 15.17 & 0.34 & 1.67 & 0.30 & 0.12 & 1.32 & 4.41 & 4.45 & 8.86 & TS11_8 \\
\hline TU-1 & 147 & 72.41 & 14.95 & 0.34 & 1.58 & 0.31 & 0.12 & 1.32 & 4.41 & 4.56 & 8.97 & TS11_9 \\
\hline TU-1 & 148 & 72.99 & 14.45 & 0.38 & 1.49 & 0.27 & 0.18 & 1.17 & 4.16 & 4.89 & 9.05 & TS11_10 \\
\hline TU-1 & 149 & 72.28 & 15.12 & 0.32 & 1.73 & 0.27 & 0.08 & 1.46 & 3.99 & 4.73 & 8.72 & TS11_11 \\
\hline TU-1 & 150 & 71.33 & 15.81 & 0.30 & 1.69 & 0.30 & 0.10 & 1.54 & 4.32 & 4.61 & 8.93 & TS11_12 \\
\hline TU-1 & 158 & 71.72 & 15.34 & 0.45 & 1.86 & 0.30 & 0.13 & 1.59 & 4.23 & 4.37 & 8.60 & TS12_1 \\
\hline TU-1 & 159 & 71.12 & 15.72 & 0.44 & 1.91 & 0.33 & 0.04 & 1.82 & 4.11 & 4.49 & 8.60 & TS12_2 \\
\hline TU-1 & 160 & 70.29 & 16.07 & 0.39 & 1.99 & 0.27 & 0.09 & 1.87 & 4.48 & 4.53 & 9.01 & TS12_3 \\
\hline TU-1 & 163 & 71.18 & 15.55 & 0.38 & 1.67 & 0.34 & 0.10 & 1.64 & 4.65 & 4.47 & 9.13 & TS12_4 \\
\hline TU-1 & 164 & 70.89 & 15.59 & 0.42 & 1.87 & 0.38 & 0.07 & 1.68 & 4.73 & 4.33 & 9.07 & TS12_5 \\
\hline TU-1 & 165 & 71.11 & 15.50 & 0.40 & 1.88 & 0.39 & 0.14 & 1.70 & 4.45 & 4.40 & 8.85 & TS12_6 \\
\hline TU-1 & 167 & 70.73 & 15.47 & 0.44 & 1.93 & 0.30 & 0.14 & 1.79 & 4.79 & 4.40 & 9.18 & TS12_7 \\
\hline TU-1 & 175 & 74.81 & 13.83 & 0.36 & 1.08 & 0.16 & 0.13 & 0.74 & 3.63 & 5.22 & 8.85 & TS13_1 \\
\hline TU-1 & 176 & 74.71 & 13.52 & 0.35 & 1.35 & 0.14 & 0.16 & 0.62 & 3.75 & 5.36 & 9.12 & TS13_2 \\
\hline TU-1 & 177 & 70.84 & 16.02 & 0.28 & 1.25 & 0.30 & 0.15 & 2.03 & 5.08 & 4.06 & 9.13 & TS13_3 \\
\hline TU-1 & 178 & 73.36 & 14.33 & 0.41 & 1.83 & 0.21 & 0.11 & 1.04 & 3.50 & 5.20 & 8.69 & TS13_4 \\
\hline TU-1 & 180 & 73.00 & 14.42 & 0.41 & 1.82 & 0.22 & 0.17 & 1.16 & 3.86 & 4.93 & 8.79 & TS13_5 \\
\hline TU-1 & 181 & 71.76 & 14.77 & 0.30 & 1.88 & 0.83 & 0.18 & 1.65 & 4.32 & 4.30 & 8.61 & TS13_6 \\
\hline TU-1 & 183 & 73.08 & 13.34 & 0.33 & 1.89 & 0.80 & 0.26 & 1.45 & 3.78 & 5.06 & 8.83 & TS13_7 \\
\hline TU-1 & 184 & 74.43 & 13.99 & 0.36 & 1.30 & 0.14 & 0.09 & 0.80 & 3.70 & 5.18 & 8.87 & TS13_8 \\
\hline TU-1 & 186 & 65.47 & 17.27 & 0.67 & 3.91 & 0.93 & 0.10 & 2.42 & 4.88 & 4.34 & 9.22 & TS13_9 \\
\hline TU-1 & 187 & 73.34 & 13.92 & 0.42 & 1.79 & 0.32 & 0.15 & 0.92 & 3.72 & 5.40 & 9.12 & TS13_10 \\
\hline TU-1 & 188 & 69.08 & 17.51 & 0.25 & 1.35 & 0.22 & 0.09 & 3.05 & 4.84 & 3.60 & 8.44 & TS13_11 \\
\hline
\end{tabular}




\begin{tabular}{|c|c|c|c|c|c|c|c|c|c|c|c|c|}
\hline Section & Sample & $\mathrm{SiO}_{2}$ & $\mathrm{Al}_{2} \mathrm{O}_{3}$ & $\mathrm{TiO}_{2}$ & $\mathrm{FeO}$ & MgO & MnO & $\mathrm{CaO}$ & $\mathrm{Na}_{2} \mathrm{O}$ & $\mathrm{K}_{2} \mathrm{O}$ & $\mathrm{NA}_{2} \mathrm{O}+\mathrm{K}_{2} \mathrm{O}$ & Correlative \\
\hline EE-1 & 191 & 72.64 & 14.81 & 0.33 & 1.65 & 0.31 & 0.14 & 1.37 & 4.01 & 4.74 & 8.74 & TS14_1 \\
\hline EE-1 & 192 & 72.87 & 14.81 & 0.32 & 1.54 & 0.28 & 0.12 & 1.39 & 4.02 & 4.61 & 8.63 & TS14_2 \\
\hline $\mathrm{EE}-1$ & 193 & 72.42 & 14.97 & 0.32 & 1.62 & 0.29 & 0.05 & 1.37 & 4.37 & 4.58 & 8.95 & TS14_3 \\
\hline $\mathrm{EE}-1$ & 194 & 72.90 & 14.95 & 0.31 & 1.32 & 0.28 & 0.10 & 1.33 & 4.15 & 4.66 & 8.81 & TS14_4 \\
\hline $\mathrm{EE}-1$ & 195 & 74.65 & 15.04 & 0.32 & 1.56 & 0.30 & 0.10 & 1.38 & 2.06 & 4.58 & 6.63 & TS14_5 \\
\hline $\mathrm{EE}-1$ & 196 & 72.58 & 14.78 & 0.32 & 1.68 & 0.32 & 0.10 & 1.37 & 4.26 & 4.58 & 8.84 & TS14_6 \\
\hline $\mathrm{EE}-1$ & 197 & 72.65 & 14.86 & 0.31 & 1.44 & 0.30 & 0.14 & 1.41 & 4.18 & 4.71 & 8.88 & TS14_7 \\
\hline EE-1 & 198 & 72.79 & 14.86 & 0.31 & 1.42 & 0.30 & 0.11 & 1.39 & 4.25 & 4.56 & 8.80 & TS14_8 \\
\hline $\mathrm{EE}-1$ & 199 & 72.48 & 14.85 & 0.31 & 1.69 & 0.30 & 0.13 & 1.36 & 4.20 & 4.66 & 8.86 & TS14_9 \\
\hline EE-1 & 200 & 72.65 & 14.84 & 0.31 & 1.50 & 0.30 & 0.08 & 1.39 & 4.25 & 4.66 & 8.91 & TS14_10 \\
\hline EE-1 & 201 & 72.40 & 14.81 & 0.33 & 1.56 & 0.31 & 0.15 & 1.37 & 4.43 & 4.64 & 9.06 & TS14_11 \\
\hline EE-1 & 202 & 72.31 & 14.78 & 0.34 & 1.62 & 0.28 & 0.09 & 1.41 & 4.35 & 4.79 & 9.13 & TS14_12 \\
\hline EE-1 & 203 & 72.86 & 14.86 & 0.33 & 1.46 & 0.29 & 0.11 & 1.39 & 4.08 & 4.60 & 8.67 & TS14_13 \\
\hline EE-1 & 204 & 72.75 & 14.72 & 0.31 & 1.45 & 0.31 & 0.07 & 1.41 & 4.41 & 4.57 & 8.98 & TS14_14 \\
\hline EE-1 & 210 & 72.56 & 14.96 & 0.30 & 1.57 & 0.28 & 0.08 & 1.34 & 4.32 & 4.57 & 8.90 & TS15_1 \\
\hline $\mathrm{EE}-1$ & 211 & 72.32 & 14.92 & 0.37 & 1.76 & 0.30 & 0.17 & 1.47 & 4.13 & 4.54 & 8.67 & TS15_2 \\
\hline $\mathrm{EE}-1$ & 212 & 73.05 & 14.70 & 0.33 & 1.47 & 0.28 & 0.13 & 1.32 & 4.01 & 4.70 & 8.71 & TS15_3 \\
\hline $\mathrm{EE}-1$ & 213 & 72.70 & 14.76 & 0.32 & 1.55 & 0.29 & 0.12 & 1.38 & 4.26 & 4.61 & 8.87 & TS15_4 \\
\hline EE-1 & 214 & 72.51 & 14.84 & 0.32 & 1.47 & 0.31 & 0.11 & 1.40 & 4.42 & 4.57 & 8.99 & TS15_5 \\
\hline EE-1 & 215 & 72.84 & 14.97 & 0.34 & 1.49 & 0.30 & 0.14 & 1.34 & 3.92 & 4.66 & 8.59 & TS15_6 \\
\hline $\mathrm{EE}-1$ & 216 & 72.81 & 14.84 & 0.32 & 1.50 & 0.28 & 0.04 & 1.36 & 4.19 & 4.62 & 8.82 & TS15_7 \\
\hline $\mathrm{EE}-1$ & 217 & 72.60 & 14.82 & 0.34 & 1.65 & 0.32 & 0.10 & 1.41 & 4.19 & 4.55 & 8.74 & TS15_8 \\
\hline $\mathrm{EE}-1$ & 218 & 72.90 & 14.87 & 0.32 & 1.42 & 0.26 & 0.10 & 1.41 & 4.09 & 4.61 & 8.70 & TS15_9 \\
\hline EE-1 & 220 & 72.75 & 14.88 & 0.30 & 1.52 & 0.28 & 0.12 & 1.39 & 4.13 & 4.59 & 8.72 & TS15_10 \\
\hline EE-1 & 221 & 72.78 & 14.88 & 0.33 & 1.59 & 0.28 & 0.11 & 1.34 & 4.18 & 4.51 & 8.69 & TS15_11 \\
\hline EE-1 & 222 & 72.63 & 14.71 & 0.33 & 1.60 & 0.32 & 0.14 & 1.39 & 4.31 & 4.53 & 8.84 & TS15_12 \\
\hline $\mathrm{EE}-1$ & 223 & 72.63 & 14.82 & 0.35 & 1.64 & 0.25 & 0.07 & 1.39 & 4.34 & 4.49 & 8.83 & TS15_13 \\
\hline EE-1 & 224 & 72.62 & 14.97 & 0.34 & 1.60 & 0.32 & 0.11 & 1.34 & 4.15 & 4.52 & 8.67 & TS15_14 \\
\hline EE-1 & 225 & 72.73 & 14.91 & 0.30 & 1.55 & 0.29 & 0.13 & 1.37 & 4.04 & 4.68 & 8.72 & TS15_15 \\
\hline EE-1 & 226 & 72.53 & 14.86 & 0.31 & 1.55 & 0.29 & 0.09 & 1.43 & 4.40 & 4.53 & 8.94 & TS15_16 \\
\hline EE-1 & 227 & 72.29 & 15.02 & 0.32 & 1.56 & 0.31 & 0.16 & 1.52 & 4.16 & 4.64 & 8.80 & TS15_17 \\
\hline NA & 247 & 67.81 & 16.34 & 0.50 & 2.71 & 0.76 & 0.10 & 1.93 & 4.90 & 4.90 & 9.80 & TS17_1 \\
\hline NA & 248 & 67.43 & 16.97 & 0.45 & 2.68 & 0.65 & 0.14 & 2.35 & 4.67 & 4.66 & 9.33 & TS17_2 \\
\hline NA & 250 & 67.90 & 16.22 & 0.52 & 2.67 & 0.73 & 0.13 & 1.82 & 4.97 & 5.00 & 9.97 & TS17_3 \\
\hline NA & 251 & 66.30 & 17.73 & 0.50 & 2.55 & 0.66 & 0.12 & 3.02 & 4.86 & 4.25 & 9.11 & TS17_4 \\
\hline NA & 252 & 67.61 & 16.42 & 0.56 & 2.93 & 0.71 & 0.16 & 1.96 & 4.66 & 4.96 & 9.62 & TS17_5 \\
\hline NA & 254 & 67.92 & 16.65 & 0.54 & 2.54 & 0.64 & 0.14 & 2.36 & 4.50 & 4.69 & 9.18 & TS17_6 \\
\hline NA & 258 & 67.84 & 16.40 & 0.54 & 2.80 & 0.69 & 0.12 & 1.98 & 4.80 & 4.82 & 9.62 & TS17_7 \\
\hline SQ-1 & 260 & 72.61 & 14.98 & 0.31 & 1.60 & 0.31 & 0.06 & 1.37 & 4.19 & 4.56 & 8.75 & TS18_1 \\
\hline SQ-1 & 261 & 72.37 & 14.96 & 0.33 & 1.58 & 0.29 & 0.13 & 1.48 & 4.11 & 4.73 & 8.84 & TS18_2 \\
\hline SQ-1 & 262 & 72.38 & 14.91 & 0.30 & 1.53 & 0.29 & 0.12 & 1.41 & 4.04 & 5.01 & 9.06 & TS18_3 \\
\hline SQ-1 & 263 & 72.30 & 15.06 & 0.32 & 1.67 & 0.30 & 0.04 & 1.36 & 4.15 & 4.77 & 8.93 & TS18_4 \\
\hline SQ-1 & 264 & 72.60 & 14.86 & 0.33 & 1.65 & 0.27 & 0.13 & 1.37 & 3.89 & 4.89 & 8.78 & TS18_5 \\
\hline SQ-1 & 265 & 72.14 & 15.05 & 0.33 & 1.81 & 0.29 & 0.06 & 1.51 & 3.98 & 4.80 & 8.78 & TS18_6 \\
\hline SQ-1 & 266 & 71.98 & 15.07 & 0.31 & 1.65 & 0.31 & 0.06 & 1.53 & 4.26 & 4.79 & 9.05 & TS18_7 \\
\hline
\end{tabular}




\begin{tabular}{|c|c|c|c|c|c|c|c|c|c|c|c|c|}
\hline Section & Sample & $\mathrm{SiO}_{2}$ & $\mathrm{Al}_{2} \mathrm{O}_{3}$ & $\mathrm{TiO}_{2}$ & $\mathrm{FeO}$ & $\mathrm{MgO}$ & MnO & $\mathrm{CaO}$ & $\mathrm{Na}_{2} \mathrm{O}$ & $\mathrm{K}_{2} \mathrm{O}$ & $\mathrm{NA}_{2} \mathrm{O}+\mathrm{K}_{2} \mathrm{O}$ & Correlative \\
\hline SQ-1 & 267 & 72.72 & 14.82 & 0.33 & 1.56 & 0.29 & 0.12 & 1.42 & 3.74 & 4.96 & 8.70 & TS18_8 \\
\hline SQ-1 & 268 & 72.52 & 14.78 & 0.31 & 1.64 & 0.28 & 0.09 & 1.42 & 4.01 & 4.92 & 8.93 & TS18_9 \\
\hline SQ-1 & 269 & 70.40 & 16.90 & 0.27 & 1.24 & 0.23 & 0.10 & 2.47 & 4.40 & 3.97 & 8.37 & TS18_10 \\
\hline SQ-1 & 270 & 72.17 & 14.95 & 0.33 & 1.72 & 0.33 & 0.09 & 1.48 & 4.23 & 4.68 & 8.91 & TS18_11 \\
\hline SQ-1 & 271 & 72.61 & 14.95 & 0.30 & 1.51 & 0.33 & 0.10 & 1.41 & 4.03 & 4.73 & 8.76 & TS18_12 \\
\hline SQ-1 & 272 & 71.88 & 15.11 & 0.36 & 1.81 & 0.30 & 0.12 & 1.59 & 3.93 & 4.88 & 8.81 & TS18_13 \\
\hline SQ-1 & 273 & 72.20 & 15.03 & 0.35 & 1.69 & 0.35 & 0.18 & 1.41 & 4.19 & 4.58 & 8.77 & TS18_14 \\
\hline SQ-1 & 274 & 72.02 & 15.18 & 0.37 & 1.68 & 0.30 & 0.19 & 1.47 & 4.08 & 4.70 & 8.78 & TS18_15 \\
\hline SQ-1 & 275 & 72.56 & 15.01 & 0.33 & 1.48 & 0.28 & 0.07 & 1.40 & 4.13 & 4.72 & 8.85 & TS18_16 \\
\hline VQ-1 & 281 & 69.95 & 15.83 & 0.42 & 2.08 & 0.50 & 0.13 & 1.87 & 4.80 & 4.40 & 9.20 & TS19_1 \\
\hline VQ-1 & 282 & 70.26 & 15.95 & 0.44 & 2.06 & 0.47 & 0.13 & 1.80 & 4.44 & 4.42 & 8.86 & TS19_2 \\
\hline VQ-1 & 283 & 70.15 & 15.84 & 0.42 & 2.07 & 0.51 & 0.12 & 1.77 & 4.70 & 4.40 & 9.10 & TS19_3 \\
\hline VQ-1 & 284 & 69.83 & 15.93 & 0.44 & 2.07 & 0.48 & 0.10 & 1.81 & 4.78 & 4.56 & 9.33 & TS19_4 \\
\hline VQ-1 & 285 & 70.25 & 15.79 & 0.46 & 2.11 & 0.49 & 0.13 & 1.81 & 4.52 & 4.42 & 8.94 & TS19_5 \\
\hline VQ-1 & 286 & 69.98 & 15.95 & 0.46 & 2.14 & 0.47 & 0.15 & 1.79 & 4.62 & 4.42 & 9.04 & TS19_6 \\
\hline VQ-1 & 287 & 69.82 & 15.83 & 0.42 & 2.20 & 0.53 & 0.15 & 1.87 & 4.74 & 4.42 & 9.16 & TS19_7 \\
\hline VQ-1 & 288 & 69.96 & 15.89 & 0.45 & 2.15 & 0.48 & 0.09 & 1.86 & 4.83 & 4.28 & 9.11 & TS19_8 \\
\hline VQ-1 & 289 & 70.01 & 15.94 & 0.41 & 2.11 & 0.54 & 0.09 & 1.82 & 4.61 & 4.43 & 9.05 & TS19_9 \\
\hline VQ-1 & 290 & 69.84 & 16.04 & 0.39 & 2.14 & 0.48 & 0.10 & 1.87 & 4.65 & 4.46 & 9.11 & TS19_10 \\
\hline VQ-1 & 291 & 70.33 & 15.93 & 0.43 & 1.91 & 0.46 & 0.07 & 1.86 & 4.63 & 4.37 & 9.00 & TS19_11 \\
\hline VQ-1 & 292 & 69.82 & 15.97 & 0.45 & 1.98 & 0.49 & 0.11 & 1.88 & 4.82 & 4.46 & 9.29 & TS19_12 \\
\hline VQ-1 & 294 & 68.88 & 16.18 & 0.47 & 2.54 & 0.60 & 0.15 & 2.18 & 4.86 & 4.13 & 8.99 & TS19_13 \\
\hline VQ-1 & 295 & 69.99 & 15.99 & 0.42 & 2.16 & 0.47 & 0.12 & 1.83 & 4.58 & 4.43 & 9.01 & TS19_14 \\
\hline VQ-1 & 6 & 69.44 & 15.89 & 0.50 & 2.51 & 0.53 & 0.18 & 2.06 & 4.32 & 4.53 & 8.86 & TS20_1 \\
\hline VQ-1 & 7 & 69.87 & 15.79 & 0.43 & 2.21 & 0.47 & 0.13 & 1.96 & 4.79 & 4.32 & 9.11 & TS20_2 \\
\hline VQ-1 & 8 & 69.90 & 15.90 & 0.47 & 2.26 & 0.50 & 0.15 & 2.04 & 4.28 & 4.46 & 8.74 & TS20_3 \\
\hline VQ-1 & 9 & 70.45 & 15.87 & 0.42 & 2.13 & 0.48 & 0.15 & 1.94 & 4.11 & 4.41 & 8.52 & TS20_4 \\
\hline VQ-1 & 13 & 70.13 & 15.62 & 0.44 & 2.21 & 0.46 & 0.13 & 1.94 & 4.70 & 4.34 & 9.05 & TS20_5 \\
\hline VQ-1 & 14 & 70.18 & 15.77 & 0.43 & 2.21 & 0.46 & 0.09 & 1.96 & 4.47 & 4.38 & 8.85 & TS20_6 \\
\hline VQ-1 & 15 & 69.90 & 15.76 & 0.41 & 2.12 & 0.48 & 0.09 & 2.00 & 4.85 & 4.38 & 9.22 & TS2O_7 \\
\hline VQ-1 & 16 & 70.01 & 15.85 & 0.42 & 2.03 & 0.48 & 0.12 & 1.94 & 4.87 & 4.27 & 9.13 & TS20_8 \\
\hline VQ-1 & 17 & 69.95 & 15.76 & 0.42 & 2.16 & 0.51 & 0.14 & 1.98 & 4.81 & 4.26 & 9.07 & TS20_9 \\
\hline VQ-1 & 18 & 69.82 & 15.70 & 0.44 & 2.37 & 0.48 & 0.14 & 2.00 & 4.67 & 4.37 & 9.04 & TS20_10 \\
\hline VQ-1 & 20 & 72.47 & 14.88 & 0.45 & 2.07 & 0.33 & 0.13 & 1.08 & 3.26 & 5.29 & 8.55 & TS20_11 \\
\hline VQ-1 & 21 & 73.76 & 16.33 & 0.44 & 2.06 & 0.44 & 0.14 & 2.08 & 1.05 & 3.68 & 4.72 & TS20_12 \\
\hline VQ-1 & 22 & 68.32 & 16.59 & 0.41 & 2.14 & 0.43 & 0.20 & 2.91 & 4.84 & 4.13 & 8.98 & TS20_13 \\
\hline VQ-1 & 24 & 72.32 & 15.03 & 0.32 & 1.64 & 0.29 & 0.12 & 1.42 & 4.13 & 4.68 & 8.81 & TS21_1 \\
\hline VQ-1 & 25 & 72.58 & 14.97 & 0.33 & 1.57 & 0.31 & 0.11 & 1.36 & 4.20 & 4.55 & 8.75 & TS21_2 \\
\hline VQ-1 & 29 & 72.06 & 14.97 & 0.35 & 1.60 & 0.35 & 0.18 & 1.41 & 4.31 & 4.74 & 9.06 & TS21_3 \\
\hline VQ-1 & 30 & 72.20 & 14.93 & 0.34 & 1.63 & 0.30 & 0.05 & 1.39 & 4.52 & 4.62 & 9.13 & TS21_4 \\
\hline VQ-1 & 31 & 72.77 & 15.03 & 0.34 & 1.80 & 0.30 & 0.06 & 1.36 & 3.68 & 4.63 & 8.31 & TS21_5 \\
\hline VQ-1 & 32 & 72.44 & 15.05 & 0.35 & 1.63 & 0.34 & 0.09 & 1.35 & 4.22 & 4.51 & 8.74 & TS21_6 \\
\hline VQ-1 & 33 & 72.61 & 14.86 & 0.34 & 1.45 & 0.31 & 0.11 & 1.34 & 4.32 & 4.65 & 8.97 & TS21_7 \\
\hline VQ-1 & 34 & 72.42 & 14.96 & 0.36 & 1.64 & 0.32 & 0.10 & 1.37 & 4.23 & 4.59 & 8.81 & TS21_8 \\
\hline VQ-1 & 35 & 72.27 & 15.01 & 0.35 & 1.53 & 0.28 & 0.11 & 1.38 & 4.55 & 4.51 & 9.07 & TS21_9 \\
\hline
\end{tabular}




\begin{tabular}{|c|c|c|c|c|c|c|c|c|c|c|c|c|}
\hline Section & Sample & $\mathrm{SiO}_{2}$ & $\mathrm{Al}_{2} \mathrm{O}_{3}$ & $\mathrm{TiO}_{2}$ & $\mathrm{FeO}$ & MgO & MnO & $\mathrm{CaO}$ & $\mathrm{Na}_{2} \mathrm{O}$ & $\mathrm{K}_{2} \mathrm{O}$ & $\mathrm{NA}_{2} \mathrm{O}+\mathrm{K}_{2} \mathrm{O}$ & Correlative \\
\hline VQ-1 & 44 & 70.92 & 15.17 & 0.40 & 2.22 & 0.63 & 0.09 & 2.04 & 4.16 & 4.35 & 8.51 & TS22_1 \\
\hline VQ-1 & 46 & 71.15 & 15.58 & 0.42 & 2.11 & 0.44 & 0.12 & 1.66 & 4.25 & 4.25 & 8.50 & TS22_2 \\
\hline VQ-1 & 47 & 70.67 & 15.69 & 0.42 & 1.93 & 0.47 & 0.09 & 1.80 & 4.56 & 4.32 & 8.88 & TS22_3 \\
\hline VQ-1 & 48 & 72.07 & 14.44 & 0.35 & 2.08 & 0.40 & 0.18 & 1.71 & 4.36 & 4.33 & 8.69 & TS22_4 \\
\hline VQ-1 & 50 & 72.06 & 15.98 & 0.40 & 1.81 & 0.32 & 0.06 & 1.52 & 3.88 & 3.93 & 7.81 & TS22_5 \\
\hline VQ-1 & 53 & 71.32 & 15.08 & 0.39 & 2.08 & 0.56 & 0.11 & 1.69 & 4.14 & 4.62 & 8.75 & TS22_6 \\
\hline YR-1 & 56 & 72.94 & 15.03 & 0.32 & 1.53 & 0.30 & 0.07 & 1.34 & 3.86 & 4.59 & 8.45 & TS-23-1 \\
\hline YR-1 & 58 & 72.41 & 14.83 & 0.33 & 1.57 & 0.31 & 0.07 & 1.40 & 4.56 & 4.50 & 9.06 & TS-23-2 \\
\hline YR-1 & 59 & 72.54 & 15.01 & 0.34 & 1.56 & 0.25 & 0.11 & 1.38 & 4.22 & 4.56 & 8.78 & TS-23-3 \\
\hline YR-1 & 61 & 72.38 & 14.61 & 0.38 & 1.71 & 0.27 & 0.13 & 1.36 & 4.30 & 4.84 & 9.14 & TS-23-4 \\
\hline YR-1 & 62 & 72.57 & 14.94 & 0.33 & 1.65 & 0.30 & 0.16 & 1.42 & 4.02 & 4.58 & 8.60 & TS-23-5 \\
\hline YR-1 & 63 & 72.60 & 14.79 & 0.38 & 1.62 & 0.27 & 0.14 & 1.29 & 4.34 & 4.54 & 8.88 & TS-23-6 \\
\hline YR-1 & 64 & 72.57 & 14.79 & 0.32 & 1.48 & 0.27 & 0.10 & 1.32 & 4.60 & 4.53 & 9.13 & TS-23-7 \\
\hline YR-1 & 65 & 72.58 & 15.02 & 0.35 & 1.47 & 0.29 & 0.06 & 1.32 & 4.31 & 4.59 & 8.90 & TS-23-8 \\
\hline YR-1 & 72 & 72.55 & 14.82 & 0.33 & 1.36 & 0.29 & 0.12 & 1.37 & 4.58 & 4.56 & 9.14 & TS24_1 \\
\hline YR-1 & 73 & 72.21 & 14.82 & 0.34 & 1.73 & 0.31 & 0.11 & 1.40 & 4.44 & 4.61 & 9.05 & TS24_2 \\
\hline YR-1 & 75 & 72.77 & 14.77 & 0.35 & 1.48 & 0.29 & 0.09 & 1.33 & 4.30 & 4.59 & 8.89 & TS24_3 \\
\hline YR-1 & 76 & 72.80 & 14.77 & 0.37 & 1.54 & 0.29 & 0.10 & 1.28 & 4.26 & 4.58 & 8.84 & TS24_4 \\
\hline YR-1 & 77 & 72.74 & 14.87 & 0.38 & 1.53 & 0.29 & 0.08 & 1.32 & 4.14 & 4.64 & 8.78 & TS24_5 \\
\hline YR-1 & 78 & 73.89 & 15.50 & 0.28 & 1.40 & 0.28 & 0.13 & 1.11 & 2.98 & 4.42 & 7.40 & TS24_6 \\
\hline YR-1 & 79 & 72.83 & 14.97 & 0.31 & 1.41 & 0.27 & 0.12 & 1.56 & 4.12 & 4.39 & 8.51 & TS24_7 \\
\hline YR-1 & 80 & 72.82 & 14.68 & 0.33 & 1.49 & 0.29 & 0.09 & 1.36 & 4.18 & 4.74 & 8.92 & TS24_8 \\
\hline YR-1 & 81 & 72.07 & 14.87 & 0.33 & 1.89 & 0.31 & 0.11 & 1.33 & 4.51 & 4.55 & 9.06 & TS24_9 \\
\hline YR-1 & 82 & 72.45 & 14.71 & 0.38 & 1.72 & 0.26 & 0.13 & 1.38 & 4.23 & 4.70 & 8.93 & TS24_10 \\
\hline YR-1 & 85 & 73.24 & 15.18 & 0.36 & 1.38 & 0.27 & 0.05 & 1.21 & 3.77 & 4.51 & 8.28 & TS24_11 \\
\hline YR-1 & 86 & 72.58 & 14.55 & 0.37 & 1.88 & 0.27 & 0.13 & 1.35 & 4.16 & 4.71 & 8.87 & TS24_12 \\
\hline YR-1 & 89 & 71.85 & 15.09 & 0.42 & 1.90 & 0.36 & 0.14 & 1.23 & 4.09 & 4.89 & 8.98 & TS-25_1 \\
\hline YR-1 & 93 & 68.64 & 16.45 & 0.45 & 2.49 & 0.53 & 0.15 & 2.43 & 4.88 & 3.92 & 8.81 & TS-25_2 \\
\hline YR-1 & 95 & 69.31 & 16.04 & 0.44 & 2.31 & 0.53 & 0.16 & 2.04 & 4.91 & 4.23 & 9.14 & TS-25_3 \\
\hline YR-1 & 96 & 69.50 & 16.36 & 0.38 & 2.25 & 0.55 & 0.09 & 2.18 & 4.44 & 4.23 & 8.67 & TS-25_4 \\
\hline YR-1 & 97 & 70.41 & 15.55 & 0.40 & 2.01 & 0.45 & 0.13 & 1.71 & 4.77 & 4.54 & 9.30 & TS-25_5 \\
\hline YR-1 & 98 & 69.39 & 16.10 & 0.46 & 2.32 & 0.51 & 0.12 & 2.19 & 4.48 & 4.42 & 8.89 & TS-25_6 \\
\hline YR-1 & 100 & 69.84 & 15.89 & 0.45 & 2.22 & 0.50 & 0.09 & 1.94 & 4.57 & 4.48 & 9.04 & TS-25_7 \\
\hline YR-1 & 101 & 69.61 & 15.94 & 0.46 & 2.32 & 0.51 & 0.09 & 2.01 & 4.63 & 4.42 & 9.04 & TS-25_8 \\
\hline VQ-1 & 296 & 73.07 & 14.72 & 0.34 & 1.41 & 0.26 & 0.05 & 1.31 & 4.01 & 4.80 & 8.82 & TS28_1 \\
\hline VQ-1 & 297 & 72.80 & 14.71 & 0.34 & 1.48 & 0.30 & 0.07 & 1.29 & 4.12 & 4.87 & 8.99 & TS28_2 \\
\hline VQ-1 & 299 & 72.98 & 14.64 & 0.35 & 1.53 & 0.26 & 0.11 & 1.29 & 4.17 & 4.63 & 8.80 & TS28_3 \\
\hline VQ-1 & 300 & 72.74 & 14.87 & 0.31 & 1.42 & 0.26 & 0.12 & 1.31 & 4.18 & 4.77 & 8.96 & TS28_4 \\
\hline VQ-1 & 301 & 72.70 & 14.64 & 0.33 & 1.47 & 0.29 & 0.12 & 1.28 & 4.46 & 4.68 & 9.15 & TS28_5 \\
\hline VQ-1 & 302 & 73.01 & 14.70 & 0.34 & 1.34 & 0.28 & 0.10 & 1.29 & 4.22 & 4.69 & 8.91 & TS28_6 \\
\hline VQ-1 & 303 & 72.63 & 14.83 & 0.35 & 1.45 & 0.30 & 0.14 & 1.31 & 4.26 & 4.70 & 8.96 & TS28_7 \\
\hline VQ-1 & 304 & 72.71 & 14.70 & 0.38 & 1.59 & 0.23 & 0.14 & 1.32 & 4.25 & 4.66 & 8.90 & TS28_8 \\
\hline VQ-1 & 305 & 72.99 & 14.59 & 0.30 & 1.52 & 0.28 & 0.08 & 1.34 & 4.23 & 4.64 & 8.88 & TS28_9 \\
\hline VQ-1 & 306 & 72.91 & 14.71 & 0.35 & 1.49 & 0.27 & 0.05 & 1.33 & 4.30 & 4.56 & 8.86 & TS28_10 \\
\hline TU-2 & 313 & 73.44 & 14.20 & 0.37 & 1.62 & 0.17 & 0.10 & 1.01 & 4.09 & 4.98 & 9.07 & TS29_1 \\
\hline
\end{tabular}




\begin{tabular}{|c|c|c|c|c|c|c|c|c|c|c|c|c|}
\hline Section & Sample & $\mathrm{SiO}_{2}$ & $\mathrm{Al}_{2} \mathrm{O}_{3}$ & $\mathrm{TiO}_{2}$ & $\mathrm{FeO}$ & MgO & $\mathrm{MnO}$ & $\mathrm{CaO}$ & $\mathrm{Na}_{2} \mathrm{O}$ & $\mathrm{K}_{2} \mathrm{O}$ & $\mathrm{NA}_{2} \mathrm{O}+\mathrm{K}_{2} \mathrm{O}$ & Correlative \\
\hline TU-2 & 314 & 72.47 & 15.21 & 0.33 & 1.55 & 0.16 & 0.13 & 1.50 & 4.15 & 4.48 & 8.63 & TS29_2 \\
\hline TU-2 & 316 & 69.69 & 17.40 & 0.26 & 1.14 & 0.11 & 0.07 & 2.64 & 5.04 & 3.66 & 8.69 & TS29_3 \\
\hline TU-2 & 318 & 67.62 & 18.69 & 0.17 & 0.99 & 0.15 & 0.07 & 3.37 & 5.77 & 3.17 & 8.94 & TS29_4 \\
\hline TU-2 & 319 & 69.46 & 17.56 & 0.27 & 1.17 & 0.13 & 0.08 & 2.86 & 4.72 & 3.75 & 8.47 & TS29_5 \\
\hline TU-2 & 320 & 70.36 & 17.01 & 0.25 & 1.16 & 0.12 & 0.07 & 2.50 & 4.68 & 3.84 & 8.53 & TS29_6 \\
\hline TU-2 & 323 & 74.27 & 13.70 & 0.39 & 1.40 & 0.21 & 0.09 & 0.81 & 3.86 & 5.24 & 9.11 & TS29_7 \\
\hline TU-2 & 325 & 74.20 & 13.94 & 0.35 & 1.43 & 0.19 & 0.09 & 0.72 & 3.75 & 5.33 & 9.07 & TS29_8 \\
\hline TU-2 & 326 & 73.80 & 13.88 & 0.33 & 1.55 & 0.48 & 0.14 & 1.03 & 3.91 & 4.87 & 8.78 & TS29_9 \\
\hline TU-2 & 329 & 69.95 & 15.88 & 0.43 & 2.29 & 0.47 & 0.10 & 1.86 & 4.63 & 4.38 & 9.01 & TS30_1 \\
\hline TU-2 & 330 & 70.02 & 16.29 & 0.38 & 1.91 & 0.38 & 0.07 & 2.10 & 4.72 & 4.12 & 8.84 & TS30_2 \\
\hline TU-2 & 331 & 70.46 & 15.80 & 0.43 & 1.96 & 0.50 & 0.11 & 1.71 & 4.58 & 4.44 & 9.02 & TS30_3 \\
\hline TU-2 & 332 & 70.44 & 15.57 & 0.41 & 1.94 & 0.48 & 0.12 & 1.70 & 4.74 & 4.59 & 9.33 & TS30_4 \\
\hline TU-2 & 333 & 70.48 & 15.67 & 0.43 & 2.09 & 0.46 & 0.14 & 1.71 & 4.43 & 4.58 & 9.01 & TS30_5 \\
\hline TU-2 & 334 & 70.13 & 15.71 & 0.42 & 2.16 & 0.39 & 0.05 & 1.80 & 4.72 & 4.61 & 9.33 & TS30_6 \\
\hline TU-2 & 335 & 70.15 & 15.72 & 0.42 & 1.95 & 0.46 & 0.19 & 1.75 & 4.85 & 4.48 & 9.33 & TS30_7 \\
\hline TU-2 & 336 & 70.10 & 15.96 & 0.40 & 1.88 & 0.50 & 0.15 & 1.86 & 4.68 & 4.45 & 9.13 & TS30_8 \\
\hline TU-2 & 337 & 69.96 & 15.84 & 0.43 & 2.16 & 0.48 & 0.09 & 1.84 & 4.79 & 4.38 & 9.17 & TS30_9 \\
\hline TU-2 & 338 & 70.12 & 15.87 & 0.46 & 1.99 & 0.49 & 0.15 & 1.87 & 4.64 & 4.39 & 9.02 & TS30_10 \\
\hline TU-2 & 339 & 70.06 & 15.71 & 0.47 & 2.05 & 0.52 & 0.14 & 1.70 & 4.81 & 4.52 & 9.32 & TS30_11 \\
\hline TU-2 & 340 & 69.92 & 16.04 & 0.42 & 2.03 & 0.47 & 0.08 & 1.81 & 4.86 & 4.37 & 9.22 & TS30_12 \\
\hline TU-2 & 341 & 70.17 & 15.80 & 0.43 & 1.95 & 0.46 & 0.15 & 1.82 & 4.81 & 4.37 & 9.18 & TS30_13 \\
\hline TU-2 & 342 & 70.06 & 15.85 & 0.41 & 1.97 & 0.50 & 0.12 & 1.80 & 4.85 & 4.42 & 9.28 & TS30_14 \\
\hline TU-2 & 343 & 70.32 & 15.83 & 0.39 & 2.09 & 0.43 & 0.11 & 1.71 & 4.61 & 4.50 & 9.11 & TS30_15 \\
\hline TU-2 & 344 & 70.10 & 15.88 & 0.41 & 1.90 & 0.38 & 0.14 & 1.81 & 4.87 & 4.48 & 9.35 & TS30_16 \\
\hline TU-2 & 345 & 70.01 & 15.76 & 0.46 & 2.05 & 0.48 & 0.09 & 1.69 & 4.91 & 4.52 & 9.43 & TS30_17 \\
\hline TU-2 & 346 & 69.66 & 15.94 & 0.49 & 2.24 & 0.43 & 0.14 & 1.83 & 4.85 & 4.39 & 9.24 & TS30_18 \\
\hline
\end{tabular}




\section{Appendix C: Sedimentological Data}

\section{C1 - Clast Shape and Roundness field data including Largest Clasts.}

The $\mathrm{a}, \mathrm{b}$ and $\mathrm{c}$ axis are measured in $\mathrm{mm}$ and roundness measured using the Krumbein roundness scale for two samples Vickers Quarry and one sample from York Road sites according to the method outlined in Section Four - Chapter Two. Each group of measurements are divided into $2 \phi$ categories (e.g. -6 to $-7 \phi)$. For each sample, the largest five clasts from the lithostratigraphic unit were measured. For sample stratigraphic positions see A1 - Appendix A.

\begin{tabular}{|c|c|c|c|c|c|c|c|c|c|c|c|c|}
\hline \multicolumn{12}{|c|}{ VQ-S1 } & \multirow[b]{3}{*}{ Largest Clasts (m) } \\
\hline \multicolumn{4}{|c|}{-6 to -7} & \multicolumn{4}{|c|}{-7 to -8} & \multicolumn{4}{|c|}{$>-8$} & \\
\hline $\mathbf{a}$ & b & c & roundness & a & b & c & roundness & a & b & c & roundness & \\
\hline 90 & 65 & 50 & 0.3 & 230 & 180 & 120 & 0.5 & 270 & 160 & 140 & 0.5 & 3.2 \\
\hline 115 & 75 & 70 & 0.5 & 150 & 120 & 95 & 0.5 & 290 & 210 & 170 & 0.4 & 0.75 \\
\hline 80 & 45 & 40 & 0.5 & 140 & 125 & 60 & 0.3 & 300 & 220 & 170 & 0.5 & 1.8 \\
\hline 100 & 90 & 65 & 0.4 & 145 & 115 & 70 & 0.4 & 350 & 280 & 170 & 0.6 & 1.6 \\
\hline 110 & 85 & 65 & 0.5 & 220 & 150 & 130 & 0.5 & 280 & 200 & 120 & 0.4 & 0.8 \\
\hline 80 & 65 & 45 & 0.5 & 150 & 110 & 100 & 0.5 & 300 & 230 & 190 & 0.6 & 1 \\
\hline 90 & 50 & 40 & 0.3 & 210 & 160 & 120 & 0.6 & 340 & 260 & 200 & 0.6 & \\
\hline 100 & 90 & 45 & 0.5 & 250 & 150 & 120 & 0.4 & 320 & 280 & 200 & 0.7 & \\
\hline 110 & 100 & 60 & 0.4 & 180 & 130 & 110 & 0.5 & 410 & 326 & 280 & 0.5 & \\
\hline 120 & 80 & 50 & 0.5 & 150 & 80 & 80 & 0.5 & 460 & 320 & 200 & 0.4 & \\
\hline 80 & 65 & 35 & 0.5 & 150 & 65 & 60 & 0.6 & 270 & 200 & 150 & 0.5 & \\
\hline 110 & 90 & 55 & 0.5 & 150 & 80 & 70 & 0.6 & 520 & 370 & 220 & 0.5 & \\
\hline 80 & 55 & 30 & 0.5 & 220 & 170 & 160 & 0.5 & 540 & 400 & 240 & 0.4 & \\
\hline 115 & 95 & 55 & 0.3 & 250 & 170 & 160 & 0.4 & 350 & 280 & 170 & 0.5 & \\
\hline 120 & 85 & 80 & 0.6 & 230 & 170 & 90 & 0.5 & 380 & 230 & 190 & 0.5 & \\
\hline 75 & 60 & 60 & 0.3 & 160 & 120 & 110 & 0.5 & 340 & 290 & 190 & 0.5 & \\
\hline 85 & 65 & 65 & 0.4 & 190 & 120 & 40 & 0.3 & 300 & 270 & 130 & 0.5 & \\
\hline 75 & 70 & 35 & 0.3 & 150 & 90 & 80 & 0.4 & 350 & 210 & 100 & 0.4 & \\
\hline 95 & 70 & 50 & 0.4 & 220 & 170 & 120 & 0.4 & 380 & 300 & 260 & 0.6 & \\
\hline 105 & 75 & 55 & 0.5 & 170 & 140 & 120 & 0.4 & 340 & 270 & 230 & 0.4 & \\
\hline
\end{tabular}

\begin{tabular}{|c|c|c|c|c|c|c|c|}
\hline \multicolumn{8}{|c|}{ VQ-S5 } \\
\hline \multicolumn{4}{|c|}{-6 to -7} & \multicolumn{4}{|c|}{$>7$} \\
\hline a & b & c & roundness & a & b & c & roundness \\
\hline 90 & 80 & 60 & 0.4 & 240 & 220 & 90 & 0.4 \\
\hline 90 & 50 & 40 & 0.5 & 170 & 110 & 90 & 0.5 \\
\hline 110 & 100 & 90 & 0.4 & 210 & 140 & 110 & 0.5 \\
\hline 120 & 80 & 60 & 0.5 & 170 & 150 & 120 & 0.5 \\
\hline 65 & 45 & 40 & 0.3 & 150 & 100 & 70 & 0.4 \\
\hline 110 & 90 & 50 & 0.5 & 190 & 150 & 100 & 0.5 \\
\hline 110 & 80 & 60 & 0.4 & 160 & 140 & 120 & 0.5 \\
\hline 110 & 90 & 70 & 0.5 & 110 & 80 & 60 & 0.4 \\
\hline 100 & 90 & 60 & 0.3 & 150 & 110 & 80 & 0.4 \\
\hline 60 & 55 & 40 & 0.3 & 230 & 190 & 150 & 0.5 \\
\hline 90 & 80 & 70 & 0.3 & 230 & 190 & 170 & 0.5 \\
\hline 90 & 80 & 50 & 0.4 & 140 & 100 & 90 & 0.6 \\
\hline 65 & 50 & 40 & 0.5 & 150 & 120 & 90 & 0.5 \\
\hline 100 & 80 & 70 & 0.5 & 130 & 90 & 70 & 0.4 \\
\hline 80 & 65 & 30 & 0.3 & 220 & 160 & 120 & 0.5 \\
\hline 65 & 55 & 40 & 0.6 & 210 & 200 & 160 & 0.5 \\
\hline 70 & 60 & 50 & 0.4 & 170 & 150 & 100 & 0.3 \\
\hline 60 & 55 & 40 & 0.3 & 150 & 110 & 80 & 0.4 \\
\hline 65 & 50 & 30 & 0.5 & 140 & 80 & 70 & 0.5 \\
\hline 90 & 60 & 55 & 0.6 & 230 & 140 & 130 & 0.5 \\
\hline
\end{tabular}




\begin{tabular}{|c|c|c|c|c|c|c|c|c|}
\hline \multicolumn{8}{|c|}{ YR-1 } & \multirow[b]{3}{*}{ Largest Clasts (m) } \\
\hline \multicolumn{4}{|c|}{-5 to -6} & \multicolumn{4}{|c|}{-6 to -7} & \\
\hline a & b & c & roundness & a & b & c & roundness & \\
\hline 45 & 30 & 20 & 0.2 & 65 & 55 & 40 & 0.4 & 0.3 \\
\hline 33 & 20 & 20 & 0.4 & 70 & 50 & 30 & 0.3 & 0.25 \\
\hline 45 & 35 & 20 & 0.6 & 105 & 65 & 40 & 0.6 & 0.2 \\
\hline 55 & 35 & 30 & 0.5 & 100 & 60 & 40 & 0.6 & 0.4 \\
\hline 50 & 25 & 20 & 0.5 & 80 & 80 & 30 & 0.5 & 0.18 \\
\hline 35 & 25 & 20 & 0.5 & 80 & 65 & 40 & 0.8 & \\
\hline 45 & 40 & 20 & 0.4 & 115 & 75 & 50 & 0.7 & \\
\hline 40 & 35 & 15 & 0.5 & 120 & 100 & 70 & 0.5 & \\
\hline 50 & 30 & 20 & 0.4 & 110 & 55 & 30 & 0.3 & \\
\hline 50 & 40 & 30 & 0.5 & 75 & 50 & 40 & 0.4 & \\
\hline 50 & 35 & 25 & 0.3 & 100 & 75 & 55 & 0.3 & \\
\hline 60 & 35 & 20 & 0.3 & 65 & 45 & 40 & 0.4 & \\
\hline 50 & 25 & 20 & 0.3 & 70 & 45 & 40 & 0.3 & \\
\hline 40 & 30 & 15 & 0.5 & 65 & 50 & 40 & 0.3 & \\
\hline 60 & 40 & 40 & 0.6 & 75 & 55 & 35 & 0.3 & \\
\hline 45 & 40 & 25 & 0.3 & 85 & 65 & 45 & 0.4 & \\
\hline 60 & 40 & 35 & 0.4 & 90 & 65 & 40 & 0.5 & \\
\hline 40 & 30 & 25 & 0.4 & 90 & 50 & 40 & 0.4 & \\
\hline 35 & 30 & 15 & 0.6 & 110 & 100 & 65 & 0.5 & \\
\hline 55 & 30 & 10 & 0.4 & 120 & 95 & 70 & 0.4 & \\
\hline
\end{tabular}




\section{C2 - Laboratory Sieve Stack Dataset}

Twenty samples were analysed using laboratory sieve stack analysis. The samples were collected from Vickers Quarry, York Road, Tariki Underpass and Kaimata Sawmills sections. The samples were analysed at $0.5 \phi$ increments as set out in Section Four -Chapter Two and presented in weight percentage of the sample.

\begin{tabular}{|c|c|c|c|c|c|c|c|c|c|c|c|c|c|c|c|c|c|c|c|c|}
\hline \multirow[b]{2}{*}{ Size $\left(^{\phi}\right)$} & \multicolumn{20}{|c|}{ Laboratory Sieve Stack Data (Weight \%) } \\
\hline & \multirow[t]{8}{*}{ TU2-S1 } & \multirow[t]{9}{*}{ TU2-S2 } & \multirow[t]{8}{*}{ TU2-S3 } & \multirow[t]{2}{*}{ TU2-S4 } & \multirow[t]{8}{*}{ TU2-S5 } & YR1-S1 & YR1-S2 & YR1-S3 & \multirow[t]{10}{*}{ MG-S1 } & \multirow[t]{7}{*}{ MG-S2 } & \multirow[t]{2}{*}{ MG-S3 } & \multirow[t]{2}{*}{ MG-S4 } & \multirow[t]{2}{*}{ MG-S5 } & \multirow{2}{*}{$\begin{array}{c}\text { VQ-S1 } \\
3.39\end{array}$} & \multirow[t]{2}{*}{ VQ-S2 } & \multirow[t]{2}{*}{ vQ-s3 } & \multirow[t]{2}{*}{ vQ-s4 } & \multirow{2}{*}{$\begin{array}{c}\text { VQ-S5 } \\
13.71\end{array}$} & \multirow{2}{*}{$\begin{array}{c}\text { VQ-S6 (A) } \\
23.56\end{array}$} & \multirow[t]{2}{*}{ VQ-S6 (B) } \\
\hline-5 & & & & & & & & & & & & & & & & & & & & \\
\hline-4.5 & & & & 13.25 & & & & 11.55 & & & & 4.46 & & 12.51 & 2.91 & & & 20.34 & & 4.43 \\
\hline-4 & & & & 3.48 & & & & & & & & 2.30 & & 13.53 & 0.00 & 8.08 & & 10.44 & 0.99 & 3.36 \\
\hline-3.5 & & & & 5.36 & & & 1.54 & 8.33 & & & & 1.42 & & 9.64 & 1.04 & & & 5.48 & 2.81 & 4.42 \\
\hline-3 & & & & 4.23 & & & 1.73 & 7.47 & & & 0.59 & 3.57 & & 4.79 & 3.93 & 0.46 & 1.44 & 3.47 & 2.83 & 1.33 \\
\hline-2.5 & & & & 4.06 & & 3.06 & 4.89 & 9.21 & & & 2.39 & 8.31 & 0.70 & 4.66 & 7.16 & 3.30 & 1.35 & 2.67 & 2.50 & 3.73 \\
\hline-2 & & & & 4.47 & & 7.50 & 7.33 & 7.22 & & 0.15 & 3.20 & 7.84 & 1.11 & 3.48 & 9.54 & 6.37 & 3.12 & 2.00 & 2.42 & 3.72 \\
\hline-1.5 & 0.33 & & 0.09 & 3.36 & 0.23 & 13.47 & 8.81 & 7.87 & & 0.23 & 4.38 & 6.42 & 2.28 & 2.66 & 8.74 & 5.78 & 3.71 & 1.73 & 2.54 & 3.52 \\
\hline-1 & 0.32 & 0.02 & 0.18 & 2.15 & 0.78 & 14.44 & 9.30 & 5.39 & & 1.01 & 4.89 & 5.43 & 2.73 & 2.42 & 6.53 & 6.03 & 3.84 & 2.04 & 2.58 & 3.52 \\
\hline-0.5 & 0.57 & 0.05 & 0.72 & 2.16 & 3.53 & 18.06 & 10.61 & 5.73 & 0.03 & 4.54 & 5.82 & 6.11 & 5.02 & 3.21 & 6.21 & 7.40 & 6.62 & 2.57 & 3.51 & 4.89 \\
\hline 0 & 1.06 & 0.06 & 1.65 & 1.95 & 6.89 & 11.28 & 10.20 & 5.44 & 1.17 & 8.20 & 7.40 & 6.58 & 6.56 & 3.38 & 6.32 & 8.82 & 8.08 & 3.10 & 4.56 & 5.56 \\
\hline 0.5 & 3.04 & 0.08 & 4.13 & 2.91 & 10.55 & 6.01 & 8.88 & 4.56 & 1.67 & 10.65 & 9.66 & 7.61 & 10.76 & 4.72 & 6.76 & 8.66 & 2.59 & 4.11 & 5.79 & 7.26 \\
\hline 1 & 7.77 & 0.45 & 10.28 & 7.24 & 16.66 & 4.10 & 9.34 & 5.57 & 1.77 & 12.68 & 11.49 & 7.86 & 16.46 & 4.98 & 6.77 & 10.84 & 10.67 & 4.34 & 6.58 & 8.49 \\
\hline 1.5 & 12.97 & 1.44 & 16.72 & 9.88 & 16.02 & 2.53 & 6.64 & 4.58 & 2.16 & 12.78 & 11.11 & 7.19 & 17.62 & 4.60 & 5.97 & 9.00 & 10.46 & 4.08 & 6.44 & 7.73 \\
\hline 2 & 19.19 & 2.63 & 18.33 & 11.68 & 14.57 & 2.11 & 5.42 & 3.86 & 5.96 & 13.14 & 10.58 & 6.76 & 14.49 & 4.61 & 5.88 & 7.39 & 9.54 & 4.06 & 6.78 & 7.86 \\
\hline 2.5 & 19.40 & 2.26 & 16.41 & 8.02 & 10.86 & 2.13 & 3.91 & 2.89 & 15.35 & 11.30 & 8.06 & 5.32 & 8.72 & 3.61 & 5.02 & 5.31 & 8.19 & 3.85 & 5.78 & 6.91 \\
\hline 3 & 15.19 & 4.55 & 13.17 & 5.51 & 8.08 & 2.51 & 3.24 & 2.47 & 23.51 & 9.15 & 6.70 & 4.18 & 5.40 & 3.38 & 4.32 & 4.14 & 7.16 & 3.83 & 5.17 & 6.22 \\
\hline 3.5 & 8.30 & 16.69 & 6.31 & 2.91 & 4.21 & 2.34 & 1.88 & 1.49 & 15.24 & 5.32 & 4.06 & 2.39 & 2.42 & 2.50 & 2.91 & 2.30 & 5.11 & 2.85 & 3.71 & 4.00 \\
\hline 4 & 4.97 & 17.82 & 4.10 & 1.98 & 2.35 & 2.95 & 1.56 & 1.36 & 12.96 & 3.16 & 2.72 & 1.47 & 1.61 & 0.98 & 2.03 & 1.66 & 4.59 & 0.59 & 3.10 & 3.23 \\
\hline$<4$ & 6.89 & 53.97 & 7.90 & 5.38 & 5.26 & 7.53 & 4.74 & 5.00 & 20.17 & 7.70 & 6.93 & 4.79 & 4.12 & 6.97 & 7.97 & 4.46 & 13.53 & 4.74 & 8.35 & 9.82 \\
\hline
\end{tabular}




\section{Appendix D: Palaeomagnetic Data}

\section{D1 - Magnetic Susceptibility with Temperature}

The magnetic susceptibility was measured between ambient temperature and $700^{\circ} \mathrm{C}$ was carried out on three samples from the Main Lower Unit Investigation (S10.3, S11.2 and S12.1) and one sample from the Preliminary Upper Unit Investigation (S19.1). The change in magnetic susceptibility with temperature measurements indicate that the ferrimagnetic minerals in the sample lose their magnetic susceptibility by $550^{\circ} \mathrm{C}$ suggesting a curie temperatures in the order of $550^{\circ} \mathrm{C}$ and a composition within the titanomagnetite series $\left(20 \% \mathrm{Fe}_{3} \mathrm{O}_{4}\right.$ to $\left.80 \% \mathrm{Fe}_{2} \mathrm{TiO}_{4}\right)$.
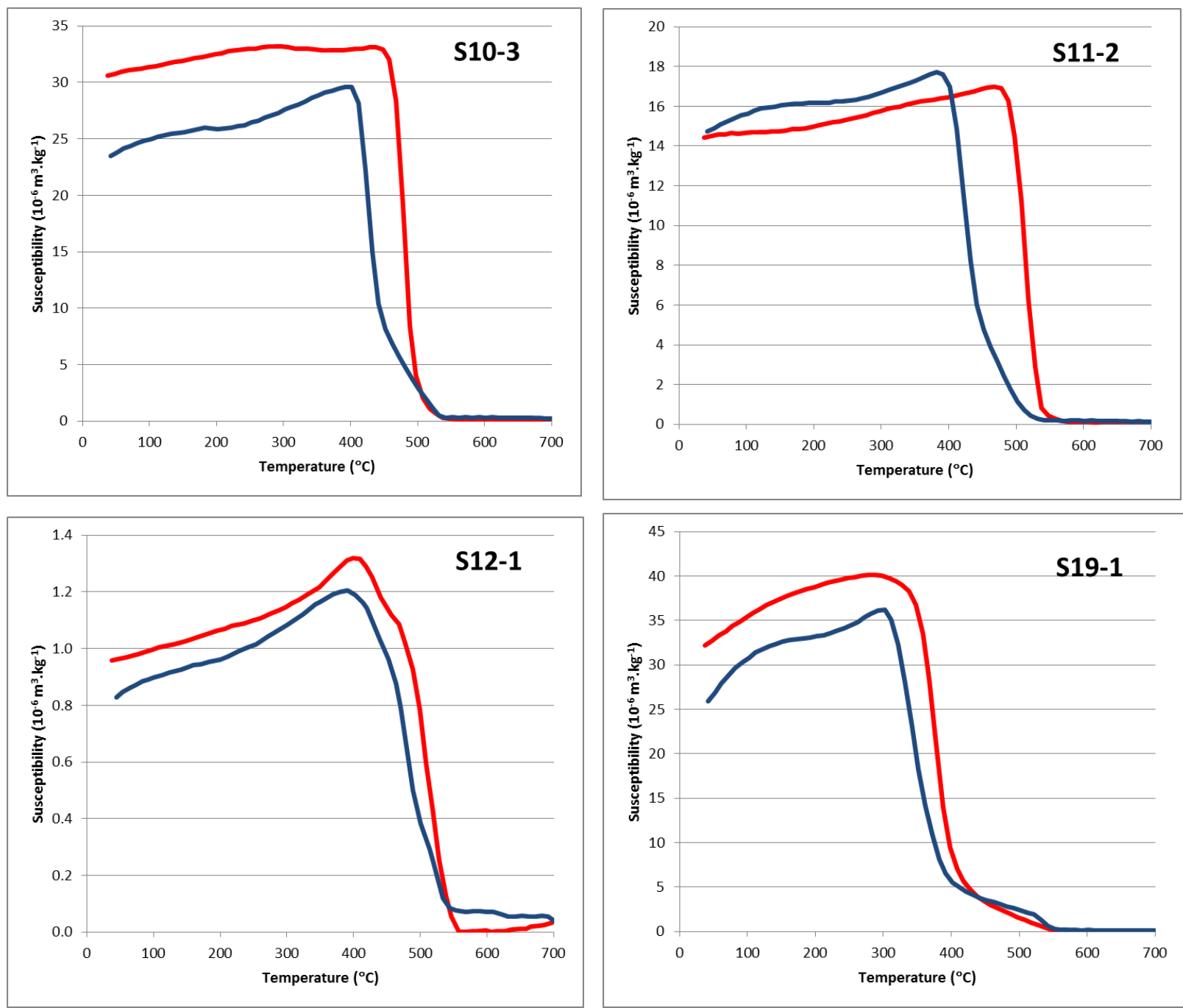


\section{D2 - Room Temperature Palaeomagnetic Susceptibility Dataset}

Room temperature magnetic susceptibility measurements were carried out between each thermal demagnetisation step. The following tables present the dataset from the Main Lower Unit Investigation and Preliminary Upper Unit Investigation. Data was collected using a Bartington Instruments Ltd MS2 Magnetic Susceptibility Meter.

\section{Main Lower Unit Investigation - Magnetic Susceptibility}

\begin{tabular}{|c|c|c|c|c|c|c|c|c|c|c|c|c|}
\hline Sample & 0 & 50 & 100 & 150 & 200 & 250 & 300 & 350 & 400 & 450 & 500 & 550 \\
\hline S3.1A & & 0.045 & 0.046 & 0.045 & 0.046 & 0.048 & 0.049 & 0.049 & 0.049 & 0.049 & 0.048 & 0.047 \\
\hline S3.1D & & 0.045 & 0.046 & 0.046 & 0.046 & 0.046 & 0.047 & 0.048 & 0.049 & 0.049 & 0.048 & 0.049 \\
\hline S3.3A & & 0.041 & 0.041 & 0.042 & 0.043 & 0.043 & 0.043 & 0.042 & 0.042 & 0.041 & 0.041 & 0.040 \\
\hline S3.3C & & 0.044 & 0.044 & 0.044 & 0.044 & 0.045 & 0.045 & 0.044 & 0.045 & 0.044 & 0.044 & 0.045 \\
\hline S4.2A & & 0.096 & 0.097 & 0.097 & 0.097 & 0.096 & 0.096 & 0.098 & & 0.094 & 0.090 & 0.085 \\
\hline S4.2C & & 0.097 & 0.098 & 0.098 & 0.098 & 0.098 & 0.098 & & & 0.097 & 0.091 & 0.087 \\
\hline S4.3A & & 0.093 & 0.093 & 0.094 & 0.094 & 0.094 & 0.094 & 0.096 & 0.099 & 0.093 & 0.088 & 0.083 \\
\hline S4.3C & & 0.090 & 0.092 & 0.091 & 0.091 & 0.091 & 0.091 & 0.093 & 0.095 & 0.091 & 0.085 & 0.080 \\
\hline S5.1A & & 0.091 & 0.092 & 0.090 & 0.089 & 0.086 & 0.084 & 0.081 & 0.081 & 0.078 & 0.075 & 0.073 \\
\hline S5.1B & & 0.088 & 0.089 & 0.087 & 0.087 & 0.085 & 0.083 & 0.081 & 0.081 & 0.077 & 0.075 & 0.073 \\
\hline S5.2A & & 0.087 & 0.087 & 0.086 & 0.085 & 0.082 & 0.080 & 0.078 & 0.078 & 0.075 & 0.072 & 0.072 \\
\hline S5.2B & 0.087 & 0.087 & 0.087 & 0.087 & 0.085 & 0.083 & 0.080 & 0.079 & 0.079 & 0.075 & 0.071 & 0.069 \\
\hline S7.1A & 0.088 & 0.088 & 0.089 & 0.089 & 0.088 & 0.088 & 0.087 & 0.084 & 0.082 & 0.078 & 0.078 & 0.076 \\
\hline S7.1C & 0.089 & 0.089 & 0.089 & 0.089 & 0.089 & 0.089 & 0.087 & 0.084 & 0.082 & 0.077 & 0.077 & 0.074 \\
\hline S7.3A & 0.075 & 0.076 & 0.076 & 0.075 & 0.075 & 0.075 & 0.075 & 0.072 & 0.071 & 0.068 & 0.070 & 0.068 \\
\hline S7.3B & 0.077 & 0.077 & 0.077 & 0.077 & 0.077 & 0.077 & 0.076 & 0.074 & 0.072 & 0.069 & 0.071 & 0.069 \\
\hline S10.1A & 0.079 & 0.080 & 0.080 & 0.080 & 0.079 & 0.078 & 0.075 & 0.072 & 0.073 & 0.071 & 0.071 & 0.070 \\
\hline S10.1B & 0.080 & 0.080 & 0.080 & 0.080 & 0.079 & 0.079 & 0.077 & 0.073 & 0.073 & 0.071 & 0.072 & 0.070 \\
\hline S10.3A & 0.075 & 0.075 & 0.076 & 0.076 & 0.074 & 0.074 & 0.071 & 0.069 & 0.068 & 0.067 & 0.068 & 0.066 \\
\hline $\mathrm{S} 10.3 \mathrm{C}$ & 0.082 & 0.083 & 0.082 & 0.082 & 0.082 & 0.081 & 0.079 & 0.076 & 0.077 & 0.073 & 0.075 & 0.073 \\
\hline S11.1A & 0.040 & 0.040 & 0.040 & 0.040 & 0.040 & 0.040 & 0.040 & 0.040 & 0.040 & 0.038 & 0.040 & 0.042 \\
\hline S11.1C & 0.041 & 0.041 & 0.041 & 0.041 & 0.041 & 0.041 & 0.041 & 0.040 & 0.040 & 0.039 & 0.039 & 0.042 \\
\hline S11.2A & & 0.037 & 0.038 & & 0.037 & 0.037 & 0.037 & 0.037 & 0.037 & 0.035 & 0.037 & 0.038 \\
\hline S11.2D & & 0.042 & 0.042 & & 0.042 & 0.042 & 0.042 & 0.042 & 0.041 & 0.040 & 0.042 & 0.043 \\
\hline S12.1A & & 0.003 & 0.003 & & 0.003 & 0.003 & 0.003 & 0.003 & 0.003 & 0.003 & 0.003 & 0.003 \\
\hline S12.1C & & 0.002 & 0.002 & & 0.002 & 0.002 & 0.002 & 0.002 & 0.002 & 0.002 & 0.002 & 0.002 \\
\hline S12.2A & & 0.002 & 0.003 & & 0.003 & 0.003 & 0.003 & 0.003 & 0.003 & 0.003 & 0.003 & 0.003 \\
\hline S12.2B & & 0.002 & 0.002 & & 0.003 & 0.003 & 0.003 & 0.003 & 0.003 & 0.003 & 0.003 & 0.003 \\
\hline S15.1A & & 0.075 & 0.075 & & 0.076 & 0.076 & 0.075 & 0.077 & 0.077 & 0.074 & 0.071 & 0.065 \\
\hline S15.1C & & 0.062 & 0.062 & & 0.063 & 0.062 & 0.063 & 0.064 & 0.064 & 0.063 & 0.059 & 0.055 \\
\hline S15.3A & & 0.072 & 0.073 & & 0.073 & 0.073 & 0.072 & 0.074 & 0.074 & 0.072 & 0.068 & 0.064 \\
\hline S15.3C & & 0.060 & 0.059 & & 0.060 & 0.059 & 0.059 & 0.060 & 0.061 & 0.060 & 0.057 & 0.054 \\
\hline
\end{tabular}


Preliminary Upper Unit Investigation - Magnetic Susceptibility

\begin{tabular}{|c|c|c|c|c|c|c|c|c|c|c|c|c|}
\hline Sample & 0 & 50 & 100 & 150 & 200 & 250 & 300 & 350 & 400 & 450 & 500 & 550 \\
\hline S16.1A & 0.088 & 0.088 & 0.089 & 0.089 & 0.089 & 0.089 & 0.088 & 0.088 & 0.087 & 0.083 & 0.079 & 0.078 \\
\hline S16.1B & 0.085 & 0.084 & 0.086 & 0.086 & 0.087 & 0.085 & 0.085 & 0.083 & 0.083 & 0.079 & 0.075 & 0.074 \\
\hline S16.3A & 0.090 & 0.091 & 0.090 & 0.092 & 0.093 & 0.090 & 0.090 & 0.087 & 0.088 & 0.083 & 0.079 & 0.078 \\
\hline S16.3B & 0.079 & 0.079 & 0.080 & 0.081 & 0.081 & 0.080 & 0.079 & 0.077 & 0.077 & 0.073 & 0.070 & 0.068 \\
\hline S17.1B & 0.083 & 0.083 & 0.085 & 0.086 & 0.087 & 0.088 & 0.087 & 0.086 & 0.087 & 0.086 & 0.079 & 0.072 \\
\hline S17.1C & 0.064 & 0.064 & 0.065 & 0.066 & 0.067 & 0.065 & 0.065 & 0.065 & 0.066 & 0.065 & 0.060 & 0.054 \\
\hline S17.3B & 0.087 & 0.086 & 0.088 & 0.090 & 0.089 & 0.090 & 0.089 & 0.089 & 0.089 & 0.085 & 0.079 & 0.071 \\
\hline S17.3C & 0.083 & 0.082 & 0.083 & 0.084 & 0.085 & 0.085 & 0.084 & 0.083 & 0.083 & 0.080 & 0.073 & 0.066 \\
\hline S18.1A & 0.052 & 0.052 & 0.053 & 0.055 & 0.057 & 0.056 & 0.056 & 0.053 & 0.052 & 0.052 & 0.053 & 0.050 \\
\hline S18.1C & 0.077 & 0.077 & 0.078 & 0.079 & 0.079 & 0.078 & 0.077 & 0.068 & 0.067 & 0.065 & 0.062 & 0.056 \\
\hline S18.2B & 0.066 & 0.066 & 0.067 & 0.070 & 0.071 & 0.070 & 0.068 & 0.062 & 0.061 & 0.060 & 0.058 & 0.055 \\
\hline $\mathrm{S} 18.2 \mathrm{C}$ & 0.054 & 0.053 & 0.055 & 0.058 & 0.058 & 0.057 & 0.056 & 0.053 & 0.053 & 0.053 & 0.051 & 0.051 \\
\hline S19.1A & 0.073 & 0.072 & 0.073 & 0.074 & 0.072 & 0.070 & 0.072 & 0.071 & 0.070 & 0.066 & 0.063 & 0.062 \\
\hline S19.1B & 0.090 & 0.090 & 0.092 & 0.093 & 0.093 & 0.091 & 0.092 & 0.093 & 0.089 & 0.086 & 0.080 & 0.078 \\
\hline S19.3A & 0.093 & 0.092 & 0.094 & 0.095 & 0.096 & 0.092 & 0.093 & 0.092 & 0.088 & 0.086 & 0.078 & 0.075 \\
\hline S19.3B & 0.088 & 0.089 & 0.089 & 0.090 & 0.090 & 0.087 & 0.088 & 0.088 & 0.083 & 0.078 & 0.073 & 0.071 \\
\hline
\end{tabular}




\section{D3 - Main Lower Unit Investigation Results}

Lambert (equal area) stereoplots, Zijderveld diagrams and Remanent magnetisation intensity versus temperature plots for the specimens analysed in the Main Lower Unit Investigation. 

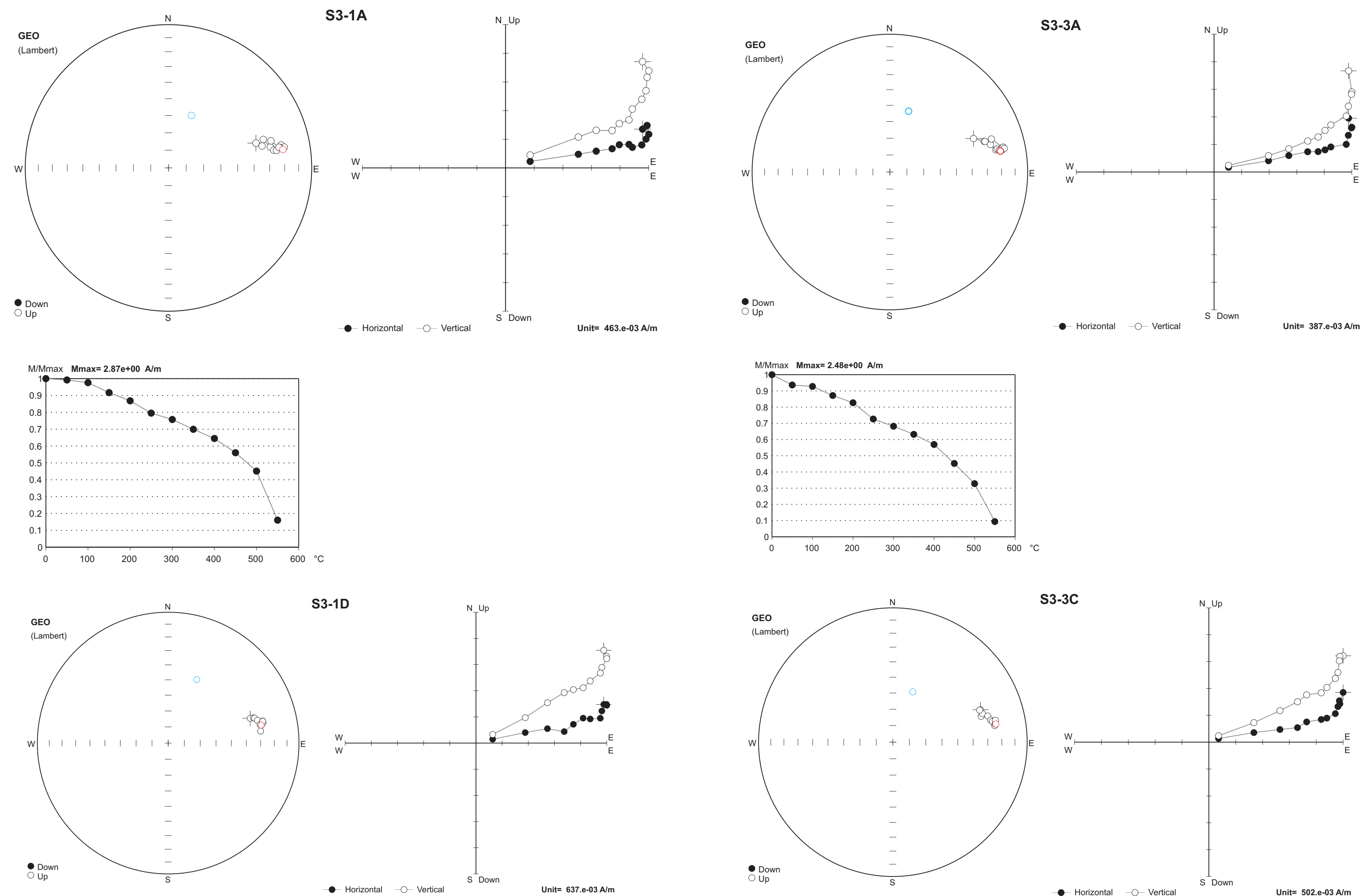

$\stackrel{0}{0}$
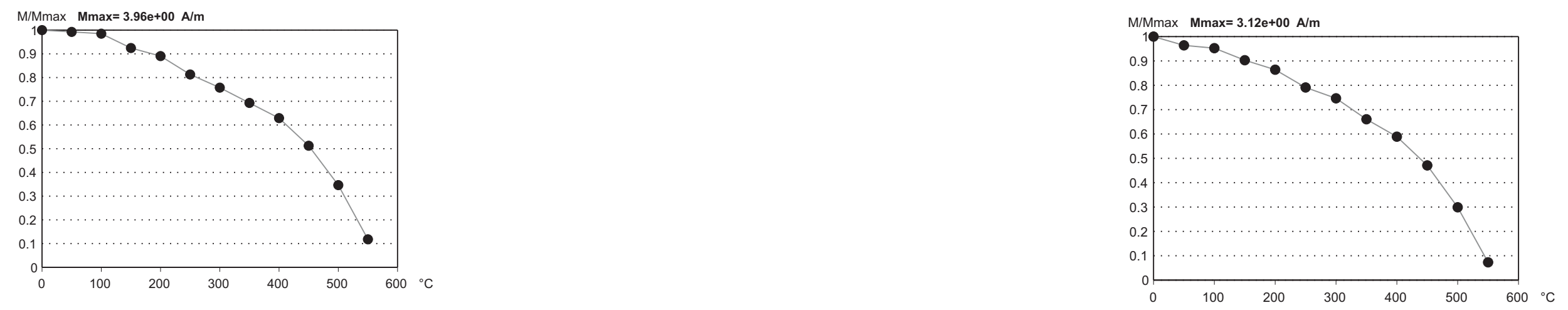


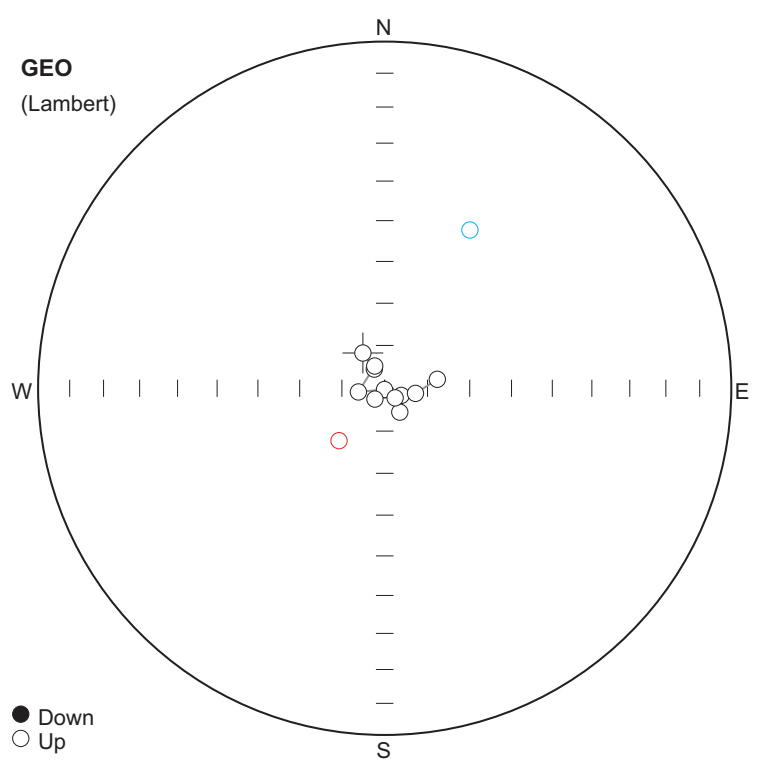

S4-2A
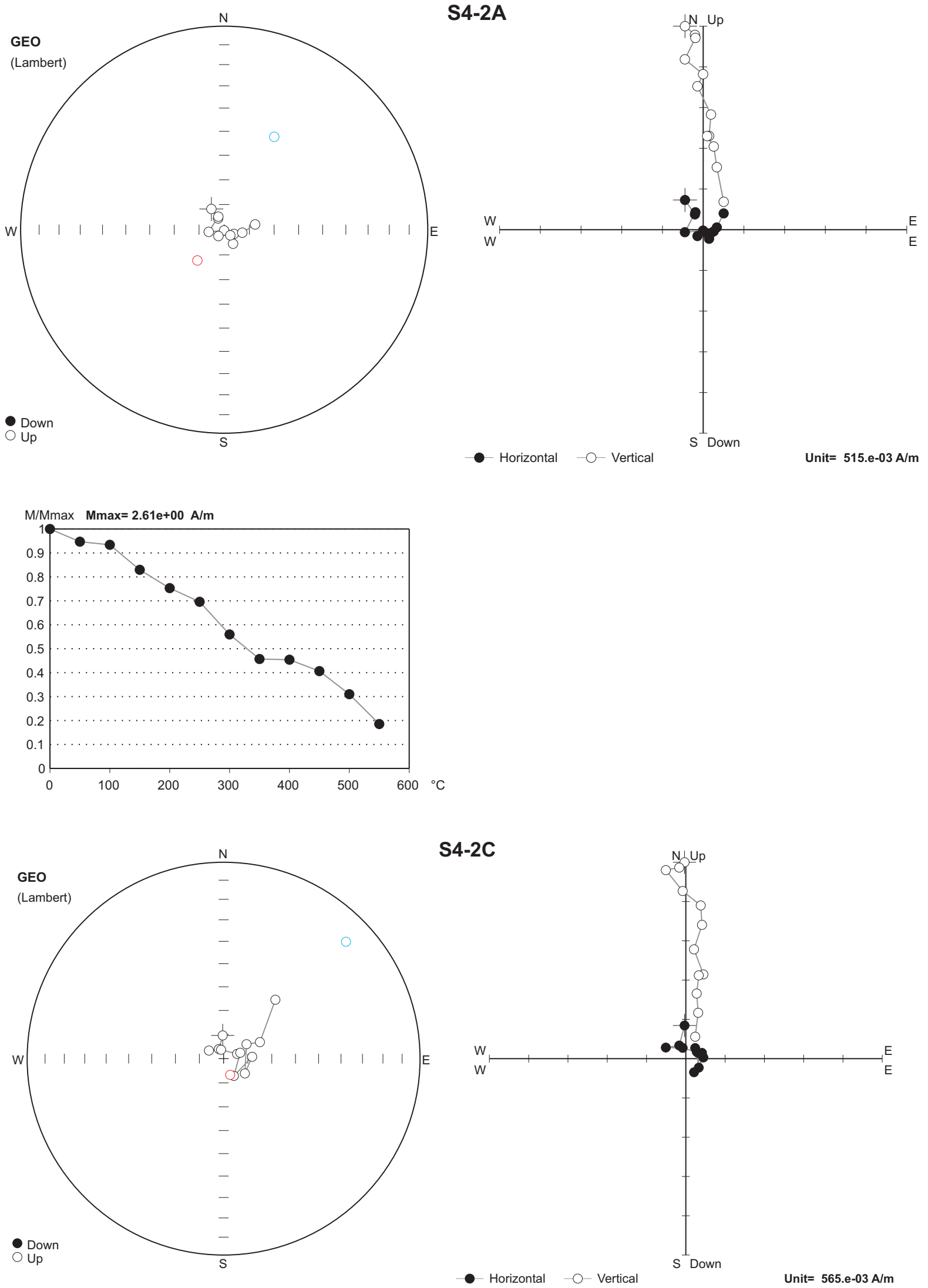

옴

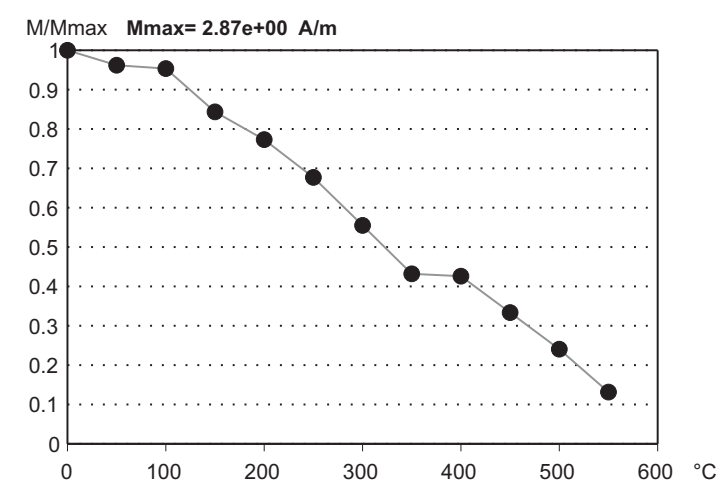

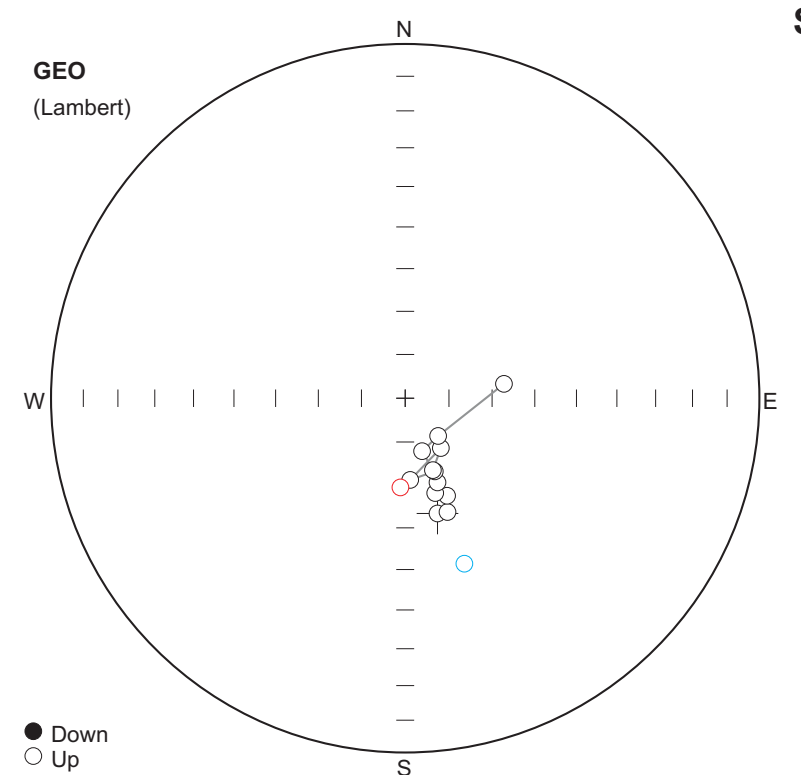

S4-3A
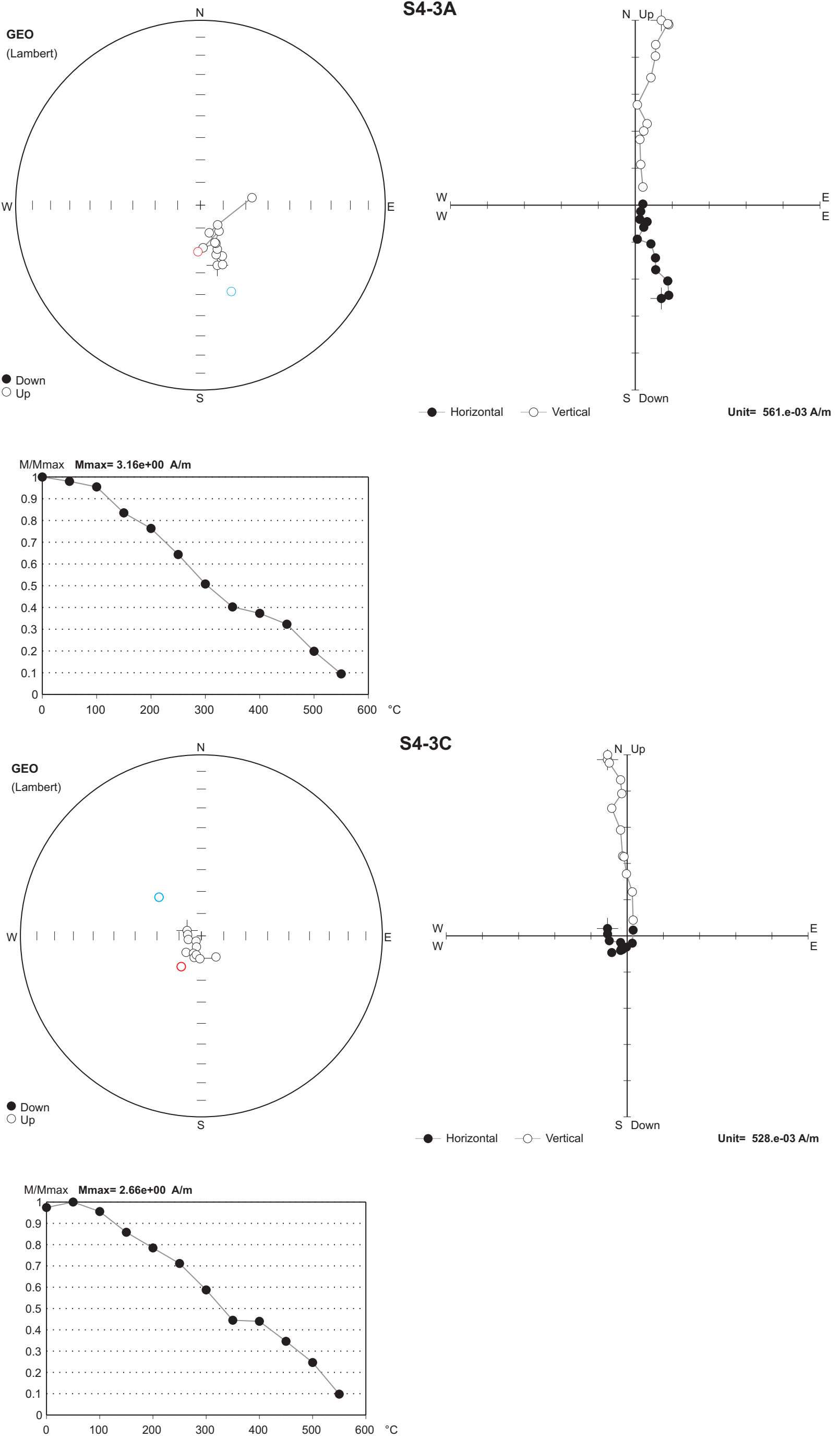

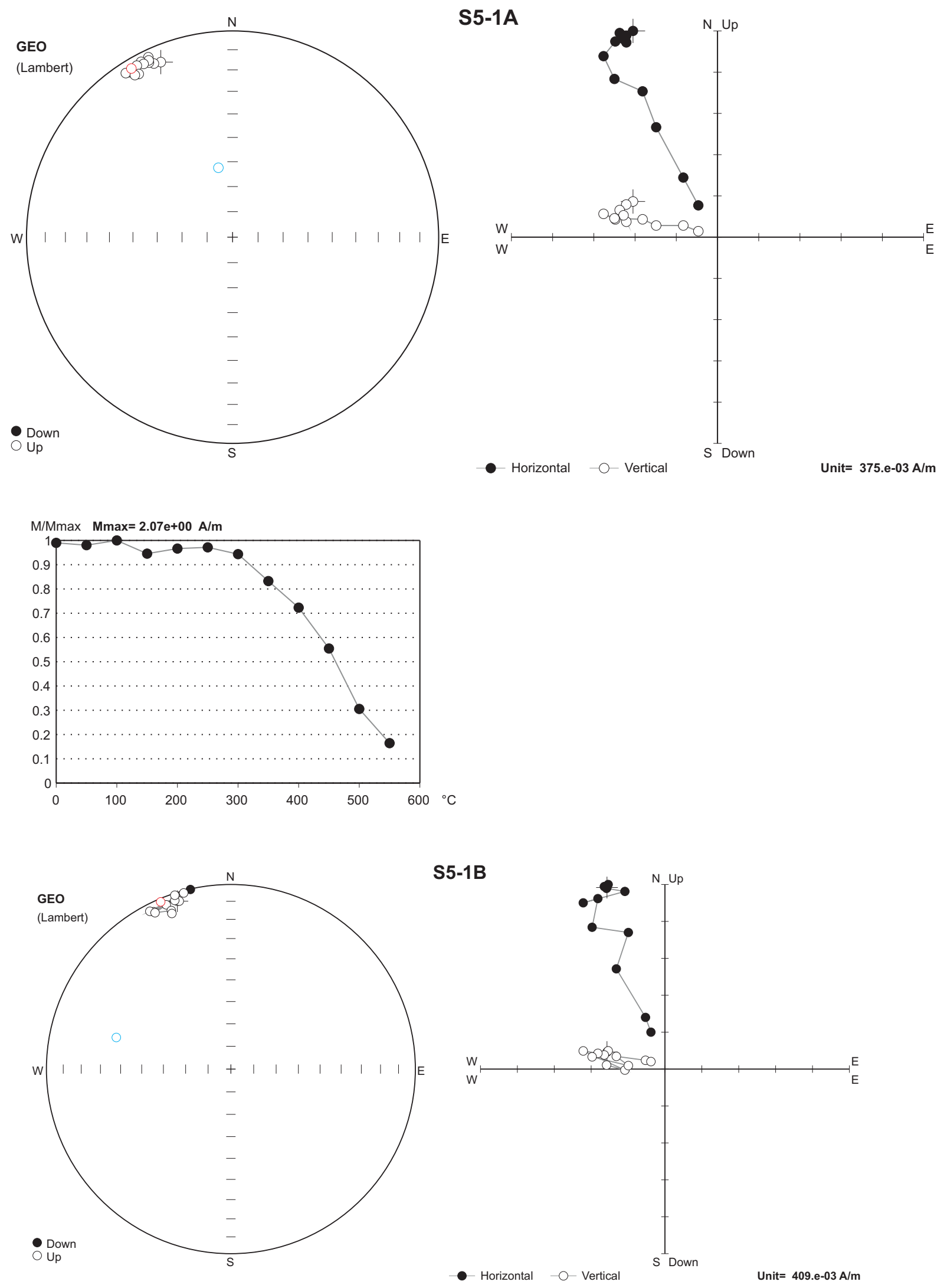

이

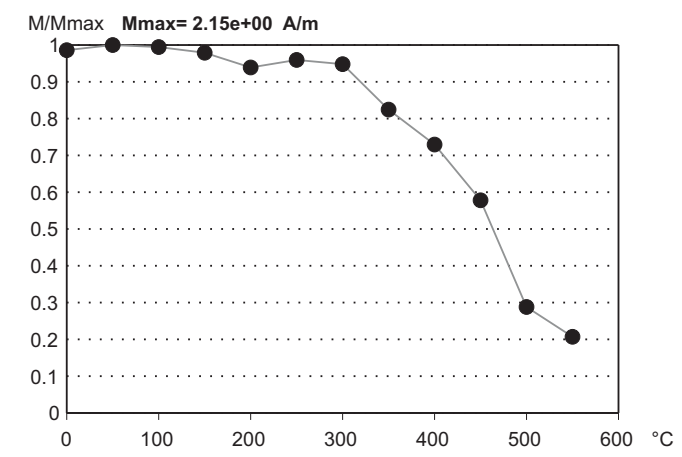

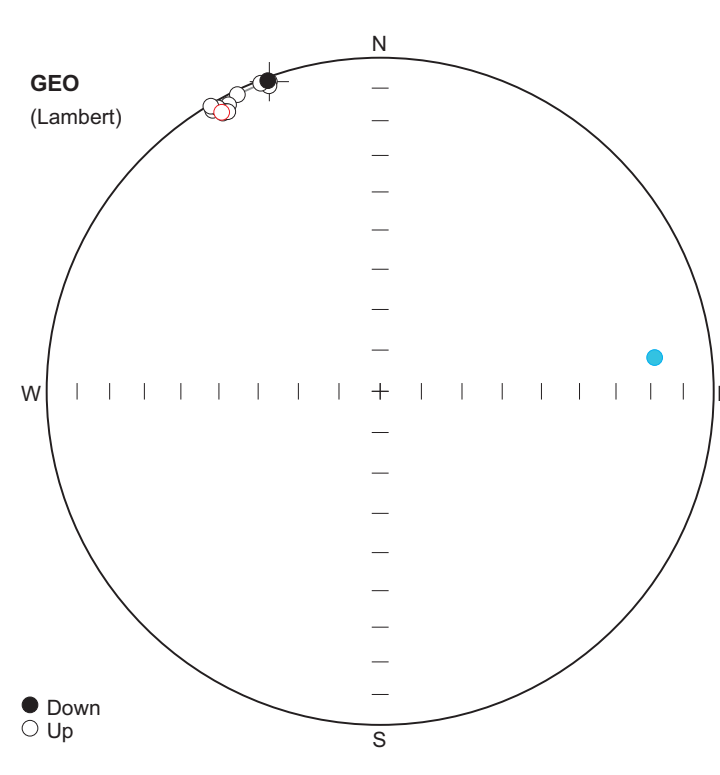
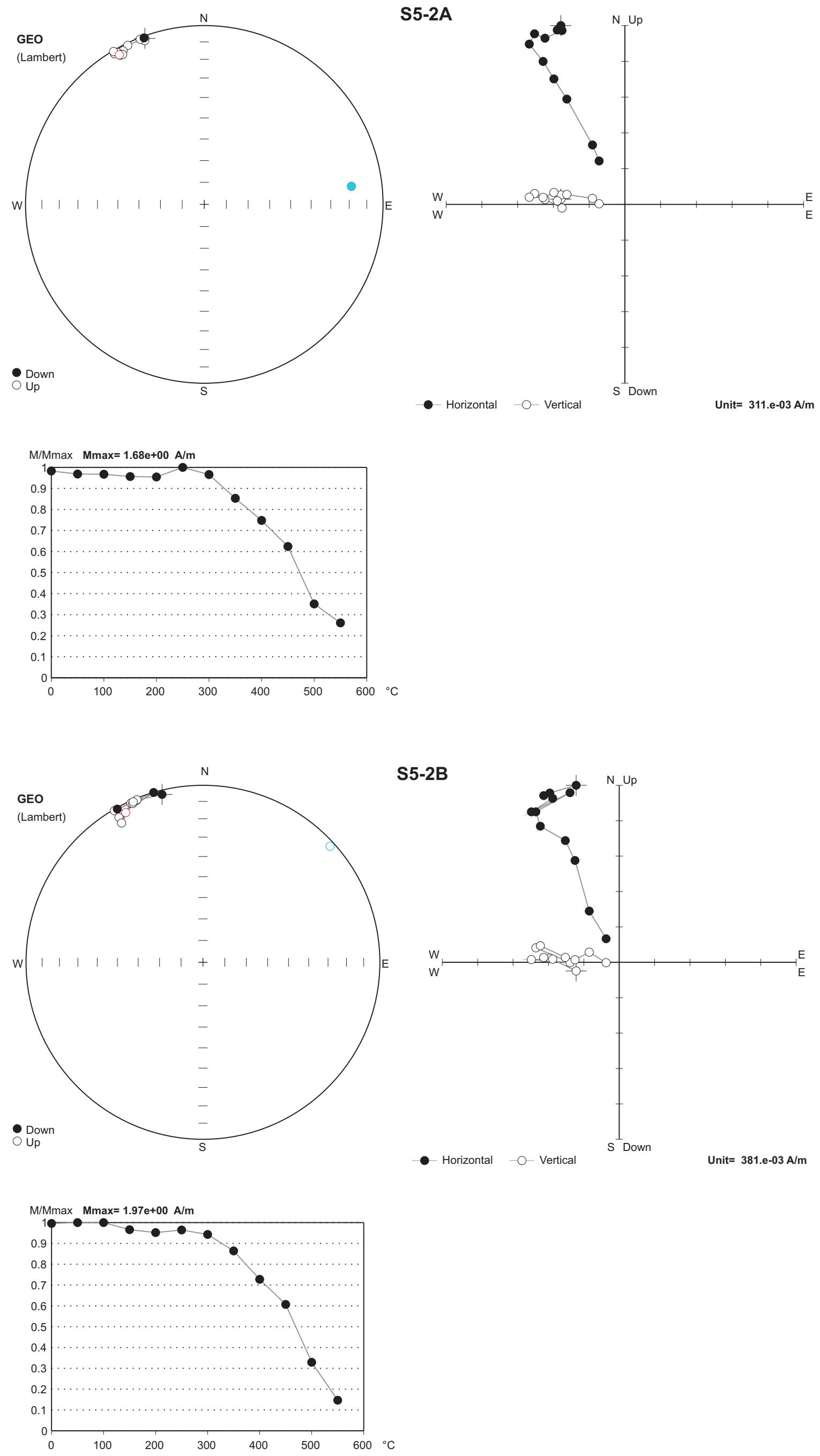


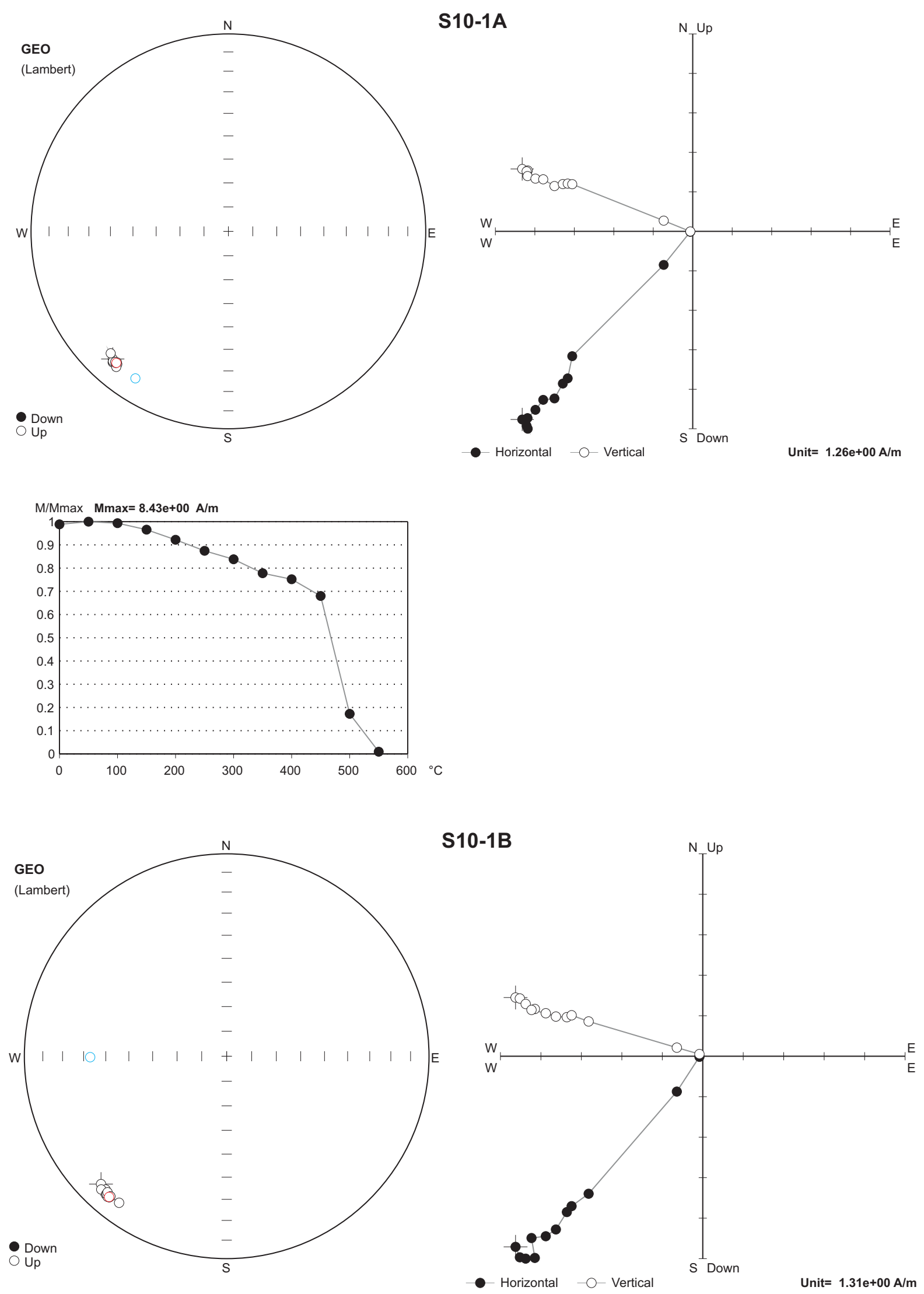

ัํ

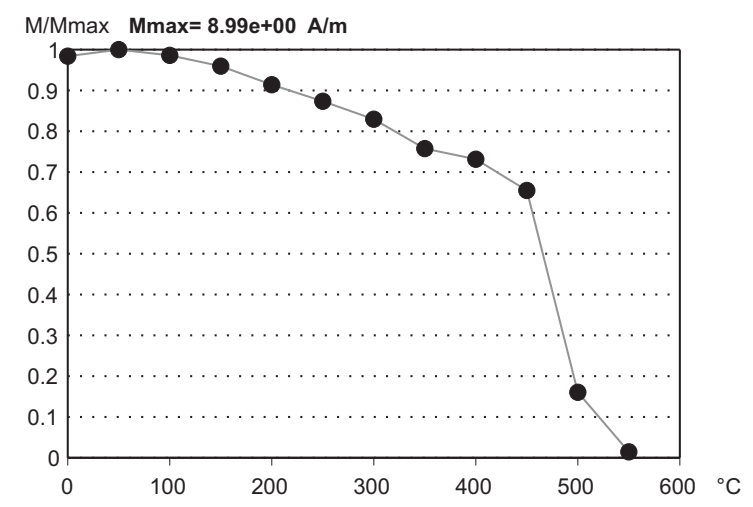

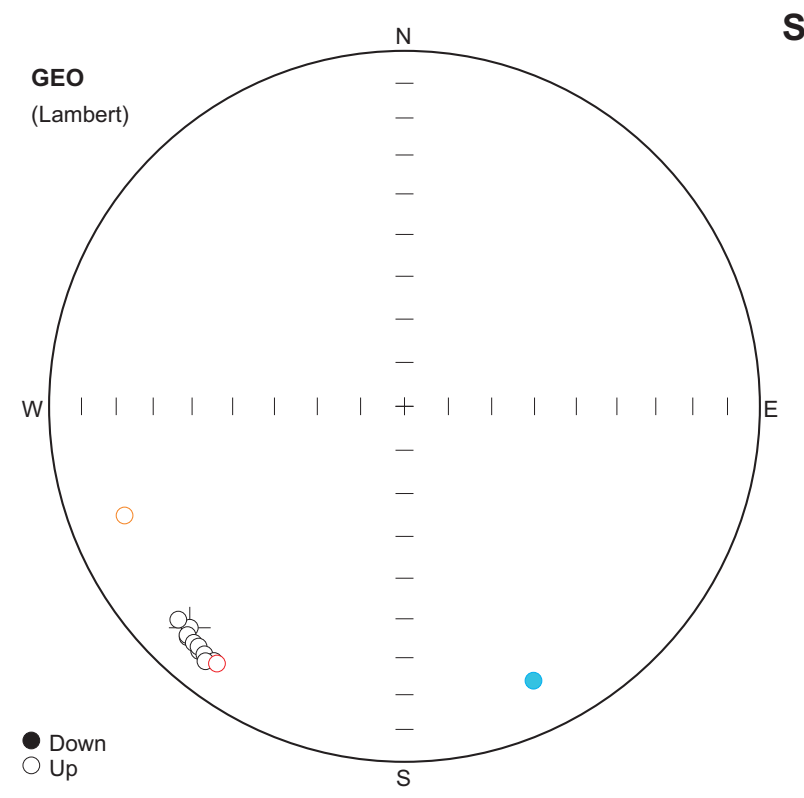
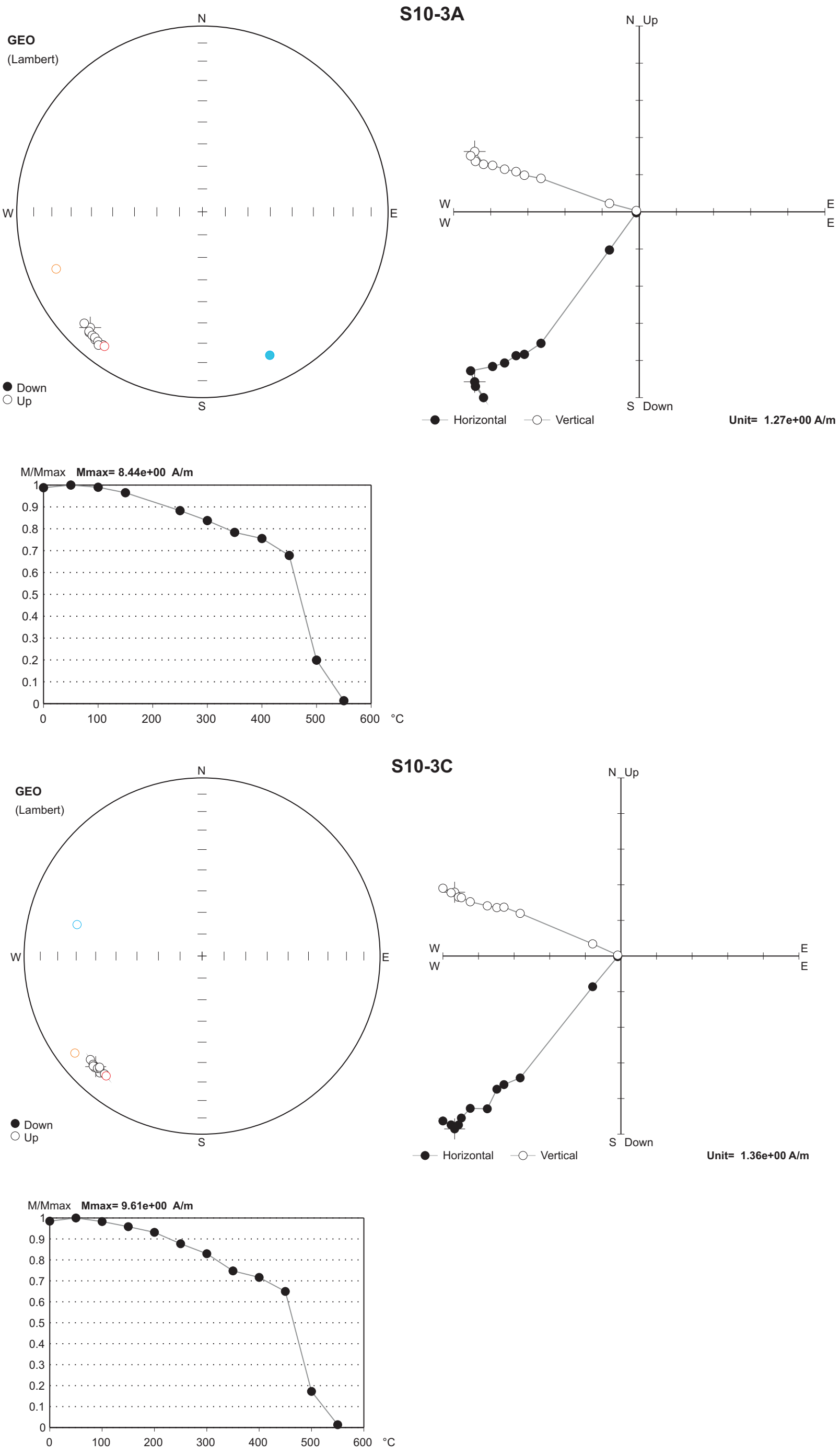

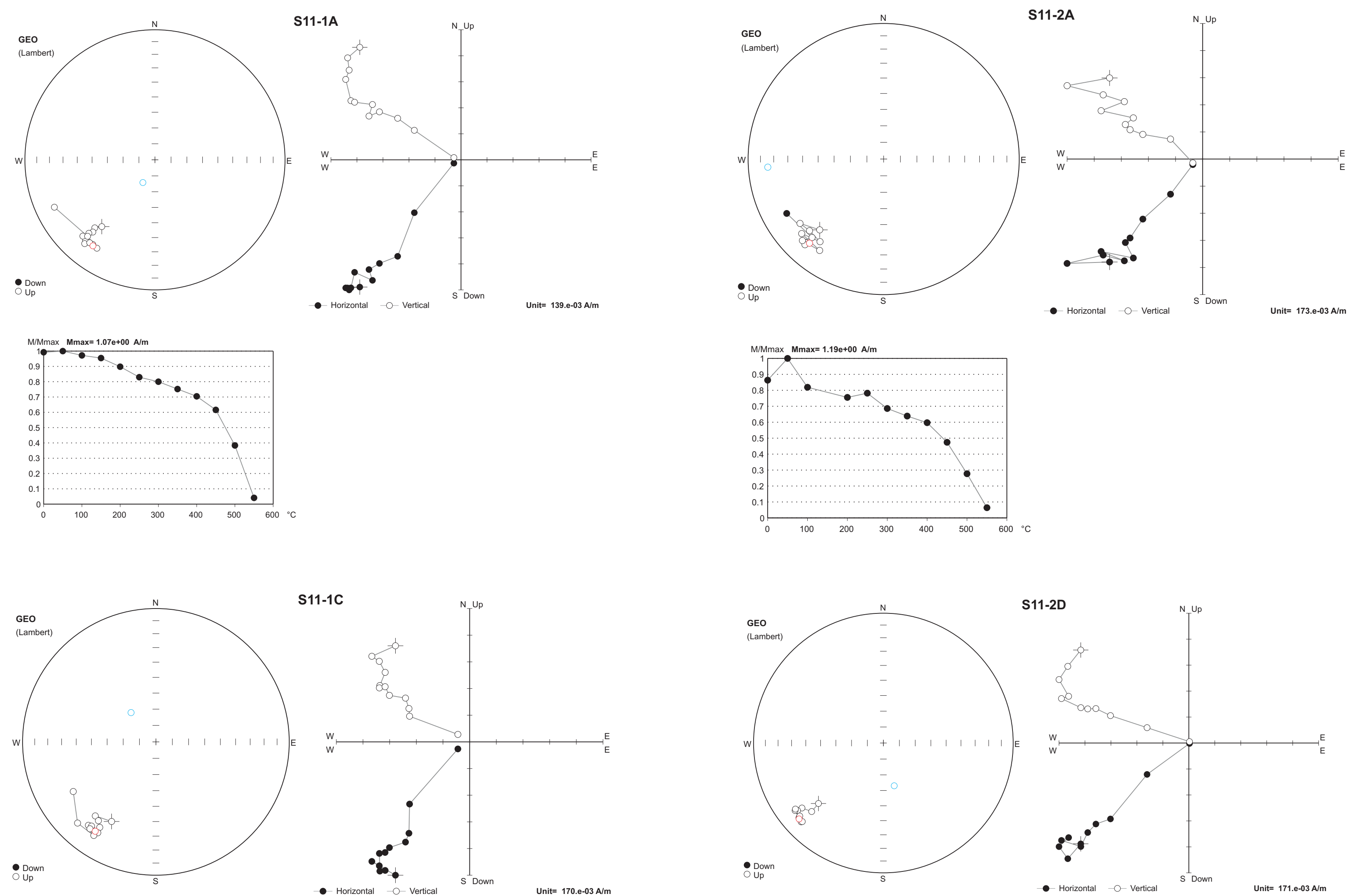

ㅇํㅇ
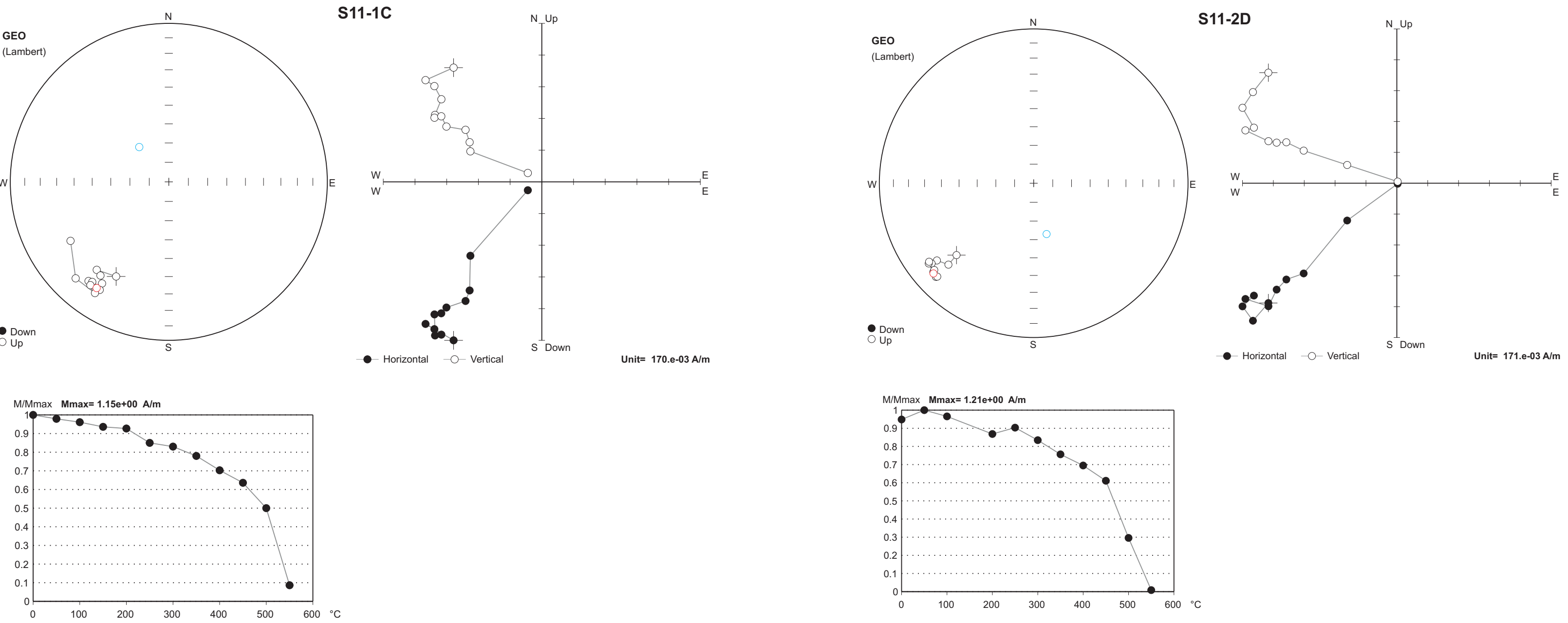

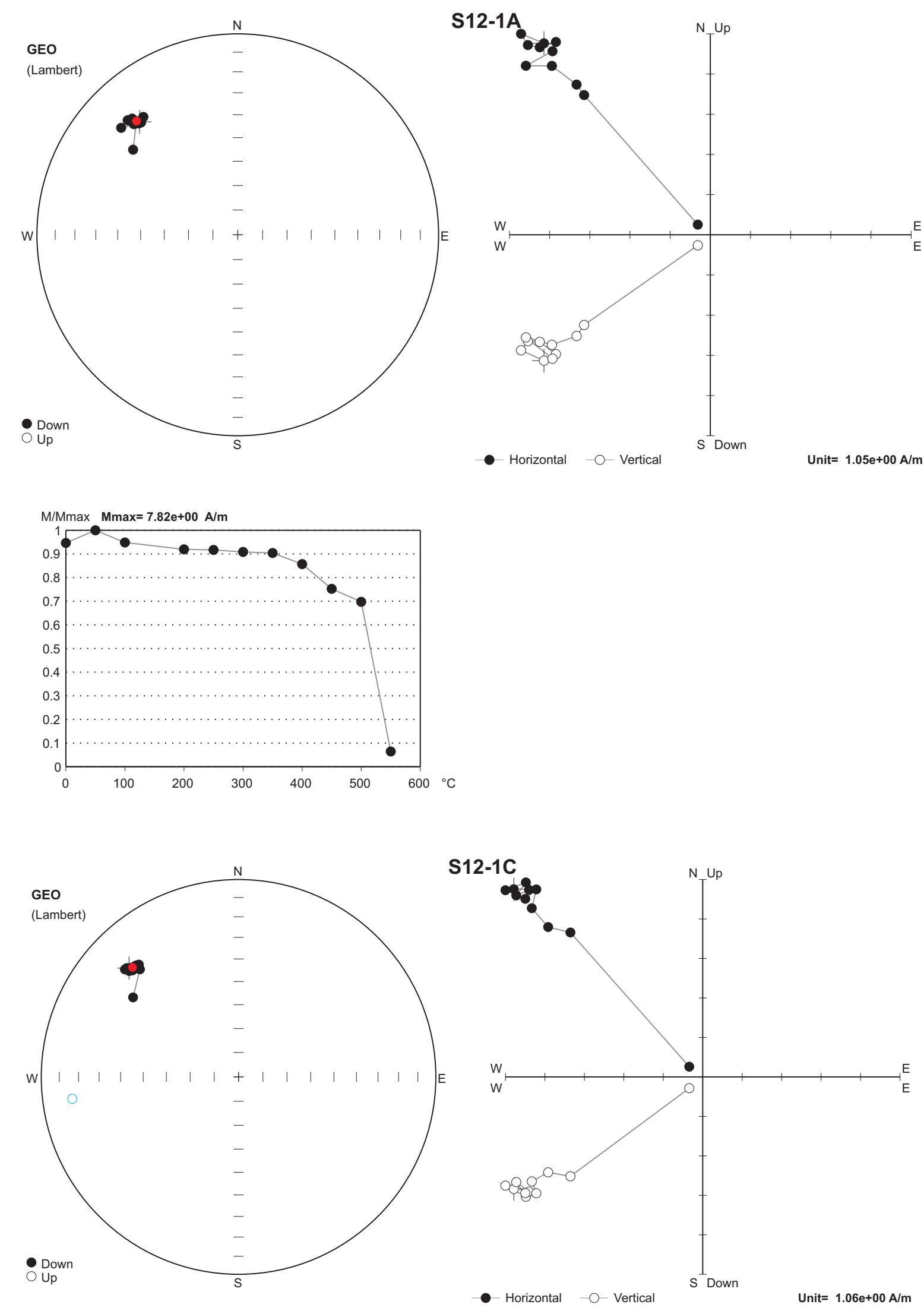

ㅇํำ
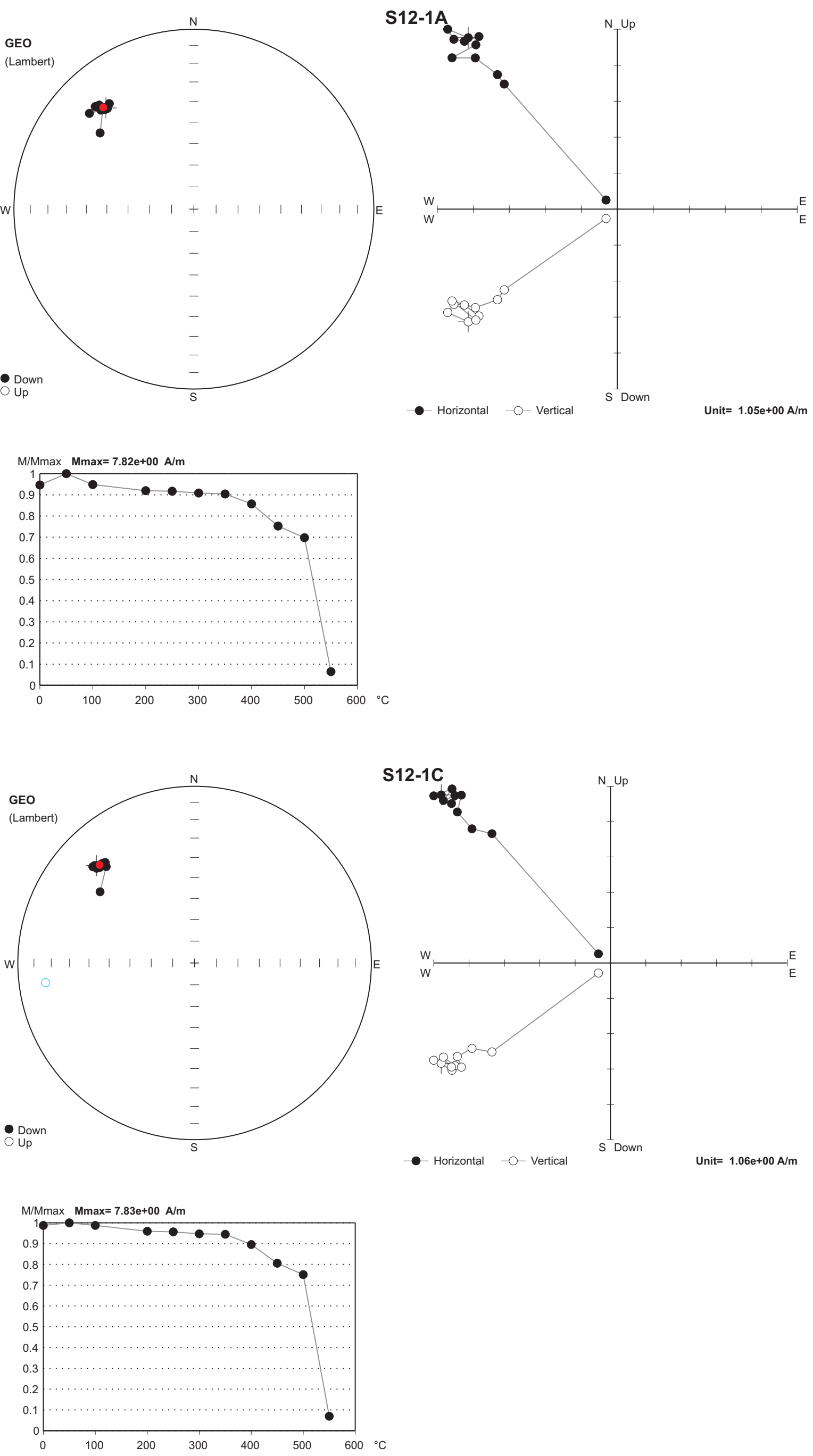
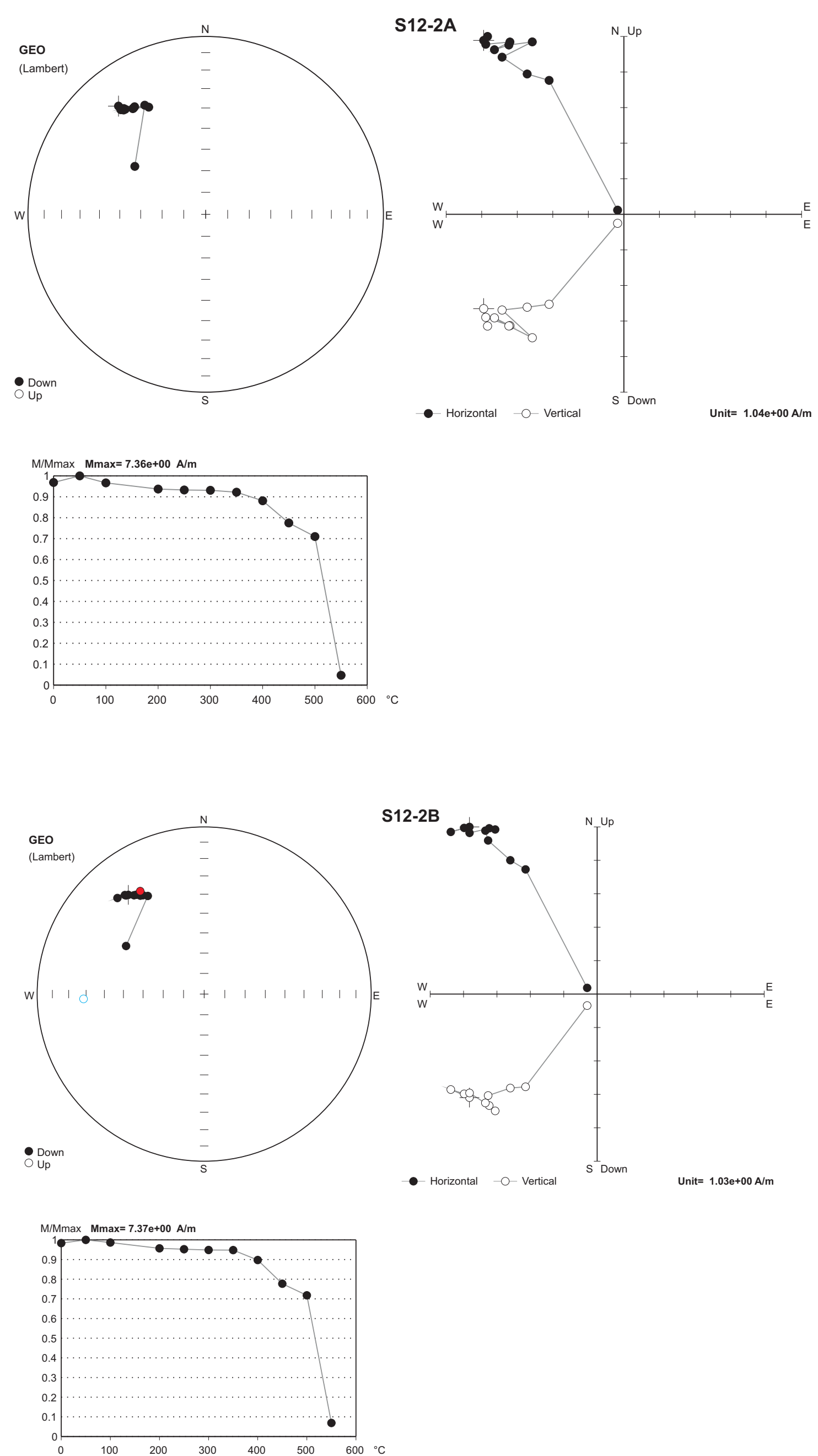

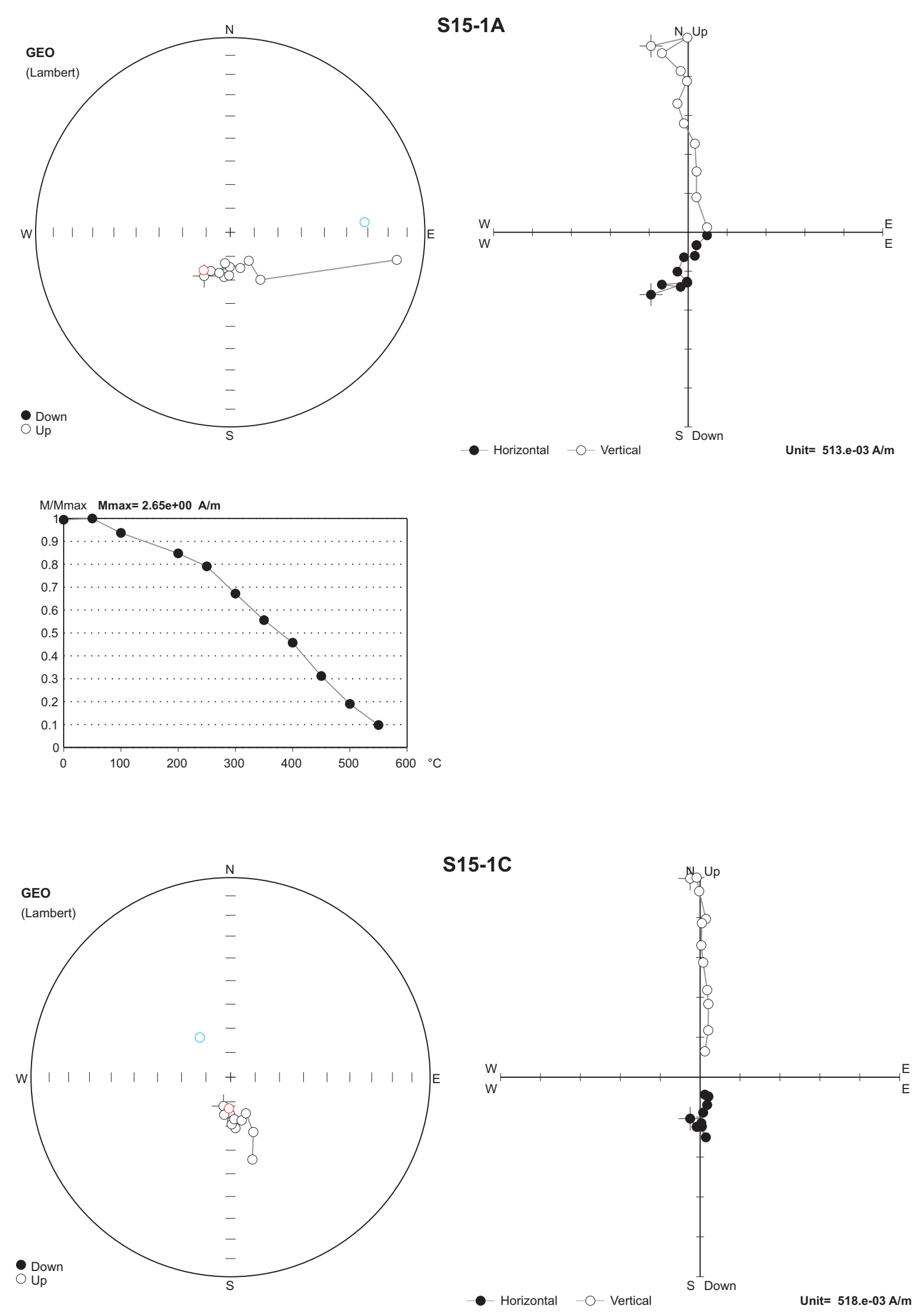

잉

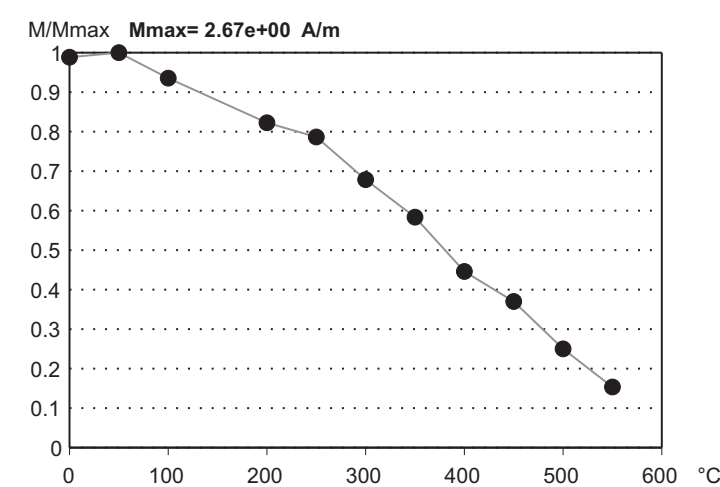

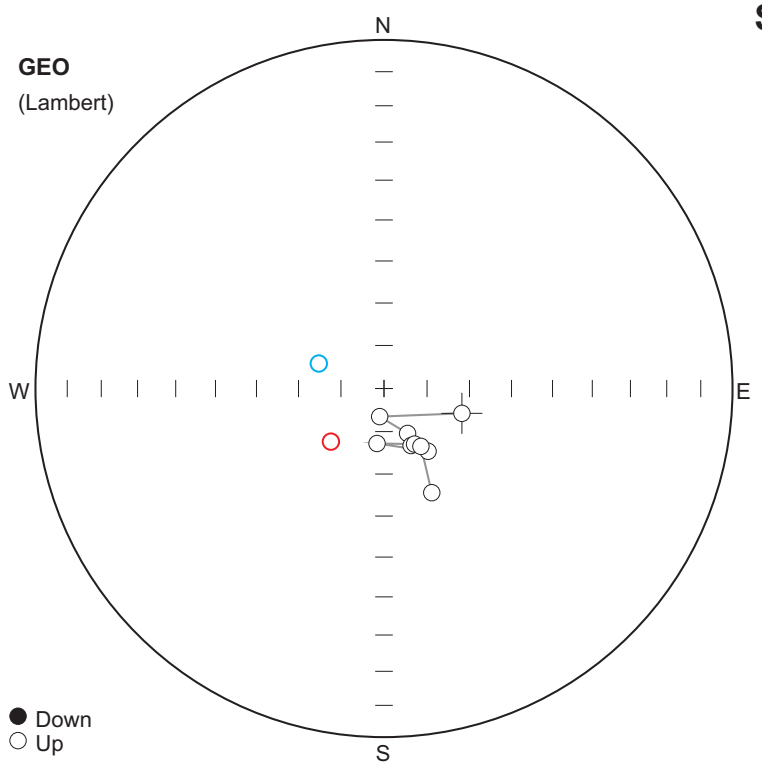
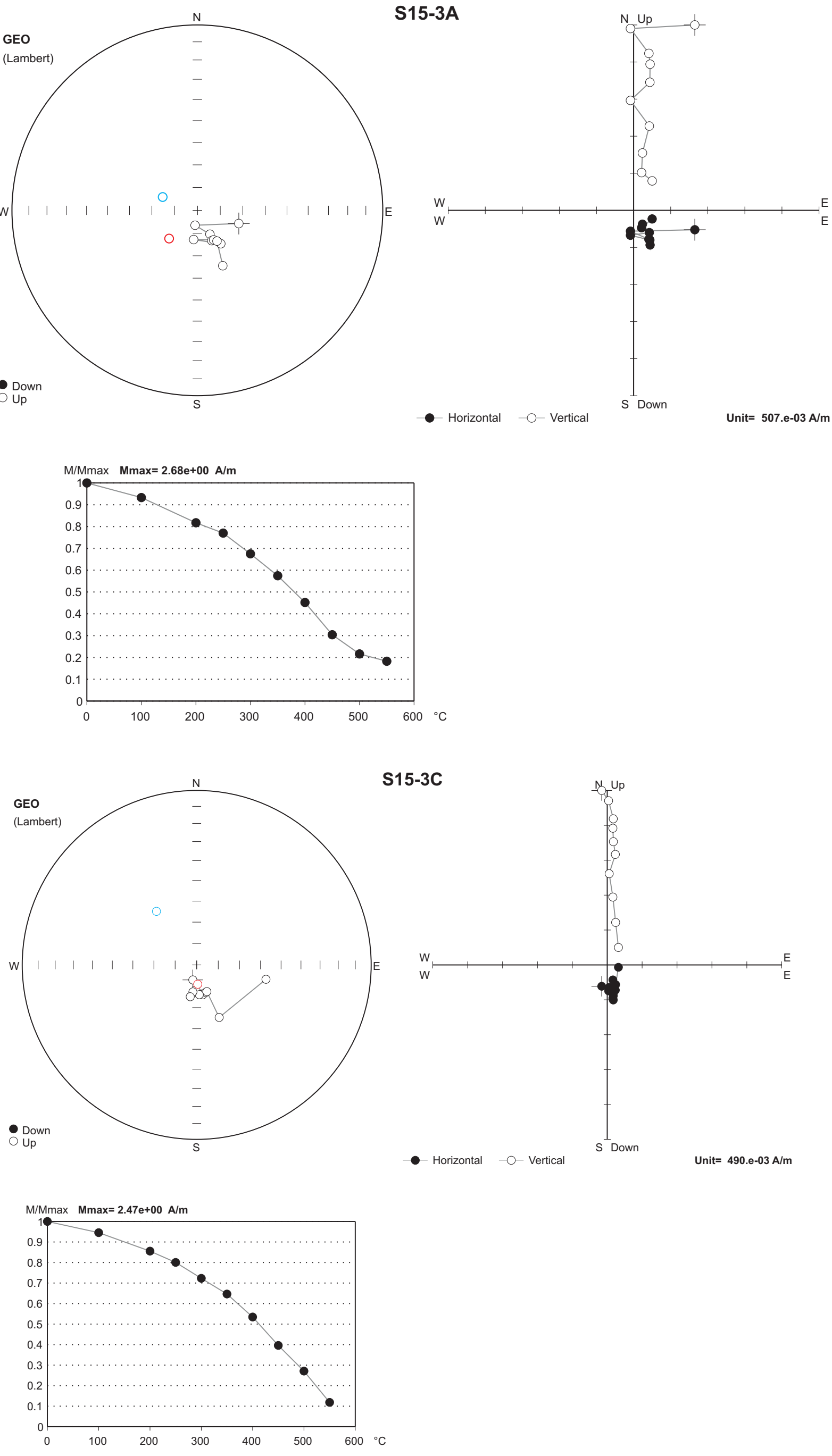


\section{D4 - Preliminary Upper Unit Investigation Results}

Lambert (equal area) stereoplots, Zijderveld diagrams and Remanent magnetisation intensity versus temperature plots for the specimens analysed in the Preliminary Upper Unit Investigation. 


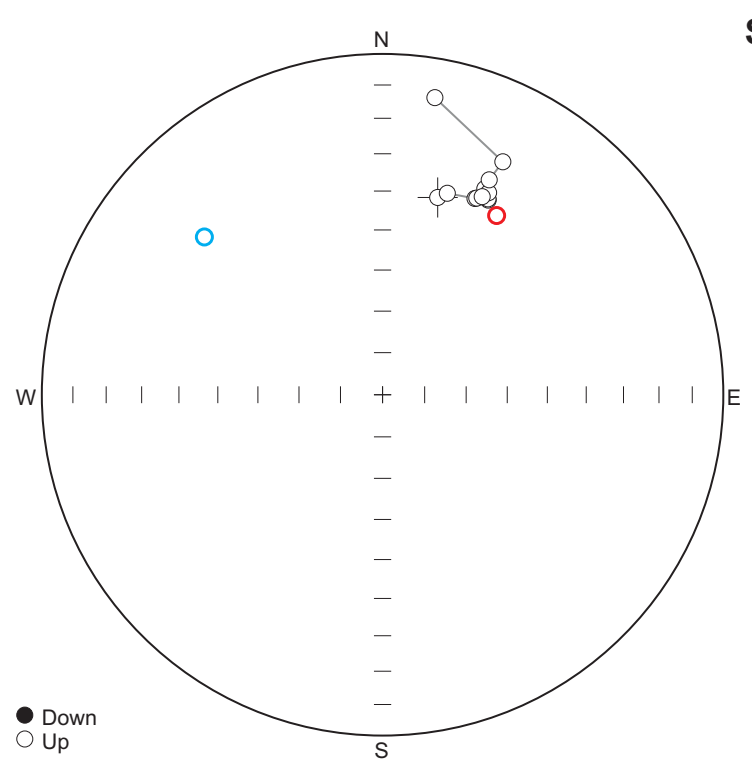

S16-1A
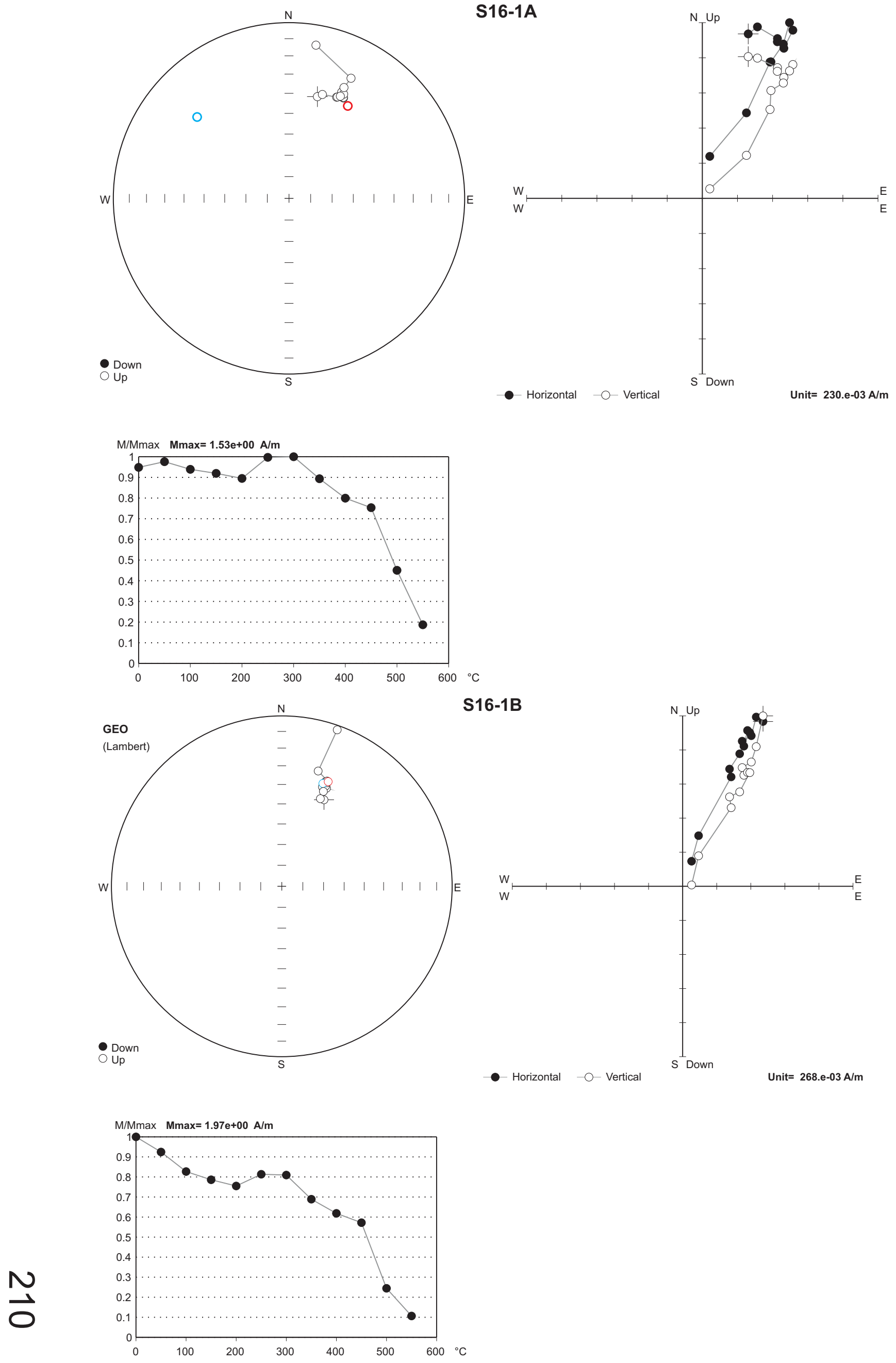
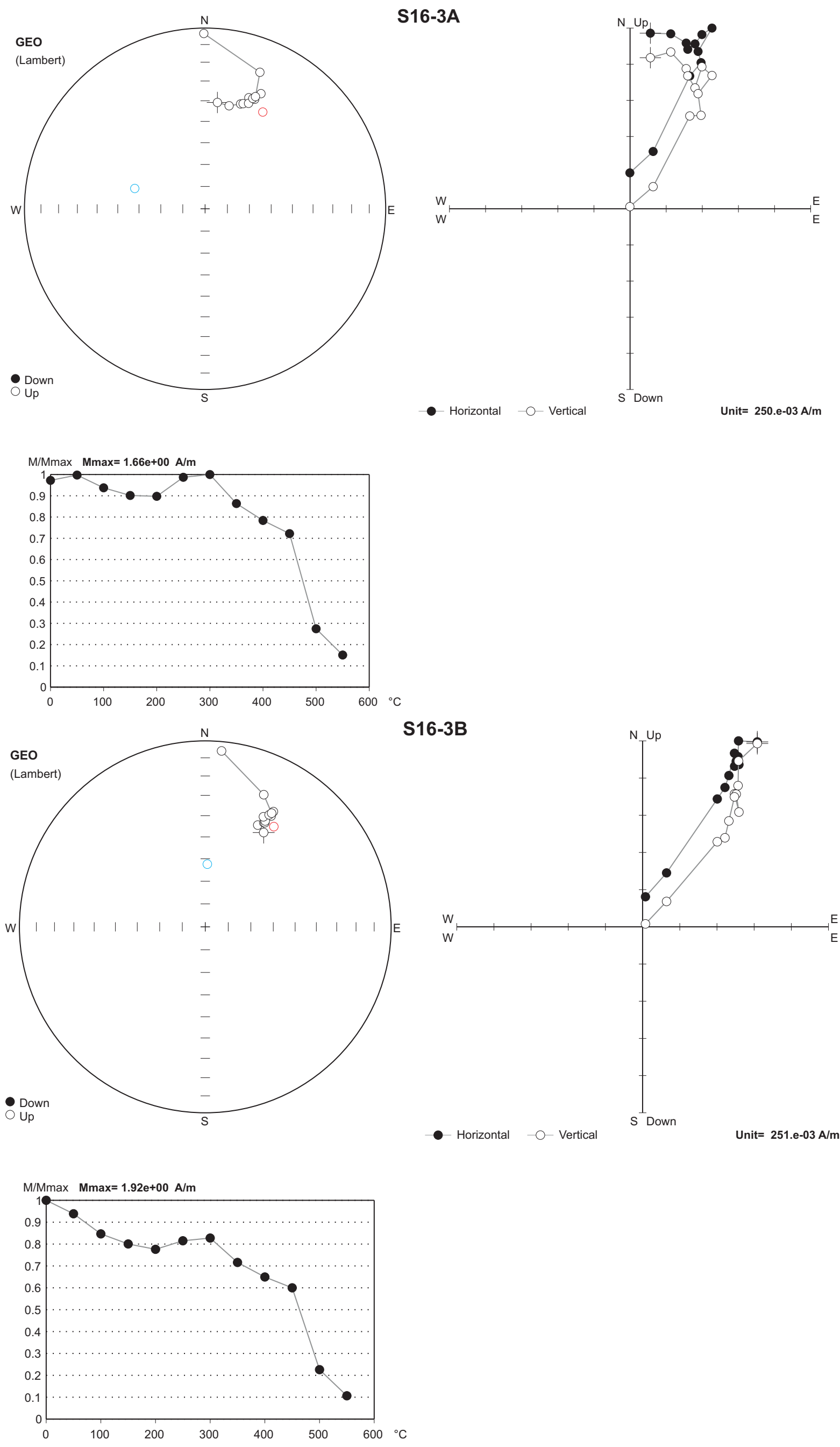

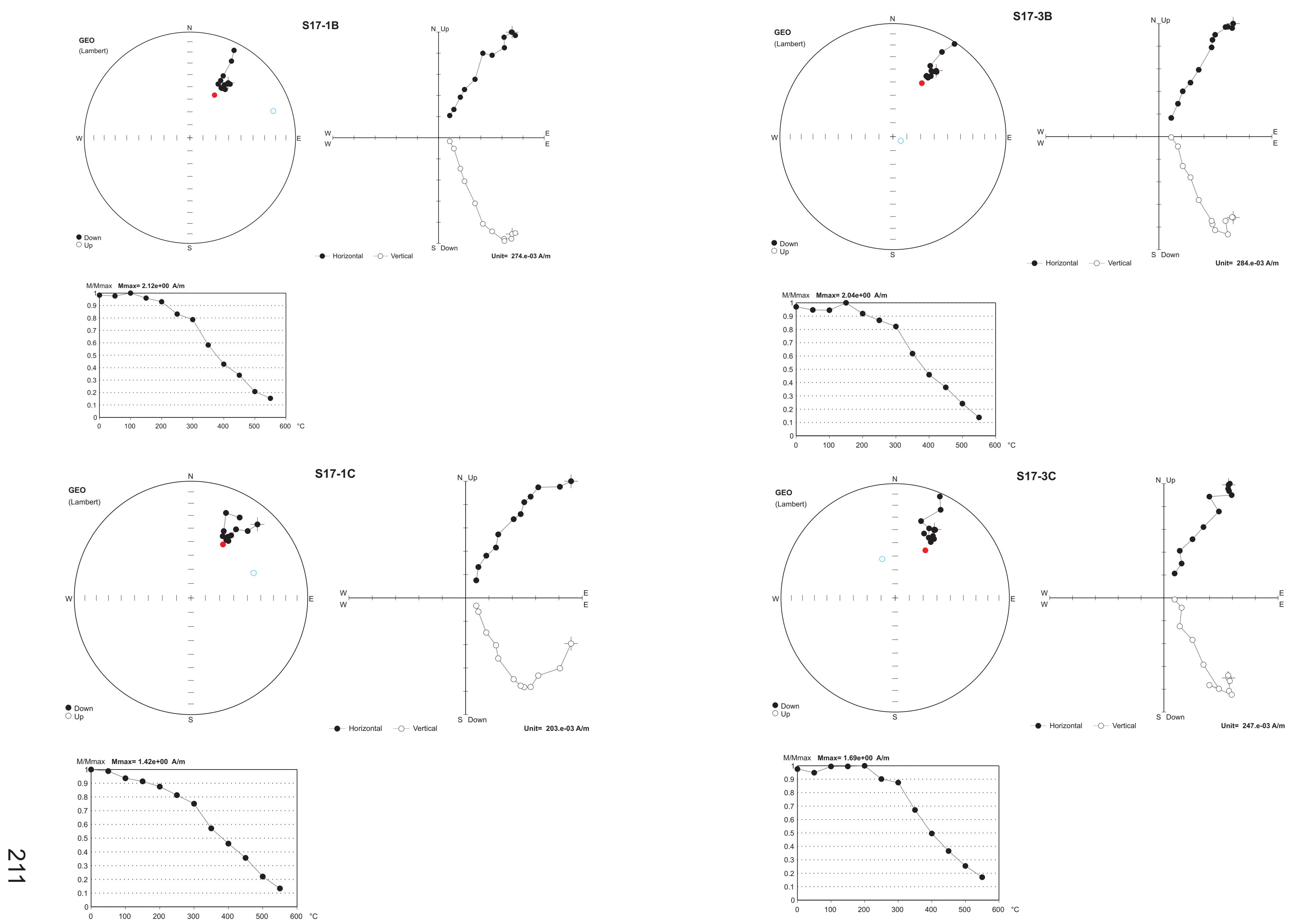


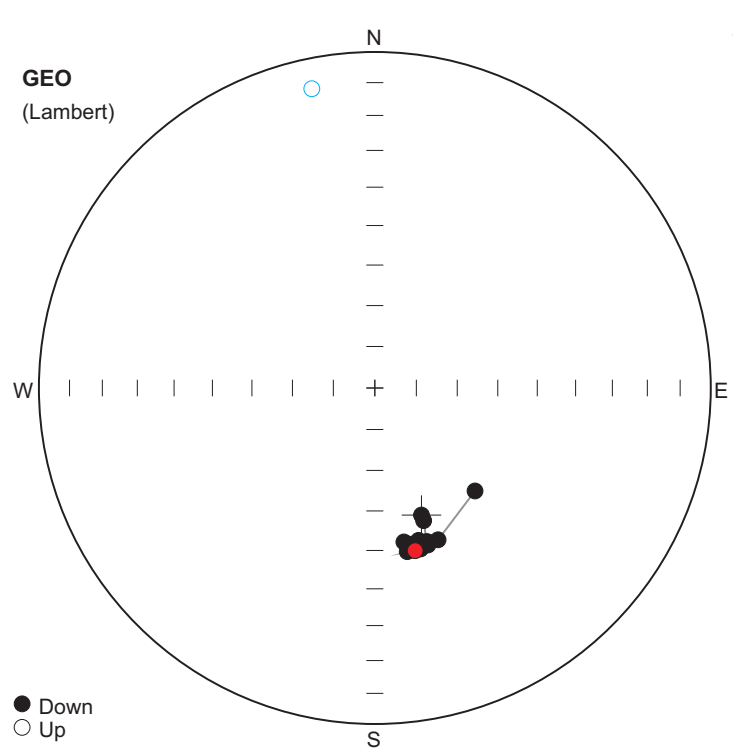

S18-1A
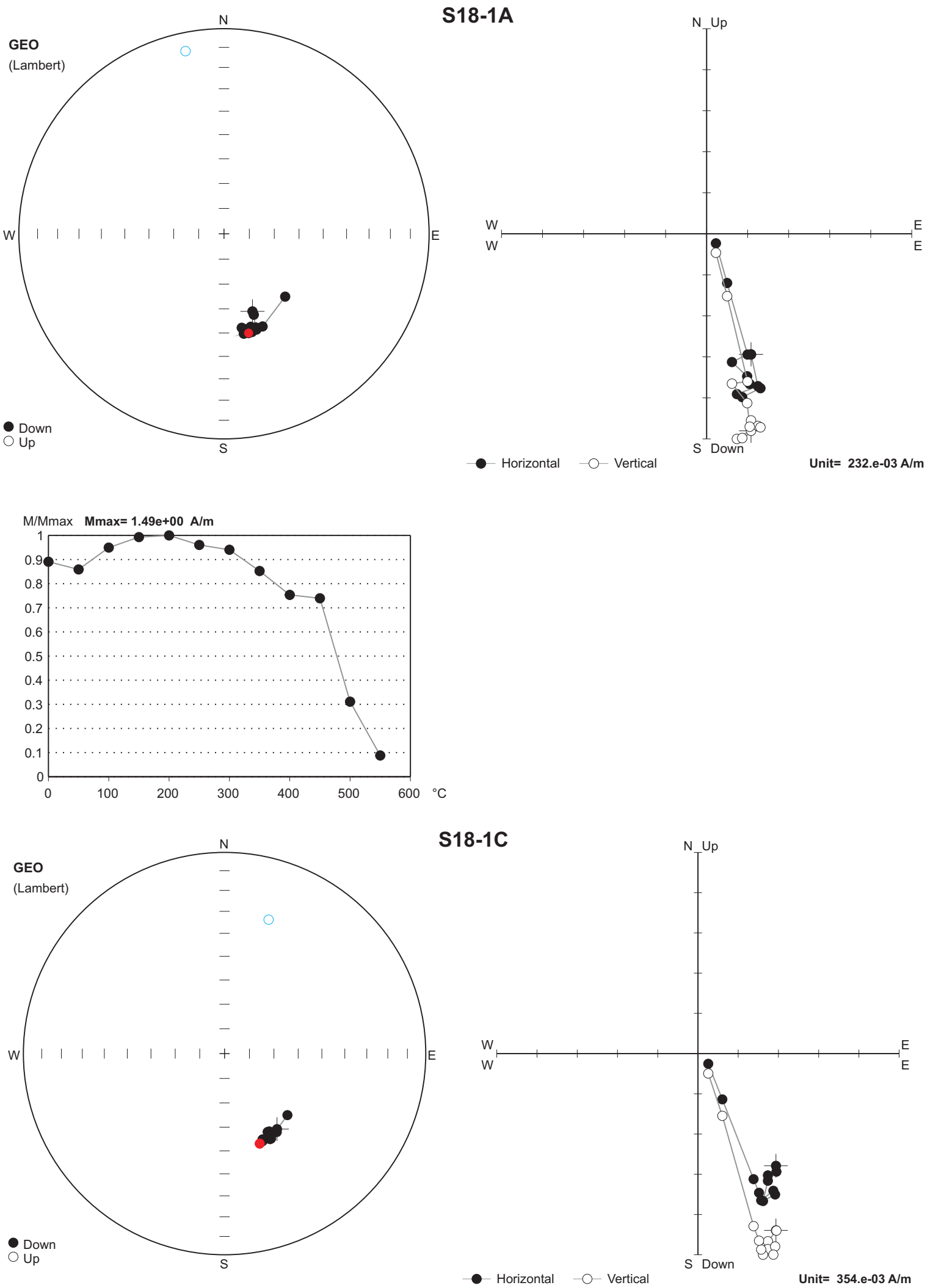

$\stackrel{N}{N}$

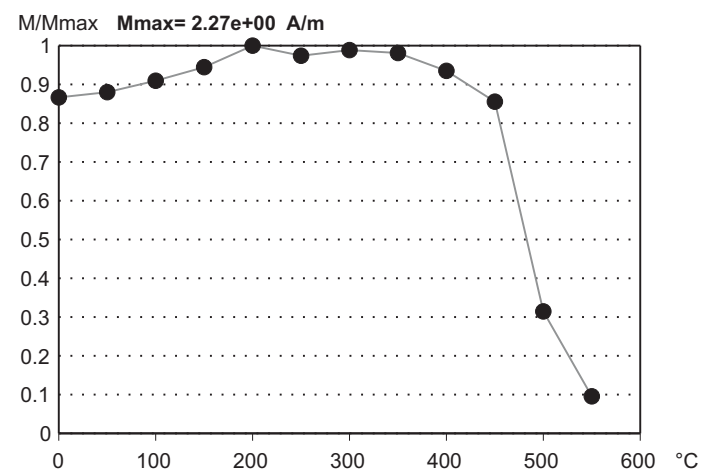

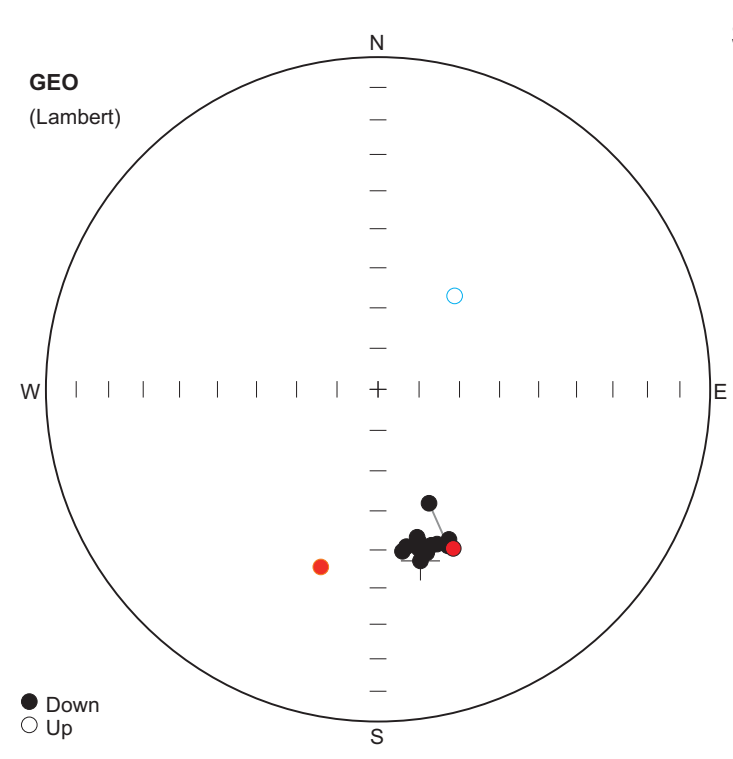

S18-2B
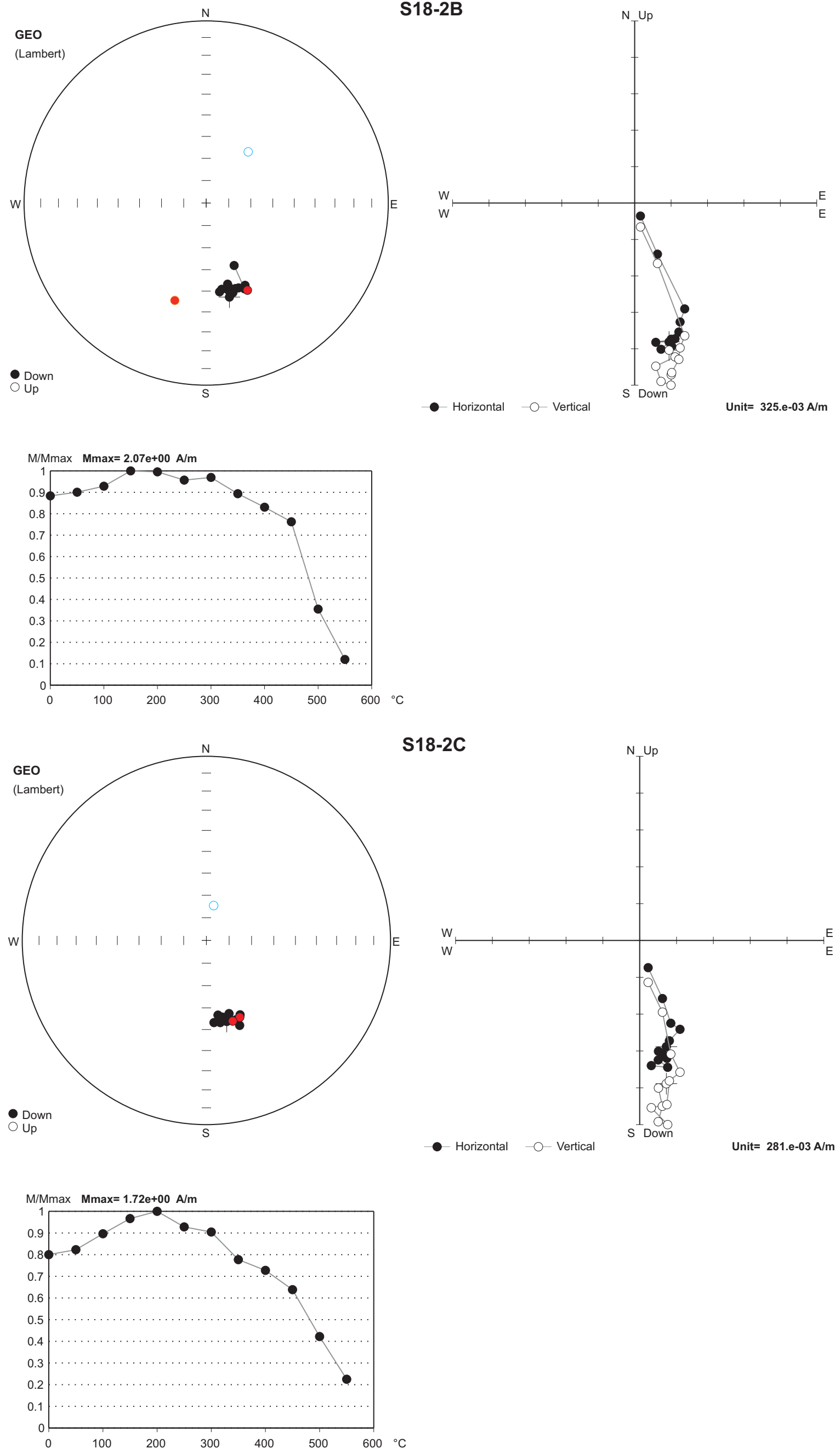

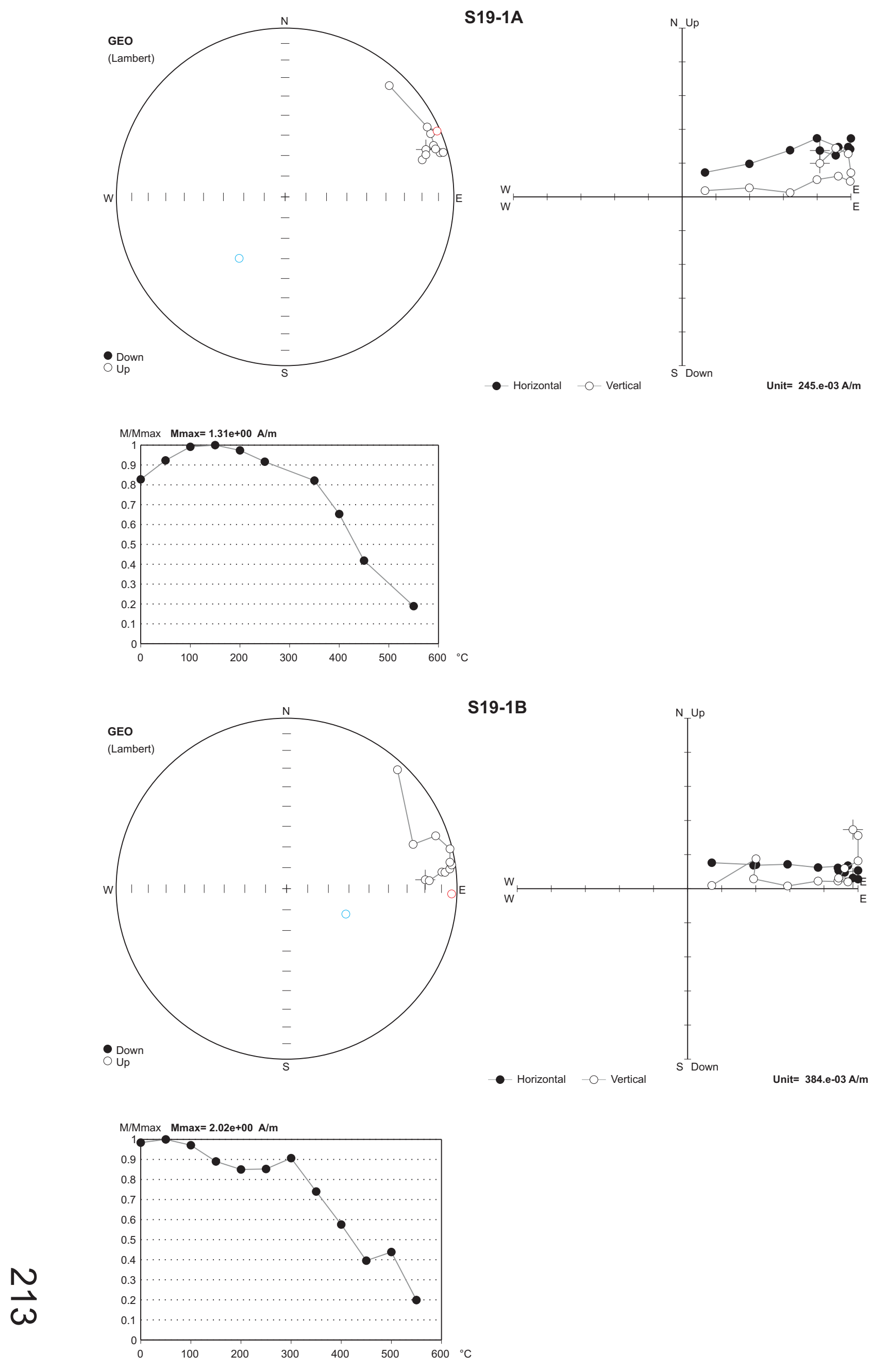
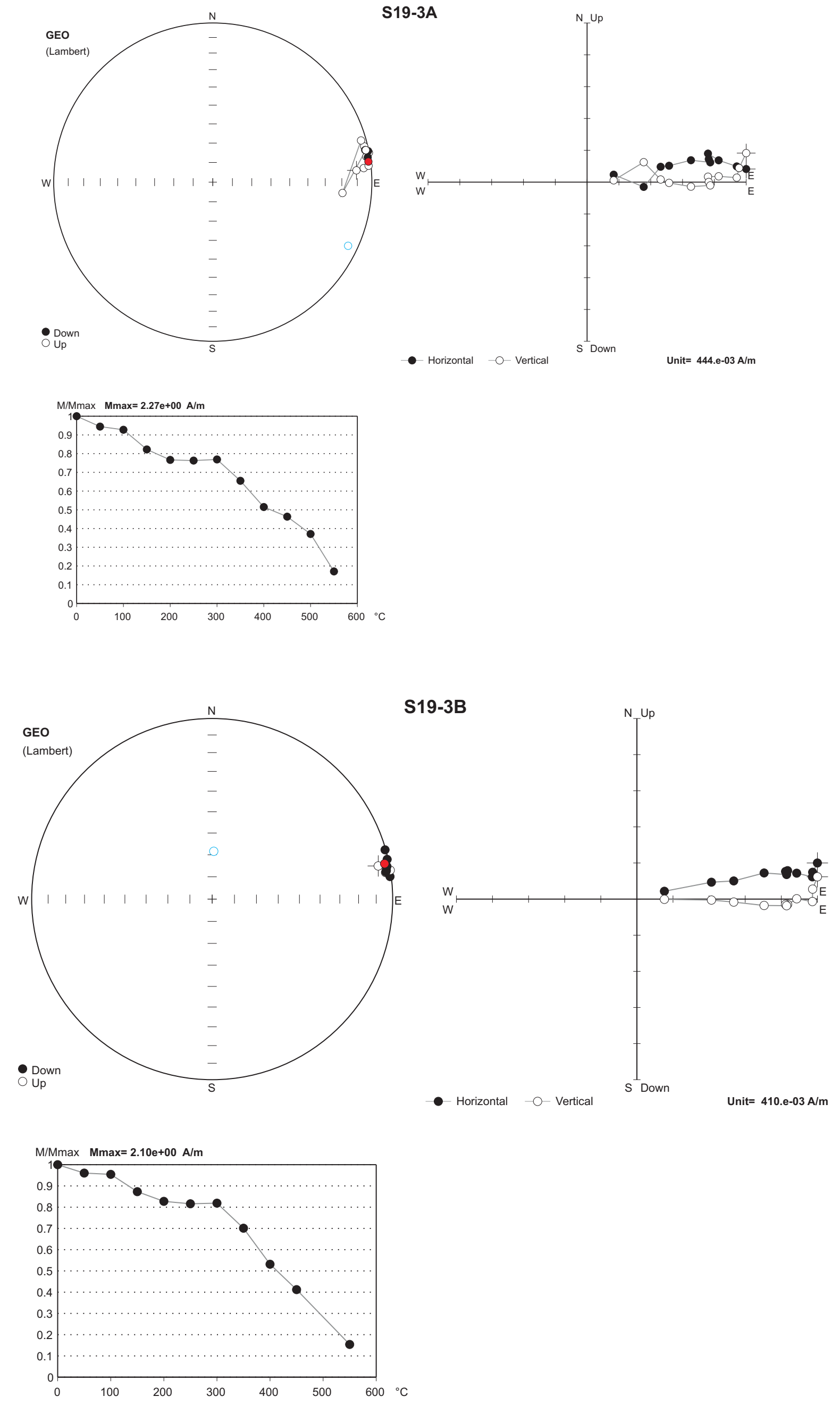